\title{
Numerical and experimental simulation of fault reactivation and earthquake rupture applied to induced seismicity in the Groningen gas field
}

Arendje Jozina Louise Buijze

\author{
PhD Thesis
}

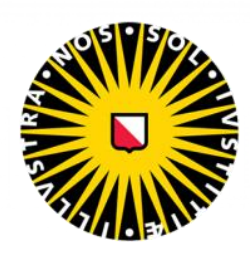

Universiteit Utrecht

Utrecht Series in Earth Sciences (USES)

No. 217 


\title{
Members of the dissertation committee
}

\author{
Prof. Dr. Jean-Paul Ampuero
}

Université Côte d'Azur, Nice, France

Prof. Dr. Jean-Philippe Avouac

California Institute of Technology, Pasadena, California, United States of America

\section{Prof. Dr. Frédéric Cappa}

Université Côte d'Azur, Nice, France

\section{Dr. Ylona van Dinther}

Utrecht University, Utrecht, The Netherlands

\section{Prof. Dr. Eiichi Fukuyama}

National Research Institute for Earth Science and Disaster Resilience (NIED), Tsukuba, Japan

This research was performed at

The High Pressure and Temperature Laboratory, Faculty of Geosciences, Utrecht

University (Princetonlaan 4, 3584 CB Utrecht, the Netherlands)

and at

State Key Laboratory of Earthquake Dynamics, Institute of Geology, China Earthquake Administration (A1, Huayanli, Chaoyang District, Beijing, 100028, China)

and at

Applied Geosciences, EnergieTransitie, Nederlandse Organisatie voor toegepastnatuurwetenschappelijk onderzoek (TNO) (Princetonlaan 6, 3584 CB, Utrecht, the Netherlands)

Printed by: ProefschriftMaken, the Netherlands. Copyright: (C) 2020 A.J.L.Buijze

All rights reserved. No part of this publication may be reproduced in any form, by print or photo print, microfilm or any other means, without the written permission of the author.

ISBN/EAN: 978-90-6266-581-5 


\section{Numerical and experimental simulation of fault reactivation and earthquake rupture applied to induced seismicity in the Groningen gas field}

Numerieke en experimentele simulatie van breuk reactivatie en aardbevingen, toegepast op geïnduceerde seismiciteit in het Groningen gas veld

(met een samenvatting in het Nederlands)

\section{Proefschrift}

ter verkrijging van de graad van doctor aan de

Universiteit Utrecht

op gezag van de

rector magnificus, prof.dr. H.R.B.M. Kummeling, ingevolge het besluit van het college voor promoties in het openbaar te verdedigen op

vrijdag 3 juli 2020 des middags te 2.30 uur

door

Arendje Jozina Louise Buijze 
Promotor: Prof. Dr. Christopher J. Spiers

Co-promotoren: Dr. André R. Niemeijer en Dr. Peter A. Fokker

This thesis is financed by the Nederlandse Aardolie Maatschappij (NAM), as part of the larger data acquisition and study programme on induced seismicity in the Groningen gas field, North-East Netherlands, initiated following the magnitude 3.6 Huizinge earthquake that occurred on 16 August 2012.

Dit proefschrift is gefinancierd door de Nederlandse Aardolie Maatschappij (NAM), als onderdeel van een groter data aquisitie- en studieprogramma voor geïnduceerde seismiciteit in het Groningen gasveld, gestart naar aanleiding van de magnitude 3.6 Huizinge aardbeving die plaatsvond op 16 augustus 2012. 


\section{Table of Contents}

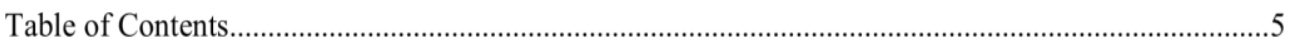

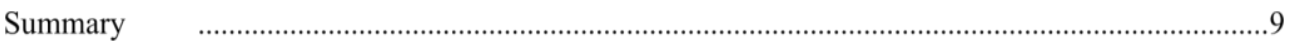

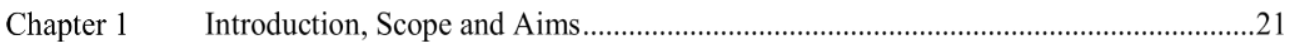

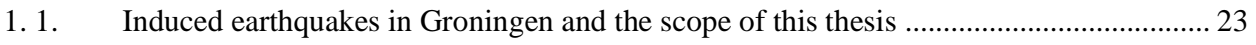

1. 2. Background on the Groningen gas field and the induced seismicity recorded .................. 26

1. 2. 1. Reservoir geology, gas production and reservoir compaction ...................................... 26

1. 2. 2. Characteristics of the seismicity observed in the Groningen field................................ 31

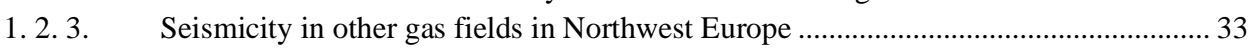

1.3. Mechanisms of depletion-induced seismicity and modeling approaches ........................... 35

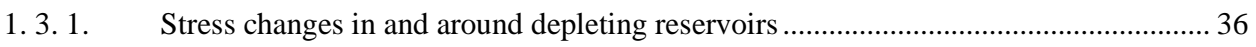

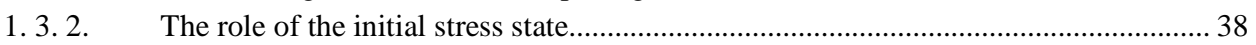

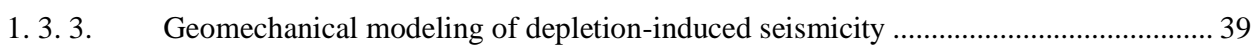

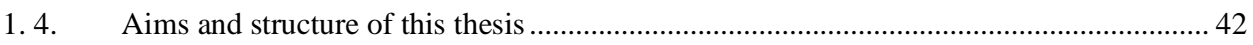

Chapter 2 Nucleation and Arrest of Dynamic Rupture induced by Reservoir Depletion..............47

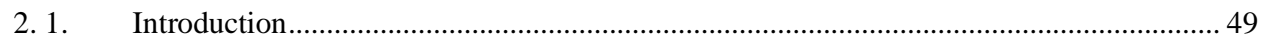

2. 2. Numerical model set-up, input parameters, and modeling procedure ............................... 52

2. 2. 1. Governing equations, assumptions and modeling workflow ....................................... 52

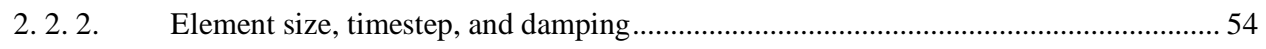

2. 2.3. Initial stresses and pressures, pressure changes, and input parameters ........................ 55

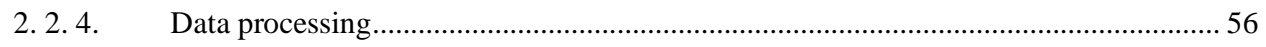

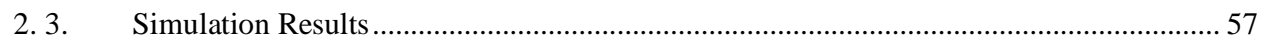

2. 3. 1. Seismic rupture induced on a fault cross-cutting two depleting reservoir compartments

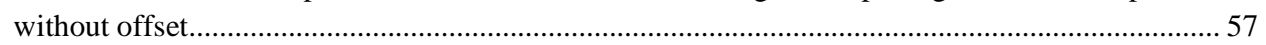

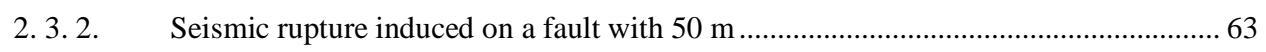

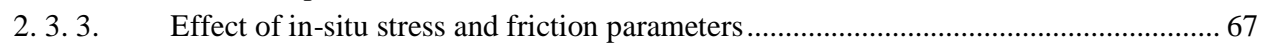

2. 3. 4. Effect of various reservoir offset on nucleation and seismic rupture ............................ 74

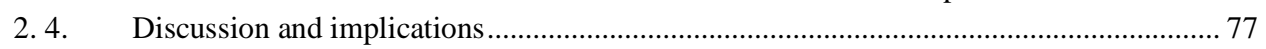

2. 4. 1. Production-induced stressing causing fault reactivation and nucleation of rupture..... 77

2. 4. 2. Dynamic rupture propagation and criterion for runaway ruptures ............................... 78

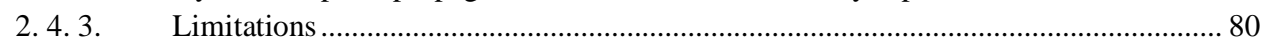

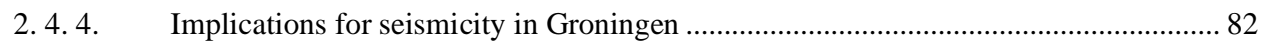

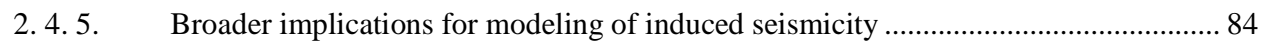

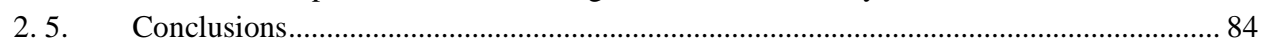

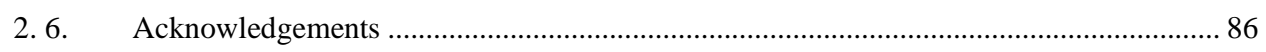

Chapter 3 The effect of elastoplastic reservoir properties on reservoir stress path and fault

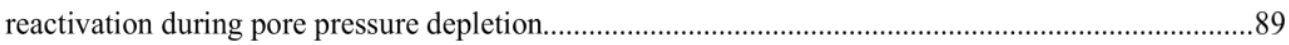

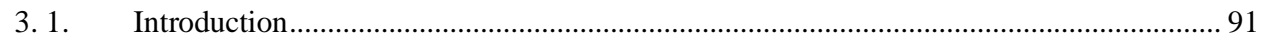

3. 2. Modified Cam-Clay model: Validation against experimental data and effect of initial

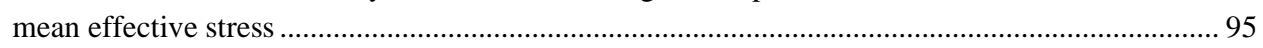

3. 2. 1. Modified Cam-Clay material model ........................................................................ 95

3. 2. 2. Validation of MCC model against triaxial experiments on the Slochteren sandstone. 99 
3. 2. 3. Comparison of triaxially calibrated MCC model with uniaxial compaction experiments 101

3. 2. 4. Model predictions of the effect of initial stress state and pore pressure reduction on stress path and compressibility for a representative volume of reservoir sandstone ....................... 105

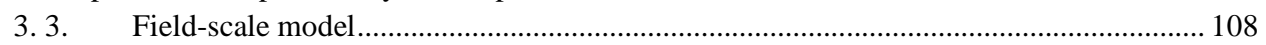

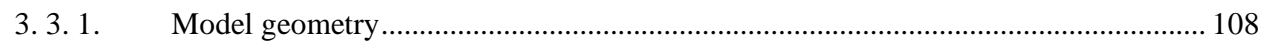

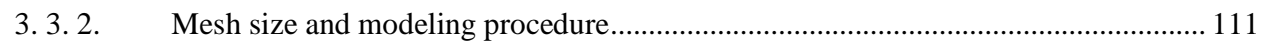

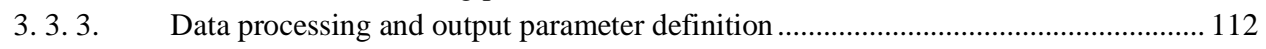

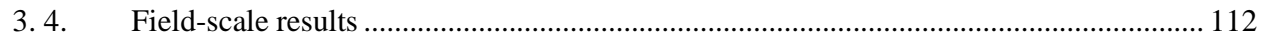

3. 4. 1. Quasi-static stress changes in the axisymmetric model: MCC and linear elasticity.. 112

3. 4. 2. Stress changes and fault reactivation due to compaction of a faulted reservoir......... 114

3. 4. 3. Comparison of rupture length, slip and slip rates from dynamic rupture models with

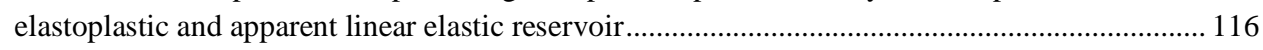

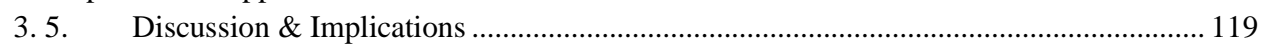

3. 5. 1. Departures of present MCC model from triaxial experiments and the MCC model

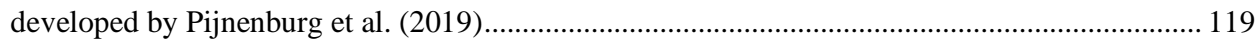

3. 5. 2. Validity of the MCC model in the field-scale models.............................................. 121

3. 5. 3. The effect of elastoplasticity on uniaxial compressibility and reservoir compaction 121

3. 5. 4. Implications of the MCC model for the stress and pressure dependence of the stress

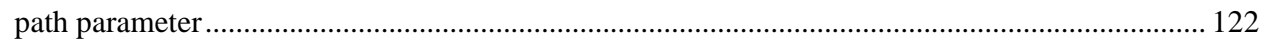

3. 5. 5. Approximation of MCC behavior with apparent linear elasticity............................... 123

3. 5. 6. Implications for fault reactivation and induced seismicity in Groningen.................... 124

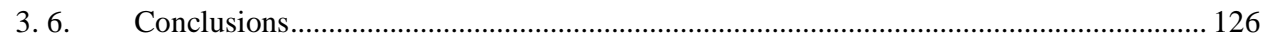

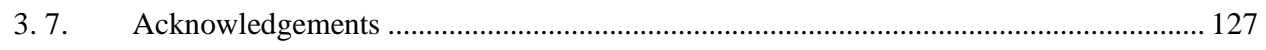

Chapter 4 Nucleation of stick-slip instability within a large-scale experimental fault: Effects of

stress heterogeneities due to loading and gouge-layer compaction ...................................................131

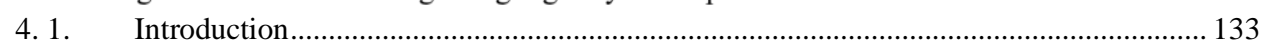

4. 1. 1. Rate-and-state friction and theoretical nucleation lengths ...................................... 135

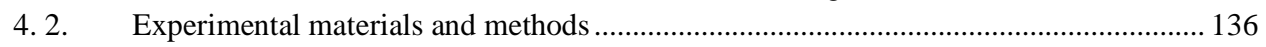

4. 2. 1. Fault gouge material and frictional properties ........................................................... 137

4. 2. 2. Sample assembly, deformation apparatus and experimental procedure ...................... 137

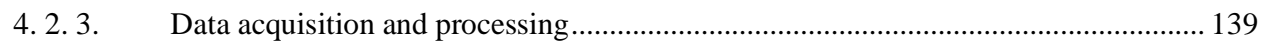

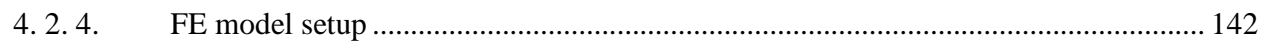

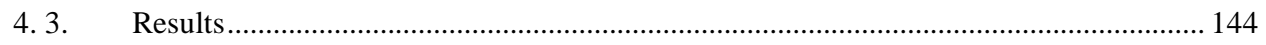

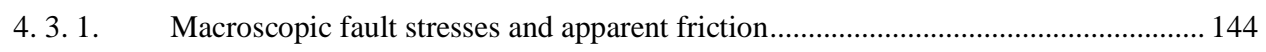

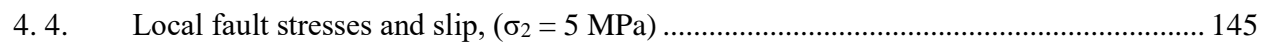

4. 4. 1. Comparison between gouge-filled faults and bare PMMA fault ................................ 149

4. 4. 2. Stresses observed on the gouge-filled faults and bare PMMA fault and FE modeling of

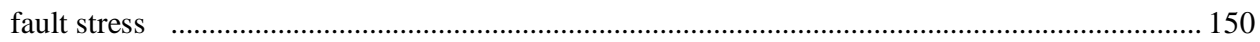

4. 4. 3. Fault relative shear and normal displacements during loading and $\sigma_{2}=5 \mathrm{MPa} \ldots \ldots . .156$

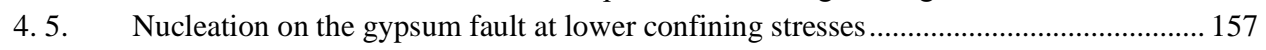

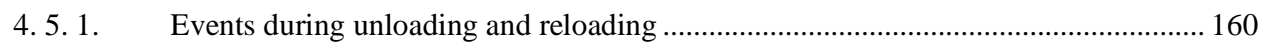

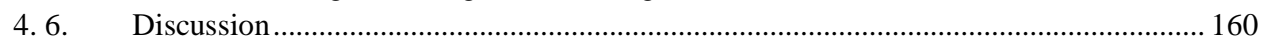

4. 6. 1. Heterogeneous fault stress and location of rupture nucleation and propagation ......... 160

4. 6. 2. Effect of gouge layer on rupture velocity and secondary rupture fronts ..................... 165

4. 6.3. Nucleation length at different confining stresses and relation to theory ..................... 167

4. 6. 4. Implications for natural and induced seismicity ....................................................... 168 


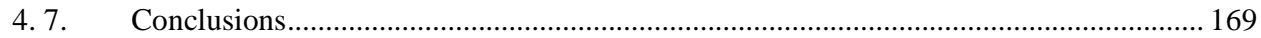

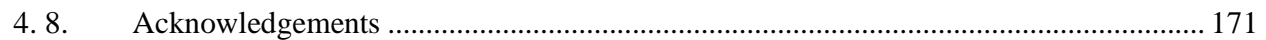

Chapter 5 Effects of heterogeneous gouge segments on the slip behavior of experimental faults

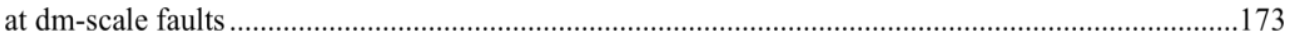

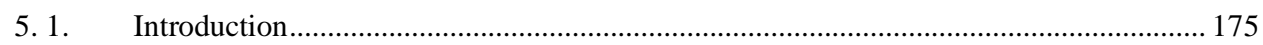

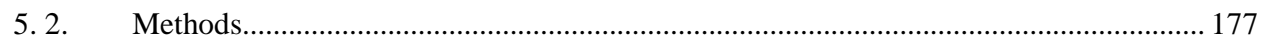

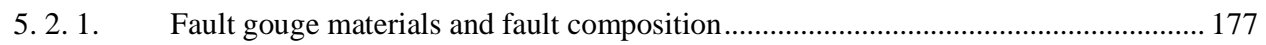

5. 2. 2. Sample assembly, loading apparatus, and experimental procedure.............................. 181

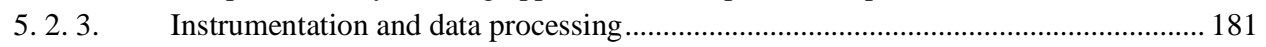

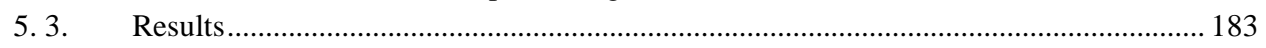

5. 3. 1. Mechanical data at different confining stresses for the four fault compositions......... 183

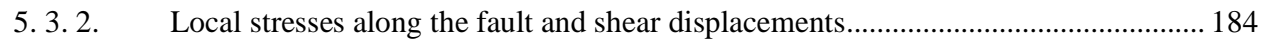

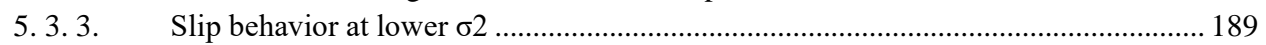

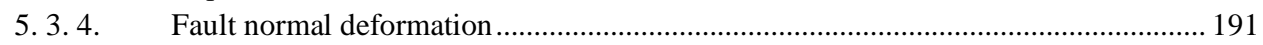

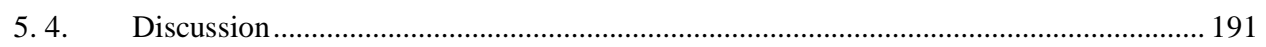

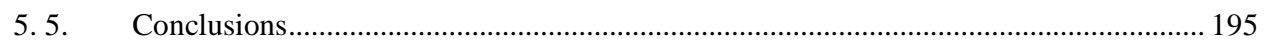

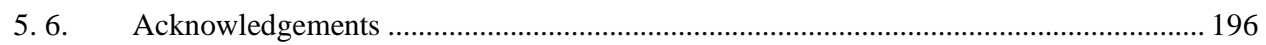

Chapter 6 Modeling of rupture induced by reservoir production: Effect of heterogeneous fault

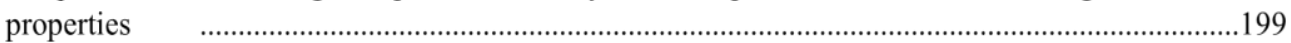

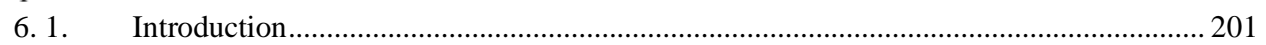

6. 2. Modeling workflow for production-induced stresses, fault reactivation, and rupture size

6. 2. 2. Generic 2D model for a faulted reservoir segment and specification of initial stress

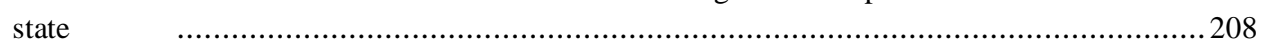

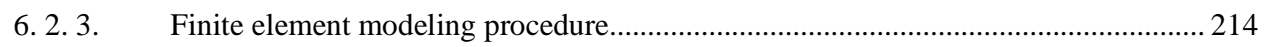

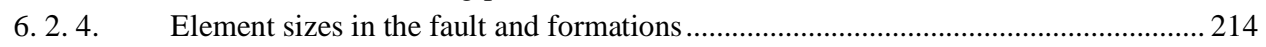

6. 2. 5. Approximating rupture size using linear elastic fracture mechanics .......................... 215

6. 3. Variability of rupture lengths and nucleation styles for depletion-induced stress profiles...

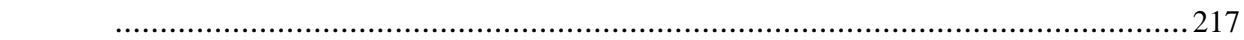

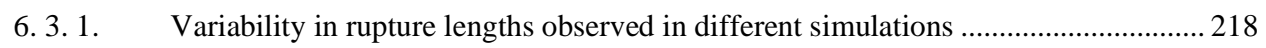

6. 3. 2. Different types of unstable slip nucleation ................................................................ 222

6. 4. Pressure change at the onset of instability and rupture lengths obtained for model

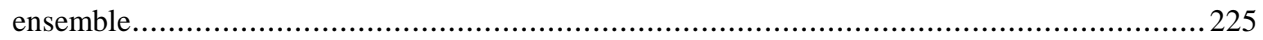

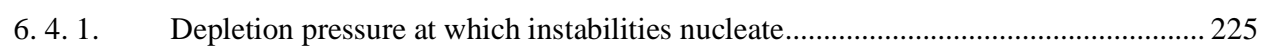

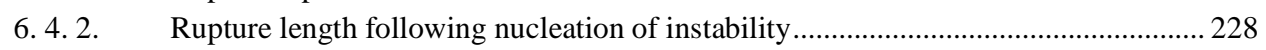

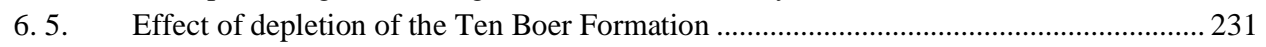

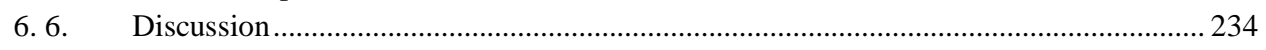

6. 6. 1. Rupture lengths and the effect of assumed formation properties.................................235

6. 6. 2. Rupture lengths and the effect of assumed fault properties ........................................ 237

6. 6. 3. Potential for ruptures to propagate into the underburden............................................2239

6. 6. 4. Comparison with seismological observations from the Groningen field and

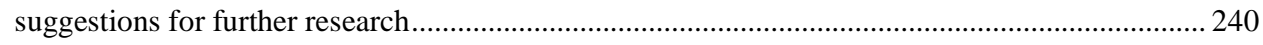

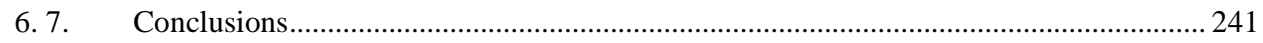

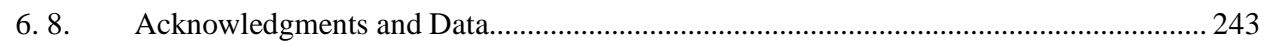

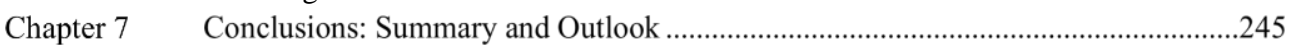

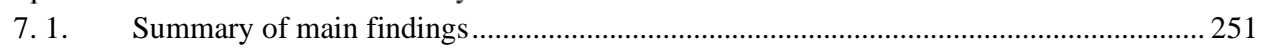


7. 1. 1. Stress changes and nucleation of seismic instability in geomechanical models and large-scale experiments

7. 1. 2. Pressure changes required for nucleation of instability in a producing gas reservoir 254

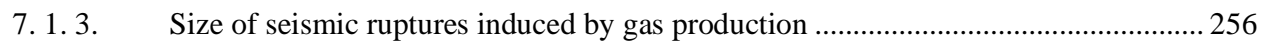

7. 1.4. Effects of elastoplastic reservoir behavior on fault reactivation and rupture size...... 258

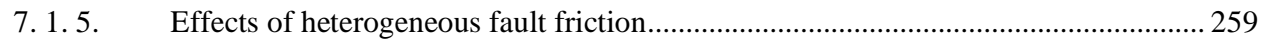

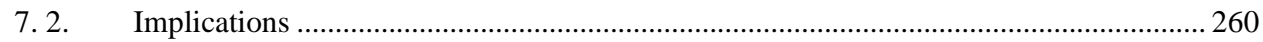

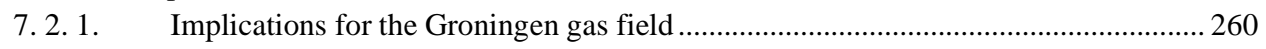

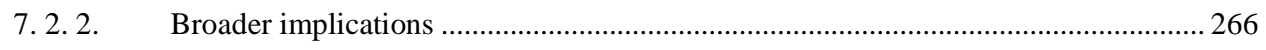

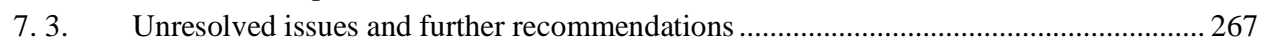

7. 3. 1. Limitations of the current work and suggestions for improvement ............................. 267

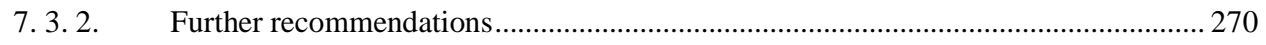

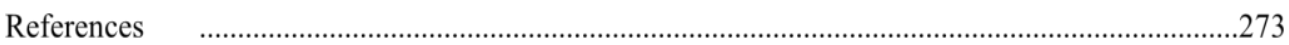

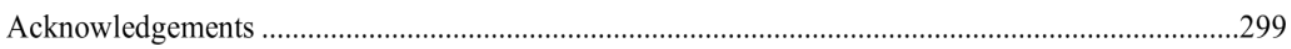

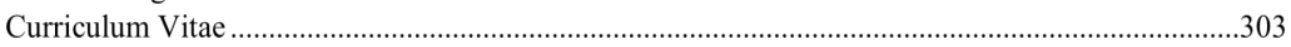




\section{Summary}

The occurrence of felt seismic events that are induced by human activities in the subsurface is presenting an increasingly serious challenge for geo-resources production and geological storage operations already in progress and planned for the future. Such activities include natural gas production and storage, for example, but also key strategies for the energy transition, such as geothermal energy production, $\mathrm{CO}_{2}$ storage, and hydrogen energy storage - as well as reservoir stimulation by hydraulic fracturing and deep waste water disposal. Events induced by these activities may be of large enough magnitude to damage infrastructure and buildings, causing loss of support from local communities, and suspension or even termination of subsurface activities. One of the best-known examples of induced seismicity globally is related to natural gas production from the Groningen field in the north of the Netherlands, the largest gas field in Europe. In recent years, seismic events $\left(\mathrm{M}_{\mathrm{L}}<3.6\right)$ induced by gas production from the Groningen field have led to damage to over a thousand houses, social unrest and political upheaval, culminating in an early phase-out of gas production.

The first earthquake in the Groningen gas field was recorded in 1991, and since then over 1,000 events with $\mathrm{M}_{\mathrm{L}}$ up to 3.6 have been recorded in the field. Over the years, it has become clear that these events are induced by reservoir compaction and related poroelastic stress changes occurring on pre-existing faults within the reservoir formation, which is located at about $3 \mathrm{~km}$ depth. Geomechanical models have confirmed this broad causal picture. However, for seismic hazard analysis, it is important to understand the mechanisms underlying the nucleation of induced seismic rupture events, as well as the key geomechanical parameters that govern event size.

In this thesis, I report the results of geomechanical studies investigating the nucleation and size of depletion-induced, seismic rupture events, and the controlling geomechanical properties. Appropriate reservoir properties and slip-dependent fault weakening behavior are included in the geomechanical modeling approach to simulate the nucleation of seismic instability. Special emphasis is placed on the integration of independent experimental results, obtained on the compaction and friction behavior of reservoir and fault rocks that are representative for the Groningen system, into the field-scale geomechanical models presented in this thesis. Additionally, I report the results of scaled experiments designed to study the relationship between heterogeneous fault stresses, heterogeneous fault friction and the nucleation of seismic instability - i.e. seismic events.

In Chapter 1, I describe the motivation for this study. I first give the historical background of the seismicity recorded in the Groningen field and of the political measures 


\section{Summary}

taken over the last 8 years. I go on to summarize the main geological, operational, and seismological observations made on the Groningen field, I list the main mechanisms of depletion-induced seismicity inferred from previous studies, and I identify key outstanding questions. Finally, the aims and structure of this thesis are outlined.

In Chapter 2, I study in detail the interaction between depletion-induced stress changes, earthquake nucleation, and earthquake propagation on a fault in a generic Groningen-like reservoir system, using a 2D Finite Element model. Slip-dependent frictional weakening behavior (as also used for modeling of natural seismicity) is implemented to simulate earthquake rupture in a fully dynamic calculation. The effects of the initial stress, fault geometry (reservoir offset), and the frictional weakening properties of the fault, on the pressure change required for nucleation and the resulting rupture length along the fault, are evaluated - with special emphasis on the potential for ruptures to propagate beyond the reservoir interval. For the parameter space that is investigated, rupture remains mostly confined to the fault segment within the reservoir interval. Larger rupture sizes and rupture propagation on fault segments beyond the reservoir interval are promoted by a critical in-situ stress, a large stress drop upon rupture, a small fracture energy (i.e. energy input into the faulting process), and no or little reservoir offset along the fault. With increasing reservoir offset (up to the reservoir thickness), higher stress concentrations form along the fault, thus promote nucleation of seismicity. As a result, nucleation of instability occurs at lower pressure changes for large reservoir offsets on faults than for small offsets. At the same time, though, dynamic rupture size decreases for larger reservoir offsets, as the stresses adjacent to the stress concentrations are relatively low.

The reservoir modeled in Chapter 2 is assumed to have linear elastic properties. However, recent experiments on the reservoir sandstone of the Groningen field (the Slochteren sandstone) have shown that up to $50 \%$ of the deformation may be inelastic (Hol et al., 2018; Pijnenburg et al., 2018; Pijnenburg et al., 2019). Therefore, in Chapter 3, inelastic (elastoplastic) behavior of the reservoir formation, described by a Modified Cam-Clay model, is incorporated into the generic Finite Element models of fault reactivation. The material behavior is validated against experimental data on the Slochteren sandstone provided by Pijnenburg et al. (2019). I compare the stress changes and rupture length obtained for the elastoplastic reservoir against results obtained for a reservoir with equivalent or apparent linear elastic behavior. The apparent elastic properties were determined from the near-linear stress-strain evolution seen in single-element model runs simulating compaction of a sandstone sample with MCC elastoplastic properties undergoing unidirectional pore pressure depletion under uniaxial strain conditions. For the field-scale models, the stress changes computed using an elastoplastic reservoir can to a first order be approximated with linear elastic behavior, providing the proper assumed 'apparent' elastic properties are used. However, dynamic rupture sizes and hence events sizes were smaller for the elastoplastic reservoir, with final slip displacements being $10-20 \%$ less than for those obtained for an 'equivalent' linear elastic reservoir. Moreover, for some dynamic ruptures elastoplasticity 
also resulted in smaller final rupture lengths than those that develop using the linear elastic approximation, depending on the state of stress on the fault.

The geomechanical models show the large effect that the (depletion-induced) stress state has on fault behavior and specifically on rupture nucleation. Densely instrumented, large-scale laboratory experiments can be used to study in more detail the relation between stress and nucleation of rupture in a controlled setting. In such large-scale experiments, the state of stress on a fault can be measured and can be associated with the observed rupture nucleation and propagation. In Chapter 4, I present the results of a scaled laboratory experiment on a 350mm-long simulated fault located between two low-stiffness PMMA forcing blocks. The fault was filled with gypsum gouge, which exhibits unstable velocityweakening (VW) sliding behavior at the low normal stress ( $<15 \mathrm{MPa})$ and room temperature conditions at which the experiment was performed. Additionally, a control experiment on a fault without gouge was conducted to study the effect of gouge. As in the field-scale geomechanical models, stresses on the fault were found to be locally concentrated. However, in the experiments, the stresses on the fault do not result from pore pressure depletion, but from the experimental boundary conditions. Finite Element modeling was used to calculate the stress field along the fault, which was then compared with strain gauge and optical measurements made close to the fault and to site(s) of rupture nucleation. My results show that rupture in the experiments nucleates in regions of concentrated stresses, as in the geomechanical models. The presence of gouge results in smaller-scale stress variations, resulting from heterogeneous compaction of the gouge layer. These smaller-scale stress variations occasionally lead to more complex nucleation behavior. The results illustrate the importance of fault stress distribution in controlling rupture nucleation and propagation. Assuming average far-field stresses on a fault leads to different estimates of the stress state that causes fault failure and rupture nucleation than the actual, locally concentrated, stresses that are related to the nucleation sites. In addition, local stress lows around the highly stressed nucleation site may decelerate or quench a nucleating rupture, as seen in some of the geomechanical field-scale models with highly concentrated fault stresses. The results demonstrate that fault zone architecture and gouge composition can contribute to strong stress variability within and around a fault zone. For example, intense normal stress concentrations may develop on fault zone segments or rigid lenses experiencing less compaction, promoting nucleation of instability on those segments or lenses.

In the models presented in Chapters 2 and 3, and in the experiments in Chapter 4, the fault zone lithology and/or properties were uniform along the fault. However, for faults cross-cutting sedimentary sequences or different lithological units, the fault lithology and related frictional behavior vary strongly along the fault. In Chapter 5, the results of sliding on a large-scale experimental fault with heterogeneous frictional properties are presented. Fault gouge patches were used to control the frictional properties along the fault, creating an $80 \mathrm{~mm}$ long central fault segment exhibiting velocity-weakening (VW) behavior (unstable, prone to generate seismic events), flanked by two segments of $135 \mathrm{~mm}$ long with velocity- 


\section{Summary}

strengthening (VS) behavior (stable). As in Chapter 4, gypsum gouge is used for the center segment, and three different gouges were used for the flanking velocity-strengthening segments (quartz, calcite, and kaolinite). I investigate the nucleation of rupture and the macroscopic sliding behavior of the fault as a function of the fault stresses, the combination of different gouges, and the relation between the length-scale of the center segment and the critical nucleation length-scale. For stresses at which the length of the VW segment is close to the critical nucleation length scale, unstable sliding (seismic slip) events were observed, with events that nucleated in the VW segment propagating partly into the VS segments. In the time interval between unstable slip events, significant aseismic slip occurred in the VS segments but also in the VW segment. When the critical nucleation length was increased to become much larger than the extent of the VW segment, by lowering the normal stress in the scaled experiments, the macroscopic slip behavior changed, depending on the combinations of fault gouges present along the fault. For VS kaolinite segments with a central VW gypsum segment, unstable slip events persisted with decreasing normal stress. However, for VS quartz gouge with a central VW gypsum segment, only small slip events rupturing the end of the VW segment persisted to large critical nucleation lengths. For VS calcite segments flanking the VW gypsum segment, fault-wide slow slip events were observed. These different slip behaviors observed in the experiments are consistent with slip event modes seen in RSF models of slip on a heterogeneous fault with a similar geometry.

The effect of fault zone heterogeneity is also important for field-scale geomechanical models simulating depletion-induced seismicity. In Chapter 6, the fully dynamic models presented in Chapter 2 are extended to incorporate five different lithological units, based on the Groningen field stratigraphy, plus the associated variability in friction along the fault. The aim here was to study the effect of heterogeneous rock and fault properties on rupture nucleation and size. Special emphasis is placed on incorporating laboratory measurements of friction and reservoir compaction behavior. The fault friction properties used were based on the lithologies found in the Groningen field and corresponding gouge frictional properties measured in previous laboratory studies. Reservoir compaction behavior was described using the apparent elastic behavior obtained from compaction experiments performed under uniaxial strain conditions, similar to the apparent elastic behavior specified in Chapter 3. To incorporate uncertainties related to the input parameters (initial stress field, the frictional weakening properties, the apparent elastic properties of the reservoir, fault strike, dip, and offset), over 1,500 simulations were run with input parameters drawn from experiment-based probability density distributions or (in case of the fault geometry) from the fault model of the Groningen field data. Simulations were ran to the point of rupture nucleation and give the state of stress at the onset of rupture. To compute rupture size, an approximation using linear elastic fracture mechanics theory was used to reduce computation time with respect to the fully dynamic simulations in Chapter 2. The model ensemble thus gives a physics-based estimate of the pressure changes required for ruptures to occur in the Groningen field and the likely rupture sizes in the reservoir. The pressure change required for reactivation increased 
with increasing initial stress ratio, fault dip, and the angle between the fault strike and the orientation of the maximum horizontal stress, whereas it decreased with increasing reservoir offset, horizontal stress path parameters (i.e. the magnitude of change in horizontal stress per unit pressure change) and the reservoir compressibility (i.e. amount of vertical strain per unit pressure change). For a significant fraction (50\%) of the simulations, no nucleation of instability occurred at all, as many fault segments in the Groningen fault model are not well oriented with respect to the regional stress field. The computed rupture sizes show that the majority of ruptures remained confined to the reservoir depth interval; propagation beyond the reservoir depth interval was only observed for a small fraction $(<2 \%)$ of the simulations. Rupture size increased with decreasing initial stress ratio, decreasing reservoir offset, decreasing fault dip, decreasing angle between the maximum horizontal stress and the fault strike, increasing reservoir thickness, and decreasing dynamic friction in the Slochteren reservoir fault segments and the underburden fault segments. When depletion of the Ten Boer claystone was included in the models, in addition to depletion of the directly underlying Slochteren sandstone reservoir, rupture nucleation in the Slochteren was promoted by the occurrence of aseismic slip on fault segments in the Ten Boer claystone. These results aid in understanding at which locations and under what pressure change conditions seismic rupture can be expected to occur in the Groningen field, and place useful constraints on rupture lengths.

In Chapter 7, I summarize and draw together the main findings obtained in the different chapters, and give the implications for seismicity in the Groningen field. The geomechanical models presented in this thesis aid understanding of the physical mechanisms causing depletion-induced seismic events in a faulted reservoir system and place constraints on the sizes of induced ruptures as a function of key geological and geomechanical input parameters. For the experiment-based compaction and friction parameters used in Chapter 6, most rupture sizes remained limited to the reservoir depth interval, which implies that event magnitudes remain limited too, though this depends strongly on the initial state of stress which is highly uncertain. I give recommendations on how the geomechanical models can be improved further and how they can be used to be calibrated against the observed seismic events, so that in the future the most uncertain input parameters (e.g. the initial stress) can be better constrained, the predictive value of the models improved, and seismic hazard analysis advanced - in the final years gas of production from Groningen but also in the years beyond when seismicity may continue for some time. 
Summary 


\section{Samenvatting}

Aardbevingen als gevolg van menselijk handelen in de ondergrond, zogenaamde geïnduceerde aardbevingen, kunnen optreden bij de productie van olie en gas, maar ook bij andere technologieën die gebruik maken van de ondergrond. Hierbij kan men denken aan geothermie of opslag van $\mathrm{CO} 2$ en energie in de ondergrond - belangrijke technologieën in de naderende energie transitie. Als de geïnduceerde aardbevingen groot genoeg zijn om voelbaar te zijn aan het aardoppervlak kan er schade optreden aan gebouwen en infrastructuur, hetgeen leidt tot sociale onrust, en, in sommige gevallen, tot gedwongen stopzetting van de operaties. Onder de meest prominente voorbeelden van geïnduceerde seismiciteit zijn de aardbevingen in het Groningen gasveld in Noordoost Nederland. De eerste aardbeving in het Groningen veld werd gemeten in 1991, en sindsdien zijn er meer dan 1,500 aardbevingen geregistreerd, met magnitudes tot $\mathrm{M}_{\mathrm{L}}$ 3.6. Een deel van deze aardbevingen was groot genoeg om schade te veroorzaken, in het bijzonder de Huizinge beving van 16 augustus $2012\left(\mathrm{M}_{\mathrm{L}}\right.$ 3.6), en de Zeerijp beving van 8 januari $2018\left(\mathrm{M}_{\mathrm{L}}\right.$ 3.5). De bevingen hebben in geleid tot meer dan 50,000 schadeclaims van in totaal meer dan 200 miljoen euro, tot grote onrust onder de lokale bevolking, en tot politieke spanningen. Dit resulteerde in meerdere verlagingen van de jaarlijks toegestane gasproductie, en uiteindelijk in het besluit tot stopzetten van de gaswinning in de nabije toekomst. Een beter begrip van waar en wanneer geïnduceerde aardbevingen kunnen optreden, en hoe groot deze bevingen kunnen worden, is van groot belang.

In dit proefschrift presenteer ik de resultaten van mijn onderzoek, waarin ik de mechanismes van aardbevingen veroorzaakt door gasproductie bestudeer. Dit doe ik door middel van numerieke modellen (computer modellen), en door middel van geschaalde experimenten in het laboratorium.

In Hoofdstuk 1 geef ik een algemene inleiding, beginnend met de historie van de aardbevingen in Groningen en de politieke maatregelen die zijn genomen om de bevingen te beperken. Verder beschrijf ik in dit hoofdstuk de geologie van het Groningen gasveld, de productie geschiedenis, en de eigenschappen van de geïnduceerde aardbevingen in het veld, alsook wat al bekend is over de onderliggende oorzaak van deze bevingen.

In Hoofdstuk 2 presenteer ik de resultaten van de numerieke modellen. In deze computermodellen, boots ik een gedeelte van het Groningen gasveld na. Ik wijs aan de aardlagen in het model eigenschappen toe en simuleer wat er gebeurt met verdeling van de spanning in de ondergrond als de druk in de gashoudende laag omlaag gaat door de productie van gas. De gashoudende laag (het reservoir) in het Groningen veld is de Slochteren zandsteen, een $200 \mathrm{~m}$ dikke, poreuze zandsteenlaag op $3 \mathrm{~km}$ diepte. Eerdere studies hebben al laten zien dat onttrekking van gas uit zo'n poreuze laag leidt tot drukdaling in die laag, die 


\section{Samenvatting}

vervolgens inklinkt, of 'compacteert'. De drukdaling en compactie veroorzaken een verandering van de al bestaande spanningen in en rondom het gasveld. In en onder het reservoir zijn bestaande breuken aanwezig, die gevormd zijn door plaattektoniek. Deze breuken zijn al miljoenen jaren inactief - er vindt geen tectonische beweging meer langs plaats. De drukdaling en compactie zorgen er echter voor dat de spanningstoestand op deze breuken in het reservoir verandert. Als de breukspanning de breuksterkte overschrijdt, kan de breuk gaan bewegen. Een snelle breukbeweging genereert seismische golven; dit is wat men noemt een aardbeving. Om het ontstaan van de bevingen beter te begrijpen bestudeer ik in dit proefschrift de eigenschappen van breuksterkte in de computermodellen, en dan met name de snelle afname van breuksterkte met toenemende breukbeweging. Dit verzwakkingsmechanisme is fundamenteel voor het ontstaan van snelle breukbeweging en aardbevingen, maar werd in eerdere studies nog niet meegenomen. Ik onderzoek de effecten van de mate van dynamische breukverzwakking, van de initiële, al aanwezige, tectonische spanningen op de breuken, en van de lokale geometrie van het reservoir, bijvoorbeeld hoeveel de reservoirlaag in het verleden is verplaatst langs de breuk: het verzet. Voor de onderzochte combinaties van deze parameters laat ik zien dat de breukbeweging veelal beperkt blijft tot het gebied rondom de reservoirlaag.

In Hoofdstuk 3 focus ik op de effecten van de eigenschappen van het zandsteen reservoir, in plaats van de breukeigenschappen. Laboratorium experimenten op boorkernen van zandsteen uit het Groningen veld laten zien dat de compactie tijdens de drukdaling niet alleen bestaat uit elastisch (omkeerbaar) gedrag, maar dat de laag ook permanent compacteert, ofwel plastische (onomkeerbare) deformatie ondergaat. Waar ik in Hoofdstuk 2 nog elastisch gedrag aannam voor het reservoir, neem ik in de numerieke modellen in Hoofdstuk 3 elastoplastisch gedrag aan, en simuleer nogmaals wat de impact is van gasproductie op de spanningen en op het ontstaan van de aardbevingen. Ik laat zien dat de berekende spanningsveranderingen met een elastoplastisch reservoir tot op de eerste orde ook berekend kunnen worden met elastisch gedrag (dat makkelijker te simuleren is), mits de juiste elastische eigenschappen worden toegekend. Echter, tijdens de aardbeving zelf leidt het elastoplastisch gedrag tot een afname van $10-20 \%$ van de breukbeweging ten opzichte van een elastisch reservoir.

In Hoofdstuk 4 en 5 bestudeer ik het ontstaan van aardbevingen in het laboratorium. Dit helpt bij het begrijpen van aardbevingen op de schaal van het gasveld. Hiervoor creëer ik een $350 \mathrm{~mm}$ lang bij $50 \mathrm{~mm}$ hoog breukvlak, door een rechthoeking blok Plexiglass (PMMA) van 300 x 200 x $50 \mathrm{~mm}$ langs de diagonaal door te zagen. De breuk is gemaakt in Plexiglas en niet in steen, omdat Plexiglas flexibeler is en op deze manier het aardbevingsproces geschaald wordt naar de lengte-schaal van het laboratorium. Langs de breuk kan ik verschillende poeders plaatsen met verschillende eigenschappen, om zo het effect van de breukeigenschappen op het ontstaan van aardbevingen te onderzoeken. De poederlaag is aan weerszijden ingeklemd tussen de PMMA blokken, en de hele constructie wordt dan in een biaxiale testmachine gezet, zodat ik vanaf twee kanten spanningen kan aanbrengen op de 
PMMA blokken, en zodoende ook de breuk kan laten bewegen. In Hoofdstuk 4 gebruik ik gipspoeder in de breuk. Gipspoeder vertoont onder de gebruikte experimentele condities een afname in sterkte als de breuk beweegt - het vereiste onstabiele gedrag voor aardbevingen. Tijdens het bewegen langs de breuk vinden dan ook veel kleine aardbevingen plaats. Deze kan ik in detail bestuderen, omdat ik de breuk goed instrumenteer met op elke centimeter een meting van de lokale spanningen en bewegingen. Door de experimentele randvoorwaarden is de spanningsopbouw langs de breuk niet uniform. Met een computer model simuleer ik de spanningsopbouw en ik vergelijk deze met de gemeten spanning. Ik laat verder zien hoe belangrijk de spanningstoestand is op de locatie van deze laboratorium aardbevingen. Net als in de veldschaal modellen ontstaan de bevingen op plaatsen langs de breuk waar de spanningsopbouw het grootst is. In de computermodellen die ik beschrijf in Hoofdstuk 2 en 3 , en langs de experimentele breuk in Hoofdstuk 4 zijn de breukeigenschappen uniform langs de hele breuk. Echter, in de natuur, ook in het Groningen gas veld, doorsnijden de breuken aardlagen met verschillende eigenschappen, en dit leidt tot een verschil in breukeigenschappen langs de breuk. In Hoofdstuk 5 simuleer ik het effect van ruimtelijk heterogene breukeigenschappen door mijn experimentele breuk op te delen in drie segmenten, waarbij het middelste segment van $80 \mathrm{~mm}$ lang nog steeds bestaat uit gipspoeder, maar de andere twee segmenten bestaan uit een ander materiaal zoals calciet, kwarts of klei. In tegenstelling tot gips, dat zwakker wordt met breukbeweging en zo kleine aardbevingen kan veroorzaken, worden deze andere materialen onder de gebruikte experimentele condities niet of nauwelijks zwakker met toenemende breukbeweging. Dit soort materialen zijn dus niet aardbevingsgevoelig. Als verplaatsing wordt opgelegd langs deze heterogene breuk, ontstaat de laboratoriumbeving dan ook in het gipspoeder. Echter, waar bij de homogene gips breuk nog het hele breukvlak bewoog tijdens de laboratorium bevingen, wordt de breukbeweging nu afgeremd buiten het gipssegment. Dit maakt de laboratoriumbeving veel minder krachtig. Onder bepaalde omstandigheden ontstaan zelfs helemaal geen laboratoriumbevingen meer. Dit hangt af van de lengteschaal van het gipssegment ten opzichte van een kritische aardbevingslengteschaal, en van de materiaaleigenschappen van de andere twee segmenten. De observaties sluiten goed aan bij theoretische voorspellingen van breukgedrag voor breuken met ruimtelijk heterogene eigenschappen.

Ruimtelijk heterogene breukeigenschappen zijn ook zeer relevant voor de numerieke modellen op de veldschaal. In Hoofdstuk 6 breid ik de modellen die beschreven zijn in Hoofdstuk 2 uit, door een meer realistische stratigrafie mee te nemen. Ik simuleer nu het Groningen gasveld met vijf verschillende aardlagen, bestaande uit de laag onder het gasveld, de reservoirlaag (de Slochteren zandsteen), een $50 \mathrm{~m}$ dikke kleilaag die op het reservoir ligt (de Ten Boer klei), daar bovenop een $50 \mathrm{~m}$ dikke laag van carbonaat en anhydriet (de Basale Zechstein), en overliggend het Zechstein zout. In dit hoofdstuk besteed ik veel aandacht aan de integratie van fysische eigenschappen, gemeten in het laboratorium of in het Groningen gasveld, met de numerieke modellen. Voor elke laag die langs de breuk aanwezig is zijn de laag- en breukeigenschappen verschillend. Zowel de laag- als de breukeigenschappen zijn 


\section{Samenvatting}

gebaseerd op metingen in het gesteentelaboratorium. Deze parameters, en ook andere input parameters zoals de verschillende breukgeometrieën die aanwezig zijn in het gasveld en de initiële spanningstoestand, gaan echter gepaard met (grote) onzekerheden. Om deze goed mee te kunnen nemen voer ik meer dan 1,500 simulaties uit, waarbij ik een willekeurige combinatie van input parameters gebruik, gebaseerd op een statische verdeling van elke input parameter binnen de onzekerheidsmarge. Voor elke simulatie bereken ik de drukdaling en de daaraan gerelateerde spanningsveranderingen. Als die tot het ontstaan van een aardbeving leiden bereken ik vervolgens de resulterende hoeveelheid breukbeweging; deze is verwant aan de aardbevingsgrootte. Waar ik in Hoofdstuk 2 nog een dynamische berekening deed om de hoeveelheid breukbeweging te bepalen, gebruik ik hier een snellere analytische benadering, die het mogelijk maakt de vele simulaties uit te voeren. Op deze manier krijg ik een fysisch onderbouwd inzicht in de aardbevingsrespons van het Groningen gasveld op gasproductie, met inachtneming van de onzekerheden. De resultaten helpen te begrijpen met welke hoeveelheid drukdaling en op welke plaats in het gasveld bevingen kunnen ontstaan, en tot hoe ver breukbeweging zich kan uitbreiden.

In Hoofdstuk 7 geef ik een samenvatting van de belangrijkste bevindingen, en behandel ik verschillende implicaties die de bevindingen hebben voor het optreden van bevingen in het Groningen gasveld. Verder geef ik aanbevelingen voor hoe het onderzoek en de numerieke modellen kunnen worden verbeterd of uitgebreid, en hoe ze in de toekomst gekalibreerd zouden kunnen worden aan observaties uit het veld. Daarmee kunnen de onzekerheden van de verschillende input parameters (bijvoorbeeld de initiële spanning) worden verkleind, de voorspellende waarde van de modellen vergroot, en de inschatting van het seismisch risico verbeterd. Dit is van belang voor de laatste jaren van gasproductie uit het Groningen veld, maar ook voor de jaren daarna als er nog bevingen kunnen optreden, alsook voor andere, toekomstige activiteiten in de ondergrond. 
Samenvatting 
Samenvatting 


\section{Chapter 1}

Introduction, Scope and Aims

20:

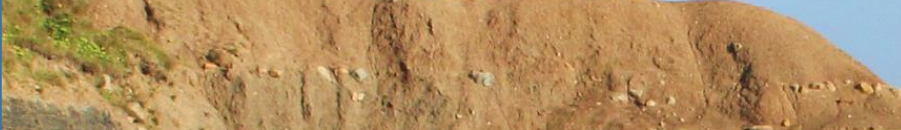

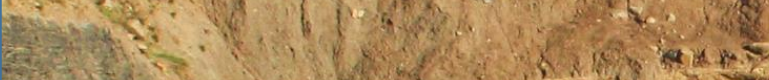

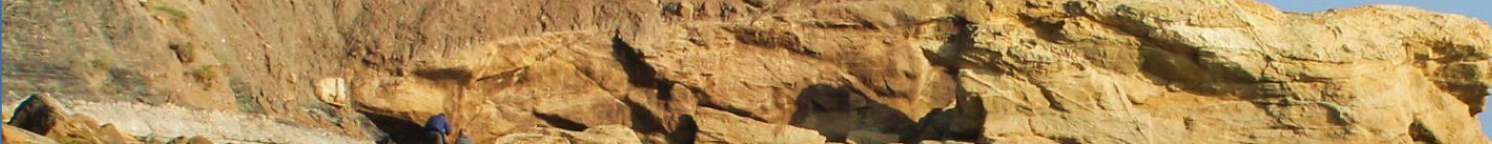

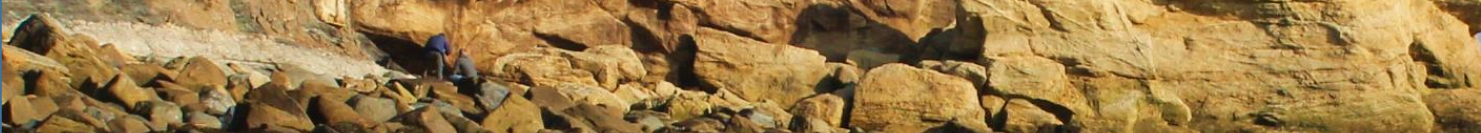

1.

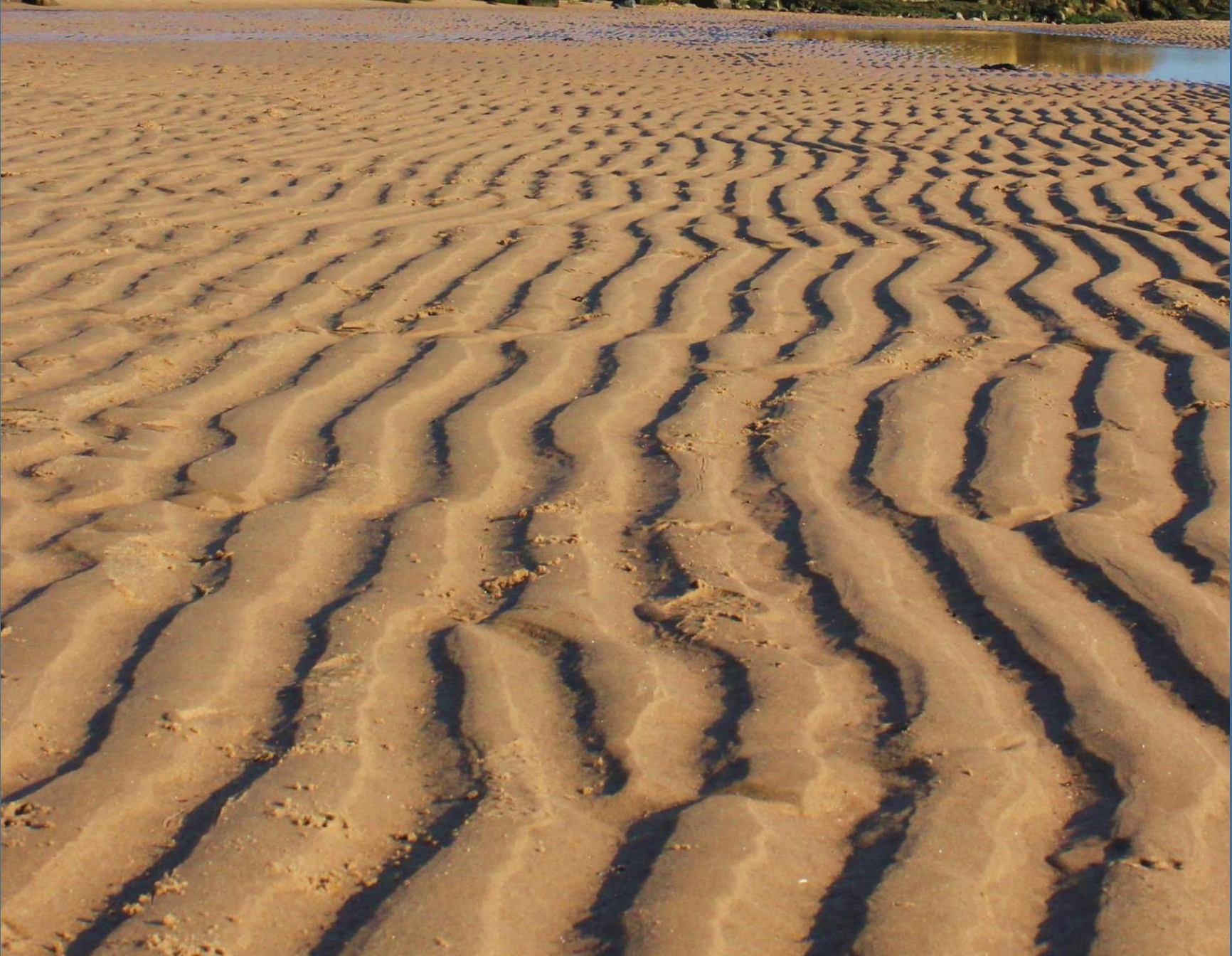





\section{Introduction, Scope and Aims}

\section{1. Induced earthquakes in Groningen and the scope of this thesis}

On the night of the $16^{\text {th }}$ of August 2012, 22:31 local time, the province of Groningen in the N.E. Netherlands shook as a magnitude $\mathrm{M}_{\mathrm{L}} 3.6$ earthquake occurred near the village of Huizinge. The earthquake was the result of gas production from the Groningen gas field Europe's largest - situated at $3 \mathrm{~km}$ depth below the province of Groningen (Figure 1-1). The event was not the first one to be recorded above the Groningen field, but it was special because it was the strongest to date and its duration was longer than previous earthquakes (Dost \& Kraaijpoel, 2013). It was felt throughout the province of Groningen and caused structural damage to over a thousand buildings. As some of the local inhabitants describe it: "A thundering sound was heard. The whole house was shaking in different directions, and we heard cracking sounds emitted from the house". The Huizinge earthquake turned out to be a gamechanger event for the perception of induced seismicity in the Netherlands and for the future of Dutch gas production.

Prior to the occurrence of the first earthquake near a gas field to the south of the Groningen field in 1986 (Assen, $\mathrm{M}_{\mathrm{L}} 2.8$ ), the north of the Netherlands was an aseismic area. Tectonic earthquakes with magnitudes up to $\mathrm{M}_{\mathrm{L}} 5.8$ (Roermond, 13 April 1992) have only been observed in the south of the Netherlands (Figure 1-1). The first earthquake in the Groningen field was recorded in 1991 with a magnitude of 2.5; from then on the number and size of the induced earthquakes has increased (Figure 1-2). By December 2012 more than 600 events with magnitudes up to $\mathrm{M}_{\mathrm{L}} 3.6$ had been recorded in Groningen by the Royal Netherlands Meteorological Institute (KNMI) seismic network (www.knmi.nl). Before the Huizinge event, it was thought that the size of earthquakes in the gas fields in the Netherlands would remain limited; indeed, analysis of the frequency-magnitude relationship shown by seismic events recorded from 1986 to 2010 suggested that events would not exceed a local magnitude $\mathrm{M}_{\mathrm{L}} 3.9$ (Dost et al., 2012). However, after the 2012 Huizinge event, the seismological and geomechanics community in the Netherlands realized that this limiting size might not hold true, and that the seismicity might not be stationary - i.e. not exhibiting a constant frequency and magnitude distribution in time. Following an alarming report by the national regulator, the State Supervision of Mines (SodM), early in 2013, in which the previously accepted notion of $\mathbf{M}_{\max } 3.9$ was abandoned (Muntendam-Bos \& De Waal, 2013),

\footnotetext{
Photograph previous page: Outcrop of Permian Yellow Sands at the beach of Cullercoats, $15 \mathrm{~km}$ north of Newcastle, United Kingdom. These sands are of Permian Rotliegendes age and are of aeolian origin. At the base of the outcrop, the 90 Fathom Fault (a normal fault with 120 m offset) juxtaposes the Permian Yellow Sands against Upper Carboniferous coal measures consisting of shale, mudstones, and coal seams. Similar juxtapositions of Permian sandstone and Carboniferous shale are likely present along the normal faults cross-secting the Groningen reservoir.
} 


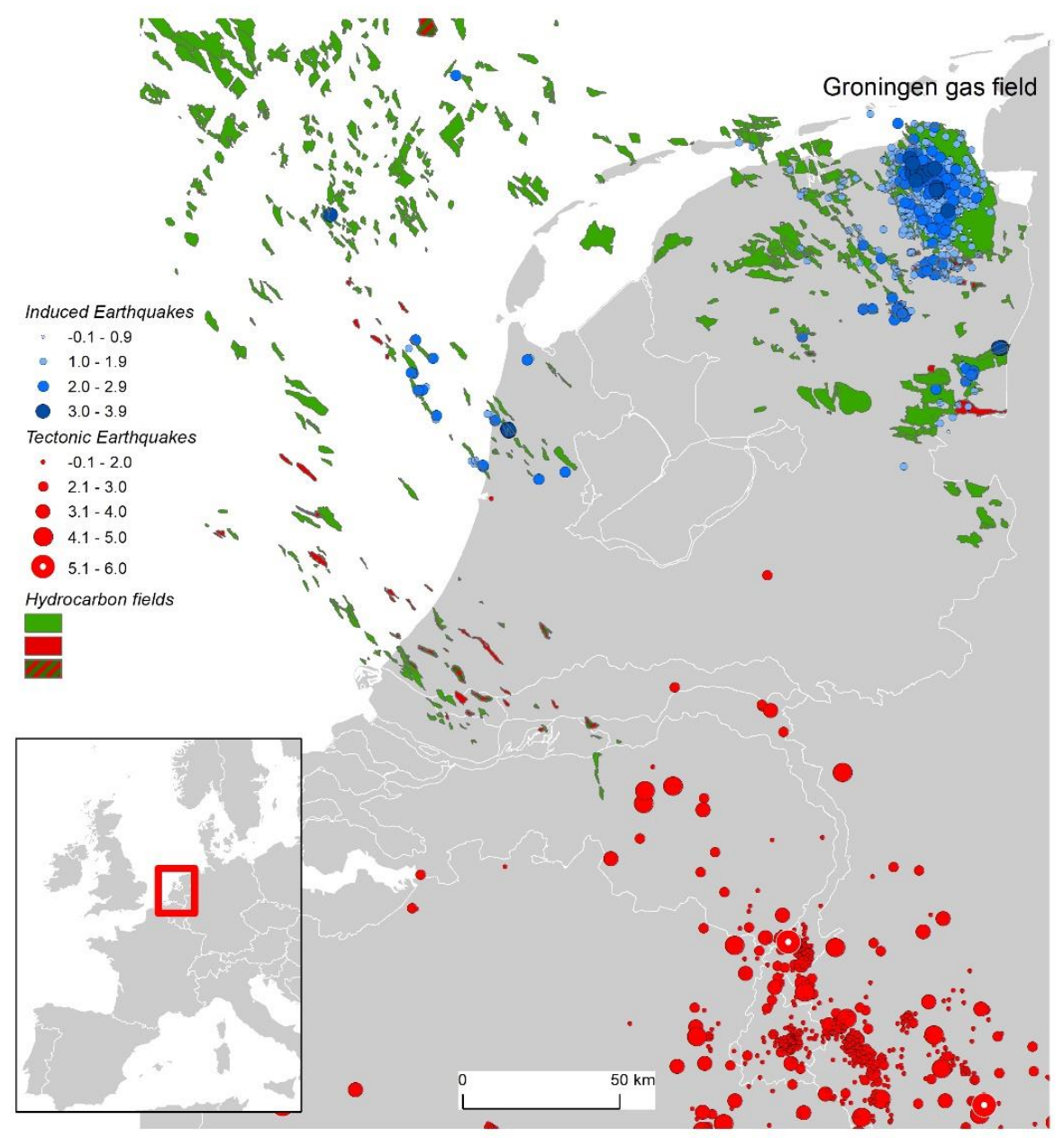

Figure 1-1. Hydrocarbon fields in the Netherlands and incidence of natural and induced seismicity up to January 2020. The location of the Groningen field in the north of the Netherlands is indicated. Seismic events: www.knmi.nl,. Hydrocarbon fields: www.nlog.nl, with green: gas fields, red: oil fields, hatched: oil/gas fields.

research on the relationship between production and the seismic hazard above the Groningen field intensified. Major studies were initiated in 2013 by the field operator NAM (NAM, 2013) and the Netherlands Organisation for Applied Scientific Research TNO (TNO, 2013), leading to the decision to reduce gas production in part of the Groningen field within a total field production cap of $42 \mathrm{BCM}$ (billion cubic meters, $10^{9} \mathrm{~m}^{3}$ ) in 2014 and $27 \mathrm{BCM}$ in 2015 - i.e. a reduction of over $40 \%$ compared with the years before (Figure 1-2a). Since then, research at NAM, TNO, KNMI, and other companies, institutes and universities progressed and seismic hazard models for the Groningen field have improved further and further (e.g. Bommer et al., 2017; Bourne et al., 2014; Bourne et al., 2015; Bourne \& Oates, 2017b; Dost et al., 2017). Following the 'Winningsplan 2016' (production operational plan 2016) 
submitted by the operator NAM (NAM, 2016b; NAM, 2016c), stricter production measures were imposed with the announcement of a production cap of 24 BCM in June 2016 (Ministry of Economic Affairs, 2016). Further announcements in May 2017 lowered the annual production cap to 21.6 BCM (Ministry of Economic Affairs, 2017; NAM, 2019a). Even so, the earthquakes continued (albeit at lower rates) and the number of damage claims and societal unrest grew. Following another damaging $\mathrm{M}_{\mathrm{L}} 3.4$ earthquake on the $8^{\text {th }}$ of January 2018 near the village of Zeerijp, on the $18^{\text {th }}$ of March 2018 it was decided that the annual gas production from Groningen should be lowered further to $12 \mathrm{BCM}$ in 2022 at the latest, with a full phase-out of gas production in 2030 (Ministry of Economic Affairs and Climate Policy, 2018). In September 2019, the minister of Economic Affairs decided to phase out production of the Groningen field by 2022 instead, assuming normal annual national energy demand (Ministry of Economic Affairs and Climate Policy, 2019). The impact of the induced seismic events on Dutch society since 2012, and perhaps even after field closure, and the consequences of ceasing gas production from this giant field for the national energy landscape and economy, have sharply highlighted the need for a better understanding of the hazards posed by, and the nature and underlying origin of, the induced events in Groningen.

To assess the seismic hazard related to gas production, it is important to understand the physical mechanisms causing the induced earthquakes. Under which conditions and at which locations in and around the fields are the earthquakes expected to occur? Do they originate within the reservoir itself? How are they generated? And how large can they become as gas production progresses? This thesis revolves around understanding the mechanisms and answering questions such as these. Since gas production from Groningen started in 1963 and in particular in the last five years, a wealth of information and data on the field and on the induced seismicity detected have become available. In this introduction to my thesis, I summarize the main characteristics of the Groningen field, the properties of the induced seismic events, the proposed mechanisms behind the seismic events, and the modeling approaches used to understand the seismicity and their role in seismic hazard calculations. Against this background, I then define the aims of the present work and outline the structure of the thesis. 

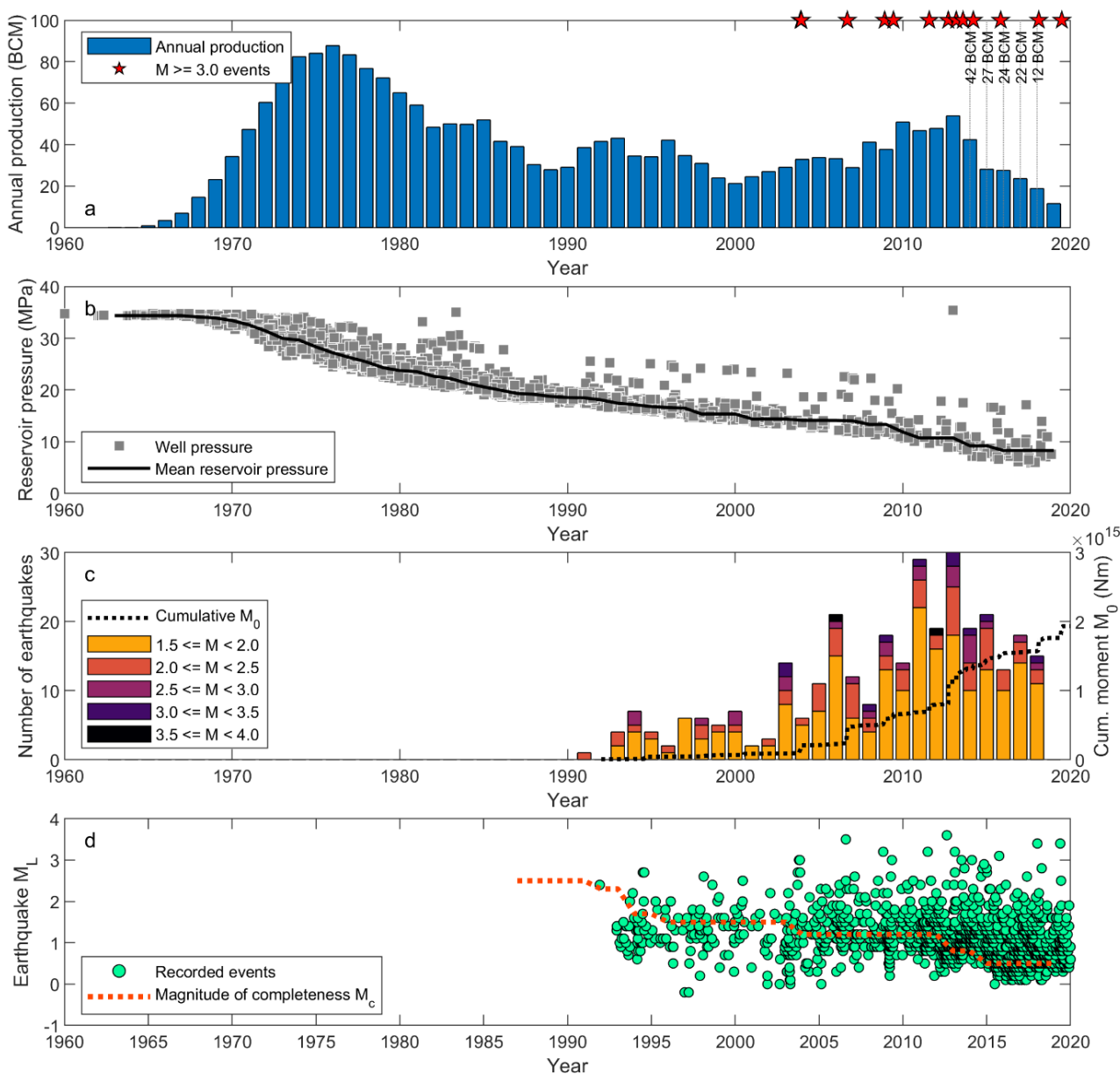

Figure 1-2. Operational parameters and seismicity in the Groningen gas field. a) Annual production volume in BCM (billion cubic meters) (www.nam.nl/feiten-en-cijfers), b) Reservoir pressure (www.nam.nl/feiten-en-cijfers), c) Number of seismic events and cumulative seismic moment (www.knmi.nl), d) Richter or local Earthquake magnitude $\left(M_{L}\right)$ and magnitude of completeness $M_{c}$ (Dost et al., 2012; Dost et al., 2017).

\section{2. Background on the Groningen gas field and the induced seismicity recorded}

\section{2. 1. Reservoir geology, gas production and reservoir compaction}

At the time of its discovery in 1959, the Groningen gas field was the largest onshore gas field in the world with an initial gas in place (GIIP) estimate of $2100 \mathrm{BCM}$. The geology of the field is described in detail by de Jager \& Visser (2017). The main reservoir rock is the Slochteren Formation (ROSL) of the Upper Rotliegend Group (Permian Age). The Slochteren Formation is composed of a sequence of predominantly ( 80\%) fluvial and 
aeolian sandstones with porosities mainly between 10 and $26 \%$ and permeabilities ranging from 1 to $1000 \mathrm{mD}$. In the south of the field, more pebbly and conglomeratic intervals occur, whereas in the north the formation becomes more clay-rich and the porosity tends to be higher (de Jager \& Visser, 2017). The Slochteren Formation can be subdivided into a Lower and Upper Slochteren Member, with the Lower Member containing more conglomerate intervals. In the northernmost parts of the Groningen field the Upper and Lower Member are separated by the Ameland Claystone, which becomes more sandy towards the south so the Upper and Lower Slochteren Member can no longer be discerned (www.dinoloket.nl/nomenclator). The depth of the top of the Rotliegend Formation increases from $2400 \mathrm{~m}$ in the south down to $2900 \mathrm{~m}$ in the north of the field (Figure 1-3b). At the same time, the thickness increases from $50 \mathrm{~m}$ in the southeast to over $300 \mathrm{~m}$ in the north of the field. At the location of the Stedum01 (SDM-01) well, the Slochteren Formation is encountered at $2843 \mathrm{~m}$ depth and has a thickness of $201 \mathrm{~m}$ (Figure 1-3a), for example. The original gas pressure in the reservoir was 34.7 MPa, and the gas-water contact was located at 2980 - $3000 \mathrm{~m}$ depth (NAM, 2016a). The Slochteren Formation is overlain by the Ten Boer Claystone, which has a thickness of several tens of meters in the south to over $80 \mathrm{~m}$ in the north. The Ten Boer Claystone is comprised of silts and shales, and also contains thin, gas-laden sandstone lenses that may also experience pore pressure depletion during gas production from the main reservoir. The Ten Boer Claystone is overlain by the Triassic Zechstein formation, the base of which consists of a $50 \mathrm{~m}$ thick sequence of anhydrite and carbonate members. The anhydrite-carbonate sequence is overlain by 100's of meters of predominantly halite. The Slochteren Formation unconformably overlies the Carboniferous substrate or "underburden" which is comprised of fine-grained fluvial siliciclastics (siltstones and shales) intercalated with occasional coal seams (Filippidou et al., 2019; van Assema, 2017).

Over a thousand almost exclusively normal faults have been recognized in the Slochteren Formation from reflection seismics (de Jager \& Visser, 2017; Kortekaas \& Jaarsma, 2017; NAM, 2016b). The dominant fault trend in the field is NNW-SSE, but also E-W and N-S fault trends are recognized (Figure 1-3b and c). The faults were formed and reactivated during different tectonic events. The formation of the E-W faults in the Upper Carboniferous underburden is associated with the Variscan Orogeny occurring during the late Carboniferous (Kortekaas \& Jaarsma, 2017; Ligtenberg et al., 2011). Subsequent thermal uplift and oblique faulting at the end of the Carboniferous led to the formation of the NNW-SSE and N-S faults. Following deposition of the Permian and younger sediments, reactivation of these preexisting normal faults during later tectonic events (extension in the Triassic to Early Cretaceous, and inversion in the Late Cretaceous) resulted in growth of these faults into the Upper Rotliegend Group. Above the Rotliegend Group, the faults terminate in the Zechstein salt, which mechanically decouples the formations below and above because of its ductile nature. However, the faults extend for more than $1000 \mathrm{~m}$ into the Carboniferous underburden, down to the Dinantian carbonate platforms that are locally found below the field from $4.7 \mathrm{~km}$ depth (Kortekaas \& Jaarsma, 2017; NAM, 2016b). Within the Rotliegend, the dip of the faults 


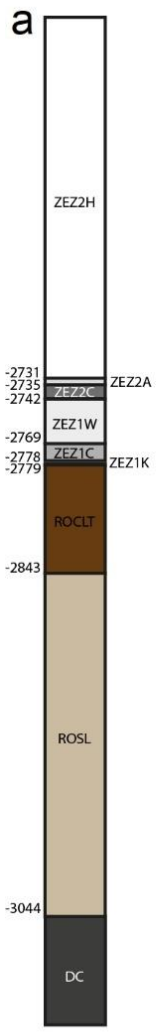

ZEZ2H: Mainly halite, continues to $-2155 \mathrm{~m}$

ZEZ2A Basal Anhydrite: relatively pure anhydrite

ZEZ2C Z2 Carbonate: Finely laminated, argillaceous limestone

ZEZ2W Z1 Anhydrite Member: Massive anhydrite, potentially containing dolomite stringers

ZEZ1C Z1 Carbonate Member:Transitioning from argillaceous limestone at the base to anhydrite at the top

ZEZ1K Coppershale: 0.5 - 1 m thick brown blac shale

ROCLT Ten Boer Clay: Red-brown, sandy clayand siltstone interval, occasionally containing sandstone stringers

ROSL Slochteren Formation: Sandstones and conglomerates, sometimes intercalated with clay layers

DC Limburg Group: Grey-black fine-grained siliciclastic sediments with commonly intercalated coal seams. Also sand bodies are present in this formation.

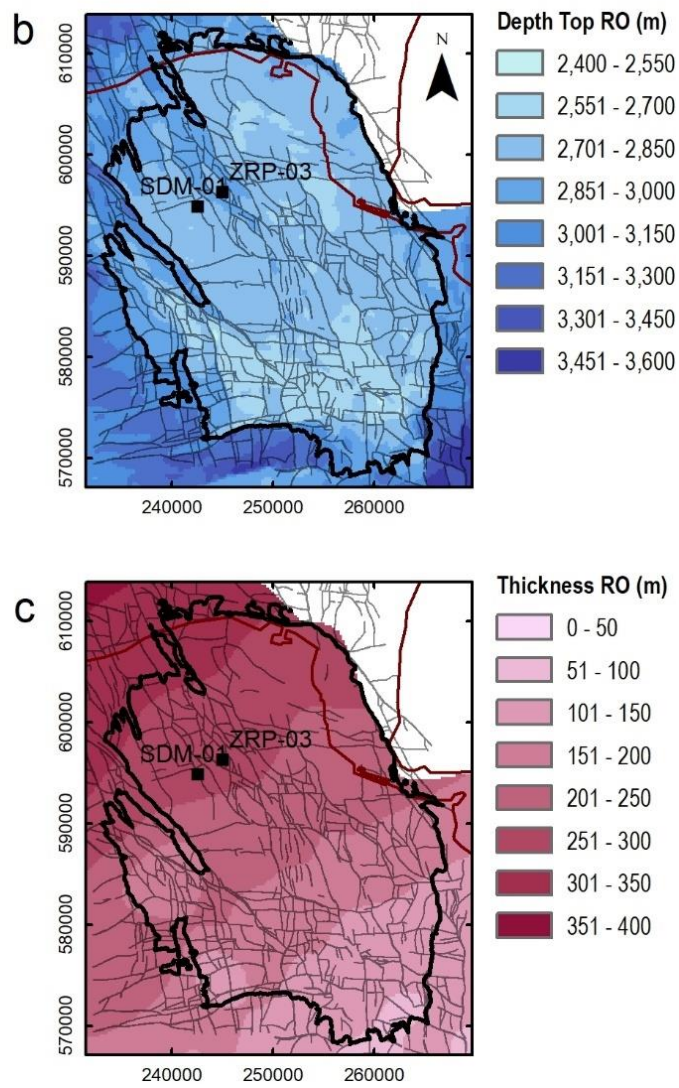

Figure 1-3. Stratigraphy of the Groningen field and depth and thickness of the reservoir formation. a) Stratigraphy along the Stedum-01 (SDM-01) well in the north of the field. DC: Carboniferous, RO: Upper Rotliegend Group, ZE: Zechstein Group. (see also www.dinloket.nl/nomenclator). Depth (b) and thickness (c) of the top of the Upper Rotliegend Group (DGM-diep V4, www.nlog.nl). Black line: Groningen field, dark red line: coastline. Coordinate system: Rijksdriehoek (Amersfoort/RD New).

is generally quite steep with an average dip of $75^{\circ}$ (NAM, 2016b; Wentinck, 2016). Vertical offset along the fault is mostly smaller than $100 \mathrm{~m}$ and occasionally ranges up to $200-300 \mathrm{~m}$ (Figure 1-4a), thus juxtaposing many of the various lithologies described above against each other. The present-day tectonic stress field is extensional with the maximum horizontal stress striking NNW-SSE, parallel to the strike of the dominant fault structures in the field (van Eijs, 2015).

Gas production from the field started in 1963, reaching a peak annual production of over 80 BCM in 1976 (Figure 1-2a). After this peak, the annual production from Groningen was decreased to $35-40 \mathrm{BCM}$ per year, which was compensated by production from smaller gas fields in the Netherlands. Currently, 20 clusters with a total of 258 production wells are present in the field, as well as 22 observation wells, 3 water disposal wells, and 24 abandoned wells (NAM, 2016a). Note that the annual production is cyclic, with higher production in the 
winter and lower production in the summer. For the period $2005-2015$, a production cap of a total production of $425 \mathrm{BCM}$ was imposed for security of supply. After the occurrence of the Huizinge earthquake in 2012, production was capped further to reduce the seismic hazard. In 2015 the annual production was capped at 27 BCM and production from a cluster of wells near the seismically active Loppersum area in the north of the field was shut down entirely. Since 2015, production has been decreased further and a total phase-out of gas production is expected in 2022 (Ministry of Economic Affairs and Climate Policy, 2019). See Section 1.1 for further details on the production measures.
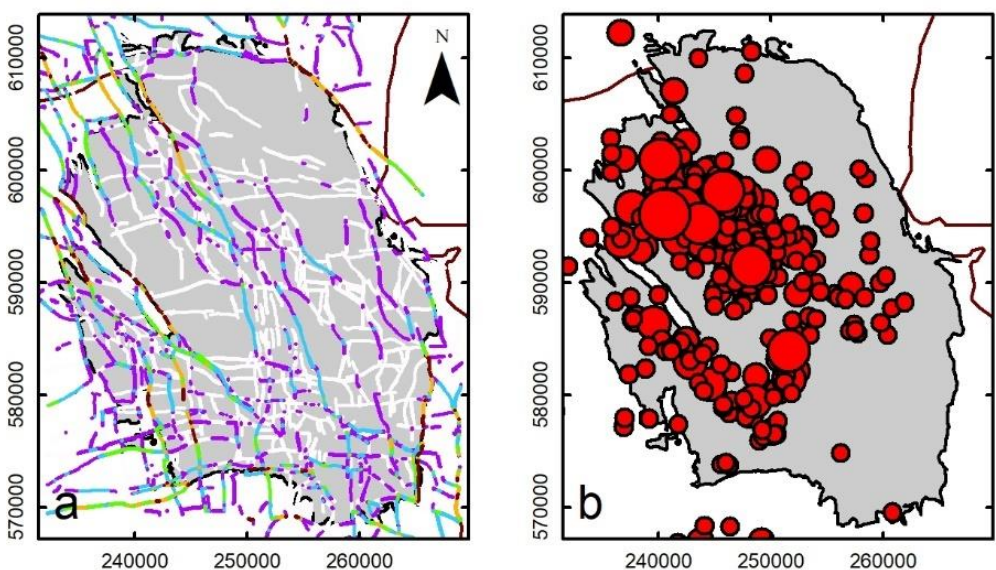

Fault normal offset $(\mathrm{m})$

- 0.50

- $51-100$

- $101-150$

- $151-200$

- $201-250$

- $251-300$
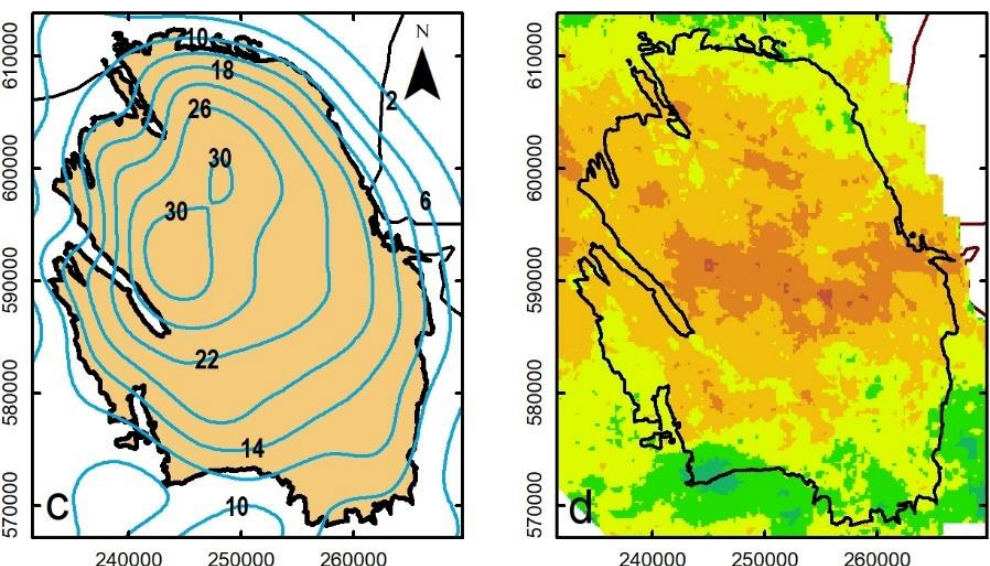

Induced event $\mathrm{M}$

- $1.5-2.0$

( $2.1-2.5$

$2.6-3.0$

$3.1-3.5$

3.6

Average porosity ROSL

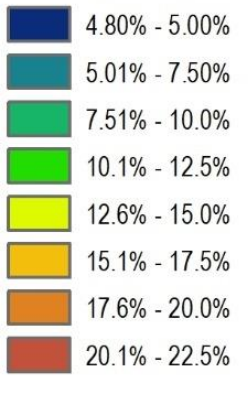

Figure 1-4. Faults, earthquakes, subsidence, and compaction in the Groningen field. a) Fault offset map (courtesy of NAM, 2017) $t$, b) Seismicity with $M_{L}>1.5$ recorded since 1991 (www.knmi.nl), c) Surface subsidence contours showing measured subsidence up to 2013 (courtesy of NAM), d) porosity averaged over the thickness of the reservoir formation (courtesy of NAM). Field outline from www.nlog.nl. 
As indicated already, the initial pressure in the reservoir formation was $34.7 \mathrm{MPa}$ in 1963 (Figure 1-2b). With ongoing depletion, pressure decreased to $10 \mathrm{MPa}$ at the time of the Huizinge earthquake in 2012, and to $8 \mathrm{MPa}$ at the present day (van Oeveren et al., 2017, http://www.nam.nlfeiten-en-cijfers). 'Aquifer support' is weak except in the westernmost part of the field, so repressurization by water (brine) inflow is limited (NAM, 2016a). While the gas-water contact was originally found at 2980 - $3000 \mathrm{~m}$ depth, it has moved up by $20-$ $40 \mathrm{~m}$ since the start of production (NAM, 2016b). The pressure decrease in the reservoir is relatively uniform demonstrating that the different compartments are in communication (Burkitov et al., 2016; NAM, 2016b). Most faults thus appear to be permeable although there may be a small pressure difference across some (a few MPa), in particular faults on the periphery of the field (Burkitov et al., 2016; NAM, 2016b). Pressure measurements show that the Ten Boer Claystone is also experiencing pore pressure depletion, but lags behind with respect to the depletion of the reservoir (Burkitov et al., 2016). The pore pressure difference between the Ten Boer and the Slochteren Formation may be up to $7.5 \mathrm{MPa}$ at present. In-situ compaction measurements show that the Ten Boer is also experiencing compaction, in agreement with the observed pressure decrease (Cannon \& Kole, 2018). These compaction measurements also showed that the upper $80 \mathrm{~m}$ of the Carboniferous underburden is compacting, suggesting that it may also experience some degree of depletion.

The pressure decrease in any reservoir due to fluid production causes the reservoir to compact, as a result of the increase in vertical (effective) stress carried by the grain framework. Understanding reservoir compaction in Groningen is crucial as it is an important driver for the induced seismic events. Reservoir compaction also leads to subsidence at the surface above the Groningen field. Using this subsidence data provides one way to constrain the spatiotemporal compaction behavior of the reservoir. Various subsidence measurement data have been obtained for the Groningen field over the years, including optical leveling, GPS and INSAR data. Optical leveling campaigns have been performed over the field approximately every three years since 1964, with the first complete survey taking place in 1972. Initially, little subsidence was observed, but subsidence rates accelerated from 1975 (Hettema et al., 2002; van Thienen-Visser \& Fokker, 2017). The last leveling campaign was in 2013, and measured a maximum subsidence of just over $0.3 \mathrm{~m}$ in the central parts of the field (Figure 1-4c). Inversion of this subsidence data can be used to obtain the compaction behavior of the reservoir, through reducing the mismatch between the observed subsidence and modeled subsidence. Modeled subsidence requires computation of reservoir compaction which is achieved using the static reservoir model, which contains information about the geology, porosity, and permeability (Visser \& Viota, 2017), in combination with the dynamic reservoir model, which contains history-matched field pressures (Bourne et al., 2014; van Oeveren et al., 2017; van Thienen-Visser \& Fokker, 2017; van Thienen-Visser et al., 2015). The inversion results show that the amount of compaction of the reservoir is strongly dependent on the reservoir porosity (Figure 1-4d), as well as the reservoir thickness, and is largest in the center and northern region of the field with a maximum of $0.3 \mathrm{~m}$ vertical 
thickness reduction in 2017 and a predicted maximum of $0.45 \mathrm{~m}$ at full reservoir depletion (e.g. van Thienen-Visser \& Fokker, 2017). For a reservoir thickness of $200 \mathrm{~m}$, this corresponds to a vertical strain of $0.2 \%$. In terms of uniaxial compressibility $C_{m}$, which is the vertical strain $\varepsilon_{y}$ divided by the pressure change $\Delta P$, this corresponds to a $C_{m}$ of up to 0.8 . $10^{-4} \mathrm{MPa}^{-1}$. INSAR and GPS data (from 2013 on) indicated similar compaction patterns with a time-independent $C_{m}$ up to $0.7 \cdot 10^{-4} \mathrm{MPa}$ (Smith et al., 2019). Independent in-situ measurements of compaction have also been performed using gamma ray markers embedded in the wellbore casing and in the reservoir (Cannon \& Kole, 2018; Kole, 2015) . More recently, and as already mentioned in the context of depletion of the Ten Boer formation, distributed strain sensing (DSS) methods using a glass-fiber cable have been employed along the casing of the Zeerijp-03 well (Cannon \& Kole, 2018). Uniaxial compressibility values measured within the Slochteren sandstone using the latter method range from 1 to $2 \cdot 10^{-4}$ $\mathrm{MPa}^{-1}$, slightly above the $C_{m}$ values determined from laboratory measurements conducted on sandstone cores (Hol et al., 2018) and those derived from INSAR and GPS data (Smith et al., 2019).

\section{2. 2. Characteristics of the seismicity observed in the Groningen field}

The Royal Dutch Meteorological Institute (KNMI) manages the national seismic network in the Netherlands. Since the first earthquake occurred in 1991, the seismic network coverage in the north of the Netherlands has been improved in several steps whereby the following instruments were added thanks to investments by operator NAM (Dost et al., 2012; Dost et al., 2017):

- 1995:

8 shallow borehole stations with geophones

- 1997:

7 accelerometers

- 2004-2010:

8 accelerometers

- 2010:

6 shallow borehole stations

- 2011:

1 accelerometer

- 2014-2016: 70 shallow borehole stations with geophones and accelerometer

As a result, the magnitude of completeness $M_{c}$ has improved from an $M_{L}$ value of 1.5 at the end of the 1990's to the current $M_{L}$ value of 0.5 (Figure 1-2d). In addition, in 2016 two deep borehole geophone stations were placed in two wells in the north of the field by the field operator NAM; the Zeerijp-03 and Stedum-01 well (Figure 1-3b). By 2019, these deep arrays had recorded 1230 locatable events, with magnitude between M -3 and 2.6 (NAM, 2015; NAM, 2019b). 


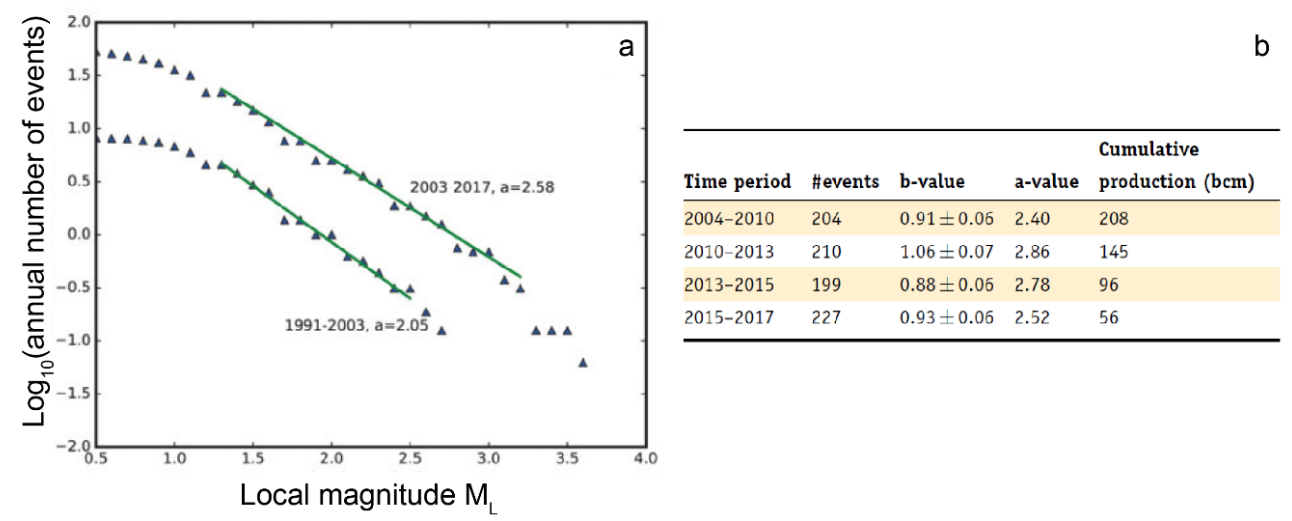

Figure 1-5. Frequency-magnitude distribution of seismic events in the Groningen gas field (from: Dost et al., 2017). a) Log of the cumulative annual number of events as a function of local magnitude $M_{L}$ for the Groningen field, in time periods 1996 - 2003 and 2003 - 2017. b) Table showing the b-value (slope of the frequency magnitude relation) for different time periods between 2004 and 2017.

In the period 1986 to December 2019, the KNMI network recorded >1300 events with magnitudes between $\mathrm{M}_{\mathrm{L}}-0.2$ and 3.6, amounting to a cumulative seismic moment of 2 - $10^{15} \mathrm{Nm}$ (Figure 1-2c and d). Seismic activity increased after 2003, which was reflected both in a change in activity rate and in b-value - i.e. the slope of the frequency-magnitude distribution, with smaller values indicating a larger fraction of large events (Figure 1-5a). The b-value decreased from 1.06 to 0.93 after 2003, and mostly remained stable around 0.9 afterwards (Dost \& Kraaijpoel, 2013; Dost et al., 2017) (Figure 1-5b). The earthquake activity appeared temporally correlated with the production rate. Specifically, for example, a decrease in the seismic activity rate was observed in the Loppersum area after the shut-down of the Loppersum production cluster in 2015, with a delay time of $2-8$ months (Nepveu et al., 2016).

In order to understand the mechanisms causing the seismicity, it is important to know the location of the earthquakes with respect to the faults, the reservoir formation, and other geological structures. However, before 2014 station coverage was still limited, a 1D velocity model was used (Dost et al., 2017) and uncertainties in location were too large to link the events to geological structure. At that time, location uncertainty was \pm 0.5 to $1 \mathrm{~km}$ horizontally and $> \pm 1 \mathrm{~km}$ vertically, and most events in the catalog from this period are listed with a fixed depth of $3 \mathrm{~km}$ (www.knmi.nl). The improvements in the seismic network from 2014 and the 3D velocity model made available by NAM from 2017 (Romijn, 2017) reduced the uncertainty to $\pm 0.1-0.3 \mathrm{~km}$ horizontally and $\pm 0.3 \mathrm{~km}$ vertically (Dost et al., 2017). Relocation of 87 events recorded by the upgraded networks in 2014 - 2016 showed two things: the relocated events were often located on or near known faults, and the majority of the events was located within the reservoir formation (Spetzler \& Dost, 2017a; Willacy et al., 2018). These findings are consistent with the data recovered from the deep borehole arrays (NAM, 2014; NAM, 2019b). Comparison of the recorded data with waveform modeling also 
indicates that the vast majority of events nucleate in or close to the (fault-offset) reservoir depth interval.

Source parameters of the recorded waveform data give additional information about the induced seismic events and the underlying physical processes. Moment tensor inversion of four of the larger events recorded up to 2010 (the Westeremden $\mathrm{M}_{\mathrm{L}}$ 3.5, 8 August 2006, Loppersum $M_{L}$ 3.2, 30 October 2008, Huizinge $M_{L}$ 2.6, 14 April 2009, and the Zeerijp $M_{L}$ 3.0, 8 May 2009 events) has indicated a normal faulting mechanism on faults trending NWSE (Kraaijpoel \& Dost, 2013), in agreement with the regional stress field which has a maximum horizontal stress striking NNW-SSE (van Eijs, 2015). Full waveform modeling, conducted using data acquired from 50 events recorded by the deep boreholes in the period 2013 - 2015, and 100 events recorded by the updated shallow borehole network in the period 2015 - 2017, gives consistent results demonstrating predominantly normal faulting mechanisms close to or on the known mainly NNW-SSE striking faults (Willacy et al., 2018). This study also shows that a number of faulting mechanism solutions have indicated strikeslip motion on a few faults, specifically near fault junctions. Assuming circular rupture surfaces, the radius of the area that slipped during the four larger events listed above has been estimated using the Brune source model (which assumes a circular rupture source) to be 300 $-400 \mathrm{~m}$, with an average slip of 5 to $20 \mathrm{~mm}$, and a stress drop of 0.3 to $1.7 \mathrm{MPa}$ (Kraaijpoel \& Dost, 2013). For the Huizinge earthquake ( $M_{L} 3.6,16$ August 2012), the rupture radius was similar $(390 \mathrm{~m})$ but the slightly higher stress drop of $2.5 \mathrm{MPa}$ indicated a larger average slip of $50 \mathrm{~mm}$ (Dost \& Kraaijpoel, 2013). For the Zeerijp rupture $\left(\mathrm{M}_{\mathrm{L}}\right.$ 3.4, 8 January 2018), a larger stress drop of $3-5 \mathrm{MPa}$ was estimated (Wentinck, 2018). Stress drop estimates computed for 22 earthquakes with $\mathrm{M}_{\mathrm{L}}>2.5$ varied between $0.4-40 \mathrm{MPa}$ (Bommer et al., 2017). To summarize, the rupture size of the largest $\left(M_{L} 3.0-3.6\right)$ events in the Groningen field are less than $1 \mathrm{~km}$, with a stress drops mostly between $1-10 \mathrm{MPa}$, and an average slip of several $\mathrm{mm}$ to several $\mathrm{cm}$. Note, however, that the computation of slip area and stress drop depends on underlying model assumptions concerning the shape of the seismic rupture and rupture velocity. Also, the slip is the slip averaged over the rupture area; locally, dynamic shear slip may be higher.

\section{2. 3. Seismicity in other gas fields in Northwest Europe}

Several other gas fields in the Netherlands and Germany have also been associated with induced seismicity of comparable magnitude. The tectonic setting of these fields is comparable to Groningen and the reservoir rocks are often similar. Therefore, it is interesting to consider observations from these fields besides the observations from Groningen, as additional insight into the physical mechanisms can be gained. In the Netherlands, seismicity was recorded near or within about 20 other gas fields, with magnitudes from 1.0 to 3.5 (www.knmi.nl). In Northwest Germany (Lower Saxony) seismicity was recorded near or within 11 gas fields. Figure 1-6 shows hydrocarbon fields associated with M 2.0 or larger, the majority of which are gas fields. 


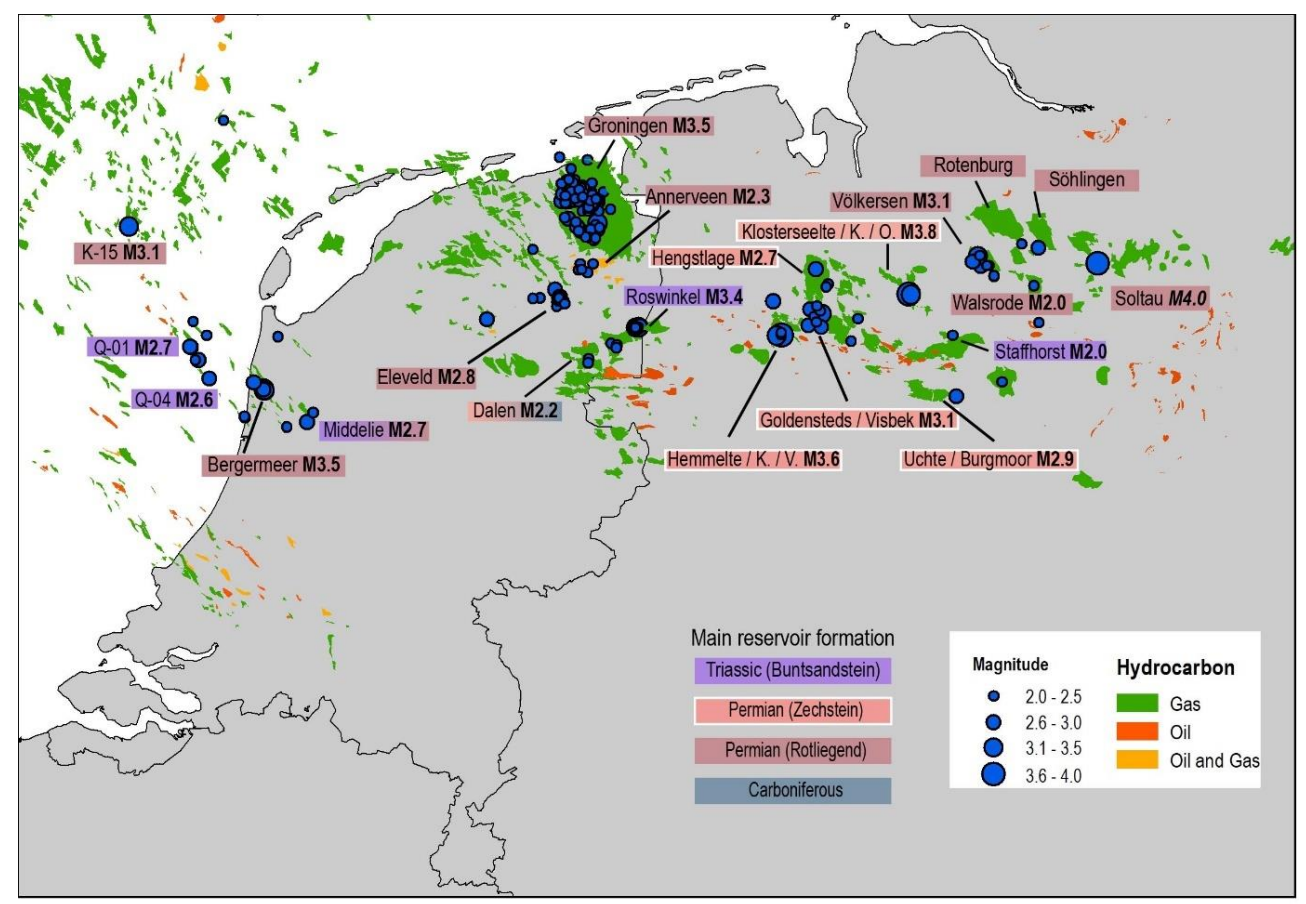

Figure 1-6. Seismicity induced by hydrocarbon production in the Netherlands and Northern Germany. Fields from www.nlog.nl. Induced seismic events Netherlands: www.knmi.nl. Induced seismic events Germany (Bischoff et al., 2013; Bischoff et al., 2014; Bischoff et al., 2015; Bischoff et al., 2016; Bischoff et al., 2019)

Seismic events up to M 3.5 were observed in the Bergermeer field, a Rotliegend reservoir in the west of the Netherlands (Haak et al., 2001; Orlic \& Wassing, 2012; Van Eck et al., 2006). Gas production took place from 1970 to 2007 with a pressure drop from $23 \mathrm{MPa}$ in 1970 to $7 \mathrm{MPa}$ in 1994 to $3 \mathrm{MPa}$ in 2007 . The reservoir is located in a small horst structure with an uplift of a few hundred meters with respect to the surrounding formations. Directly below and above the reservoir are the Carboniferous and a few hundred meters of Zechstein dolomite/anhydrite and salt, respectively. The earthquakes were located on a scissor-like fault situated in the center of the reservoir (i.e. a fault with locally zero offset but with increasing offset in both directions along strike).

In Germany, two larger earthquakes occurred within a few $\mathrm{km}$ of the gas reservoirs located in the Lower Saxony, specifically an $\mathrm{M}_{\mathrm{L}} 4.0$ event near Soltau in 1977 and an $\mathrm{M}_{\mathrm{L}} 4.5$ event near Rotenburg in 2005 but these may be of natural origin (Dahm et al., 2007). About 50 other events with several attaining $\mathrm{M}_{\mathrm{L}}>3.0$ were recorded in the vicinity of the gas fields further to the west (Figure 1-6), reaching up to an $\mathrm{M}_{\mathrm{L}} 3.8$ event near the village of Syke on the 15th of July, 2008 (Bischoff et al., 2013; Bischoff et al., 2014; Bischoff et al., 2015; Bischoff et al., 2016; Bischoff et al., 2019). As in the Netherlands, most events seen in German gas fields occurred decades after initiation of production. About half of the 
seismogenic gas reservoirs in Germany are Permian Rotliegend sandstone reservoirs, but the other seismogenic reservoirs produce from the porous and/or permeable Zechstein (Staßfurt) carbonates and dolomites. Generally, the gas reservoirs are deeper than those in the Netherlands, up to $4.8 \mathrm{~km}$ depth, as are the induced events. Also, many of the reservoirs are stacked reservoirs, producing from multiple horizons. The NW German fields are bounded or intersected by NW-SE striking faults (Bischoff et al., 2019; Haug et al., 2018), but unfortunately little is known about the source characteristics of the events or their relation to the structural geology of the gas fields.

\section{3. Mechanisms of depletion-induced seismicity and modeling approaches}
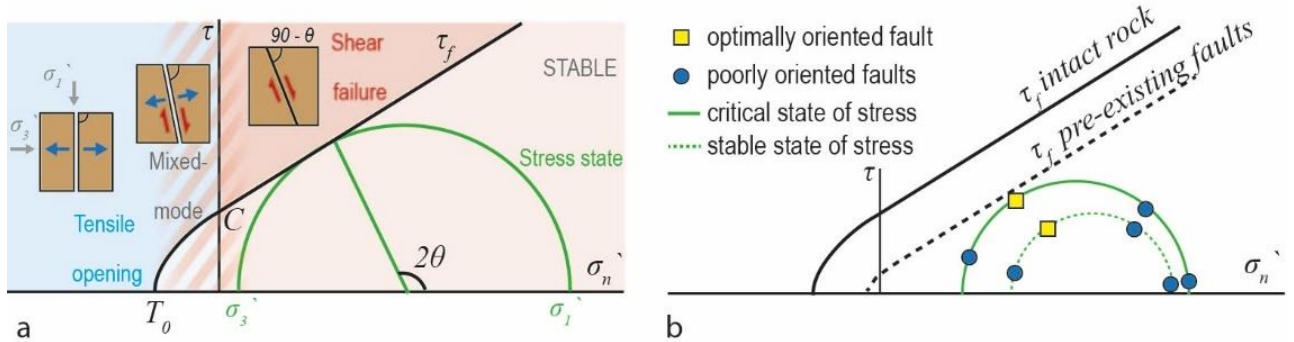

Figure 1-7. Example Mohr diagrams illustrating initial state of stress and Mohr-Coulomb static failure criterion. a) Failure diagram in Mohr space, showing the Mohr-Coulomb failure criterion (linear portion of black line in the compressible normal stress field) plus curved extensional failure envelope: Green circle: state of stress for which reactivation of optimally oriented fault can fail in shear mode. b) Different states of stress and optimally and poorly oriented faults.

Induced seismicity occurs because anthropogenic activities cause stress changes that perturb the pre-existing state of stress in the subsurface in such a way that failure can occur. Usually, failure occurs on pre-existing faults, which form persistent planes of weakness in the subsurface. Taking compressive stresses as positive, the stresses acting on these fault planes can be specified pointwise in terms of a fault-normal component, i.e. the Terzaghi effective normal stress $\sigma_{n}{ }^{\prime}=\sigma_{n}-P$, where $\sigma_{n}$ is the normal stress and $P$ the pore fluid pressure, and a fault parallel component, i.e. the shear stress $\tau$ (Figure 1-7). The effective normal stress acts as a clamping force on the fault, whereas the shear stress promotes sliding along the fault plane. When shear stresses exceed the fault failure strength $\tau_{f}$, sliding can occur. Under compressive effective normal stress states, static fault failure strength is often expressed by the Mohr-Coulomb failure criterion, which is a function of effective normal stress $\sigma_{n}$ ', the internal fault friction $\mu_{s}$ and the cohesive shear strength of the fault or cohesion $C$ (Figure $1-7)$

$$
\tau_{f}=\mu_{s} \sigma_{n}^{\prime}+C=\mu_{s}\left(\sigma_{n}-P\right)+C .
$$

Anthropogenic activities can cause changes in both the effective normal and shear stresses on the fault. The following sections discuss the different mechanisms causing stress changes and how these may lead to induced seismicity. 


\section{3. 1. Stress changes in and around depleting reservoirs}

In the case of reservoir depletion, the decrease in pore fluid pressure $\Delta P$ causes stress changes in a number of ways. The combination of these stress changes determines whether failure will occur. In the case of a gas reservoir, such as Groningen, production of gas causes the reduction in pore pressure, the local evolution of which depends on the produced volume and on the flow characteristics of the reservoir and faults. Through the definition of effective normal stress above, pore pressure decrease causes the effective normal stresses in the reservoir and acting on faults to increase.

Assuming that linear poroelasticity theory applies, pore pressure decrease in a reservoir rock also results in a negative volumetric strain, or contraction (Geertsma, 1973). In the case of a near-horizontal reservoir formation, this volumetric strain results in displacement of the overburden and free surface - i.e. in surface subsidence. In laterally extensive reservoirs, the strain is mainly vertical and uniaxial strain conditions apply (e.g. Geertsma, 1973; Soltanzadeh \& Hawkes, 2008; Soltanzadeh \& Hawkes, 2009). The horizontal strains are then zero and therefore volumetric strain causes a reduction in total horizontal stress $\Delta \sigma_{h}$ with depletion $\Delta P$ (1 in Figure 1-8a), given by the stress path parameter $\gamma_{h}=\Delta \sigma_{h} / \Delta P$ (Hettema et al., 2000). Applying linear poroelastic theory (Biot, 1941), the stress path parameter for uniaxial strain conditions is related to the Biot coefficient $\alpha$ and Poisson's ratio $v$ via (Geertsma, 1973; Hettema et al., 2000; Soltanzadeh \& Hawkes, 2008)

$$
\gamma_{h}=\frac{\Delta \sigma_{h}}{\Delta P}=\frac{\alpha(1-2 v)}{(1-v)} .
$$

where a negative $\Delta \mathrm{P}$ indicates depletion. The corresponding effective horizontal stress $\left(\Delta \sigma_{h}{ }^{\prime}=\Delta \sigma_{h}-\alpha \Delta P\right)$ is changed according to

$$
\frac{\Delta \sigma_{h}{ }^{\prime}}{\Delta P}=\alpha \frac{1-2 v}{1-v}-\alpha .
$$

For uniaxial conditions the total vertical stress change is zero and the effective vertical stress change equals the pore pressure change

$$
\frac{\Delta \sigma_{v}}{\Delta P}=0, \frac{\Delta \sigma_{v}{ }^{\prime}}{\Delta P}=\alpha
$$

For typical values of Poisson's ratio $v(0.1-0.35)$ in rocks, the effective vertical stress change is thus larger than the effective horizontal stress change. For a normal faulting regime $\left(\sigma_{v}>\right.$ $\sigma_{h}$ ) and assuming that the principal stresses $\sigma_{l}$ and $\sigma_{3}$ are vertical and horizontal, reservoir (i.e. pore pressure) depletion thus results in an increase in differential stress $\sigma_{1}-\sigma_{3}$. Depending on the magnitude of $\gamma_{h}$, the state of stress converges to or diverges from the fault failure line (Figure 1-8b), with larger $\gamma_{h}$ resulting in a more convergent hence unstable stress path. Measured values of $\gamma_{h}$ in hydrocarbon fields mostly range between 0.5 and 0.85 
(Soltanzadeh \& Hawkes, 2009). Field measurements for Groningen have indicated a value of $\gamma_{h}=0.4 \pm 0.2$ (Hettema et al., 2000), while uniaxial strain measurements in the lab on sandstone cores have yielded values in the range of $0.7-0.8$ (Hettema et al., 2000; Hol et al., 2018). Note that it is often difficult to determine the in-situ value of $\gamma_{h}$ for depleting reservoirs as stress measurements are scarce or uncertain. Also, $\gamma_{h}$ may vary strongly throughout gas fields, due to spatial variations in rock porosity and Poisson's ratio, for example. At the same time, strain conditions may also vary, departing significantly from uniaxial in reservoirs with a relatively large height/width aspect ratio, near faults, and near the reservoir edges. An example often referred to in the literature is from stress measurements in the Ekofisk field, a high porosity chalk field in the North Sea. An in-situ $\gamma_{h}$ value of 0.8 was measured in the central part of the Ekofisk, where only a few faults are present, but a very different value of 0.42 was measured in heavily faulted regions of the field (Santarelli et al., 1998).

In depleting reservoirs that have high height/width ratio, i.e. which are not laterally extensive, or at locations near the edges of extensive reservoirs, strain gradients are steep so that strains are non-uniaxial and stress changes are generated in the surrounding rocks (stress arching), which also leads to different $\gamma_{h}$ and $\gamma_{v}\left(=\Delta \sigma_{v} / \Delta P\right)$ values at different locations within the reservoir (e.g. Segall, P. \& Fitzgerald, 1998; Segall, P., 1989; Soltanzadeh \& Hawkes, 2008; Soltanzadeh \& Hawkes, 2009). The horizontal stress decreases within the reservoir are partly transferred to the formations at the periphery of the reservoir, whereas compaction of the reservoir near the periphery leads to an increase in vertical stress in the laterally adjacent formations ( 2 in Figure 1-8a). Above and below the reservoir, poroelastic stress changes are much smaller than inside the reservoir (Segall, P. \& Fitzgerald, 1998; Segall, P., 1989; Segall, P. \& Lu, 2015). Nonetheless, these small changes can also cause fault reactivation on optimally oriented faults. As a result of these various stress changes, normal faulting is promoted horizontally adjacent to a depleting reservoir, while above and below the reservoir, thrust faulting is promoted (Orlic \& Wassing, 2013; Segall, P., 1989; Segall, P. et al., 1994). Stress changes in the rock volume surrounding the Lacq gas field in southern France (though probably not exclusively poroelastic stress changes as it is a faulted carbonate reservoir), for example, could be related to the occurrence of induced events around the field (Segall, P. et al., 1994).

Local stress changes occurring around faults that cut depleting reservoirs are also different from the stress changes occurring under the uniaxial strain conditions encountered in the body of a uniform and laterally extensive reservoir. Compaction of reservoir compartments that are offset by a fault results in displacement gradients across that fault. These displacement gradients can generate strong local stress concentrations on the fault at the reservoir level, promoting fault reactivation. This effect was first postulated by Pennington et al. (1986), and was later observed around offset faults in numerical simulations of compacting reservoirs (Mulders, 2003; Nagelhout \& Roest, 1997; Roest \& Kuilman, 1994). Examples include modeling work addressing the Bergermeer reservoir in the West of 


\section{Chapter 1}

the Netherlands (Figure 1-6), which showed the development of stress concentrations on a central fault with increasing offset along its strike, at locations consistent with the occurrence of seismic events up to $\mathrm{M}_{\mathrm{L}} 3.5$ (Orlic \& Wassing, 2012). This type of local stress concentration, due to offset reservoir compaction and associated vertical strain gradients across the fault offsetting the reservoir compartments, typically shows larger changes than the purely poroelastic stress changes occurring within the reservoir - thus emphasizing the important effect of (irregular) reservoir and fault geometry on stress development (Buijze, 2019; Mulders, 2003; van den Bogert, 2015; van den Bogert, 2018). Development of stress concentrations at faults is also consistent with the observation already mentioned that most seismicity occurring in the Groningen field is located within the reservoir interval and on faults visible in seismic images (Spetzler \& Dost, 2017a; Willacy et al., 2018). Fault reactivation through poroelastic stressing and differential compaction is also consistent with the strong link that is observed between the amount of compaction and seismicity in the Groningen field (Bourne, 2014). Additionally, pore pressure diffusion effects may play a role in fault reactivation in any depleting reservoir where significant pore pressure gradients exist. Delayed diffusion from faults that are less permeable than the reservoir may cause the stress path to become steeper with ongoing depletion, promoting fault reactivation (Zbinden et al., 2017). In this case, the pressure in the fault is elevated with respect to that of the reservoir, causing a lower effective normal stress than for a permeable fault, which results in more unstable behavior. Additionally, if a salt cap rock is present as in Groningen, salt creep can result in lower effective normal stresses on faults with offset in the formations underlying the salt formation which also promotes fault reactivation (Haug et al., 2018; Orlic \& Wassing, 2012; Orlic \& Wassing, 2013; Wassing et al., 2017). This is the result of the discontinuity in horizontal stresses across the juxtaposition of salt against another formation in the footwall (e.g. for the Groningen stratigraphy the Ten Boer, or Slochteren formation) across the fault, as in the salt the stress is isotropic, but in the other lithologies the horizontal stress is a certain fraction of the vertical stress. This difference in horizontal stress is resolved by a horizontal displacement of the non-salt rock formation towards the footwall direction. This horizontal displacement also persists directly below the salt-juxtaposition, and leads to a reduced normal stress on the fault.

\section{3. 2. The role of the initial stress state}

The initial or in-situ state of stress is a very important factor affecting the reactivation potential of faults, but it is often very uncertain. If the initial state of stress is critical (located very close to or on the fault failure envelope) and optimally oriented faults are present, fault reactivation requires very small stress changes (Figure 1-7b). This has been observed in several instances of induced seismicity as a result of fluid injection, e.g. in Oklahoma (Goebel et al., 2017; Keranen et al., 2014). On the other hand, if the stress state is further away from failure, fault reactivation requires larger stress changes. In Groningen, the minimum horizontal stress is poorly constrained (van Eijs, 2015). However, the long delay before the 
onset of seismicity (of large enough magnitude to be recorded), which did not occur until 1991 when around $10 \mathrm{MPa}$ of gas pressure depletion had occurred (Figure 1-2), plus the fact that most events are located within or close to the reservoir depth interval (Spetzler \& Dost, 2017a; Willacy et al., 2018), plus the results of seismic source modeling (Dempsey \& Suckale, 2017), all indicate that the initial state of stress was not critical.

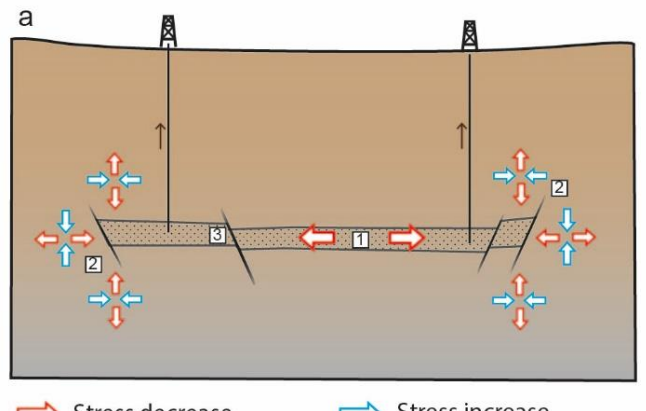

b

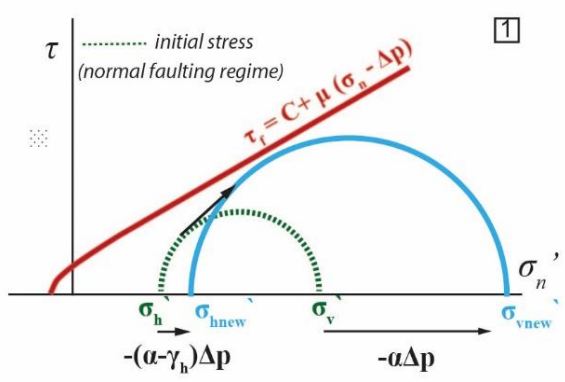

Figure 1-8 Schematic illustration of stress changes in and around a depleting reservoir. a) Changes in horizontal and vertical stresses generated in and around a depleting reservoir after e.g. Orlic et al. (2013). 1: stress change under uniaxial conditions - i.e. in a laterally extensive reservoir compartment, 2: stress transfer to formations around the reservoir, 3: local stress changes around fault due to differential compaction and delayed pressure diffusion in faults. b) Mohr diagram for stress change under uniaxial strain conditions at location (1) in Figure 1-7a for a normal faulting regime. Dotted green line gives the initial state of stress, blue line an example of the stress state after a certain amount of depletion $\triangle P$ for a stress path converging towards the failure line (red line). $\sigma_{h}$ ': minimum effective horizontal stress, $\sigma_{v}{ }^{\prime}$ : vertical stress, $\Delta P$ : pressure change, $\alpha$ : Biot coefficient $\gamma_{h}$ : horizontal stress path parameter $\Delta \sigma_{h} / \Delta P=\alpha(1-2 v) /(1-v)$, where $v$ : Poisson's ratio, $\sigma_{n}{ }^{\prime}$ ': effective normal stress on fault, $\tau$ : shear stress on fault, $\tau_{f}$ : shear failure strength, $\mu$ : friction coefficient.

\section{3. 3. Geomechanical modeling of depletion-induced seismicity}

Different modeling techniques have been and are being used to understand, describe and/or forecast induced seismicity in Groningen. These include a) probabilistic seismic source models that may be used in probabilistic seismic hazard analysis (PSHA), as well as b) more deterministic geomechanical models that focus on stress changes in the reservoir or on individual faults. In this thesis, I focus on the more deterministic side of modeling and on obtaining a physical understanding of the earthquake source process. In the following, I introduce some of the probabilistic models developed in the context of the Groningen field as well as some of the geomechanical approaches taken.

PSHA gives the probability of ground motion exceeding a specific threshold at a given location in a given window of time. PSHA combines elements such as seismic source modelling (Bourne et al., 2014; Bourne \& Oates, 2017b; Dost et al., 2017) and empirical ground motion prediction equations (Bommer et al., 2017). The seismic source model can be purely statistical with a field-wide response or incorporate seismic sources that may be distributed, zonal, or related to certain faults. All sources have a corresponding frequencymagnitude distribution based on the observed seismicity, giving the activity rate (i.e. height 


\section{Chapter 1}

of the frequency-magnitude distribution, see e.g. Figure 1-5a) and characteristic b-value, as well as a maximum magnitude. A PSHA approach, using a statistical seismic source model for the Groningen, is reported by Spetzler (2017b). In other seismological models used for PSHA in Groningen, physics-based parameters or observations were incorporated, such as a spatiotemporal relationship between reservoir compaction and earthquake occurrence (Bourne et al., 2014), and the effect of reservoir offset, which was included as a smoothed topographical variation linked to an increased probability for the occurrence of seismic events (Bourne \& Oates, 2017b). In another seismic source model, the pressure change, the stress path parameter, the in-situ stress, and the orientation and strength properties of several of the main faults were used to generate synthetic earthquake catalogs (Dempsey \& Suckale, 2017). All of these models can be compared and calibrated against field data, and used for forecasting by simulating seismicity rates under future reservoir depletion scenarios, using the input parameters calibrated against historical seismicity.

Geomechanical models are mostly used in a more deterministic sense, and aim for a better understanding of the physical processes occurring as a result of depletion: e.g. the stress changes occurring in the reservoir and surrounding system, the effect of the reservoir geometry on stress changes, the conditions for - and the location and pressure change (and implicitly the timing) of - fault reactivation, and how large seismic events may grow. Geomechanical models may simulate the stress response of an entire field or large parts of a field, as was done for the Groningen field (Lele et al., 2015; Lele et al., 2016; Sanz et al., 2015) and the Bergermeer field (Orlic \& Wassing, 2012). Alternatively, geomechanical models may zoom in on a specific fault or use a generic reservoir or fault geometry to study the faulting process in more detail (Mulders, 2003; van den Bogert, 2015). Both field-scale models and generic fault models show that offset reservoir compaction at faults is an important factor leading to fault reactivation, as discussed in the previous section. Geomechanical models are often too computer-intensive to be used in a probabilistic sense, but can yield general insights and constraints that can be included in the more probabilistic seismic source modeling approaches described above, e.g. the stress-concentration effect of fault offsets. 


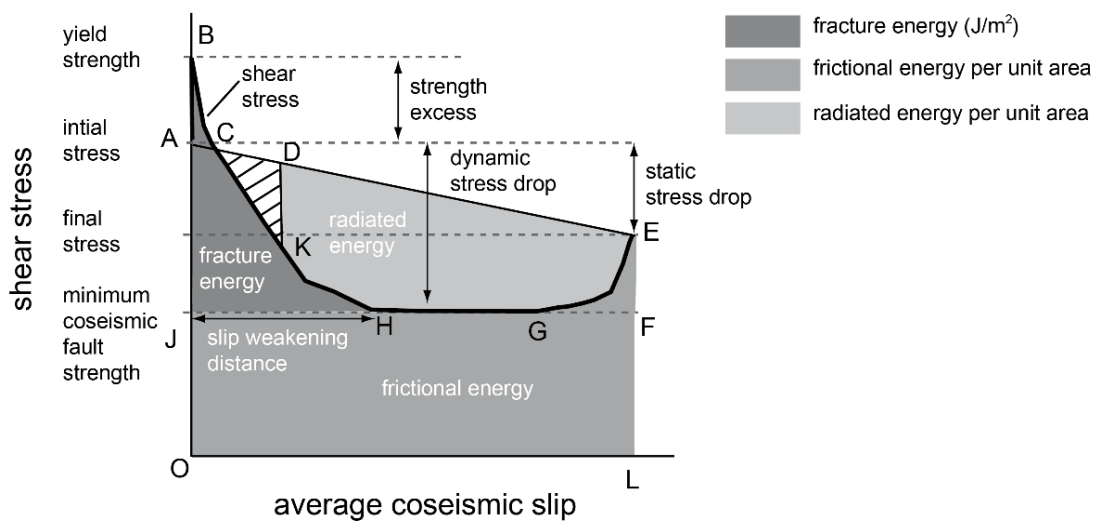

Figure 1-9. Evolution of shear stress and average energy budget on unit area of a fault plane during earthquake rupture (from: Niemeijer, A. et al., 2012). Black curve: shear stress, with initial shear stress given by A. The strength excess is defined as the difference between the yield strength (i.e. $\left.\tau_{f}\right)$ and the initial shear stress. The static stress drop is the difference between the initial shear stress and the final shear stress (E), whereas the coseismic stress drop is the difference between the initial shear stress and the minimum shear stress during rupture. The total available energy per unit fault area released by the earthquake (elastic strain energy + gravitational energy) is given by the area AELO. This energy is partitioned into radiated energy (i.e. seismic waves) given by the area DEGHK, and frictional energy (JHGFELO) and fracture energy (JABCKH). The frictional and fracture energy indicate dissipation of energy on the fault through frictional heating, creation of new fracture surface, etc.

Although stress changes are modeled in detail in many geomechanical models of reservoir depletion, using constitutive parameters chosen for the reservoir and surrounding formations, the fault reactivation process is usually incorporated in a simplified manner. Often, a static friction coefficient is assumed for the fault, in line with a cohesionless MohrCoulomb failure envelope (Figure 1-7), and the fault slides stably once it is reactivated. However, this is not how a seismic instability develops. For a seismic instability to develop, the friction or strength of the fault must weaken rapidly with slip and/or slip rate, causing the shear stress on the fault to drop below ambient levels, resulting in acceleration (e.g. Dieterich, 1979; Ruina, 1983). Frictional weakening of the fault results in the conversion of elastic strain energy stored in the medium around the fault into energy consumed by the fault slip process (fracture energy and dissipated thermal energy) and radiated as seismic energy (Figure 1-9). Static friction values of siliciclastic or limestone fault rocks fall mostly in the range $0.6-0.8$, but high-velocity experiments indicate that friction may drop to low values $0.1-0.3$ during seismic slip (e.g. Toro et al., 2011). Numerical simulations of natural and induced earthquakes usually include this frictional weakening effect through a slip-weakening friction function (e.g. Ampuero et al., 2002; Cappa \& Rutqvist, 2012; Day et al., 2005; Dunham, 2007; Galis et al., 2017; Ripperger et al., 2007; Zbinden et al., 2017) or rate-and-state dependent friction where friction depends on state and slip rate (e.g. Chen, T. \& Lapusta, 2009; Kaneko et al., 2008; Lapusta et al., 2000; Rice, J. R., 1993). To assess how earthquakes induced by reservoir production nucleate, and how large they can grow in relation to the locally altered state of stress around the reservoir, it is accordingly important to incorporate 


\section{Chapter 1}

the appropriate fault behavior and frictional weakening behavior in the geomechanical models of producing reservoirs.

\section{4. Aims and structure of this thesis}

From the above, it is evident that a realistic description of the main physical processes behind the induced seismic rupture is required if we wish to understand where, under what reservoir conditions, and when events are induced, and how large a magnitude they may attain. Key questions in the context of Groningen are: What magnitudes are likely to occur on faults in the tectonic and structural setting of the Groningen field? Can we deploy a model that reproduces seismic ruptures with source parameters compared to those observed (see Section 1.2)? What is the maximum magnitude $M_{\max }$ that is likely to occur in the Groningen field? Indeed, the maximum magnitude is a crucial input parameter for PSHA. For understanding the physical processes and the expected magnitudes of the induced earthquakes it is essential to use appropriate fault mechanical behavior.

In this thesis, I aim to improve our understanding of the nucleation and magnitudes of production-induced earthquakes in Groningen by incorporating the appropriate reservoir properties and fault weakening behavior into a geomechanical modeling approach. I integrate experimental results obtained on the compaction and friction behavior of reservoir and fault rocks that are representative for the Groningen system into my field-scale geomechanical models, and I validate the field-scale models against field observations. Additionally, I performed scaled experiments to study the relationship between heterogeneous fault stresses and heterogeneous fault friction and the nucleation of seismic events in order to build confidence in the field-scale models.

An important difference with respect to natural seismicity is that depletion-induced earthquakes are driven by specific stress changes occurring mostly within the reservoir. Therefore, in Chapter 2, I study in detail the interaction between these induced stress changes, earthquake nucleation, and earthquake propagation on a fault in a generic Groningen-like reservoir system, using a Finite Element model. Approaches common for modeling frictional weakening behavior in natural seismicity are implemented to simulate earthquake rupture in a fully dynamic calculation. To gain insight into the maximum earthquake magnitudes to be expected, the likelihood of induced earthquake rupture beyond the reservoir interval was investigated. Chapter 2 accordingly addresses the dependence of rupture growth outside the reservoir on the initial stress, fault geometry, and the frictional weakening properties of the fault.

Induced seismic events in a depleting reservoir are strongly influenced by depletioninduced stress changes. Computation of these stress changes must incorporate the appropriate reservoir deformation (compaction) behavior. Experimental studies have shown that a 
significant fraction of compaction strain occurring in the Groningen reservoir (Slochteren) sandstone is inelastic - i.e. irreversible or phenomenologically plastic (Hol et al., 2018; Pijnenburg et al., 2018; Pijnenburg et al., 2019). However, conventional geomechanical models often assume linear elastic reservoir behavior. Therefore, in Chapter 3, I incorporate inelastic (elastoplastic) behavior of the reservoir formation into Finite Element models of fault reactivation. The models are validated against experimental data on the Slochteren sandstone provided by Pijnenburg et al. (2019). I compare the effects of elastoplastic and linearly elastic reservoir behavior on the stress changes generated by reservoir depletion, and on the size of induced earthquake ruptures by performing dynamic rupture simulations.

Chapters 2 and 3 show that both the initial stress state and the production-induced stress evolution have a large effect on the size of induced ruptures. A comparison of modeled stresses with field observations would be advantageous, but stress distributions on a fault in the field can never be determined. The closest alternative is formed by densely instrumented, large-scale experiments in which the state of stress on a fault is quantified and can be associated with rupture nucleation and propagation. In Chapter 4, I present the results of a scaled experiment on a $350 \mathrm{~mm}$ long fault (gouge-filled, or bare). As in the field, stresses on the fault are heterogeneous. However, in the experiments, the stresses on the fault do not result from production, but from the controlled experimental boundary conditions. Finite Element modeling is used to calculate the stress field on the fault, which is then compared with measurements made close to the fault and to site(s) of rupture nucleation.

In the geomechanical models presented in Chapter 2 and 3, and in the large-scale experiments in Chapter 4, the fault friction properties are uniform along the fault. However, faults in Groningen cross-cut many different lithologies such as the Basal Zechstein formation, the Ten Boer Claystone, the reservoir itself, and the Carboniferous substrate or " underburden" (see e.g. Figure 1-3). Fault properties likely depend on the material from which the gouge is derived, i.e. the adjacent formations (Hunfeld et al., 2017; Tesei et al., 2014). This will result in a variable fault rock composition along the fault dip. Indeed, low-velocity friction and slide-hold-slide (healing) experiments on simulated fault materials (gouges) from the Groningen field have shown that the different simulated gouges have different static friction coefficients and different dependences of friction coefficient on slip rate (Hunfeld et al., 2017). High velocity experiments on these gouges also have shown different amounts of frictional weakening (Hunfeld, 2020). Such heterogeneity in mechanical fault properties will have a large effect on the nucleation and size of induced earthquakes, and may be just as important as geometrical heterogeneities or irregularities in fault strike and dip, for example. In Chapter 5 I accordingly study the effect of frictional heterogeneity in a generic large-scale experimental fault setup. Fault gouges are used to control the frictional properties along the fault, creating a central fault segment exhibiting velocity-weakening behavior (unstable, prone to generate seismic events), flanked by two segments with velocity-strengthening (stable) properties. Different gouges were used for the velocity-strengthening segments. As in Chapter 4, I investigate the nucleation of rupture as a function of the fault stresses, as well 
as the effect of the variations in frictional properties, and their relation to the critical nucleation length scale, on the macroscopic sliding behavior of the fault.

In Chapter 6 the models presented in Chapter 2 are extended to incorporate fault zone heterogeneity and study its effect on rupture nucleation and size. Fault properties are based on the lithologies found in the Groningen field and related frictional properties measured in the laboratory (Hunfeld, 2020). To incorporate uncertainties related to the frictional parameters and other input parameters (initial stress field, the elastic properties of the reservoir, fault strike, dip, and offset), over a 1,500 simulations are run with input parameters drawn from distributions based on experimental or field data. Simulations are run to the point of nucleation of rupture. To compute rupture size, an approximation using linear elastic fracture mechanics theory is used to reduce computation time with respect to the fully dynamic simulations in Chapter 2. The model ensemble gives a physics-based estimate of likely rupture sizes in the reservoir, as well constraints on the conditions under which rupture propagation outside of the reservoir can potentially occur. This aids in understanding at which location and under what pressure change conditions ruptures occur in the Groningen field, and in placing constraints on event magnitudes.

In Chapter 7 I summarize the content of the various Chapters and present integrated conclusions. Furthermore, I list the implications for induced seismicity in the Groningen field, as well as broader implications. Finally, I give recommendations for future studies. 
Chapter 1 
Chapter 1 


\title{
Chapter 2
}

\section{Nucleation and Arrest of Dynamic}

\section{Rupture induced by Reservoir Depletion}

\begin{abstract}
1113

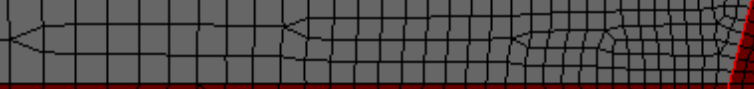

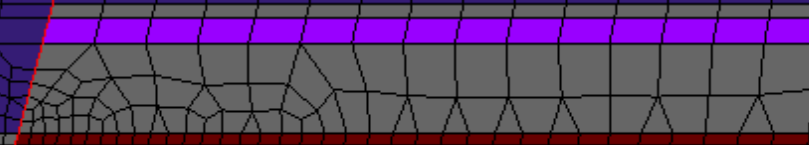


Chapter 2

Nucleation and Arrest of Dynamic Rupture induced by Reservoir Depletion

\author{
Loes Buijze ${ }^{1,2}$, Peter van den Bogert ${ }^{3}$, Brecht B.T. Wassing ${ }^{1}$ and Bogdan Orlic ${ }^{1}$ \\ ${ }^{1}$ TNO, Applied Geosciences, Princetonlaan 6, Utrecht, The Netherlands. \\ ${ }^{2}$ Utrecht University, Faculty of Geosciences, Budapestlaan 4, Utrecht, The Netherlands \\ ${ }^{3}$ Shell Global Solutions B.V. Rijswijk, The Netherlands
}

Published: Buijze, L., van den Bogert, P. A. J., Wassing, B. B. T., \& Orlic, B. (2019). Nucleation and arrest of dynamic rupture induced by reservoir depletion. Journal of Geophysical Research: Solid Earth, 124(4), 3620-3645. 


\section{Nucleation and Arrest of Dynamic Rupture induced by Reservoir Depletion}

\section{1. Introduction}

Production-induced seismicity can cause damage to housing and infrastructure and have significant societal and economic impact, in particular in densely populated areas. One prominent example is the Groningen field in the Netherlands, where damage and unrest due to induced seismicity have led to a premature phase out of the gas production (e.g. van Thienen-Visser et al., 2015). To assess the hazard from induced seismic events knowledge about the mechanisms, as well as the likely location, magnitude, and magnitude distribution of the induced events is key. In particular it is important to assess whether seismic events remain mainly confined to the reservoir interval or can nucleate and/or propagate outside of the reservoir interval.

The production of gas from porous reservoir formations in the subsurface causes i) a reduction of pressure (pressure depletion) and ii) subsequent compaction (volume reduction) of the depleting reservoir. Past studies show that the decrease in pressure causes a reduction in reservoir volume which results in stress changes within and around the reservoir, so-called poroelastic stressing (Hettema et al., 2000; Segall, P. \& Fitzgerald, 1998; Segall, P., 1989; Segall, P. et al., 1994), and also in subsidence at the earth's surface, which may be significant depending on the compressibility of reservoir rock, the depth, thickness and areal extent of the reservoir (Hough \& Page, 2016; van Thienen-Visser et al., 2015; Yerkes \& Castle, 1976). Poroelastic stress changes on pre-existing faults within and around the depleting reservoir can bring those faults to failure so that fault slip can occur, depending on the tectonic stress regime and the location and orientation of those fault (Orlic \& Wassing, 2012; Segall, P., 1989). Shallow surface faulting may also occur at the edges of subsidence bowls in cases of significant subsidence (Yerkes \& Castle, 1976). The extraction of a large volume (mass) of hydrocarbons could also cause triggering of deep earthquakes below the reservoir (Segall, Paul, 1985). Geomechanical modeling studies show how particular geometries such as production from reservoir compartments offset by a fault can locally enhance the stress changes and promote fault slip within the reservoir (Haug et al., 2018; Mulders, 2003; Nagelhout \& Roest, 1997; Orlic \& Wassing, 2013; van den Bogert, 2015; Wassing et al., 2017; Zbinden et al., 2017). Of particular interest for seismic hazard is the possibility for the seismicity nucleating within the reservoir interval to propagate outside the

Picture previous page: Computer model of a fault cross-cutting several geological formations. The formations and fault are meshed with small elements to calculate in detail the stresses and displacements due to gas production. 


\section{Chapter 2}

reservoir. However, the majority of geomechanical modeling studies focused on the development of stresses and their effect on the onset of fault slip, but for post-failure behavior often simplified fault behavior is used, e.g. ideal-plastic fault slip or a quasi-static analysis of frictional weakening. When one is interested in the size and propagation of seismic events, understanding dynamic fault behavior which simulates fast slip is essential since it exerts a dominant control on both the nucleation of the seismic rupture, and more importantly the propagation and arrest (termination) of seismic rupture.

In the framework of natural seismicity numerous modeling studies have investigated the earthquake source process, simulating dynamic fault slip through inclusion of a slipdependent (e.g. Andrews, D. J., 1976; Day, 1982; Harris \& Day, 1997) or velocity-dependent decrease of fault friction (e.g. Ben-Zion \& Rice, 1997; Lapusta et al., 2000; Okubo, 1989). Fully dynamic rupture simulations are the most computer intensive simulations which solve the full elasto-dynamic equations and include the effect of inertia and radiated seismic waves on the rupture process. Such simulations are typically used to model single events in detail and investigate for example the effect of initial stress and stochastic stress variability (e.g. Day, 1982; Duan \& Oglesby, 2006; Ripperger et al., 2007) on e.g. fault slip rate, rupture velocity and radiated waves. In particular, some of these studies investigated the conditions under which ruptures will arrest, which is important and useful in the light of analyzing (induced) earthquake sizes. A sharp transition is observed from arrested rupture (where only a small part of the fault ruptured), to runaway rupture in which the rupture continues indefinitely (Galis et al., 2015; Ripperger et al., 2007). This transition is favored by a critical initial stress state and/or large friction drop but also depends on the nucleation procedure used to initiate the dynamic models (Galis et al., 2015) and the distribution of stress heterogeneity over the fault (Ripperger et al. 2007).

Nucleation of rupture in the aforementioned models is mostly simulated in an artificial manner, e.g. using a prescribed overstressed asperity as the nucleation zone (Galis et al., 2015). Besides artificial nucleation, other simplifications in the dynamic models include a uniform initial normal and shear stress, simplified planar geometry, and uniform elastic properties. Production-induced earthquakes on the other hand will nucleate due to specific production-induced stresses which are spatially variable on faults. The locally perturbed fault stress will influence rupture nucleation and propagation. For induced seismicity recently a number of studies have used fully dynamic simulation of rupture, in the framework of injection (Cappa \& Rutqvist, 2012; Jin \& Zoback, 2018; Pampillón et al., 2018; Urpi et al., 2016) or production (Buijze et al., 2017; Wassing et al., 2017). However, the conditions leading to induced rupture nucleation and rupture arrest in depleting gas fields have not been investigated for a broad range of parameters and reservoir geometries.

This study investigates the nucleation and size of production induced earthquakes, and in particular their propensity to propagate far outside of the producing reservoir interval, by modeling the stress changes due to production-induced seismicity, nucleation of the 
seismic instability, and propagation and arrest of dynamic rupture in a single model workflow in a 2D Finite Element model (DIANA FEA). The modeling study was based on the Groningen gas reservoir in the Netherlands (Spetzler \& Dost, 2017a; van Thienen-Visser et al., 2015). Production from one or two compartments separated by a fault with or without offset was modeled quasi-statically in a 2D model. The depletion-induced stress changes drive reactivation of the fault, aseismic slip and nucleation of the seismic instability. Linear slip-weakening friction was used to simulate fault behavior and seismic slip. Sensitivity analysis of reactivation and nucleation to the in-situ stress, friction parameters, and reservoir offset was conducted. In the subsequent dynamic analysis rupture propagation and arrest were modeled, and sensitivity of the along-dip size of the dynamic event and potential of transition to runaway rupture to in-situ stress, friction parameters and reservoir geometry was analyzed.
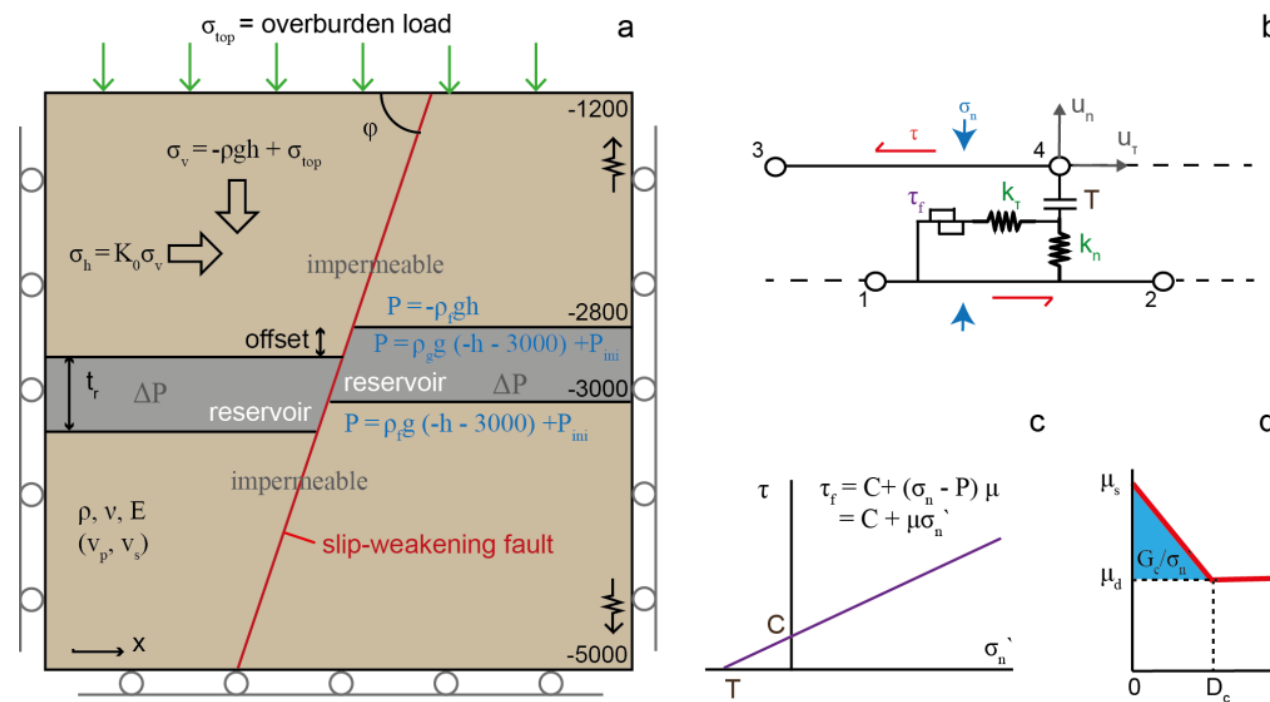

C

d
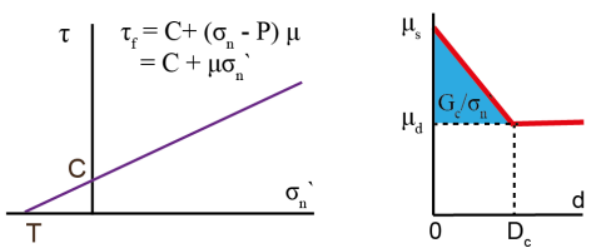

Figure 2-1. Model set-up, description of the interface elements used to model the fault, and the fault friction properties. a) Geometry of the 2D plane-strain model simulating a slip-weakening fault offsetting a producing reservoir formation. The model box is centered around the reservoir fault section. $\sigma_{\text {top }}=$ simulated overburden weight, $\sigma_{y}=$ vertical stress, $h=$ depth, $K_{0}\left(=\sigma_{h} / \sigma_{v}\right)=$ stress ratio, and $\varphi=$ fault dip. Elastic parameters are uniform across all formation $\left(E=15 \mathrm{GPa}, v=0.15, \rho=2400 \mathrm{kgm}^{-3}\right)$, corresponding to a $P$-wave velocity $V_{p}$ of $2568 \mathrm{~ms}^{-1}$ and an $S$-wave velocity $V_{s}$ of $1645 \mathrm{~ms}^{-1}$. A uniform pressure change $\triangle P$ was prescribed in the reservoir formation (one or both sides) to simulate production. b) Schematic representation of an interface element with nodes (open circles), normal and shear displacements $u_{n}$ and $u_{\tau}$ normal and shear stiffness $k_{n}$ and $k_{\tau,}$, tensile strength $T$, and fault strength $\left.\tau_{f} . c\right)$ Mohr Coulomb friction with fault strength $\tau_{f}$, cohesion $C$, effective normal stress $\sigma_{n}{ }^{\prime}$, pore pressure $P$, and friction coefficient $\mu$. d) slip-weakening friction with shear slip $d$ (relative plastic shear displacement across the fault), with static friction coefficient $\mu_{s}$, dynamic friction coefficient $\mu_{d}$, critical slip distance $D_{c}$, and fracture energy $G_{c}$. 


\section{2. Numerical model set-up, input parameters, and modeling procedure}

Depletion-induced stress changes, the subsequent nucleation and propagation of seismic rupture, and associated wave propagation into the subsurface were simulated in a $2 \mathrm{D}$ plane-strain model setup using the general-purpose Finite Element package DIANA FEA v. 10.1 (DIANA 10.1 User Manual, 2016). In the following sections the model setup, governing equations, numerical considerations, and the input parameters are presented. The model input parameters were based on the Groningen field lithologies.

\section{2. 1. Governing equations, assumptions and modeling workflow}

The model space is a rectangular box centered around the intersection of a $70^{\circ}$ dipping fault with a $200 \mathrm{~m}$ thick reservoir formation (Figure 2-1). The modeling procedure consists of three phases; (1) stress and pressure initialization, (2) quasi-static reservoir depletion and nucleation of seismic slip, and (3) fully dynamic rupture simulation. The key governing equations and assumptions used in these phases are briefly listed in the following.

During the first two phases the static equilibrium equation that is solved is

$$
\nabla \cdot \boldsymbol{\sigma}+\boldsymbol{F}=\nabla \cdot\left(\boldsymbol{\sigma}^{\prime}+\alpha P\right)+\boldsymbol{F}=0
$$

with the total stress tensor $\boldsymbol{\sigma}$, the effective stress tensor $\boldsymbol{\sigma}^{\star}$, the body forces $\boldsymbol{F}$ (including gravity), and Biot's coefficient $\alpha$, and pore pressure $P$. The kinematic relationship between the strain vector $\boldsymbol{\varepsilon}$ and displacement vector $\boldsymbol{u}$ is

$$
\boldsymbol{\varepsilon}=\frac{1}{2}\left[\nabla \mathbf{u}+(\nabla \mathbf{u})^{T}\right]
$$

linear elasticity is assumed in the formations, with the constitutive equation (Hooke's Law)

$$
\sigma=C: \varepsilon
$$

where $\boldsymbol{C}$ is a fourth-order elasticity tensor. For an isotropic material this becomes

$$
\boldsymbol{\sigma}+\alpha P=\frac{E}{(1+v)}\left(\frac{v}{(1-2 v)} \operatorname{tr}(\boldsymbol{\varepsilon})+\boldsymbol{\varepsilon}\right)
$$

where $E$ is Young's modulus, and $v$ is Poisson's ratio (see Table 1 for elastic properties). Plane-strain conditions were assumed with displacement in the out-of-plane strains $\varepsilon_{x z}=\varepsilon_{y z}$ $=\varepsilon_{z x}=\varepsilon_{z y}=\varepsilon_{z z}=0$ and out-of-plane stress $\sigma_{H}=v\left(\sigma_{h}+\sigma_{v}\right)$. At the sides and bottom of the model space displacement boundaries are imposed with $u_{x}=0$ at $x=0$ and $x=4000 \mathrm{~m}$, and $u_{y}=0$ at $\mathrm{y}=-5000 \mathrm{~m}$. At the top of the model a constant stress boundary was prescribed, $\sigma_{t o p}$ $=23.6 \mathrm{MPa}$ at $\mathrm{y}=-1200 \mathrm{~m}$, so that $\sigma_{v}$ at the reservoir level was $66 \mathrm{MPa}$, in agreement with observations.

The fault strength was controlled by Mohr-Coulomb friction (Figure 2-1c) 


$$
\tau_{f}=C+\left(\sigma_{n}-P\right) \mu_{s}
$$

where $\tau_{f}$ is the failure strength, $\sigma_{n}$ is the normal stress, $C$ is cohesion and $\mu_{s}$ is the static friction coefficient. Once the criterion is exceeded the fault deforms plastically. The post-failure behavior was governed by linear slip-weakening (Ida, 1972), where $\mu$ decreases linearly as a function of shear slip $d$ (the relative plastic shear displacement across the fault) from the static friction coefficient $\mu_{s}$ at $d=0$ to the dynamic friction coefficient $\mu_{d}$ at $d \geq$ critical slip distance $D_{c}$ (Figure 2-1d, Table 1). The equations were solved with a Newton-Rhapson solver. During the quasi-static depletion phase pressure load steps were prescribed until the fault started to slip plastically. The pressure step size was then reduced based on the number of iterations required for convergence, until numerical instability was reached. At this point a small additional pressure change ( $<0.1 \%$ of the initial reservoir pressure) was added to cause a disequilibrium, and the analysis was switched to a fully dynamic calculation, including inertial effects and Rayleigh damping. The equation of motion is given by

$$
\nabla \cdot \boldsymbol{\sigma}+\boldsymbol{F}=\varrho \ddot{\boldsymbol{u}}+a \varrho \dot{\boldsymbol{u}}
$$

where $\ddot{\boldsymbol{u}}$ is the acceleration vector. The use of Rayleigh damping gives rise to the added ratedependent term $a \dot{\boldsymbol{u}}$, where $\dot{\boldsymbol{u}}$ is the velocity vector and $a$ is one of the Rayleigh damping parameters. The constitutive equation for linear elasticity including Rayleigh damping becomes

$$
\boldsymbol{\sigma}=\boldsymbol{C}: \boldsymbol{\varepsilon}+b \boldsymbol{C}: \dot{\varepsilon}
$$

where $b$ is the second Rayleigh damping parameters. The elastodynamic equation was solved with explicit time integration. The displacement boundaries remained active during the dynamic phase; the modeled time of interest was much shorter than the time it took for the waves to reach the model boundaries and cause reflections.

The fault was modeled with interface elements (L8IF), which allow elastic deformation until the Mohr Coulomb criterion is reached (Equation 2-5). Elastic deformation was controlled by a normal stiffness $k_{n}$ and shear stiffness and $k_{\tau}$ (Figure 2-1b), which could be related to the formation stiffness through the factor $f_{k}$, with $k_{\tau}=f_{k} G$ and $k_{n}=f_{k} E$, where $G$ is the shear modulus. Interface elements should have a very high (in theory infinite) stiffness to simulate a fault zone with $0 \mathrm{~m}$ thickness. However, faults in nature have a finite width and $f_{k}$ may be used to allow elastic shear and normal deformation on a fault zone of thickness $w$ by setting $f_{k}=1 / w$ (Mulders, 2003). Here the default $f_{k}=10$, which corresponds to $w$ of $0.1 \mathrm{~m}$ as is typical for faults with an offset of $10-100 \mathrm{~m}$ (Beach et al., 1997; Childs et al., 2009). During the dynamic simulation phase the stiffness was reset to $f_{k}=1$ to avoid rapid waves propagating along the fault zone. 


\section{Chapter 2}

Table 2-1 Model parameters for the base case scenario. Elastic parameters from (Sanz et al., 2015). '( The values between brackets indicate the interface element stiffness values used in the fully dynamic analysis where the stiffness is set 10 times lower $\left(f_{k}=1\right)$ than in the quasi-static analysis $\left(f_{k}=10\right)$.

\begin{tabular}{|l|l|l|l|}
\hline Base case values: Rock mass & \multicolumn{3}{l}{ Base case values: Fault } \\
\hline Young's modulus $\mathrm{E}(\mathrm{GPa})$ & 15 & Dip $\varphi\left({ }^{\circ}\right)$ & 70 \\
\hline Poisson's ratio $v(-)$ & 0.15 & Normal stiffness $\mathrm{k}_{\mathrm{n}}(\mathrm{GPa})$ & $150(15)^{1}$ \\
\hline Density $\rho\left(\mathrm{kgm}^{-3}\right)$ & 2400 & Shear stiffness $\mathrm{k}_{\mathrm{s}}(\mathrm{GPa})$ & $65(6.5)^{1}$ \\
\hline Density gas in reservoir $\rho_{\mathrm{g}}\left(\mathrm{kgm}^{-3}\right)$ & 200 & Static friction $\mu_{\mathrm{s}}(-)$ & 0.6 \\
\hline Initial gas pressure reservoir $3000 \mathrm{~m}$ depth $(\mathrm{MPa})$ & 35 & Dynamic friction $\mu_{\mathrm{d}}(-)$ & 0.45 \\
\hline Density fluid over- and underburden $\rho_{\mathrm{f}}\left(\mathrm{kgm}^{-3}\right)$ & 1150 & Critical slip distance $\mathrm{D}_{\mathrm{c}}$ & 0.005 \\
\hline Stress ratio $\mathrm{K}_{0}=\sigma_{\mathrm{h}} / \sigma_{\mathrm{v}}(-)$ & 0.75 & Cohesion $\mathrm{C}(\mathrm{MPa})$ & 0 \\
\hline Biot coefficient $\alpha(-)$ & 1 & & \\
\hline
\end{tabular}

\section{2. 2. Element size, timestep, and damping}

An automated model-generator was constructed to generate the plane-strain model geometry. The linear slip-weakening relationship that governs post-failure faulting behavior leads to a minimum resolution constraint to capture adequately the seismic shear slip on the fault The interface element length $\Delta y$ was chosen such that at least 15 elements were within the low velocity limit of the process zone $\Lambda_{0}$ (Day et al., 2005; Palmer \& Rice, 1973)

$$
\Lambda_{0}=\left(\frac{9 \pi}{32}\right)\left(\frac{G_{I I}}{W}\right)
$$

where $\mathrm{G}_{\mathrm{II}}$ is the shear modulus for mode II cracks $G /(1-v)$, and $W$ is the weakening rate $\left(\tau_{f}\right.$ $\left.\tau_{f}\right) / D_{c}$. The cohesive zone size $\Lambda$ decreases with increasing rupture velocity, and it is recommended to have enough $(15-20)$ elements within $\Lambda_{0}$ to resolve the rupture process (Day et al., 2005), which corresponds to an element size of $0.75-1 \mathrm{~m}$ for the default parameters in Table 1 for a normal stress of $20 \mathrm{MPa}$. This element size adequately resolved the process zone at higher rupture speeds by 4 or more elements (Figure 2-2d). Along the fault segments in the overburden and away from the reservoir formation the element size gradually increased to a maximum of $50 \mathrm{~m}$. For conditions under which rupture propagated far into the underburden and overburden a more refined mesh was used. The formations were meshed with an linear quadrilateral elements which coarsened away from the fault up to the $50 \mathrm{~m}$, bringing the total number of elements to $\sim 40,000-80,000$. The explicit dynamic analysis requires a minimum timestep for convergence, which is related to the element size via the Courant-Friedrichs-Lewy (CFL) criterion (e.g. Day et al., 2005) 


$$
\Delta t=\eta \Delta y / V_{p}
$$

vwhere $\eta$ is the Courant-Friedrich-Lewy (CFL) number $(0<\eta<1), \Delta y$ is the element size (1 $\mathrm{m}$ ), and $\mathrm{V}_{\mathrm{P}}$ is the $\mathrm{P}$-wave speed (here $2.57 \mathrm{kms}^{-1}$ ). The CFL number $\eta$ used in other studies ranged from 0.25 - 0.5 (e.g. Day et al., 2005; Fukuyama \& Madariaga, 1998). Here a $C F L$ number of 0.5 is used (e.g. Day et al., 2005; Fukuyama \& Madariaga, 1998) which gives a timestep of $2 \times 10^{-4} \mathrm{~s}$. During the dynamic phase artificial Rayleigh damping was used to reduce high frequency numerical noise (Section 2.2.1). The low frequencies were not damped $(a=0)$ and the high frequencies were damped by setting $b=0.1 \Delta t$ (e.g. Duan \& Oglesby, 2006). The effect of damping on the fault slip rates is illustrated in Figure 2-2b; high frequency vibrations are effectively removed by the damping.
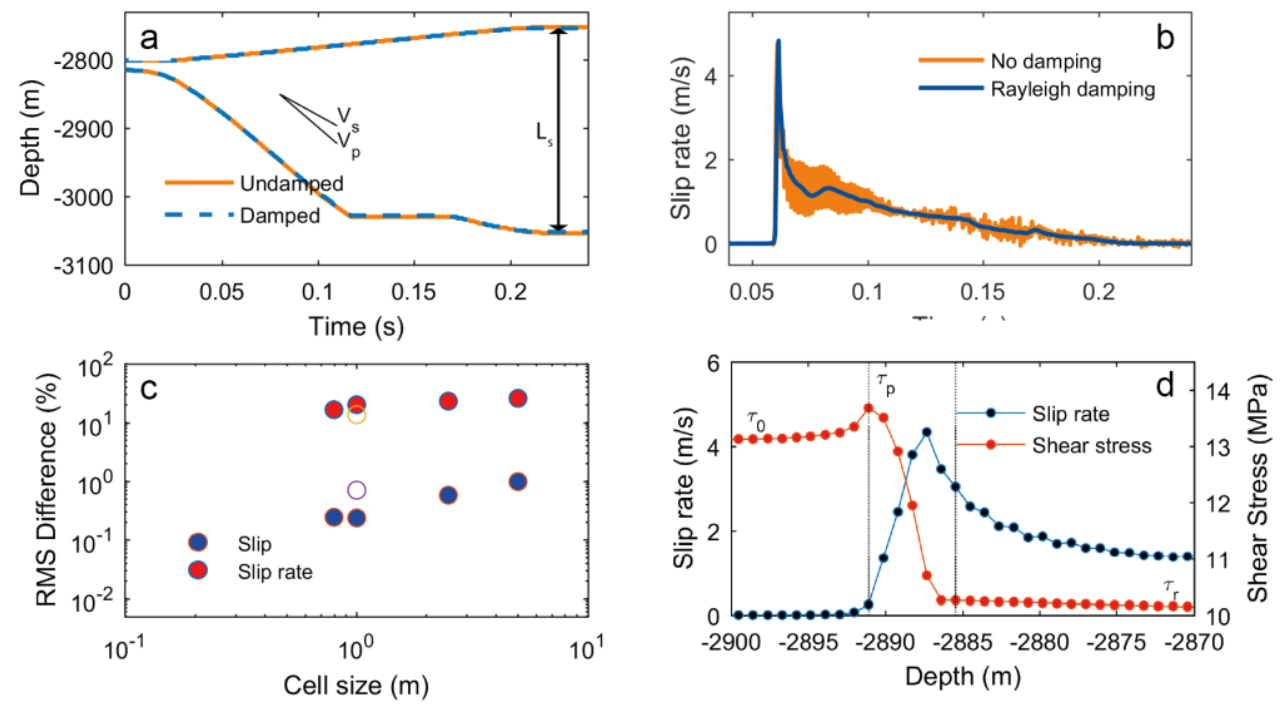

Figure 2-2. Effect of damping and cell size on rupture calculation shown for a $0 \mathrm{~m}$ offset reservoir. a) Updip and downdip growth of the rupture along the fault as a function of time. The $P$-wave and $S$-wave velocities $V_{p}$ and $V_{s}$ are indicated for reference. b) Timeseries of slip rate on the fault at $-2900 \mathrm{~m}$ depth comparing the damped versus undamped results for 1 m element size c) Convergence of RMS difference (\%) in peak slip rate and final velocity as a function of element size. Differences were calculated on 40 different location on the fault with respect to the reference model which used an element size of $0.25 \mathrm{~m}$ and Rayleigh damping. $d$ ) Slip rate and shear stress on the fault at $t=0.056$ s. Markers indicated the position of nodes of the interface elements on the fault.

\section{2. 3. Initial stresses and pressures, pressure changes, and input parameters}

The initial horizontal stresses were defined through the total stress ratio $K_{0}$ as $\sigma_{h}=$ $K_{0} \sigma_{v}$. The initial pore pressure gradients (Figure 2-1a) were imposed assuming a saline water density $\rho_{f}$ of $1150 \mathrm{kgm}^{-3}$, a gas density $\rho_{g}$ of $200 \mathrm{kgm}^{-3}$ and an initial gas pressure $P_{\text {ini }}$ of 35 $\mathrm{MPa}$ at $-3000 \mathrm{~m}$ (van Oeveren et al., 2017). At the reservoir level this resulted in a hydrocarbon overpressure of $3 \mathrm{MPa}$ w.r.t. the saline water gradient (4.6 MPa overpressure 


\section{Chapter 2}

w.r.t. a fresh water gradient), which is a commonly observed value in the Northern Netherlands (Verweij et al., 2012). Pore pressures in the fault segments having a reservoir formation on one or both sides were assumed to be similar to the pore pressure of the reservoir formation. For the other fault segments the overburden or underburden pore pressure was prescribed. Depletion was modeled in a simplified manner; a uniform pore pressure changes $\triangle P$ was prescribed for the reservoir formation and adjacent fault segments, with gas flow not explicitly modeled. This assumption is based reservoir models of the Groningen field which show relatively uniform depletion and no or little pressure differential across the faults (NAM, 2016a; van Oeveren et al., 2017). No fluid flow occurred from the rocks or fault in underburden and overburden to the depleting reservoir. Pressure changes were coupled oneway to stress changes, as the pore fluid (gas) is very compressible compared to the reservoir rock.

The default parameters are summarized in Table 2-1. A variable reservoir offset could be incorporated by adjusting the depth of the hanging wall. Results for a $0 \mathrm{~m}$ and $50 \mathrm{~m}$ offset reservoir are studied in detail, as most of the faults in the Groningen field have offsets varing varying between 0 and half the reservoir thickness (Buijze et al., 2017; Wentinck, 2015). The default $K_{0}$ was 0.75 ; however the $K_{0}$ in the Groningen field is highly uncertain (van Eijs, 2015) and sensitivity of rupture nucleation and size to $K_{0}$ in the range of $0.7-0.8$ was investigated. A static friction coefficient $\mu_{s}$ of 0.6 was assumed which is consistent with the steady state friction coefficient of Rotliegend sandstone fault gouges deformed at the insitu conditions of the Groningen field (Hunfeld et al., 2017). Representative values for $\mu_{d}$ and $D_{c}$ are difficult to obtain from laboratory experiments. We chose $D_{c}$ and $\mu_{d}$ such that the fracture energy $G_{c}$ (Figure 2-1d) was consistent with that estimated for typical Groningen earthquakes with a slip of $\mathrm{mm}-\mathrm{cm}$ (Kraaijpoel \& Dost, 2013) which was $10^{3}-10^{5} \mathrm{~J} / \mathrm{m}^{2}$ (Nielsen et al., 2016), and the stress drop was in the range of $0.1-10 \mathrm{MPa}$ as observed thus far in Groningen (Kraaijpoel \& Dost, 2013). For the base case a $D_{c}$ of $5 \mathrm{~mm}$ and a $\mu_{d}$ of 0.45 were used, which gives a $G_{c}$ of $7500 \mathrm{Jm}^{-2}$ for a $\sigma_{n}{ }^{\prime}$ of $20 \mathrm{MPa}$ (Table 2-1). Sensitivities of rupture to $\mu_{d}(0.35-0.55)$ and $D_{c}(1-100 \mathrm{~mm})$ were analyzed.

\section{2. 4. Data processing}

The criticality of the fault was indicated with the Shear Capacity Utilization $(S C U)$

$$
S C U=\frac{\tau}{\tau_{f}}=\frac{\tau}{C+\left(\sigma_{n}-P\right) \mu_{s}}
$$

An $S C U$ of 1 indicates the fault element is at failure and can slip plastically in the normal direction, whereas an SCU of 0 indicates the absence of shear stress. Negative values are used in case the shear stress is positive in the reverse direction.

The pressure change at the onset of fault slip (fault reactivation) $\Delta P_{r}$ was defined as the pressure drop at which the shear stress on one of the fault element reached the shear 
strength $\tau_{f}(S C U=1)$. To eliminate the effect of pressure load step size the $\triangle P_{r}$ was determined by fitting the evolution of $S C U$ of the most critical fault element versurs with $\triangle P$, and determine at which $\triangle P$ the $S C U$ becomes 1 . After the onset of fault reactivation a phase of aseismic fault slip started in which incremental reservoir depletion $\Delta P_{a}$ was required to increase the size of the slipping fault patch. When the aseismic slip patch reached a critical size the aseismic nucleation phase ended at $\Delta P_{n}=\Delta P_{r+\Delta P_{a}}$. The corresponding along-fault length of the aseismic slip patch $L_{a}$ at the end of the nucleation phase was termed $L_{n}$. The length of the subsequent seismic rupture $L_{s}$ was determined by the length of the fault zone where slip rates (derivative of the relative plastic shear displacement across the fault) had exceeded $0.01 \mathrm{~ms}^{-1}$.

\section{3. Simulation Results}

\section{3. 1. Seismic rupture induced on a fault cross-cutting two depleting reservoir} compartments without offset.

This section describes the simulation results of seismic rupture induced by the depletion of a reservoir without offset; the simplest scenario in terms of geometry. The initial stresses and depletion-induced stress changes are presented, and are compared to analytical solutions of linear poroelasticity. The aseismic nucleation process is shown and compared against a theoretical estimate for the critical nucleation length, and simulation results for the evolution of the subsequent seismic event are described.

\section{3. 1. 1Depletion-induced stresses on the fault and comparison to analytical solutions}

The initial fault stresses in the reservoir interval, as well as in the overburden and underburden, were not (close to) critical. For the in-situ stress ratio $K_{0}$ of 0.75 , the initialized effective normal stress $\sigma_{n}{ }^{\text {' }}$ and shear stress $\tau$ on the fault at the reservoir depth interval were 15 - $17 \mathrm{MP}$ and $6 \mathrm{MPa}$ respectively (dark lines in Figure 2-3b and c). The overpressure resulting from the presence of the hydrocarbon column in the reservoir was manifested in the steplike $3 \mathrm{MPa}$ increase in pore pressure at $-2800 \mathrm{~m}$ (Figure 2-3a) and the corresponding decrease in $\sigma_{n}{ }^{`}$ (Figure 2-3b). The proximity to failure as given by the Shear Capacity Utilization $S C U$ (see Equation 2-10) ranged from 0.5 at the base of the reservoir to 0.6 at the top (Figure 2-3e) and signified that the fault was far from failure $(S C U=1)$. In the overburden and underburden the initial $S C U$ was 0.5 .

Depletion resulted in more critical fault stresses in the reservoir interval. The uniform reduction pore pressure in the reservoir formations (Figure 2-3a) caused the effective normal stress and the shear stress on the fault to increase linearly with depletion (Figure 2-3b and c). The combined effect of the increasing stresses was a linear increase in $S C U$, until fault reactivation occurred at $-29.95 \mathrm{MPa}$ (Figure 2-3e). The corresponding stress path for a point on the fault within the reservoir interval (at $-2807 \mathrm{~m}$ depth) is shown in a Mohr-circle 


\section{Chapter 2}

diagram (red circles in Figure 2-4). The initial and final states of stress are shown for reference (orange circles). The pressure drop caused the Mohr circle to shift to higher effective stresses, but simultaneously caused the differential stress to increase. This increase was the result of a decrease in total horizontal stress with decreasing pressure (Equation 2-4), whilst the total vertical stress remained constant. The increase in differential stress caused the fault stress to converge towards the failure line and become more critical (increasing $S C U$ ). The increase in $S C U$ was uniform over the entire reservoir interval, whereas outside of the reservoir interval the fault stresses and the $S C U$ were not affected by depletion.
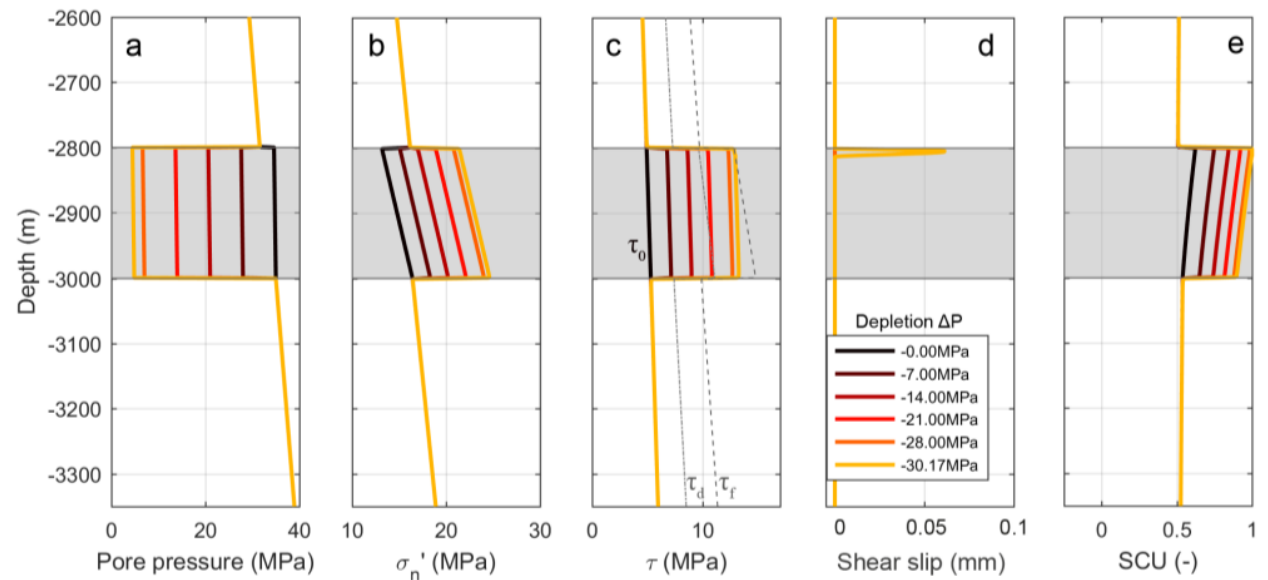

Figure 2-3. On-fault data for depletion of a reservoir without offset (fault dip $\varphi 70^{\circ}$ ). a) pore pressure, $b$ ) normal effective stress, c) shear stress. The failure shear stress $\tau_{f}$ and dynamic shear stress $\tau_{d}$ at $\triangle P=30.17$ are shown by the dashed and dotted grey lines, $d$ ) (relative) shear slip displacement, and e) the Shear Capacity Utilisation (SCU) as a function of depth along the fault for a reservoir without offset and for different depletion pressures $\triangle P$, as indicated by the legend in $d)$. The gray areas indicate the depth interval of footwall and hanging wall reservoir formations.

The simulation results for fault reactivation agree well with the analytical solution for a laterally extensive depleting reservoir undergoing uniaxial compaction (e.g. Fjaer et al., 2008; Hettema et al., 2000). To compare between numerical simulation results and the analytical solution we defined stress path parameters $\gamma_{n}$ and $\gamma_{t}$, which are the changes in effective normal stress and shear stress on the fault plane as a function of depletion pressure $\Delta P$. These stress path parameters are calculated defined in terms of the horizontal stress path parameter $\gamma_{h}$ which for a poroelastic medium under uniaxial strain conditions is defined as (Geertsma, 1973; Hettema et al., 2000)

$$
\gamma_{h}=\frac{\Delta \sigma_{h}}{\Delta P}=\alpha \frac{1-2 v}{1-v}
$$

which is a function of Biot coefficient $\alpha$ and Poisson's ratio $v$. Translating the principal stresses to shear an normal stresses on the fault gives 


$$
\gamma_{n}=\frac{\Delta \sigma_{n}^{\prime}}{\alpha \Delta P}=0.5 \gamma_{h}(1+\cos 2 \theta)-1
$$

and

$$
\gamma_{\tau}=\frac{\Delta \tau}{\alpha \Delta P}=-0.5 \gamma_{h} \sin 2 \theta
$$

where $\theta(=90$ - fault dip $\varphi)$. Dividing Equation 2-13 with Equation 2-12 gives slope of the stress path $\beta$ in the Mohr diagram

$$
\beta=\frac{\Delta \tau}{\Delta \sigma_{n}^{\prime}}=\frac{-0.5 \gamma_{h} \sin 2 \theta}{0.5 \gamma_{h}(1+\cos 2 \theta)-1}
$$

and the pressure drop at which reactivation occurs $\Delta P_{c r}$ (stress path intersects the failure line) is given by

$$
\Delta P_{c r}=\frac{C-\tau_{i n i}+\sigma_{n i n i}^{\prime} \mu_{s}}{\gamma_{\tau}-\gamma_{n} \mu_{s}}
$$

where $\tau_{i n i}$ and $\sigma_{n i n i}$ are the initial shear and normal stresses on the fault plane and $\mathrm{C}$ is the cohesion. For the base case $v$ of $0.15, \varphi$ of $70^{\circ}$ and $\mu_{s}$ of 0.6 the resulting slope of the stress path $\beta$ is 0.970 , and the reactivation pressure is $-29.8 \mathrm{MPa}$. The fact that $\beta>\mu_{s}$ indicates convergence with the failure line (a destabilizing stress path), and because $\Delta P_{c r}$ is smaller than the intial reservoir pressure $P_{i n \mathrm{i}}$ reactivation can occur as a result of poroelastic stressing. In the simulations the stress path had a slope of 0.968 which is a small difference $(<0.2 \%)$ with respect to the analytical solutions. Reactivation occurred at a $\triangle P$ of $-29.95 \mathrm{MPa}$, which is $0.5 \%$ more than the analytical solution. Differences between the analytical and numerical results may arise from elastic deformation on the interface elements, and it is important to set the stiffness parameters appropriately (see Section 2. 2. 2. ).

The analytical solutions give basic insights into how the key factors Poisson's ratio and fault dip affect the stress path and potential for reactivation for the zero offset fault scenario. Poisson's ratio $v$ strongly affects the slope of the stress path $\beta$; the smaller the Poisson's ratio the steeper the stress path and the more unstable the stresses (Figure 2-4a). The calculated $\beta$ (Equation 12) varied from 1.8 if $v=0.05$ to 0.52 if $v=0.25$. The onset of fault slip will not occur at any (theoretical) depletion pressure if the stress path does not intersect the Mohr-Coulomb failure line ( $\beta=<\mu_{s}$ ), which was found for a Poisson's ratio equal to or larger than 0.22 . The fault dip angle $\varphi$ influenced three factors: i) the initial stress on the fault and proximity to failure, ii) the length of the stress path for a given pressure drop, and iii) the slope of the stress path $\beta$ (Figure 2-4b; van den Bogert, 2015). First, the fault dip determined the initial stress on the fault. The initial fault stress was most critical for a fault $\operatorname{dip} \varphi$ of $59^{\circ}$, i.e. the tangent to the failure line atan $\left(\mu_{s}\right)$. The proximity to failure decreased for lower and higher dips. The base case fault dip of $70^{\circ}$ was thus not the dip most critical at 


\section{Chapter 2}

the initial conditions. Second, a decreasing fault dip resulted in a longer stress path. This was predominantly the effect of an increase in $\gamma_{n}$ with decreasing fault dip (Equation 2-12). Third, the slope of the stress path had a non-linear relation with fault dip angle, with a minimum of 0 at a fault angle of $0^{\circ}$ and a maximum of 0.98 at a fault angle of $67^{\circ}$. The slope of 0 showed that reservoir depletion does not cause any shear stress on a vertical fault plane intersecting a reservoir without offset, irrespective of the value for Poisson's ratio. Which dip was most prone to reactivation depended on the combination of the initial stress state and the fault friction properties, the slope of the stress path and the Poisson's ratio.

For the current study zero cohesion was assumed on the fault. However, at the shallow depths and resulting low stresses a small amount of cohesion may have a large effect on the reactivation potential, e.g. $3 \mathrm{MPa}$ of cohesion would require an unrealistically low Poisson's ratio for reactivation (Figure 2-4a).
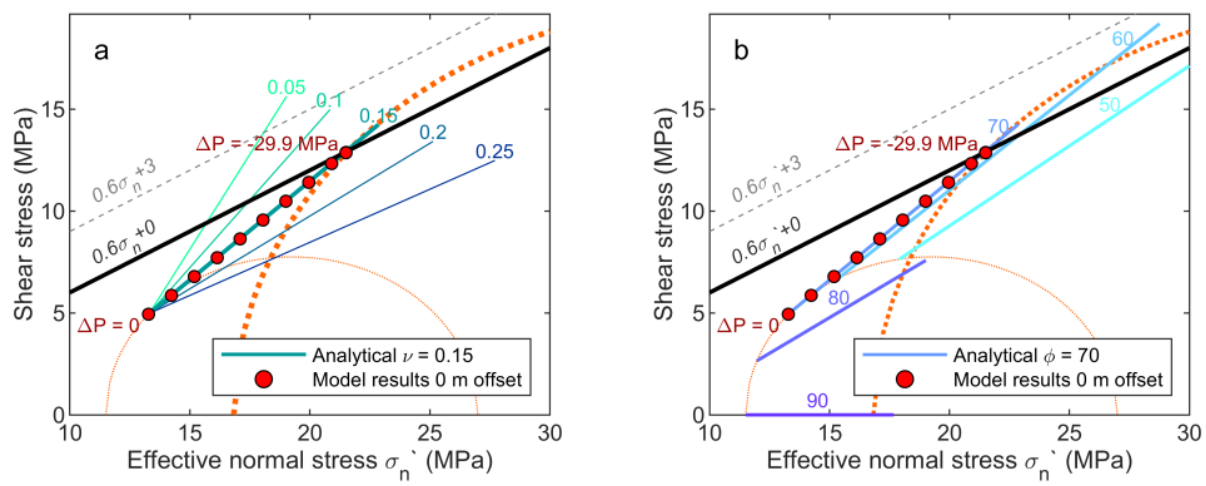

Figure 2-4. Effect of Poisson's ratio $v$ and dip angle $\varphi$ on stress paths on the fault for depletion of a $0 \mathrm{~m}$ offset reservoir: numerical results and analytical solutions. The stresses on the fault are resolved at $2807 \mathrm{~m}$ depth. The Mohr Coulomb failure line is shown as the black solid line; grey dashed line indicates Mohr Coulomb failure including $3 \mathrm{MPa}$ cohesion. The model results for reservoir depletion from $\Delta P=0$ (initial stress state) to fault reactivation $\Delta P_{r}=-29.95$ are indicated by the red solid circles, and corresponding initial and reactivation states of stress are shown by the thin orange dotted semi-circle and the fat orange dotted semi-circle. a) Effect of Poisson's ratio $v$ on the on-fault stress path. The analytical stress path corresponding to the model results $(v=0.15)$ is plotted with the dark cyan line. Analytically computed stress paths for other $v(0.05,01,0.2,0.25)$ are shown for reference, for a depletion $\triangle P=0$ to $\triangle P=-35 \mathrm{MPa}$ (full reservoir depletion at $2807 \mathrm{~m}$ depth). b) Effect of fault dip $\varphi$ on the on-fault stress path. The analytical stress path corresponding to the model results $\left(\varphi=70^{\circ}\right)$ is plotted with the lilac line. Analytically computed stress paths for other $\varphi\left(50^{\circ}, 60^{\circ}, 80^{\circ}, 90^{\circ}\right)$ are shown for reference, for a depletion $\triangle P$ $=0$ to $\triangle P=-35 \mathrm{MPa}$.

\section{3. 1. 2 Fault reactivation and the onset of seismic rupture}

Fault reactivation occurred at the top of the reservoir $(-2807 \mathrm{~m})$ at a depletion pressure $\Delta P_{r}$ of $-29.95 \mathrm{MPa}$ (Figure 2-3e). After reactivation plastic slip on the fault occurred an aseismic slip patch developed at the top of the reservoir, growing in size as more and more fault elements were reactivated (Figure 2-3d). Below the reactivation pressure no plastic 
deformation occurred and $\mathrm{L}_{\mathrm{a}}$ was zero. At $P<-30 \mathrm{MPa}$ the aseismic slip patch increased until at a nucleation pressure change $\Delta P_{n}$ of $-30.18 \mathrm{MPa}$ instability was approached, so-called snap-through behavior, where the increasing stresses due to depletion pressure could no longer be sustained. This signified the onset of unstable, seismic rupture. Upon reaching instability, the aseismic slip patch evolved to a $L_{n}$ of $13 \mathrm{~m}$, which was in agreement with a theoretical estimate for the critical nucleation length for linear slip-weakening friction $L_{U R}$. This length was derived analytically as the solution to an eigenvalue problem, and depends on the slope of the frictional weakening diagram, or weakening rate, $W=\left(\tau_{f}-\tau_{d}\right) / D_{c}$ (Uenishi \& Rice, 2003)

$$
L_{U R}=1.158 \frac{G}{(1-v) W}=1.158 \frac{G D_{c}}{(1-v)\left(\tau_{f}-\tau_{d}\right)} .
$$

where $G /(1-v)$ is the shear modulus for mode II and $\tau_{f}$ is the fault shear strength $\mu_{s} \sigma_{n}{ }^{`}$ and $\tau_{d}$ is the dynamic shear stress $\mu_{d} \sigma_{n}$ '. The smaller $D_{c}$ and/or the larger the strength drop $\tau_{f}-\tau_{d}$, the smaller $L_{U R}$. The theoretical critical nucleation length $L_{U R}$ was computed for the simulation results using the average $\sigma_{n}{ }^{\prime}$ in the aseismic slip zone, and was $13.8 \mathrm{~m}$ for the current scenario. The modeled $L_{n}$ of $13 \mathrm{~m}$ corresponded closely to the theoretical $L_{U R}$, but not exactly because the $L_{U R}$ was not an exact multiple of the element size of $1 \mathrm{~m}$ used in the model. The $L_{n}$ is smaller than the fault length cross-cutting the reservoir depth interval (220 $\mathrm{m})$, and hence seismic rupture could nucleate within the reservoir interval. At the onset of seismic rupture the stresses over the whole reservoir were close to critical with an $S C U$ of 1 in the nucleation zone at the top of the reservoir, decreasing linearly to an $S C U$ of 0.85 at the base of the reservoir (Figure 2-3e).

\section{3. 1. 3Dynamic rupture simulation and evolution of seismic slip length}

After the critical nucleation size was reached during depletion, the subsequent evolution of seismic rupture was computed in a fully dynamic analysis. Rupture propagated predominantly in the downdip direction from its nucleation site at the top of the reservoir (Figure 2-5a,d). Downdip propagation into the reservoir interval was favored by the fault stresses that were elevated during reservoir depletion and were close to the failure strength $\tau_{f}$ (Figure 2-5c). During the rupture the stress dropped by $2-3 \mathrm{MPa}$ to its dynamic value $\tau_{d}$ within the slipping zone, whereas a stress concentration was present in front of the propagating rupture tip (see also Figure 2-2d). The rupture front reached the base of the reservoir after $0.12 \mathrm{~s}$ of slip and entered the underburden. In the underburden the in-situ stress was far from its failure strength. In fact, the in-situ stress in both the underburden and overburden was such that the static stress drop $\Delta \tau\left(=\tau_{0}-\tau_{d}\right)$ was positive, which is inherently stabilizing. The stable stress state prevented significant updip propagation arresting the rupture at $-2753 \mathrm{~m}$ in the overburden, and at $-3053 \mathrm{~m}$ in the underburden. In front of both rupture limits a shear stress concentration remained on the fault (Figure 2-5c). The total 

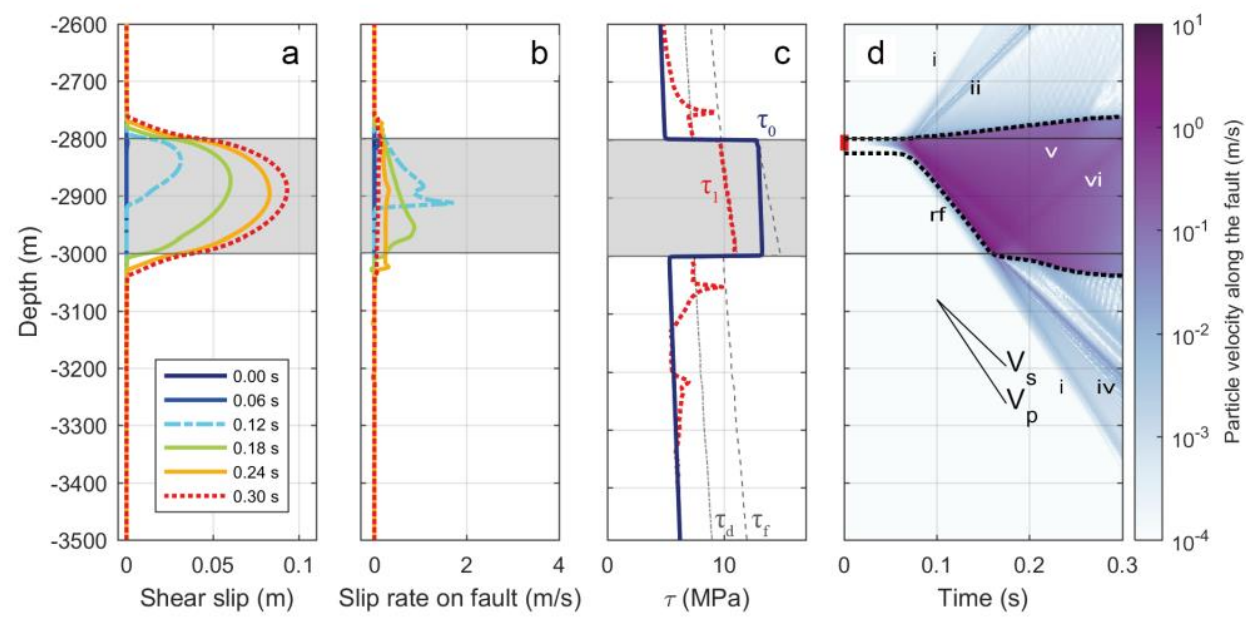

Figure 2-5. Simulation results for on-fault slip, slip rate, shear stress and particle velocities during dynamic rupture on a $0 \mathrm{~m}$ offset fault. . The depth interval of the reservoir compartments is indicated by the shaded area. Model parameters $K_{0}=0.75, \mu_{d}=0.45$, and $D_{c}=5 \mathrm{~mm}$. a) Shear slip as a function of depth along the fault for different points in time. b) On-fault slip rates as a function of depth along the fault for different points in time. $c$ ) Shear stress as a function of depth along the fault, for $t=0 \mathrm{~s}$ (dark blue line) and $t=0.30 \mathrm{~s}$ (red dotted line). The failure stress $\tau_{f}$ (gray dashed line) and dynamic shear stress $\tau_{d}$ (gray dotted line) are shown. d) Fault-parallel particle velocities along the fault with time. The upper and lower limits of the seismic slip zone are indicated by the dotted black line; outside of this line all the motions are elastic. Particle velocities indicate different waves generated y the rupture with i) $P$-wave generated by nucleation on the rupture, ii) $S$-wave, iii) mother rupture, iv)S-wave emitted by arrest of daughter rupture, $v$ ) reflected $P$-wave, vi) reflected $S$-wave, $r f)$ rupture front.

rupture length $L_{s}$ along the fault was $326 \mathrm{~m}(=(-2753-3053) / \sin (70))$, thus rupturing mainly the reservoir but also part of the overburden and underburden.

Rupture propagated in a crack-like manner; i.e. slip increased at all locations within the seismic slip patch for the duration of the rupture (Figure 2-5a). The largest slip of $0.1 \mathrm{~m}$ occurred in the center of the slip patch, roughly in the center of the reservoir depth interval. Outside of the reservoir interval slip decreased rapidly as rupture was arrested. The simulated fault slip rates were largest at the crack tip and exceeded $4 \mathrm{~ms}^{-1}$ (Figure 2-5b), well into the seismic slip rate regime. Note that slip rate may be sensitive to cell size, however total slip is not (Figure 2-2a).

The fault-parallel particle velocities (here taken from the hanging wall side of the fault) are indicative for the seismic slip rate and seismic waves recorded along the fault zone (Figure 2-5). The dotted line shows the expansion of the seismic slip patch with time. Rupture expanded slowly for the first $0.03 \mathrm{~s}$, and then accelerated, emitting a P- and and S-wave (i and ii). High velocities in the order of $1 \mathrm{~ms}^{-1}$ were associated with the rupture front (rf), as was also observed from the slip rate in Figure 2-5b. The downdip propagation speed of the rupture front (rupture velocity $v_{r}$ ) was constant in the reservoir interval, and nearly equal to the P-wave velocity - i.e. rupture was supershear. This can occur for Mode II ruptures where a stress peak develops ahead of the main rupture and nucleates a so-called daughter rupture 
propagating at intersonic velocity (Burridge - Andrews mechanism). The original mother rupture is also distinguishable, propagating at a velocity smaller than the $\mathrm{S}$-wave velocity (iii in Figure 2-5d), and it is visible as the second peak in slip rate at $0.10 \mathrm{~s}$, at a depth of -2900 $\mathrm{m}$ depth. As the daughter rupture reached the base of the reservoir at $-3000 \mathrm{~m}$ it decelerated rapidly, reflecting a $\mathrm{P}$ - and S-wave upwards ( $\mathrm{v}$ and vi), before being arrested at $-3020 \mathrm{~m}$ after $0.13 \mathrm{~s}$. Meanwhile the mother rupture continued to propagate downdip, and advanced the rupture front to $-3050 \mathrm{~m}$ before being arrested. Hence, supershear caused a relatively large rupture. Supershear is often related to Mode II and relatively critical pre-rupture stress (Dunham et al., 2011); whether this is likely in the shallow subsurface will be discussed further in the Discussion.

\section{3. 2. Seismic rupture induced on a fault with $50 \mathrm{~m}$}

The previous section showed the results of the full analysis for a $0 \mathrm{~m}$ offset fault. Previous studies have shown fault offset affects the stress changes during depletion and fault reactivation (Buijze et al., 2017; Mulders, 2003; Orlic \& Wassing, 2013; Roest \& Kuilman, 1994; van den Bogert, 2015). Here the effect of a reservoir offset of $50 \mathrm{~m}$ (a common offset in the Groningen field) on the depletion-induced fault stresses and fault reactivation (3.2.1) and dynamic rupture and final event size (3.2.2) is presented. Fault reactivation and rupture for other offsets is presented in Section 2. 3. 4. .

\section{3. 2. 1 Depletion-induced stresses on a fault with $50 \mathrm{~m}$ offset}

Reservoir offset did not significantly affect the initial fault stresses with respect to the $0 \mathrm{~m}$ offset case, and the initial state of stress was not close to critical (Figure 2-7, Figure 2-6). The initial effective normal stress in the reservoir was $14-17 \mathrm{MPa}$, and the $3 \mathrm{MPa}$ overpressure resulting from the gas pressure was visible as stepwise decrease in pressure and increase in effective normal stress above - $2800 \mathrm{~m}$ (Figure 2-7b). The shear stress increased more linearly with depth, but contrary to the $0 \mathrm{~m}$ offset case showed small deviations from 2800 to -2850 . Reservoir offset created a horizontal discontinuity in pressure across the fault, and hence a discontinuity in effective stresses, which caused small local variations in the initial stress field around the fault (see Figure 2-6g). The resulting $S C U$ decreased at the top of the reservoir depth interval was $0.6-0.65$ with a peak at the top of the footwall. The $S C U$ decreased towards at the top of the reservoir depth interval to 0.5 at the base. Note that initial stresses may become more heterogeneous if elastic properties and $K_{0}$ vary per formation. 

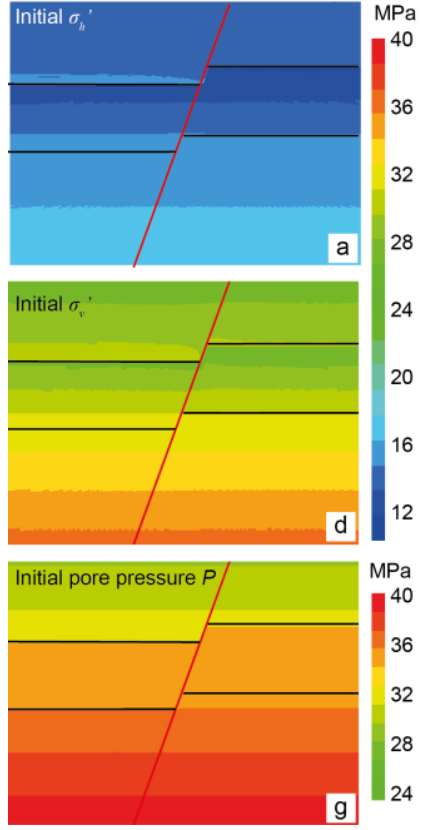

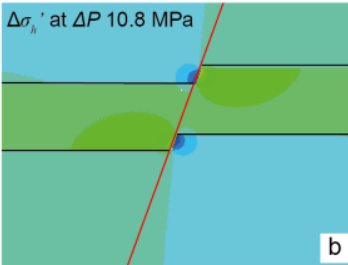

b
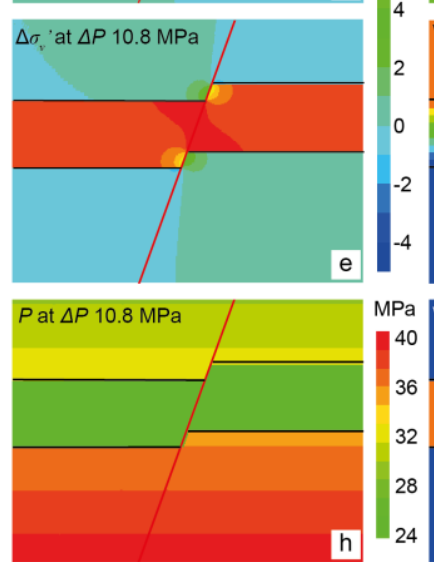
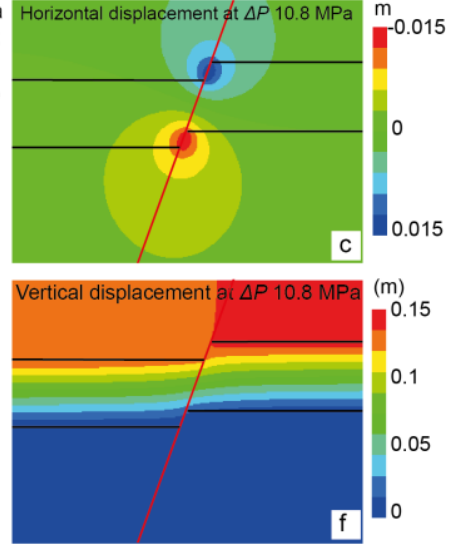

Vertical strain at $\triangle P 10.8 \mathrm{MPa}$

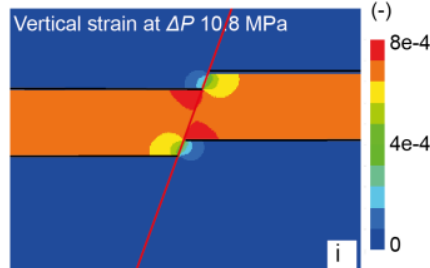

Figure 2-6. Stresses, strains, and displacements in the formations with depletion of two reservoir compartments offset $50 \mathrm{~m}$ by $a 70^{\circ}$ dipping fault. The reservoir formations are bounded by the black lines, the fault is shown as the red line. a) Initial effective horizontal stress $\left.\sigma_{h}{ }^{\prime}\left(=\sigma_{h}-P\right), b\right)$ effective horizontal stress change $\Delta \sigma_{h}$ ' after $10.8 \mathrm{MPa}$ depletion, c) horizontal displacement at $\triangle P=10.8 \mathrm{MPa}$, positive towards the left, $d$ ) initial effective vertical stress $\sigma_{v}{ }^{\prime}\left(=\sigma_{v}-P\right)$, e) effective vertical stress change $\Delta \sigma_{v}{ }^{\prime}$ at $\Delta P=10.8 \mathrm{MPa}$, f) vertical displacement at $\triangle P=10.8 \mathrm{MPa}$, $g$ ) initial pore pressure $P, h$ ) pore pressure at $\triangle P 10.8 \mathrm{MPa}$, i) vertical strain at $\triangle P=10.8 \mathrm{MPa}$.

Reservoir offset did result in heterogeneous stress and promoted fault reactivation, as local stress concentrations developed during depletion. Uniaxial compaction conditions prevailed far away from the offset fault ( $>1$ reservoir thickness), which is reflected by the horizontal displacements were zero far away from the fault (Figure 2-6c). However, the offset of the depleting reservoir compartments along the fault caused local deviations from uniaxial compaction conditions. Horizontal displacements were non-zero near the top of the foot wall and base of the hanging wall, indicating contraction towards respectively the depleting formation in the foot wall and depleting formation in the hanging wall. The vertical displacement (compaction) was $\sim 0.15 \mathrm{~m}$; the offset caused a gradient in compaction from the footwall to the hanging wall, i.e. a form of differential compaction (Figure 2-6f). Both the vertical and horizontal effective stress changes $\Delta \sigma_{v}{ }^{`}$ and $\Delta \sigma_{h}{ }^{`}$ were concentrated near the top of the footwall and the base of the hanging wall, whereas $\Delta \sigma_{v}{ }^{`}$ and $\Delta \sigma_{h}{ }^{`}$ were relatively small in the overburden just above the hanging wall and the underburden right below the footwall (Figure 2-6b and e). On the fault this was visible in both the effective normal stress $\sigma_{n}$ ' and shear stress $\tau$ that increased with depletion, with the strongest increase in the interval where reservoir was juxtaposed against reservoir (-2850 to $-3000 \mathrm{~m}$ depth) (Figure 2-7b, c). The net effect of these stress increases was bringing this fault interval closer to failure - i.e. the 

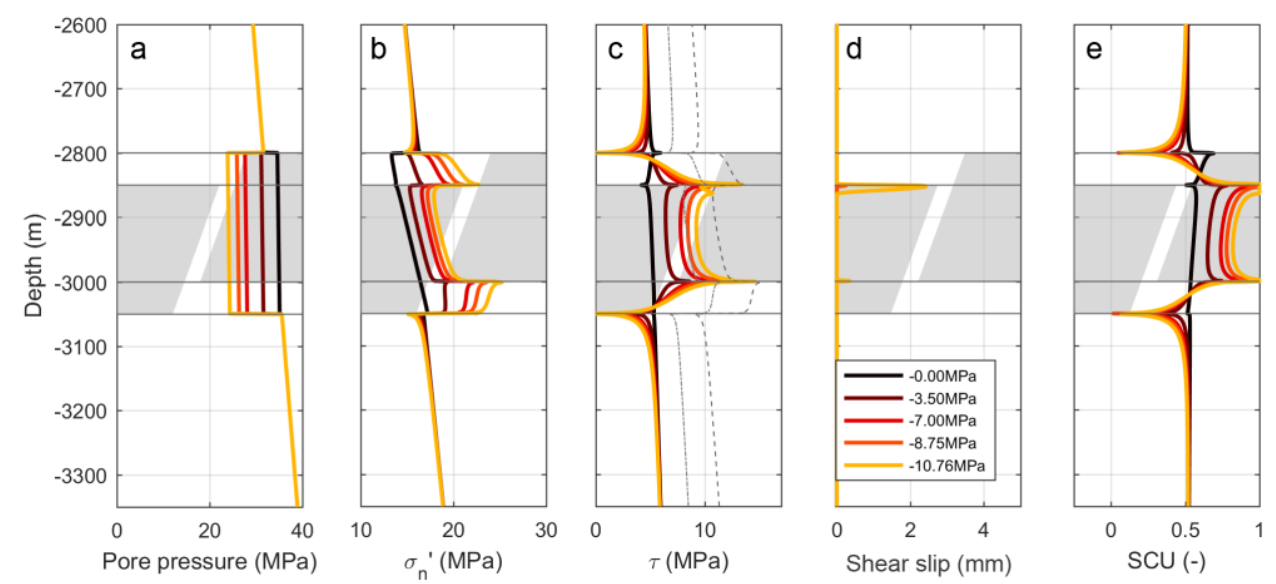

Figure 2-7. Simulated pressures, stresses and plastic slip on the fault during depletion of two reservoir compartments with a $50 \mathrm{~m}$ offset. Simulation results are shown as a function of depth along the fault for different depletion pressures, as indicated by the legend in d). The gray areas indicate the depth interval of footwall (right) and hanging wall (left) reservoir formations. a) pore pressure in the fault, b) effective normal stress $\left.\sigma_{n}{ }^{\prime}, c\right)$ shear stress $\tau, d$ ) shear slip and e) the Shear Capacity Utilization (SCU).

$S C U$ increased (Figure 2-7e). The increases in the stresses and the $S C U$ were amplified near the top of the hanging wall $(-2850 \mathrm{~m})$ and the base of the footwall $(-3000 \mathrm{~m})$. The shallowest of these two stress concentrations led to fault reactivation after a $\triangle P$ of $-9 \mathrm{MPa}$. The peak stresses were then several MPa larger compared to the stress in the center of the juxtaposition interval (-2925 m).

The criticality on the fault did not increase at every depth. The proximity to failure $S C U$ decreased over the top $50 \mathrm{~m}$ of the footwall and bottom $50 \mathrm{~m}$ of the hanging wall, even though the shear stress increased over most of these intervals (Figure 2-7c). The shear stress increase in these intervals was small with respect to the effective normal stress increase. The normal stress caused a high fault strength so that the resulting $S C U$ decreased and the fault became more stable. The minimum $S C U$ was found at the top of the footwall $(-2800 \mathrm{~m})$ and base of the hanging wall $(-3050 \mathrm{~m})$. The fault stress also stabilized outside of the reservoir depth intervals, because the shear stress decreased above the footwall and below the hanging wall. Hence, the offset reservoir geometry caused a heterogeneous stress distribution along the fault, with some regions becoming more critical and others more stable.

After a $\triangle P$ of $-9 \mathrm{MPa}$ fault reactivation occurred at the shallowest stress peak. This $\Delta P_{r}$ was three times less than for the $0 \mathrm{~m}$ offset reservoir $\left(\Delta P_{r}=-29.9 \mathrm{MPa}\right)$. The modeled slope of the stress path $\Delta \tau / \Delta \sigma_{n}$ ' at the reactivation depth of $-2855 \mathrm{~m}$ was 1.6 , which is much steeper and more unstable compared to the $\beta$ of 0.97 for uniaxial conditions calculated in Section 2. 3. 1. 1. Hence offset promoted failure and caused the stress evolution to deviate from the uniaxial conditions. The non-uniaxial conditions are also visible in the stress field around the offset fault, e.g. in the local non-zero horizontal strains. The non-uniaxial 


\section{Chapter 2}

conditions were dominant near the fault; more than one reservoir thickness away from the fault deformation became uniaxial (see Figure 2-6).

The aseismic slip patch that developed upon fault reactivation required a larger pressure drop to grow to its critical size than for the $0 \mathrm{~m}$ offset case. Beyond the reactivation pressure an additional $\Delta P_{a}$ of $-1.8 \mathrm{MPa}$ pressure was required to attain the critical nucleation length $L_{n}$ of $11 \mathrm{~m}$, at a $\Delta P_{n}$ of $-10.8 \mathrm{MPa}$. The modeled $L_{n}$ matched the theoretical critical nucleation length $L_{U R}$, which for this scenario was $12 \mathrm{~m}$. Although $L_{n}$ was similar to the $L_{n}$ for $0 \mathrm{~m}$ offset reservoir, the amount of aseismic slip was 40 times larger as a result of the locally enhanced stresses, reaching a maximum of $2 \mathrm{~mm}$ of slip (Figure 2-7d). Aseismic fault slip reduced the friction in the center of the nucleation zone by 0.06 , which equaled a reduction in shear stress of $1.3 \mathrm{MPa}$.

\section{3. 2. 2 Dynamic simulation of rupture on a fault with $50 \mathrm{~m}$ offset}

Rupture nucleated from the shallowest of two slip zones that developed during reservoir depletion, at $-2855 \mathrm{~m}$ depth (Figure 2-7). The slip patch expanded slowly for about $0.05 \mathrm{~s}$, and then accelerated rapidly propagating primarily in the down-dip direction
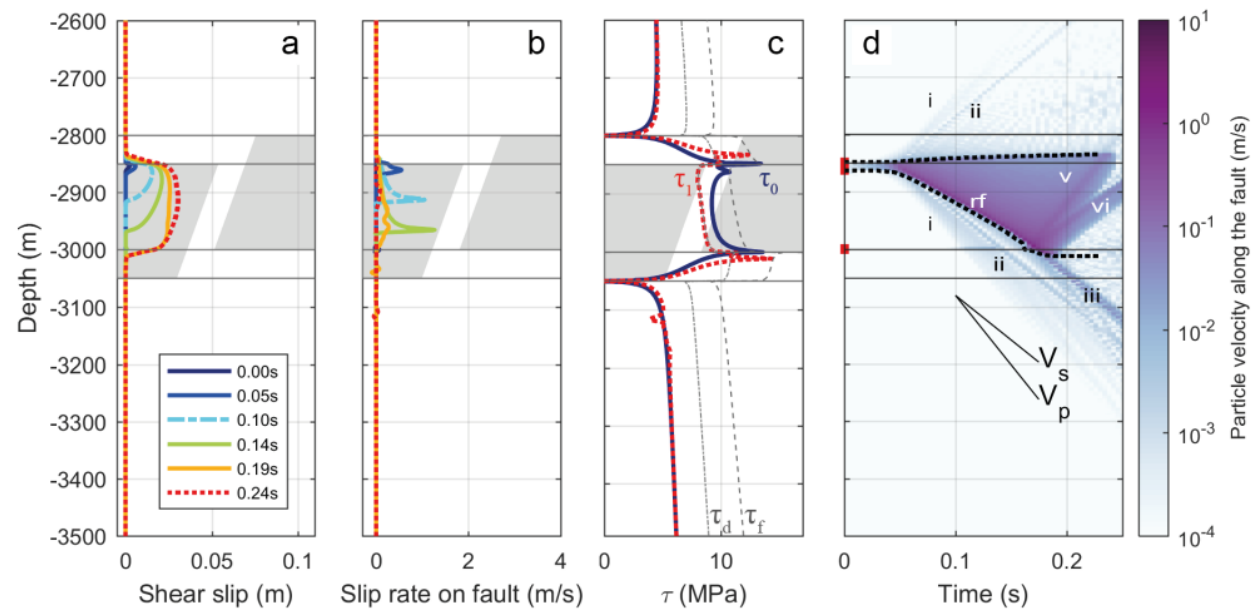

Figure 2-8. On-fault slip, slip rate and shear stress during dynamic rupture on a $50 \mathrm{~m}$ offset fault. Base case value of $K_{0}$ of 0.75, a $\mu_{d}$ of 0.45, and a $D_{c}$ of $5 \mathrm{~mm}$ were used. The depth interval of the reservoir compartments is indicated by the shaded area. a) Shear slip as a function of depth along the fault for different points in time. $b$ ) On-fault slip rates as a function of depth along the fault for different points in time. c) Shear stress as a function of depth along the fault for different points in time Failure stress $\tau_{f}$ and dynamic shear stress $\tau_{d}$ computed at the start of rupture (at $\left.\Delta p_{n}\right)$ is shown by the grey dashed line and grey dotted line. d) ) Fault-parallel particle velocities along the fault with time. The upper and lower limits of the seismic slip zone are indicated by the dotted black line; outside of this line all the deformation is elastic. Particle velocities indicate different waves generated y the rupture with i) $P$-wave generated by nucleation on the rupture, ii) $S$-wave, iii) mother rupture, v) reflected $P$-wave, vi) reflected $S$-wave, $r f$ ) rupture front. 
(Figure 2-8a, d). Down-dip rupture was facilitated by the depletion-induced increased shear stress and related high $S C U$ of $0.8-1$ along the reservoir-reservoir juxtaposition interval (Figure 2-8c, Figure 2-7e). After 0.18 s rupture reached the deeper stress concentration, and was then arrested abruptly at the base of the footwall at $-3010 \mathrm{~m}$. Arrest occurred because rupture encountered a low shear stress region which acted as a barrier. Stresses were stable at this location from -3000 to $-3050 \mathrm{~m}$ depth (as well as at the top of the footwall from -2800 to $-2850 \mathrm{~m}$ depth) for two reasons. The relatively large effective normal stresses in these intervals (Figure 2-7b) were responsible for a high shear strength $\tau_{f}$ (Figure 2-8c). In addition, reservoir depletion had caused a reduction of the shear stress in these intervals (Figure 2-7c), so that the shear stress was far from failure, as also expressed by the low $S C U$ of $0-0.5$ (Figure 2-7e). Hence the depletion from the $50 \mathrm{~m}$ offset reservoir caused stress peaks which promoted nucleation of rupture, but at the same time had caused stress lows which led to rupture arrest and prevented rupture from entering the underburden.

Rupture growth was crack-like, as for the $0 \mathrm{~m}$ offset scenario (Figure 2-8a). However, the rupture velocity was slower, and no supershear was observed. After 0.05 the rupture front ( $\mathrm{rf}$ in Figure 2-8d) propagated downwards at a constant rupture velocity of 1275 $\mathrm{ms}^{-1}$, which was 0.78 times the $\mathrm{S}$-wave speed of $1650 \mathrm{~ms}^{-1}$ - i.e. at sub-sonic rupture velocity. Hence, the arrival of the rupture front was preceded by the P- and S-waves emitted at the start of rupture (i and ii). The deeper stress peak at $-3000 \mathrm{~m}$ was dynamically triggered by the advancing rupture front, locally increasing the rupture velocity before abruptly deceleration and arrest of rupture at $-3010 \mathrm{~m}$. P- and S-waves were emitted from rupturing of the deeper stress concentration at $-3000 \mathrm{~m}$ depth, which travelled upwards ( $\mathrm{v}$ and vi), and rupture arrest also emitted $\mathrm{P}$ - and $\mathrm{S}$ - waves traveling downwards (iii).

Besides the rupture velocity, also the rupture length, total slip, and the slip rate were smaller than observed in the $0 \mathrm{~m}$ offset scenario. The final rupture had a size of about $180 \mathrm{~m}$ because it remained confined to the reservoir interval. A maximum slip of $0.03 \mathrm{~m}$ was attained at $-2900 \mathrm{~m}$ depth (Figure 2-8a). Seismic slip rates up to $2 \mathrm{~ms}^{-1}$ were observed, increasing as rupture propagated downwards. Also the stress drop was more variable than for the $0 \mathrm{~m}$ offset case due to the heterogeneous shear stress, ranging from $1 \mathrm{MPa}$ in the center of the reservoir interval to $5 \mathrm{MPa}$ at the two stress peaks at -2855 and $-3000 \mathrm{~m}$. Reservoir offset thus resulted not only in different depletion-induced stress changes, but through these stress changes also resulted in different dynamic rupture characteristics and radiated waves.

To summarize, stresses developed by depletion of an offset reservoir promoted fault reactivation and rupture nucleation, but led to a smaller event with lower rupture velocity and smaller slip and slip rates.

\section{3. 3. Effect of in-situ stress and friction parameters}

In this section we evaluate sensitivity of the fault reactivation and final rupture length to the in-situ stress, and friction parameters, for $0 \mathrm{~m}$ and $50 \mathrm{~m}$ reservoir offset. 


\section{Chapter 2}

2. 3. 3. 1 Effect of in-situ stress and friction parameters on fault reactivation $(0 \mathrm{~m}$ and $50 \mathrm{~m}$ reservoir offset)

The pressure required for reactivation $\left(\Delta P_{r}\right)$ and nucleation of instability $\left(\Delta P_{r}\right)$ increased linearly with increasing initial stress ratio $K_{0}$ (i.e. an increasingly stable in-situ stress) for both the $0 \mathrm{~m}$ and $50 \mathrm{~m}$ offset reservoirs (Figure 2-9. a). At a stress ratio of 0.7 the fault was relatively close to failure, requiring a $\triangle P$ of -2 to $-3 \mathrm{MPa}$ for reactivation for both 50 and $0 \mathrm{~m}$ offset reservoir formations. For the $0 \mathrm{~m}$ offset the increase of reactivation pressure with the stress ratio was strongest, and at $K_{0}>0.75$ reactivation no longer occurred. However, for the $50 \mathrm{~m}$ offset formations reactivation occurred over the entire range of stress ratios, as the stress path was more critical due to the formation of stress concentrations (see Section 2. 3. 2. 1). At the most stable $K_{0}$ of 0.8 the required pressure change for reactivation was only about $1 / 3$ of the initial reservoir pressure. The pressure increment required to bridge the aseismic phase $\left(\Delta P_{a}\right)$ and the nucleation pressure also increased linearly with the stress ratio, and was larger for the $50 \mathrm{~m}$ offset case than for the $0 \mathrm{~m}$ offset. The larger aseismic pressure increment for $50 \mathrm{~m}$ offset reservoirs resulted from a slower expansion of the aseismic slip patch for the peaked loading stresses, compared to the more uniform stress distribution for 0 $\mathrm{m}$ offset. A decrease in Biot coefficient $\alpha$ required a larger pressure change for reactivation and nucleation (Figure 2-9b). The Biot coefficient controls the extent to which pressure changes translate into effective stress changes (Equation 2-1), and a lower Biot coefficient results in smaller fault stress path parameters (Equations 2-12 and 2-13) and hence requires a larger pressure change. For $0 \mathrm{~m}$ offset no reactivation occurred for $\alpha<0.95$. For $50 \mathrm{~m}$ offset the relation between Biot and reactivation pressure was nonlinear, with reactivation becoming increasingly difficult at lower Biot values.

A larger dynamic friction $\mu_{d}$ and $D_{c}$ (i.e. a lower weakening rate $W^{*}$, where $\left.W^{*}=W / \sigma_{n}{ }^{`}=\left(\mu_{s}-\mu_{d}\right) / D_{c}\right)$ did not affect the reactivation pressure, but led to a larger aseismic pressure increment and higher pressure required for nucleation on instability (c and d). Larger pressure changes are required to attain the critical nucleation length which increased with the lower $W^{*}$ (Equation 2-16). For $0 \mathrm{~m}$ offset the aseismic pressure increment increased from $0.03 \mathrm{MPa}\left(\mu_{d}=0.2\right)$ to $-0.7 \mathrm{MPa}\left(\mu_{d}=0.55\right)$, whereas for $50 \mathrm{~m}$ offset formation the aseismic pressure increment showed a stronger dependency on the dynamic friction, increasing from -1.5 $\mathrm{MPa}\left(\mu_{d}=0.2\right)$ to $-4.5 \mathrm{MPa}\left(\mu_{d}=0.5\right)$.

For some parameters combinations nucleation of instability did not occur, even though the fault was reactivated. This was observed in three different scenarios. First, it could be that the nucleation length could not be reached before full reservoir depletion $\left(\triangle P_{n}>\right.$ $\left.\Delta P_{i n i}\right)$. This occurred at for example a Biot of 0.7 for the $50 \mathrm{~m}$ offset case (Figure 2-9b). Second, instability could not nucleate if the nucleation length was much larger than the reservoir interval - i.e. the length over which the stress build-up occurred. This happened at a critical slip distance $D_{c}>100 \mathrm{~mm}$, where the theoretical nucleation length $L_{U R}$ was $>300 \mathrm{~m}$. Third, instability did not occur when aseismic slip in the nucleation zone $d_{a}$ exceeded the 
critical slip distance $\left(d_{a}>D_{c}\right.$, red dotted lines in Figure 2-9. c and d). Upon further loading (pressure change) the aseismic slip patch continued to grow beyond the nucleation length. Other studies showed that still small instabilities could occur under these conditions (Viesca \& Rice, 2012), but under the current loading conditions no dynamic instability was observed for $0 \mathrm{~m}$ offset. For $50 \mathrm{~m}$ offset however, dynamic instability occurred even though $d_{a}>D_{c}$ ( $\mu_{d}=0.55$ and 0.58 in (Figure 2-9c), due to the merging of the shallower slip zone with the deeper slip zone at $-3000 \mathrm{~m}$ depth. Hence, merging of multiple slip zones related to the stress peaks that formed in the offset reservoir caused an additional possibility for the nucleation of instability.
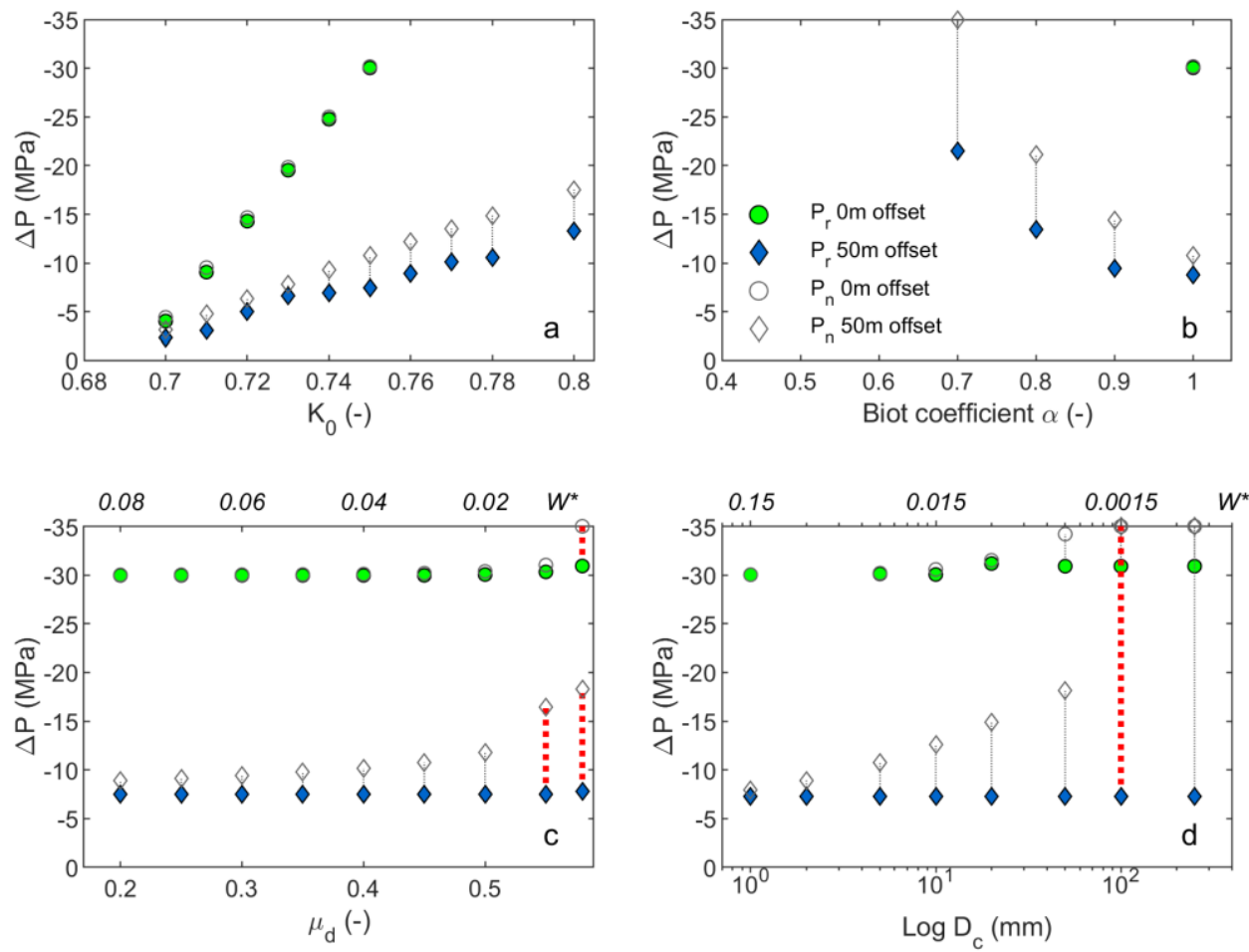

Figure 2-9. Sensitivity of reactivation pressure $\Delta P_{r}$ and nucleation pressure $\Delta P_{n}$ to various model input parameters. Lines connecting $\Delta P_{r}$ and nucleation $\Delta P_{n}$ show aseismic pressure increment $\Delta P_{a}$ Where red dotted lines were used fault slip had exceeded the critical slip distance $D_{c}$. Unless otherwise specified the base case input parameters for the sensitivity runs are: $K_{0}=0.75, \mu_{s}=0.6, \mu_{d}=0.45$, and $D_{c}=0.005 \mathrm{~m}$. Sensitivities of fault reactivation are shown for a)) initial state of stress $\left.K_{0}, b\right)$ the Biot coefficient $\left.\alpha, c\right)$ the dynamic friction coefficient $\mu_{d}$ and d) critical slip distance $D_{c}$. The numbers shown above the graphs in $c$ and $d$ are the weakening rates $W^{*}=\left(\mu_{s}-\mu_{d}\right) / D_{c}$ corresponding to the different $D_{c}$ and $\mu_{d}$ used, in $\mathrm{mm}^{-1}$. 

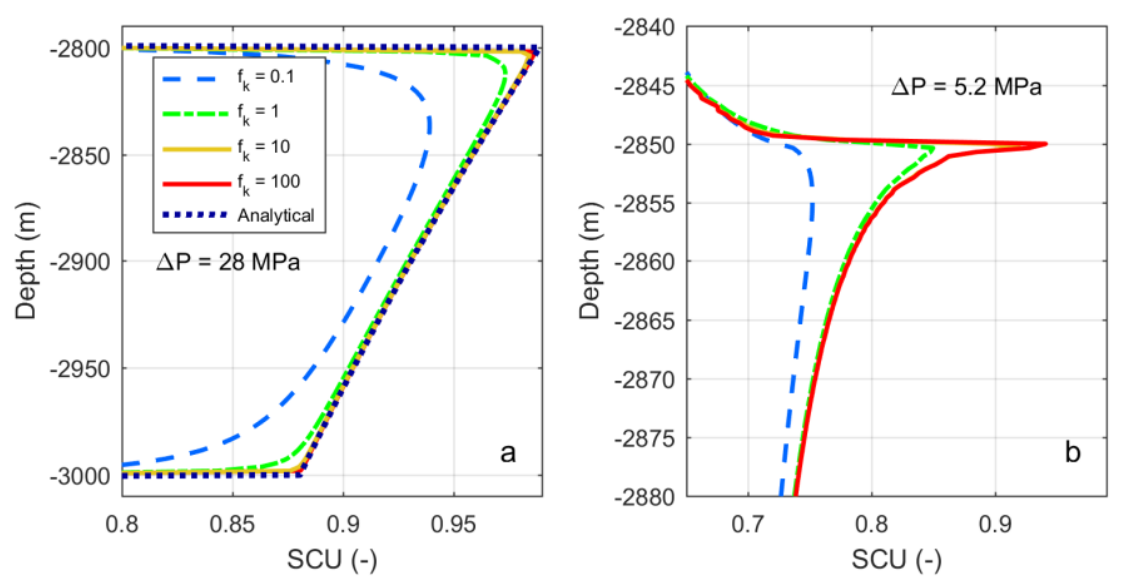

Figure 2-10. Influence of interface element stiffness factor $f_{k}$ on the fault stress. The Shear Capacity Utilization is shown as a function of depth along the fault plane, for different values of $f_{k}$, at a certain depletion pressure. a) $0 \mathrm{~m}$ offset reservoir at $\triangle P=28 \mathrm{MPa}$. For comparison the analytical solution is given (dotted line). b) $50 \mathrm{~m}$ offset reservoir at $\triangle P=28 \mathrm{MPa}$.

\section{3. 3. 2 Effect of fault interface stiffness}

The fault was modeled with interface elements, whose elastic behavior was governed by the normal and shear stiffness $k_{n}\left(=f_{k} E\right)$ and $k_{\tau}\left(=f_{k} G\right)$. Default values for $f_{k}$ of 10 were assumed during the initialization and static modeling phases (Section 2. 2. 1. ). Here the effects of different interface stiffness on fault stresses are analyzed, using an $f_{k}$ of $0.1,1,10$, and 100 .

Figure 2-10 a shows the $S C U$ with fault depth for a $0 \mathrm{~m}$ offset reservoir at a $\triangle P=28$ MPa which is just before the onset of fault reactivation, i.e. fault deformation is purely elastic. The largest element stiffness $\left(f_{k} 100\right)$ gave a nearly identical distribution of SCU along the fault as was calculated analytically. With decreasing stiffness the difference between the model results and the analytical solutions increased. The sharp discontinuity of $S C U$ at the reservoir top and bottom boundaries became smoother, and the $S C U$ value over the reservoir interval was reduced. Also, the depth at which the maximum SCU was found deviated increasingly from the analytical solution, shifting more towards the center of the reservoir interval. For $f_{k}=0.1$ the maximum $S C U$ was at $2847 \mathrm{~m}$ depth, which is $42 \mathrm{~m}$ deeper than for the $f_{k}=10$ scenario.

For $50 \mathrm{~m}$ offset reservoir compartments the stress was locally peaked, showing a maximum at the top of the hanging wall at $2851 \mathrm{~m}$ (Figure 2-10b). High stiffness of $f_{k} 10$ and $f_{k} 100$ showed a sharp peak with a maximum $S C U$ of 0.93 . For a lower stiffness $f_{k}=1$ the stress peak was less sharp and had a maximum of 0.85 . The largest difference was observed for $f_{k}=0.1$, where the stress peak was very smooth and the maximum $S C U$ was 0.75 . Also the maximum $S C U$ shifted to a slightly deeper point on the fault $(-2855 \mathrm{~m})$. This was a small 
amount with respect to the shift observed for the $0 \mathrm{~m}$ offset case. However, the magnitude of the difference in $S C U$ with stiffness was much larger for the offset case than for the $0 \mathrm{~m}$ offset case. This will result in larger differences in reactivation pressure, and aseismic slip during the nucleation phase.

Therefore the effect of interface element stiffness should be considered when evaluating model results. For comparison to analytical results a very high stiffness should be set (e.g. $f_{k} 100$ ), but not much higher otherwise convergence of numerical results becomes poor. If elastic deformation on the fault is anticipated or desired, the stiffness should be lower. In the dynamic phase an $f_{k}$ of 1 should be used to avoid fast / slow waves propagation along the fault zone.

\section{3. 3. 3 Effect of in-situ stress and friction parameters on the seismic rupture length ( $0 \mathrm{~m}$ and $50 \mathrm{~m}$ reservoir offset)}

Here the sensitivity of the seismic rupture length to the in-situ stress and friction parameters is presented for the $0 \mathrm{~m}$ offset and $50 \mathrm{~m}$ offset scenarios. Three different values for the dynamic friction were evaluated $\left(\mu_{d}=0.35,0.45,0.55\right)$. For each $\mu_{d}$ three different weakening rates were analyzed $\left(W^{*}=0.03,0.0075\right.$, and $\left.0.0038 \mathrm{~mm}^{-1}\right)$. Particular attention is paid to the conditions that may cause so-called run-away ruptures, which is characterized by self-sustained rupture propagation far outside the reservoir depth interval towards the top and bottom surface of the model.

Rupture length $\mathrm{L}_{\mathrm{s}}$ increased for lower dynamic friction coefficients - i.e. larger stress drops. The largest rupture lengths were observed for the lowest dynamic friction coefficient of 0.35 (Figure 2-11a,d). Ruptures propagation outside of the reservoir interval (shaded area) occurred with final rupture lengths of several hundreds of meters. Moreover, a transition to runaway rupture was observed towards the lower end of the in-situ stress ratios evaluated. The rupture length and in-situ stress at which the transition to runaway occurred i) increased with the weakening rate $W^{*}$, and ii) decreased with the reservoir offset.

First, higher weakening rates $\mathrm{W}^{*}$ resulted in larger ruptures and a transition to runaway rupture at the higher (more stable) stress ratios. Runaway rupture was observed at a stress ratio $\mathrm{K}_{0}<=0.74$ for a weakening rate of $0.03 \mathrm{~mm}^{-1}$ and at $\mathrm{K}_{0}<=0.72$ for a weakening rate of $0.0038 \mathrm{~mm}^{-1}$ (Figure 2-11a). The lower weakening rate resulted in a longer nucleation length (Equation 2-16). The longer nucleation length caused the stress to drop to the dynamic value over a longer fault length during the aseismic phase, so less stress was available for rupture in the reservoir. Figure 2-12a shows for example how the nucleation zone covered half of the reservoir interval (red line on y-axis), and how the initial expansion of rupture out of the nucleation zone was slow. Also rupture did not transition to supershear within the reservoir interval. Additionally, the lower weakening rate cause a larger fracture energy $G_{c}$ so that more energy was consumed by the fracture process, leaving less energy to propagate, thus resulting in smaller ruptures. 

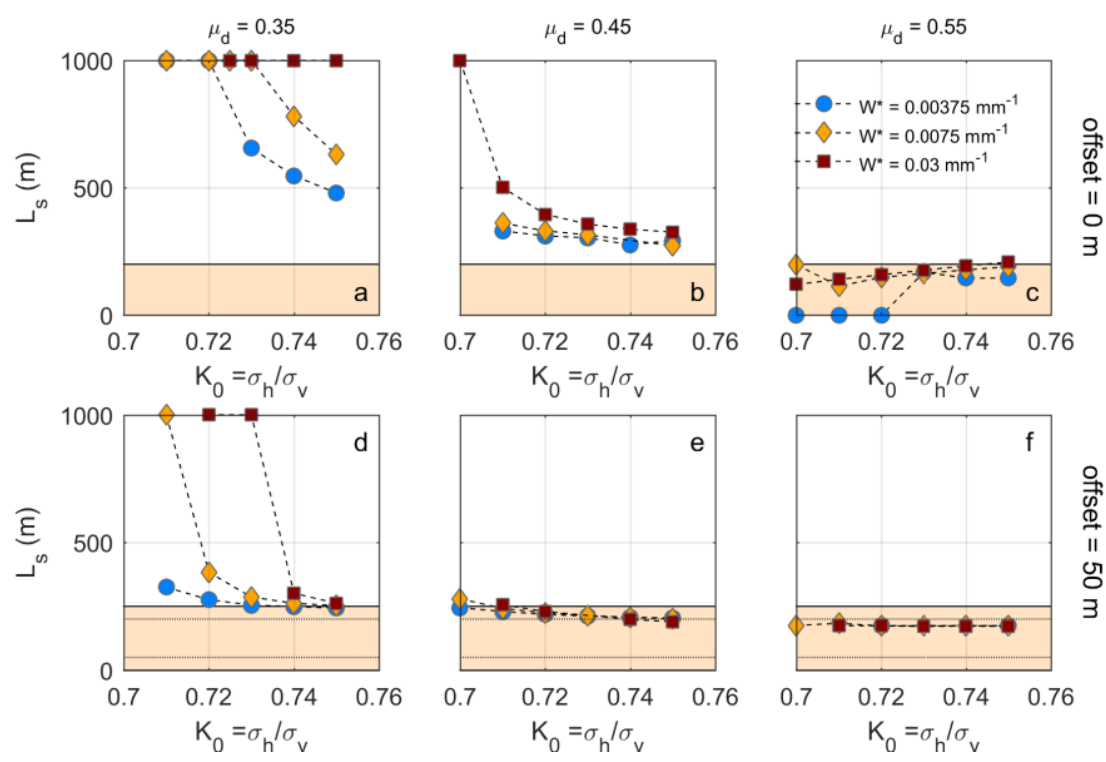

Figure 2-11. Rupture arrest as a function of $K 0, \mu d$ and $W^{*}$. The symbols show the upper and lower limit of seismic rupture for $0 \mathrm{~m}$ offset (circles) and $50 \mathrm{~m}$ offset (diamonds) simulations. The shaded area indicates the reservoir depth interval. Runaway ruptures that rupture the entire fault are truncated at $1000 \mathrm{~m}$.

Second, the heterogeneous stresses formed during depletion of the $50 \mathrm{~m}$ offset reservoir compartments tended to confine ruptures to the reservoir, in particular for lower weakening rates (Figure 2-11d). Transition to runaway rupture did occur, but at a more critical in-situ stress ratio than for the $0 \mathrm{~m}$ offset case, compare e.g. the difference between Figure 2-11a and d. At a stress ratio $>0.74$ all ruptures remained confined to the reservoir. For example, at a stress ratio of 0.75 a sub-sonic rupture propagated down-dip from the nucleation zone at $-2855 \mathrm{~m}$ (Figure 2-12b). The deeper stress peak was dynamically triggered, locally increasing the rupture velocity and emitting $\mathrm{P}$ - and $\mathrm{S}$-waves upwards and downwards. However, abrupt arrest occurred at $-3050 \mathrm{~m}$ and $-2800 \mathrm{~m}$ where depletioninduced stress was stable (see e.g. Figure 2-8c).

A higher dynamic friction coefficient of 0.45 caused smaller rupture lengths compared to runs with a dynamic friction of 0.35 . Rupture propagation outside of the reservoir was only observed the $0 \mathrm{~m}$ reservoir offset (Figure 2-11b). For this offset rupture transitioned into runaway rupture only at the most critical in-situ stress ratio explored $\left(\mathrm{K}_{0}=\right.$ 0.70). At higher stress ratios rupture was arrested, decreasing from $500 \mathrm{~m}\left(\mathrm{~K}_{0}=0.71\right)$ to 300 $\mathrm{m}\left(\mathrm{K}_{0}=0.75\right)$. As in Figure 2-11a, high weakening rates promoted larger ruptures compared to low weakening rates. No rupture propagation outside the reservoir interval was observed for $50 \mathrm{~m}$ reservoir offset; again the stable depletion-induced stresses at the base of the 
hanging wall and top of the footwall acted as a barrier and limited rupture extent to $200 \mathrm{~m}$ for all stress ratios evaluated.

For the largest dynamic friction coefficient of 0.55 rupture did not propagate outside of the reservoir interval for any of the stress ratios considered. In the $0 \mathrm{~m}$ offset case rupture length decreased with decreasing stress ratio, contrary to previously observed dependencies on stress ratio. Inspection of the results indicated that at smaller stress ratios rupture propagated with sub-sonic velocities, whereas at larger stress ratios supershear occurred which led to larger ruptures, for example at a stress ratio of 0.75 (Figure 2-11c). The difference may be explained by the difference in stress drop. At a smaller stress ratio the insitu stress is more critical, so that the required increase in shear and effective normal stress for reactivation is small. At the onset of rupture the effective stress was relatively low and hence the stress drop was also low which prevented a transition to supershear. For the $50 \mathrm{~m}$ offset case the rupture length remained constant at $180 \mathrm{~m}$ with in-situ stress ratio. In many cases the critical slip distance was reached during the aseismic slip phase and instability occurred only due to merging of the two slip zones. This resulted in a relatively small and slow rupture event (e.g. Figure 2-12d). Despite rupture being slow, it did rupture the entire reservoir because a large part of the fault was already slipping and stresses had been lowered to the dynamic value during the aseismic slip phase (red line along y-axis) according to the linear slip-weakening friction on the fault.
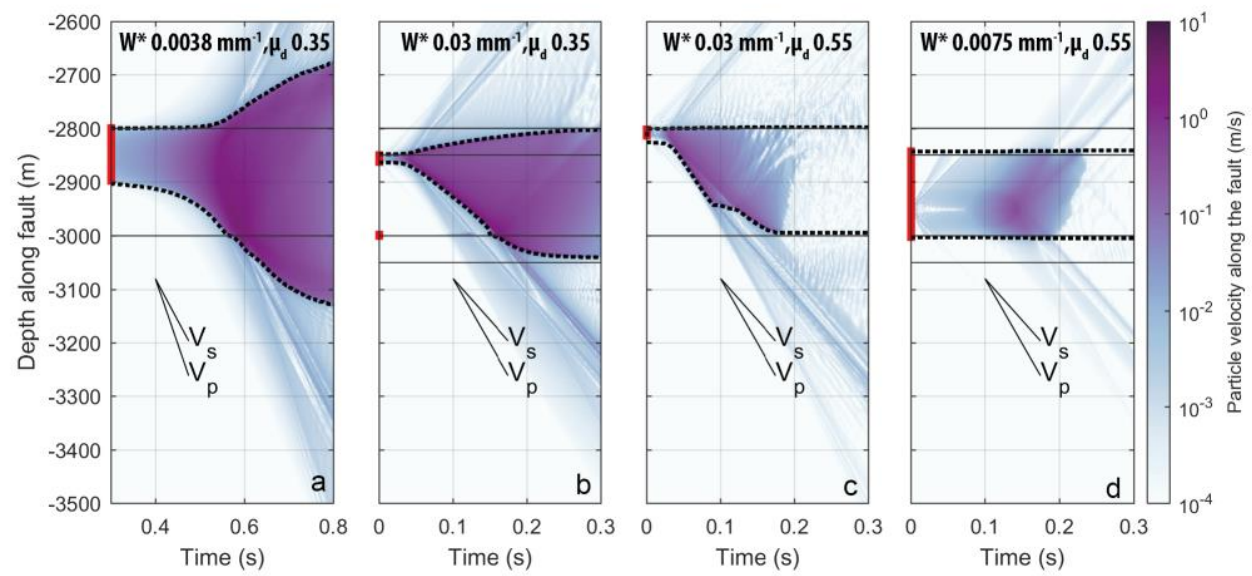

Figure 2-12. Rupture growth and wave propagation recorded on the fault for various $W^{*}\left(=W / \sigma_{n}{ }^{\prime}\right)$ for 0 and $50 \mathrm{~m}$ offset reservoir compartments. The colors indicate the fault-parallel particle velocities recorded along the fault as a function of time. The black dotted lines show the boundaries of seismic slip patch as a function of time; within these lines plastic fault slip occurred. The horizontal solid lines outline the depth interval of the reservoir (footwall, 2800 - $3000 \mathrm{~m}$ depth), and the dashed lines outline the depth interval of the hanging wall for the $50 \mathrm{~m}$ offset case (2850 - $3050 \mathrm{~m}$ depth). The vertical fat red line plotted on top of the y-axes shows the length of the fault that was slipping aseismically at the start of the seismic instability $\left(L_{n}\right)$. For reference the $P$-wave $\left(V_{P}\right)$ and $S$-wave $\left(V_{S}\right)$ velocities are indicated in the plots. The $K_{0}$ was 0.75 and the fault dip was $70^{\circ}$. Results are shown for a) $0 \mathrm{~m}$ offset, 


\section{Chapter 2}

$\mu_{d}=0.35$, and $W^{*}=0.0038 \mathrm{~mm}^{-1}$, b) $50 \mathrm{~m}$ offset, $\mu_{d}=0.35$, and $\left.W^{*} 0.03 \mathrm{~mm}^{-1}, c\right) 0 \mathrm{~m}$ offset $\mu_{d}=0.55$, and $W^{*} 0.03$ $\mathrm{mm}^{-1}$, d) $50 \mathrm{~m}$ offset and $W^{*} 0.0075 \mathrm{~mm}^{-1}$.

\section{3. 4. Effect of various reservoir offset on nucleation and seismic rupture}

The previous sections focused on nucleation and seismic rupture induced by depletion of reservoir compartments without offset and with $50 \mathrm{~m}$ offset. Here the effect of various offsets on reactivation and final rupture size is presented.

\section{3. 4. 1 Effect of reservoir offsets on stress path parameters and fault reactivation}

The influence of the reservoir offset on the is shown by the $S C U$ along the fault plane, and the normal and shear stress path coefficients $\gamma_{n}$ and $\gamma_{\tau}$ respectively and their ratio $\beta=\gamma_{\tau} / \gamma_{n}$.

The $S C U$ showed two peaks for all offsets at the onset of seismic rupture, except for an offset of $0 \mathrm{~m}$ and $200 \mathrm{~m}$ (Figure 2-13). In the case without offset the absence of shear stress concentration cause reactivation at larger depletion pressure compared to cases with offset For normal offsets these peaks were located at the top of the hanging wall and bottom of the foot wall reservoir. In the depth interval between the two peaks the SCU was also elevated with respect to the initial $S C U$. This high $S C U$ interval reduced in size as offset increased and the $S C U$ peaks at the top of the hanging wall and bottom of the footwall approached each other. Concurrently both the stress path parameters $\gamma_{n}$ and $\gamma_{t}$ (Figure 2-13b) and the slope of the stress path $\beta$ increased (Figure 2-13c), which caused a reduction of reactivation pressure with offset (Figure 2-13d). At a reservoir offset equal to the reservoir thickness $(200 \mathrm{~m})$ the peaks coincided to form a single peak. The co-location of the two shear stress peaks resulted in the largest stress path parameters, and reactivation occurred at the smallest pressure drop. At a reservoir offset larger than the thickness again two stress peaks developed. Here nucleation occurred also at the shallow stress peak which is now located at the bottom of the foot wall. Depletion also caused local lows in SCU at the top of the foot wall and at the bottom of the hanging wall, for all normal offsets. These lows can act as barriers to propagating rupture (e.g. section 2. 3.3.2).

For a reverse offset the stress peaks still developed at the top of the hanging wall and base of the footwall. These now formed the deepest and shallowest parts of the reservoir interval. The stress lows were located between the stress peaks, rather than above and below. The stress path was relatively steep but the stress path parameters were small, so the reactivation pressure was larger than for normal offsets.

When only the hanging wall (HW) of footwall (FW) was depleted an asymmetric stress pattern developed with a single maximum at the top (HW) or the base (FW) of the reservoir and a single minimum at the opposite side. In fact, the stress pattern on a fault crosscutting two depleting formations is the superposition of the HW and FW cases. The asymmetric stresses may promote ruptures predominantly in one direction. 

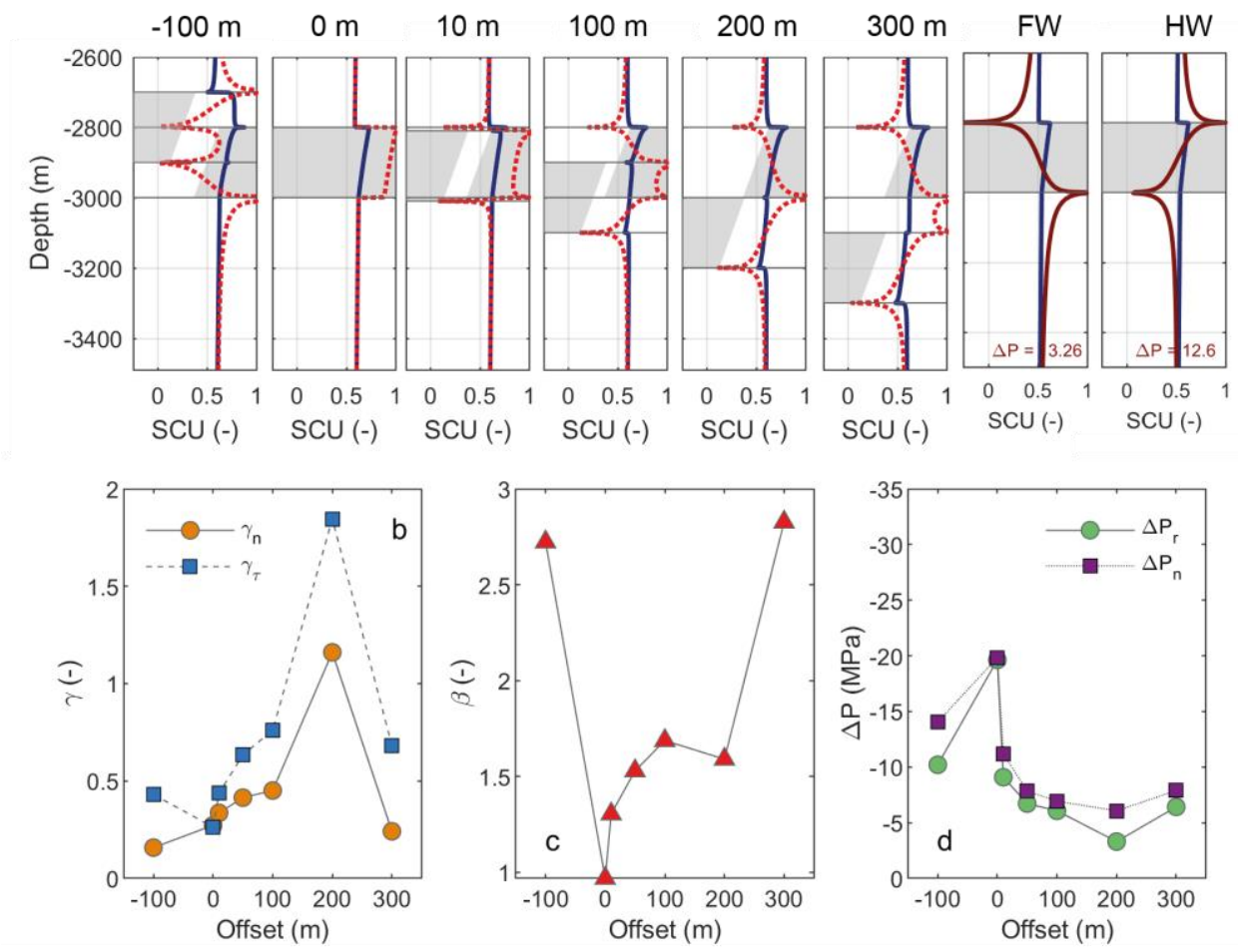

Figure 2-13. Effect of offset on fault stress, stress path, and pressure required for failure. a) Influence of reservoir offset on the evolution of stress criticality (SCU) along a 70॰ dipping fault for an initial $K_{0}$ of 0.75 . The dark blue line indicates the initial SCU, the red line the state of stress when seismic instability occurred. The value at the bottom of the figures indicates the pressure required to reach this instability. The grey areas indicate on the left the depth interval of the hanging wall, on the right the depth interval of the footwall reservoir formation. The offsets are normal offsets indicated by the number above the figures. $F W=$ depletion of the footwall only, HW = depletion of the hanging wall only. $b$ ) Stress paths parameters $\gamma_{n}\left(=\Delta \sigma_{n} / \Delta P\right)$ and $\gamma_{\tau}(=\Delta \tau / \Delta P)$ at the center of the reactivated slip zone for different formation offsets. c) Stress path slope $\beta$ at the center of reactivated slip zone for different formation offsets. d) $\Delta P$ required for reactivation $\left(\Delta P_{r}\right)$ and nucleation $\left(\Delta P_{n}\right)$ for different offsets.

\section{3. 4. 2 Effect of reservoir offsets on rupture length}

Rupture length decreased with increasing reservoir offset, up to offsets equal to the reservoir thickness (Figure 2-14). For a dynamic friction of 0.35 runaway rupture was observed for the smallest offsets of 0,10 , and $50 \mathrm{~m}$. For these offsets the length of the stable stress regions at the base of the hanging wall and top of the footwall was relatively small (see Figure 2-13a), and did not prevent rupture propagation outside of the reservoir. For larger offsets, the stable stresses had developed over a larger depth interval above and below the 


\section{Chapter 2}

reservoir, effectively confining rupture to the reservoir interval. For example, for $100 \mathrm{~m}$ offset rupture was arrested at the base of the hanging wall, and propagated only a short distance above the top of the footwall. For $200 \mathrm{~m}$ offset rupture was fully confined to the reservoir interval. At offsets larger than the reservoir thickness rupture length increased again, rupturing both reservoir depth intervals plus the depth section between the hanging wall and the foot wall where a high $S C U$ had developed (Figure 2-13). Ruptures were very large for depletion of only the hanging wall or footwall (reservoir bounding faults); only a single stress concentration and a single stress low formed (Figure 2-13a) so that rupture propagation to respectively the overburden and underburden was easy. For the reverse offset a large rupture length was observed. In fact, the event consisted of two separate slip patches. Rupture nucleated at the deeper stress concentration and could propagate hundreds of meters into the underburden as no stress barrier formed during depletion (Figure 2-13). In addition, this rupture dynamically triggered the shallow stress concentration which also ruptured and propagated upwards, adding to the total event size. This shows that dynamic effects can have a significant effect on rupture length.
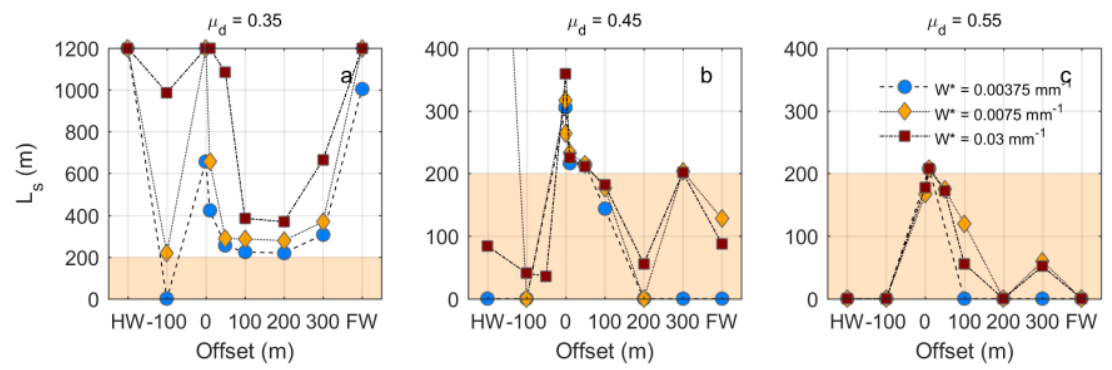

Figure 2-14. Rupture length $L_{s}$ against reservoir offset for different dynamic friction values $\mu_{d}$ and weakening rates $W^{*}$. The in-situ stress ratio $K_{0}=0.73$ for all runs; close to the transition to runaway rupture for the 0 and $50 \mathrm{~m}$ offsets at $\mu_{d}=0.35$. The reservoir thickness is indicated with the shaded area. HW indicates depletion of the hanging wall only, FE depletion of the footwall only. Runaway ruptures that rupture the entire fault are truncated at 1200 m. a) $L_{s}$ for $\mu_{d}=0.35$, b) $L_{s}$ for $\left.\mu_{d}=0.35, c\right) L_{s}$ for $\mu_{d}=0.35$.

Similarly for a dynamic friction $\mu_{d}$ of 0.45 rupture length decreased with offset, but rupture lengths were smaller than for the dynamic friction of 0.35 (Figure 2-14b). Rupture was mostly confined to the reservoir interval, except for the $0 \mathrm{~m}$ scenario $\left(L_{s}=360 \mathrm{~m}\right)$ and depletion of the hanging wall. For larger offsets rupture decreased to about the reservoir thickness of $200 \mathrm{~m}$. Only a small part of the reservoir ruptured for the $200 \mathrm{~m}$ offset scenario, where a single stress peak had formed during depletion. Also for a reverse offset of $-100 \mathrm{~m}$ the event remained small as only the deeper stress concentration ruptured locally. No dynamic triggering of the shallow concentration was observed. With decreasing weakening rate rupture size became smaller, and for some offsets $(-100,200 \mathrm{~m}, \mathrm{HW}, \mathrm{FW})$ no instability nucleated and only aseismic slip occurred, as the critical slip distance was attained prior to reaching the critical nucleation length. 
Ruptures were smallest for a dynamic friction $\mu_{d}$ of 0.55 , and decreased also with offset. For $0 \mathrm{~m}$ offset the entire reservoir rupture, but only part of the reservoir ruptured for the $100 \mathrm{~m}$ offset and the $300 \mathrm{~m}$ offset ( $L_{s} 50-100 \mathrm{~m}$ depending on the weakening rate). For many runs aseismic slip occurred as $D_{c}$ was reached during the nucleation phase.

To summarize, dynamic rupture size decreased with reservoir offset, increasing dynamic friction coefficient, and decreasing weakening rate (equivalent to increasing fracture energy or larger $D_{c}$ ).

\section{4. Discussion and implications}

Understanding the potential for depletion-induced rupture to propagate outside of the reservoir interval is important to constrain (maximum) magnitudes that can occur as a result of reservoir production. Previous studies modeling depletion-induced seismic events often employed simplified faulting behavior to evaluate rupture size. However, it is important to include the depletion-induced stresses, as well as realistic dynamic faulting behavior to properly model rupture propagation. In this study we simulated reservoir stresses leading to fault reactivation and nucleation of seismic instability, and the subsequent fully dynamic rupture process using linear slip-weakening fault friction which is often used to model natural earthquakes. The results showed that rupture mostly remained confined to the reservoir depth interval, but under some circumstances could propagate outside of the reservoir interval. A critical in-situ stress, large friction drop, small fracture energy and small reservoir offset promoted large ruptures exiting the reservoir interval. In the following we discuss modeling of poroelastic stressing and fault reactivation in the light of previous studies, the dynamic rupture length and propagation beyond the reservoir boundaries, and limitations and additional factors affecting rupture growth. Additionally we discuss the implications for the Groningen field, and more general implications for modeling of induced seismicity.

\section{4. 1. Production-induced stressing causing fault reactivation and nucleation of rupture}

Fault reactivation on faults offsetting two depleting reservoir formations was promoted with respect to faults without offset. This finding is in accordance with previous studies that also showed that fault offset and differential compaction enhanced reactivation (Mulders, 2003; Nagelhout \& Roest, 1997; Orlic \& Wassing, 2013; Roest \& Kuilman, 1994; van den Bogert, 2015). Whereas the depletion-induced stress changes on a fault without offset were equivalent to the analytical solutions for poroelastic stress changes in laterally extensive reservoirs (e.g. Segall, P. \& Fitzgerald, 1998), the offset case locally resulted in a steeper stress path, a locally concentrated, more critical fault stress, and a lower pressure decrease required for reactivation. Using analytical solutions for poroelastic stressing within a reservoir to assess the fault reactivation potential will thus overestimate the critical pressure required for reactivation in a reservoir containing offset faults. 
An increasing amount of elastic deformation of the fault prior to reactivation caused deviations from the analytical solutions for no offset faults, and reduced the peakedness of stress concentrations for offset faults (see S3). Elastic deformation on the fault was controlled by the interface element stiffness which could be used as a proxy for fault thickness. An alternative approach is to model the fault with ubiquitous joint elements which have a finite thickness with a matrix that deform elastically or elastoplastically, and weak joint planes that can accommodate fault slip and weakening (Cappa \& Rutqvist, 2012; Zbinden et al., 2017). Either way, care must be taken to set a realistic elastic deformation on the fault as it will influence the stress path and the pressure at which reactivation occurs. The stress concentrations may in part be artificial due to the sharp boundaries and linear elasticity prescribed to the depleting formations. Cores and outcrops show the boundaries between formations can be rather sharp (Buijze et al., 2017). Nonetheless, any form of deformation will (partly) relax the stress concentrations and cause a reduced and less sharp peak, as was observed for a low stiffness fault zone. If the damage zone surrounding the fault has a lower stiffness and accommodates more strain, the peakedness and amplitude of the stress concentrations could be reduced. Also elastoplastic deformation of the fault zone and the reservoir can relax the stress concentrations.

Slip-weakening friction gave rise to a nucleation phase where a certain fault length was slipping aseismically, and subsequent instability of dynamic rupture. This resulted in extra pressure changes required for nucleation, e.g. for a nucleation length of $10-20 \mathrm{~m}$ several $\mathrm{MPa}$ pressure change were required between reactivation and seismic instability. For ideal plastic fault behavior such a nucleation phase is lacking, and in . several other studies the critical slip displacement was one or two orders smaller than the one used in the current study, so that the nucleation phase would have been much shorter, and the onset of reactivation and seismic instability much closer together (Cappa \& Rutqvist, 2012; Zbinden et al., 2017). For modeling the timing of seismicity the potential existence of a nucleation phase may be very important, since several MPa depletion may correspond to years of production.

On the other hand, the reservoir thickness imposes a constraint on the maximum $D_{c}$ and nucleation length; for $D_{c}$ of centimeters the nucleation zone exceeded the reservoir thickness and no seismic instability could nucleate. Seismic instability also could not nucleate when $D_{c}$ was reached before the critical nucleation length was attained. This occurred for very peaked stress concentrations. The uncertainty in the physics of the nucleation process of earthquakes, and (scaling of) $D_{c}$ and the nucleation length is however significant.

\section{4. 2. Dynamic rupture propagation and criterion for runaway ruptures}

Most ruptures remained confined to the reservoir depth interval, but under some conditions rupture propagated into the overburden and underburden, or transitioned into a runaway rupture. A convenient parameter to study the propensity for (runaway) rupture propagation outside of the reservoir is the ratio between the stress drop and the strength drop $T=\left(\tau_{0}-\tau_{d}\right) /\left(\tau_{f}-\tau_{d}\right)$ (e.g. Ripperger 2007). This parameter is similar to e.g. the excess strength 
ratio $S$ (Galis et al., 2015) with $T=1 /\left(1+S\right.$ ), or to $C_{f}$ which is defined as $\tau_{d} / \tau_{0}$ (Norbeck \& Horne, 2018), and captures the effect of in-situ stress and the friction drop on rupture potential. For $T<0$ the $\tau_{d}$ is larger than $\tau_{0}$ (i.e. negative stress drop), which inherently stabilizes and arrests rupture, and for $T>0$ the fault is increasingly critical. To analyze the propensity for rupture to propagate into the overburden and underburden an average $T$ was calculated for fault outside of the reservoir depth interval. Inside the reservoir $T$ was variable as both the normal and shear stress changed during depletion; in the nucleation zone $T$ was 1.

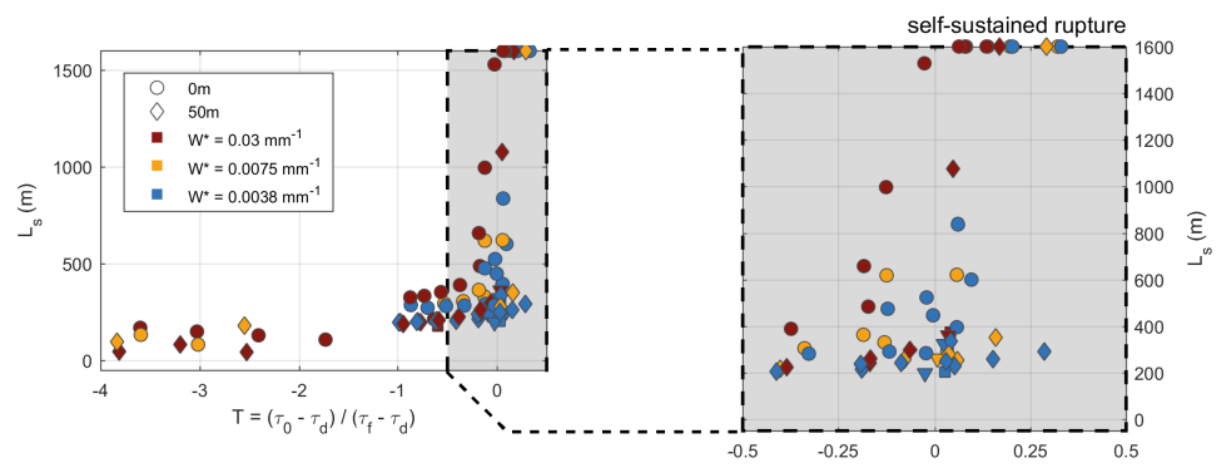

Figure 2-15. Rupture length $L_{s}$ versus ratio of stress drop and strength drop $T=\left(\tau_{0^{-}} \tau_{d}\right) /\left(\tau_{f^{-}} \tau_{d}\right)$. Circles show no offset runs, diamonds show 50 m offset runs. The colors indicate the different weakening rates $W^{*}$. Runaway ruptures that rupture the entire fault are truncated at $1600 \mathrm{~m}$.

The dynamic simulations showed a gradual transition from events smaller than or equal to the reservoir thickness to ruptures exiting the reservoir and runaway rupture (Figure $2-15)$. For $T<-0.2$ all ruptures were arrested within or within $100 \mathrm{~m}$ of the reservoir interval. For $-0.2<T<0$ the state of stress was still stable but closer to critical which allowed for some propagation into the over- and underburden even though the stress drop was negative or zero. In particular for $0 \mathrm{~m}$ offset rupture could propagate to several 100 `s $\mathrm{m}$ into the underburden; for the $50 \mathrm{~m}$ offset case rupture was arrested at the reservoir interval $\left(L_{s}=\sim 200\right.$ m) due to the more heterogeneous stresses that developed during depletion. For $T>0$ more ruptures propagated outside the reservoir interval and propagated several $100 \mathrm{~m}$. Runaway rupture occurred at $T=0.1$ for $0 \mathrm{~m}$ offset and high $W^{*}$ runs. A lower weakening rate $W^{*}$ of 0.0038 (larger $D_{c}$ and larger fracture energy) decreased rupture length and shifted the transition to runaway rupture to higher $T$ of $0.15-0.35$, since more energy was consumed by the fracturing and less energy was available for propagation. Formation offset also lead to reduced rupture propagation, because stable stress areas formed along the fault at the reservoir top and bottom during depletion.

The findings are in agreement with criteria for runaway rupture in other studies, but show also that increasing fracture energy and stress heterogeneity due to reservoir offset caused smaller ruptures and more diverse rupture sizes. For quasi-static and quasi-dynamic 


\section{Chapter 2}

models with a critical slip distance $D_{c} \rightarrow 0$ slip will occur where T $>0$, and will not occur where $T<0$. A very sharp transition between arrested ruptures and runaway ruptures was observed at $C_{f}=1(T=0)$ for injection-induced ruptures with a $D_{c}$ of $50 \mu \mathrm{m}$ (Norbeck \& Horne, 2018). When larger $D_{c}$ are used the transition to runaway rupture will shift to higher $T$. In this study the transition was found at a T $0.05-0.15$ for $D_{c}=0.005-0.04 \mathrm{~m}$ and fracture energy $G_{c}=10^{4}-10^{5} \mathrm{~Pa}$ (Figure 2-15) Ripperger et al. (2007) observed the transition to runaway rupture at $T 0.3-0.4$ for a $D_{c}=0.2 \mathrm{~m}, G_{c}=1.8 \times 10^{6} \mathrm{~Pa}$, and also showed that a variable stress field as a result of roughness caused a more gradual transition to runaway rupture, with more distributed event sizes. Likewise, the presence of different reservoir offsets (and other heterogeneities) resulting in a heterogeneous fault stress caused a variable event sizes in our study, or in some cases could inhibit rupture propagation into the underburden even for high $T$. This shows the importance of incorporating (an approximation of) the depletion-induced stresses in the assessment of rupture propagation potential into the underburden.

In addition to the fracture energy and stress heterogeneity, also the size of the highly stressed zone where rupture nucleates can affect the transition to runaway ruptures. In fully dynamic simulations with artificial nucleation a relatively long critically stressed asperity with respect to the critical nucleation size promoted runaway rupture (Galis et al., 2015). For the reservoir geometry in our study this would imply thicker reservoir would create a higher potential for rupture propagation into the underburden, for the same friction parameters. We recommend to investigate the effect of reservoir thickness in future studies.

The shear stress ratio $T$ can be a useful first order indicator for rupture potential into the underburden, before starting a time-consuming dynamic rupture analysis. However, we showed how the critical slip distance (and fracture energy), and the depletion-induced stress distribution, also had a large influence on the rupture potential. We recommend future work on establishing a rupture arrest criterion which incorporates the initial state of stress, stress drop and fracture energy, and (an approximation of) stresses induced by reservoir depletion, and to validate it against dynamic simulations, cf. e.g. Galis et al. (2017).

\section{4. 3. Limitations}

In our modeling approach necessarily simplifications have been made. Here we discuss a number of the assumptions that are relevant for the modeled induced events.

The formations were modeled using linear elastic behavior. Recent experiments showed however that inelastic strain constituted a significant fraction of compaction strain in porous sandstones (Pijnenburg et al., 2018). Modeling reservoir compaction with elastoplastic or viscoelastic formation properties will cause a more stable stress path and fault reactivation at higher pressure changes. Also the dynamic rupture characteristics will be affected, as energy is dissipated outside of the fault (e.g. Andrews, DJ, 2005). Further 
modeling efforts into elastoplastic reservoir behavior and its effect on the size of induced ruptures is recommended.

The imposed uniform pressure changes to simulate depletion and the one-way coupling with stress are simplifications. However, for a subsection of the Groningen a uniform gas pressure change may justified, as the observed pressure gradients across the field are small and most faults are not sealing and thus hold no or very little pressure differential. In other settings the pressure distribution may be more variable, and in that case it is important to include fully coupled flow models to simulate depletion. In particular when pressure depletion in the fault zone is slower than in the reservoir because of low fault permeability the stress path can become more nonlinear and more unstable (Zbinden et al., 2017). On the other hand, depletion of the fault section in the underburden would reduce rupture potential into the underburden. Another assumptions concerns the Biot coefficient, which was taken as 1. Figure 2-9. b showed that reactivation pressure increase strongly with decreasing the Biot coefficient, which mainly prevented nucleation on the $0 \mathrm{~m}$ offset fault. On the $50 \mathrm{~m}$ offset fault more pressure change was required for nucleation, but at nucleation the stress criticality on the fault was rather similar, and may have limited effect on the rupture extent. However, further analysis of the effect of Biot coefficient on rupture size is advised for future work. Also further research on the effect of coupled poroelasticity on dynamic rupture for faults in gas fields and the fluid-filled faults of the underburden is recommended, as coseismic poroelasticity may affect rupture velocity and size (Jin \& Zoback, 2018)

Here we focused on the down-dip rupture extent in a 2D model geometry. Many gas reservoirs are laterally extensive, and hence elongated stress concentrations will be expected along the fault's strike. The nucleation length in 2D is likely similar to that in a $3 \mathrm{D}$ case (Uenishi 2018), but the along-strike dimension will be very important for the total ruptured area and seismic moment. We recommend further research on the rupture sizes that can be expected for dynamic rupture along elongated stress concentrations. Another effect of 2D is the occurrence of supershear which was observed in our models. Supershear can occur for Mode II ruptures only. In 3D the rupture would be a mixture of Mode II (down-dip) and Mode III (along-strike) propagation. Supershear is unlikely, and hence the rupture lengths for the $0 \mathrm{~m}$ offset case in this study may be overestimated.

To model friction and rapid earthquake slip a linear slip-weakening friction was used; a simplified model for fault slip used in many earthquake simulations. In laboratory experiments friction is often described as a function of velocity and time, by the rate and state friction model. Using rate and state friction can result in more pulse-like ruptures, which are different from the crack-like rupture observed in this study. Furthermore rate-and-state friction leads to rate effects which are not captured with slip-weakening, e.g. the effect of loading rate on the critical nucleation length. This is interesting, as in this case the depletion rate may have an effect on the seismicity rate, which could lead to a different production strategy. 


\section{Chapter 2}

In general our study showed that the rupture size was strongly affected by the assumed dynamic friction, which is a key parameter for both slip-weakening and rate-and-state friction behavior. However, the relevant in-situ dynamic behavior of fault rocks in general is poorly known, and in particular for small earthquakes the dynamic friction and dynamic weakening (and healing) mechanisms are poorly understood. Also faults may have significant cohesion due to healing and cementation, especially the cataclastic faults in the Rotliegend formation of the Groningen field, which have been inactive for long periods of time. Laboratory experiments indicate a significant strength gain with healing time, possibly even up to intact rock strength if healing time is long (Muhuri et al., 2003). This would strengthen the faults, but also cause a larger stress drop when the fault breaks. Further understanding of the relevant frictional properties for small to moderate earthquakes on upper crustal faults is vital (Spiers et al., 2017).

\section{4. 4. Implications for seismicity in Groningen}

Dynamic rupture length increased for increasing strength ratio $T$ that followed from the in-situ stress state, and stress drop, which were both assumed uniform in the model. In and around the Groningen field however the state of stress and the stress drop may vary with depth because various stratigraphic units are present which have different deformation properties. This will affect the rupture potential outside of the reservoir. The $\sim 50 \mathrm{~m}$ thick Ten Boer formation above the Rotliegend consists of clays and sandy material, which may have a higher horizontal stress due to creep (Sone \& Zoback, 2014). The Triassic overburden (Zechstein Group) overlying the Groningen Slochteren sandstone and the Ten Boer is comprised of a basal anhydrite and carbonate section of $50 \mathrm{~m}$ thick, overlain by 100's of meters of rocksalt (e.g. de Jager \& Visser, 2017). Creep of salt relaxes shear stresses and will create a near-isotropic state of stress over geological time, i.e. a stress ratio $K_{0}$ of 1 and an initial shear stress $\tau_{0}=0$ (e.g. Haug et al., 2018). This isotropic stress is supported by nearlithostatic pore pressure measurements in the Zechstein (Verweij et al., 2012), A high $K_{0}$ will strongly reduce $T$, and prevent propagation into the overburden (e.g. Buijze et al., 2017). Although upwards propagation is thus prevented by the presence of salt, a local reduction in normal stress on offset faults just below the salt can locally promote failure (Haug et al., 2018; Orlic \& Wassing, 2012). The presence of salt may thus lead to lower reactivation pressure than observed in our study, but also lead to smaller dynamic ruptures compared to those in Figure 2-15.

Faults continue below the reservoir for at least several hundreds of meters into the Carboniferous underburden (Kortekaas \& Jaarsma, 2017), which is comprised of a tilted succession of shales, silts and sandstone beds intercalated with coal seams (de Jager \& Visser, 2017). No stress measurements have been conducted in the underburden. However, timedependent deformation of clay-rich rocks is expected to relax a (significant) fraction of differential stress over geological time (Sone \& Zoback, 2014). As the underburden is more clay-rich than the reservoir, the in-situ horizontal stress is expected to be larger, resulting in 
a larger $K_{0}$ and smaller in-situ shear stress. This in turn yields a lower $T$, making propagation into the underburden less favorable and lowering rupture sizes even further.

Also wave propagation may be strongly influenced by velocity contrast between layers. For a low velocity formation such as the Rotliegend in the Groningen field this may potentially trap a lot of seismic energy within the formation (Buijze et al., 2017). Note that here the elastic properties are equivalent for the quasi-static compaction phase and the dynamic rupture. In reality dynamic elastic properties can be different from the static elastic properties, which will affect wave propagation.

In the model the friction properties along the fault were uniform. However, as the faults cross-cut different stratigraphic formations, the fault rock is expected to vary. Different fault rock mineralogies yield different fault strengths and frictional behavior (Hunfeld et al., 2017). The frictional strength and stress drop also strongly affect $T$ and rupture size. Propagation into fault rocks with low frictional strength such as the clay-rich Ten Boer and underburden may be favorable. However, the velocity dependence of this rocks is likely stabilizing, and the expected stress drop under the conditions of rupture propagation at the in-situ pressures and temperatures is highly uncertain. We recommend further research on the potential dynamic weakening of Groningen type fault rocks, and include a broader range of uncertainties in future modeling.

The model results indicated that fault offset promoted fault reactivation. This is supported by the location of recent events the Groningen field which could be located with greater accuracy due to the new monitoring network (Spetzler \& Dost, 2017a). Most of these events were mapped on known faults, that is faults that are visible on seismics because they offset the reservoir with a certain amount (>20 m). A relationship between earthquake occurrence and fault offset was however not obvious, apart from some larger earthquakes which occurred often on faults with offsets of $100 \mathrm{~m}$ (Wentinck, 2016), but within all the uncertainties in location of the earlier events a correlation may however be difficult. On the other hand the results of this study also indicated that propagation into the underburden was more likely for small offset where no or only small parts of the faults became more stable during depletion. Larger events could occur, even for $T<0$. Interestingly enough, the largest magnitude events in the Groningen field seem to support this finding. The largest magnitude observed thus far is the 12-08-2012 M 3.6 Huizinge earthquake, with an estimated slip 0.07 $\mathrm{m}$ with a radius of $400 \mathrm{~m}$ based on a circular rupture (Dost \& Kraaijpoel, 2013). Such a size could be confined to the reservoir but this would require a very high aspect ratio. At first no fault was recognized at the hypocenter location, but recent improvements in the fault model showed a fault with small throw at the hypocenter location (Kortekaas \& Jaarsma, 2017). Rupture into the underburden may thus have occurred for this event. Small offset faults are reactivated later in the lifetime of the field, but may pose a larger hazard for rupture propagation. 


\section{Chapter 2}

\section{4. 5. Broader implications for modeling of induced seismicity}

The dynamic model results showed that the stress distribution in and around the depleting reservoir had a strong effect on rupture length (see also 2. 4. 2. and Figure 2-15). Some models relating operational parameters and the potential magnitude of induced seismicity do not consider explicitly the stress distribution (McGarr, 2014; Shapiro et al., 2011). These models also assume the rupture remains confined to the interval affected by fluid injection. Although in most of our results rupture did remain confined to the reservoir interval, propagation outside of the reservoir interval also occurred. This was more likely for the smooth stress perturbation related to $0 \mathrm{~m}$ offset reservoir compartments, compared to the more heterogeneous stress that developed along offset faults. To estimate potential rupture sizes the effect of a (geometry-specific) stress distribution must not be ignored.

Dynamic effects were also observed to be important for rupture size, with supershear causing additional propagation into the underburden ( $0 \mathrm{~m}$ offset) and triggering of the stress concentrations for the offset case. A previous study showed that for $0 \mathrm{~m}$ offset the rupture size computed in a fully dynamic analysis was $10 \%$ larger than in a (less computer-intensive) quasi-static analysis (Wassing et al., 2016), which may be an acceptable difference in the framework of all other uncertainties. For more heterogeneous fault stress the difference could be larger.

Deterministic modeling as done in this study thus involves parameters with significant uncertainties (in particular $\mathrm{D}_{\mathrm{c}}, \mu_{\mathrm{d}}$, and in-situ stress) and simplifying assumptions on the physics governing induced seismic events. The results are subject to uncertainties, and should not be used directly; rather the modeled trends are of importance and give insight in the mechanics that plays a role in generating induced events. Extending the model approach to a more stochastic analsysis including broader parameter ranges and validation against field observations is recommended as a next step.

\section{5. Conclusions}

We performed dynamic simulations of fault reactivation and seismic rupture induced by the depletion of two reservoir compartments cross-cut by a fault with or without offset. The model geometry, formation and fault properties, and stress state were based on the Groningen reservoir, but were kept uniform for the reservoir and the underburden and overburden, to highlight the development of stresses during depletion. Note that these findings apply to relatively uniform depletion of a gas reservoir with faults that are not sealing. The in-situ stress, weakening rate (through the dynamic friction and the critical slip distance), and reservoir offset were varied to study the effect on fault reactivation, and on the along-dip dynamic rupture length. The main trends and findings are summarized here:

- The modeled poroelastic stress changes and pressure required for reactivation for depletion of $0 \mathrm{~m}$ offset reservoir compartments agreed with the analytical solutions 
for a stiff fault zone (> 10 times the elastic properties of the medium). For fault zones with a lower stiffness the poroelastic stressing rates were lower than the analytically calculated rates, and more depletion was required for reactivation. This is not necessarily wrong or unphysical, in contrary, an interface stiffness smaller than the adjacent formations may account for the fault thickness and elastic deformation of the thicker fault.

- Onset of fault slip occurs at a reservoir depletion pressure $\Delta \mathrm{P}_{\mathrm{r}}$ which increased with the total horizontal in-situ stress ratio $K_{0}$. Onset of fault slip was strongly promoted by with reservoir offset (for offsets smaller than reservoir thickness) due to shear stress peaks at the top of the hanging wall and at the base of the foot wall reservoir.

- Inclusion of linear slip-weakening friction required a critical nucleation length to be slipping aseismically, before seismic instability could nucleate. The nucleation length agreed with theoretical estimates. However, merging of two stress peaks could cause the nucleation length to deviate. Also when the critical slip distance is reached, continued aseismic slip occurred and instability was suppressed.

- The down-dip rupture length $\mathrm{L}_{\mathrm{s}}$ decreased for more stable in-situ stress, smaller stress drop, and smaller weakening rate (which is equivalent to larger critical slip distance and larger fracture energy.

- Whereas fault offset promoted the nucleation of rupture, it reduced the down-dip rupture size. Rupture arrest occurred at stable stress regions which had formed during depletion. The smaller the offset on the other hand, the larger the potential for rupture propagation into the underburden.

- The transition from arrested ruptures to runaway ruptures was consistent with the findings of Galis (2015) and Ripperger (2007). However, the heterogeneous stresses in the nucleation zone (= depleting reservoir interval) caused the transition to vary. Fault offset and large fracture energy caused the transition to occur at more critical stress drop/strength drop ratios.

- Note that the previous findings apply to a normal faulting regime. For a strike-slip or reverse stress regime the poroelastic stress changes would stabilize the fault, although differential compaction across the fault could still cause local stress concentrations. However, overall stresses on the steeply dipping normal fault in a reverse stress regime do not favor large ruptures.

- The ratio stress drop/strength drop provides a convenient measure for the propensity of rupture to propagate outside of the reservoir. However, for negative stress drop in the underburden and/or overburden, still some propagation can occur into the before rupture is arrested. 
Chapter 2

\section{6. Acknowledgements}

This research was in part funded by Nederlandse Aardolie Maatschappij BV (NAM) in the framework of Research Agreement UI49294 'Studies on Fault (re)activation and dynamic friction and failure behaviour'. Part of the research has also been conducted within the framework of the M4ShaleGas project that was funded by the European Union's Horizon 2020 research and innovation program under grant agreement number 640715. Furthermore we thank all colleagues and friends at TNO, Utrecht University, Shell, and NAM for their support and discussions on modeling of earthquakes. TNO is thanked for providing the license for DIANA FEA. In particular we thank Gerd-Jan Schreppers from DIANA FEA BV for his support and helpful discussions. 
Chapter 2 
Chapter 2 


\section{Chapter 3}

\section{The effect of elastoplastic reservoir}

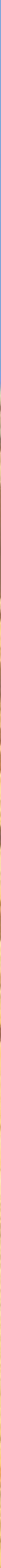


Chapter 3 


\title{
The effect of elastoplastic reservoir properties on
}

\section{reservoir stress path and fault reactivation during}

\author{
pore pressure depletion
}

\section{1. Introduction}

Seismic events $\left(\mathrm{M}_{\mathrm{L}}<3.5\right)$ induced by gas production from the Groningen gas field in the N.E. Netherlands have become a serious problem in recent years, causing damage to thousands of houses, social unrest and political turmoil, and resulting in early phase-out of gas production from what is one of the world's largest gas fields. Geomechanical modeling indicates that these events are likely induced by (a combination of) production-related poroelastic stress changes, stress changes caused by gradients in compaction of the sandstone reservoir where the depleting reservoir compartments are offset by faults (i.e. differential compaction), stress changes due to salt caprock creep (where salt caprock is present), and by delayed pore pressure diffusion from faults into the depleting reservoir (Buijze, van den Bogert et al., 2019; Haug et al., 2018; Mulders, 2003; Nagelhout \& Roest, 1997; Orlic \& Wassing, 2013; Roest \& Kuilman, 1994; Segall, P., 1989; Segall, P. et al., 1994; van Wees et al., 2019; Zbinden et al., 2017). The relationship between pressure decrease, reservoir compaction, fault stressing and thus-forced fault reactivation is one of the key ingredients for understanding the spatiotemporal behavior of seismicity and assessing the potential size of the induced events. This applies not only to the Groningen field but also to other hydrocarbon fields that exhibit induced seismicity in the Netherlands, Germany (Bischoff et al., 2014; Bischoff et al., 2015; Bischoff et al., 2016; Bischoff et al., 2019; Dahm et al., 2007) and the USA (Dahm et al., 2007; Doser et al., 1991; Doser et al., 1992; Hough \& Page, 2016) for example. Stress changes and compaction resulting from reservoir depletion are usually modeled assuming linear elastic or poroelastic behavior of the reservoir rock (e.g. Buijze, van den Bogert et al., 2019; Candela, Thibault et al., 2019; Haug et al., 2018; Mulders, 2003). However, laboratory experiments on core samples of the Groningen reservoir rock, the Slochteren sandstone, show that up to $50 \%$ of the deformation occurring during simulated depletion is inelastic at in-situ conditions (Hol et al., 2015; Hol et al., 2018; Pijnenburg et al., 2018; Pijnenburg et al., 2019) The question that then arises is how will this affect a) the stress

\footnotetext{
Photograph previous page: Deformation bands in the Hopeman sandstone, Clashach Cove, Lossiemouth, Scotland, UK. The Hopeman sandstone was deposited in the Late Permian - Early Triassic and is of aeolian origin, similar to parts of the Slochteren Formation in the Groningen field. The deformation bands are localized zones of deformation related to a nearby large fault structure. The bands are resistant to erosion because they are more compacted and/or cemented than the surrounding undeformed sandstone, which makes them stand out.
} 


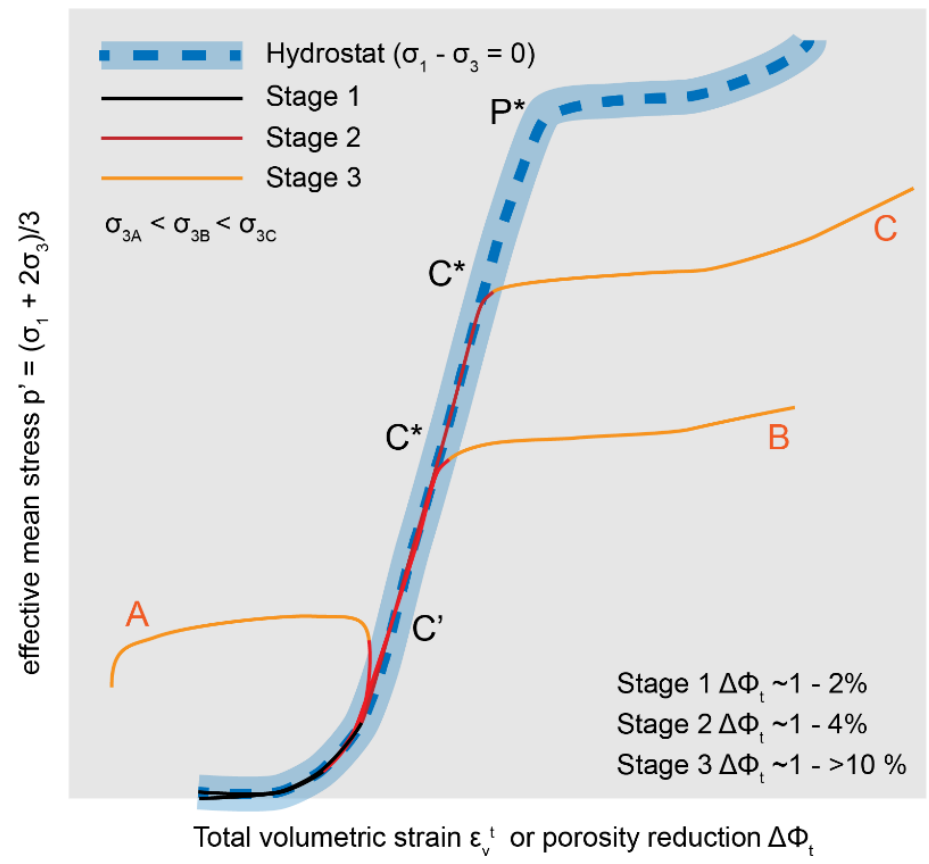

Figure 3-1. Idealized diagram of porosity change (elastic + inelastic) during triaxial loading of a porous sandstone. Different characteristic stages, as described for example by Pijnenburg et al. (2019), are indicated in black, red, and orange, with Stage 1: initial nonlinear part of the stress-strain curve, Stage 2: near-linear part of the stressstrain curve, and Stage 3: nonlinear stress-strain response after beyond $C^{*}$ or $C^{\prime}$. $P^{*}$ : hydrostatic grain crushing pressure (e.g. Wong et al., 1997), C*: critical mean effective stress before onset of accelerated porosity reduction under triaxial loading , $C^{\prime}$ : critical mean effective stress before the onset of dilatant failure. A, $B$, and $C$ indicate stress-strain responses obtained in conventional triaxial compression tests at increasing confining pressures (i.e. $\sigma_{2}$ $=\sigma_{3}$ in a conventional triaxial test).

changes resulting from depletion and b) the elastic strain energy stored in the reservoir and available for seismicity.

The notion that inelastic (i.e. permanent, irreversible, or plastic) deformation behavior plays an important role in sandstones is not new. Significant inelastic porosity changes have been recorded during triaxial experiments on different sandstones (Darley Dale, Berea, Adamswiller, Bentheim sandstones) with porosities from $13-25 \%$. The confining pressures (i.e. $\sigma_{2}=\sigma_{3}$ in a conventional triaxial test) in these experiments were in the range of 5 - 150 (Wong et al., 1997) and 40 - $350 \mathrm{MPa}$ (Baud et al., 2006). During hydrostatic loading $\left(\sigma_{1}=\sigma_{2}=\sigma_{3}\right)$ porosity always decreases, and at a critical effective stress $P^{*}$ (Figure 3-1) significant inelastic volumetric strain occurs through intragranular cracking and pore collapse (Zhang et al., 1990). Under deviatoric or triaxial loading conditions, this accelerated inelastic porosity reduction is observed at lower critical yield stresses $C^{*}$, defined as the point of departure from the hydrostatic loading curve or hydrostat (the start of Stage 3 in Figure $3-1)$. Both $P^{*}$ and $C^{*}$ increase as the initial sample porosity decreases. The critical yield 
stress $C^{*}$ also decreases with confining stress, and at low confining stresses dilatant behavior is observed above a critical stress $C^{\prime}$. Beyond $C^{*}$, the stresses increase as a function of the porosity reduction (i.e. plastic hardening), whereas beyond $\mathrm{C}^{\prime}$ yield stresses may decrease (softening). Up to strains of the order of $1-2 \%$, the yielding behavior can be explained by isotropic associated plasticity models with elliptical yield surfaces - e.g. critical state models or cap models (Baud et al., 2006), but at higher strains the behavior exhibits non-associative plastic behavior (Pijnenburg et al., 2019). The stresses and strains at which $C^{*}$ (Stage 3 ) is attained are typically much larger than those expected in the Groningen field $(<0.2 \%$ starting from the initial field conditions).

For this reason, the contribution of inelastic porosity reduction at smaller strains, i.e. in Stage 2, has recently been investigated in detail by means of progressive cyclic loading performed in triaxial compression experiments specifically on samples of the Groningen reservoir, i.e. the Slochteren sandstone (Pijnenburg et al., 2018; Pijnenburg et al., 2019). This stage was previously assumed to be, or treated as, mainly elastic by some authors (e.g. Wong et al., 1997). The experiments revealed that combined elastic and inelastic behavior occurs throughout the entire experiment - i.e. at stresses below the critical yield stresses $C^{*}$ mentioned above. The preceding nonlinear Stage 1 is generally thought to represent closure of cracks induced during extraction of the cores from the field and subsequent handling, and was shown to give way to the near-linear Stage 2 behavior at mean effective stresses that are comparable to in-situ values (Pijnenburg et al., 2018; Pijnenburg et al., 2019) On this basis, Pijnenburg et al $(2018,2019)$ proposed that the near-linear behavior seen in Stage 2 can be taken as representative for the compaction behavior of the Slochteren sandstone during reservoir production. On the basis of microstructural studies, the inelastic reduction of porosity in Stage 2 was attributed to combined consolidation and shear of thin intergranular clay films that are widespread in the Slochteren sandstone. The authors found that the observed Stage 2 behavior could be described by a Modified Cam-Clay elastoplasticity model. Independent measurements performed under uniaxial strain conditions on samples derived from the same Slochteren sandstone core also show near-linear stress-strain behavior under depleting conditions, with a similar fraction of inelastic compaction occurring as seen in the triaxial experiments (Hol et al., 2018). Incorporation of this inelastic behavior into geomechanical models addressing stress-strain evolution during reservoir depletion must to some extent influence stress redistribution, elastic strain development and elastic energy storage versus dissipation, especially in the neighborhood of faults that offset the compacting reservoir. This might lead to enhanced stressing on the offset faults and promote fault reactivations The size of the subsequent dynamic rupture events may also be affected by inelastic reservoir rock properties.

Previous numerical modeling studies have shown that incorporation of an elastoplastic constitutive model for the target aquifer, reservoir, and/or the caprock can have major effects on the compaction behavior and stress changes resulting from subsurface activities. In a study on the compaction resulting from reservoir depletion, Modified Cam- 


\section{Chapter 3}

Clay elastoplasticity was compared with behavior equivalent to the elastic component of the MCC model during the initial stages of reservoir depletion (Firme et al., 2014). Initially MCC caused less compaction as elastic hardening (i.e. an increase in the bulk modulus induced by increasing effective stress) occurred. However, the additional plastic deformation resulting from MCC behavior caused significantly more reservoir compaction and subsidence than the linear elastic behavior - depending on input parameters such as the preconsolidation stress (i.e. mean effective stress below which only elastic deformation occurs) which was set to a value larger than the initial mean effective stress in the reservoir. In addition, when pumping from an aquifer or aquifer-supported hydrocarbon field is stopped, elastoplastic behavior suppresses rebound behavior upon pressure re-equilibration (Simoni et al., 1999). A study that addressed the effect of an elastoplastic medium on dynamic rupture propagation showed that for off-fault elastoplasticity with a compression cap the fault slip and slip velocities were significantly smaller (Liu \& Borja, 2013). For compaction of the Slochteren sandstone of the Groningen field it may be argued that linear elasticity can adequately describe the stresses and strains during depletion, as the observed stress-strain response is near-linear (Stage 2) (Hol et al., 2018, Pijnenburg et al., 2019) However, it is not known whether this is the case throughout the reservoir (e.g. in areas where the stress is concentrated near faults), and the effect of incorporating elastoplasticity instead of the equivalent linear elastic approximation for Stage 2 behavior over the range of actual reservoir strains and stress changes that occur during reservoir depletion has not been investigated yet. Specific questions that need to be considered in the context of a depleting reservoir such as Groningen are: When and where in a depleting faulted reservoir will elastoplasticity result in different stress evolution and differences in fault reactivation with respect to linear elastic behavior that equally well describes the near-linear Stage 2 behavior observed in the experiments (from hereon called 'apparent' linear elastic behavior)? Will fault reactivation and nucleation of dynamic rupture be different for an elastoplastic reservoir compared to an apparent linear elastic reservoir? And more importantly, what is the effect of elastoplastic behavior of the Slochteren reservoir rock on the magnitude of the depletion-induced seismic events with respect to an apparent linear elastic reservoir?

Here I address these points by simulating depletion, fault reactivation, and dynamic rupture for an elastoplastic and an equivalent linear elastic reservoir model. Pressure depletion for an elastoplastic medium was simulated in DIANA Finite Element Analysis, in which the Modified Cam-Clay (MCC) model is available as a standard material model. Special emphasis is placed on comparing the MCC behavior simulated with a single-element model with two independent sets of experiments on the Slochteren sandstone: the Stage 2 stress-strain behavior observed in the conventional triaxial compression experiments performed by Pijnenburg et al. (2019) and uniaxial compaction experiments (Hol et al., 2018) (Section 2.2 and 2.3). Sensitivity of MCC behavior to the applied initial mean effective stress was evaluated further (Section 2.4). Two simplified field-scale models based on the characteristics of the Groningen field were used to simulate depletion-induced stresses and 
strains; an axisymmetric reservoir model and a plane-strain model with a fault offsetting the reservoir formation (Section 3). The MCC model was assigned to the reservoir sandstone formation, whereas the surrounding formations were modeled with linear elastic properties. The stresses and strain obtained with MCC behavior were compared against the aforementioned 'apparent' linear elastic behavior (Section 4.1). The effect of MCC behavior on fault reactivation and dynamic rupture was further investigated in the plane-strain fieldscale model (Section 4.2 and 4.3).

\section{2. Modified Cam-Clay model: Validation against experimental data and effect of initial mean effective stress}

The recent experimental work on the compaction behavior of the Groningen (Slochteren) reservoir sandstone described above employed samples taken from core that was recovered in 2015 from the Zeerijp well (ZRP-03). This well is located in the seismogenic center of the Groningen field where gas production has led to a pressure drop of $25 \mathrm{MPa}$ from the initial reservoir pressure of $35 \mathrm{MPa}$ to $10 \mathrm{MPa}$ (www.nam.nl/feiten-encijfers/gasdruk.html). Both conventional triaxial compression (Pijnenburg et al., 2018; Pijnenburg et al., 2019) and uniaxial compaction strain experiments (Hol et al., 2018) were performed on these samples. Pijnenburg et al. (2019) showed that the inelastic component of sandstone deformation behavior can be described using a Modified Cam-Clay (MCC) yield surface. In the following sections, I describe the classical formulation of the MCC model used in this study and compare the model behavior to both the triaxial and uniaxial datasets. Throughout, I will use the term plastic strain or plastic deformation to describe the inelastic or irreversible component of deformation.

\section{2. 1. Modified Cam-Clay material model}

The Modified Cam-Clay (MCC) model is an empirical elastoplastic model developed for soils and granular materials in the context of critical state soil mechanics (Roscoe et al., 1958; Roscoe \& Burland, 1968). The model is available as a standard material model in many finite element software packages. Here I describe the basic features of the Modified Cam-Clay model as incorporated in the DIANA FEA package.

The state of soils and granular materials can be described in terms of mean effective stress $p$ ', which equals $\left(\sigma_{1}^{\prime}+2 \sigma_{3}{ }^{\prime}\right) / 2$ (with prime' indicating Terzaghi effective stresses) for triaxial tests $\left(\sigma_{2}=\sigma_{3}\right)$, differential stress $q=\sigma_{1}-\sigma_{3}$, and the specific volume $v$, which is the gross volume divided by grain-material volume. The specific volume is defined as

$$
v=1+e=1+\frac{\phi}{1-\phi}
$$

where $e$ is the void ratio and $\phi$ porosity. The critical state of soils and granular materials is a state at which the material undergoes shear strain, without experiencing any volume changes 
(zero volumetric strain $\varepsilon_{v}$ hence constant void ratio $e$ ) or stress changes (Roscoe et al., 1958). The critical state or critical state line (state boundary surface) in $p^{\prime}-q$ space (Figure 3-2a) is defined as

$$
q=M p^{\prime}
$$

Here, $M$ is the slope of the critical state line given

$$
M=\frac{6 \sin \mu_{i}}{\left(3-\sin \mu_{i}\right)}
$$

where $\mu_{i}$ is the internal friction angle (Figure 3-2a). The critical state is also a function of the specific volume and in $v-p$ ' space relating the void ratio to the mean effective stress, and is defined as

$$
v=\Gamma-\lambda \ln \left(p^{\prime}\right)
$$

where $\Gamma$ is the critical specific volume of the material at a reference mean effective stress of $1 \mathrm{kPa}$, and $\lambda$ is the total hardening parameter, one of the soil constants which describes how the void ratio changes with the natural logarithm of the mean effective stress for elastic + plastic deformation (Figure 3-2b).

The yield surface (also called the state boundary surface) described by the MCC model (Roscoe \& Burland, 1968) represents the onset of plastic deformation. It is defined as a symmetric elliptical function in $p^{\prime}-q$ space, given

$$
q^{2}+M^{2} p^{\prime}\left(p^{\prime}-p_{c}{ }^{\prime}\right)=0
$$

Here $p_{c}{ }^{\prime}$ is the preconsolidation stress which determines the length of the major axis of the yield surface. It is assumed that when $p^{\prime}<p_{c}$ ' no plastic behavior will occur. An initial value of $p_{c}{ }^{\prime}\left(p_{c 0}{ }^{\prime}\right)$ can be specified as an input parameter in DIANA, determining the initial position of the yield surface. The apex of the yield surface is intersected by the critical state line (Figure 3-2a). To the left side of this intersection the yield surface is also called the 'dry side' or dilatant side; when the state of a material is on this side the material will dilate during drained shearing (or cause a decrease in pore pressure during undrained shearing). On the other side of the intersection lies the 'wet side' or compactive side of the critical state line; here the opposite will happen and materials will compact or cause pore pressure to increase. Note that in DIANA the shape of both the dilatant and compactive sides of the yield surface may be altered ('Egg' Cam-Clay) and can be described by a modified form of Equation 2 (see DIANA 10.3 User Manual); here only the classical elliptical shape of the Modified CamClay cap is used as given by Equation 3-5. 

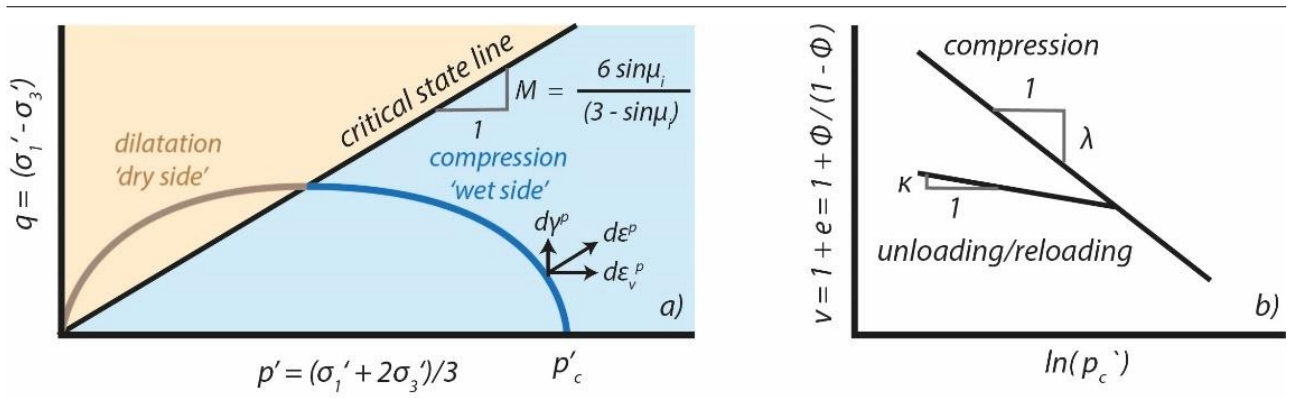

Figure 3-2. Modified Cam Clay model (modified from DIANA v. 10.1 manual). a) critical state line and yield surface in $p^{\prime}-q$ space, $b$ ) critical state line and hardening parameters shown in $v-\ln \left(p^{\prime}\right)$ space. The parameter $\lambda$ gives the hardening rate during compression (elastic + plastic), and $\kappa$ gives the slope of the unloading curve.

Allowable stress states fall within the yield surface, or on it. Within the yield surface, the material behavior is assumed to be purely elastic. Within and on the yield surface, where elasticity always applies, the tangential bulk modulus relates the changes in mean stress and elastic volumetric strain $\varepsilon_{v}^{e}$ via

$$
K\left(p^{\prime}\right)=\frac{-d p^{\prime}}{d \varepsilon_{v}^{e}}
$$

It has been observed experimentally that (clay) samples show nonlinear elastic behavior with a bulk modulus $K$ that depends on the mean stress and void ratio $e$ via

$$
K=\frac{1+e}{\kappa}\left(p^{\prime}+p_{t e l}\right) .
$$

where $\kappa$ is the elastic hardening parameter, i.e. the slope of the unloading curve in $v-\ln \left(p^{\prime}\right)$ space (see Figure 3-2b), and $p_{\text {tel }}$ is a parameter that accounts for the limiting tensile strength at $p^{\prime}=0$. Combining and rewriting Equations 3-6 and 3-7 gives

$$
\frac{d p^{\prime}}{p^{\prime}+p_{t e l}}=-\frac{1+e}{\kappa} d \varepsilon_{v}^{e}
$$

and integration of Equation 8 shows that the mean effective stress changes due to an increment in elastic volumetric strain through

$$
p^{\prime}=-p_{t e l}+\left(p_{0}{ }^{\prime}+p_{t e l}\right) \exp \left(-\frac{1+e_{0}}{\kappa} \Delta \varepsilon_{v}^{e}\right)
$$

where $p_{0}$ ' and $e_{0}$ are the reference mean effective stress and void ratio at the start of a load step (i.e. before the incremental change in strain). The change in elastic shear strains $\gamma^{e}$ are related to the shear modulus $G$ (DIANA 10.3 User Manual, 2019)

$$
d \gamma^{e}=\frac{d q}{3 G\left(p^{\prime}\right)}
$$


which, assuming isotropic behavior, is related to $p$ ' by

$$
G=\frac{3(1-2 v) K\left(p^{\prime}\right)}{2(1+v)}=\frac{3(1-2 v)(1+e) p^{\prime}}{2(1+v) \kappa}
$$

Here, $v$ is the Poisson's ratio. In this study, a constant Poisson's ratio was assumed; alternatively a constant shear modulus $G$ and a variable Poisson's ratio can be assumed.

As stresses evolve during loading from an initially unloaded or elastically loaded state, the yield surface is eventually reached and both elastic and plastic strains occur. For isotropic behavior, the resulting plastic strain vector is perpendicular to the yield surface (as a consequence of normality rule or associated flow rule) and has both a volumetric strain component $\varepsilon_{v}{ }^{p}$ and a shear strain component $\gamma^{p}$ (Figure 3-2a) As a key component of the MCC model, the plastic volumetric strain occurring as the yield surface is reached is assumed to cause plastic hardening of the material, changing the size of the yield surface. Note that the yield surface only changes as a function of volumetric strain $\varepsilon_{v}{ }^{p}$, not shear strain. The incremental change in the yield surface is captured through a change in preconsolidation stress $p_{c}$ ' (i.e. the intersection of the ellipse with the $p$ '-axis) via the relation

$$
p_{c}^{\prime}=p_{c 0}{ }^{\prime} \exp \left(-\frac{1+e_{0}}{\lambda-\kappa} \Delta \varepsilon_{v}^{p}\right)
$$

where $\lambda$ is the total hardening parameter which includes both elastic and inelastic deformation - i.e. the slope of the loading curve in $v-\ln \left(p^{\prime}\right)$ space (Figure 3-2b). Depending on whether a material is on the dilatant side or compactive side of the critical state line respectively, contraction or expansion of the yield surface will occur. Plastic shear strains are related to plastic volumetric strains through the shape of the yield function, assuming associated plasticity, through the relation (DIANA 10.3 User Manual, 2019; Munda et al., 2014)

$$
\frac{d \varepsilon_{v}^{p}}{d \gamma^{p}}=\frac{M^{2}-\left(q / p^{\prime}\right)^{2}}{2\left(q / p^{\prime}\right)}
$$

As both elastic and plastic volumetric changes occur, the void ratio $e$ is updated as a function of the volumetric strain increment $\Delta \varepsilon_{v}$ according to the equation

$$
e=\left(1+e_{0}\right) \exp \left(\Delta \varepsilon_{v}\right)-1
$$

where $\Delta \varepsilon_{v}$ is the sum of the elastic and plastic volumetric strain increments $\Delta \varepsilon_{v}{ }^{e}+\Delta \varepsilon_{v}{ }^{p}$. This means that as elastic and/or plastic strains occur during deformation, the void ratio (hence material density) will change, which in turn causes the elastic parameters to change and, if plastic strain occurs, also the pre-consolidation stress $p_{c}$ ' and the yield envelope size. 

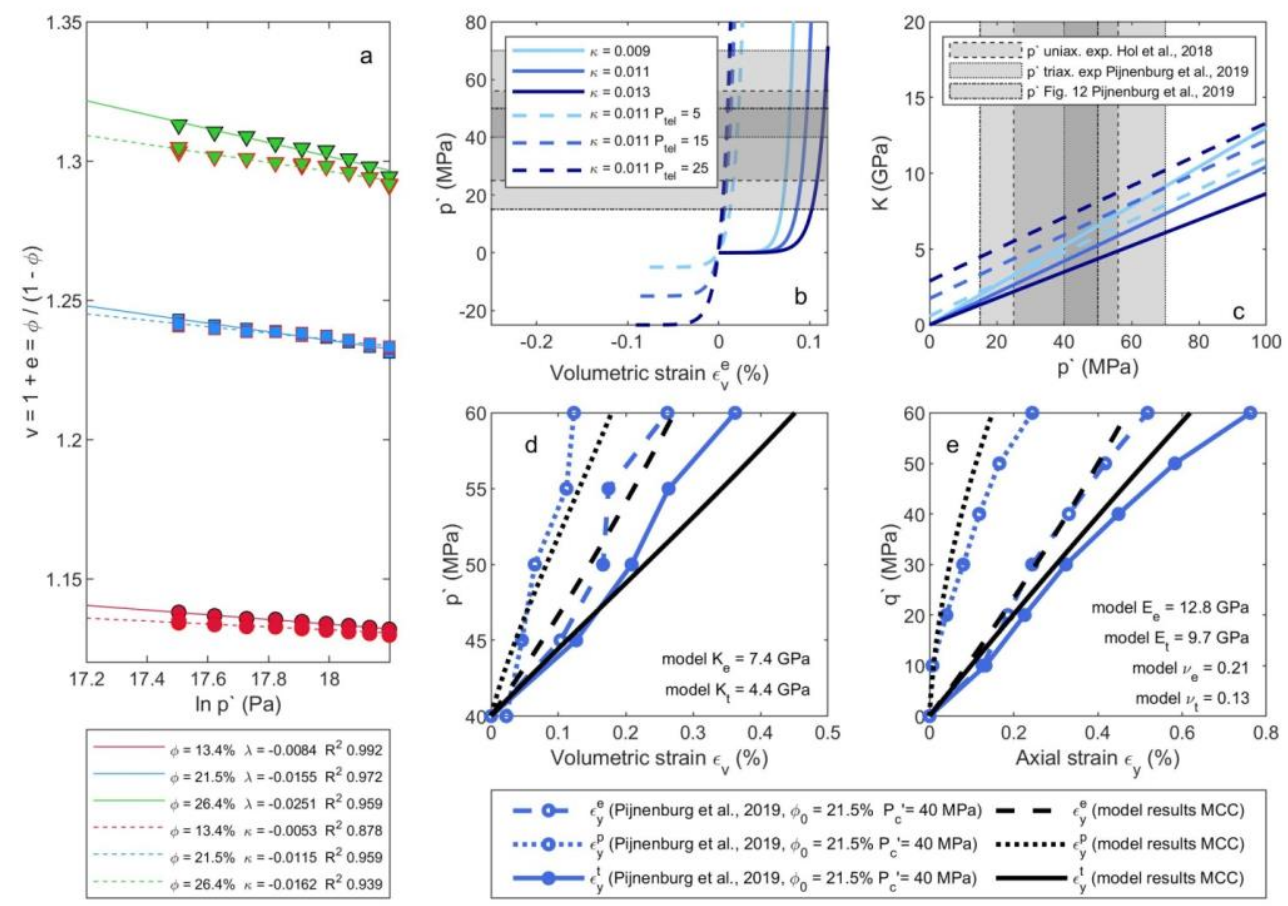

Figure 3-3. Comparison of Modified Cam-Clay model with experimental data obtained for Slochteren sandstone by Pijnenburg et al. $(2018,2019)$. a) fits of elastic and plastic hardening parameters $\kappa$ and $\lambda$ to experimental data by Pijnenburg et al. (2019) in v-ln(p') space during hydrostatic loading. $b$ and c)Effect of elastic hardening parameter $\kappa$ and $p_{\text {tel }}$ on elastic volumetric strains and bulk modulus $K_{t}$. Gray areas indicate the range of $p^{\prime}$ covered during deviatoric loading in the experiments of Pijnenburg et al. $(2018,2019)$ and during pore pressure reduction under uniaxial conditions in the experiments of Hol et al. (2018), as well as p' assumed during field production by Pijnenburg et al. (2019). Comparison of MCC model results to observed axial strain with $q(d)$ and volumetric strains with $p^{\prime}(e)$ on cores with $\phi_{0}=21.5 \%$ under a confining pressure of $40 \mathrm{MPa} . M=1.5, \kappa=0.0011, \lambda=0.0015$, $p_{\text {tel }}=15 \mathrm{MPa}, \mathrm{p}_{\mathrm{c}}{ }^{\prime}=5 \mathrm{MPa}, \alpha=1$.

\section{2. 2. Validation of MCC model against triaxial experiments on the Slochteren} sandstone

Results from the triaxial compression experiments on Slochteren sandstone samples obtained from the Zeerijp-03 well in the Groningen field have shown that plastic behavior

occurs throughout deformation. As already discussed, the linear stress-strain behavior reported by Pijnenburg et al. (2018, 2019) (Stage 2, Figure 1) is regarded as representative for the compaction behavior of the Slochteren sandstone in-situ during depletion. During Stage 2, the normality rule was observed (associated plasticity) and plastic strain development and plastic hardening could be modeled with the MCC yield surface. Here, I compare FE model results with the MCC material model (Section 3. 2. 1. ) with results from the triaxial experiments of Pijnenburg et al. (2019). Note that the authors assumed linear elasticity and linear plastic hardening. Here I follow the classical form of the MCC using 
nonlinear elasticity (Figure 3-2b). The nonlinear hardening parameters $\kappa$ and $\lambda$ were obtained by respectively fitting Equation 3-9 and 3-12 to the elastic and total (elastic + plastic) strains recorded by Pijnenburg et al (2018) during Stage 2 (at $\sigma_{3}{ }^{\prime}=40 \mathrm{MPa}$ ) for three samples with an initial porosity of $13.4 \%, 21.5 \%$, and $26.4 \%$ (Figure $3-3 a$ ). The higher the initial porosity, the higher the values of $\kappa, \lambda$, and $\lambda-\kappa$ obtained from the fits, indicating more compliant behavior and more plastic deformation than for lower values of $\kappa, \lambda$, and $\lambda-\kappa$. For example, Figure 3-3b and Figure 3-3c show how a higher $\kappa$ results in more elastic volumetric strain $\varepsilon_{v}{ }^{e}$ to develop with $p$ '. The corresponding bulk modulus $K$ increases less with $p$ ' than for lower values of $\kappa$, as can also be seen from Equations 3-6, 3-7 and 3-12. The nonlinear hardening function results in significant strains and a low bulk modulus at low $p^{\prime}$ (Figure 3-2c), i.e. a lower bulk modulus than expected at these $p$ ' values for the cohesive Slochteren core samples. By tuning the tensile strength $p_{t e l}$ (Equations 3-7 and 3-9), the hardening curve can be adjusted, so that the bulk modulus is several $\mathrm{GPa}$ at $p^{\prime}=0$ and matches values of $K$ measured by Pijnenburg et al. (2019) in the range $p^{\prime} 10-60 \mathrm{MPa}$, without having to use a low value of $\kappa$ that would be inconsistent with the fits (Figure 3c).

The triaxial loading conditions imposed during the experiments were reproduced in a single-element FE model (DIANA FEA v10.3). This is single axisymmetric element with MCC behavior, and the appropriate boundary conditions - i.e. for the uniaxial case fixed lateral displacements, a fixed vertical load, and a varying pore pressure, and for the triaxial case a constant radial load and an increasing axial stress. Results of this models are compared with the experimental data. Figure $3 \mathrm{~d}$ and e show such a comparison for the data obtained for the sample with $21.5 \%$ initial porosity. Taking the fitted parameters $\kappa$ and $\lambda$ for a $\phi_{0}$ of $21.5 \%, p_{\text {tel }}=15 \mathrm{MPa}\left(K=6 \mathrm{GPa}\right.$ at $\left.p^{\prime}=40 \mathrm{MPa}\right)$, and $M=1.5, p_{c 0}{ }^{\prime}=5 \mathrm{MPa}$ and $v=0.21$ (Pijnenburg et al., 2019) gives a relatively good match of the modeled strains to the experimental data, though the plastic axial strains are slightly underestimated by the model. The corresponding evolution of the yield surface in $p^{\prime}-q$ space is shown in Figure 3-4b. Note that Pijnenburg et al. (2019) observed a variable $M$ with values in the range 1.3 to 2.1 ; here an average value of 1.5 was used. The modeled stress-strain behavior is near-linear in the relevant range of $p^{\prime}$, consistent with the experiments. Linear fits of the modeled elastic and total volumetric strains with $p$ ' yield the true (elastic deformation only) bulk modulus $K_{e}$ and apparent or total (elastic + plastic deformation) bulk modulus $K_{t}$ of respectively $7.4 \mathrm{GPa}$ (as in Figure 3-3c) and $4.4 \mathrm{GPa}$, averaged over $p^{\prime}=40-60 \mathrm{MPa}$. The axial strains $\varepsilon_{y}$ against differential stress $q$ give Young's modulus $E$

$$
E(q)=\frac{-d q}{d \varepsilon_{y}^{e}}
$$

Linear fits of the modeled axial strains give a more compliant apparent behavior compared to the true elastic behavior, with $E_{t}=9.7 \mathrm{GPa}$ versus $E_{e}=12.8 \mathrm{GPa}$, in agreement with Pijnenburg et al. (2019). From $K$ and E, the Poisson's ratio $v$ can be calculated using 


$$
v=0.5-\frac{E}{6 K}
$$

which yields a true $v_{e}=0.21$ (i.e. the input value) and a lower apparent $v_{t}$ of 0.13 . This is different from the experimental observations where $v_{t}>v_{e}$ (see further the discussion in Section 3. 5. ).

The MCC parameters and evolution of the yield surface for the $13.4 \%$ porosity and $26.4 \%$ porosity samples are shown in Figure $3-4$. For the $13.4 \%$ porosity sample the $M$ value required to match the experimental data was significantly lower than reported in Pijnenburg et al. (2019), but using an $M$ value of 1.3 gives a good match with the experimental data (not shown). For the most porous sample with $\phi_{0}=26.4 \%$, the fitted hardening parameter $\lambda-\kappa$ in Figure 3-4 is too large to match the experimental results, and hence a smaller $\lambda-\kappa$ was used. Despite these differences, the overall agreement between the model and experiments is reasonable.
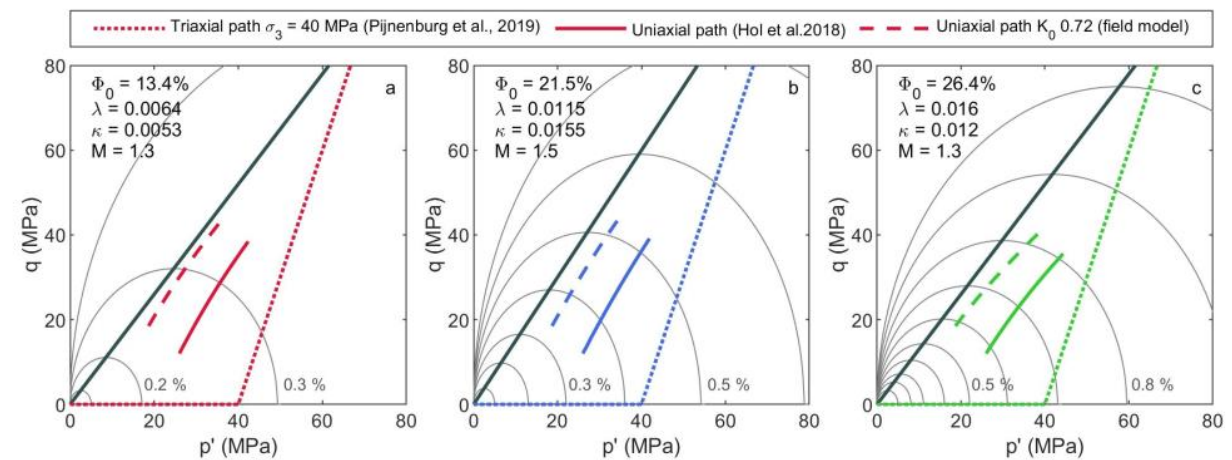

Figure 3-4. Modified Cam-Clay yield surfaces and experimental stress paths. MCC yield surfaces are drawn assuming the MCC parameters (see top left corners) obtained from a comparison with data obtained from triaxial experiments by Pijnenburg et al. $(2018,2019)$.

\section{2. 3. Comparison of triaxially calibrated MCC model with uniaxial compaction} experiments

During gas production, most of the reservoir formation is generally assumed to compact under uniaxial conditions as the reservoir is laterally extensive. These uniaxial conditions were simulated in experiments using the so-called Uniaxial-strain Pore Pressure Depletion (UPPD) protocol in the study reported by Hol et al. (2018). In these experiments, the stresses and pressures were first brought to the in-situ, pre-production reservoir conditions, under triaxial loading conditions, with an axial stress of $69 \mathrm{MPa}$, a confining stress of $57 \mathrm{MPa}$ and pore pressure of $35 \mathrm{MPa}$ (initial $p^{\prime}=26 \mathrm{MPa}$ ). Subsequently, pore 
pressure was decreased stepwise while keeping lateral strains at zero by changing the confining stress. At several stages pore pressure was increased partially to investigate the unloading (elastic) response. Primary geomechanical parameters obtained from the uniaxial experiments include the horizontal stress path parameter $\gamma_{h}$ and the uniaxial compaction coefficient or uniaxial compressibility coefficient $C_{m p}$ (Geertsma, 1966). The stress path parameter gives the total horizontal stress change with pore pressure change $\left(\Delta \sigma_{h} / \Delta P\right)$, and for a poroelastic medium under uniaxial conditions can be expressed as a function of Biot coefficient $\alpha$ and Poisson ratio $v$

$$
\gamma_{h}=\frac{\Delta \sigma_{h}}{\Delta P}=\frac{\alpha(1-2 v)}{(1-v)}
$$

The uniaxial compressibility coefficient $C_{m p}$ gives the total axial strain response to pore pressure changes under uniaxial conditions

$$
C_{m p}=-\left(\frac{\Delta \varepsilon_{y}}{\Delta P}\right)_{\varepsilon_{x}, \varepsilon_{z}, \sigma_{y}}=\alpha C_{m c}=\alpha\left(\frac{\Delta \varepsilon_{y}}{\Delta \sigma_{y}}\right)_{\varepsilon_{x}, \varepsilon_{z}, P}
$$

where the subscript $y$ denotes the vertical (axial) component, and subscripts $x$ and $z$ the horizontal components, and $C_{m c}$ is the uniaxial compressibility coefficient under constant pore pressure conditions. As for the bulk modulus, Young's modulus, and Poisson's ratio determined from triaxial experiments and model results (Equations 3-6, 3-15, and 3-16), I distinguish the true (elastic) and apparent or total (elastic + plastic) values of the stress path parameter and the uniaxial compressibility. The apparent stress path parameter $\gamma_{h t}$ and compaction coefficient $C_{m p t}$ are measured during loading (here: pore pressure decrease), whereas the true elastic $\gamma_{h e}$ and $C_{m p e}$ are determined during unloading (here: pore pressure increase). Both values represent average values during the entire depletion range, unless otherwise indicated. Measured apparent stress path parameters $\gamma_{h t}$ (Figure 3-5d) are larger $(0.7-0.85)$ than the true stress path parameter $\gamma_{h e}(0.55-0.7)$, and the measured uniaxial compaction coefficients (Figure 3-5e) are also larger during loading $\left(C_{m p t}=5-15 \cdot 10^{-4}\right.$ $\left.\mathrm{MPa}^{-1}\right)$ than during unloading $\left(C_{m p e}=3-9 \cdot 10^{-4} \mathrm{MPa}^{-1}\right)$. Note that the true uniaxial compaction coefficient $C_{m p e}$ decreases with depletion, indicating elastic hardening of the samples as the effective stresses increase (Figure 3-5e).

As for the triaxial experiments, a single-element model was used to model MCC elastoplasticity, but now also using uniaxial strain boundary conditions. Pressures were applied according to the UPPD protocol as described by Hol et al. (2018). In this protocol the in-situ stresses and pressure were applied under triaxial loading conditions. Subsequently, uniaxial boundary conditions (zero lateral strain) were imposed, and the pore pressure was reduced to $1 \mathrm{MPa}$ and then brought back up to $35 \mathrm{MPa}$, to investigate the unloading behavior (solid lines in Figure 3-4). Note that the initial effective mean stress $p_{\text {in }}$ ' applied during the uniaxial experiments (26 MPa assuming $\alpha=1$ ) is lower than the initial mean effective stress in the triaxial experiments (40 MPa assuming $\alpha=1$, see stress paths in Figure 3-4). The 
parameter $p_{\text {tel }}$ was adjusted such that the bulk modulus at the $p_{\text {ini }}$ ' of the uniaxial test was the same $(6 \mathrm{GPa})$ as at $p_{\text {ini }}$ ' in the triaxial test. The modeled horizontal stresses and vertical strains with pressure depletion show near-linear behavior (Figure 3-5b and c) with a slightly concave up trend (Figure 3-4). Linear fits to the model results show that the average apparent $\gamma_{h t}(0.8)$ and $C_{m p t}\left(1 \cdot 10^{-4} \mathrm{MPa}^{-1}\right)$ values are higher than the corresponding unloading values of respectively 0.74 and $7.8 \cdot 10^{-5} \mathrm{MPa}^{-1}$. Conversely, the Poisson's ratio values calculated from the modeled stress path by rearranging Equation 3-17 are larger during unloading $\left(v_{e}=0.21\right)$ than during loading $\left(v_{t}=0.17\right)$, as also observed in the uniaxial experiments (Figure 3-5d). Note that this is opposite to the trend in the triaxial experiments, where the apparent Poisson ratio was larger than the unloading Poisson ratio (Pijnenburg et al., 2019). The modeled apparent and true $\gamma_{h}$ and $C_{m p}$ are within the range of the results from the uniaxial experiments, but somewhat larger than the average values. In particular, the true elastic $\gamma_{h e}$ is on the upper end of the experimental results. Besides variability in experimental results and uncertainties resulting from the measurement methods in the experiments, the assumed value of the Biot coefficient can affect the stress path.

The assumed Biot coefficient $\alpha$ influences the stress path parameter and the apparent and true Poisson's ratio calculated from the measured or modeled stress path parameter (Figure 3-5). Experiments on the Slochteren sandstone showed that the Biot coefficient is 0.7 - 0.9 (Filippidou et al., 2019). Model results with $\alpha=0.8$ give an apparent horizontal stress path parameter $\gamma_{h t}$ of 0.66 instead of the value 0.8 obtained assuming $\alpha=1$ (Figure 3-5b). Computing the apparent Poisson's ratio $v_{t}$ from the $\alpha=0.8$ stress path, but erroneously assuming $\alpha=1$, would give a $v_{t}$ of 0.25 , whereas the actual value $v_{t}$ would be 0.15 , closer to the apparent $v_{t}$ in the model with a Biot coefficient of 1 , and the apparent $v_{t}$ in the triaxial experiment. An error in the assumed value for the Biot coefficient would give a mismatch with the (apparent) elastic parameters obtained in triaxial experiments, as the elastic parameters obtained during conventional triaxial loading are independent of the value of the Biot coefficient. Here, a Biot coefficient of 0.9 would give a stress path $\gamma_{h t}$ of 0.73 , close to the stress paths observed in the uniaxial experiments.

A Biot coefficient $<1.0$ will also lead to a larger initial effective mean stress, as visible for the model run with $\alpha=0.8$ (Figure 3-5b). This is important, as the initial stress itself also affects the stress path, and the uniaxial compressibility (Figure 3-5c). In the next section I further explore the effect of initial mean effective stress on the stress path and the compressibility. 


\section{Chapter 3}
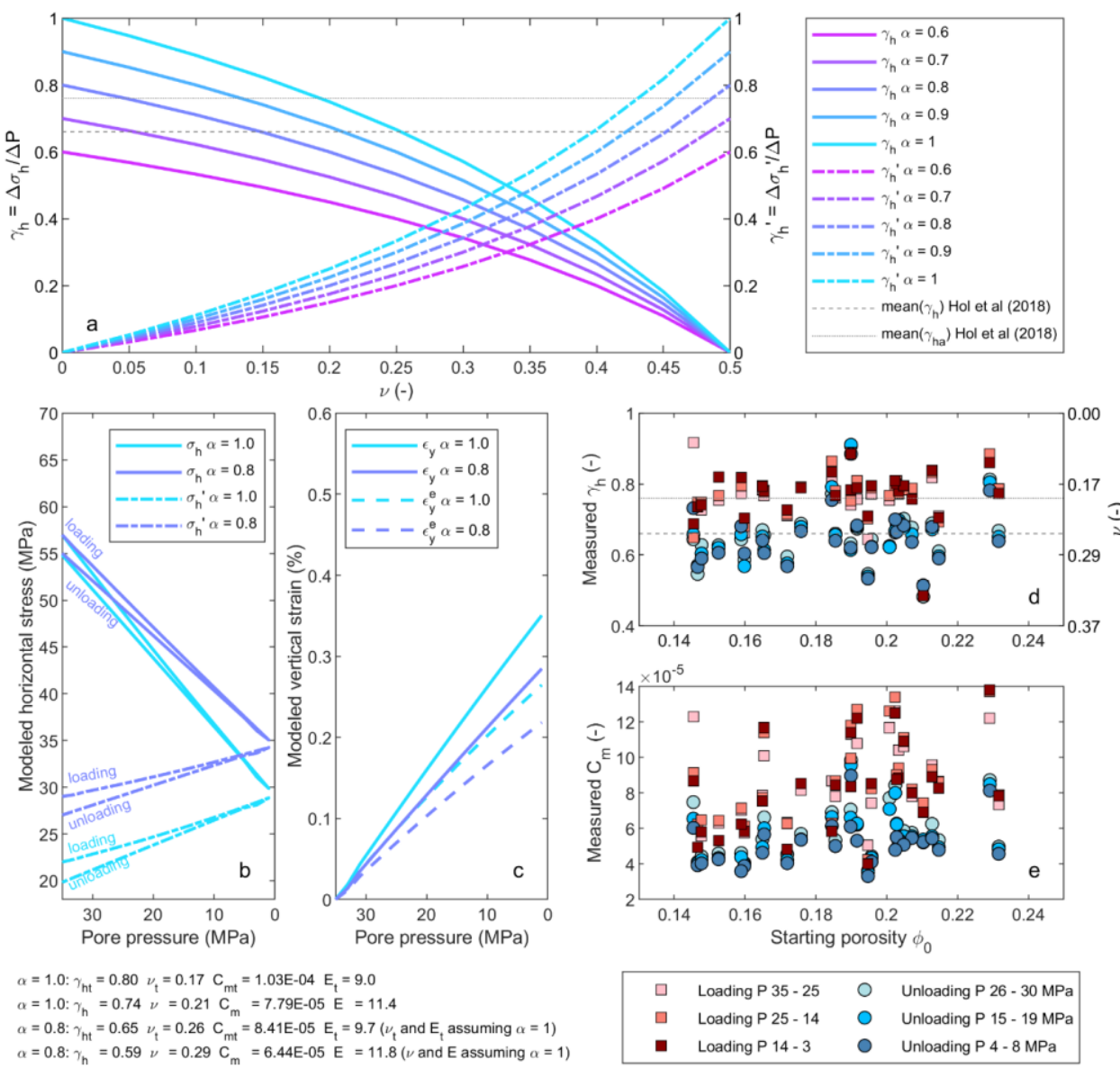

Figure 3-5. Stress path and compaction coefficient for uniaxial experiments and Modified Cam-Clay model under uniaxial conditions. a) Relation between Poisson's ratio $v$ and total and effective stress path parameters $\gamma_{h}$ and $\gamma_{h}$ ' for different Biot coefficients assuming poroelastic behavior. Dashed and dotted lines give the mean $\gamma_{\text {he }}$ measured during pressure increase (unloading, elastic deformation only) and mean apparent $\gamma_{h t}$ measured during pressure depletion (loading, elastic + plastic deformation) observed by Hol et al. (2018). Model results for horizontal stresses (b) and vertical strains (c) with pressure depletion and unloading for $\alpha=1.0$ and $\alpha=0.8(M=1.5, \kappa=0.0011, \lambda$ $=0.0015, v=0.21)$ and initial bulk modulus of 6 GPa. Effective horizontal stress in $b$ are shown as $\sigma_{h}{ }^{\prime}=\sigma_{h}-\alpha P$ (Biot, 1941). Initial stresses are applied as in the loading protocol by Hol et al. (2018). Values for linear fits of respectively the modeled $\gamma_{h}$ and uniaxial compaction coefficient $C_{m}$ are given in the text below $b$ and $c$ for loading (apparent) and unloading (true) curves. Calculated from these fits are apparent Poisson's ratio $v_{t}$ and Young's modulus $E_{t}$ and true elastic $v_{e}$ and $E_{e}$. For reference the elastic parameters assuming a Biot coefficient of 1.0 are also given, denoted by subscript $\alpha=1.0$. Measured $\gamma_{h}(d)$ and $C_{m p}(e)$ as a function of porosity, from various stages of pressure decrease or increase in Hol et al. (2018). The dashed and dotted grey lines give the mean values of experimentally determined $\gamma_{h}$ and $\gamma_{h}^{\prime}$ 'during unloading and loading, respectively. 


\section{2. 4. Model predictions of the effect of initial stress state and pore pressure reduction} on stress path and compressibility for a representative volume of reservoir sandstone

For a linear elastic material, the stress path and compressibility do not depend on the initial state of stress nor on the depletion pressure. However, in the case of an elastoplastic material, the stress-strain behavior is nonlinear. This results in changes in stress path and compressibility both with the initial state of stress and with ongoing depletion. In this section, I evaluate the effect of the initial mean effective stress $p_{i n i}$ ' and pore pressure reduction using the single element model. MCC behavior for the three porosity materials validated against the experimental results of Pijnenburg et al. (2019) (Figure 3-4) were used, with bulk modulus $K_{b}$ set to the same value at each $p_{i n i}$ ' by adjusting $p_{t e l}$, as well as the $21.5 \%$ MCC material with a constant $p_{\text {tel }}$ and hence a variable bulk modulus at each $p_{\text {ini }}$ ' (Table 3-1).

Table 3-1. Input parameters of the single element model used to evaluate the effect of initial mean effective stress and depletion pressure on the stress path and compresibility. Models are run for MCC behavior of three different porosities $(13.4 \%, 21.5 \%$, and $26.4 \%)$, with bulk modulus $K_{b}$ set to the given value in the table at each initial mean effective stress value evaluated by adjusting $p_{t e l}$, and one material for which $p_{\text {tel }}$ was instead kept constant so the bulk modulus varied with $p_{\text {ini }}$ '. $\Phi_{0}$ : initial porosity, E: Young's modulus, $v_{e}$ : Poisson's ratio of elastic part of the MCC model, $\rho$ : rock density, $\alpha$ : Biot coefficient, $M$ : slope of the critical state line, $\kappa$ : elastic hardening parameter, $\lambda$ : plastic hardening parameter, $K$ : bulk modulus (at give pressure shift $p_{\text {tel }}$ ), and $p_{\text {ini }}$ ': initial mean effective stress.

\begin{tabular}{l|l|l|l|l|l} 
& unit & MCC13 & MCC21 & MCC21 $\boldsymbol{p}_{\text {tel }} \mathbf{1 5}$ & MCC26 \\
\hline$\Phi_{0}$ & {$[\%]$} & 13.4 & 21.5 & 21.5 & \\
\hline $\mathrm{E}$ & {$[\mathrm{GPa}]$} & - & - & - & - \\
\hline$v_{\mathrm{e}}$ & {$[-]$} & 0.17 & 0.17 & 0.21 & 0.23 \\
\hline$\rho$ & {$\left[\mathrm{kgm}^{-3}\right]$} & 2600 & 2600 & 2600 & 2600 \\
\hline$\alpha$ & {$[-]$} & 1 & 1 & 1 & 1 \\
\hline $\mathrm{M}$ & {$[-]$} & 1.3 & 1.3 & 1.5 & 1.3 \\
\hline$\kappa$ & {$[-]$} & 0.0064 & 0.0115 & 0.0115 & 0.012 \\
$\lambda$ & {$[-]$} & 0.0053 & 0.0155 & 0.0155 & 0.016 \\
\hline K $\left(\mathrm{p}_{\text {tel }}\right)$ & {$[\mathrm{GPa}]$} & $9(\mathrm{var})$ & $6(\mathrm{var})$ & $3.3-5.2(15)$ & $4.5(\mathrm{var})$ \\
$\operatorname{p}_{\text {ini }}$, & {$[\mathrm{MPa}]$} & $15-32$ & $15-32$ & $15-32$ & $15-32$
\end{tabular}

The effect of the initial effective mean stress on the stress path and compressibility was investigated with the single-element model for depletion under uniaxial strain conditions . The pre-depletion radial stress was applied as in the UPPD loading protocol, but such that the vertical stress $\sigma_{y}$ was now $66 \mathrm{MPa}-$ i.e. a representative value for the Groningen field (van Eijs (2015) - and the total stress ratios $K_{0}\left(=\sigma_{h} / \sigma_{y}\right)$ were varied from 0.6 to 1 . These values correspond to initial mean effective stresses $p_{\text {ini }}$ ' of 15 to $32 \mathrm{MPa}$. Other parameters 


\section{Chapter 3}

were kept the same as in Section 2.3. Figure 3-6 shows the modeled apparent stress path parameter $\gamma_{h t}$ and corresponding $v_{t}(\alpha=1)$, as well as the apparent compressibility $C_{m p t}$. The stress path parameter increased nonlinearly with increasing initial mean stress, from 0.75 $\left(p_{\text {ini }}{ }^{\prime}=15 \mathrm{MPa}\right)$ to 0.84 ( $\left.p_{\text {ini }}{ }^{\prime}=32 \mathrm{MPa}\right)$. This was also noted by Pijnenburg et al. (2019) who found that the apparent stress path parameter increases with $p_{i n i}$ '. The increase of the stress path parameter was greatest for the highest porosity material. Results for the $21.5 \%$ porosity material also show that if the bulk modulus is not adjusted using pressure shift $p_{t e l}$ (Equation 3-7) so that the bulk modulus is the same at each $p_{\text {ini }}$, but instead $p_{\text {tel }}$ was kept at $15 \mathrm{MPa}(\mathrm{K}$ 3.3 - 5.2 GPa), the effect of the initial mean effective stress on the stress path parameter was even larger. Hence, the higher the initial mean effective stress, the higher the horizontal stress path parameter - which implies a more unstable stress path as the initial effective stress increases.

The effect of pressure change was similarly investigated with the single-element model. For a fixed value of $p_{i n i}$ ', the apparent stress path parameter decreased with depletion pressure $\triangle P$. The apparent stress path parameter determined at the final stage of depletion ( $\triangle P=-30$ to $-34 \mathrm{MPa}$ ) was $\sim 0.1-0.15$ lower than the stress path parameter determined at the initial stages of depletion ( $\triangle P=0$ to $-4 \mathrm{MPa}$ ) (Figure 3-6c). This decrease of the stress path parameter was similar for the different porosities and for the different initial mean effective stresses. The decrease in $\gamma_{h t}$ is also visible in the slightly concave-up trend of the uniaxial stress paths in Figure 3-4. So although the stress path increased with initial mean effective stress, it decreased during depletion. The latter effect is not obvious in the stress path parameters measured in the uniaxial compaction experiments on the Slochteren sandstone (Figure 3-5d). However, the scatter in the data is significant. Also, the experiments were performed on a sample that was taken from the field after a $\triangle P$ of $-25 \mathrm{MPa}$, so part of the plastic behavior during loading may have been removed.

The unloading stress path parameters do not change in the model result, as true Poisson's ratio $v_{e}$ was assumed constant (Figure 3-6a). The relative magnitude of the loading and unloading stress paths can therefore change as a function of $p_{i n i}$ ' and as a function of $\Delta P$, and the unloading stress path can be either larger (i.e. more unstable) or smaller than the loading stress path.

The model results also showed that the uniaxial compaction coefficient decreased with the initial mean effective stress, e.g. from $1.5 \cdot 10^{-4}$ to $1.4 \cdot 10^{-4} \mathrm{MPa}^{-1}$ for the $21.5 \%$ sample. For a constant $p_{\text {tel }}$ of $15 \mathrm{MPa}$ (i.e. $K 3.3-5.2 \mathrm{GPa}$ at $p_{\text {ini }}{ }^{\prime} 15-32 \mathrm{MPa}$ ) the decrease is more pronounced, from $1.9 \cdot 10^{-4}$ to $1 \cdot 10^{-4} \mathrm{MPa}^{-1}$. This underlines the importance of the assumed elastic parameters and elastic hardening relations. Though some elastic hardening is observed in the uniaxial experiments (Figure 3-5d), nonlinear hardening as in Equation 3-7 results in a too strong increase of $C_{m p t}$ with lower initial mean effective stress. For example, extrapolating the behavior at the stress conditions of the triaxial experiments towards the stresses in the uniaxial experiment without adjusting the initial $K$ through $p_{\text {tel }}$ yields a 
compressibility that is much higher than the compressibility measured at lower stresses in the uniaxial experiment. Uniaxial compressibility is largest for the $26.4 \%$ porosity material, and the modeled $C_{m p t}$ values are in agreement with the values measured in the uniaxial experiments (Figure 3-5e). The uniaxial compaction coefficient also decreased with progressive depletion. For the two lower porosities $13.4 \%$ and $21.5 \%$ the compaction coefficient determined at the end of depletion was 5 - $15 \%$ lower than at the initial stages of depletion (Figure 3-6d). For the higher porosity material the decrease in $C_{m p t}$ was larger with an almost $30 \%$ decrease at $p_{\text {ini }}{ }^{\prime}=16 \mathrm{MPa}$. With increasing initial mean effective stress, the decrease in $C_{m p t}$ with $\triangle P$ became less.
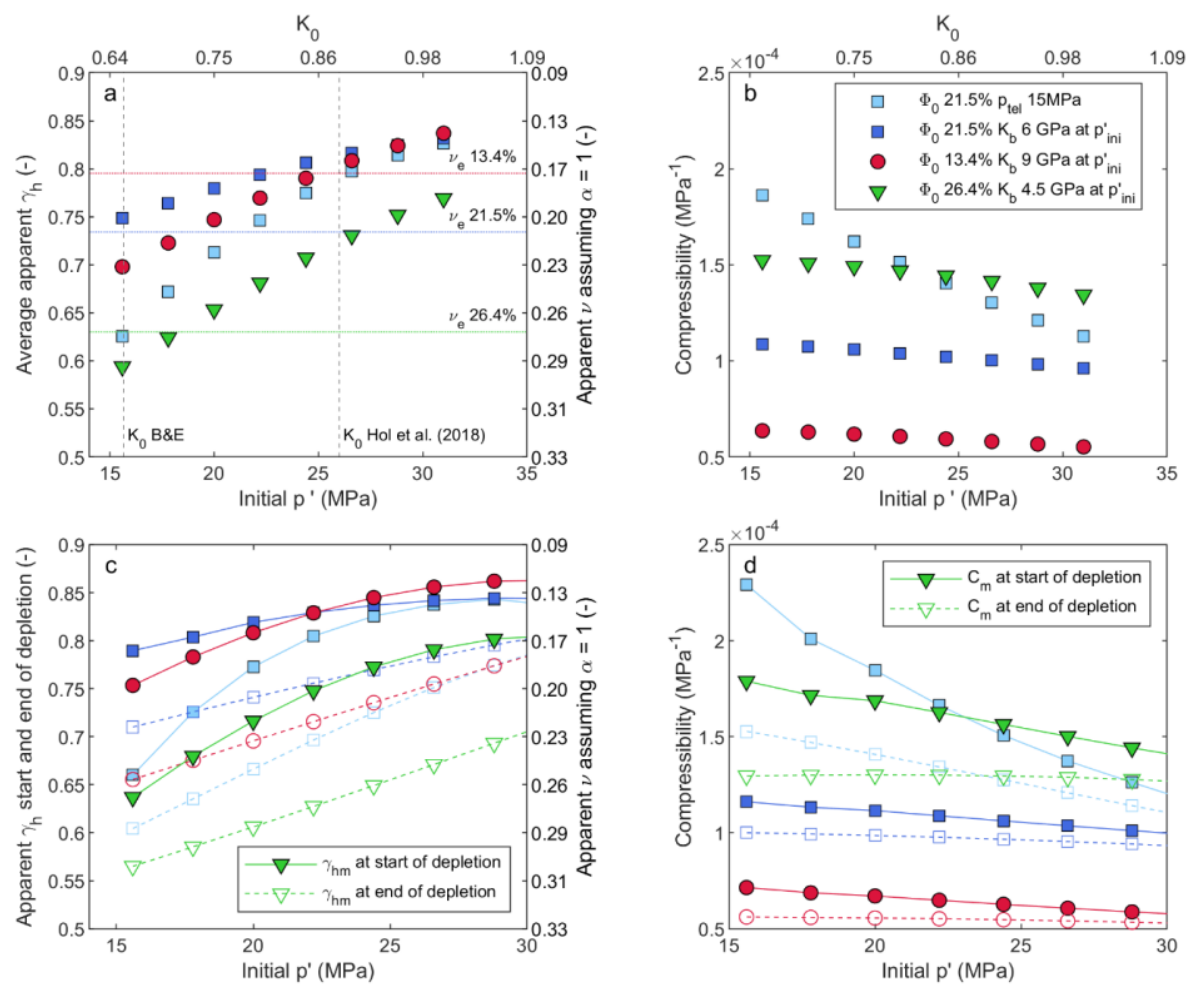

Figure 3-6. Effect of initial effective mean stress and depletion pressure on modeled stress path and compressibility for the present MCC elastoplastic constitutive model obtained here for Slochteren sandstone. a) Apparent $\gamma_{h t}$ obtained from linear fits of horizontal stress during simulated depletion $(\triangle P=0-35 \mathrm{MPa})$ under uniaxial conditions, against initial mean effective stress p' at the start of depletion. Symbols indicate the three porosities for which MCC parameters were determined on the basis of the experimental results of Pijnenburg et al. (2018). In the simulations represented by the light-blue squares, the bulk modulus also increased with p' as $p_{\text {tel }}$ was kept constant. Dotted lines show the unloading stress paths. Dashed lines show the initial stress states as used in the experiments by Hol et al. (2018) and in Van Breckels \& van Eekelen (1982) (B\&E). Legend is shown in b) which shows the apparent uniaxial compressibility $C_{m p t}$ obtained from linear fits of simulation results of vertical strain versus pressure change under uniaxial conditions for different porosity samples. c) Comparison of the stress path parameter determined during the early stages of simulated depletion ( $\triangle P=0$ to $-4 \mathrm{MPa}$, filled symbols) to the stress path parameter determined at the latest stages of depletion $(\triangle P=-30$ to $-34 \mathrm{MPa}$, open symbols). d) Comparison 
of the uniaxial compressibility determined during the early stages of depletion $(\triangle P=0$ to $-4 \mathrm{MPa}$, filled symbols) to the uniaxial compressibility determined at the latest stages of depletion ( $\triangle P=-30$ to $-34 \mathrm{MPa}$, open symbols).

\section{3. Field-scale model}

The effect of Modified Cam-Clay elastoplasticity on stress evolution and fault reactivation induced by depletion of generic portions of a Groningen-like reservoir was evaluated using an axisymmetric and a plane-strain model, employing the DIANA FEA v 10.3 package. In the following sections, the model geometry, the input parameters and modeling procedure used are described.

\section{3. 1. Model geometry}

Two simplified model geometries were used to analyze the effect of MCC elastoplastic behavior of the reservoir on depletion-induced stress changes on the field-scale, namely an axisymmetric model and a plane-strain model with a reservoir cross-cut by a fault (Figure 3-7). In the axisymmetric model, a disc-shaped reservoir was modeled, assuming a radius of $2000 \mathrm{~m}$ in the $\mathrm{x}$-direction, a thickness of $200 \mathrm{~m}$ and a depth to top of $-2800 \mathrm{~m}$ in the $\mathrm{y}$-direction. The total radius $W$ of the model was $16000 \mathrm{~m}$, and the model depth is $-6000 \mathrm{~m}$, measured from the free surface. In the plane-strain model two $200 \mathrm{~m}$ thick reservoir compartments offset by a normal fault were modeled. The reservoir in this model was also $200 \mathrm{~m}$ thick, with the footwall between -2800 and $3000 \mathrm{~m}$ depth. The footwall compartment is separated from the hanging wall compartment by a normal fault with a dip $\varphi$ of $70^{\circ}$ and a vertical offset of $50 \mathrm{~m}$ (1/4 the reservoir thickness). The width of the modeled region was $4000 \mathrm{~m}$, and the total height was $3800 \mathrm{~m}$, starting from -1200 to $-5000 \mathrm{~m}$ depth.

Within both models, the total vertical stress $\sigma_{y}$ at any depth below $-1200 \mathrm{~m}$ was computed from the weight of the formations present below this depth $\left(\rho=2400 \mathrm{kgm}^{-3}\right)$, with compressive stress taken as positive. For the axisymmetric model the density of the formation at depths below $-1200 \mathrm{~m}$ was adjusted to such that the vertical stress at the reservoir depth ($3000 \mathrm{~m}$ ) was $66 \mathrm{MPa}$, consistent with the average vertical stress gradient measured in Groningen (van Eijs, 2015). For the plane-strain model a stress load $\sigma_{t o p}$ was used to simulate the overburden stress $\sigma_{\text {top }}$ at $-1200 \mathrm{~m}$ depth, such that

$$
\sigma_{y}=-\rho g h+\sigma_{t o p}
$$

where $h$ is depth. As for the axisymmetric model, $\sigma_{\text {top }}$ was set such that the vertical stress at $3000 \mathrm{~m}$ was equal to $66 \mathrm{MPa}$. The total horizontal stress was imposed through the total stress ratio $K_{0}=\sigma_{y} / \sigma_{h}$. The pre-depletion or initial horizontal stress in Groningen is very uncertain (van Eijs, 2015). A lower-bound value of $K_{0}$ can be defined as the $K_{0}$ for which optimally oriented faults would be unstable, which would be 0.68 for a friction of 0.6 (e.g. Dempsey \& Suckale, 2017). Earlier reported values determined from leak-off tests in (Slochteren) 
sandstone formations in wells in various onshore fields in the Netherlands indicate minimum horizontal stresses in sandstone formations at depths between -2800 and $-3000 \mathrm{~m}$ in the range 48 - $54 \mathrm{MPa}$ (Breckels \& Van Eekelen, 1982; van Wees et al., 2014), which translates into initial stress ratios of 0.72 to 0.82 . A value of $43 \mathrm{MPa}\left(K_{0}=0.66\right)$ was used by Hettema et al. (2000) which would imply critically stressed faults at the start of depletion. However, most of the stress data may have been wrongly interpreted or are from different lithological units (van Eijs, 2015). Here I assumed a value of 0.72, noting that the uncertainties in $K_{0}$ are large. In this study I am primarily interested in the differences between elastoplasticity and linear elastic behavior, which should be apparent at any initial stress state. The pressure changes in the model were one-way coupled to the mechanical behavior as the gas is compressible (i.e. pore pressure changes affect the stresses, but the resulting strains do not affect the pore pressure). Pore pressure prescribed in the overburden was hydrostatic with a saline water density of $1150 \mathrm{kgm}^{-3}$. Inside the reservoir a vertical gas pressure gradient was prescribed assuming a gas density of $150 \mathrm{kgm}^{-3}$ and a reservoir pressure of $35 \mathrm{MPa}$ at $-3000 \mathrm{~m}$ depth, which resulted in an overpressure of $1.2 \mathrm{MPa}$ at $-3000 \mathrm{~m}$ depth with respect to the saline gradient. Such overpressures are commonly observed in gas fields in the northern Netherlands (Verweij et al., 2012). During depletion, a uniform pressure change of $\triangle P$ was prescribed in the reservoir - i.e. depletion and gas flow were not modeled explicitly and pressure change was one-way coupled to the mechanical response. This is consistent with the fact that most faults appear to be permeable as a rather uniform reservoir pressure change observed thoughout the Groningen field (NAM, 2016a), For the plane-strain model, the reservoir pressure was assigned to fault elements adjacent to one or both of the reservoir compartments, and pressure depletion of the fault was the same as in the reservoir compartments (permeable fault). The formations surrounding the reservoir were assumed to be impermeable. The behavior of the reservoir formation was modeled with the Modified Cam-Clay model as validated above against results from experiments on the Slochteren sandstone (Section 3. 2. ). Here I investigate the effects of the MCC model on the field-scale behavior for the three different porosity sandstones. Alternatively, apparent elastic behavior could be prescribed, using an apparent Young's modulus and Poisson's ratio (LinElasApp, Table 1) determined from linear fits to the apparent stress path $\gamma_{h t}$ and compressibility $C_{m t}$ exhibited by the MCC model when applied to a single-element uniaxial model at an initial state of stress corresponding to the initial mean effective stress $p_{\text {ini }}$ ' of $19 \mathrm{MPa}$ that is used in the field-scale model (cf. Figure $3-5 b$ and c). For the $21.5 \%$ porosity material also a comparison was made between MCC and linear elasticity with true elastic properties (LinElasTrue), which are the Poisson's ratio used in the MCC model and the Young's modulus recalculated from the Poisson's ratio and initial bulk modulus $K$. The formations surrounding the reservoir were assumed to have uniform linear elastic properties (LinElas, Table 3-2) and to be stiffer than the reservoir rock (Filippidou et al., 2019). For convenience I took the Biot coefficient to be 1.0 as for the present study I am not specifically interested in the onset of fault reactivation. 


\section{Chapter 3}

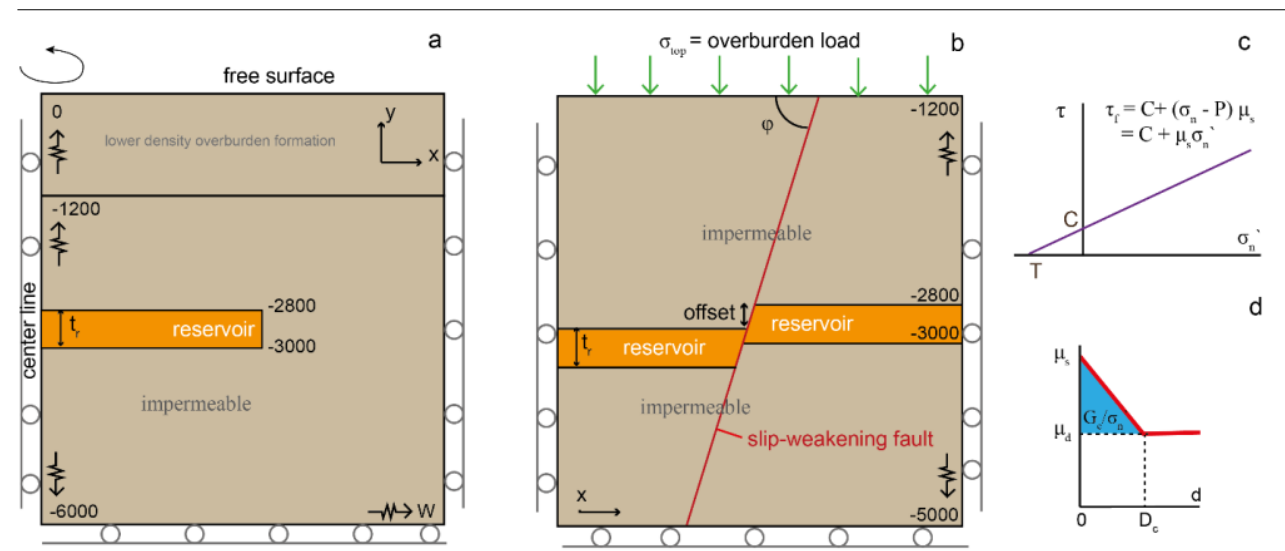

Figure 3-7. Model geometry for field-scale models. a) Axisymmetric model, b) Plane-strain model with a reservoir formation cross-cut by a normal fault. The vertical offset along this fault can be varied but is set here at $50 \mathrm{~m}$. Roller boundaries are imposed along the base and sides of both the axisymmetric and plane-strain model allowing motion in respectively the horizontal and vertical direction only. In the plane-strain model the weight of the overburden formation was simulated using a stress load $\sigma_{\text {top. }}$ ) Mohr-Coulomb criterion for the onset of plastic slip on the fault, with failure stress $\tau_{f}$, which is the effective normal stress $\sigma_{n}{ }^{\prime}\left(=\sigma_{n}-P\right)$ multiplied with the static friction coefficient $\mu_{s}$ plus cohesion $C$ (assumed zero in current models). d) Linear slip-weakening diagram showing the evolution of the friction coefficient with plastic shear displacement on the fault, with dynamic friction $\mu_{d}$, slip-weakening distance $D_{c}$, slip $d$, and fracture energy $G_{c}$.

Table 3-2. Input parameters of the field-scale models for the reservoir and the surrounding formations. MCC and the corresponding apparent linear elastic (LinElasApp) properties are prescribed to the reservoir, for three different porosities $(13.4 \%, 21.5 \%$, and $26.4 \%)$. Linear elasticity (LinElas) is prescribed to all of the surrounding formations.

\begin{tabular}{|c|c|c|c|c|c|c|c|c|c|}
\hline & unit & LinElas & MCC13 & МCC 21 & МСС26 & $\begin{array}{l}\text { LinElasA } \\
\text { pp13 }\end{array}$ & $\begin{array}{l}\text { LinElas- } \\
\text { App21 }\end{array}$ & $\begin{array}{l}\text { LinElas- } \\
\text { App26 }\end{array}$ & $\begin{array}{l}\text { LinElas- } \\
\text { True } 21\end{array}$ \\
\hline $\mathrm{E}$ & [GPa] & 25 & - & - & - & 14.2 & 8.5 & 5.4 & 10.2 \\
\hline$v$ & {$[-]$} & 0.25 & 0.17 & 0.21 & 0.23 & 0.21 & 0.18 & 0.27 & 0.21 \\
\hline$\rho$ & {$\left[\begin{array}{c}{\left[\mathrm{kgm}^{-}\right.} \\
3\end{array}\right]$} & 2600 & 2600 & 2600 & 2600 & 2600 & 2600 & 2600 & 2600 \\
\hline$\alpha$ & {$[-]$} & 1 & 1 & 1 & 1 & 1 & 1 & 1 & 1 \\
\hline M & {$[-]$} & - & 1.3 & 1.5 & 1.3 & - & - & - & - \\
\hline$\kappa$ & {$[-]$} & - & 0.0064 & 0.0115 & 0.012 & - & - & - & - \\
\hline$\lambda$ & {$[-]$} & - & 0.0053 & 0.0155 & 0.016 & - & - & - & - \\
\hline $\mathrm{K}\left(@ \mathrm{p}_{\mathrm{ini}}{ }^{\prime}\right)$ & [GPa] & & 9 & 6 & 4.5 & - & - & - & - \\
\hline
\end{tabular}


Fault strength in the plane-strain model was governed by Mohr-Coulomb friction (Figure 3-7c) with a static friction coefficient $\mu_{s}$ of 0.6 and a cohesion $C$ of $0 \mathrm{MPa}$. The postfailure behavior was controlled by linear slip-weakening, with a dynamic friction coefficient of 0.45 , and a slip-weakening distance of $0.01 \mathrm{~m}$. Further sensitivities to the friction behavior will be addressed in Chapter 6.

\section{3. 2. Mesh size and modeling procedure}

The formations were modeled with an unstructured mesh composed of linear quadrilateral and triangular axisymmetric (Q8AXI, T6AXI) or plane-strain (Q8EPS, T6EPS) elements (see DIANA v10.3 Manual). In the axisymmetric model, the cell size in the reservoir is $5 \mathrm{~m}$, coarsening up to $200 \mathrm{~m}$ outside of the reservoir. In the plane-strain model the fault was modeled with line interface elements (LI8F, see DIANA User Manual v10.3, Buijze et al., 2019). Normal and shear stiffness of these interface elements were set to be equivalent to the Young's modulus and shear modulus of the reservoir. The element size of the fault segments within the reservoir was $0.75 \mathrm{~m}$, small enough for the critical nucleation zone size length $L_{c}$ to include at least 15 elements (see also Chapter 2). The critical nucleation zone length $L_{c}$ is the length of the fault that must be slipping aseismically before the onset of seismic instability. It is written as a function of shear modulus $G$, effective normal stress and fault weakening properties (Uenishi \& Rice, 2003) as

$$
L_{c}=1.158 G D_{c} /\left(\sigma_{n}{ }^{\prime}\left(\mu_{s}-\mu_{d}\right)\right.
$$

and for an effective normal stress of $20 \mathrm{MPa}$ takes a value of $10-15 \mathrm{~m}$ in the current model. Outside the reservoir, the fault elements coarsened gradually to a size of $10 \mathrm{~m}$ on the fault segments in the other formations. The element size in the reservoir coarsened from $0.75 \mathrm{~m}$, adjacent to the fault, to a maximum of $10 \mathrm{~m}$ at the reservoir edges, whereas outside the reservoir a maximum element size of $75 \mathrm{~m}$ was prescribed.

The modeling procedure consisted of two (axisymmetric) or three (plane-strain model) phases: stress initialization, a quasi-static phase, and a fully dynamic phase (planestrain model only). During initialization of the stress, MCC behavior of the porosity of interest was prescribed to all formations to ensure a uniform initial state of stress throughout the model, and to ensure a consistent initial state for the MCC in the reservoir. Strains and displacements generated during the initialization phase were disregarded in later phases, so that only the strains generated from the start of depletion were considered. In the subsequent quasi-static phase, either MCC or the corresponding apparent linear elastic behavior (LinElasApp) was prescribed to the reservoir for the porosity of interest, whereas uniform linear elastic behavior (LinElas) was prescribed to the formations surrounding the reservoir. Reservoir depletion was simulated by imposing a uniform pressure decrease throughout the reservoir and the resulting stresses and strains were computed using a Newton-Rhapson solver. In the plane-strain model, the stress changes on the fault elements could result in fault reactivation and subsequent dynamic rupture. When the fault was reactivated, part of the fault 
started to slip aseismically. As this slip patch on the fault increased in size, the step size of the pressure change was decreased automatically based on the number of iterations required for convergence, with a tolerance for convergence between the relative imbalance of the internal forces that was set to $10^{-9}$. When convergence could no longer be achieved, divergence occurred (see e.g. Buijze et al., 2019). This signified the onset of the nucleation of dynamic instability, i.e. the slip zone could continue to grow spontaneously without further loading. At this point, the analysis was switched to a fully dynamic analysis and the evolution of dynamic rupture with time is computed using time steps of $1 \mathrm{~ms}$. Rayleigh damping was used to suppress high frequency numerical noise during the dynamic phase (see also Buijze et al., 2019).

\section{3. 3. Data processing and output parameter definition}

To describe the stress response to pressure depletion, I make use of the horizontal stress path parameter $\gamma_{h}$ (Equation 3-17) and vertical compressibility $C_{m p}$ (Equation 3-18) data, obtained from linear fits of the horizontal stress and vertical strain changes with pressure change as modeled by the FE model, at various locations throughout the model space. In addition, I use the vertical stress path parameter

$$
\gamma_{v}=\frac{\Delta \sigma_{v}}{\Delta P}
$$

The criticality of the fault stresses is expressed through the Shear Capacity Utilization parameter ( $S C U)$, which is defined as

$$
S C U=\frac{\tau}{\tau_{f}}=\frac{\tau}{\mu_{s} \sigma_{n}^{\prime}+C}
$$

An SCU of 1 or -1 signifies a fault element has reached its failure strength and will slip plastically in respectively the normal or reverse direction. Fault shear slip is defined as the relative plastic shear displacement occurring on the fault in the fault dip direction (normal motion is positive). Slip rate is the derivative of the fault shear slip with time and gives the relative material velocity measured across the fault in the fault dip direction.

\section{4. Field-scale results}

\section{4. 1. Quasi-static stress changes in the axisymmetric model: MCC and linear elasticity}

Stress changes and strains induced by reservoir depletion are computed for a reservoir with MCC elastoplastic properties (MCC 21.5\% porosity), a reservoir with apparent linear elastic properties, and a reservoir with true linear elastic properties (LinElasApp21 and LinElasTrue21). As in the experiments on the Slochteren sandstone, against which the MCC model was calibrated, plastic strains occur over the entire depletion range and amount to $50 \%$ of the total strain. The modeled stresses and strains obtained using the MCC21 and apparent elasticity material descriptions are nearly identical (Figure 3-8). For both material models, 
the vertical stress parameter $\gamma_{v}$ in the reservoir center is 0.07 . Hence, for this reservoir geometry the uniaxial strain conditions do not fully apply; within the reservoir $\gamma_{v}$ will decrease for a lower aspect ratio (height/width), and/or for more compliant surroundings, eventually reaching 0 (e.g. Geertsma, 1973; Mulders, 2003; Soltanzadeh \& Hawkes, 2009). At the reservoir edge, the value of $\gamma_{v}$ decreases gradually to -0.6. Outside the reservoir, the vertical stress path parameter increases abruptly to 0.6 as vertical stress is transferred to the surroundings due to stress arching as depletion proceeds. The horizontal stress path parameter in the center of the reservoir is 0.79 , and decreases gradually across the edge of the reservoir, tending to zero at 500-1000 m outside of the reservoir.

Even though stresses are concentrated near the reservoir ends, there is little difference between results obtained using LinElasApp and MCC properties for the reservoir. For both models the $p^{\prime}$ and $q$ values obtained just outside the reservoir are 21 and $49 \mathrm{MPa}$. Inside of the reservoir the maximum $p$ 'and $q$ are $41 \mathrm{MPa}$ and $35 \mathrm{MPa}$ respectively for both models which is far from the critical state line (see Figure 3-4b). Hence, no shear failure is expected for MCC, and the behavior is still near-linear as in the single-element uniaxial strain models (e.g. Figure 3-5b and c). Using the true elastic parameters LinElasTrue21 for the reservoir gives a different response compared to both the apparent elastic LinElasApp21 and MCC21 behavior. The horizontal stress parameter is slightly lower due to the higher true Poisson's ratio of 0.21 with respect to the apparent value of 0.19 . In particular the compressibility is much lower due to the higher Young's modulus of the true elastic material (11.6 GPa vs apparent 8.5 GPa). Hence using the true elastic properties for the reservoir would underestimate the amount of compaction with respect to the MCC behavior or the corresponding apparent elastic behavior (Figure 3-8d). In addition, the vertical stress transfer to the formation adjacent to the reservoir (Figure 3-8a) occurred for LinElasTrue, as the amount of compaction is less. 

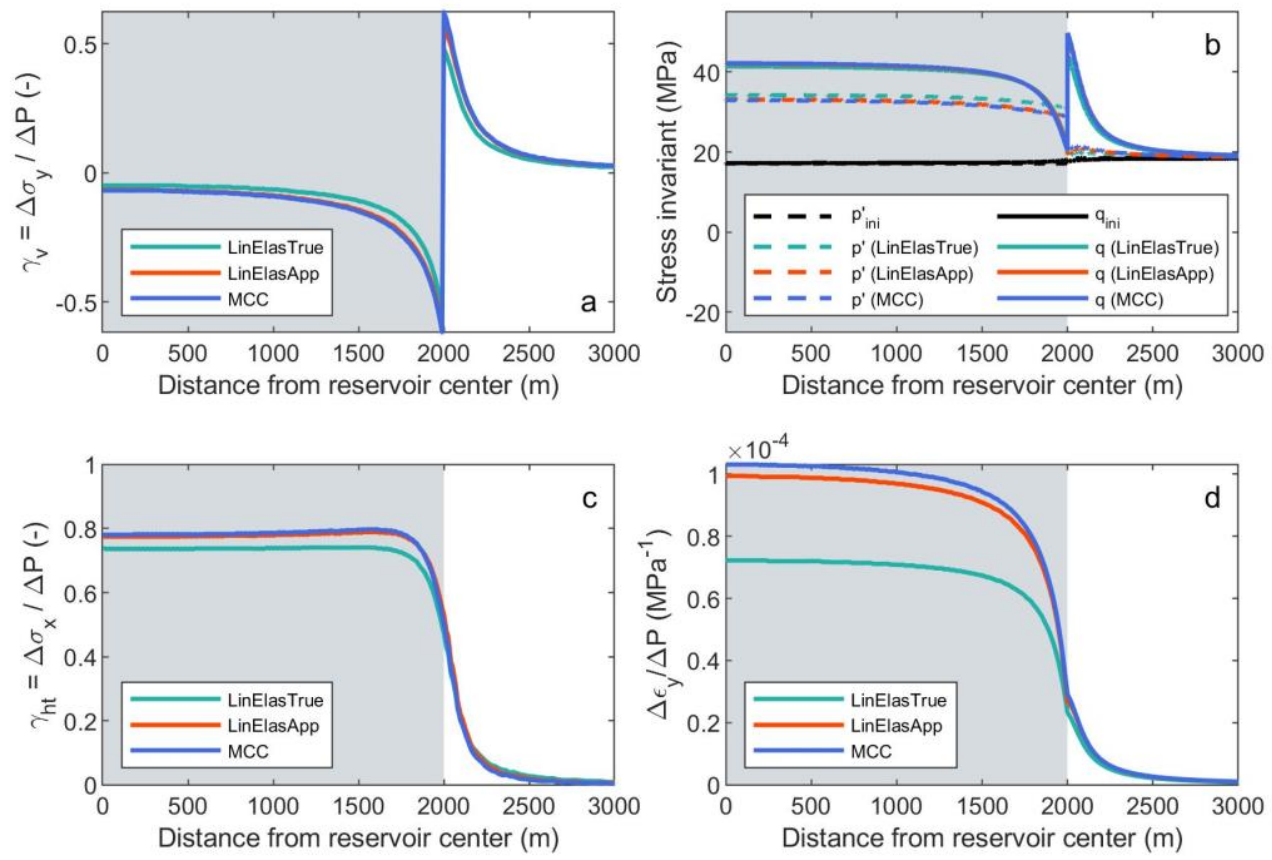

Figure 3-8. Stress changes along the centerline (2900 $\mathrm{m}$ depth) of the axisymmetric reservoir model. The gray area indicates the horizontal extent of the reservoir. Results are compared for models run using elastoplastic (MCC21), apparent linear elastic (LinElasApp21), and true linear elastic (LinElasTrue21) behavior of the reservoir.

\section{4. 2. Stress changes and fault reactivation due to compaction of a faulted reservoir}

The stress changes developing along the fault in the plane-strain model configuration are now considered for elastoplastic versus apparent linear elastic reservoir properties. In Figure 9, the on-fault results obtained for the three porosities using the MCC13, MCC21, and MCC26 constitutive model are shown, as well as the results for a reservoir with apparent linear elastic properties for the $21.5 \%$ porosity material (LinElasApp21). As shown in a number of previous studies (e.g. Buijze, van den Bogert et al., 2019; Buijze et al., 2017; Haug et al., 2018; Mulders, 2003; van Wees et al., 2019; Zbinden et al., 2017), depletion of offset reservoir compartments results in normal and shear stress concentrations developing at the top of the hanging wall and at the base of the footwall (Figure 3-9a and b), while shear stress minima develop at the top of the footwall and base of the hanging wall (Figure 3-9b). The net result of these stress changes is that maxima in $S C U$ (Equation 3-22) appear at the top of the hanging wall and at the base of the footwall, resulting in fault reactivation at these two locations after $7 \mathrm{MPa}$ of depletion (Figure 3-9d). As the two reactivated slip zones expand with on-going depletion, 3-4 mm of plastic slip occurs (Figure 3-9c). The critical nucleation length (Equation 3-21) is first attained by the shallower slip zone. The critical nucleation length was found to be larger for the MCC21 reservoir $(26 \mathrm{~m})$ than for the linear elastic reservoir $(17 \mathrm{~m})$. Simultaneously the amount of aseismic slip was also larger for the MCC21 
reservoir $(3.7 \mathrm{~mm})$ than for the linear elastic reservoir $(2.2 \mathrm{~mm})$. Despite the larger nucleation length, the MCC21 reservoir model led to nucleation at slightly lower $\Delta P$ values than the LinElas 21 model $(\triangle P=-8.5 \mathrm{vs}-8.8 \mathrm{MPa})$. The difference may be due to the slightly nonlinear behavior of the MCC reservoir material, as we are looking at only the first $9 \mathrm{MPa}$ of depletion. In this range, discrepancies can arise between the MCC reservoir and the apparent linear elastic reservoir because the properties of the latter are averaged over the entire depletion range $(\triangle P=35 \mathrm{MPa})$. During the first stages of depletion the stress path parameter will be larger than the average value over the full depletion range (Figure 3-6)

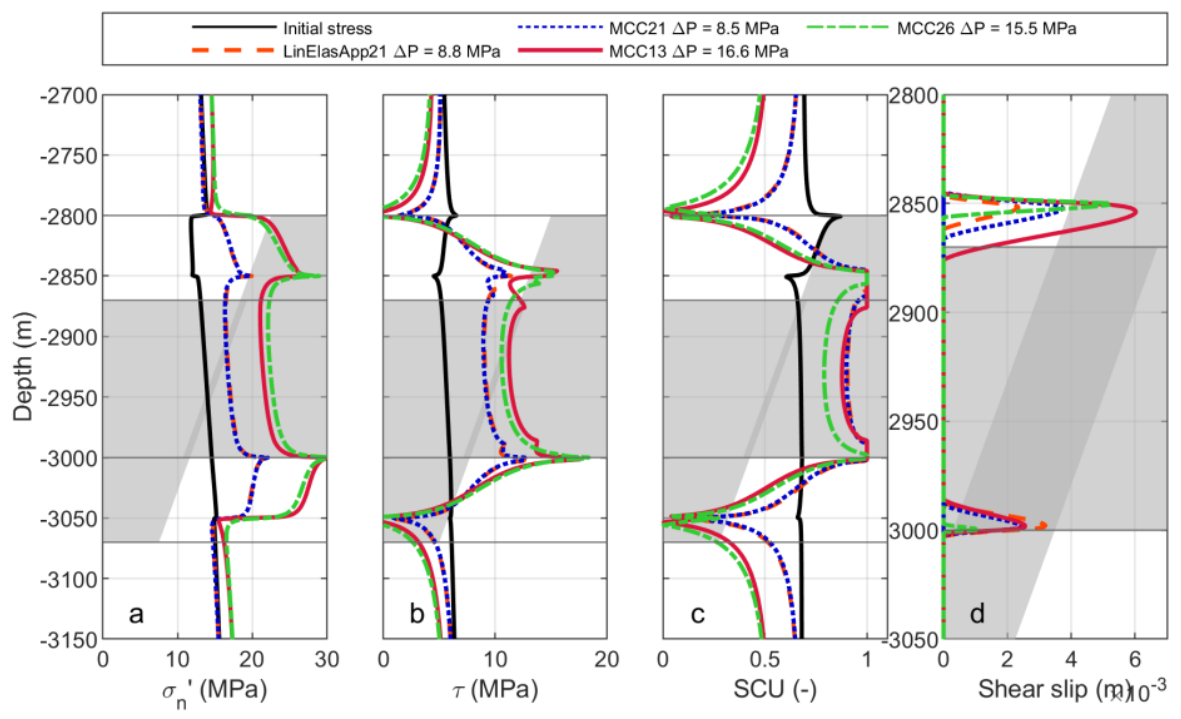

Figure 3-9. Stresses computed along a fault offsetting two equally depleting reservoir compartments. Results are shown for the pre-depletion state of stress and the stress at nucleation of instability, for a reservoir with MCC elastoplasticity for three different porosities (red line: $13.4 \%$, blue dotted line: $21.5 \%$ green line: $26.4 \%$ ). For the $21.5 \%$ porosity reservoir also the results for a linear elastic reservoir with apparent elastic parameters (LinElasApp21) are shown. The depth ranges of the reservoir compartments in the hanging wall and footwall are indicated by the gray areas. a) Effective normal stress, b) shear stress, c) ) shear capacity SCU, and d) plastic shear slip, as a function of depth along the fault.

For the other reservoir porosities considered (MCC13 \& MCC26), the stress distribution is similar to that obtained for MCC21, but reactivation requires a larger $\triangle P$ (Figure 3-9). For these porosities, the apparent Poisson ratios of $0.21\left(\Phi_{0}=13.4 \%\right)$ and 0.27 $\left(\Phi_{0}=26.4 \%\right)$ are larger than for the $21.5 \%$ porosity reservoir, so that the apparent horizontal stress path $\gamma_{t h}$ is more stable (Figure 3-6a). Indeed, for these porosities, nucleation of dynamic instability occurs at a $\triangle P$ value of respectively $-16.6 \mathrm{MPa}$ and $-15.5 \mathrm{MPa}$, instead of -8.5 $\mathrm{MPa}$ as in the $21 \%$ porosity case. However, contrary to what is expected from the lower Poisson's ratio of the $13.4 \%$ porosity reservoir rock relative to the $26.4 \%$ porosity reservoir 
rock, nucleation of instability occurs at lower $\Delta P$ for the $26.4 \%$ reservoir than for the $13.4 \%$ reservoir. This is because the nucleation length is lower for the $26.4 \%$ porosity reservoir (10 $\mathrm{m})$ than for the $13.4 \%$ porosity reservoir $(30 \mathrm{~m}$ ) (Figure $3-8 \mathrm{~d}$ ). The difference in nucleation lengths is caused mainly by a lower shear modulus related to the $26.4 \%$ reservoir ( $3 \mathrm{GPa}$ at $\left.\mathrm{p}_{\text {ini }}{ }^{\prime}\right)$ compared to the $13.4 \%$ reservoir ( $7.6 \mathrm{GPa}$ at $\mathrm{p}_{\text {ini }}$ ') (Equation 3-20). Note further that for the $26.4 \%$ porosity reservoir rock, the normal and shear stress concentrations are stronger and deformation is more localized than for the $13.4 \%$ porosity reservoir rock (Figure 3-8a and $b$ ). This is the result of the increased compressibility of the $26.4 \%$ porosity reservoir (Figure $3-6 b$ ) relative to the $13.4 \%$ porosity reservoir, which causes a larger vertical strain and differential displacement across the fault and thus larger and more spatially constricted stress concentrations. At the pressure change at which nucleation of instability occurs, the difference in $S C U$ in the nucleation area w.r.t. the rest of the fault is larger for the $26.4 \%$ porosity reservoir than in the reservoirs with $13.4 \%$ and $26.4 \%$ porosity (Figure $3-8 \mathrm{~d}$ ). This difference in stress state may affect the subsequent dynamic rupture.

\section{4. 3. Comparison of rupture length, slip and slip rates from dynamic rupture models} with elastoplastic and apparent linear elastic reservoir

In this section, I present the results for the fully dynamic calculation of rupture (following nucleation of instability as presented in the previous section) for a reservoir with MCC elastoplastic properties representative of reservoir rocks with $13.4 \%, 21.5 \%$ and $26.4 \%$ porosity, as well as for a reservoir with the corresponding apparent elastic properties. To eliminate the effect of small stress differences resulting from the different nucleation lengths obtained for the MCC vs. LinElasApp constitutive models, both the simulations with the MCC reservoir and a LinElasApp reservoir start with the stress field obtained using the MCC model. The simulation results show that the rupture starts to expand from the nucleation zone at the top of the hanging wall, and propagates down-dip along the reservoir interval. Updip propagation does not occur because of the low shear stresses that form at the top of the footwall during depletion (Figure 3-9b). Using both the linear elastic and elastoplastic reservoir model, rupture propagates to a depth of $-3050 \mathrm{~m}$ where it is arrested (Figure 3-10a, c, e). Arrest occurs because the rupture enters a region of stable stress (low $S C U$ ) at the base of the reservoir (Figure 3-9d). 

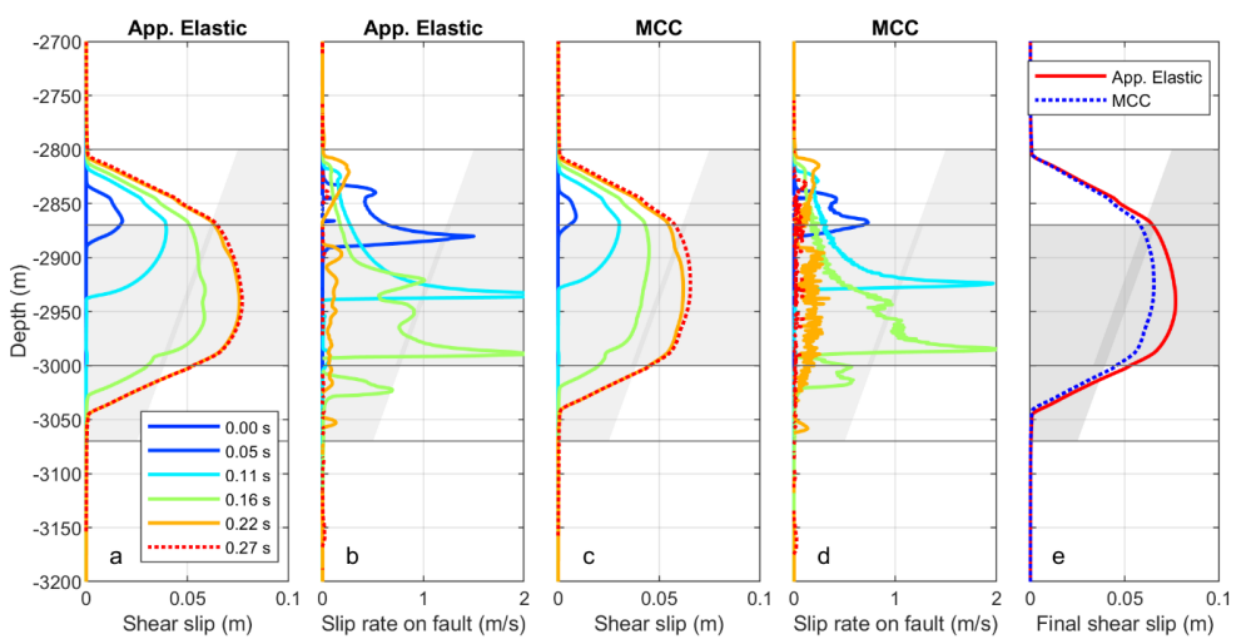

Figure 3-10. On-fault slip and slip rate computed in simulations of dynamic rupture with a $21.5 \%$ porosity reservoir (MCC21) and corresponding apparent linear elastic reservoir (LinElasApp21). Slip and slip rate distributions along the fault are shown at specific points in time. The depth ranges of the reservoir compartments in the hanging wall and footwall are indicated by the gray areas. (a) Slip and (b) slip rate distribution with time along the fault for an apparent linear elastic reservoir. (c) Slip and (d) slip rate distribution with time along the fault for an elastoplastic reservoir. e) Final shear slip distribution for LinElasApp and MCC.

MCC elastoplasticity of the reservoir rock results in $10-20 \%$ less dynamic shear slip compared with the corresponding linear elastic reservoir for all three porosity materials (Figure 3-10e, Figure 3-11b). This difference in slip is manifested along the segment of the fault where reservoir rock is juxtaposed against reservoir rock - i.e. where the medium on both sides of the fault is sandstone which is governed by MCC elastoplasticity (Figure 3-10e). Along the fault segments, where the reservoir is juxtaposed against the linear elastic overburden ( -2800 to $-2850 \mathrm{~m}$ ) or underburden $(-3000$ to $-3050 \mathrm{~m})$, the amount of slip is comparable for both models. The rupture length using the $21.5 \%$ porosity reservoir rock is the same for both material models. As mentioned in the previous paragraph, arrest of rupture is determined by the stress lows at the base of the footwall and top of the hanging wall (Figure $3-9 d)$. This is not always the case; for the $13.4 \%$ porosity reservoir rock rupture also arrests at the top and base of the reservoir compartments, but for the $26.4 \%$ reservoir rupture arrests within the reservoir depth interval (Figure 3-11a), because the relatively low depletioninduced stress (low $S C U$ ) in the center of the reservoir is lower than for the other porosity reservoir rocks (Figure 3-9d). Once rupture is arrested in a region with more uniform stresses within the reservoir (as opposed to the strong stress concentrations at the bottom and top of the reservoir), MCC elastoplasticity causes both a reduction in total dynamic shear slip and in rupture length (Figure 3-11a and b). MCC elastoplasticity in the reservoir also reduces the maximum slip rate (Figure 3-11c) and the rupture velocity (Figure 3-11d, i.e. propagation velocity of the rupture front) with respect to the linear elastic behavior. Rupture velocity is markedly low for the $26.4 \%$ porosity reservoir rock; this may be related to the lower stresses 
in the reservoir depth interval. Once rupture starts to propagate outside of the nucleation zone, it enters a region with relatively low stress (low $S C U$ ) and starts to decelerate. For the other porosities, the $S C U$ is higher in the reservoir depth interval and rupture does not decelerate until it has propagated across the full reservoir depth interval. To summarize, elastoplastic behavior of the reservoir thus results in smaller and less 'violent' earthquakes compared with a linear elastic reservoir. For the higher porosity reservoir rock of $26.4 \%$, smaller and slower ruptures were observed compared to the $13.4 \%$ and $21.5 \%$ porosity rocks.
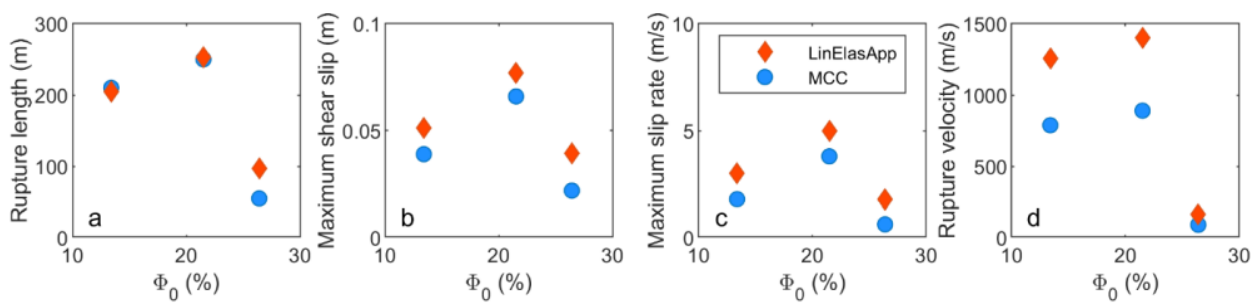

Figure 3-11. Dynamic rupture characteristics obtained in the simulations performed using elastoplastic reservoir properties versus apparent linear elastic reservoir properties, for the different reservoir rock porosities considered. a) Rupture length b) Maximum shear slip, c) Maximum slip rate attained during rupture, and d) rupture velocity recorded between -2880 and -2920 m depth.

Figure 12 shows the evolution of coseismic stresses and strain changes in the hanging wall, $5 \mathrm{~m}$ from the fault obtained during dynamic rupture, shown now for the simulation with a $13.4 \%$ porosity reservoir. Near the nucleation zone, i.e. at the top of the hanging wall, the mean effective stress and the differential stress decrease (Figure 12a). Correspondingly, the shear strain decreases during the first $0.15 \mathrm{~s}$ of rupture, but subsequently increases to $8 \cdot 10^{-4}$ during the remainder of rupture (Figure $12 \mathrm{~b}$ ). Since the stresses decrease, the shear strain change at this location is fully elastic. In the center of the reservoir at -2925 $m$ depth (i.e. in the footwall block) both the mean effective stress and differential stress increases as the rupture front arrives, with $p$ ' changing from 26.9 to a maximum of $28.2 \mathrm{MPa}$, and $q$ from 30 to $31 \mathrm{MPa}$ (Figure 12a). Concurrently, the shear strain decreases and the volumetric strain increases during the first $0.1 \mathrm{~s}$ related to the approach of the rupture front, but decreases rapidly after $0.1 \mathrm{~s}$, indicative of the rupture passing by and lowering part of the stored shear strain. Plastic shear strain only increases by $1 \cdot 10^{-5}$ due to the passage of the rupture front, but volumetric strain increases by $5 \cdot 10^{-5}$, almost half of the maximum total volumetric strain change. After $0.15 \mathrm{~s}$, part of the elastic shear strain decrease and volumetric strain increase at $-2925 \mathrm{~m}$ depth is recovered (total strain change here reflects elastic strain change as there are no plastic strain changes), which is reflected in a decrease in mean effective stress and differential stress. The stresses did not become more critical (i.e. closer to the CSL) during rupture. 

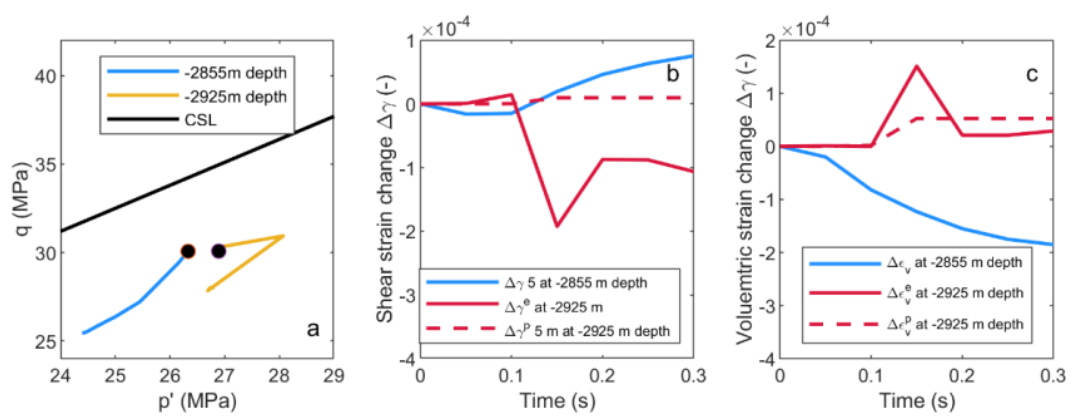

Figure 3-12 Coseismic stresses and strain changes during rupture on the $13.4 \%$ porosity reservoir rock. Both stress paths and strain curves are taken in the hanging wall, at $5 \mathrm{~m}$ horizontally from the nucleation zone at -2855 $\mathrm{m}$ depth, and $5 \mathrm{~m}$ horizontally from the fault at $-2925 \mathrm{~m}$ depth. a) Evolution of mean effective stress $p$ ' against differential stress q' with time. The black dot depicts the initial state. b) Shear strain change with time. Solid lines are total strain changes, dashed line gives the plastic shear strain change. There is no plastic shear or volumetric strain change near the nucleation zone as the stress decreases.

\section{5. Discussion \& Implications}

In this study, the compaction behavior of the Slochteren sandstone (i.e. the reservoir rock of the Groningen field) has been modeled using Modified Cam-Clay (MCC) elastoplasticity (Roscoe et al., 1958; Roscoe \& Burland, 1968). The MCC model was fitted to and validated against both triaxal and uniaxial experiments using a single-element $\mathrm{FE}$ model. Field-scale FE model simulations showed that the MCC elastoplasticity model thus obtained could be approximated with linear elastic behavior with apparent elastic properties, in the stress range relevant to production from the Groningen reservoir. However, dynamic rupture simulations showed that MCC elastoplasticity resulted in less dynamic slip compared to an equivalent apparent linear elastic reservoir. In the following, I discuss the applicability of the MCC model behavior to the experimental observations, the effect of MCC elastoplasticity on the uniaxial compressibility and the stress path parameter, the use of a linear elastic vs. elastoplastic constitutive models to describe reservoir compaction, and the implications of the present results for induced fault slip and seismicity in the Groningen field.

\section{5. 1. Departures of present MCC model from triaxial experiments and the MCC model} developed by Pijnenburg et al. (2019)

Although the triaxial experiments performed by Pijnenburg et al. $(2018,2019)$ could be matched by the MCC model used in this study, a few differences remain. One of these differences is the assumed elastic behavior. Pijnenburg et al., 2019 assumed constant elastic properties, whereas the MCC model used in this study assumes nonlinear elasticity. The data in Stage 2 can be fit equally well with the linear and the nonlinear behavior, as the nonlinear elasticity function is near-linear at the stresses of interest. Also, results from uniaxial experiments showed that the true Young's modulus measured during unloading increases 


\section{Chapter 3}

with increasing effective stress (Hol et al., 2018), suggesting that elasticity is not constant. However, assuming nonlinear elasticity in Equation 3-7 without any adjustment gives behavior that is too compliant at lower stresses, with values that are too low compared to the experimental values obtained for the Slochteren sandstone. Equation 3-7 was developed for granular materials, and may not be directly applicable to cohesive sandstone rocks as the Slochteren sandstone. To account for cohesion the elasticity was adjusted by using the artificial parameter $p_{\text {tel }}$ (Equation 7) such that a certain bulk modulus $K$ was assigned at the starting stress in agreement with values measured by Pijnenburg et al. (2019). Another difference between the MCC formulation used here and the MCC model presented by Pijnenburg et al. 2019 is the slope of the critical state line $M$. In this study $M$ is a constant, whereas it decreases with ongoing mean effective stress and plastic strain in Pijnenburg et al. (2019). Taking the low-stress values for $M$ (i.e. the highest values) for the MCC model does not always lead to a good match between the modeled behavior and the experimental results; in particular for the $13.4 \%$ porosity sample, the $M$ of 1.3 required to get a good match with the data was much lower than the M of 2.1 in Pijnenburg et al. (2019). The lower $M$ results in shear failure at lower stresses than observed in the experiments. For the present study, shear failure is not reached in any of the single-element or field-scale models, but for other scenarios with different stress paths the slope of the critical state line will be important and must be better constrained. Currently, the critical state line and yield cap pass through the origin. It would be interesting to relax this boundary condition and allow the lower limit of the yield caps to shift towards $p$ ' $<0$ to allow for cohesive behavior (e.g. DIANA FEA manual v 10.3).

The MCC model used in this study leads to the unloading horizontal stress parameter, $\gamma_{h}$, modeled at the single-element scale, often being smaller than the loading value of $\gamma_{h}$ (Figure 3-6a). This kind of stress path hysteresis has also been observed in experiments on the Castlegate sandstone, with lower unloading $\gamma_{h}$ than loading $\gamma_{h}$ (Rafieepour et al., 2017). Similarly, in uniaxial experiments on the Slochteren sandstone the unloading $\gamma_{h}$ was lower than the loading $\gamma_{h}$ (Hol et al., 2018). This conflicts with the relative magnitude of the stress path parameters calculated from the apparent and true Poisson's ratio by Pijnenburg et al. (2019). The relative magnitude of the loading and unloading values depended on the initial mean effective stress, the slope of the CSL $M$, and the true Poisson's ratio obtained from triaxial experiments. Here and in the paper by Pijnenburg et al (2019), the true Poisson's ratio and Biot coefficient were taken at relatively high mean stress and assumed constant; but this may not be the case (Holt et al., 2016). As understanding stress path hysteresis may become more and more important in the future (e.g. for $\mathrm{CO}_{2}$ injection into depleted reservoirs), these discrepancies between loading and unloading stress path call for a better understanding of the evolution of the elastic properties with stress. An interesting approach could be to perform an inversion of the MCC parameters from the experimental data to quantify the optimal combination of parameters and the related uncertainties, which is beyond the scope of the current work. Clearly, further investigation into the true elastic properties of cohesive 
sandstone as a function of stress is warranted. An alternative approach could be to formalize the model by Pijnenburg et al. (2019) with a fitted value of the critical slope parameter $M$ as a function of the inelastic volumetric strain (Singh et al, in preparation).

\section{5. 2. Validity of the MCC model in the field-scale models}

The MCC model used by Pijnenburg et al. (2019) and in this study is valid for the near-linear Stage 2 behavior, but it is not valid for shear failure or Stage 3 behavior (Figure 1). In neither the single-element or the field-scale models in this study do the modeled stress changes reach the critical state line (Figure 3-4), and the related volumetric strains remain relatively small, with for example a maximum $\Delta \varepsilon_{v}<0.4 \%$ for the highest porosity $(26.4 \%)$ reservoir in a highly stressed region near the offset fault. Acoustic Emission monitoring during uniaxial compaction experiments on Slochteren sandstones has also suggested that intragranular cracking becomes dominant only for samples with $\Phi_{0}>27 \%$ at the end of depletion (Zotz-Wilson et al., 2020). Porosities in the Groningen field are lower on average, with values between $14-18 \%$, up to $20 \%$ in the center of the field (see e.g. Pijnenburg et al., 2019). Stage 2 behavior and the MCC model are thus applicable for modeling of reservoir compaction in Groningen. However, for modeling of gas fields or aquifers with a high porosity (e.g. $>25 \%$ ) or with a very different stress path it is important to consider whether Stage 3 behavior occurs and, if so, to account for it accordingly. Also during dynamic rupture, the stresses remain far from shear failure. In the dynamic rupture modeling I have implicitly assumed that the MCC behavior based on the low strain rate compaction experiments was also applicable to the higher strain rate behavior during rupture propagation. In the work by Aben et al. (2017) no pervasive intragranular cracking or pulverization was observed in the deformation of sandstone at strain rates of $60-150 \mathrm{~s}^{-1}$, but whether the same MCC parameters can be used at these high strain rates remains to be tested.

\section{5. 3. The effect of elastoplasticity on uniaxial compressibility and reservoir compaction}

One important issue for reservoir compaction is whether compaction is expected to proceed linearly with stress change. The MCC elastoplastic behavior modelled here resulted in a decrease of $10-30 \%$ in apparent uniaxial compressibility with depletion, depending on the initial porosity (Figure 3-6). This suggests that in an elastoplastic reservoir rock less compaction will occur per unit pore pressure drop as pressure depletion progresses.

A whole suite of papers have been published on compaction in the Groningen gas field, based on surface displacement measurements. A recent inversion study combining leveling, INSAR, and GPS data of the Groningen field indicated that uniaxial compressibility is time and pressure independent (Smith et al., 2019), but the time range studied is limited. Most other studies suggest a delay of the subsidence with respect to the driving pressure depletion (Hettema et al., 2002; Van Eijs \& van der Wal, 2017; van Thienen-Visser \& Fokker, 2017). The origin of the time-delay can be due to several mechanisms including pressure-diffusion-related phenomena (Mossop, 2012), and the effect of the evaporite 


\section{Chapter 3}

overburden (Marketos et al., 2015), but also to non-linear and/or time-dependent rockmechanical processes in the reservoir rock (De Waal et al., 2012; Pruiksma et al., 2015; van Thienen-Visser \& Fokker, 2017; van Wees et al., 2018). This study targets the latter type of mechanisms. For the low and intermediate porosities evaluated in this study $(13.4 \%$ and $21.5 \%$ ) the change of compressibility with $\triangle P$ is about $10 \%$ or $1 \cdot 10^{-5} \mathrm{MPa}^{-1}$ (Figure 3-6b and d) over a depletion range of 0 to $-35 \mathrm{MPa}$, which corresponds to decades of production. Such a change may only be seen in a careful investigation of all available surface movement measurements during the complete period of gas production. More work is required to relate our approach to the field-wide geology and reservoir dynamics. For higher porosity rocks the expected change in compressibility is larger with a decrease of up to $5 \cdot 10^{-5} \mathrm{MPa}^{-1}$ with depletion, and the change in compressibility may be more readily observed. In general, the inferred values for the compressibility $\left(5-1.5 \cdot 10^{-4} \mathrm{MPa}^{-1}\right)$ agree with the measurements from uniaxial strain experiments by Hol et al. (2018) and with the compressibilities observed from the single element model (Smith et al., 2019; Van Eijs \& van der Wal, 2017).

\section{5. 4. Implications of the MCC model for the stress and pressure dependence of the stress path parameter}

The effects of elastoplasticity on the horizontal stress path parameter are more profound than on the compressibility. The horizontal stress path parameter $\gamma_{h}(\Delta \sigma / \Delta P)$ is an important geomechanical parameter, and is indicative for whether reservoir depletion will lead to a more critical stress state. Together with differential compaction across fault offsets and fluid pressure diffusion effects, the horizontal stress changes in depleting reservoirs and the related change in differential stress is an important driver for induced seismicity. For a linear elastic isotropic material under uniaxial conditions, the horizontal stress path parameter is given by Equation 3-17, and it remains the same under different loading and unloading conditions. However, this is not the case when plastic deformation occurs. The stress path parameters modeled with MCC elastoplasticity also changed with depletion pressure. Even though the stress-strain response is near-linear, it is not fully linear and the slope of the total stress path parameter decreased by about 0.1 over the full depletion range (Figure 4 ). Hence, as the effective stresses increase due to depletion, plasticity causes the stress path to become more stable as the horizontal stress path parameter becomes lower. This effect was also recognized in uniaxial compaction experiments on synthetic sandstone cores, which show an increase in $\Delta \sigma_{h}{ }^{\prime} / \Delta \sigma_{v}$ ' (i.e. a decrease in $\gamma_{h}$ ) with axial stress (Holt, 1999). The nonlinearity is larger for weaker (more porous) samples. Unloading and reloading may remove part of the stress path dependency on $\triangle P$ (Holt, 1999). This is important to consider for the Slochteren cores studied by Pijnenburg et al. (2019) and Hol et al. (2018), which were extracted from the field after $25 \mathrm{MPa}$ depletion.

Last, the horizontal stress path parameter also increased with initial mean effective stress - i.e. the stress response became more unstable. This was also reported by Pijnenburg et al. (2019) who used the MCC model to compute stress path at lower stresses than those of 
the experiment, which resulted in a significantly higher $\Delta \sigma^{\prime} / \Delta P$ (i.e. lower $\gamma_{\mathrm{h}}$ ). This demonstrates that it is important to perform experiments at the appropriate stress conditions, or have a constitutive model that can extrapolate the results to the desired stress state. The increase of the stress path parameter with increasing initial mean effective stress suggests that depletion of a deep reservoir may result in a more unstable stress path than depletion of a shallower reservoir with the same porosity.

\section{5. 5. Approximation of MCC behavior with apparent linear elasticity}

Many modeling studies have assumed linear elastic material properties to model the stresses induced by depletion of the Groningen field as well as the response of other fields to a variety of subsurface activities (Buijze, van den Bogert et al., 2019; Haug et al., 2018; Mulders, 2003; Nagelhout \& Roest, 1997; Orlic \& Wassing, 2013; Roest \& Kuilman, 1994; Segall, 1989; Segall et al., 1994; van Wees et al., 2019, Zbinden et al., 2017). The stressstrain response resulting from the present elastoplasic MCC model was near-linear in the stress range of interest. Field-scale modeling in this study has further shown that this elastoplastic behavior could be approximated by linear elastic behavior during quasi-static loading. However, as highlighted in the previous section, it is important to select the appropriate apparent elastic properties, as they depend on the applied stress. Taking elastic properties from an experiment performed at stresses beyond the range relevant for the modeled system could result in large errors in stress path and compressibility calculations. Moreover, the single-element and field-scale model show that the stress path during depletion is slightly nonlinear, which is not captured in linear elastic models. With increasing porosity and strain, this nonlinearity may become more important, and also for different stress paths, as expected near open-hole sections of wells, or around geothermal wells. So, even though stress changes that develop during reservoir depletion may be approximated with linear elastic behavior, it is still advantageous to have a constitutive material model describing the elastoplastic response. In addition, it is important to consider time-dependent effects (creep) in future studies. Pore pressure changes in a reservoir incorporating time-dependent behavior are non-linearly related to stress changes, which may result in a non-linear dependency of seismic moment on pressure changes.

In the present study, MCC elastoplasticity resulted in different behavior during dynamic rupture compared with an apparent linear elasticity of the reservoir (Figure 3-11 and Figure 3-12). The MCC elastoplasticity resulted in less dynamic slip and (depending on the state of stress) smaller rupture lengths. In addition, the total slip and slip rate were lower for the MCC reservoir model. Smaller slip and rupture velocities were also observed for dynamic rupture modeling on a fault embedded in a medium governed by Modified Cam-Clay behavior, or Drucker Prager behavior with a compression cap (Liu \& Borja, 2013). These authors showed high stresses near the rupture tip caused plastic volumetric strains in the medium around the fault which acts to dissipate energy as also depicted in Figure 3-12c. Models without a compression cap resulted in larger ruptures. 


\section{5. 6. Implications for fault reactivation and induced seismicity in Groningen}

Compared with assuming apparent elastic behavior, MCC elastoplasticity of the reservoir unit affected the compressibility, stress path, nucleation length, and dynamic rupture length obtained in the numerical simulations reported here. All of these in turn can be expected to affect seismicity in the Groningen field. The stress path parameter decreased with simulated depletion (Section 3. 5. 4. ). This result implies that rates of change of Coulomb Stress on faults decrease with ongoing depletion, which may lead to a decrease in seismicity rates over time (Candela et al., 2019). However, fault reactivation also occurs due to stress concentrations caused by gradients in compaction and deformation across faults (differential compaction). These will continue to develop as depletion progresses, bringing more and more fault orientations closer to failure. The effect of the decrease in stress path parameter on seismicity may thus be masked by ongoing compaction. It would be an interesting avenue for future studies to evaluate the effect of stress path changes on fault reactivation in a field-scale model with multiple faults - such as the geomechanical reservoir simulator MACRIS (Candela, Thibault et al., 2019; van Wees et al., 2019).

The most important observation made in this study for induced seismicity is the reduced slip magnitude (20\% less) and (depending on the fault stress) the reduced rupture length (20\% less) that develop as a result of coseismic energy dissipation through plastic strain development in the reservoir rock. Consistent with geomechanical models (Buijze, van den Bogert et al., 2019; Haug et al., 2018; Mulders, 2003; Orlic \& Wassing, 2013; Zbinden et al., 2017), most earthquakes in Groningen seem to nucleate within the reservoir interval (Spetzler \& Dost, 2017a) and will thus be affected by elastoplasticity of the reservoir. To assess the effect on earthquake magnitude, the seismic moment and moment magnitude can be estimated from the present model results. The seismic moment $\mathrm{M}_{0}$ can be computed from the area, $A$,that slipped during the dynamic event, the average coseismic slip, $d$,over that area, and the shear modulus $G$ of the medium, using the relation (Aki, 1966)

$$
M_{0}=G A d \text {. }
$$

To estimate the seismic moment for the ruptures in this study, an assumption of rupture extent in the third dimension must be made. The seismic moment was accordingly computed for several aspect ratios $W: L_{s}$, where $L_{s}$ is the modeled dynamic rupture length along the fault in the dip direction, and $W$ is the rupture width along the strike of the fault. The moment magnitude was computed from the seismic moment using (Hanks \& Kanamori, 1979)

$$
M_{w}=\frac{2}{3}\left(\log 10\left(M_{0}\right)-7.1\right)
$$


Table 3-3. Rupture characteristics, and associated seismic moments and moment magnitudes predicted in model runs employing reservoir materials with different porosities and MCC constitutive behavior versus equivalent apparent elastic behavior.

\begin{tabular}{ll|l|l|l|l|l|l} 
Reservoir & $\boldsymbol{G}(\mathbf{G P a})$ & $\boldsymbol{L}_{\boldsymbol{d}}(\boldsymbol{m})$ & $\boldsymbol{W}: \boldsymbol{L}_{\boldsymbol{d}}$ & $\boldsymbol{A}\left(\boldsymbol{m}^{2}\right)$ & $\boldsymbol{d}_{\text {avg }}(\boldsymbol{m})$ & $\boldsymbol{M}_{\boldsymbol{0}}(\mathbf{N m})$ & $\boldsymbol{M}_{w}$ \\
\hline LinElas13 & 9 & 205 & 1 & $4.2 \cdot 10^{4}$ & 0.039 & $1.4 \cdot 10^{13}$ & 2.7 \\
\hline MCC13 & 9 & 200 & 1 & $4.0 \cdot 10^{4}$ & 0.03 & $1.0 \cdot 10^{13}$ & 2.6 \\
\hline LinElas13 & 9 & 205 & 4 & $1.7 \cdot 10^{5}$ & 0.039 & $6.0 \cdot 10^{13}$ & 3.1 \\
\hline MCC13 & 9 & 200 & 4 & $1.6 \cdot 10^{5}$ & 0.03 & $4.3 \cdot 10^{13}$ & 3.0 \\
\hline LinElas21 & 6.5 & 254 & 1 & $6.5 \cdot 10^{4}$ & 0.054 & $2.2 \cdot 10^{13}$ & 2.8 \\
\hline MCC21 & 6.5 & 250 & 1 & $6.3 \cdot 10^{4}$ & 0.048 & $1.9 \cdot 10^{13}$ & 2.8 \\
\hline LinElas26 & 3.6 & 99 & 1 & $9.8 \cdot 10^{3}$ & 0.025 & $9.1 \cdot 10^{11}$ & 1.9 \\
\hline MCC26 & 3.6 & 55 & 1 & $3.0 \cdot 10^{3}$ & 0.014 & $1.6 \cdot 10^{11}$ & 1.4 \\
\hline LinElas26 & 3.6 & 99 & 4 & $3.9 \cdot 10^{4}$ & 0.025 & $3.6 \cdot 10^{12}$ & 2.3 \\
\hline MCC26 & 3.6 & 55 & 4 & $1.2 \cdot 10^{4}$ & 0.014 & $6.3 \cdot 10^{11}$ & 1.8
\end{tabular}

Table 3-3 summarizes the rupture characteristics and related seismic moments and moment magnitudes obtained from simulations performed for different reservoir properties and different aspect ratios. Moment magnitudes range from 1.8 to 3.1, comparable to those observed in the field. In Section 4.3, it was shown that for the $13.4 \%$ and $21.5 \%$ porosity reservoir rocks rupture was arrested at the fault regions with low shear stresses at the top and bottom of the reservoir interval that developed during production. For these simulations, the rupture lengths were similar for the MCC reservoirs (MCC13 and MCC21) compared to the apparent linear elastic reservoirs (LinElasApp13 and LinElasApp21), and only the shear slip was smaller for the MCC reservoirs with respect to the reservoir with linear elastic properties. This translates into a moment magnitude that was 0.1 lower for the elastoplastic reservoir compared to the apparent linear elastic reservoir. For the $26.4 \%$ reservoir, rupture was arrested within the reservoir interval, as the production-induced stress was less critical here than in the two other porosity cases. In this case, both the rupture length and the shear slip were smaller for the elastoplastic reservoir MCC26 compared to the linear elastic reservoir LinElasApp26 (Figure 3-11a and b). Here, the elastoplastic behavior caused a reduction in moment magnitude of 0.5 with respect to the apparent linear elastic (LinElasApp26). The reduction in magnitude due to reservoir elastoplasticity is thus also affected by the depletioninduced stress state and its control on rupture arrest. For different reservoir offsets, and thus 
different stress distributions along the fault, the differences between MCC and reservoirs with apparent linear elastic properties (LinElasApp) may thus be different. For very heterogeneous stress states where rupture spans across just one of the stress concentrations, the difference is expected to be largest. This can occur for e.g. thicker reservoirs and lower horizontal stress path parameters (see Chapter 6 for rupture sizes and their dependencies on reservoir geometry).

For the current simulations, the imposed friction drop was the same for all three reservoir porosities. However, the rupture velocity and slip rates were lower for the MCC26 reservoir compared to the lower porosities. This may result in less dynamic weakening and a smaller stress drop, and hence less frictional weakening. It is worthwhile to investigate the effect of various slip rate functions on frictional weakening in sandstone gouges, as in Hunfeld (2020).

Hence, depending on the state of stress, the reservoir porosity and elastoplastic parameters, elastoplasticity may thus cause a reduction in moment magnitude of 0.1 up to 0.5 with respect to the assumption of linear elasticity. The effects of elastoplastic behavior for a broader range of in-situ stresses and dynamic weakening properties on induced event magnitudes should be investigated.

\section{6. Conclusions}

This study has analyzed the effect of elastoplastic behavior of the Slochteren sandstone reservoir rock of the Groningen gas field (The Netherlands) on production-induced stress changes, fault reactivation, and induced seismic rupture. The Modified Cam-Clay (MCC) elastoplasticity model was compared with conventional triaxial compression and uniaxial compressive strain experiments on Slochteren sandstone. Subsequently, productioninduced stress changes on the field-scale were modeled in a finite element package (DIANA FEA), using an axisymmetric reservoir model and a plane-strain model of two depleting reservoir compartments offset by a fault. For the latter model geometry, production-induced fault reactivation and dynamic rupture was also simulated. The reservoir formation was modeled with MCC behavior for three different porosities of the sandstone reservoir. The effect of MCC was compared against models with a linear elastic reservoir with equivalent apparent elastic properties - i.e. elastic properties determined during loading, including elastic and plastic behavior. I conclude the following:

- Results from the standard Modified Cam-Clay elastoplastic material behavior largely match with observations from both triaxial and uniaxial strain experiments on Slochteren sandstone taken from the Groningen field. In both the experiments and the model, the stress-strain behavior is near-linear in the stress range relevant to production-induced stress changes within the Groningen reservoir. To compare the model against the 
uniaxial strain experiments it is important to consider the correct value for the Biot coefficient.

- For MCC elastoplastic behavior, the apparent (elastic plus plastic) horizontal stress path parameter $\gamma_{h}$ during reservoir depletion increased with initial effective mean stress. Because the stress path was slightly nonlinear, $\gamma_{h}$ decreased with progressive depletion. The apparent compressibility decreases with initial effective mean stress and with depletion. MCC behavior also resulted in stress path hysteresis, with the value of $\gamma_{h}$ during unloading mostly being lower than the $\gamma_{h}$ during loading.

- Field-scale modeling shows that the depletion-induced stress changes in a reservoir with MCC behavior can be approximated with linear elastic behavior with apparent elastic parameters obtained from fits of MCC behavior under uniaxial conditions. These apparent elastic parameters must, however, be taken at the appropriate mean effective stresses. Small differences between the stress changes computed with apparent linear elastic behavior and MCC behavior can result from the nonlinearity of the stress path for the MCC behavior.

- Dynamic rupture simulations showed that $10-20 \%$ less fault slip occurs for ruptures in a reservoir with MCC behavior compared to a reservoir with apparent linear elastic properties, for the same starting stress. Depending on the state of stress, MCC behavior also resulted in a smaller rupture length. Elastoplasticity thus resulted in smaller magnitudes of the induced seismic events. The estimated decrease in moment magnitude for a MCC reservoir with respect to a linear elastic reservoir was 0.1 to 0.5 for the assumed model geometry of a fault with $50 \mathrm{~m}$ offset.

- The results imply that linear elasticity may be used to model stress development in the Groningen reservoir, provided the appropriate apparent elastic parameters are used. However, rupture lengths that one would obtain using an apparent linear elastic reservoir would be an overestimate by $\sim 20 \%$.

\section{7. Acknowledgements}

This research was in part funded by Nederlandse Aardolie Maatschappij BV (NAM) in the framework of Research Agreement UI49294 'Studies on Fault (re)activation and dynamic friction and failure behaviour'. André Niemeijer is supported by the European Research Council, starting grant SEISMIC (335915) and by the Dutch Research Council (NWO) Vidi-grant 854.12.001. Furthermore I thank all colleagues and friends at TNO, Utrecht University, Shell, and NAM for their support and discussions on modeling of 
Chapter 3

earthquakes and in particular Ronald Pijnenburg for discussions on elastoplasticity. In particular I thank Gerd-Jan Schreppers from DIANA FEA BV for his support and helpful discussions on the implementation of the Modified Cam-Clay model in DIANA FEA. TNO is thanked for providing the license for DIANA FEA. 
Chapter 3 
Chapter 3 


\section{Chapter 4}

Nucleation of stick-slip instability

within a large-scale experimental fault:

Effects of stress heterogeneities due to

loading and gouge-layer compaction 
Chapter 4

Nucleation of stick-slip instability within a large-scale experimental fault: Effects of stress heterogeneities due to loading and gouge-layer compaction

Loes Buijze ${ }^{1,2}$, Yanshuang Guo ${ }^{3}$, André R. Niemeijer ${ }^{1}$, Shengli $\mathrm{Ma}^{3}$, and Christopher J. Spiers ${ }^{1}$

${ }^{1}$ Utrecht University, Faculty of Geosciences, Princetonlaan 4, Utrecht, The Netherlands

${ }^{2}$ TNO, Applied Geosciences, Princetonlaan 6, Utrecht, The Netherlands.

${ }^{3}$ State Key Laboratory of Earthquake Dynamics, Institute of Geology, China Earthquake Under Review: Journal of Geophysical Research: Solid Earth. 


\title{
Nucleation of stick-slip instability within a large-
}

\author{
scale experimental fault: Effects of stress
}

\author{
heterogeneities due to loading and gouge-layer
}

\author{
compaction
}

\section{1. Introduction}

Understanding the nucleation process of both natural and induced earthquakes is important, as it determines not only when, where, and how an earthquake starts, but also influences the ultimate size of a seismic event (Ellsworth \& Beroza, 1995). The existence of a nucleation phase follows from the frictional weakening behavior that governs fault strength. Analytical and numerical studies have shown that nucleation on faults characterized by rateand-state friction (Dieterich, 1992; Rice, J. R., 1993; Rubin \& Ampuero, 2005) or slipweakening friction (Campillo \& Ionescu, 1997; Uenishi \& Rice, 2003) requires a finite fault length that must slip aseismically before seismic instability can nucleate. This is termed the critical nucleation length, which is a function of the friction law, the frictional weakening parameters, the normal stress, and the elastic properties of the medium surrounding the fault (see further Section 2). It is unclear how this nucleation length applies to earthquake nucleation in nature. For some natural earthquakes the nucleation process has been observed or inferred. For example, aseismic creep during the nucleation phase has been inferred from the occurrence of small repeating foreshocks near the hypocenters of intermediate and large earthquakes (Bouchon et al., 2011; Bouchon et al., 2013; Dodge et al., 1995; Dodge et al., 1996). Recently, aseismic slip accompanied by small foreshocks has been observed from combined geodetic and seismological measurements, prior to the occurrence of both a megathrust earthquake of $M_{w} 8.1$ (Ruiz et al., 2014; Socquet et al., 2017) and a $M_{w} 6.9$ event (Ruiz et al., 2017) at the Chile subduction zone in respectively 2014 and 2017. A slow nucleation phase was also recognized prior to a much smaller event of $\mathrm{M}_{\mathrm{w}} 3.8$ in Alaska (Tape et al., 2018). However, in many other cases the nucleation process could not be observed due to limited in situ geodetic data at sufficient spatiotemporal resolution. Improvement of our understanding of the nucleation process could help to guide future

\footnotetext{
Photograph previous page: Strain gauges used to detect deformation along a $350 \mathrm{~mm}$ long experimental fault. The gauges (orange rectangles) contain a metal grid, over which the electrical resistance is measured. The resistance depends on the strain (extension of compression) of the grid, and thus provides a measurement of the deformation at different positions along the experimental fault. This gives insight into how laboratory earthquakes form.
} 


\section{Chapter 4}

instrumentation of earthquake-prone faults to detect the rupture nucleation phase before earthquake rupture starts. This could potentially provide an early warning or forecast of the location and timing of natural events and of induced seismic events.

Laboratory experiments allow systematic investigation of the nucleation process and of the effects of loading conditions and fault properties on the size and duration of nucleation. In particular, in experiments using m-scale samples, dense instrumentation (e.g. strain gauges, piezo-electric sensors, displacement sensors) along a laboratory fault allows the faulting process to be studied in detail. Such experiments, typically performed at low normal stresses ( $<5 \mathrm{MPa}$ ), have shown how nucleation of an instability often starts as a localized slow slip zone covering a portion of the fault, which expands slowly at first and then accelerates rapidly leading to unstable rupture propagation (Latour et al., 2013; Ma et al., 2002; McLaskey \& Kilgore, 2013; Ohnaka et al., 1986; Okubo \& Dieterich, 1981; Zhuo et al., 2018). The observed nucleation zone in these tests was generally centimeters to decimeters (bare rocks) or millimeters to centimeters (polymers) in length scale. The expansion of the nucleation zone in an experiment using $1.5 \mathrm{~m}$ long granite blocks was accompanied by foreshocks indicating failure of highly stressed asperities within a creeping zone (McLaskey \& Kilgore, 2013; Zhuo et al., 2018), similar to that observed in some natural fault zones. In accordance with theory (see Section 1.1) the nucleation length was observed to increase with decreasing normal stress (e.g. Latour et al., 2013). When the nucleation length is close to the laboratory fault length, the mode of fault sliding (seismic vs. slow or aseismic slip) can be controlled by changing the loading conditions such as the normal stress (Mclaskey \& Yamashita, 2017). Both experimental (Guérin-Marthe et al., 2019; Kato et al., 1992; Xu et al., 2018) and numerical (Kaneko et al., 2016, Kaneko \& Lapusta, 2008) studies further show that the nucleation length decreases with increasing loading rate, whereas it increases with fault roughness (Ohnaka \& Shen, 1999; Yamashita et al., 2018).

Most of the above $\mathrm{dm}$ - to $\mathrm{m}$-scale experiments investigating nucleation were performed using bare, smoothed surfaces of crystalline rocks, such as granite (e.g. Ohnaka \& Kuwahara, 1990; Okubo \& Dieterich, 1981) or granodiorite (Ma et al., 2002), or on polymers (e.g. Guérin-Marthe et al., 2019; Latour et al., 2013). In nature, fault zones are usually filled with fault gouge or cataclastic rocks produced by wear of the formations flanking the fault. Many smaller scale experiments have focused on the friction of gouge, rather than bare rock surfaces (e.g. Ikari et al., 2011; Marone, 1998). Fault gouge may also be generated at asperities along initially bare rock surfaces but this requires a considerable amount of displacement - e.g. several centimeters for smooth gabbro rocks (Yamashita et al., 2015). Gouge and bare rocks surfaces generally exhibit different frictional properties because the (time-dependent) internal microstructure of the gouge, for example, can affect the strength, fault dilatancy, and the evolution of rate-and-state parameters with slip (e.g. Rathbun \& Marone, 2013). These different frictional characteristics may lead to different nucleation behavior within gouge-filled faults compared to bare rock faults. 
Here, we study the nucleation process on gouge-filled faults using simulated fault gouge sandwiched between two planar fault surfaces in a dm-scale biaxial loading experiment. For the simulated gouge material we used gypsum gouge; we conducted independent small-scale experiments which showed that gypsum gouge exhibits stick-slip at room temperature and normal stresses $<20 \mathrm{MPa}$. To be able to capture the nucleation process within the $350 \mathrm{~mm}$ long fault that was used in our experiments, we used polymethylmethacrylate (PMMA) forcing blocks to reduce the nucleation length. Polymer forcing blocks have a stiffness 20 - 25 times lower than rocks, such as granite, and have previously been used to simulate rupture nucleation in the laboratory. They have also been used in experiments that successfully reproduce earthquake phenomena such as the nucleation phase and supershear as well as crack-like and pulse-like rupture (e.g. Bayart et al., 2016; Lu et al., 2007). Rupture nucleation and propagation on the gouge-filled fault was tracked using an array of strain gauges along the experimental fault. The location of nucleation was considered in the light of the fault stresses that were observed from the strain data and obtained from Finite Element modeling.

\section{1. 1. Rate-and-state friction and theoretical nucleation lengths}

In this section rate-and-state friction, conditions for instability, and several theoretical formulations for the nucleation length are presented, as well as relevant observations from numerical modeling and experiments. Rate-and-state friction is an empirical relationship widely used to describe fault frictional behavior, where friction $\mu$ is a function of slip velocity $V$ and state $\theta$ (Dieterich, 1979; Ruina, 1983)

$$
\mu=\mu^{*}+a \ln \frac{V}{V^{*}}+b \ln \frac{V^{*} \theta}{D_{c}}
$$

where $a$ and $b$ are constitutive rate-and-state parameters, $D_{c}$ is the critical slip distance over which weakening (or strengthening occurs), $\mu^{*}$ is a reference friction value, $V^{*}$ is a reference sliding velocity. Two equations for $\theta$ are predominantly used; the aging law

$$
\frac{d \theta}{d t}=1-\frac{V \theta}{D_{c}}
$$

and the slip law

$$
\frac{d \theta}{d t}=-\frac{V \theta}{D_{c}} \ln \frac{V \theta}{D_{c}}
$$

At steady-state sliding the parameter $\Omega=V \theta / D_{c}=1$ so $d \theta / d t=0$. For the aging law, $\theta$ increases at a sliding velocity of 0 , whereas for the slip law $\theta$ can only change with slip.

Instability requires a negative $a-b$ so that decreases with velocity (velocityweakening), whereas for a positive $a-b$ friction increases with velocity which is stabilizing (velocity-strengthening). For instability in for example a spring-slider systems the spring 
stiffness $k$ must be smaller than the critical stiffness $k_{c}\left(=\sigma_{n}(b-a) / D_{c}\right)$. Note that for the slip law instability can also occur when $k>k_{c}$ when the perturbation is large. Different formulations for the critical nucleation length exist, depending on the state-law and weakening parameters, the sliding velocity, and the state of the fault (e.g. Ampuero \& Rubin, 2008; Rubin \& Ampuero, 2005). Equating the crack stiffness $k\left(=G^{*} 2 L\right.$, where $2 L$ is the $2 \mathrm{D}$ crack length and $G^{*}$ is the $2 \mathrm{D}$ shear modulus which for out-of-plane strain is $G$ and for inplane sliding $G /(1-v)$, where $v$ is the Poisson's ratio) to the critical stiffness $k_{c}$ gives a critical fault patch half-length for instability to develop as $L_{a-b}=2 G^{*} D_{c} / \pi(b-a) \sigma_{n}$ (Rice, J. R., 1993; Ruina, 1983). For small perturbations this critical length is the same for the slip and the aging laws. Numerical modeling studies have shown that for velocities well over the steady-state $(\Omega>>1)$ a lower bound of the critical nucleation half-length for the aging law is given by $L_{b}$ $=G^{*} D_{c} /\left(b \sigma_{n}\right)$ (Dieterich, 1992). Linear stability analysis shows that for a slip zone at velocities close to steady state $(\Omega \sim 1)$ and $a / b>0.3781$ an upper limit of the nucleation halflength for the aging law is given by $L_{\infty}=\left(G^{*} D_{c} / \pi\right)\left(b /\left(\sigma_{n}(b-a)^{2}\right)\right)$ (Ampuero \& Rubin, 2008; Rubin \& Ampuero, 2005). Recent simulations of nucleation on a velocity-weakening patch show that nucleation in simulations with the aging law are better approximated by $L_{\infty}$. The modeled nucleation half-lengths using the slip law are smaller and match better with $L_{b}$ ${ }_{a}$ (Chen, Ting \& Lapusta, 2019). Linear stability analysis also shows the nucleation halflengths under the slip law are smaller than for the aging law, and also, when a fault governed by the slip law is perturbed to values well above steady state the nucleation length may become several times smaller than expected from linear stability analysis (Ampuero \& Rubin, 2008). Experimental data is often modeled with the slip or aging law to obtain the rate-andstate parameters. Several studies have shown that velocity steps (and more recently, also slide-hold-slide steps) in experiments on bare rock or gouge are better described using the slip law (Ampuero \& Ben-Zion, 2008; Bhattacharya et al., 2015; Bhattacharya et al., 2017).

\section{2. Experimental materials and methods}

The experiments presented in this study were performed in the horizontal biaxial machine at the Institute of Geology, China Earthquake Administration in Beijing (Figure 4-1a). This horizontal rig allows biaxial loading of plate-shaped samples up to $0.5 \mathrm{~m}$ in width, length, and/or thickness. The sample assembly used in this study (300 x 200 x $50 \mathrm{~mm}$ ) was composed of two triangular forcing blocks, made of cast polymethylmethacrylate (PMMA), sandwiching a vertically oriented fault zone $(347$ x $50 \mathrm{~mm})$ along the diagonal of the assembly, i.e. orientated at an angle $\theta=33.7^{\circ}$ to the largest horizontal stress $\sigma_{l}$ (Figure 4-1ab). In two of the experiments the fault zone was filled with a gouge layer. For comparison, also an experiment without gouge was performed - i.e. on a bare PMMA fault zone. 


\section{2. 1. Fault gouge material and frictional properties}

For the experiments using a gouge-filled fault the fault zone was filled with a $2 \mathrm{~mm}$ thick gypsum gouge layer. This gouge was obtained by sieving crushed natural gypsum from the Paris Basin (de Meer \& Spiers, 1997) to < $150 \mu \mathrm{m}$. XRD analysis indicated that the crushed and sieved gypsum was $98.8 \%$ pure, with a small fraction of quartz $(0.9 \%)$ and molybdenite $(0.3 \%)$. Small-scale, triaxial shearing experiments performed on a $2 \mathrm{~mm}$ thick layer of this gypsum gouge placed along the sawcut interface of $35 \mathrm{~mm}$ diameter PMMA forcing blocks, at a confining pressure of $5 \mathrm{MPa}$ and load point velocities in the range 0.1 $10 \mu \mathrm{ms}^{-1}$, showed that the gypsum gouge had a friction coefficient of $0.75-0.85$. Stick-slip behavior was observed at all load point velocities. Rate-and-state parameters for the gypsum were obtained from velocity steps performed during friction experiments on gypsum gouge in a biaxial machine, using steel forcing blocks, a normal stress of 10 - $13 \mathrm{MPa}$, loading rates $3-1000 \mu \mathrm{ms}^{-1}$ and $100 \%$ relative humidity RH (pers. comm. Marone). Only the velocity steps from 100-300 and 300-1000 $\mu \mathrm{m} / \mathrm{s}$ showed stable sliding; at the other loading rates stickslips occurred. These steps were best modeled with a two-state variable friction law which can model an initial rapid drop in friction, as well as a longer term weakening trend. The fits gave the following rate-and-state parameters for the ageing law: $a-b=-0.003$ to -0.005 , $b_{1}=0.002-0.005, b_{2}=0.001-0.0035, D_{c l}=3-7 \mu \mathrm{m}$, and $D_{c 2}=50-150 \mu \mathrm{m}$, and a steady state friction coefficient of 0.8 . For reference, also an experiment without gouge was performed.

\section{2. 2. Sample assembly, deformation apparatus and experimental procedure}

The PMMA forcing blocks (\#1 in Figure 4-1a) were manufactured by WSV Kunststoffen BV. The elastic properties provided for these block were a (static) Young's modulus $E$ of $3.21 \mathrm{GPa}$, Poisson's ratio $v$ of 0.37 , and a density $\rho$ of $1190 \mathrm{kgm}^{-3}$. Note that the high strain rate Young's modulus of PMMA is significantly larger, e.g. 5.6 MPa. The shear wave, Rayleigh wave, and P-wave velocities for PMMA blocks reported in a different study are respectively $\mathrm{V}_{\mathrm{s}}=1345 \mathrm{~ms}^{-1}, \mathrm{~V}_{\mathrm{R}}=1245 \mathrm{~ms}^{-1}$, and $\mathrm{V}_{\mathrm{P}} 2700 \mathrm{~ms}^{-1}$ (Bayart et al., 2016; Svetlizky \& Fineberg, 2014). The corresponding high-strain-rate or dynamic Young's modulus computed from these velocities was $5.6 \mathrm{GPa}$, which is significantly larger than the static value of $3.21 \mathrm{GPa}$. The fault surfaces of the forcing blocks were prepared by manual grinding \#80 SiC powder. To prepare the gouge layer, the fault surface of one of the PMMA blocks was rotated to a horizontal position. The fault gouge (see Section 2.1) was wetted and distributed evenly along the fault surface with a thickness of $2 \mathrm{~mm}$, and was left to dry at ambient conditions. Afterwards the block and gouge layer were equilibrated to a relative humidity $(\mathrm{RH})$ of $75 \%$ in an enclosed container for $>1$ day. The relative humidity in the container was maintained by a saturated $\mathrm{NaCl}$ solution. Subsequently, the block and gouge layer were taken out of the container, and the second PMMA block was then added so that the gouge layer was sandwiched by the two PMMA blocks, thereby minimizing exposure of the gouge to ambient conditions. Tape was applied at the lower fault margin and fault ends 


\section{Chapter 4}

to hold the sample assembly together and prevent gouge from extruding. The sample assembly was rotated and placed horizontally in the biaxial machine (\#1 in Figure 4-1a). The assembly was supported at the base by two steel cylinders of $50 \mathrm{~mm}$ in diameter. Slidebearing plates (\#7 in Figure 4-1a) were placed along the sides of the sample assembly to accommodate lateral motion as the blocks were displaced along the fault zone. Steel spacers blocks (\#6 in Figure 4-1a) bridged the gap between the hydraulic presses and the slidebearing plates.
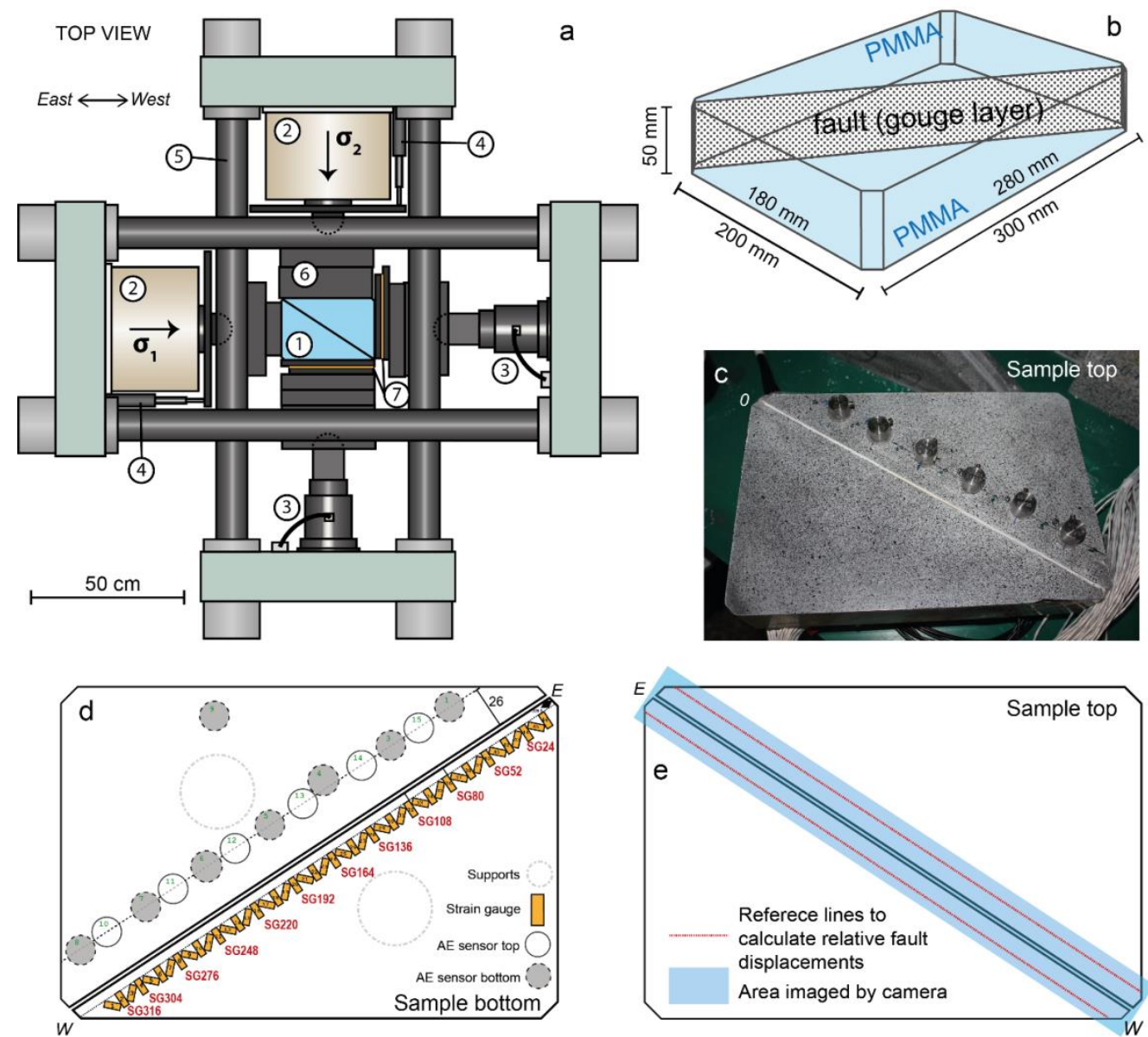

Figure 4-1. Biaxial deformation apparatus, sample assembly, and instrumentation. a) Schematic drawing of the horizontal biaxial deformation rig, with 1 : Sample assembly, 2 : hydraulic presses, 3 : load cell, $4:$ LVDT, 5 : loading frame, $6:$ steel spacers, 7 : slide-bearing steel plates. b) Sample assembly. c) Top of the sample assembly showing speckled surface and AE sensors. d) Schematic drawing of the bottom of the sample assembly showing strain gauge configuration and AE sensors. E: east, W: west. e) Schematic drawing of sample top showing the area imaged by the high-speed camera, and the reference lines at $10 \mathrm{~mm}$ from the fault which are used to compute relative fault displacements. 
Testing of the experimental fault zones containing gouge commenced with a loadcontrolled pre-compaction phase, subjecting the sample assembly to horizontal stresses $\sigma_{l}$ and $\sigma_{2}$ of $20 \mathrm{MPa}$ for 10 minutes. The principal stresses $\sigma_{1}$ and $\sigma_{2}$ were then simultaneously reduced to $5 \mathrm{MPa}$. . For the bare PMMA fault the pre-compaction phase was skipped and the sample was directly loaded to $5 \mathrm{MPa}$. Subsequently, shear displacement was imposed along the fault by switching loading in the $\sigma_{1}$-direction to displacement control, whilst keeping loading in the $\sigma_{2}$-direction under load control. This shear phase started with a run-in stage where the hydraulic press in the $\sigma_{l}$ direction was advanced at fixed load point velocity $v_{l}$ of $5 \mu \mathrm{ms}^{-1}$, increasing $\sigma_{l}$ whilst retaining the minimum horizontal stress or 'confining stress' $\sigma_{2}$ $=5 \mathrm{MPa}$. After a load point displacement $d_{1}$ of $3 \mathrm{~mm}$ the load point velocity was reduced to $1 \mu \mathrm{ms}^{-1}$ for a load point displacement of $1.5 \mathrm{~mm}$. Subsequently, for one of the gouge-filled faults (run number hbr-17-19) and the bare PMMA fault $\sigma_{2}$ was changed stepwise to vary the critical stiffness and the critical nucleation length (see Section 4.1.1) which could affect the sliding behavior. To step $\sigma_{2}$, first the load point displacement in the $\sigma_{1}$-direction was halted, $\sigma_{2}$ was changed to the desired value, and then loading in the $\sigma_{1}$-direction was reinitiated. The range of $\sigma_{2}$ evaluated was $0.3-5 \mathrm{MPa}$, starting with reduction of $\sigma_{2}$ and then increasing $\sigma_{2}$ towards the end of the experiment. For upsteps in $\sigma_{2}$ the load point velocity was first set to 5 $\mu \mathrm{ms}^{-1}$ and reduced to $1 \mu \mathrm{ms}^{-1}$ when steady state was reached. For each value of $\sigma_{2}$ a total load point displacement of $0.5-1 \mathrm{~mm}$ was imposed at a load point velocity of $1 \mu \mathrm{ms}^{-1}$. The cumulative load point displacement over the experiment was $10 \mathrm{~mm}$. The control experiment without gouge followed the normal confining stress stepping procedure. A second experiment with gouge (run number hbr-17-18) was performed, where only sliding at $\sigma_{2}=5$ $\mathrm{MPa}$ was performed, up to $4.5 \mathrm{~mm}$ of load point displacement.

\section{2. 3. Data acquisition and processing}

The mechanical data acquired includes the orthogonal loads applied by the hydraulic presses (\#2 in Figure 4-1a) and the load point displacements. Two load cells (\#3 in Figure 4-1a) measured the loads applied to the sample to a resolution of $\pm 3 \mathrm{~kg}$, yielding the principal stresses $\sigma_{1}$ and $\sigma_{2}( \pm 0.003 \mathrm{MPa})$ applied at the outer sample edges. Using the sample geometry, these stresses were translated into the normal stress $\sigma_{n}{ }^{*}$ and shear stress $\tau^{*}$ acting on the fault surface, where $*$ is used to denote macroscopic, or far-field, values on the fault. The ratio between these stresses gives the macroscopic fault friction $\mu^{*}=\tau^{*} / \sigma_{n} *$. The load point displacements $d_{1}$ and $d_{2}$ were measured using two LVDTs situated between the frame and a metal bar attached to the hydraulic presses (Figure 4-1a \#4) to within $\pm 0.25 \mu \mathrm{m}$. The macroscopic imposed displacement along the fault can be expressed as $d_{t} *=d_{1} / \cos \theta \approx 1.2$ $d_{1}$. Both the loads and the load point displacements were recorded continuously at $1 \mathrm{kHz}$. The mechanical data were filtered with a Savitsky-Golay filter to remove high frequency noise yet retain the rapid changes during stick-slip events. 
$10 \mathrm{~mm}$
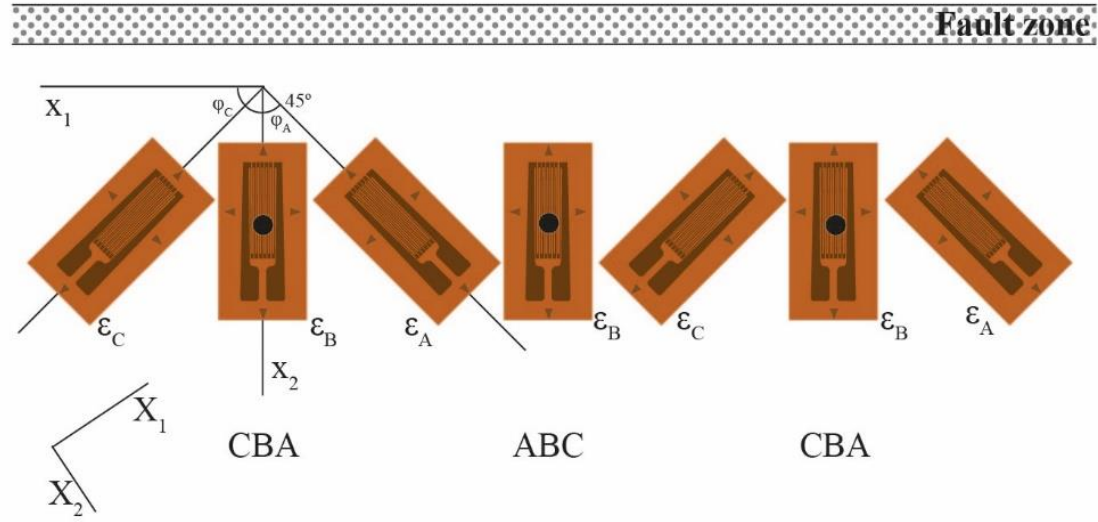

Figure 4-2. Planar rectangular strain gauge rosette setup with respect to the fault zone (view from the top of the sample). Local axis $x_{1}$ and $x_{2}$ are defined perpendicular and parallel to the fault. Strain gauges $A$ and $C$ are positioned at a 45 degree and 135 angle to $x_{1}$ respectively, whereas $B$ is perpendicular to $x_{1} . X_{1}$ and $X_{2}$ indicate the global axes along which loading $\left(\sigma_{1}\right.$ and $\left.\sigma_{2}\right)$ was applied.

Strains along the fault were measured using 46 single-component metal foil resistance strain gauges BE120-5AA (HT Sensor Technology Co. Ltd.), which have dimensions of $9 \times 4.5 \mathrm{~mm}$ (grid size $5 \times 2.5 \mathrm{~mm}$ ). The strain gauges were glued along the fault zone on the base of one the PMMA forcing blocks, with the center of each gauge located $10 \mathrm{~mm}$ from the fault zone (Figure 4-1d). The gauges were oriented at angles alternating between $135^{\circ}, 90^{\circ}, 45^{\circ}$, and $90^{\circ}$ to the fault zone (A, B, C, B in Figure 4-2), thus forming 22 rectangular strain gauge rosettes. The rosettes are labeled SG24 through SG316, with the number indicating the along-fault distance of the rosette center from the eastern end of the fault in $\mathrm{mm}$. The maximum frequency $\varphi_{c}$ that can be recorded the strain gauges is determined by their length $L_{g}(5 \mathrm{~mm})$ with respect to the wavelength of the longitudinal waves, through $\varphi_{c}=V_{P} /\left(n L_{g}\right)$. For the current setup frequencies up to $250 \mathrm{kHz}$ would be detected by the gauges $(n=2)$, but for good resolution of the recorded waveforms a higher value for $n$ is required, e.g. $n=10$ which yields a $\varphi_{c}$ of $50 \mathrm{kHz}$. The strain gauge signals were conditioned by a 28000 Signal Conditioning system with 28454A Quad-channel conditioners (Precision Filters Inc.), with a cut-off frequency set to $102.3 \mathrm{kHz}$. Strain signals were recorded continuously at $500 \mathrm{kHz}$ at a 16-bit resolution by a DS-128 High Speed Data Acquisition Instrument (Beijing Softland Times Scientific \& Technology Co. Ltd.). Four gauges malfunctioned during the experiment, causing gaps in the strain data at some locations. Strain gauge recordings were filtered with a Savitsky-Golay filter. From the strain gauge recordings, the $2 \mathrm{D}$ strain tensor can be derived for each rosette. The strains in the gauges $\mathrm{A}, \mathrm{B}$, and $\mathrm{C}$ with respect to the local principal axes $x_{1}$ and $\mathrm{x}_{2}$ can be expressed in local principal strains $\varepsilon_{1}$ (fault-normal) and $\varepsilon_{2}$ (fault-parallel) as follows: 


$$
\varepsilon_{A, B, C}=\varepsilon_{1} \cos ^{2} \varphi+\varepsilon_{2} \sin ^{2} \varphi+\gamma_{12} \sin \varphi \cos \varphi
$$

where $\varphi$ is the angle with respect to $x_{1}$. Rewriting Equation 4-4 gives

$$
\varepsilon_{A, B, C}=\frac{\varepsilon_{1}+\varepsilon_{2}}{2}+\frac{\varepsilon_{1}-\varepsilon_{2}}{2} \cos 2 \varphi+\frac{\gamma_{12}}{2} \sin 2 \varphi,
$$

which gives the strain in gauge $\mathrm{A}\left(\varphi_{\mathrm{A}}=135^{\circ}\right)$

$$
\varepsilon_{A}=\frac{\varepsilon_{1}+\varepsilon_{2}}{2}-\frac{\gamma_{12}}{2}
$$

the strain in gauge $\mathrm{B}\left(\varphi_{\mathrm{B}}=90^{\circ}\right)$

$$
\varepsilon_{B}=\varepsilon_{2}
$$

and the strain in gauge $\mathrm{C}\left(\varphi_{\mathrm{C}}=45^{\circ}\right)$

$$
\varepsilon_{C}=\frac{\varepsilon_{1}+\varepsilon_{2}}{2}+\frac{\gamma_{12}}{2}
$$

Substituting Equations 4-6, 4-7, and 4-8 gives the principal strain in the $\mathrm{x}_{1}$ direction

$$
\varepsilon_{1}=\varepsilon_{C}-\varepsilon_{B}+\varepsilon_{A}
$$

and shear strain

$$
\gamma_{12}=\varepsilon_{C}-\varepsilon_{A}
$$

The stress-strain relationship for 2D plane-stress (the bottom of the block is a free surface) is given by

$$
\left[\begin{array}{c}
\sigma_{1} \\
\sigma_{2} \\
\tau_{12}
\end{array}\right]=\left[\begin{array}{ccc}
E /\left(1-v^{2}\right) & E v /\left(1-v^{2}\right) & 0 \\
E v /\left(1-v^{2}\right) & E /\left(1-v^{2}\right) & 0 \\
0 & 0 & G
\end{array}\right]\left[\begin{array}{c}
\varepsilon_{1} \\
\varepsilon_{2} \\
\gamma_{12}
\end{array}\right]
$$

where E is Young's modulus, $v$ is Poisson's ratio, and $G$ is the shear modulus. The local shear stress along the fault $\tau$ in the area covered by the strain gauge rosette is

$$
\tau=G \gamma_{12}
$$

and the local normal stress $\sigma_{n}$ which is parallel to $\mathrm{x}_{2}$ is given as

$$
\sigma_{n}=\frac{E}{1-v^{2}}\left(\varepsilon_{2}+v \varepsilon_{1}\right)
$$




\section{Chapter 4}

The stresses computed from each rosette are given at the location of the center strain gauge (gauge B). From the changes in shear stress the nucleation process can be observed. We consider the nucleation zone as the fault length that was slipping slowly before the slip zone expanded at a steady rupture velocity of $>10 \%$ of the shear wave speed. We consider the local stress drop $\Delta \tau$ as the difference between the shear stress $0.1 \mathrm{~s}$ before the slip event and $0.1 \mathrm{~s}$ after the slip event.

The top surfaces of both PMMA forcing blocks were painted white with a black speckle pattern (Figure 4-1c) which was used for Digital Image Correlation. During the experiments the top surface was imaged by a Photron Fastcam SA2 high speed camera which was suspended in a frame above the sample. LED lights were used to illuminate the sample surface. Continuous images ( 2048 x 228 pixels) of a $350 \times 38 \mathrm{~mm}$ area centered around the fault zone $(1$ pixel $=0.17 \mathrm{~mm}$ for the gouge-filled faults, 1 pixel $=0.24 \mathrm{~mm}$ for the PMMA fault) were acquired at $1 \mathrm{~Hz}$ during parts of the experiment (Figure 4-1e). Selected slip events were imaged at framerates up to $9000 \mathrm{fps}$. Relevant image data was processed using the freely available PIVLab (Thielicke \& Stamhuis, 2014) to obtain the displacement field around the fault. The smallest window size that was used for the image processing was 22 pixels (gougefilled fault) or 16 pixels (PMMA fault), and the resolution in displacement was $\pm 5 \mu \mathrm{m}$ (Zhuo et al., 2018). The displacement field was expressed in a fault-normal or a fault-parallel direction, with respect to a given starting situation (e.g. start of shearing). To compute the relative fault-normal displacement $d_{n}$ (positive is compaction) and fault-parallel displacement $d_{t}$ (positive is left-lateral motion) the displacements along two lines parallel to the fault zone at a distance of $10 \mathrm{~mm}$ from the fault were subtracted (Zhuo et al., 2018). The fault-normal displacement can be interpreted as compaction of the fault zone, assuming the fault-normal elastic deformation is small relative to the deformation of the fault zone itself. The maximum slip rate was determined as the maximum difference in shear slip between image frames.

\section{2. 4. FE model setup}

Fault stresses were also modeled in a Finite Element model using DIANA Finite Element Analysis v10.1 (DIANA 10.1 User Manual, 2016). Both 3D model and a 2D plane stress model were constructed. The model geometry was based on the experimental set-up, including the PMMA blocks, and steel spacers of $25 \mathrm{~mm}$ along the sides. Linear elasticity was assigned to the PMMA blocks and the steel spacers, with elastic moduli for the PMMA equal to the moduli of PMMA used in the experiments ( $E: 3.3 \mathrm{GPa}, v: 0.37, \rho: 1190 \mathrm{kgm}-3$ ), and with representative elastic moduli for the steel spacers ( $E: 200 \mathrm{GPa}, v: 0.3, \rho: 7600 \mathrm{kgm}-$ 3 ). The PMMA blocks and steel spacers were modeled using linear solid elements with an unstructured mesh which was refined close to the fault zone (Figure 4-3a). Five frictional interfaces were included in the model, representing the fault zone and the four interfaces between the steel spacers and PMMA forcing blocks. The fault and steel-PMMA interfaces were modeled using planar rectangular interface elements (see also Figure 2-1b). The strength of these interfaces was governed by Mohr-Coulomb friction (Figure 2-1c) with a 
friction coefficient of 0.78 for the fault, similar to that measured in small scale experiments. The steel-PMMA interface was also modeled as a frictional interface. Here a steel-PMMA friction coefficient $\mu_{S I F}$ of 0.3 was prescribed, after measurements obtained from conventional triaxial tests where PMMA was sheared against steel along a sawcut interface. The elastic behavior of the interface elements was controlled by a normal and shear stiffness $k_{n}$ and $k_{t}$ (Figure 2-1b). High stiffnesses of $1000 \mathrm{GPA} / \mathrm{m}$ were assigned to model a stiff fault (e.g. for thin fault zones such as in the bare PMMA fault experiment) was For the compliant fault a value of $k_{n}$ was chosen such that the elastic fault-normal deformation matched the fault normal compaction observed from DIC measurements at the start of shearing $\left(k_{n}=10\right.$ $\mathrm{GPa} / \mathrm{m})$. The shear stiffness of the fault was assumed 10 times larger.
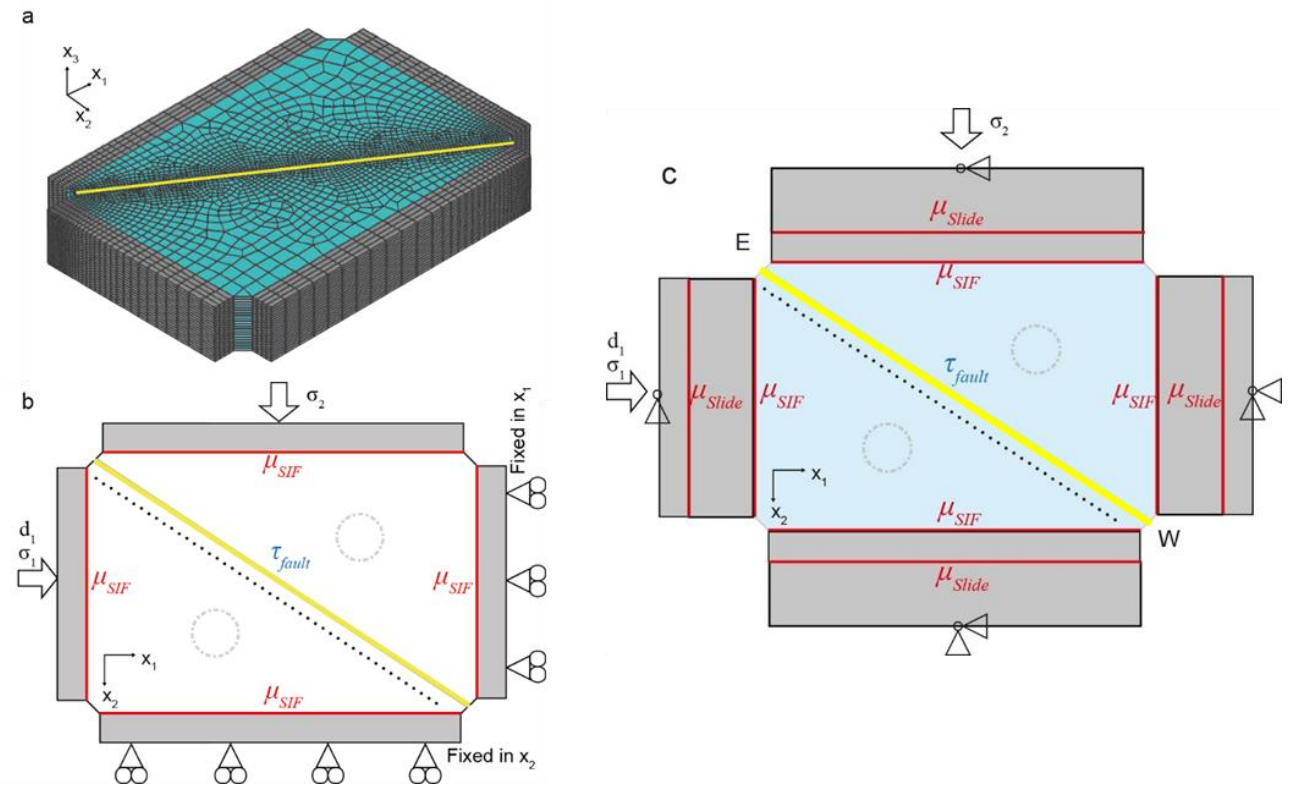

Figure 4-3. Finite Element model setup. $a$ and $b$ show the 3D model setup (model setup A), with a) example of mesh of the PMMA forcing blocks and fault. b) Top view showing the experimental geometry and the imposed boundary conditions. Stresses $\sigma_{1}$ and $\sigma_{2}$ indicate the load-controlled boundary conditions, and $d_{1}$ displacement-controlled boundary conditions. Triangles indicate roller boundaries preventing motion in either $X_{1}$ or $X_{2}$, whilst allowing motion in respectively $X_{2}$ and $X_{3}$ or $X_{1}$ and $X_{3}$. The dots along the fault indicate the position of strain measurements on the bottom of the PMMA block, agreeing with the strain gauge positions in the experiment. c) Model setup B: plane stress model setup including slide bearing plates and rotation degrees of freedom of the steel spacers.

For the 3D model roller boundaries were included to support two of the steel spacers (Figure 4-3b). These rollers prevent motion in the $\mathrm{X}_{1}$-direction (normal to the short side) and $\mathrm{x}_{2}$-direction (normal to the long side), but allow motion in the respectively $\mathrm{X}_{2}$ - and $\mathrm{X}_{1}$ direction. A constant stress load or constant displacement load was applied to the other two steel spacers. For the 2D model loads and supports were applied to the center of the steel spacers, allowing also rotation of the steel spacers (Figure 4-3c). Slide-bearing plates were 
included with low shear stiffness $(1 \mathrm{GPa} / \mathrm{m})$ to allow shear displacement along the steel spacers.

The model procedure started with initialization of gravitational body stresses. Second, the sample was loaded biaxially to $5 \mathrm{MPa}$. Third, a fixed displacement rate was prescribed parallel to $\mathrm{x}$ and the stress accordingly increased until first activation of slip in the gypsum fault.

\section{3. Results}

Here we summarize the experimental results, including the far-field mechanical data, the local stresses recorded by the strain gauge array, and the deformation field obtained from Digital Image Correlation. We focus on the experiment with the gypsum fault (hbr-17-19), but show some results for the second experiment with a gypsum fault and the experiment with a bare PMMA fault for reference.

\section{3. 1. Macroscopic fault stresses and apparent friction}

The evolution of macroscopic friction $\tau^{*} / \sigma_{n}{ }^{*}$ with time showed rapid initial hardening, followed by "yielding" towards a value of $0.75-0.8$ for both the gouge-filled faults (Figure 4-4a) or $0.45-0.5$ for the bare PMMA fault (Figure 4-4c). After a $d_{1}$ of 4.5 $\mathrm{mm}$ on the gouge-filled fault (hbr-17-19) the confining stress $\sigma_{2}$ was decreased stepwise for one of the gouge-filled experiments (hbr-17-19), during which the macroscopic shear stress decreased stepwise to reach a minimum value of $0.6 \mathrm{MPa}$ at $\sigma_{2}=0.3 \mathrm{MPa}$. Fitting the average macroscopic shear stress $\tau^{*}$ and normal stress $\sigma_{n} *$ for the different stress steps with the Mohr Coulomb criterion gives a friction coefficient of 0.78 , and a cohesion of $0.35 \mathrm{MPa}$ (Figure 4-4e). The confining stress was also varied on the bare PMMA fault, and the measured macroscopic stresses indicated a lower friction coefficient of 0.47 .

For both the gouge-filled faults and the bare PMMA fault stick-slip events persisted throughout the experiment at all $\sigma_{2}$ steps. For the gouge-filled fault the associated macroscopic stress drop $\Delta \tau^{*}$ was $0.4 \mathrm{MPa}$ at the highest stress $\left(\sigma_{2}=5 \mathrm{MPa}\right)$, with a recurrence interval of $\sim 120 \mathrm{~s}$ (Figure 4-4b). For some stick-slips, smaller friction drops were observed prior to the main stick-slip event. The macroscopic stress drop decreased from 0.4 to $0.1 \mathrm{MPa}$ at the lowest stresses, i.e. at $\sigma_{2}=0.3 \mathrm{MPa}$. The corresponding recurrence interval decreased from $120 \mathrm{~s}$ to $16 \mathrm{~s}$. The stick-slips were audible at $\sigma_{2}$ of 5, 2.5, and $1.2 \mathrm{MPa}$, but became inaudible at lower stresses. For the bare PMMA fault the $\Delta \tau^{*}$ was larger, exceeding $1 \mathrm{MPa}$ with a recurrence interval of $200 \mathrm{~s}$ (Figure 4-4d). At lower $\sigma_{2}$ the stress drop decreased to 0.3 and $0.1 \mathrm{MPa}$. 

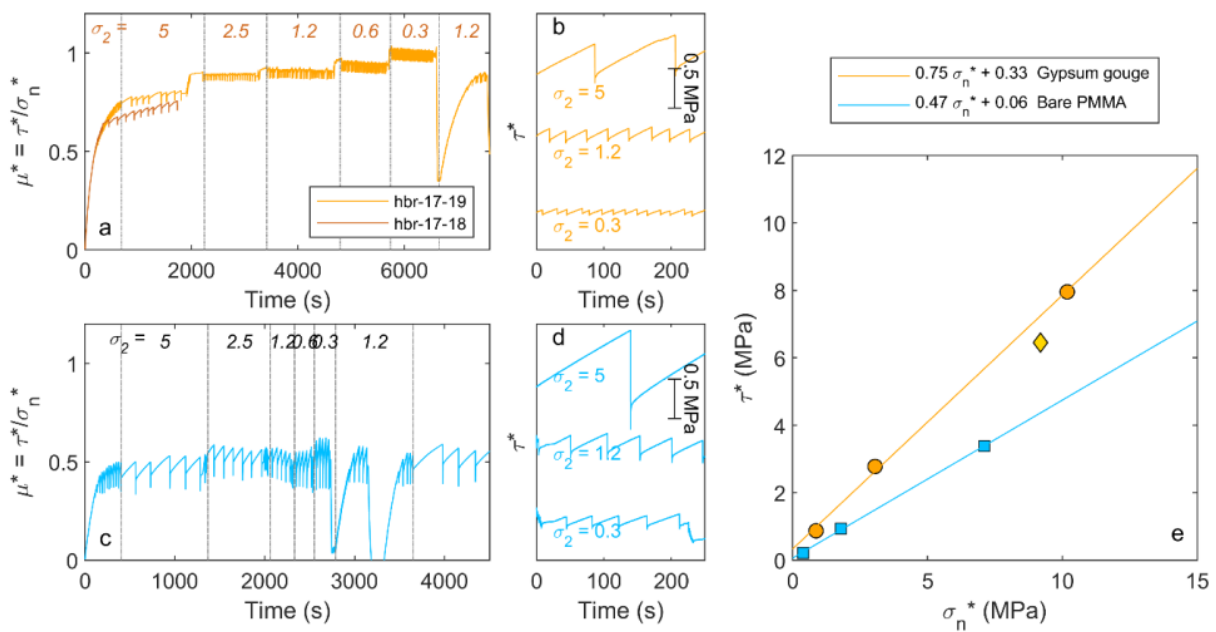

Figure 4-4. Macroscopic stresses for gypsum faults and PMMA fault.. Friction coefficient $\mu^{*}$ against time since start of shearing for a) gypsum gouge faults, and c) bare PMMA fault. The italic numbers indicate the value of constant stress boundary $\sigma_{2}$. The first dotted line indicates when the sliding velocity was stepped down from 5 to 1 $\mu \mathrm{ms}^{-1}$. Zoom in of macroscopic shear stress $\tau^{*}$ during stick-slip events at $\sigma_{2}=5, \sigma_{2}=1.2$, and $\sigma_{2}=0.3 \mathrm{MPa}$ for b)gypsum gouge faults and d) bare PMMA fault. The magnitude of the macroscopic shear stress $\tau^{*}$ is indicated by the scale bar. e) Macroscopic shear and normal stresses for gypsum gouge fault and bare PMMA fault.

\section{4 .}

\section{Local fault stresses and slip at $\sigma_{2}=5 \mathrm{MPa}$}

Local shear stresses $\tau$ along the fault margin were obtained from the strains measured by the strain gauge array plus elastic properties of the PMMA blocks (section 4. 2. 3. Figure 4-5a shows the local shear stress changes during the first loading stage following the run-in $\left(\sigma_{2}=5 \mathrm{MPa}, v_{1}=1 \mu \mathrm{ms}^{-1}\right)$. The local shear stress changes clearly show the stick-slip events which were also visible in the macroscopic mechanical data (Figure 4-4). Stick-slip events occurred at regular intervals of $\sim 120$ seconds, apart for event S1-5 which had a recurrence interval of $230 \mathrm{~s}$. The largest stress drops were observed near the ends of the fault. Several smaller stress drop events occurred near the ends of the fault between the main stick-slip events, e.g. at 1080s, 1190s, and 1670s (red arrows). The increase in local shear stress due to loading was not uniform along the fault zone; near the eastern end (i.e. at the side where loading is applied) the shear stress increase was larger than near the western end of the fault. The local shear stresses between stick-slip events increased in a near-linear manner in response to loading imposed by the machine, but in particular near the fault ends the shear stress increase deviated from the linear trend. Such deviations indicate the onset of precursory slip related to nucleation of stick-slip instability (see e.g. Dieterich, 1992; McLaskey \& Kilgore, 2013; Ohnaka et al., 1986; Yamashita et al., 2018), as slip relaxes the shear stresses in the medium around the fault. 

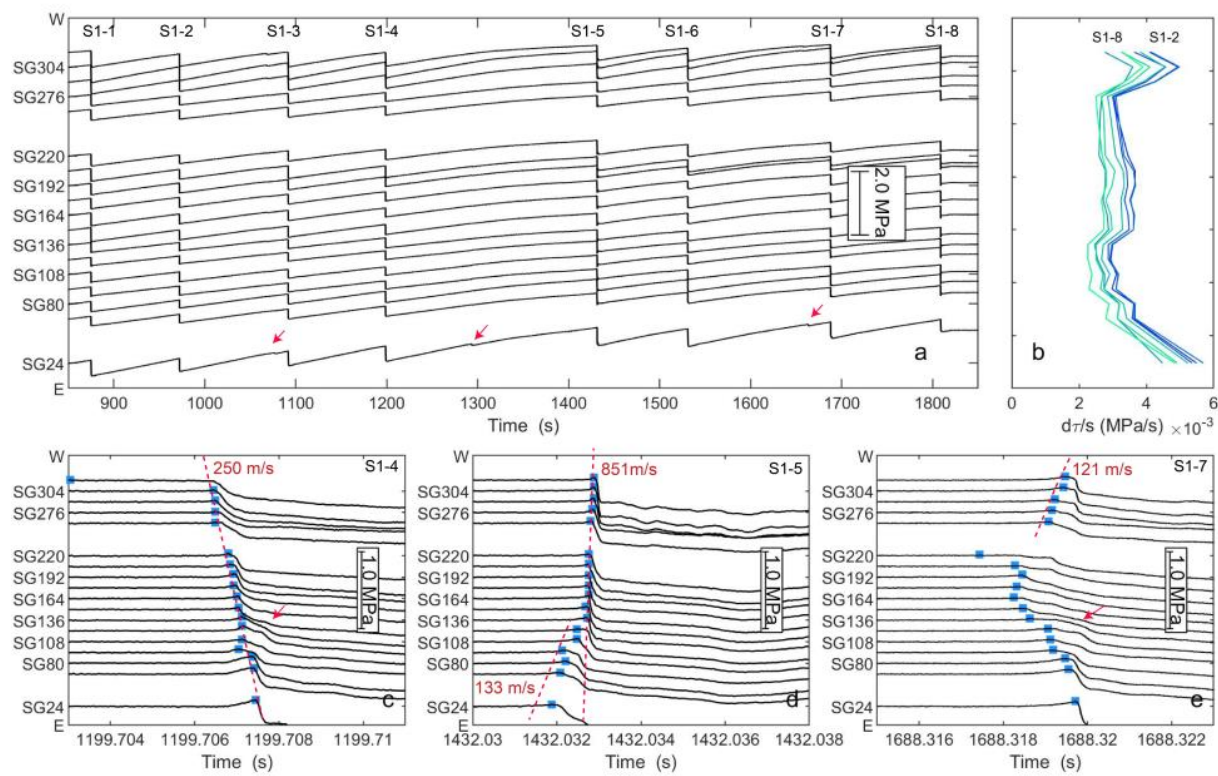

Figure 4-5. Overview of local shear stresses obtained from the strain gauge measurements during stick-slip events observed the gypsum fault (hbr-17-19) during sliding at a confining stress $\sigma_{2}$ of 5 MPa and a load point velocity $v_{1}$ of $1 \mu \mathrm{ms}^{-1}$. The locations of the strain gauges are indicated by the SG axes labels, where the number indicates the position in $\mathrm{mm}$ with respect to the eastern end $(E)$. The magnitude of the stress change is given by the scale bar. a) Local shear stresses 850 - $1850 \mathrm{~s}$ (load point displacement $3.7-4.2 \mathrm{~mm}$ ), b) shear stress rate between stick-slip events. This rate is obtained by linear fits of the shear stress over the time interval $2 \mathrm{~s}$ after the previous events to $2 \mathrm{~s}$ before the next event, $c-e$ ) Zoomed-in view of local shear stresses during stick-slip events S1-4, S1-5, and S1-7. Blue markers indicate peak shear stresses. The dotted lines show fits of the peak stresses which give rupture velocity $v_{r}$.

A closer inspection of the shear stresses recorded during the stick-slip events shows that nucleation of (fast) slip starts from either end of the fault zone (Figure 4-5c and e) or from a broader zone near the center of the fault (Figure 4-5e). The nucleation location of all events shown in Figure 4-5a is summarized in Figure 4-6. For the events nucleating at the ends the local shear stress was observed to decrease prior to the stick-slip at the gauge locations closest to the end indicating slow slip, e.g. at SG318 in case of event S1-4 (Figure 4-5c). This slow slip zone then accelerated into a dynamic event propagating from SG304 to the other end of the sample at an average rupture velocity $v_{r}$ of $250 \mathrm{~ms}^{-1}$, i.e. 0.2 times the Rayleigh wave speed $\left(V_{R}=1350 \mathrm{~ms}^{-1}\right)$. The size of the nucleation zone for this event was thus $\sim 40 \mathrm{~mm}$ (distance from western edge to SG304). A larger nucleation zone of $\sim 120 \mathrm{~mm}$ was observed for events starting at the other end of the sample. For event S1-5, for example, yielding started at SG24 and the slow slip zone expanded up to SG124 before transitioning into a dynamic event (Figure 4-7c). The average rupture velocity $v_{r}$ of this event was larger with $851 \mathrm{~ms}^{-1}$, which is $>60 \%$ of $\mathrm{V}_{\mathrm{S}}$. For both events, local accelerations and deceleration of rupture velocity were observed. The rupture velocity was typically fastest in the center of the fault (SG136 - SG220) and the W-end of the fault (SG262 - SG 318) (Figure 4-6b). Rupture 
usually decelerated between SG108 - SG136, as can for example be seen for event S1-4 (Figure 4-5c).

Other slip events nucleated from a position closer to the central portion of the fault (SG192-SG220). Some of the events were preceded by a smaller slip event which nucleated at the fault end but was arrested. For event S1-7 for example a small event was observed 0.07 $\mathrm{s}$ prior to the main event which started at the western end but was arrested between SG262 and SG220 (not shown). Following this event a gradual decrease in local shear stress (local yielding) indicated that slow slip continued in the central portion of the fault (Figure 4-5e). At $1688.318 \mathrm{~s}$ the slow slip zone accelerated towards the ends of the fault reaching a rupture velocity of $\sim 120 \mathrm{~ms}^{-1}, \sim 0.1 \mathrm{~V}_{\mathrm{R}}$ Such low velocities were characteristic for the events nucleating near the center of the fault, as the slip zone was still accelerating as it reached the fault ends (Figure 4-6). Upon reaching the one of the fault ends a secondary rupture front propagated back along the fault resulting in a large stress drop at the ends and further stress release in the center (Figure 4-5e). This rupture velocity of the secondary front is faster than for the primary rupture, but it is not resolved well enough to obtain the rupture velocity.

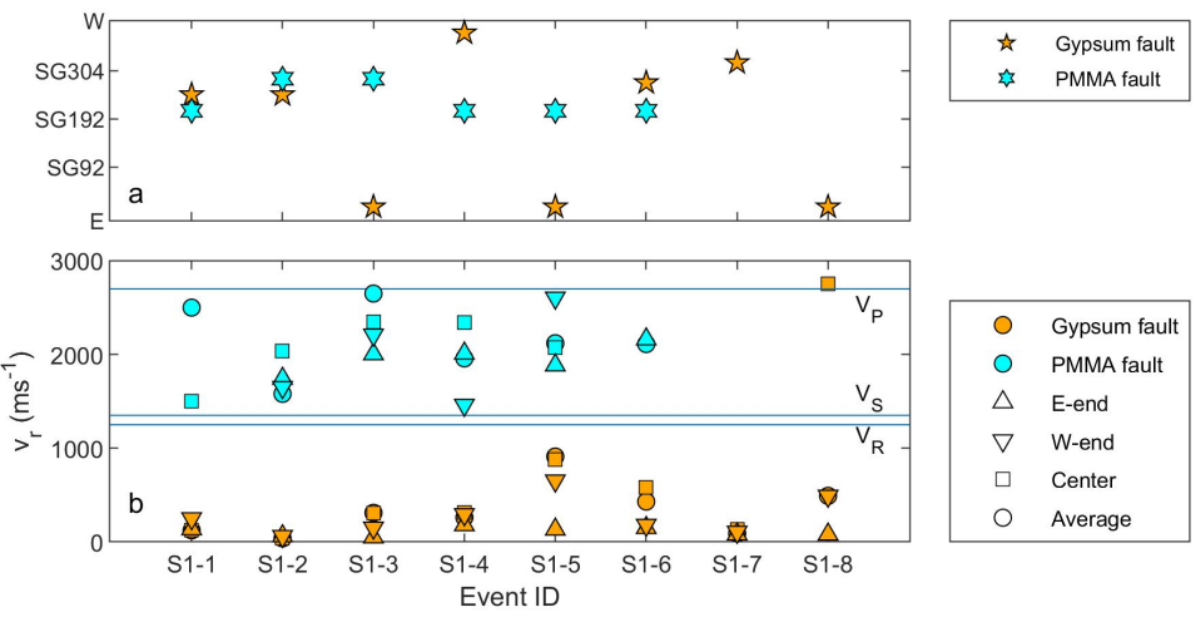

Figure 4-6. Nucleation site and rupture velocities measured on the gypsum gouge faults and the bare PMMA fault. a) Nucleation site for the different faults given as distance along the fault (sensor locations as in Figure 4-4). The nucleation site is taken as the strain gauge location at which slow yielding was first observed, or, in case no such slow slip zone is recognized, the point from which rupture accelerates. b) Rupture velocities measured by fitting peak shear stresses during rupture. The average rupture velocity (squares) is the rupture velocity measured after rupture propagates at a constant velocity, or, for events nucleating from the center, the average velocity with which the slip zone propagates towards the fault ends. The rupture velocity is also determined for the E-end, W-end, and center, where the rupture velocity is averaged between respectively SG24 - SG122, SG248 - SG318, and SG136 SG220. 


\section{Chapter 4}
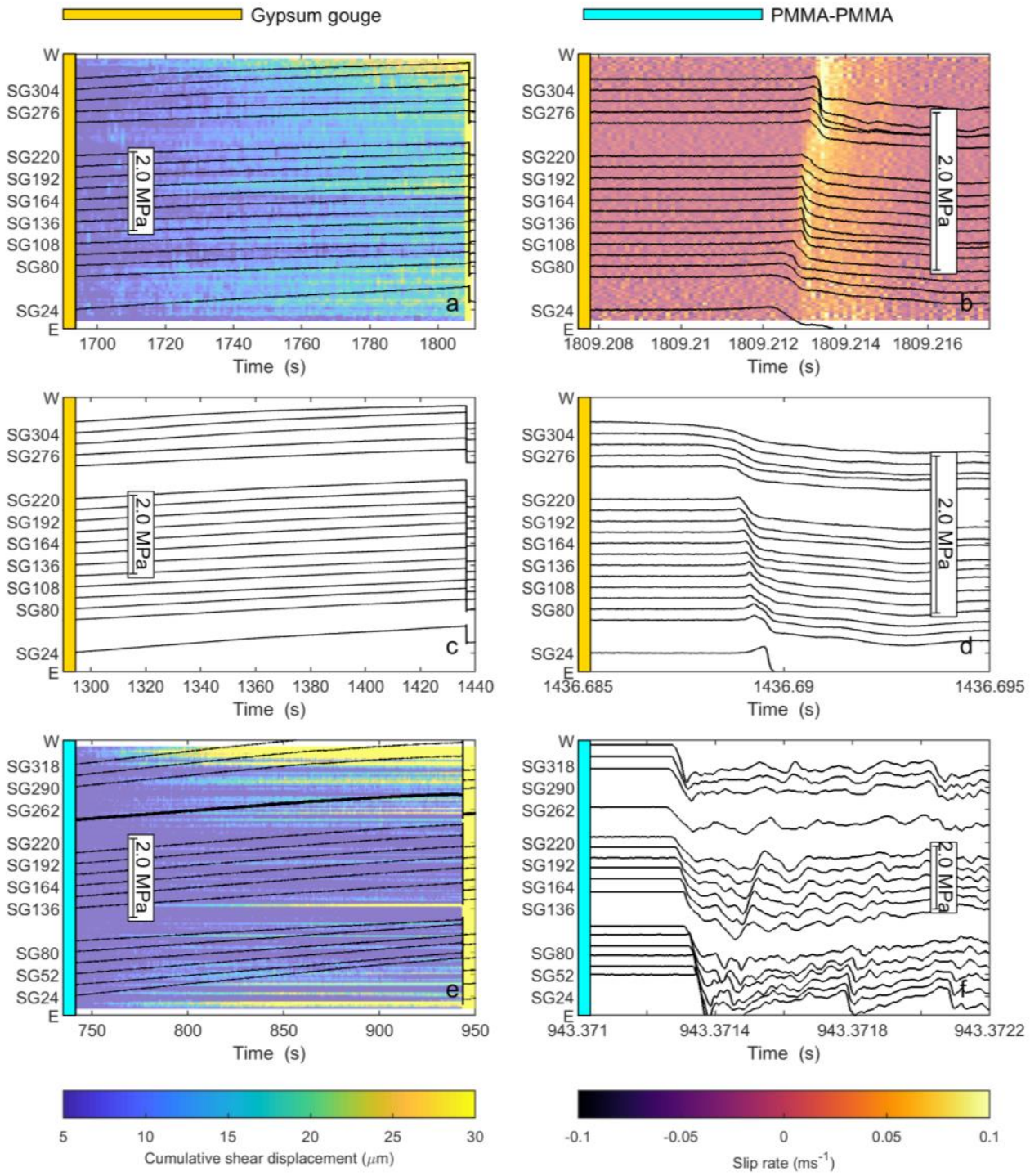

Figure 4-7. Comparison of local shear stress changes and slip during slip events on a gypsum fault (experiments hbr-17-19 and hbr-17-18) and on a bare PMMA fault (experiment hbr-19-31). All results are obtained at $\sigma_{2}=5$ MPa and a load point velocity of $1 \mu \mathrm{ms}^{-1}$. Background colors give cumulative shear slip or the slip rate obtained from Digital Image Correlation, where available. Note that the cumulative shear slip is truncated at $30 \mu m$ to highlight slip occurring prior to the slip events. a) Interseismic period following event S1-7 up to event S1-8 (Figure $4-5 a), b)$ zoomed-in view of shear stresses and slip rates for event $51-8, c$ ) shear stresses during the interseismic period for the second gypsum fault experiment (hbr-17-18), d) zoomed-in view of the shear stress changes of the event shown in $c$, e) shear stresses and cumulative slip during the interseismic period for the bare PMMA fault, and f) zoomed-in view of shear stresses during the slip event shown in e. 
Digital Image Correlation was used to analyze the fault shear and normal displacements for the last event in Figure 4-5a (S1-8), which nucleated at the E-end of the fault. Image data acquired at $1 \mathrm{fps}$ shows precursory slip occurred over almost the entire interseismic period on a large fraction of the fault (Figure 4-7a). Consistent with the nonlinear stress increase visible in the stress traces near the fault ends in Figure 4-5a, DIC showed most precursory slip occurred near the fault ends, amounting to $20-30 \mu \mathrm{m}$ just prior to the slip event. However, also in the center of the fault (SG164 - SG192) 20 - $25 \mu \mathrm{m}$ of slip was observed, whereas less slip was observed between SG80 and SG164. Note that this slip is actually the relative shear displacement across the fault which was determined by subtracting displacements $10 \mathrm{~mm}$ on either side of the fault. This displacement also contained elastic deformation of the PMMA forcing blocks. Prior to events S1-8 the stress increase along the fault varied between $0.25-0.3 \mathrm{MPa}$ in the center of the fault to $0.4-0.5 \mathrm{MPa}$ at the fault ends (Figure 4-5a, b). For such a stress increase of $0.5 \mathrm{MPa}$ the elastic shear deformation over $20 \mathrm{~mm}$ of PMMA would be $10 \mu \mathrm{m}$, leaving $10-20 \mu \mathrm{m}$ of shear displacement accommodated by the gouge layer at the fault ends.. A comparable displacement remains at the fault center after subtracting the elastic deformation. At 1809.213 yielding of the shear stress showed that a $\sim 100 \mathrm{~mm}$ wide slip zone near the E-end accelerated and transitioned into a fast slip event that propagated towards the W-end (Figure 4-7b). Rupture decelerated around SG220 - SG276, but accelerated again as the W-end of the fault ruptured. The slip obtained from DIC indicated a total shear slip of $100 \mu \mathrm{m}$, and the slip rate ranged up to 0.1 $\mathrm{ms}^{-1}$, which is a lower bound estimate as the sampling interval of the images was $0.11 \mathrm{~ms}$. The average rupture velocity of this event was $491 \mathrm{~ms}^{-1}$, but locally rupture propagated faster, attaining supershear velocities approaching $V_{P}$ in the center of the fault.

\section{4. 1. Comparison between gouge-filled faults and bare PMMA fault}

For comparison a second experiment was performed on a gypsum fault, and a third experiment on a fault without gouge (bare PMMA surfaces). For the second gypsum experiment less variability was observed for the nucleation site than for the experiment shown in Figure 4-5. Most events nucleated from the eastern end of the fault (e.g. Figure 4-7c and $\mathrm{d}$ ), but some events also nucleated from $1 / 3$ of the fault length from the $\mathrm{W}$-end near SG220 (not shown). Rupture velocities are somewhat faster with $190-400 \mathrm{~ms}^{-1}$ for the events nucleating from the ends, and $150 \mathrm{~ms}^{-1}$ for the events nucleating from SG220. Contrary to the other gouge experiment hbr-17-19, no events nucleated near the eastern end. Note however that for both experiments the total number of stick-slip events at $\sigma_{2}=5 \mathrm{MPa}$ was limited; it is possible that less variability in nucleation location would be observed for larger load point displacements.

Slip events on the PMMA fault showed different behavior compared to those observed on the gypsum gouge fault. The recurrence time (200s) and stress drop (1 MPa) were almost twice as large as for the gouge-filled faults. Even though the recurrence time was longer and the amount of stress build-up was larger, less precursory slip was observed 


\section{Chapter 4}

on the PMMA fault (almost none in the middle of the fault) except for the western end where up to $60 \mu \mathrm{m}$ of relative shear displacement was observed in the interseismic period (Figure 4-7e) $(20-30 \mu \mathrm{m}$ of which may be elastic). Events always nucleated from the same location, accelerating from $\sim \mathrm{SG} 192$ - SG248 which is adjacent to the western end of the fault where most precursory slip occurred (Figure 4-7f). This location is the same as the location from which the center events nucleated on the gypsum fault (see Figure 4-6a for comparison of the nucleation location).

Image data (2000 fps) indicated a total shear slip of 160 - $200 \mu \mathrm{m}$ was achieved along the PMMA fault over the slip event. Assuming most of this slip occurred within the duration of the main slip event shown in Figure 4-7f ( $\sim .05 \mathrm{~ms})$, slip rates may have exceeded several $\mathrm{ms}^{-1}$. Rupture propagation on the bare PMMA fault was also much faster than for the gouge experiments, reaching supershear velocities close to the P-wave speed of $2700 \mathrm{~ms}^{-1}$. As the rupture reached the eastern fault end, a secondary rupture front propagated back across the fault towards the western end, similar to secondary rupture fronts as observed by e.g. Kammer \& McLaskey (2019) and Xu et al. (2019) . The rupture velocity of this secondary front was lower than that of the primary rupture, with an average rupture velocity of $\sim 1200$ $\mathrm{ms}^{-1}$, close to the Rayleigh wave velocity of $1237 \mathrm{~ms}^{-1}$. Following the secondary front, shear stress increased near the eastern end of the fault until this fault end reruptured, about $0.4 \mathrm{~ms}$ after the main event. Such a shear stress increase and rerupture also was observed $0.2 \mathrm{~ms}$ later near the western end, and then for the second time at the eastern fault end. Rerupturing events also occurred at supershear rupture velocities. Compared to the gypsum fault experiment the rupture velocities were much faster on the bare PMMA fault, with supershear rupture velocities on the different parts of the fault (Figure 4-6b). For the gypsum fault only sub-Rayleigh rupture velocities were observed, apart from those seen on the center of the fault in S1-8 (Figure 4-7f b). For events nucleating at the fault ends the rupture velocity varied between 300 and $900 \mathrm{~ms}^{-1}\left(0.2-0.7 \mathrm{~V}_{\mathrm{R}}\right)$.

\section{4. 2. Stresses observed on the gouge-filled faults and bare PMMA fault and FE modeling of fault stress}

To understand the nucleation and propagation of the slip events in the different experiments, it is useful to consider the stress distribution. Figure 4-8 shows the shear stress and the normal stress distributions prior to the main stick-slip events observed in Figure 4-7, as well as the observed stress drop. Note that for each experiment these stress distributions are persistent for the entire slip stage at $5 \mathrm{MPa}$ and $1 \mu \mathrm{ms}^{-1}$. For PMMA the magnitude of recorded stresses also does not change significantly between events, but for the gouge-filled faults the local shear stresses increases by $0.5-1 \mathrm{MPa}$ from the beginning to the end of the slip stage, whereas the local normal stresses decrease by $1 \mathrm{MPa}$. Shear stresses are lowest for the PMMA fault, reflecting the lower friction coefficient that was also observed macroscopically. Note that the average normal stress of $5 \mathrm{MPa}$ recorded for the gouge-filled faults (Figure 4-8c) is significantly less than the macroscopic value ( $\sigma_{n}^{*}=10 \mathrm{MPa}$ ). Note 
however that normal stress measurements near the eastern fault end are not available. As for the PMMA fault, the normal stress near this fault end ay be concentrated, as also supported by the fault normal displacements derived from DIC measurements (next section). In this case the average normal stress along would be higher, underlining the importance of having good spatial resolution when comparing local fault stress to macroscopic, far-field values.
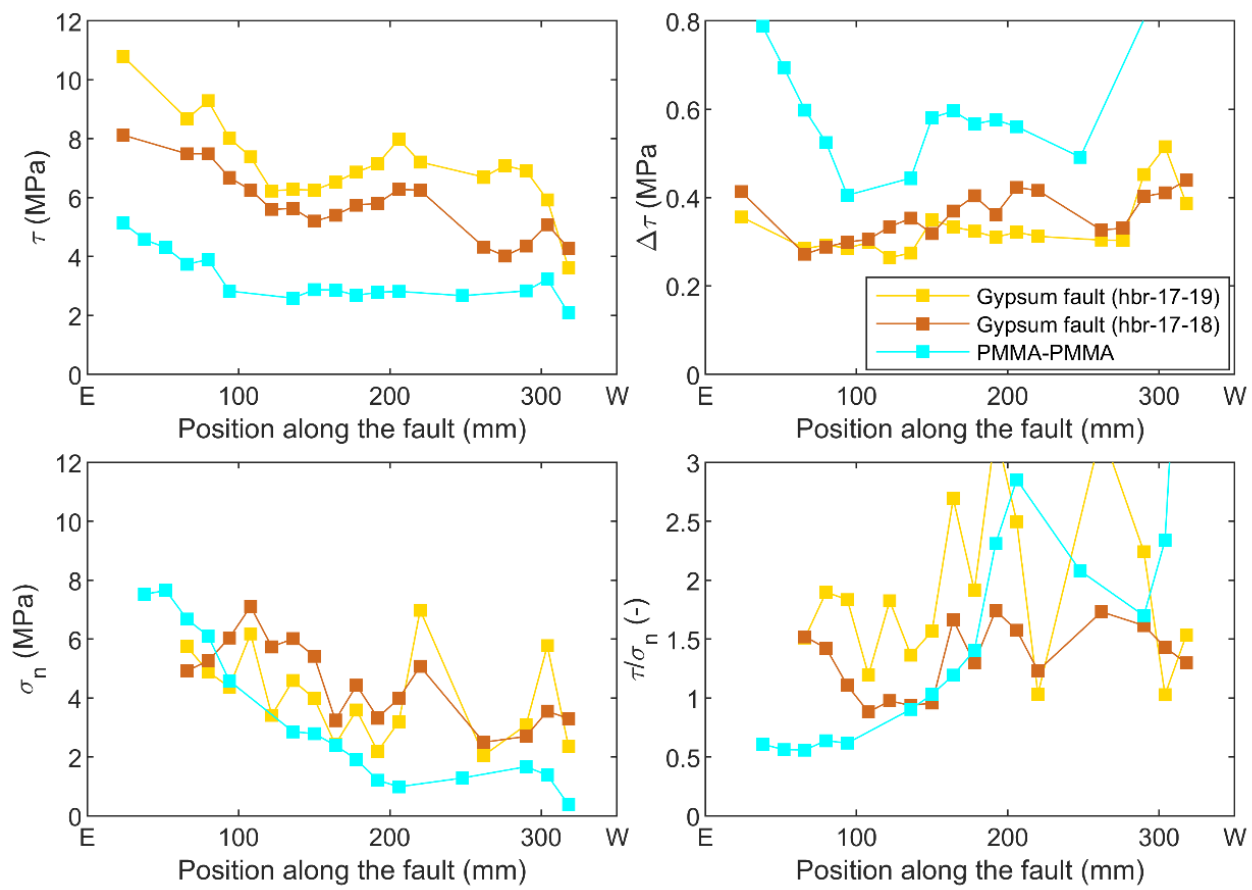

Figure 4-8. Stresses, stress drops, and stress ratio measured along the gouge-filled faults and bare PMMA fault. The shear and normal stress are the values recorded prior to stick-slip at $\sigma_{2}=5 \mathrm{MPa}$ and $v_{1}=1 \mu \mathrm{ms}^{-1}$. a) shear stress $\tau$, b) shear stress drop $\Delta \tau c$ ) normal stress $\sigma_{n}$, and d) the ratio between shear and normal stress $\tau / \sigma_{n}$.

An asymmetric shear and normal stress distribution is observed for all three experiments, with both shear and normal stress increasing towards the eastern end of the fault (i.e. the end where load was applied, Figure 4-1). In particular for the bare PMMA fault the normal stress is very high at the E-end compared to the W-end. A Finite Element model described in Section 4. 2. 4. (Figure 4-3) can qualitatively reproduce this asymmetric trend (Figure 4-9). The asymmetry of the modeled stress derived from the boundary conditions, mainly rotation of the steel spacers (Figure 4-10) and friction between the PMMA-steel interface and the slide-bearing plates (Figure 4-11). Note that the modeled stress distribution is also sensitive to deformation of the fault zone itself, which is particularly important for the experiments with a gouge-filled fault because the gouge layer may compact. In the FE model the effect of fault zone deformation on the fault stress was investigated by changing the normal and/or shear stiffness of the fault. The model results indicate that a more compliant 


\section{Chapter 4}

fault zone in the shear and/or normal direction relaxes respectively the peaks in shear and/or normal stress (Figure 4-12). Hence, compaction of the gouge-filled layer might locally reduce normal stress concentrations such as those at the fault ends; however it was not possible to place strain gauges very close to the fault ends to verify this effect.
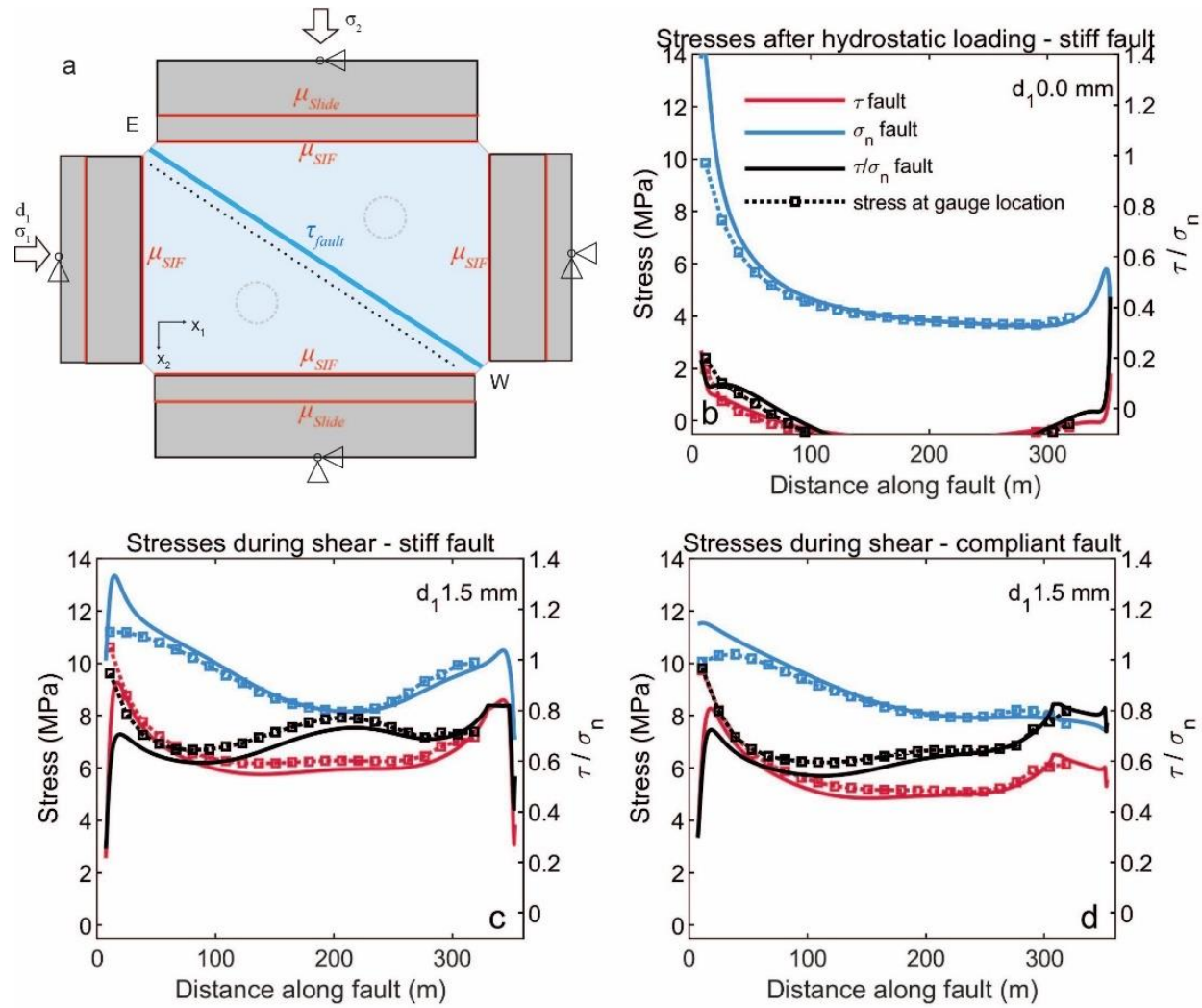

Figure 4-9. Finite Element model of fault stresses. $b$ ) Modeled stresses after hydrostatic loading to $\sigma_{1}=\sigma_{2}=5 \mathrm{MPa}$ using a stiff fault (fault normal and shear stiffness $1000 \mathrm{GPa}$ ), c) Modeled stresses after hydrostatic loading and imposed load point displacement of $1.5 \mathrm{~mm}$ using a stiff fault, d) Modeled stresses after hydrostatic loading and imposed load point displacement using a fault which is compliant in the normal direction (normal stiffness 10 GPa). Modeled stresses on the fault (solid lines) and at the gauge locations (markers). 

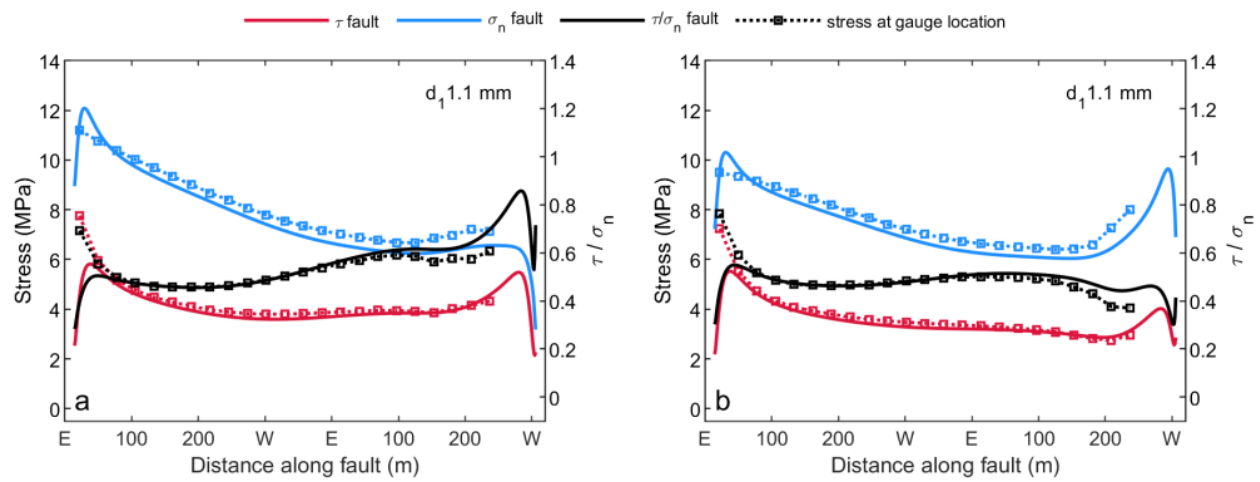

Figure 4-10. Effect of allowing rotation of steel spacers on fault stresses. a) Fault stresses for a scenario where rotation of steel spacers around vertical axis is allowed. b) Fault stresses for a scenario where rotation of steel spacers around vertical axis prohibited.
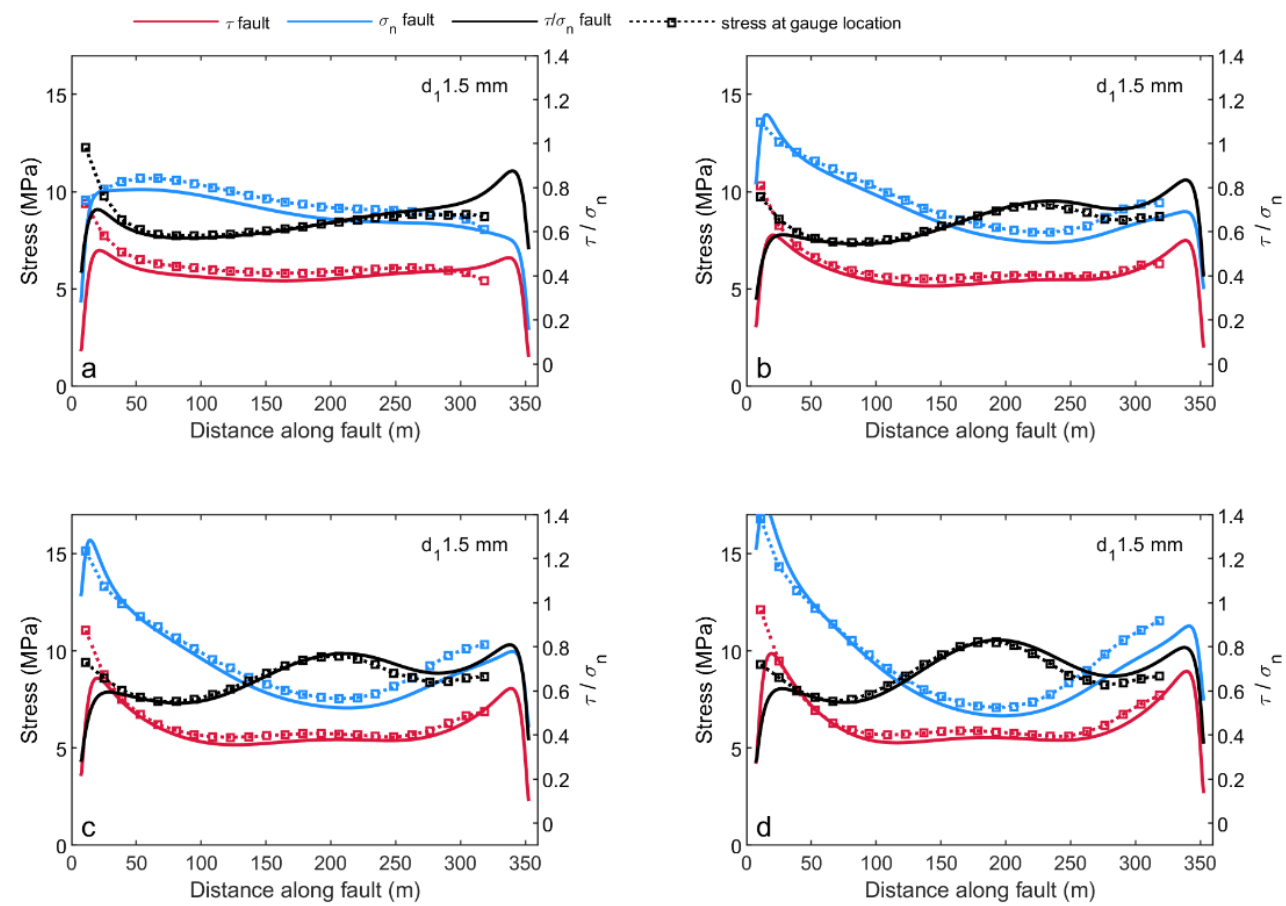

Figure 4-11. Effect of PMMA-steel interface friction on fault stresses. a) $\mu_{S I F}=0.1$, a) $\left.\mu_{S I F}=0.4, a\right) \mu_{S I F}=0.6, d$ ) $\mu_{S I F}=0.9$. Load point displacement $d_{1}$ as indicated . 

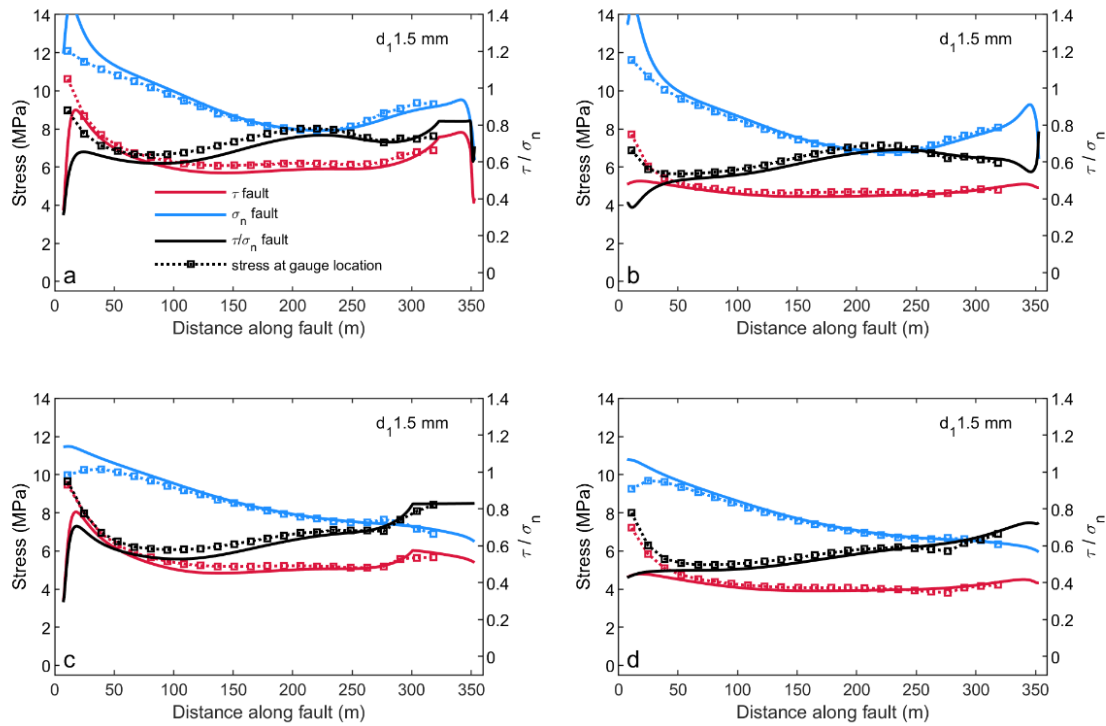

Figure 4-12. Effect of elastic deformation of the fault zone on fault stresses. Fault stresses for different values of normal stiffness $k_{n}$ and shear stiffness $k_{t}$ are shown at a load point displacement $d_{1}$ of $1 \mathrm{~mm}$. a) stiff fault with a normal and shear stiffness of $1000 \mathrm{GPa} / \mathrm{m}, \mathrm{b})$ fault zone that is compliant $(10 \mathrm{GPa} / \mathrm{m})$ in the shear direction and stiff in the normal direction $(1000 \mathrm{GPa} / \mathrm{m}), \mathrm{c})$ fault zone that is stiff $(1000 \mathrm{GPa} / \mathrm{m})$ in the shear direction and compliant $(10 \mathrm{GPa} / \mathrm{m})$ in the normal direction, d) compliant fault $(10 \mathrm{GPa} / \mathrm{m})$. Modeling of the effect of gouge loss on normal stress

An additional complication in comparing the measured stress to the macroscopic stress, and the modeled stress, is the effect of gouge loss. Visual inspection of the gouge layer and PMMA forcing blocks after the experiment showed that parts of the gouge layer were cohesive, and compacted gouge stuck to the PMMA over most of the fault surface. However, in a zone of several $\mathrm{mm}$ along the fault margins the gouge was still powdery, and no gouge remained stuck to the fault surface, indicating that the gouge may locally have been extruded, and/or too loose to support the load and compact. To evaluate the (potential) effects of gouge loss on the strain measurements the Finite Element model (model setup A) was adapted to include a gouge layer of a certain height. To simulate the effect of gouge loss, an endmember model was built where $5 \mathrm{~mm}$ at the top and bottom of the fault zone did not contain any gouge (Figure 4-13a). This endmember case was compared to the base case where the gouge layer was present over the entire surface. 

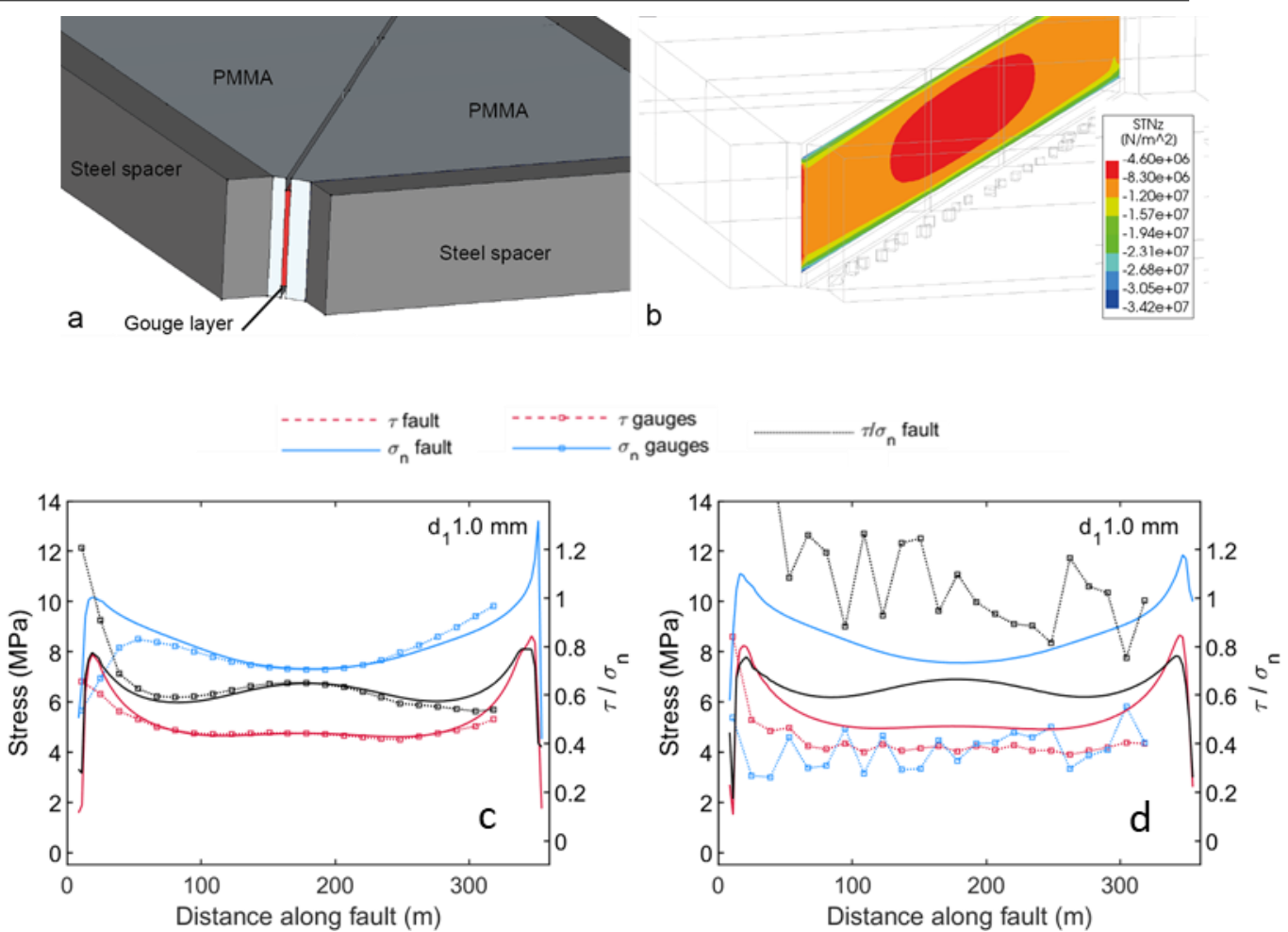

Figure 4-13. Effect of gouge loss on fault stresses. Confining pressure $\sigma_{2}=5 \mathrm{MPa}$ and the load point displacement is 1 mm.a) 3D Model geometry for evaluating the effect of gouge loss on recorded stresses at the strain gauge locations. The top and bottom $5 \mathrm{~mm}$ of the fault are left open to simulate gouge loss. $b$ ) Fault normal stress after 1 mm of load point displacement. c) Fault stresses for endmember case without gouge loss. d) Fault stresses for endmember case where $5 \mathrm{~mm}$ along the fault margins the gouge layer is absent. Solid lines indicate the normal (blue) and shear (red) stress along the center of the fault; markers indicated the normal and shear stresses at the strain gauge locations. Black line: shear stress/normal stress.

The absence of gouge along the fault margins had a strong effect on the normal stress distribution on the fault and the normal stresses recorded at the strain gauge locations. At the fault center the normal stress was similar to the base case scenario without gouge loss $(\sim=8$ $\mathrm{MPa}$ ) but at the top and bottom margins of the gouge layer the normal stress was concentrated (Figure 4-13 b). In the PMMA blocks along the top and bottom margins of the fault the normal stress decreased strongly, as near the top and bottom no gouge layer was present to support the normal stress. The modeled stress at the strain gauge locations was about $50 \%$ of the normal stress at the fault center (Figure 4-13c). The shear stress modeled at the strain gauge location was less affected by the absence of gouge along the fault margins. It was 10 $-20 \%$ lower than the shear stress at the center of the fault. Consequently, the modeled stress ratio at the strain gauge locations was significantly higher than the stress ratio acting on the fault and exceeded 1. Hence, the gouge loss may provide an additional explanation for the discrepancy between macroscopic normal stress and the local normal stress, and the effect of gouge loss may be reflected by the aforementioned decrease of $1 \mathrm{MPa}$ in normal stress with 


\section{Chapter 4}

displacement during the slip stage at $5 \mathrm{MPa}$ and $1 \mu \mathrm{ms}^{-1}$. Such a decrease in normal stress with slip was not observed for the bare PMMA fault.

The modeled normal stress on the bare PMMA fault decreased towards the $\mathrm{W}$-end of the fault, and consequently the modeled $\tau / \sigma_{n}$ was higher on the $\mathrm{W}$-end of the fault, in agreement with the strain data. For the bare PMMA this is the side where most precursory slip was observed (Figure 4-7e) and where fault rupture nucleated persistently, near SG248 (e.g. Figure 4-7f). Although the overall distribution of fault stress is similar for the gougefilled fault, smaller length-scale stress variations were observed which were lacking for the bare fault (Figure 4-8). This is in particular visible in the normal stress distribution, with for example strong normal stress concentrations near SG220 and SG306 (Figure 4-8). Stress variability was larger for hbr-17-19 than for hbr-17-18. On average $\tau / \sigma_{n}$ was larger on the western side of the fault, and lowest between $50-150 \mathrm{~mm}$ from the eastern end. The small length-scale stress variations were not reproduced in the FE model, but appear to derive from the presence of the gouge layer. In the next section we further analyze the deformation of the gouge layer itself.

\section{4. 3. Fault relative shear and normal displacements during loading and $\sigma 2=5 \mathrm{MPa}$}

The fault gouge not only accommodates shear displacement, but can also accommodate fault normal deformation - i.e. the gouge layer can experience compaction. Digital Image Correlations showed that during the pre-compaction phase ( $\left.\sigma_{1}=\sigma_{2}=20 \mathrm{MPa}\right)$, the average fault-normal displacement $d_{n}$ (hereafter: compaction) over the fault was almost $0.5 \mathrm{~mm}$, which is $25 \%$ of the original thickness of the gouge (Figure 4-14a). However, compaction was very heterogeneous along the fault, with maxima at the two fault ends and at the center, the largest of which was found near the eastern end of $\left(d_{n}=0.65 \mathrm{~mm}\right)$ where the FE model also predicts the highest normal stress (Figure 4-9). A smaller scale heterogeneity in compaction was observed at $250 \mathrm{~mm}$ from the fault end, where a local maximum was flanked by two minima at 220 and $270 \mathrm{~mm}$ from the fault end. At the start of shearing $\left(\sigma_{2}=5 \mathrm{MPa}\right)$ the same distribution was still present on the fault (note that the difference in $d_{n}$ at $20 \mathrm{MPa}$ and pre-shear $5 \mathrm{MPa}$ is due to elastic relaxation of the PMMA to the sides of the fault). Even after $4 \mathrm{~mm}$ of load point displacement the compaction pattern persisted.

Shear displacement $d_{t}$ was distributed more homogeneously along the fault. Prior to shearing, the measured shear displacement was zero except at the ends. Here, the different shape of the forcing blocks (the corner of one block has an angle of 33.7, the other of $56.3^{\circ}$ ) and the proximity to the steel forcing blocks causes differential elastic shear deformation across the fault (see also Figure 4-9a). During shearing the shear displacement was largest at the western end $(350 \mathrm{~mm})$ and decreased towards the other end, reaching a local minimum $80 \mathrm{~mm}$ from the end. At a load point displacement $d_{l}$ of $4 \mathrm{~mm}$, the average local $d_{t}$ was 2.75 $\mathrm{mm}$, showing that the PMMA blocks accommodate more than $1 \mathrm{~mm}$ of the imposed displacement elastically. 

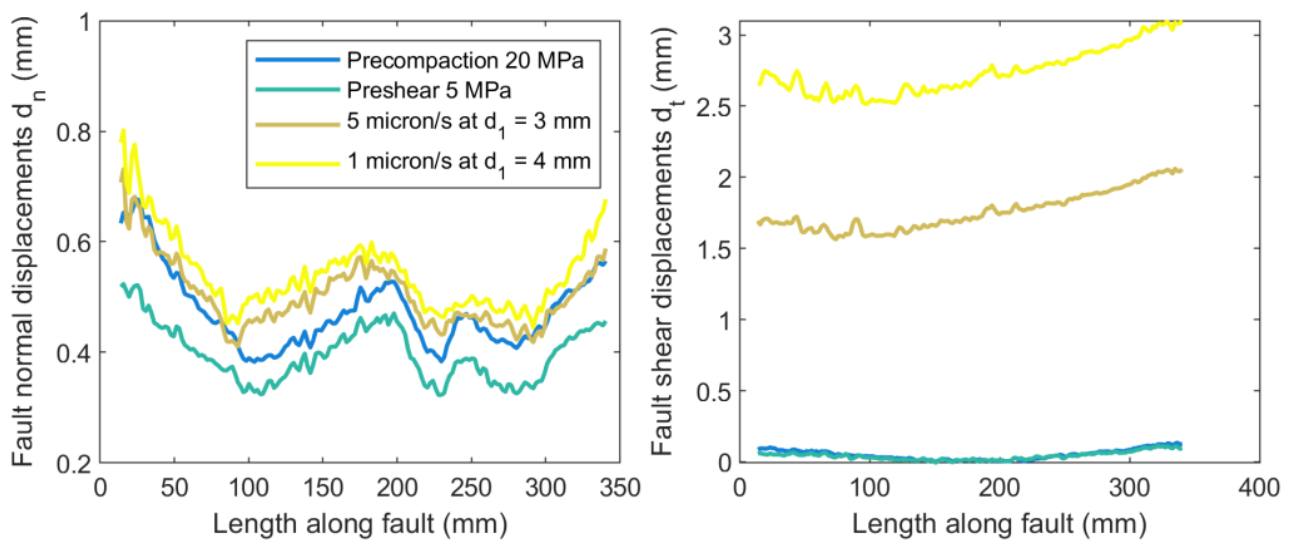

Figure 4-14. Fault normal and shear displacements along the fault obtained from DIC measurements, at various stages during the experiment. The along-fault distance is given with respect to the eastern end of the fault. Displacements are relative to the start of the experiment when the sample was not loaded. a) Fault normal displacements, b) Fault shear displacements.

\section{5. Nucleation on the gypsum fault at lower confining stresses}

With lower normal stress the nucleation zone size increased and started to interact more with the sample ends (Figure 4-15). In fact, no constant rupture velocity was attained before the nucleation zone reached the ends, indicating that the nucleation process was ongoing and the slip zone was still accelerating. Typically, stress release related to precursory slip started a few cm to the west of the fault center, near SG220 (Figure 4-15, Figure 4-16a). The image data for $\sigma_{2}=2.5 \mathrm{MPa}$ show the occurrence of precursory slip in the center of the fault (SG192 - SG220) and near the western fault end (Figure 4-15a), accumulating to $\sim 10 \mu \mathrm{m}$ prior to the onset of instability. The length of the nucleation zone increased with the lower $\sigma_{2}$ to cover most of the fault center. For example, at 1.2 MPa nucleation occurred along the fault center from SG94 - SG262, and at the lowest $\sigma_{2}$ of 0.3 MPa slow slip occurred from SG94 SG220 (Figure 4-15f). 

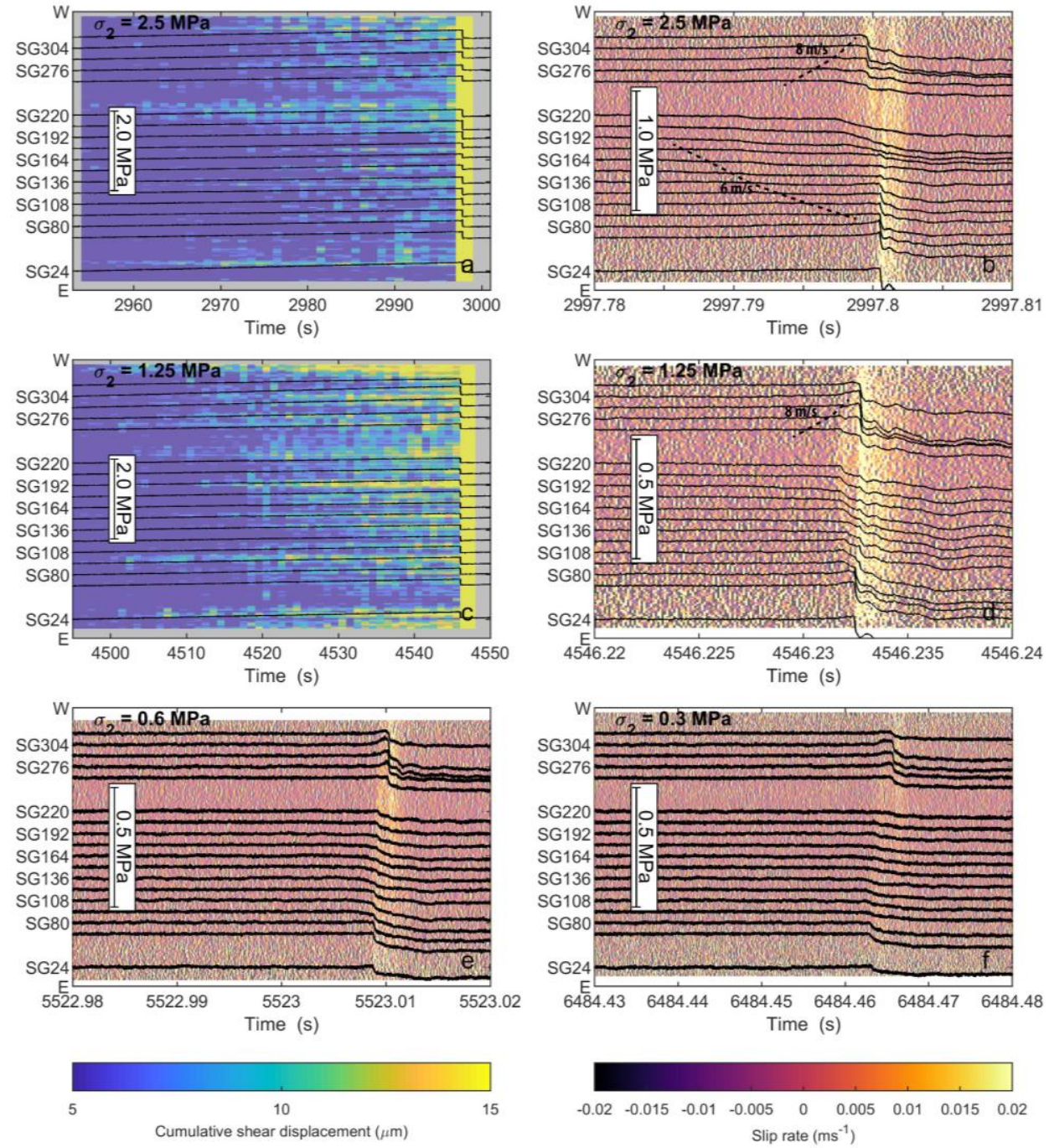

Figure 4-15. Comparison of local shear stress changes and slip during slip events on the gypsum fault (experiments hbr-17-19) at different $\sigma_{2}$. Background colors give cumulative shear slip or the slip rate obtained from Digital Image Correlation. Note that the cumulative shear slip is truncated at $15 \mu \mathrm{m}$ to highlight slip occurring prior to the slip events. a) slip event at $\left.\sigma_{2}=2.5 \mathrm{MPa}, b\right)$ zoomed-in view of the slip event in a. Dashed lines show the propagation velocity of the nucleation zone, $c$ ) slip event at $\left.\sigma_{2}=1.2 \mathrm{MPa}, b\right)$ zoomed-in view of the slip event in $c$. Dashed lines show the propagation velocity of the nucleation zone. e) slip event at $\sigma_{2}=0.6 \mathrm{MPa}$, f) slip event at $\sigma_{2}=0.3 \mathrm{MPa}$.

As the slow slip zone accelerated from the fault center, shear stress was transferred to the fault ends until one of the fault ends ruptured and rupture back-propagated along the 
fault - i.e. a secondary rupture event. This secondary rupture either propagated back across the entire fault, or was arrested and followed by another rupture event. An example of the first kind of event is shown in Figure 4-15d $\left(\sigma_{2}=1.25 \mathrm{MPa}\right)$. Here, slow yielding was observed in the center part of the fault (SG136 - SG220) until at $4546.232 \mathrm{~s}$ this slow slip zone accelerated and propagated towards the fault ends. Rupture then started at the E-end of the fault and propagated across the fault towards the western fault end (-i.e. secondary rupture) at a rupture velocity of $540 \mathrm{~m}^{-1}$. The secondary rupture resulted in a small additional stress drop in the center, and ruptured the $\mathrm{W}$-end of the fault which had not yet ruptured. In other cases the secondary rupture was arrested or strongly decelerated in the fault center, and the other fault end ruptured in a separate event (e.g. Figure 4-15b, e, and f). At $\sigma_{2}=2.5 \mathrm{MPa}$ for example, first the $\mathrm{W}$-end ruptured, but this slip event was then arrested in the fault center (Figure 4-15b). About $1 \mathrm{~ms}$ later, rupture occurred at the E-end of the fault, propagating back across the fault at a rupture velocity of $\sim 300 \mathrm{~ms}^{-1}$, resulting in a second, slower slip event at the $\mathrm{W}$-end. At lower $\sigma_{2}$ both fault ends also ruptured in separate slip events, $2-3 \mathrm{~ms}$ apart, starting with the E-end of the fault.

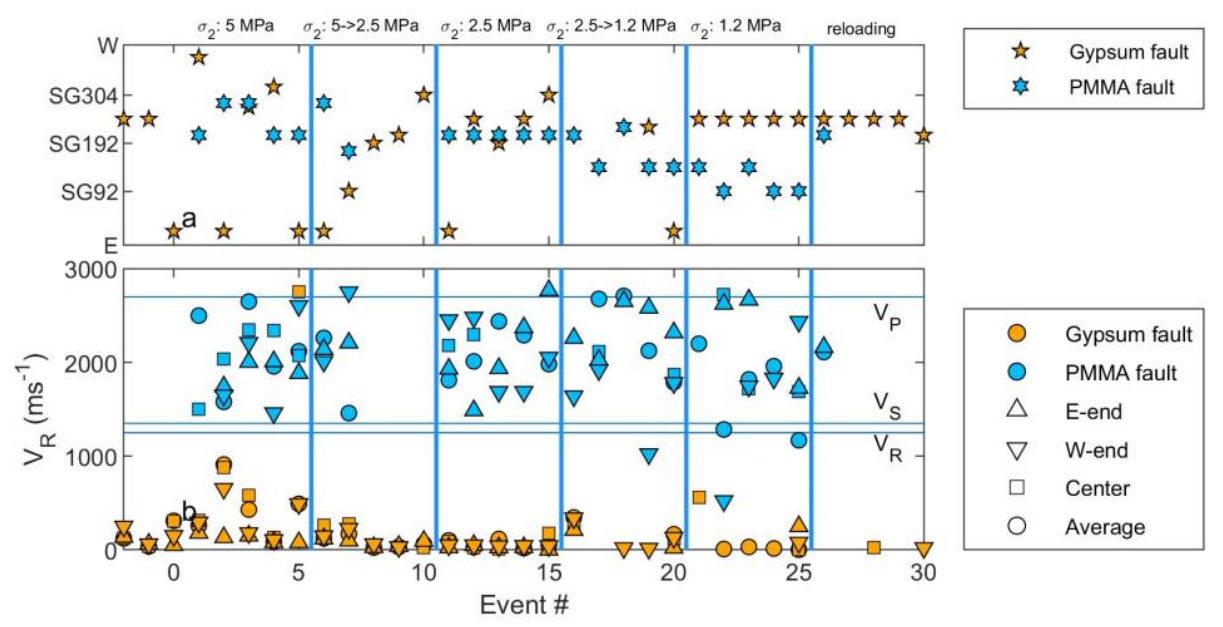

Figure 4-16. Nucleation site and rupture velocities measured on the gypsum gouge faults and the bare PMMA fault at lower confining stresses. a) Nucleation site for the different faults given as distance along the fault (sensor locations as in Figure 3). The nucleation site is taken as the strain gauge location at which slow yielding was first observed, or in case no such slow slip zone is recognized, the point from which rupture accelerates. b) Rupture velocities vr measured by fitting peak shear stresses during rupture. The average rupture velocity (squares) is the rupture velocity measured after rupture propagates at a constant velocity, or, for events nucleating from the center, the average velocity with which the slip zone propagates towards the fault ends. The rupture velocity is also determined for the E-end, W-end, and center, where the rupture velocity is averaged between respectively SG24SG122, SG248 - SG318, and SG136-SG220. Lines indicate shear wave speed $V_{S}, P$-wave speed $V_{P}$, and Rayleigh wave speed $V_{R}$. 
The largest stress drop was typically observed near the western fault end, and the smallest stress drop in the fault center, consistent with the stress drop distribution seen at $\sigma_{2}$ $=5 \mathrm{MPa}$ (Figure 4-8b). Towards lower $\sigma_{2}$ the local stress drops decreased as also observed in the macroscopic data (Figure 4-4). Although the stress drops became smaller, the duration of the stress drop increased, which was reflected by the lower slip rates computed using DIC (Figure 4-15b vs. Figure 4-15e). The velocity with which the nucleation zone propagated towards the fault ends also decreased with lower $\sigma_{2}$ (Figure 4-16b), with e.g. velocities of 10 $-20 \mathrm{~ms}^{-1}$ at $\sigma_{2}=1.2 \mathrm{MPa}$. For comparison, rupture velocities on the PMMA fault remained supershear, although locally several sub-Rayleigh velocities were observed near the $\mathrm{W}$-end and in the fault center at $\sigma_{2}=1.2 \mathrm{MPa}$ (Figure 4-16b).

The shear stress pattern at $\sigma_{2}=2.5 \mathrm{MPa}$ was similar to that at $5 \mathrm{MPa}$, but started to change towards lower confining stresses. The location of the maximum shear stress changed from close to the eastern end at higher confining stresses towards the region near SG262SG276 at lower confining stresses. With decreasing $\sigma_{2}$, the stress drop decreased, as seen in the mechanical data (Figure 4-4b). The stress drop was always largest near the western end, as also seen at $\sigma_{2}=5 \mathrm{MPa}$ (Figure 4-8b).

\section{5. 1. Events during unloading and reloading}

As $\sigma_{2}$ was lowered during the experiment (whilst the load point position of the press in the $\mathrm{x}_{1}$-direction was kept constant), the normal stress and shear stress decreased. During these unloading stages several slip events were recorded. For these events, yielding on the gouge-filled fault started from SG220 or from the E-end of the fault (Figure 4-16a). For the PMMA fault, the nucleation site shifted gradually from SG192-SG248 at the highest $\sigma_{2}$ to SG94-SG136 at the $\sigma_{2}=1.2 \mathrm{MPa}$ or lower. Upon increasing the confining stress to $5 \mathrm{MPa}$, the nucleation site shifted back to the same location as during the first loading stages.

\section{6. Discussion}

The experiments presented in this study are the first where rupture nucleation was observed closely along a fault filled with gouge, sandwiched by compliant PMMA forcing blocks. For reference, also a bare PMMA fault was deformed. Here we discuss the nucleation process in relation to the observed and modeled fault stresses and theory, compare our results to other large-scale experiments on bare rock or polymers, and relate the observed nucleation to theory.

\section{6. 1. Heterogeneous fault stress and location of rupture nucleation and propagation}

The state of stress on the fault is important for understanding rupture nucleation and propagation. Strain measurements along the fault zone indicate that the shear and normal stress are heterogeneous along the fault, with stronger small length-scale stress heterogeneities observed for the gouge-filled faults compared to the bare PMMA fault 
(Figure 4-8). The stress heterogeneities derive from the experimental boundary conditions, as well as from the interface and/or gouge properties. To understand the effect of gouge on the stress distribution, and hence rupture nucleation and propagation, it is important to also understand the stress distribution of the boundary conditions. In the following we compare stress distributions observed in other experimental setups to the stresses observed in this study, and investigate the effect of the boundary conditions and strain measurement location.

\section{6. 1. 1 Effect of experimental boundary conditions on fault stress, and its relation with nucleation}

It is commonly observed that experimental boundary conditions cause a heterogeneous shear and normal stress distribution along experimental faults. Strain gauge measurements in direct shear experiments show that shear stress concentrations develop near one or both fault ends, depending on the sample geometry and loading configuration (e.g. Bayart et al., 2016; Ben-David et al., 2010; Langer et al., 2013; Xu et al., 2018; Yamashita et al., 2018). For example, applying an along-fault displacement to the end of one of the forcing blocks whilst allowing along-fault displacement on the opposite end of the second forcing block results in a shear stress concentration near one end (at the side at which the load is applied), and a stress low near the other end (Bayart et al., 2016; Ben-David et al., 2010). When shear displacement on the opposite end of the second forcing block is resisted, shear stress concentrations develop near both ends (Bayart et al., 2016; Xu et al., 2018; Yamashita et al., 2018). Similarly, normal stress concentrations in the direct shear experiments form at one or both ends, as observed from strain gauge measurements (Bayart et al., 2016; Ben-David et al., 2010), pronounced fault wear (Mclaskey \& Yamashita, 2017), pressure sensitive films (Yamashita et al., 2018), and modeling (Kammer et al., 2015). The distribution of the shear and normal stresses along the experimental faults is furthermore affected by other geometrical factors and boundary conditions, such as the sizes of the PMMA blocks with respect to each other, whether shear loading is applied uniformly or at a point (Bayart et al., 2016), the location at which the shear load is applied (Ben-David et al., 2010), deformation of the frame containing the experimental setup (Ke et al., 2018) and whether motion is allowed between hydraulic presses and the forcing blocks (Guérin-Marthe et al., 2019; Langer et al., 2013). Depending on the relative magnitude of the shear and normal stresses, maxima in $\tau / \sigma_{n}$ will form at some distance from the fault end(s) (e.g. Guérin-Marthe et al., 2019; Yamashita et al., 2018). The stiffness of the forcing block and the surrounding are also important factors that affect the fault stress. The large stiffness contract between polymers and their surroundings may cause high stresses predominantly at the boundaries, whereas the smaller constrast in stiffness in experimetns using granite or gabbro forcing blocks stress maxima may lie further to the center of the fault (Ke et al., 2018). For constant fault friction rupture is expected to start at locations where the ratio $\tau / \sigma_{n}$ is largest (as observed by e.g. Ben-David et al., 2010; Ke et al., 2018), though sometimes rupture nucleation occur from a lower stress area (Yamashita et al., 2018). Note that rupture nucleation may be 


\section{Chapter 4}

complex as for example multiple slow slip zones can coalesce to generate instability (Fukuyama et al., 2016) which may not necessarily be at a high $\tau / \sigma_{n}$. Also increased loading rates cause a more heterogeneous stress state and more variability in the location of nucleation (Xu et al., 2018).

\section{6. 1. 2 Fault stresses and nucleation on the bare PMMA fault}

In the biaxially loaded saw-cut setup as used in this study the PMMA forcing blocks are supported on all sides, with loads being applied on two sides, and load resisted on the other two sides (Figure 4-1a). The stress distribution that was measured was asymmetric with larger shear and in particular strong normal stresses on the eastern side of the fault (Figure 4-8a, c), which is the side from which loading is applied (Figure 4-1a). This trend could be explained (qualitatively) with the Finite Element model (Figure 4-9, Section 4.4.2), which shows high normal stresses and low $\tau / \sigma_{n}$ on the E-end of the fault. Conversely, the modeled normal stress on the western side of the fault was low and the stress ratio $\tau / \sigma_{n}$ was high (Figure 4-9c, d), in accordance with the normal and shear stresses recorded by the strain gauge array along the PMMA fault (Figure 4-8c). Near the fault ends no strain gauges could be placed due to space constraints, but DIC recordings show significant precursory slip at the fault ends consistent with a high $\tau / \sigma_{n}$. The western end of the fault experienced most precursory slip. Nucleation on the PMMA fault occurred persistently at about 2/3 of the fault length (SG192 - SG248, Figure 4-6a), which is at the border of the precursory slip zone near the western fault end. The nucleation location coincides with a local maximum of $\tau / \sigma_{n}$ in the modeled stresses (Figure 4-9c).

Though the modeled stresses fit well with the observation, our study also shows that the stress on the fault is highly sensitive to the boundary conditions. In addition to the factors mentioned in the previous section (configuration and relative size of the forcing blocks, location at which and area over which the loads are applied or resisted, the stiffness of the forcing blocks and the surroundings), the FE results show that fault stress is affected significantly by friction between PMMA and the steel spacers, friction of the slide-bearing plate, and the degrees of freedom of the steel spacers (section 4.4.2). For the current setup the asymmetry in normal stress derived mainly from friction between PMMA and the steel boundaries, which was measured in a separate experiment to be $0.3-0.4$. Knowledge of the effect of the boundary conditions on the fault stress is important; it not only allows one to predict or explain nucleation location, but also allows one to predict the arrest locations of rupture (e.g. Kammer et al., 2016, Ke et al., 2019), or to manipulate the rupture nucleation and velocities by e.g. changing the location of the applied loads (Bayart et al., 2016).

\section{6. 1. 3 Effect of the gouge layer on fault stress and nucleation}

Nucleation on the gouge-filled fault was more variable than on the bare PMMA fault, with nucleation occurring from the fault ends and also from $\sim$ SG220. The latter location is 
similar to the nucleation site for events on the PMMA fault (Figure 4-6a), which corresponded to a local maximum in modeled stress ratio (see previous section). However, the nucleation process was more complex than on the bare PMMA fault. For one of the slip events nucleating from SG220 (e.g. S1-7,Figure 4-5) a precursory slip event occurred 0.1s prior to the main event but the event was arrested near SG304. Following this event slip was triggered near SG164 where the stress ratio was higher. Subsequently, the low $\tau / \sigma_{n}$ region between SG164 and SG304 also started to slip, and fast slip nucleated from SG164-SG262, rupturing the entire fault. Multiple interacting slow slip zones thus led to nucleation of unstable sliding, causing a larger nucleation length than for slip events starting at the fault ends. This was likely due to the more heterogeneous stress (in particular the normal stress) that was observed on this part of the gouge-filled fault (Figure 4-8). Note that if the lengthscale of the stress variations is much larger or much smaller than the critical nucleation length, the nucleation process may be less affected (Ray \& Viesca, 2019)

The origin of the heterogeneous normal stress is related to the behavior of the gouge. The normal stress heterogeneities correlate to the heterogeneous fault compaction observed after the pre-compaction phase and during shearing (Figure 4-17a), with high normal stresses corresponding to regions experiencing relatively little compaction (Figure 4-17a). Heterogeneous compaction could result from the (inevitably) uneven distribution of the amount of gouge material along the fault and/or locally heterogeneous gouge porosity. A simplified model setup incorporating a central segment with a lower fault normal stiffness (to simulate fault compaction) shows how fault segments that experience increased compaction support less normal stress, thus resulting in a higher $\tau / \sigma_{n}$ (Figure $4-17 b$ ). Normal stress is transferred to adjacent fault segments as observed at 100 and $205 \mathrm{~mm}$ (Figure 4-17a), which in turn would have a low $\tau / \sigma_{n}$. his is comparable to stress concentrations predicted by the anticrack model (or contractile Eshelby inclusion) (e.g. Sternlog et al., 2005).

To some extent the heterogeneous compaction is comparable to bare rock or polymer experiments, where asperities sustain high normal stresses (Selvadurai \& Glaser, 2015) and grooves form regions of low normal stress (Yamashita et al., 2018). However, the magnitude of the fault-normal deformation of the gouge layer may be much larger than the typical amplitude of the asperities, depending on the roughness of the bare rock or polymer fault. The variations in normal stress along the (center of the) gouge-filled fault are more than twice as large as variations in normal stress measured along smooth $(1-3 \mu \mathrm{m}$ roughness) bare polymer surfaces under comparable loading conditions (e.g. Bayart et al., 2016; Ben-David et al., 2010), showing how the use of gouge can create additional stress heterogeneity. Sliding on rougher bare rock fault may however cause more comparable fluctuations in normal stress on short length-scales (Yamashita et al., 2018). Note that the displacement on the fault in the current experiment is limited; heterogeneities arising from compaction might be smoothed out as the imposed shear displacement exceeds their length-scale. 

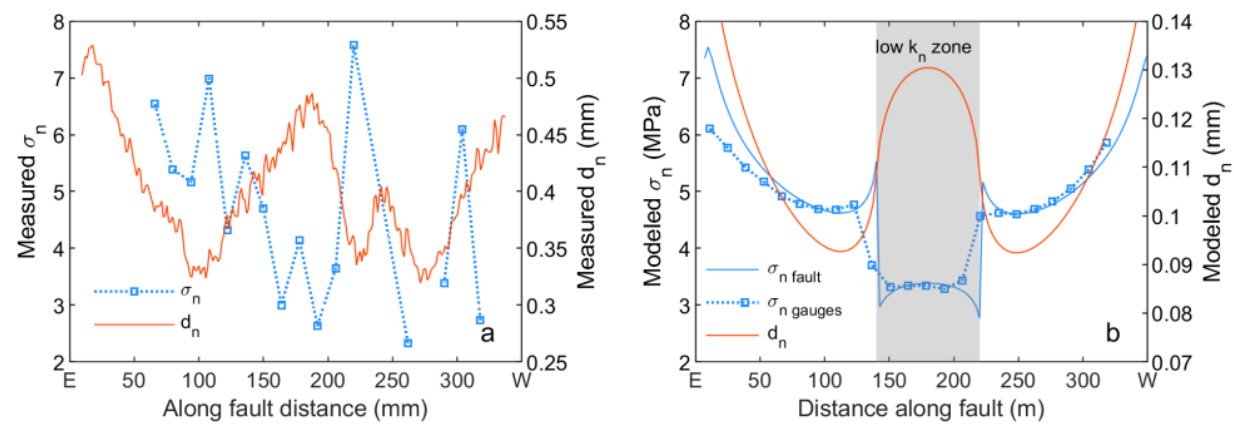

Figure 4-17. Relation between normal stress and fault normal displacement after precompaction. a) Normal stress recorded by the strain gauges and fault normal displacement $d_{n}$ obtained from DIC, $b$ ) Modeling example of the fault-normal displacement and normal stress distribution for a fault with heterogeneous fault-normal properties. The fault-normal stiffness $k_{n}$ of the center segment is 4 times lower than in the surrounding segments, causing increasing elastic fault normal deformation.

\section{6. 1. 4 Effect of loading conditions}

In the experimental setup used in this study both the shear and normal stress increase as the sample is loaded. This is similar to for example experiments by Latour et al. (2013), but different from other many other experimental setups where e.g. shear stress is increased while keeping the normal stress constant, in a sawcut setup (e.g. Kato, 1992, McLaskey \& Kilgore, 2013) or in a direct shear setup (Fukuyama et al., 2018, McLaskey \& Yamashita, 2017, Yamashita et al., 2015). The different loading conditions lead to a different state of stress on the fault (Section 4.1.5) but the non-constant normal stress can also affect the nucleation process and the location of nucleation. A modeling study by Kaneko et al. (2016) shows more variability in nucleation characteristics under increasing shear and normal stress, compared to only increasing the shear stress. Reduction of normal stress while keeping the shear stress fixed led to more variability in nucleation locations along a PMMA fault (Shlomai \& Fineberg, 2016). In our experiment the confining stress $\sigma_{2}$ was decreased several times - i.e. unloading. During unloading the normal stress decreased, but the shear stress increased triggering several slip events which reduced the shear stress. In light of the importance of the loading conditions it is interesting to compare these unloading events were compared to the events during loading. For the gouge-filled fault the nucleation location did indeed show a wider distribution (Figure 4-6a). This could be related to the heterogeneous fault stress. Note however that the loading rate during unloading is larger, which may be another explanation for the larger variability (e.g. Kaneko et al., 2016, Xu et al., 2018). More research is required to investigate the relative effects of the (un)loading conditions, loading rate, and the heterogeneous fault stresses. For the bare PMMA fault the nucleation site shifted from a position $\sim 2 / 3$ of the fault length to a position at $1 / 3$ of the fault length (Figure 4-6a). This appeared however to be correlated with the decrease of $\sigma_{2}$ in general, not just unloading. 
At lower stresses, the stress maximum predicted by the FE model on the western side of the fault becomes smoother, which may be one explanation for the shift in nucleation location (as well as for the reverse happening when increasing the stresses).

\section{6. 2. Effect of gouge layer on rupture velocity and secondary rupture fronts}

One of the differences between rupture on the bare PMMA fault and on the gougefilled faults was the rupture velocity (Figure 4-6b). The rupture front of the primary ruptures on the bare PMMA fault reached supershear velocities, but the rupture velocity observed for rupture events on the gouge-filled faults was lower. Note that although the number of slip events that was analyzed was relatively small, quite some variability in (average or local) rupture velocity was observed with average rupture velocities of $0.1-0.7 V_{R}$, the Rayleigh wave speed of the PMMA forcing blocks. In only one event did the rupture velocity locally exceed $V_{R}$ (Figure 4-6b). The rupture velocities on the gypsum fault are consistent with but in the lower range of rupture velocities seen in other large-scale experiments on bare polymer faults at similar normal stress (e.g. Ben-David et al., 2010).

At the highest confining stress $\left(\sigma_{2}=5 \mathrm{MPa}\right)$ ruptures nucleating at either one of the fault ends typically attained an average rupture velocity $0.2-0.3 V_{R}$, (Figure 4-5c, Figure 4-6b) with one event attaining an average rupture velocity of almost $0.7 V_{R}$ (Figure 4-5d). Ruptures that nucleated closer to the center propagated at lower velocities $\left(<0.1 V_{R}\right)$, but these ruptures were still accelerating as rupture reached the fault ends (e.g. Figure 4-5e) ) - i.e. the critical nucleation length had not been exceed. Similarly low rupture velocities were observed during the nucleation phase of rupture on granite (McLaskey \& Kilgore, 2013, McLaskey et al., 2015, Kato, 1992) and PMMA (Svetlizky \& Fineberg, 2014) faults. As the accelerating rupture reached the fault ends, a secondary rupture front back-propagated over the fault with a rupture velocity of $0.2-0.5 V_{R}$ (Figure $4-5 \mathrm{~d}$ ), in the same range as the rupture velocities of primary rupture nucleating at the fault ends. The velocities of the secondary fronts on the gouge-filled faults are lower than the rupture velocities typically observed for secondary ruptures occurring in bare rock experiments using granite (Kammer \& McLaskey, 2019) or gabbro (Xu et al., 2019) forcing blocks, which are in the range of $0.85-0.95 V_{R}$. Secondary ruptures were also observed on the bare PMMA fault, as the rupture propagating from the $\mathrm{W}$-end reached the E-end; these secondary fronts did have a rupture velocity close to the Rayleigh wave speed (Figure 4-7f). Note that in particular for the gouge-filled fault the secondary wavefront was only weakly visible in the strains recorded along the fault, compared to secondary rupture events on granite or gabbro faults (Kammer \& McLaskey, 2019, Xu et al., 2019). This could be due to the resolution limit of the strain gauges used in this study (see Section 4.2.3). The secondary ruptures detected on granite faults (Kammer \& McLaskey, 2019, Xu et al., 2019) and primary ruptures on PMMA (Svetlizky \& Fineberg, 2014) have a typical wavelength of $10-30 \mathrm{~mm}$. If the wave-length of the secondary ruptures in this study is similar, for the strain gauge size of $5 \mathrm{~mm}$ used here it may not be well resolved, in particular if there is no stress drop associated with the secondary rupture. Strain 


\section{Chapter 4}

measurements may show no stress drop even though a stress drop on the fault occurs, due to the distance between the fault and the location of the strain gauge (Kammer \& McLaskey, 2019). The secondary ruptures seen on the gouge-filed faults were associated with a stress drop (e.g. Figure 4-7d). The secondary ruptures were also visible as a second slip pulse in the image data (e.g. re-rupturing of the $\mathrm{W}$-end of the fault for the event in Figure 3d), indicating the fault locks after the primary event and is then rerupturing during the secondary rupture. On the PMMA fault the secondary ruptures are clearer because the amplitude of the stress changes was larger (Figure 4-7f).

The rupture velocity of both the primary and secondary rupture front on the gougefilled faults thus were much lower than on the bare PMMA fault, and were on the low side of those seen in other bare rock or bare polymer experiments. There are several factors that affect the rupture velocity, including the local state of stress, the properties of the gouge and the medium surrounding the fault, the loading rate, the size of the fault. A positive correlation was found between local rupture velocity and the (local) ratio $\tau / \sigma_{n}$ in polymer experiments (Ben-David et al. 2010) or on smaller-scale granite faults (Passelegue et al., 2013). The events on the gouge-filled faults in our study nucleated at a relatively high $\tau / \sigma_{n}$ near the western fault ends, in particular the $\mathrm{W}$-end, whilst on the rest of the fault $\tau / \sigma_{n}$ was lower, which could result in lower rupture velocities. However, for the PMMA fault the stress state was also heterogeneous with lower $\tau / \sigma_{n}$ towards the E-end, but rupture velocities were much faster than for the gouge-filled faults. Possibly the smaller wave-length normal stress concentration that were observed along the gouge-filled fault but were absent along the PMMA fault could have decelerated rupture. Laboratory experiments showed that a higher degree of stress heterogeneity causes more complex rupture behavior and a region with heterogeneous stresses may indeed cause ruptures to decelerate, though ruptures have also been observed to accelerate after overcoming the heterogeneous stress region (Latour et al., 2013). An alternative explanation for the low rupture velocities can be found in the properties of the gouge layer itself. The fault zone is likely a zone of low stiffness (though unfortunately its elastic properties are unknown) and can have a lower Rayleigh wave velocity than PMMA. For bare PMMA ruptures wave-length in the order of $10-20 \mathrm{~mm}$ have been observed for the primary front, which decrease to several $\mathrm{mm}$ at high rupture velocities (Svetlizky \& Fineberg, 2014). The gouge layer is (after compaction) $\sim 1.2 \mathrm{~mm}$ wide and may not be insignificant with respect to the wave-length of the rupture fronts. If the its Rayleigh velocity of the gouge is significantly lower than that of PMMA it may reduce the rupture velocity. Furthermore, deformation of the gouge layer during shearing could attenuate the propagating (secondary) ruptures. Attenuation due to the progressive accumulation of fault gouge was proposed as one of the explanations for the decrease in rupture velocities of secondary rupture front seen on an initially bare gabbro fault (Xu et al., 2019). The decrease in $V_{R}$ seen on the gabbro fault was small (1.4\%) but the accumulated gouge layer had a thickness of $20 \mu \mathrm{m}$. In our case the gouge layer is thicker and may cause more attenuation which may also explain why the secondary rupture fronts are only weakly visible the gouge experiments. In addition, 
the gypsum gouge has different frictional properties compared to the PMMA fault. This is reflected in the nearly twice as high stress drop observed on the PMMA fault (Figure 4-8b). A positive correlation has been observed in experiments between the stress drop and rupture velocity (e.g. Passelegue et al., 2013), so that faster rupture velocities are expected for the PMMA fault. It is difficult to quantify the relative importance of the different processes on the rupture velocity, but for the gouge it appears that its low velocity in combination with its attenuating properties and lower stress drop could have resulted in lower rupture velocities than those of the PMMA fault.

\section{6. 3. Nucleation length at different confining stresses and relation to theory}

The nucleation length-scale observed in the experiments can be compared to theoretical estimates (section 4.1.1) and rate-and-state parameter of gypsum. The rate-andstate parameters were obtained using a two state variable friction law (Section 4. 2. 1. ). If the first parameters $b_{1}$ and $D_{c l}$ are most relevant for the nucleation size, the lower limit nucleation half-length $L_{b}$ ranges from $0.07-0.3 \mathrm{~m}$, and $L_{\infty}$ ranges from $0.1-1.6 \mathrm{~m}$ for a normal stress of $10 \mathrm{MPa}\left(\sigma_{2}=5 \mathrm{MPa}\right)$. If the total $b\left(=b_{1}+b_{2}\right)$ and $D_{c}\left(=D_{c l}+D_{c 2}\right)$ control nucleation then the values for $L_{b}$ and $L_{\infty}$ range from respectively $1-2 \mathrm{~m}$ and $0.7-4 \mathrm{~m}$. Modeling and experiments show the nucleation process is divided into a stable, quasi-static phase (rupture velocities often in the order of $\mathrm{cms}^{-1}$ to $\mathrm{ms}^{-1}$ ), an accelerating phase during which rupture accelerates to the third phase, dynamic rupture propagation (e.g. Kaneko et al., 2016, Ohnaka \& Shen, 1999). Both the transition from the quasi-static phase to the accelerating phase, and from the accelerating to the dynamic phase, occur at characteristics length-scales and time-scale. Theoretical estimates of the critical nucleation length correspond to the transition from the quasi-static phase to the accelerating phase (here defined as $0.05 \mathrm{~V}_{\mathrm{R}}$ ), though this transition may be difficult to recognize in the experiments when the nucleation lengths is small relatively to the spatial resolution. For the ruptures nucleating at the fault ends no clear quasi-static nucleation zone could be recognized. In some cases rupture started from the fault end and propagated at a steady velocity of $200-400 \mathrm{~ms}^{-1}$ (Figure 4-5c), without any clear yielding at the fault end where nucleation started. In other cases the accelerating phase and the dynamic phase could both be recognized (Figure 4-5e), but no quasi-static phase. It is possible that the nucleation length was smaller than the strain gauge resolution and thus is in the order of a centimeter. Such a length would be below or on the low side of two times $L_{b}$ computed with $b_{1}$ and $D_{c l}$. For slip events that did not nucleate at the fault ends the nucleation zone was still accelerating as it reached the fault ends (e.g. Figure 4-5e), and did not yet reach a steady dynamic propagation velocity (e.g. Kaneko et al., 2016, Latour et al., 2013). The transition from quasi-static propagation to the observed could not be clearly seen from strain gauge data, nor from DIC data which showed precursory slip occurred on different parts of the fault. At lower $\sigma_{2}$ the nucleation length increased visibly, and the nucleation zone always reached the sample ends whilst it was still accelerating, similar to what is also observed in bare rock experiments (e.g. Fukuyama et al., 2016; 


\section{Chapter 4}

McLaskey \& Kilgore, 2013). At these $\sigma_{2}$ the propagation speed of the expanding nucleation zone was often in the order of $1-100 \mathrm{~ms}^{-1}$, in the quasi-static regime, and the nucleation length at e.g. 2.5 MPa was $\sim 0.2-0.25 \mathrm{~m}$ (see Figure 4-15b). This is also below the theoretical estimates mentioned above (which for $\sigma_{2}=2.5 \mathrm{MPa}$ become two times as large as the values mentioned).

Possibly the local high normal stresses due to heterogeneous compaction or higher normal stresses and /or the high shear stress rates at the fault ends caused the nucleation length to shrink (e.g. Guérin Marthe et al., 2019). It is also possible friction of the gouge is described better by the slip law, which may result in smaller nucleation lengths(see Section 2. 1), or that the rate-and-state parameters of the gouge are different at the lower loading rates used in the current experiment. Alternative to rate-and-state friction, previous studies have also shown that nucleation, rupture, and/or rupture arrest on PMMA (Bayart et al., 2016, Kammer et al., 2016, Svetlizky \& Fineberg, 2014) and bare rock (Ke et al., 2019) faults could be described by linear fracture mechanics, with slip-weakening friction. The stress intensity factor at the tip of a slip zone originating from a free edge is larger than the stress intensity factor at the tips of an embedded slip zone (Ke et al., 2019, Tada et al., 2000), which could be an alternative explanation for the short nucleation length observed for the events originating from the fault ends.

For the bare PMMA fault no clear nucleation zone was observed in the strain gauge data, although DIC does show precursory slip occurring near the $\mathrm{W}$-end of the fault, close to the nucleation site. The rate-and-state parameters of PMMA-PMMA are not known, but the nucleation length observed on PMMA faults in other studies at a lower normal stress of $\sim 5$ MPa appears to be in the order of a centimeter or less (Ben-David et al., 2010, Svetlizky \& Fineberg, 2014), which would not be resolved by the strain gauge array. Compared to the gouge-filled fault much less precursory slip was observed on the PMMA fault. The larger nucleation zone size observed for the gouge-filled fault will result in more precursory slip. This is consistent with numerical modeling which shows that velocity weakening patches with lengths just larger than the critical nucleation length accommodate significant aseismic slip (e.g. Chen \& Lapusta, 2009). Note however that in this case slip on the patches is driven by creep in the surrounding material, which is different from our fault where the ends are free; it remains to be determined whether similar trends would be observed for free fault ends versus a creeping matrix.

\section{6. 4. Implications for natural and induced seismicity}

The experimental results show that spatially heterogeneous stress ratios $\tau / \sigma_{n}$. affect the nucleation of slow slip in the present laboratory setup ${ }_{n}$. Locally, the fault stress deviates significantly from the far-field stress. The local stability criterion for rupture nucleation may thus also deviate significantly from the one obtained using far-field stresses. The transition from stable sliding to stick-slip can occur at different loading conditions (e.g. different macroscopic normal stress $\sigma_{\mathrm{n}}{ }^{*}$ ) for different experimental setups, depending on the 
development of stress heterogeneity due to the boundary conditions and heterogeneous compaction of the gouge layer.

The present experiment suggests that fault zone architecture and (variations in) fault gouge composition can be a source of stress heterogeneity within a fault zone. Fault zones cross-cutting sedimentary reservoirs may have for example a highly variable lithology along the fault plane with phyllosilicate rich fault rock and send lenses (Fredman et al., 2007), and also the degree of cementation may vary along a fault depending on the lithology and amount of brittle deformation it experienced locally (Fisher \& Knipe, 1998). Friction experiments on different siliciclastic fault gouge materials found in faults in the Groningen field show how the compaction behavior of these materials can be very different (Hunfeld et al., 2017), which can cause strong normal stress concentrations on fault portion that compact less. Field studies show that exhumed crustal-scale fault zones are often composed of a phyllosilicate-rich matrix surrounding competent lenses of other lithologies, forming so-called fault melanges (Fagereng \& Sibson, 2010; Wibberley et al., 2008). During the interseismic period the phyllosilicate-rich matrix might deform through pressure solution creep, and may thus compact more than the competent lenses within the matrix. This could lead to increased normal stresses on the more competent fault lenses, which causes a reduction of the nucleation size and an increased likelihood of unstable sliding when sufficiently loaded by the creeping fault matrix. Whether such an event is able to propagate through the surrounding matrix depends on the spatial distribution of competent fault segments, the frictional properties of both fault constituents and the amplitude and spatial distribution of the stress heterogeneities (e.g. Luo \& Ampuero, 2017).

Heterogeneous stresses also form on natural faults subject to tectonic loading, or on faults subject to anthropogenic stress changes. On naturally active faults, and faults on which motion is induced by human activity, geometrical factors (jogs, steps, seamounts) and fault roughness may produce marked stress concentrations. For anthropogenically induced seismicity, pressure- and or temperature changes may cause additional highly concentrated stresses that cause earthquakes to nucleate, e.g. around injection wells (e.g. Galis et al., 2017; Segall, P. \& Lu, 2015), around mines, or within producing reservoirs such as Groningen (e.g. Buijze, van den Bogert et al., 2019). In the case of producing reservoirs, both shear and normal stress concentrations form as a result of elevated effective stresses and reservoir geometry (e.g. Buijze, van den Bogert et al., 2019; Haug et al., 2018; Zbinden et al., 2017). The present experiment underlines that it is important to consider these stress concentrations to understand where slip events start and stop.

\section{7. Conclusions}

In this study, we investigated rupture nucleation and propagation in an experiment on a $350 \mathrm{~mm}$ long gouge-filled laboratory fault under biaxial loading conditions. The fault was created along the diagonal of a rectangular polymethylmethacrylate (PMMA, or Perspex) 


\section{Chapter 4}

block, which was used as forcing blocks because its compliancy reduces the nucleation length scale. The fault zone was filled with a $2 \mathrm{~mm}$ thick layer of gypsum gouge, which exhibits velocity weakening and produces slip instabilities at the experimental conditions (i.e. room temperature, normal stresses $<12 \mathrm{MPa}$, and load point displacement rates 1 or $5 \mu \mathrm{ms}^{-1}$ ). During the experiment the minimum horizontal stress $\sigma_{2}$ was reduced stepwise from 5 to 0.3 $\mathrm{MPa}$, and then increased again. For reference, a second experiment was performed on a gypsum fault at $\sigma_{2}=5 \mathrm{MPa}$, as well as an experiment without gouge (bare PMMA fault). Strain gauges and Digital Image Correlation were used to analyze the stress changes and displacements during the stick-slip cycle. Here we summarize our main findings:

- Stick-slip events occurred at all confining stresses investigated. These were audible at the highest confining stresses $(1.2-5 \mathrm{MPa})$ but became inaudible at lower stresses.

- Dynamic events on the gypsum gouge fault nucleated from either one of the fault ends or at $\sim 1 / 3$ of the fault length from the western end. In the latter case nucleation was often preceded by a small slip event occurring at the fault end which was arrested but caused stress transfer and triggered precursory slip towards the middle of the fault. In contrast, rupture nucleation on the PMMA fault consistently started from one location also at $\sim 1 / 3$ of the fault length from the western end of the fault. The increased complexity of nucleation on the gouge-filled fault was related to small length-scale normal stress variations which were absent for the bare PMMA fault. These variations derived from variations in compaction of the gouge. Compaction heterogeneity and the related normal stress heterogeneities persisted after at least several $\mathrm{mm}$ of sliding on the fault.

- Stresses obtained from the strain gauge array along the fault margin showed that nucleation sites occurred in areas where the stress ratio $\left(\tau / \sigma_{n}\right)$ was high on average. The stresses could be reproduced by Finite Element modeling. The modeled $\tau / \sigma n$ distribution was asymmetric, being largest at the western end of the fault, and formed as a result of experimental boundary conditions (i.e. the free fault ends, friction between loading pistons and forcing blocks, and rotation of the loading pistons).

- More precursory slip was observed on the gouge-filled fault than on the bare PMMA fault. Precursory slip was correlated to high local stress ratio $\tau / \sigma_{n}$.

- Rupture velocities and slip rates were lower on the gouge-filled faults compared to the bare PMMA fault. Subsonic ruptures were mostly observed for the gouge-filled fault ( 0.1 - $0.7 V_{R}$, the Rayleigh wave speed of PMMA), whereas supershear ruptures were observed on the bare PMMA fault. Also the velocities of secondary ruptures on the gouge-filled fault were lower $\left(0.2-0.6 V_{R}\right)$ compared to those on 
the PMMA which were close to $V_{R}$. The lower velocity of the gouge layer or its attenuating properties may have contributed to the lower rupture velocities.

- At lower confining stresses $\left(\sigma_{2}<=2.5 \mathrm{MPa}\right)$ rupture nucleation started from the center of the fault. The growth of the nucleation zone was accompanied by several local accelerations in shear stress release until the slip zone approached the fault ends, and the secondary rupture propagated over the entire fault zone. At these confining stresses the critical nucleation length was larger than the fault length. For the PMMA fault the nucleation length was much smaller.

- The results illustrate the importance of fault stress distribution in controlling rupture nucleation and propagation, a point which is equally relevant to understanding both natural and induce earthquakes. The nucleation of instability estimated from farfield stresses may be different from the actual nucleation that results from local (concentrated) stresses on the fault. Local stress lows around the highly stressed nucleation area may 'quench' a nucleating rupture, whereas broader regions of high stress promote rupture nucleation and propagation. Fault zone architecture and gouge composition can contribute to strong stress variability within and around a fault zone. Strong normal stress concentrations may develop on fault zone segments or rigid lenses experiencing less compaction.

\section{8. Acknowledgements}

This study was performed in the context of the research program "Studies on fault (re)activation and dynamic friction and failure behavior" (Research Agreement UI49294) funded by the Nederlandse Aardolie Maatschappij (NAM). This program focuses on a fundamental understanding of the physical mechanisms of production-induced reservoir compaction and induced seismicity in the Groningen gas field. The authors would like to thank Dirk Doornhof (NAM) for feedback on the manuscript. Also Gerd-Jan Schreppers of DIANA FEA B.V. is thanked for his support and discussions on numerical modeling. CEA employees Yuntao Ji, Wenbo Qi and Yan-Qun Zhuo, and UU employees Thony van der GonNetscher and Floris van Oort are thanked in particular for technical assistance in the laboratories at CEA and UU. André Niemeijer is supported by the European Research Council, starting grant SEISMIC (335915) and by the Dutch Research Council (NWO) Vidigrant 854.12.001. We thank Greg McLaskey and two anonymous reviewers for their reviews and constructive feedback. Vincent Brunst is thanked for his help with data storage and accessibility. The mechanical data, selected strain data and selected images can be downloaded from the Yoda repository of Utrecht University https://public.yoda.uu.nl/geo/UU01/OT6YIY.html, DOI: 10.24416/UU01-OT6YIY 
Chapter 4 
Chapter 5

Effects of heterogeneous gouge segments on the slip behavior of experimental faults at dm scale

Loes Buijze ${ }^{1,2}$, Yanshuang Guo ${ }^{3}$, André R. Niemeijer ${ }^{1}$, Shengli $\mathrm{Ma}^{3}$, and Christopher J. Spiers ${ }^{1}$

${ }^{1}$ Utrecht University, Faculty of Geosciences, Princetonlaan 4, Utrecht, The Netherlands ${ }^{2}$ TNO, Applied Geosciences, Princetonlaan 6, Utrecht, The Netherlands.

${ }^{3}$ State Key Laboratory of Earthquake Dynamics, Institute of Geology, China Earthquake Administration, Beijing, China.

Under Review: Earth and Planetary Science Letters 


\section{Effects of heterogeneous gouge segments on the slip behavior of experimental faults at dm scale}

\section{1. Introduction}

Observations from dense seismological monitoring networks reveal a rich variety of slip behaviors in plate-boundary faults. Besides 'regular', fast earthquakes and megathrust events, slower phenomena such as slow slip events, episodic tremors or low frequency events, and very low frequency VLF earthquakes have been observed in subduction zones in Japan (Ito et al., 2007; Obara, 2002; Obara et al., 2004), Cascadia (Rogers \& Dragert, 2003; Schmidt \& Gao, 2010) and in New Zealand (Wallace et al., 2016), as well as on the San Andreas fault (Linde et al., 1996; Nadeau \& Dolenc, 2005). The duration of these events is orders of magnitude larger than the duration of regular earthquakes of comparable seismic moment and ranges from seconds to years (Ide et al., 2007; Peng \& Gomberg, 2010). Interestingly, different slip behaviors can occur simultaneously and at the same location on individual faults. For example, slow slip events are often accompanied by tremors (Ito et al., 2007; Obara et al., 2004), and given fault segments can sometimes rupture in both fast and slow modes (Veedu \& Barbot, 2016).

Slow slip phenomena are not limited to plate boundary faults but have also been inferred on smaller scale crustal faults, in association with induced earthquakes. Long-period, long-duration events recorded during densely monitored hydraulic fracturing stimulations have been attributed to slow fault slip (Das \& Zoback, 2013; Kumar et al., 2019), though the origin of (some of) these events is debatable (Zecevic et al., 2016). In addition, during in-situ injection experiments on a decametric scale, Derode et al., (2015) observed both tremors and long-period events, in addition to aseismic slip and 'regular' microseismicity. Though difficult to image on smaller scale fault, the different slow and fast slip phenomena may thus play an important role in the faulting process, both for natural and induced fault slip.

One explanation commonly cited for the observed variety of fault slip behaviors is the heterogeneous nature of fault zones (e.g. Barbot, 2019; Luo \& Ampuero, 2018; Skarbek et al., 2012; Wei et al., 2013). Geological observations on exhumed fault zones show that fault zone lithology is heterogeneous over a broad range of length scales (Fagereng \& Sibson, 2010). Fault zones often contain lenses of rigid, brittle material derived from the host rock which are surrounded by a weaker phyllosilicate-rich matrix (Collettini et al., 2011; Faulkner

Photograph previous page: Stress concentrations along an experimental fault in Plexiglass (PMMA) blocks. PMMA is a photo-elastic material; with polarized light the stresses in the material can be made visible, with different colors indicating different stresses. 


\section{Chapter 5}

et al., 2003). The juxtaposition of contrasting lithologies along offset faults also results in spatially varying fault rock composition (Tesei et al., 2014), which is especially important on faults cross-cutting layered sedimentary sequences. These different fault rock lithologies translate into different mechanical properties, e.g. different frictional strengths and varying slip- and velocity-dependences thereof. In addition, different lithologies and their specific hydrogeological properties, as well as geometrical variations and irregularities within the fault zone, translate into varying fluid pressures and/or stress state along faults (e.g. Schmittbuhl et al., 2006).

Conceptually, the varying mechanical properties along fault zones are often represented as asperities, which are strong and/or velocity weakening (VW) and can slip unstably, surrounded by (weaker) matrix material which is velocity strengthening (VS) and slides stably (e.g. Ito et al., 2007). Numerical modeling studies using rate-and-state friction, with one or multiple (interacting) asperities, have successfully reproduced some of the slip phenomena observed in plate boundary faults, including slow slip earthquakes and migrating tremors (Ariyoshi et al., 2009), alternating slow and fast events (Veedu \& Barbot, 2016) and megathrust events (Shibazaki et al., 2011). Even numerical modeling of slip on a simplified, single-asperity fault (a VW segment flanked by VS segments) generates a wide variety of fast and slow slip behaviors, comparable to the variability observed in nature (Barbot, 2019; Luo \& Ampuero, 2018; Skarbek et al., 2012). Key parameters that control the slip behavior are the size of the asperity with respect to the critical nucleation size, the relative magnitude of the frictional weakening and strengthening parameters associated with both the VS segments and the VW asperity, the fraction of VW material on the fault, as well as the normal stress on the different segments. In the laboratory, slow slip behavior has also been observed on frictionally homogeneous faults where the length of the experimental fault was close to the critical nucleation length (Mclaskey \& Yamashita, 2017), or the stiffness was close to the critical stiffness (Leeman et al., 2016). In an experimental study by Ma \& He (2001) sliding on a frictionally heterogeneous fault in a double direct shear setup was investigated, where a 40 or $80 \mathrm{~mm}$ long and $1 \mathrm{~mm}$ thick plaster (gypsum) segment was present in the center of a $300 \mathrm{~mm}$ long granodiorite fault surface. The strain data revealed spatially heterogeneous stress build-up and release along the fault, as well as an alternation of smaller and larger events in which part of or all the fault ruptured (Ma \& He, 2001). However, further experimental evidence on the sliding behavior on frictionally heterogeneous faults is lacking. Limited experimental data is therefore available for validating numerical models simulating slip behavior on heterogeneous faults.

Densely instrumented dm- to m-scale experiments offer the opportunity to study the nucleation of unstable slip and the propagation of the instability (Mclaskey \& Yamashita, 2017; McLaskey \& Kilgore, 2013; Ohnaka et al., 1986; Okubo \& Dieterich, 1981). Experiments of this size are also suitable for simulating a frictionally heterogeneous fault and for studying the spatio-temporal evolution of fault slip. Here, we use a scaled experimental setup to investigate the effect of frictional heterogeneity on the slip behavior. The setup 
includes a VW fault segment flanked by two VS segments, similar to the single asperity fault studied by Luo et al. (2018). Compliant PMMA forcing blocks were used to reduce the critical nucleation length, and a gouge layer was used to control the frictional properties along the fault. Quartz, calcite and kaolinite gouges were used for the VS segments, whereas gypsum gouge was used as the VW segment. At the initial stresses applied, the length of the VW segment was close to the nucleation length identified from similar uniform fault experiments (Buijze et al. submitted 2019). During the experiments, the state of stress was varied to change the nucleation length. We evaluate the sliding behavior of these heterogeneous faults at the different loading conditions imposed, and compare our observations with the sliding behaviors predicted by previous numerical modeling studies.

\section{2. Methods}

Four experiments on 347 x $50 \mathrm{~mm}$ sawcut experimental faults sandwiched by PMMA forcing blocks were performed in a horizontal biaxial machine located at the Institute of Geology, China Earthquake Administration in Beijing (Zhuo et al, 2018, Buijze et al., submitted). The experiments were conducted under low normal stresses $(<11 \mathrm{MPa})$ and at room temperature. The experimental fault zone lithology was controlled by a layer of fault gouge, with one experiment having a uniform velocity-weakening fault composition and three experiments having a lithology with a center segment composed of velocity-weakening gouge, flanked by two segments filled with velocity-strengthening material (Figure 5-1).

\section{2. 1. Fault gouge materials and fault composition}

Four different types of fault gouge with different frictional strengths and velocitydependence were used to control the properties along the (heterogeneous) large-scale experimental faults. First, gypsum gouge was used, which was obtained by sieving crushed natural gypsum from Somerset U.K. (de Meer \& Spiers, 1997) to $<150 \mu \mathrm{m}$. XRD analysis indicated the crushed gypsum was $98.8 \%$ pure, with a small fraction of quartz $(0.9 \%)$ and molybdenite $(0.3 \%)$. The second material that was used was pure calcite with a grainsize 120 $-150 \mu \mathrm{m}$. Third, pure quartz powder (Fluka Chemika, no. 83340) was used with a grainsize $<63 \mu \mathrm{m}$, and d50 of $20 \mu \mathrm{m}$. The fourth fault gouge material was kaolinite (Aldrich, CAS no. 1332-58-7) with a median grain size of $5 \mu \mathrm{m}$. The intrinsic frictional properties and sliding behavior of these four gouges are shown in Figure 5-2 and summarized in Table 5-1. Gypsum has the highest frictional strength, followed by quartz and calcite, and kaolinite was significantly weaker than the other three gouges. Gypsum exhibits velocity weakening behavior at the experimental conditions. Triaxial experiments on gypsum gouge using PMMA forcing blocks showed persistent stick-slip behavior at normal stresses $<20 \mathrm{MPa}$ at displacements up to $10 \mathrm{~mm}$ (not shown). Velocity steps between $100-1000 \mu \mathrm{m} / \mathrm{s}$ in a biaxial apparatus were modeled with a two-state variable friction law which gave the following rateand-state parameters for the aging law: $a-b=-0.003$ to $-0.005,136 b_{1}=0.002-0.005, b_{2}$ $=0.001-0.0035, D_{c 1}=3-7 \mu \mathrm{m}$, and $D_{c 2}=50-150 \mu \mathrm{m}$ (Marone, pers. comm). The other 


\section{Chapter 5}
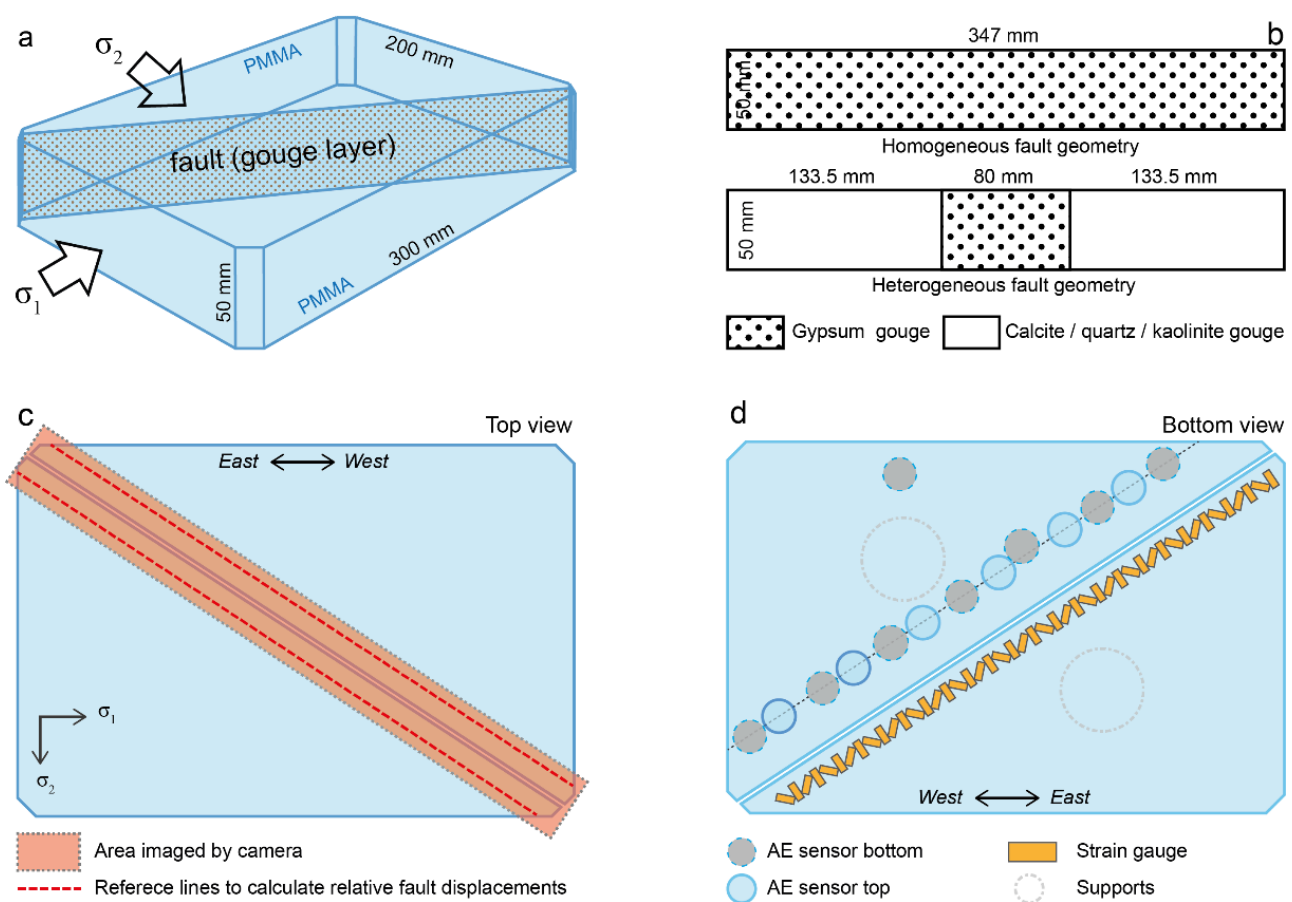

Figure 5-1. Sample assembly and instrumentation. a) PMMA forcing blocks, fault gouge layer, and principal horizontal stresses applied by a horizontal biaxial deformation apparatus. b) Fault gouge lithology for a homogeneous gypsum gouge fault and a heterogeneous fault. c) Top view of the sample assembly and the area imaged by a camera suspended above the sample assembly. d) Bottom view of the sample assembly showing the positioning and orientation of the single-component strain gauges along the fault zone.

three gouges were velocity strengthening to neutral, as shown from separate experimental studies using biaxial, triaxial, or ringshear deformation apparatuses (Ikari et al., 2016; Mair \& Marone, 1999, Baden, pers. comm, Hunfeld, pers. comm., Niemeijer, pers. comm.). Experimental conditions are listed in Table 5-2. At a shear displacement $<10 \mathrm{~mm}$ kaolinite is most velocity-strengthening, followed by quartz, and then calcite which is only weakly velocity strengthening (Table 5-1, Figure 5-2). The velocity dependence of quartz decreases strongly with displacement, and becomes velocity neutral to velocity weakening at shear displacements exceeding $10 \mathrm{~mm}$ (Figure 5-2). Note that for all gouges the scatter in $a-b$ is significant. 
Table 5-1. Frictional properties of the four gouges materials used to control fault friction. The parameters were obtained from various friction experiments in different apparatuses, at a normal stress $<15 \mathrm{MPa}$ and ambient humidity or $100 \%$ relative humidity. Rate-and-state parameters listed in the table are the averages of the measurements shown in Figure 5-2, for the given displacement range.

\begin{tabular}{|c|c|c|c|c|c|c|}
\hline & \multicolumn{3}{|c|}{ Shear displacements $<10 \mathrm{~mm}$} & \multicolumn{3}{|c|}{ Shear displacements $>10 \mathrm{~mm}$} \\
\hline & $\mu$ & $a-b$ & $D_{c}(\mu m)$ & $\mu$ & $a-b$ & $D_{c}(\mu m)$ \\
\hline Calcite & 0.63 & $0.00073 \pm 0.0009$ & $16.0 \pm 11.4$ & 0.70 & $0.00099 \pm 0.0021$ & $89.9 \pm 122.6$ \\
\hline Quartz & 0.67 & $0.00327 \pm 0.0027$ & $19.2 \pm 23.0$ & 0.53 & $-0.00102 \pm$ & $19.2 \pm 23.0$ \\
\hline Kaolinite & 0.31 & $0.00519 \pm 0.0014$ & $79.3 \pm 113.5$ & 0.27 & $0.00323 \pm 0.0004$ & $2.3 \pm 0.6$ \\
\hline Gypsum & & & & 0.8 & -0.003 to -0.006 & $\begin{array}{l}3-7\left(\mathrm{D}_{\mathrm{c} 1}\right) \\
50-150\left(\mathrm{D}_{\mathrm{c} 2}\right)\end{array}$ \\
\hline
\end{tabular}

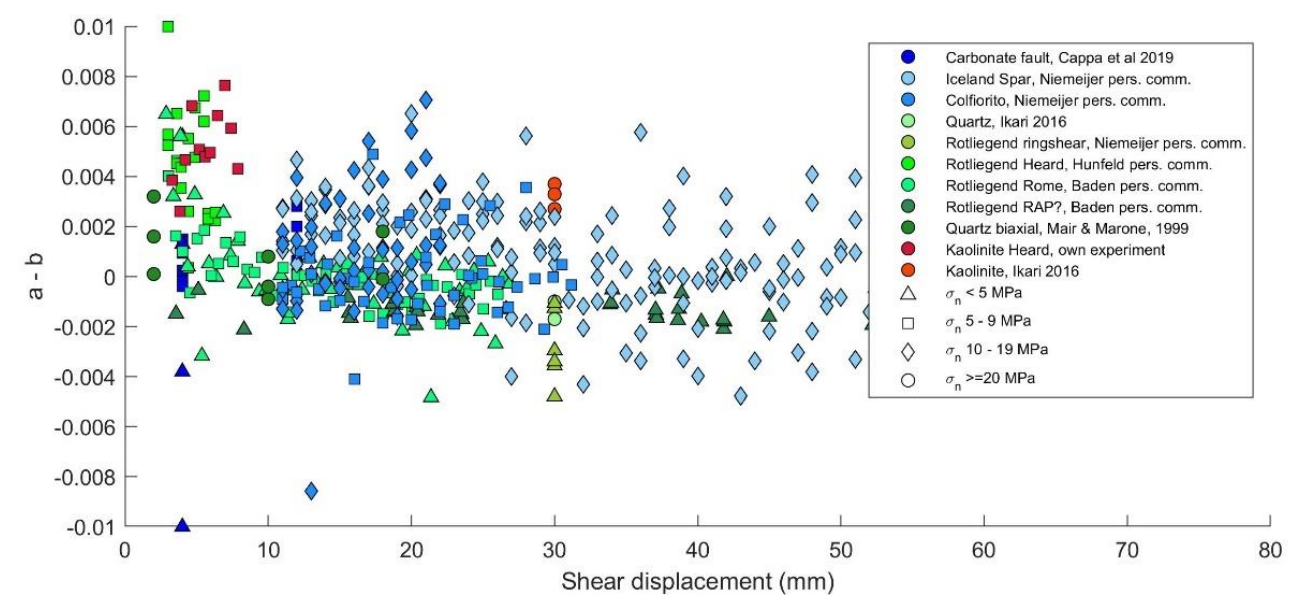

Figure 5-2. Compilation of the rate-and-state parameters a-b for calcite, quartz, and kaolinite. (Ikari et al., 2016; Mair \& Marone, 1999, Baden, pers. comm, Hunfeld, pers. comm., Niemeijer, pers. comm.) 


\section{Chapter 5}

Table 5-2. Experiments used for compilation of rate-and-state parameters of calcite, quartz, kaolinite, and corresponding experimental conditions and source.

\begin{tabular}{|c|c|c|c|c|c|c|c|c|}
\hline $\begin{array}{l}\text { Main } \\
\text { mineralogy }\end{array}$ & Material & Machine & $\begin{array}{l}\sigma_{n} \\
(\mathrm{MPa})\end{array}$ & $\boldsymbol{R H}(\%)$ & $\begin{array}{l}\text { Disp. } \\
(\mathrm{mm})\end{array}$ & $\begin{array}{l}V \\
(\mu m / s)\end{array}$ & $\mu_{0}$ & $\operatorname{Ref}$ \\
\hline Calcite & $\begin{array}{l}\text { Carbonate } \\
\text { fault }\end{array}$ & $\begin{array}{l}\text { Biaxial (double- } \\
\text { direct) }\end{array}$ & 5 & $\begin{array}{l}30 \% \text { and } \\
\text { saturated }\end{array}$ & $4-12$ & $\begin{array}{l}0.1- \\
100\end{array}$ & $\begin{array}{l}0.6- \\
0.64\end{array}$ & $\begin{array}{l}\text { Cappa et al., } \\
2019\end{array}$ \\
\hline Calcite & $\begin{array}{l}\text { Iceland } \\
\text { Spar }\end{array}$ & Ringshear & 10 & room-dry & $10-20$ & $1-100$ & $\begin{array}{l}0.65- \\
0.7\end{array}$ & $\begin{array}{l}\text { Niemeijer, } \\
\text { pers. comm. }\end{array}$ \\
\hline Calcite & Colfiorito & Ringshear & 5 & room-dry & $10-20$ & $6-630$ & $\begin{array}{l}0.57- \\
0.65\end{array}$ & $\begin{array}{l}\text { Niemeijer, } \\
\text { pers. comm. }\end{array}$ \\
\hline Quartz & Quartz & $\begin{array}{l}\text { Biaxial } \\
\text { (double direct) }\end{array}$ & 20 & $100 \%$ & $>10$ & $1-10$ & 0.61 & $\begin{array}{l}\text { Ikari et al., } \\
2016\end{array}$ \\
\hline Quartz & $\begin{array}{l}\text { Rotliegend } \\
\text { gouge }\end{array}$ & Ringshear & 3 & room-dry & 30 & $1-1000$ & $\begin{array}{l}0.55- \\
0.58\end{array}$ & $\begin{array}{l}\text { Niemeijer, } \\
\text { pers. comm. }\end{array}$ \\
\hline Quartz & Rotliegend & $\begin{array}{l}\text { Direct shear in } \\
\text { triaxial }\end{array}$ & 9 & room-dry & $3-8$ & 0.1 & 10 & $\begin{array}{l}\text { Hunfeld, } \\
\text { pers. comm. }\end{array}$ \\
\hline Quartz & Rotliegend & $\begin{array}{l}\text { Biaxial (double- } \\
\text { direct shear) }\end{array}$ & 3,9 & room-dry & $3-25$ & $1-10$ & $\begin{array}{l}0.58- \\
0.65\end{array}$ & $\begin{array}{l}\text { Baden, pers. } \\
\text { comm. }\end{array}$ \\
\hline Quartz & Rotliegend & Ringshear & 3 & room-dry & $3-70$ & $\begin{array}{l}10- \\
100\end{array}$ & $\begin{array}{l}0.45- \\
0.55\end{array}$ & $\begin{array}{l}\text { Baden, } \\
\text { pers.comm. }\end{array}$ \\
\hline Quartz & Quartz & $\begin{array}{l}\text { Biaxial (double- } \\
\text { direct) }\end{array}$ & 25 & room-dry & $2-20$ & $\begin{array}{l}1- \\
10000\end{array}$ & & $\begin{array}{l}\text { Mair \& } \\
\text { Marone, } \\
1999\end{array}$ \\
\hline Kaolinite & Kaolinite & Triaxial (sawcut) & 7 & $75 \%$ & $3-8$ & $0.1-10$ & $\begin{array}{l}0.3- \\
0.32\end{array}$ & $\begin{array}{l}\text { own } \\
\text { experiment }\end{array}$ \\
\hline Kaolinite & Kaolinite & $\begin{array}{l}\text { Biaxial (double- } \\
\text { direct) }\end{array}$ & 20 & $100 \%$ & $>10$ & $1-10$ & $\begin{array}{l}0.26- \\
0.28\end{array}$ & $\begin{array}{l}\text { Ikari et al., } \\
2016\end{array}$ \\
\hline
\end{tabular}




\section{2. 2. Sample assembly, loading apparatus, and experimental procedure}

Two PMMA forcing blocks formed a rectangular sample assembly of $300 \times 200 \times$ $50 \mathrm{~mm}$, with a vertical fault of 347 x $50 \mathrm{~mm}$ along the diagonal (Figure 5-1a). To create the gouge layer along the fault, one of the blocks was rotated so that the fault was horizontal, and a $2 \mathrm{~mm}$ thick wet gouge layer was pasted evenly along the fault's surface. The gouge layer was left to dry at ambient conditions, and subsequently left to equilibrate in an enclosed container in the presence of a saturated $\mathrm{NaCl}$ solution which provides a relative humidity at $75 \%$. The second PMMA block was placed on top of the gouge layer and tape was placed along the fault ends and bottom. The sample assembly was then rotated and placed in the biaxial loading frame (see e.g. Zhuo et al., 2018, Buijze et al., submitted). The experiment commenced with a pre-compaction phase, during which $\sigma_{1}$ and $\sigma_{2}$ were set to $15 \mathrm{MPa}$ for 5 - 10 minutes. Subsequently, $\sigma_{1}$ and $\sigma_{2}$ were lowered to $5 \mathrm{MPa}$. The shearing phase was then initiated by imposing a constant displacement rate of $5 \mu \mathrm{ms}^{-1}$ in the $\sigma_{1}$-direction whilst keeping $\sigma_{2}$ constant at $5 \mathrm{MPa}$. After $3.5 \mathrm{~mm}$ of load point displacement $d_{l}$ the displacement rate was decreased to $1 \mu \mathrm{ms}^{-1}$. During the experiment $\sigma_{2}$ was stepped down in various stages to a minimum of $0.3 \mathrm{MPa}$, and then stepped up again so that the sliding behavior under different normal stresses could be investigated. In this study we consider only the slip behaviors observed at $5 \mathrm{MPa}\left(d_{l}=3.5-4.5 \mathrm{~mm}\right), 1.25 \mathrm{MPa}\left(d_{l} \sim 5-6 \mathrm{~mm}\right)$, and $0.3 \mathrm{MPa}$ $\left(d_{1} \sim 6-7 \mathrm{~mm}\right)$.

\section{2. 3. Instrumentation and data processing}

Here we briefly summarize the main data that were recorded and used in this study; for a more detailed description see Chapter 4.

Two load cells were used to measure the loads applied to the sample assembly, which were converted into principal stresses $\sigma_{1}$ and $\sigma_{2}$ (Figure 5-1a). These stresses were translated to the macroscopic shear stress $\tau^{*}$ and macroscopic normal stress $\sigma_{n} *$ along the fault plane, the ratio of which gives the macroscopic friction coefficient $\mu^{*}=\tau^{*} / \sigma_{n} *$. Two LVDTs were used to measure the macroscopic displacement in the $\sigma_{1}$ - and $\sigma_{2}$-directions, $d_{1}$ and $d_{2}$. The macroscopic shear displacement along the fault is expressed as $d_{t}^{*}=d_{1} / \cos \theta \approx 1.2 d_{1}$. Both the loads and the load point displacements were recorded continuously at $1 \mathrm{kHz}$. The macroscopic stress drop $\Delta \tau *$ is defined as the difference in macroscopic shear stress just prior to a slip event and $0.1 \mathrm{~s}$ after the slip event. 

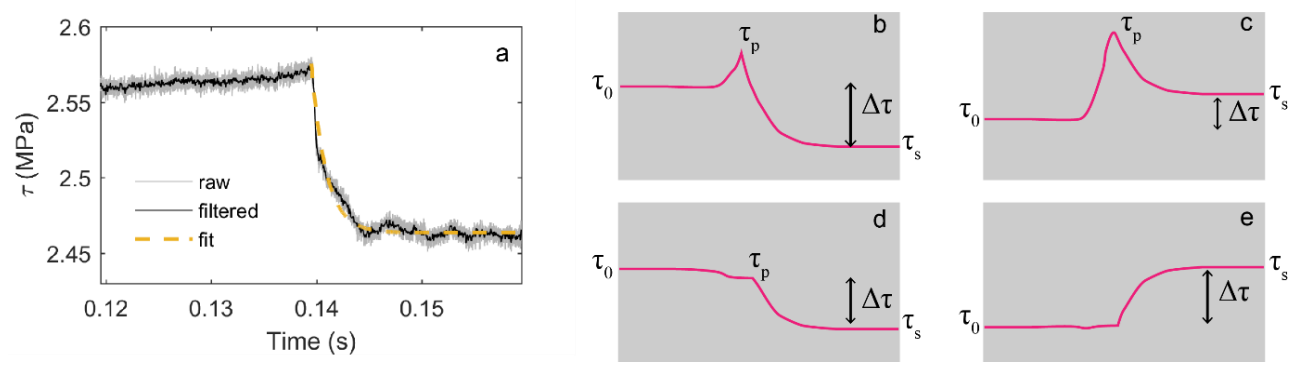

Figure 5-3. Example of exponential fit and different responses observed in the strain gauge signals.

46 single-component metal foil resistance strain gauges $(9 \times 4.5 \mathrm{~mm})$ were glued to the bottom of one of the PMMA forcing blocks along the fault's bottom margin at $10 \mathrm{~mm}$ from the fault. Strains were recorded continuously at $500 \mathrm{kHz}$ and filtered with a SavitskyGolay filter. The gauges were placed in a rectangular rosette orientation, forming 22 rosettes labeled SG24 through SG316, with the number indicating the distance from the eastern fault end in mm (Figure 5-1d). These rosettes give the local 2D strain tensor, which is converted to local shear stress $\tau$, local normal stress $\sigma_{n}$, and the local stress ratio $\tau / \sigma_{n}$ along the fault. For slip events the stress drop $\Delta \tau$ was defined as the difference in shear stress $0.1 \mathrm{~s}$ before and after the event. The shear stress response during fast slip was also fitted with an exponential function (Figure 5-3a) to obtain the characteristic duration and strength drop, as

$$
\tau=\tau_{s}+\left(\tau_{p}-\tau_{s}\right) e^{\left(-t / t_{w}\right)}
$$

where $\tau_{p}$ is the peak shear stress prior to weakening, and $\tau_{s}$ is the residual shear stress after fast slip, and $t_{w}$ is a characteristic duration over which shear stress decrease to $1 / e$ of the total strength drop $\tau_{p}-\tau_{s}$. The static stress drop $\Delta \tau$ depends on the specifics of the stress evolution; usually $\Delta \tau$ is defined as the difference between the residual shear stress and the shear stress prior to the slip event $\tau_{0}-\tau_{s}$ (Figure 5-3b,c, e)., When dynamic rupture was preceded by a slower nucleation phase, this nucleation time was excluded from the exponential fit, and $\Delta \tau$ was defined as $\tau_{p}-\tau_{s}$ (Figure 5-3d).

The top surfaces of the PMMA blocks were painted white with a black speckle pattern. An area of $\sim 350 \times 38 \mathrm{~mm}(2048 \times 228$ pixels, 1 pixel $=0.17 \mathrm{~mm})$ centered around the fault zone (Figure 5-1c) was imaged with a Photron Fastcam SA2 high speed camera which was suspended above the sample. Images were acquired throughout the experiment at $1 \mathrm{fps}$, and at $9000 \mathrm{fps}$ for a number of selected stick-slip events. During image transfer no image acquisition was possible, so $1 \mathrm{fps}$ data could not be acquired for the whole experiment. Digital Image Correlation using PIVlab v2.02 was used to obtain the displacement field at different stages during the experiment (Thielicke \& Stamhuis, 2014). The fault-normal or a fault-parallel displacement fields were expressed relative to the start of the experiment. To compute the relative fault-normal displacement $d_{n}$ (positive is compaction) and fault-parallel or shear displacement $d_{t}$ (positive is left-lateral motion) respectively the normal and shear displacements at opposing points ('slip-sensors') along two lines parallel to the fault zone at 
a distance of $10 \mathrm{~mm}$ from the fault were subtracted (Zhuo et al., 2018). For convenience the displacements were averaged for the different fault segments giving $d_{t V W}, d_{t V S 1}$, and $d_{t V S 2}$. We also define the maximum shear slip rate $\mathrm{v}$ averaged over the different segments (e.g. $v_{V W m a x}$ ) as the largest difference in $d_{t V W}$ per frame time increment. The rupture length was defined as the fault length that slipped with an amount larger than the noise level $(>5 \mu \mathrm{m})$.

\section{3. Results}

\section{3. 1. Mechanical data at different confining stresses for the four fault compositions}

Figure 5-4 shows the relative macroscopic shear stresses $\tau^{*}$ during shearing of the four fault compositions at different confining stresses $\sigma_{2}$. Stick-slip behavior was observed for the gypsum fault at all the $\sigma_{2}$ conditions evaluated (see also Buijze et al. submitted). The macroscopic stress drop $\Delta \tau^{*}$ decreased with confining stress from $0.4 \mathrm{MPa}\left(\sigma_{2}=5 \mathrm{MPa}\right)$ to $0.1 \mathrm{MPa}\left(\sigma_{2}=0.3 \mathrm{MPa}\right)$, and the recurrence interval decreased from $100 \mathrm{~s}$ to $10 \mathrm{~s}$. Stick-slips were also observed for sliding on the heterogeneous faults at $\sigma_{2}=5 \mathrm{MPa}$, but the size of the stick-slips was significantly smaller than for the homogeneous gypsum fault. Macroscopic stress drops ranged from $0.05 \mathrm{MPa}$ (calcite - gypsum fault) to $0.1 \mathrm{MPa}$ (kaolinite-gypsum fault), and recurrence times were $20-35 \mathrm{~s}$. At lower $\sigma_{2}$ markedly different sliding behaviors were observed for the three different heterogeneous fault compositions. For the calcitegypsum fault, the stick-slips changed into slow slip events $\left(\sigma_{2}=1.2 \mathrm{MPa}\right)$ with recurrence time of $30-40 \mathrm{~s}$. At the lowest $\sigma_{2}$ of $0.3 \mathrm{MPa}$ the slow slip events became more symmetric with a slip duration of $20 \mathrm{~s}$, and the recurrence time of 40 - 50s (Figure 5-4b). For the quartzgypsum fault the stick-slips became smaller and more irregular $\left(\sigma_{2}=1.2 \mathrm{MPa}\right)$ with recurrence times of $5-10 \mathrm{~s}$, and could no longer be recognized at the lowest confining stress $\left(\sigma_{2}=0.3 \mathrm{MPa}\right.$ ) (Figure 5-4c). For kaolinite-gypsum on the other hand, stick-slips persisted over the entire range of confining stresses (Figure 5-4d). So even though the confining stresses and the properties of the velocity-weakening gypsum segment are the same for all the three heterogeneous fault experiments, the combination with different velocitystrengthening gouges resulted in different sliding modes and a different response to decreasing $\sigma_{2}$.

The macroscopic friction coefficients $\mu^{*}$ are shown in Figure 5-4e. The homogeneous gypsum fault was strongest with a $\mu^{*}$ of $0.76,0.04$ lower than the friction measured in a smaller-scale experiment (Table 5-1). For calcite-gypsum and quartz-gypsum macroscopic friction was 0.71 and 0.72 respectively. Kaolinite-gypsum was weakest with a friction of 0.45 , which resulted in not only the lowest shear stress but also the lowest normal stress due to the saw-cut sample geometry. The macroscopic friction values for the heterogeneous faults are all $\sim 0.02$ - 0.05 larger compared to taking the area-weighted average of the values in Table 5-1. 


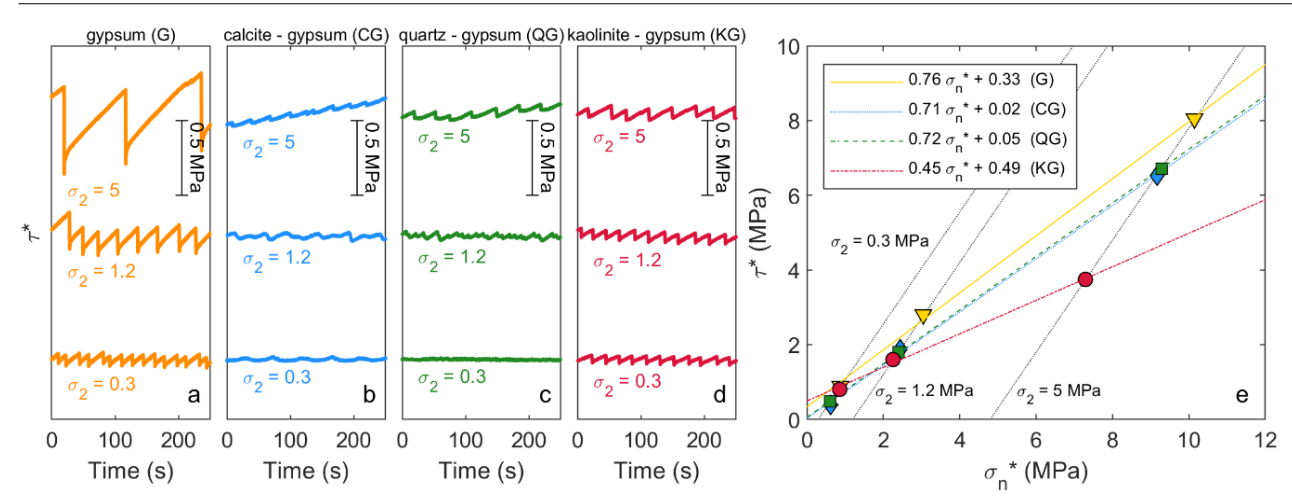

Figure 5-4. Mechanical data showing stick-slips and fault stresses for different fault lithologies at 5, 1.2, and 0.3 MPa confining stress $\sigma_{2}$. a) Homogeneous gypsum fault $\left.(G), b\right)$ calcite - gypsum fault $(C G)$, c) quartz - gypsum fault $(Q G), d)$ kaolinite - gypsum fault $(K G), e)$ average peak shear and normal stress of stick-slip events for different fault lithologies at $\sigma_{2}=5,1.2$, and $0.3 \mathrm{MPa}$ (gray dotted lines). Colored lines are Mohr-Coulomb fits through these stresses; the values for the friction and cohesion are shown in the legend.

\section{3. 2. Local stresses along the fault and shear displacements}

The stick-slips observed in the macroscopic stress data at $\sigma_{2}=5 \mathrm{MPa}$ in all experiments are also clearly visible in the local stress measurements and image data (Figure 5-5). These data give more insight in e.g. the size of the slip zone and the corresponding shear displacements and velocities.

The size of the fault length that slipped during instability (rupture length) was much larger for the homogeneous fault than for the heterogeneous faults. For the homogeneous gypsum fault the slip events propagated over the entire fault length (Figure 5-5a, Figure 5-6b). A local stress drop of $0.4-0.5 \mathrm{MPa}$ (consistent with the macroscopic stress drop in Figure 5-4a) was observed at all strain rosette locations. The shear displacement rate obtained from low framerate $(1 \mathrm{~Hz})$ image data also indicates that the entire fault slipped during the slip event (Figure 5-5a). For the heterogeneous fault compositions on the other hand slip only extended over part of the fault. The smallest events occurred for the calcite-gypsum fault, where slip was arrested just outside of the gypsum segment (Figure 5-5c, Figure 5-6b, and Figure 5-7a). During these slip events a small stress drop of $0.05 \mathrm{MPa}$ was observed over the gypsum segment and just outside the segment up to SG122 and SG220, indicating that the slip events had a length of $\sim 100 \mathrm{~mm}$. Further away from the gypsum segment the stress increased, indicating arrest of the slip event and stress transfer to adjacent regions (Figure 5-5c, Figure 5-7a). The partial slip events were also visible in the image data, where elevated shear displacement rates are seen along the gypsum segment, but can barely be discerned outside of the gypsum segment (Figure 5-5b). Larger events occurred on the quartz-gypsum fault, with a rupture length of $\sim 120-140 \mathrm{~mm}$ between SG108 and SG220-248 (Figure 5-5 e, Figure 5-7b). These slip events cause strengthening along part of the quartz segments, which was relaxed by afterslip over several seconds. The stress drops observed on the gypsum 
segment were also larger than for the events on the calcite-gypsum fault, with an average stress drop of 0.12 MPa (Figure 5-7). The rupture length was largest for the kaolinite-gypsum fault, where almost the entire fault slipped during the stick-slip event (Figure 5-7c). Slip was still strongly concentrated within the gypsum segment though, which experienced an average stress drop of $0.1-0.15 \mathrm{MPa}$. The smaller macroscopic stress drops for the heterogeneous faults (Figure 5-4) are thus reflected in smaller local stress drops and rupture size (Figure $5-5 b)$.

Correspondingly, the shear displacements and slip rates were largest for slip events on the homogeneous gypsum fault and decreased for the heterogeneous faults. The total faultaveraged shear displacement attained over the slip event in Figure 5-5a was $103 \mu \mathrm{m}$. High framerate image data revealed maximum slip rates of $0.2 \mathrm{~ms}^{-1}$ (Buijze et al., submitted). This slip rate is well above the dynamic slip rate $V_{d y n}$, which is the slip rate above which inertial effects start to play a role (Rubin \& Ampuero, 2005). $V_{d y n},=\sigma_{\mathrm{n}} \mathrm{aV}_{\mathrm{s}} / \mathrm{G}$ where $a$ is the rate-andstate parameter and $V_{s}$ is the S-wave velocity $\left(=1350 \mathrm{~ms}^{-1}\right.$ for PMMA) and $\mathrm{G}$ is the shear modulus (1.1 GPa for PMMA); for a normal stress of $10 \mathrm{MPa}$ and a $=0.003$ the $V_{d y n}$ is 0.035 $\mathrm{ms}^{-1}$ (Figure 5-8f). Displacement and slip rates are significantly lower along the gypsum segment on the heterogeneous faults. The total displacement attained on the gypsum segment of the calcite-gypsum fault was $10-15 \mu \mathrm{m}$ (Figure 5-5d). Unfortunately no high framerate data was available for these events so slip rate could not be determined. For the quartzgypsum fault the average shear displacement attained during the events on the gypsum segment was larger $\left(d_{t V W}=15-20 \mu \mathrm{m}\right)$ (Figure 5-5, Figure 5-7b). Here the average maximum slip rate in the gypsum segment was $0.011 \mathrm{~ms}^{-1}$, which is an order of magnitude lower than the slip rates on the homogeneous gypsum fault and $\sim 30 \%$ of $V_{d y n}$. Slip rate was non-uniform and was largest in the middle of the gypsum segment with $0.014 \mathrm{~ms}^{-1}$ versus $0.01 \mathrm{~ms}^{-1}$ towards the edges of the segment. Shear displacement and slip rates were larger for the kaolinite-gypsum fault, with an average slip of $25 \mu \mathrm{m}$ in the gypsum segment and an average maximum slip rate of $0.015 \mathrm{~ms}^{-1}, 45 \%$ of the dynamic value (Figure 5-8d). The kaolinite segments slipped with $10 \mu \mathrm{m}$, but slip rates were lower than in the gypsum with an average slip rate of $0.005-0.01 \mathrm{~ms}^{-1}$. 


\section{Chapter 5}
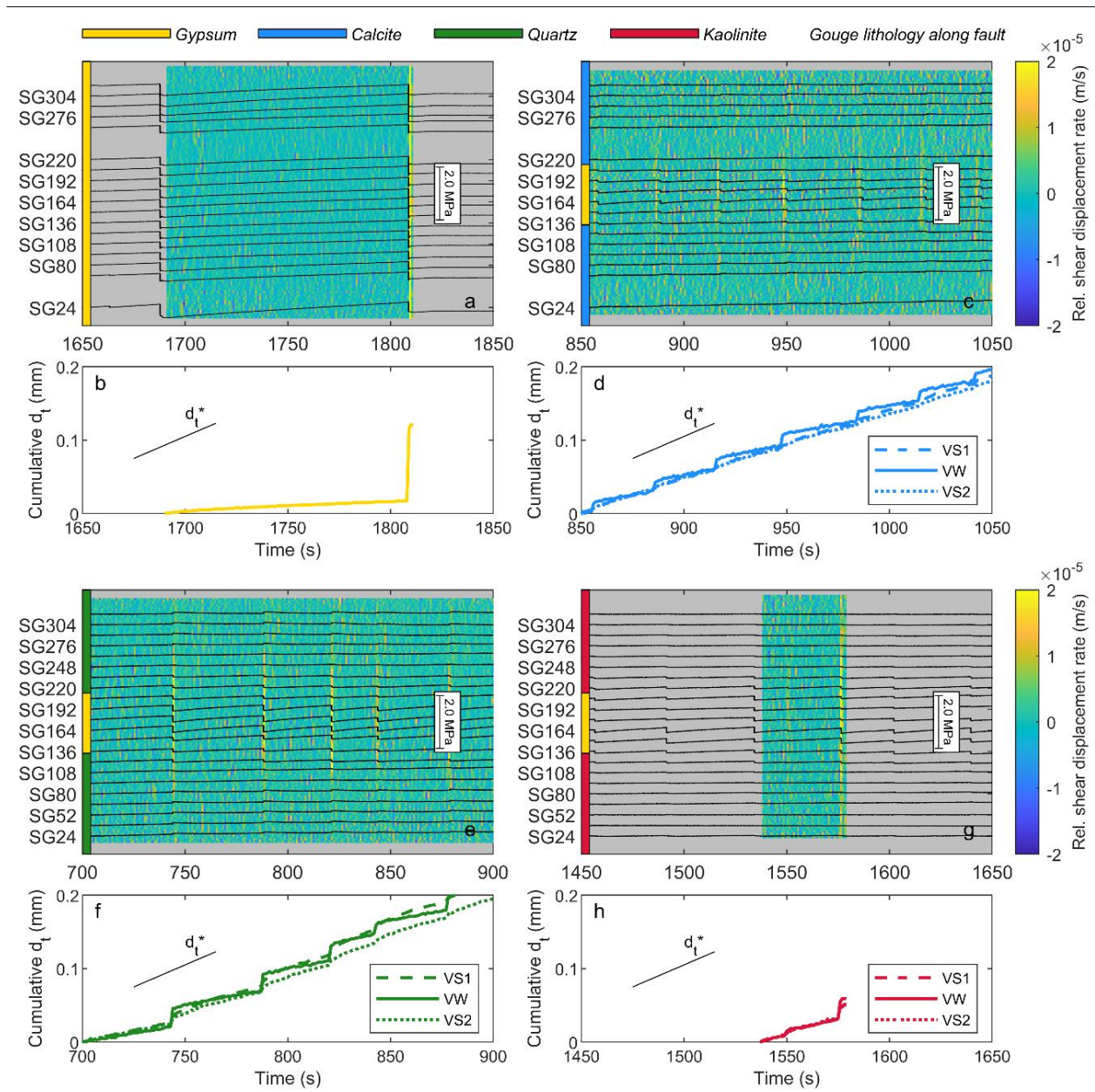

Figure 5-5. Shear stresses and displacements along the fault margin during shearing $\left(\sigma_{2}=5 \mathrm{MPa}\right)$. For a, $c$, e, and $g$, Stress traces at different locations along the fault are shown as a function of time from the start of shearing. Background colors show the relative shear displacement rate across the fault obtained from DIC of the 1 fps image data; for the gray areas no image data was available. The background is colored grey where no image data was available. a) Gypsum fault, c) Calcite - gypsum fault,e) quartz-gypsum fault, g) kaolinite - gypsum fault. Subplots $b, d, f$, and h show the cumulative displacements along the faul averaged over the VS segments and the VW segment, corresponding to the time series shown in respectively $a, c, e$, and $g$. 

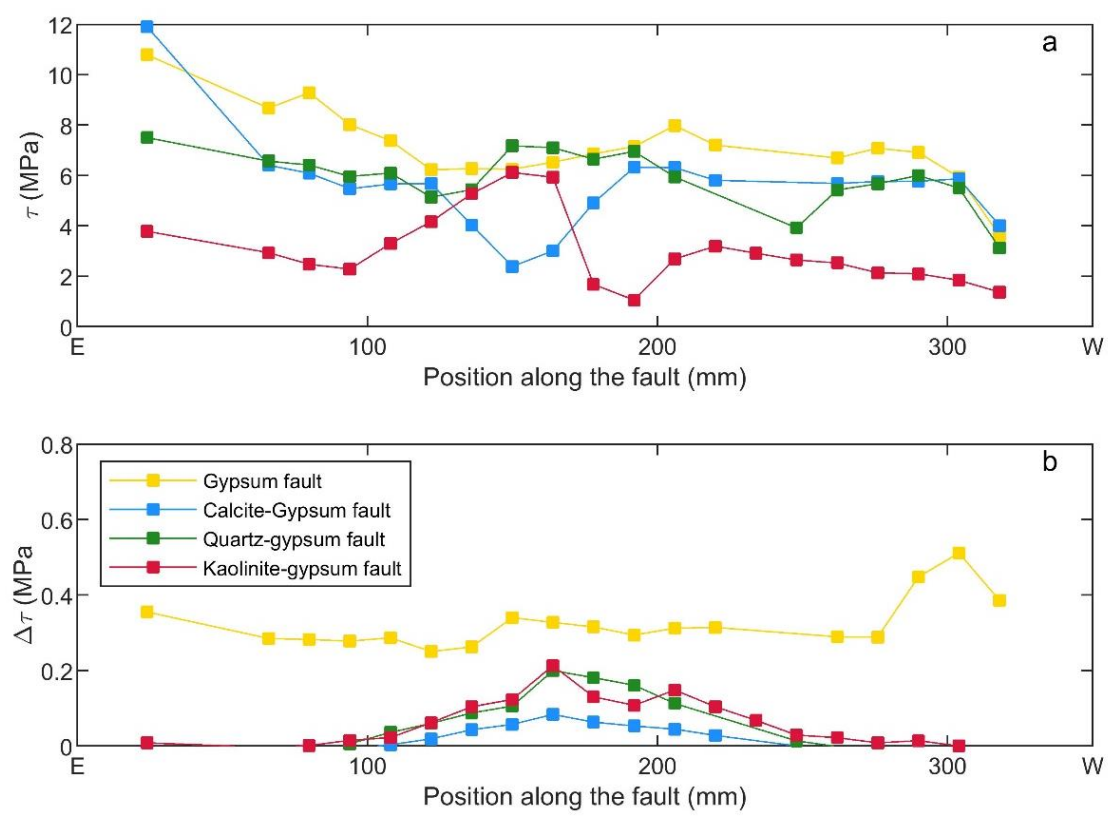

Figure 5-6. Average local fault shear stresses and stress drops for slip events observed at $\sigma_{2}=5 \mathrm{MPa}$. a) shear stress. The shear stress is the average value measured before the slip events at $\sigma_{2}=5 \mathrm{MPa} b$ ) mstress drop averaged for slip events at $\sigma_{2}=5 \mathrm{MPa}$, for different fault compositions.

In all cases, (significant) precursory slip occurred on the gypsum fault or gypsum fault segments during the entire interseismic period (i.e. the time between slip events). The contribution of precursory slip was smallest for the homogeneous gypsum fault. Shear displacement rates during the interseismic period fall below the noise level of the image data (Figure 5-5a), but a cumulative shear displacement of $18 \mu \mathrm{m}$ was observed prior to the slip event (Figure 5-5b). The cumulative shear displacement includes elastic deformation in the $20 \mathrm{~mm}$ of PMMA across which the shear displacement is calculated (see Methods), which is $\sim 10 \mu \mathrm{m}$ for the stress buildup of $0.5 \mathrm{MPa}$ in the interseismic period. This implies that $8 \mu \mathrm{m}$ of precursory slip occurred, which is $1<0 \%$ of the slip in the subsequent slip event. For the heterogeneous faults the precursory slip contribution is larger. For calcite-gypsum the calcite segments slipped at approximately the applied far-field displacement rate (Figure 5-5d). Meanwhile $18 \mu \mathrm{m}$ of precursory fault slip occurred on the gypsum segment in the interseismic period, which is comparable to the shear displacement during the slip event itself. Precursory slip on the gypsum segment for the quartz-gypsum fault was similar (Figure 5-5f). Less precursory slip was recorded on the gypsum segment for the kaolinite-gypsum fault. Here, slip in the interseismic period was $10 \mu \mathrm{m}$, which is $30 \%$ of the shear displacement of the subsequent slip event. Precursory slip just prior to the slip event can also clearly be observed in Figure 5-7c, occurring predominantly at the edges of the gypsum segment where stressing rates are likely high. 


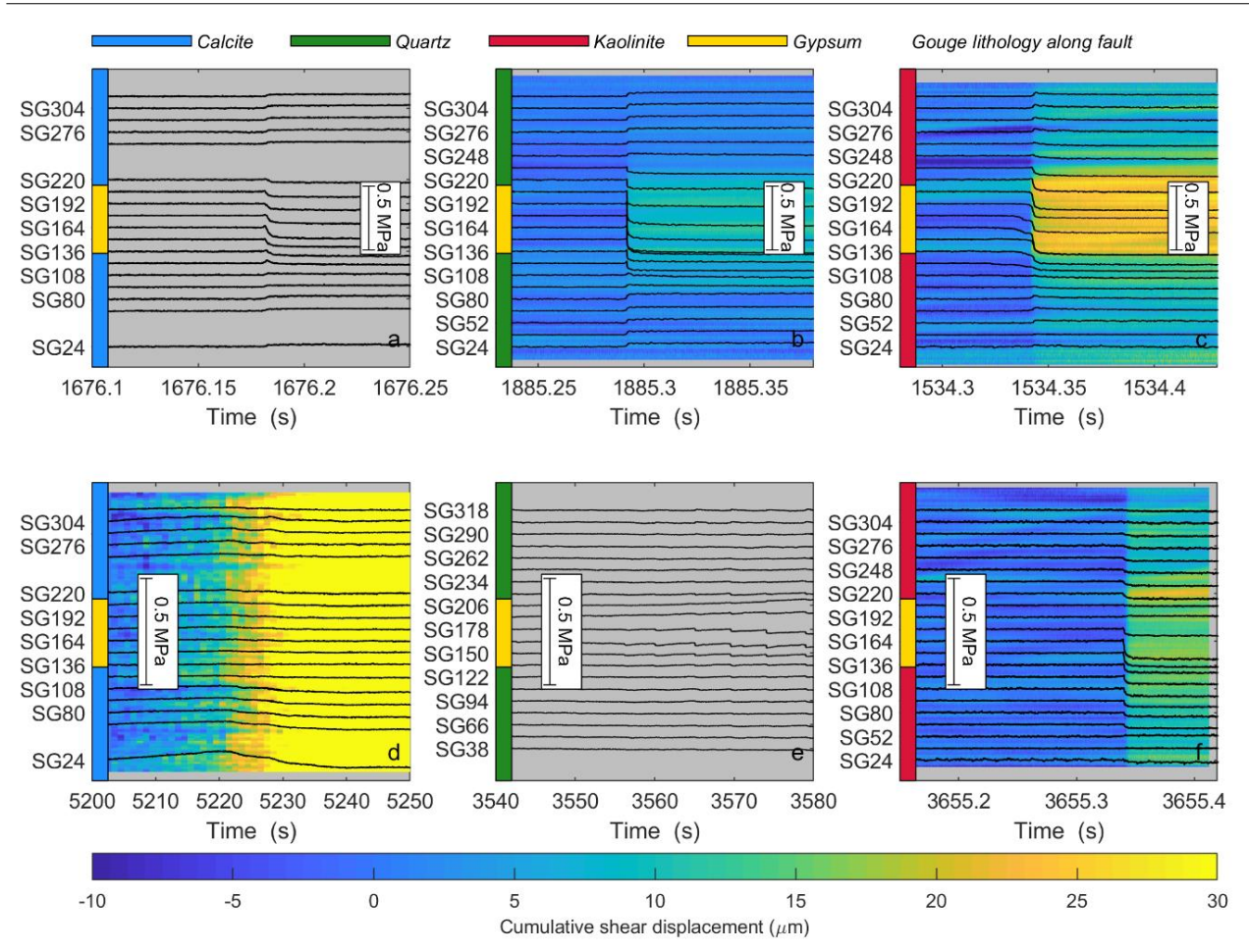

Figure 5-7. Zoom-in of selected slip events for the heterogeneous faults at different confining stresses. Background colors depict the cumulative shear displacements across the fault obtained from DIC; gray colors indicate no DIC was available, e.g. in a and e or near the fault ends. For b, $c$, and f high resolution image data was used (5000 $9000 \mathrm{fps}$ ), for $d$ the $1 \mathrm{fps}$ data was used. a) Calcite - gypsum fault at $5 \mathrm{MPa}$. b) Quartz - gypsum fault at $5 \mathrm{MPa}, \mathrm{c}$ ) kaolinite - gypsum at $5 \mathrm{MPa}$, d) calcite - gypsum at $\sigma_{2}=0.3 \mathrm{MPa}$, e) quartz-gypsum at $\sigma_{2}=0.3 \mathrm{MPa}$, f) kaolinite - gypsum at $\sigma_{2}=0.3 \mathrm{MPa}$.

Shear stresses and stresses were heterogeneous along the fault zone.Figure 5-6 shows the average shear stresses along the fault zone. In all cases the shear stress was largest at the side where loading was applied, i.e. the eastern side. The shear stress was relatively uniform along the gypsum fault. For the heterogeneous faults peaks or lows were observed around the VW segment $(135-215 \mathrm{~mm})$. In particular for kaolinite gypsum the manifestation of the stronger VW segment is clear; outside of the VE segment shear stresses are low, but a peak in shear stress forms between 100 and $180 \mathrm{~mm}$, just offset with respect to the location of the VW segment. For quartz-gypsum the shear stress is $1-2 \mathrm{MPa}$ higher along the VW segment compared to the VS segments. For calcite-gypsum a shear stress low was observed at $150 \mathrm{~mm}$. The stress drop for the gypsum fault was relatively uniform, which a marked peak near the western fault end. For the heterogeneous faults the stress drop was always less than for the uniform fault, as also observed from the macroscopic data (Figure 5-4). Stress drops were highest in the center of the VW segment $\sim 170 \mathrm{~mm}$, and decayed gradually to zero at 90 and $250 \mathrm{~mm}$ indicating the extent of slip, consistent with the arrest locations seen in 
Figure 5-5. The stress drop and slip extent for calcite-gypsum were clearly smaller than for the other two heterogeneous fault compositions.

To summarize, at $\sigma_{2}=5 \mathrm{MPa}$ sliding on the heterogeneous faults produces slip events that rupture a smaller fault length, have smaller displacement and lower slip rates, and are preceded by more precursory slip in the interseismic phase compared to the homogeneous gypsum fault.
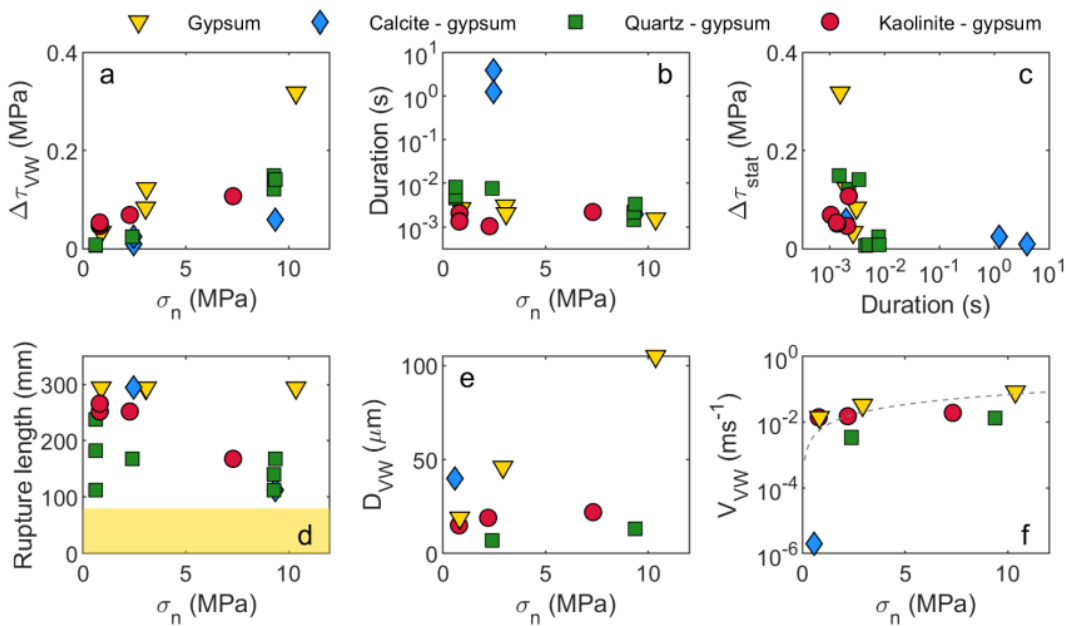

Figure 5-8. Metrics of selected stick-slip events determined from the strain gauge data (a-d) and DIC data (e-f). Blue diamond: calcite-gypsum fault, green squares: quartz-calcite fault, red circles: kaolinite-gypsum fault. a) Confining stress $\sigma_{2}$ against average stress drop in the VW segment, b) $\sigma_{2}$ against duration of the event, c) duration against average static stress drop in the gypsum segment, d) $\sigma_{2}$ against rupture length, with the yellow area indicating the initial length of the gypsum segment, e) $\sigma_{2}$ against average displacement on the gypsum segment, $f$ ) $\sigma_{2}$ against maximum slip rate on the gypsum segment. The line in $f$ shows the dynamic slip rate $V_{d y n}$ which is given as $V_{d y n}=\sigma_{n} a V_{s} / G$ (Rubin and Ampuero, 2005) above which inertial effects start to play a role.

\section{3. 3. Slip behavior at lower $\sigma 2$}

For the gypsum fault slip events persisted upon lowering $\sigma_{2}$, but a larger part of the fault was yielding and slipping slowly prior to the slip events (see also Chapter 4). Concurrently the displacement and maximum slip rates decreased, from $105 \mu \mathrm{m}$ and $0.2 \mathrm{~ms}^{-}$ ${ }^{1}\left(\sigma_{2}=5 \mathrm{MPa}\right.$, or $\left.\sigma_{n}=10.5 \mathrm{MPa}\right)$ to $20 \mu \mathrm{m}$ and $0.01 \mathrm{~ms}^{-1}\left(\sigma_{2}=0.3 \mathrm{MPa}\right.$, or $\left.\sigma_{n}=1 \mathrm{MPa}\right)$ (Figure 5-8e, f).

The sliding characteristics of the three heterogeneous fault compositions showed marked differences upon lowering $\sigma_{2}$. Periodic slow-slip events were observed for the calcite-gypsum fault, where the fault slipped uniformly over its entire length (Figure 5-7d, Figure 5b). The stress drop was $0.1 \mathrm{MPa}$, but the duration of the events increased from $3 \mathrm{~ms}$ at $\sigma_{2}=5 \mathrm{MPa}$ to over $10-20 \mathrm{~s}$ at $\sigma_{2}=0.3 \mathrm{MPa}$ (Figure 5-8b, c). The cumulative slip attained during the events was $30-40 \mu \mathrm{m}$, at a maximum slip rate of several $\mu \mathrm{ms}^{-1}$, just above the 


\section{Chapter 5}

applied load point velocity. The slip rate was not always constant during the slip event, but over several seconds slow accelerations and decelerations were seen (Figure 5-7). For the quartz-gypsum fault stable sliding was observed after lowering the $\sigma_{2}$ to $0.3 \mathrm{MPa}$, but small stick-slips appeared after $0.2 \mathrm{~mm}$ of sliding under these conditions (Figure 5-7). Small stress drops of $0.01 \mathrm{MPa}$ were observed in the gypsum segment, but the duration was several ms to $0.01 \mathrm{~s}$, indicating that the events were significantly slower than those at higher $\sigma_{2}$ which had larger stress drops and shorter durations (Figure 5-8b). For the kaolinite-gypsum fault stickslip behavior persisted down to $0.3 \mathrm{MPa}$. The stress drop on the gypsum segment was 0.05 $\mathrm{MPa}$, which is three times smaller than at $\sigma_{2}=5 \mathrm{MPa}$ (Figure 5-8a). The average slip on the gypsum patch was $15 \mu \mathrm{m}$, but slip rates were similar to those at higher $\sigma_{2}$ (Figure 5-7f, Figure $5-8, f)$.
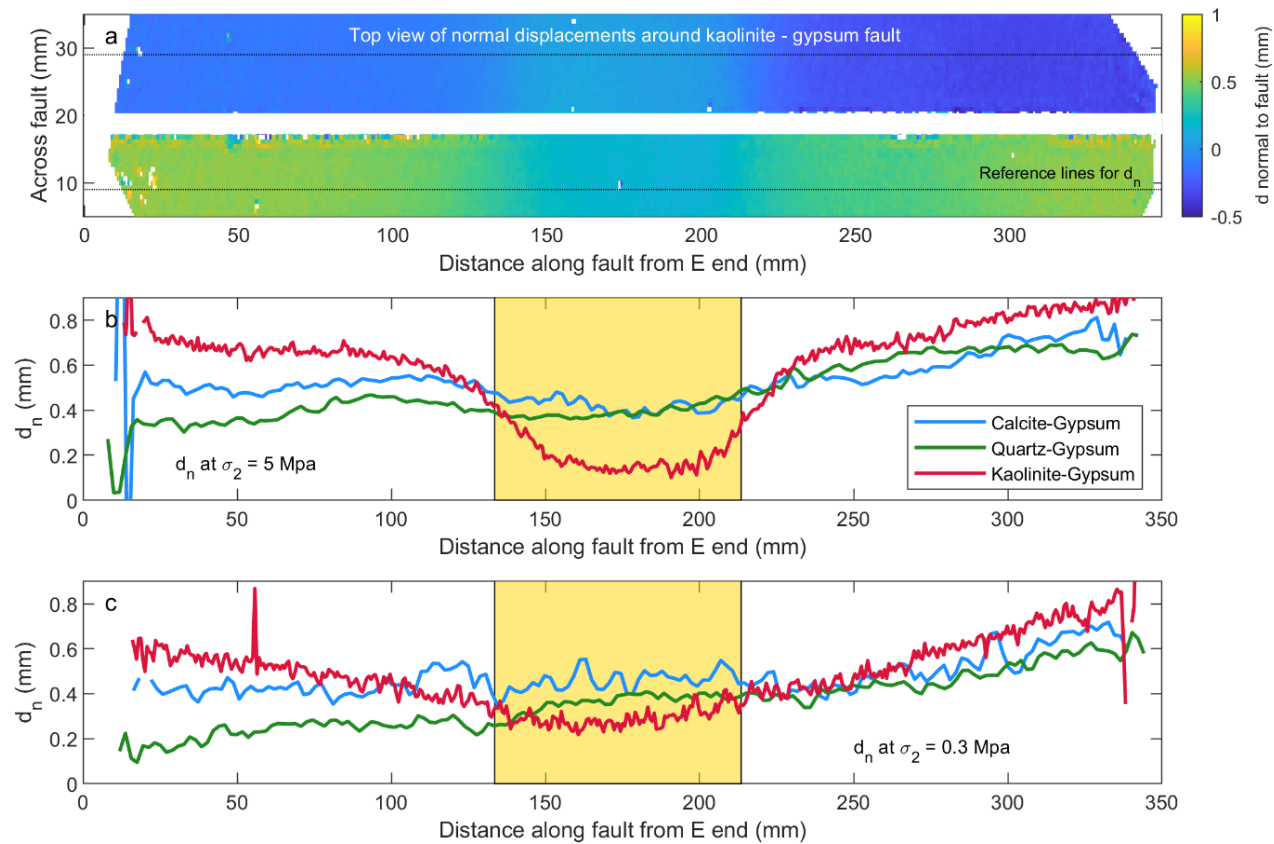

Figure 5-9. Fault normal deformation from image analysis. a) Fault-normal displacements in the area around the fault imaged by the camera. Positive indicates motion southwards, negative northwards. b) Relative fault normal displacement $d_{n}$ along the fault after precompaction and $3.5 \mathrm{~mm}$ sliding at $\sigma_{2}=5 \mathrm{MPa}$. c) Relative fault normal displacement $d_{n}$ after $5-7 \mathrm{~mm}$ of sliding and at $\sigma_{2}=0.3 \mathrm{MPa}$. In $\mathrm{b}$ and $\mathrm{c}$ the initial position of the gypsum segment is indicated. 


\section{3. 4. Fault normal deformation}

The different gouges along the fault do not only have different strengths and velocity-dependences, but also compact differently in response to the applied normal and shear loads. Heterogeneous compaction can result in stress concentrations which affect nucleation and propagation of instability (Buijze et al., submitted). Figure 5-9 shows the fault-normal deformation obtained from DIC throughout the different experiments. The compaction difference between kaolinite and gypsum is largest; the position of the gypsum segment is clearly visible in the displacement data normal to the fault (Figure 5-9a). Prior to shearing, compaction along the kaolinite segments amounted to $0.6-0.8 \mathrm{~mm}$, whereas compaction along the gypsum segment was $0.2 \mathrm{~mm}$ (Figure 5-9b). For the other fault compositions, compaction of the VS segments (calcite, quartz) was less than that of kaolinite and the difference in compaction between the VS segments and the gypsum segment was smaller, with the gypsum segment compacting $\sim 0.1$ to $0.2 \mathrm{~mm}$ less than the VS segments. The difference in compaction decreased throughout the experiment as shear displacement accumulated along the fault, as the gypsum segment compacted more during shearing (Figure 5-9c). For calcite-gypsum and quartz-gypsum the compaction of the VS and VW segments was almost equal at $\sigma_{2}=0.3 \mathrm{MPa}$. For kaolinite-gypsum the compaction difference between the segments decreased significantly and $d_{n}$ along the fault became smoother.

The largest normal stress differences are thus expected for the kaolinite - gypsum fault, with normal stress concentrated on the gypsum segment which compacts significantly less than the kaolinite segments. With shear displacement the normal stress differences are expected to decrease as the gouge compaction differences become less.

\section{4. Discussion}

Unstable sliding was observed on the heterogeneous experimental faults at nearly all conditions that were explored. At the highest confining stress $\left(\sigma_{2}=5 \mathrm{MPa}\right)$ instabilities occurred as partial ruptures, where the VW gypsum segment slipped at a slip rate of $\sim 0.01-$ $0.02 \mathrm{~ms}^{-1}\left(\sim 60 \%\right.$ of $\left.V_{d y n}\right)$ but slip was arrested or decelerated strongly in the VS segments. This is consistent with P-instabilities emerging in RSF modeling of a single-asperity fault with a VW segment flanked by VS segments (Luo \& Ampuero, 2018). These P-instabilities (Figure 5-10) occur in a regime where i) the length of the VW segment $L_{V W}$ exceeds the critical length $L_{c}\left(L_{V W} / L_{c}>1\right)$, and ii) the ratio between the amount of weakening in the VW segment relative to the strengthening VS segments $\alpha=\left(b_{w}-a_{w}\right) \sigma_{w} /\left(a_{s}-b_{s}\right) \sigma_{s}$ is smaller than a critical value $\alpha_{T c}\left(\alpha<\alpha_{t c}\right)$. The $\alpha_{T c}$ depends on the ratio of VW material to VS material (VW:VS) and fault width, but since slip is unconstrained at the fault top and bottom margins (very wide fault) $\alpha_{T c}$ just depends on VW:VS. To determine $\beta\left(=L_{V W} / L_{c}\right)$ the $\mathrm{L}_{V W}(=0.08)$ is divided by the $L_{c}\left(=G D_{c} /(a-b) \sigma_{n}\right)$ which is 0.14 to $3.2 \mathrm{~m}$ at $\sigma_{2}=5 \mathrm{MPa}\left(\sigma_{\mathrm{n}} *=10.5 \mathrm{MPa}\right)$ for the aging law (Table 1). Experiments on the homogeneous gypsum fault showed somewhat smaller nucleation lengths of $\mathrm{cm}-\mathrm{dm}$ (Buijze et al., submitted 2019). Taking 


\section{Chapter 5}

these observed values, the ratio $L_{V W} / L_{c}$ at $\sigma_{2}=5 \mathrm{MPa}$ is likely smaller than or close to 1 , placing the stability of the heterogeneous faults on the right side of the stability diagram in Figure 5-10. Note that $L_{c}$ is dependent on the normal stress on the VW segment; for the kaolinite - gypsum fault normal stress concentrations on the gypsum segment (see section 3.4) may result in a smaller $L_{c}$ and larger $\beta$ than for the other compositions. The strength ratio $\alpha$ of the three fault compositions also depends on the RSF parameters of calcite, quartz, and kaolinite (Table 1, Figure 5-2). There is significant scatter in RSF values which results in large uncertainties in $\alpha$; however we may consider the relative average magnitude of $a-b$ which is largest for kaolinite, followed by quartz, followed by calcite which is almost velocity neutral. The largest $\alpha$ is thus expected for calcite - gypsum ( $\alpha$ of $3-6$ ), followed by quartz - gypsum $(\alpha$ of $\sim 1)$ and kaolinite - gypsum $(\alpha<1)$ (Figure 5-10). The $\alpha$ for the latter two compositions is smaller than the critical $\alpha_{\mathrm{Tc}}$ which places these compositions in the Pinstability field, which sis in agreement with observations of partial ruptures in the experiments. Calcite - gypsum lies closer to or above the $\alpha_{\mathrm{Tc}}$; here partial rupture or nonuniform events are predicted by the numerical models. For all experiments, significant precursory slip and the relatively slow slip rates may indicate that fault length is close to the critical length (Chen, T. \& Lapusta, 2009).

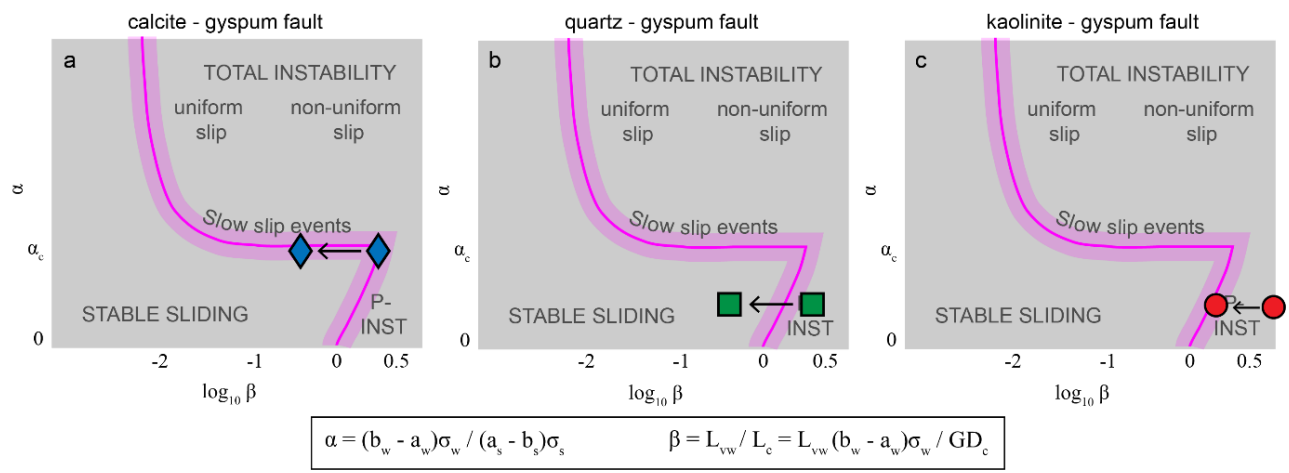

Figure 5-10. Stability diagram of a single asperity VW segment within VS material (redrawn from Luo \& Ampuero 2018). The possible positions of the three heterogeneous fault composition within the stability diagram are shown, with a ) calcite - gypsum fault, b) quartz-gypsum fault, and c) the kaolinite - gypsum fault. The arrow indicates the effect of lowering $\sigma_{2}$. The $\alpha_{c}$ indicates the critical value of $\alpha$, which is determined by the inverse of the ratio of $V W$ material to VS material (here $\alpha_{T c} \approx 3$ ).

Towards lower normal stresses the critical nucleation length increases, resulting in a $L_{V W} / L_{c}$ much smaller than 1 . According to theory and numerical modeling, stable sliding should occur at $L_{V W} / L_{c}<1$ and $\alpha<\alpha_{\mathrm{Tc}}$ (e.g. Lapusta \& Liu, 2009, Luo \& Ampuero, 2018), but this was not always observed.

Lowering the stress on the calcite-gypsum fault resulted in periodic slow slip events with a period of $\sim 40 \mathrm{~s}$ and a slip rate of several $\mu \mathrm{m} / \mathrm{s}$. Slow slip phenomena are typical for faults close to the stability boundary. Slow stick-slips with a duration of $\sim 1$ s and slip rate of 
$10 \mu \mathrm{ms}^{-1}$ have been observed in the laboratory on a uniform VW fault near the stability criterion (Leeman et al., 2016), and numerical modeling a heterogeneous fault shows slow slip transients near the stability boundary defined by $\alpha_{T c}$ (Luo and Ampuero, 2018). As the calcite-gypsum fault may be near or above $\alpha_{T c}$, the occurrence of slow slips at lower normal stress is consistent with the predicted slow-slip instabilities at $L_{V W} / L_{c}<1$. The period of slow slips may have been modulated by the loading stresses; small (+-3 kPa) oscillations of 35 $45 \mathrm{~s}$ were observed in the applied $\sigma_{2}$. VW materials near the stability boundary or materials near velocity neutral may be sensitive to small periodic loads (Perfettini \& Schmittbuhl, 2001). Resonant slow events are for example also proposed for SSE in subduction zones subject to a small seasonal stress changes (Lowry, 2006).

For quartz-gypsum stable sliding occurred after lowering the confining stress to 0.3 $\mathrm{MPa}$, but small stick-slips reappeared after $\sim 0.3 \mathrm{~mm}$ of load point-displacement, suggesting that the transition to stable sliding was near but not reached fully. Shear stress was elevated on the VW patch as it is loaded by stable sliding on the VS segments. This may cause the nucleation length to shrink (e.g. Guérin-Marthe et al., 2019) and may promote the persistence of small stick-slip events. Also, the sharp boundaries indicated by the pink line in Figure 5-10 derive from uniform slip assumptions on the VW patch; heterogeneous stresses and slip on the VW segment as expected in the experiment can result in a broader transition regime (Luo and Ampuero, 2018, Skarbek et al., 2012). Note that at displacements $>10 \mathrm{~mm}$ (not presented here) quartz gouge will transition to velocity - weakening. This causes again very different slip behaviors due to the interaction of the three VW segments, which slip individually or trigger each other and rupture the full fault.

Stronger stress concentrations were observed for the kaolinite-gypsum fault (Figure5-6a), where the frictional strength of the segments differs significantly ( 0.3 vs 0.78 ). Significant precursory slip was observed near the edges of the VW segment prior to the slip event (Figure 5-7c). In addition, the significant difference in compaction of the VW and VS segments can concentrate the normal stress on the VW segment. A Finite Element model incorporating variable fault compaction shows the stress concentration on the edge of the VW segment might be as high as 2 -3 times that of the flanking segments (Buijze et al., submitted 2019). The concentrated normal stress places the fault in a more unstable regime, with a smaller LVW / Lc and a higher $\alpha$, consistent with the stick-slips at low normal stress (Figure 5-10c).

To summarize, the observed slipiors are roughly consistent with RSF theory and numerical modeling of frictionally heterogeneous faults, but the transition regimes may be broader due to non-uniform slip on the VW segment. Also shear and normal stress concentrations could result in more unstable fault than expected from the far-field stresses. Numerical modeling of a VW fault with multiple asperities carrying a high normal load also shows how many small foreshock result from loading by aseismic slip of the surrounding fault region (Schaal \& Lapusta, 2019). This suggests stress concentrations on natural faults 


\section{Chapter 5}

could cause small, relatively slow instabilities to occur even on asperities smaller than the critical nucleation length, as seen on the kaolinite- or quartz-gypsum fault. When the VW asperity is larger rupture can propagate further into the VS region; the experiments showed rupture length varied depending on the properties of the VS material. Similarly, rupture may nucleate on VW patches on natural faults (e.g. brittle lenses, particular stratigraphic intervals) and propagate into VS regions. To assess how far ruptures could propagate on natural faults it is important to know the stresses and in-situ RSF parameters for the different fault regions, as shown for example for the Lorca fault where rupture may have nucleated in highly stressed competent fault lenses but propagated into the shallow VS region (Niemeijer, André R. \& Vissers, 2014).

In case of induced seismicity, the local state of stress may be severely altered due to operations such as fluid injection or hydrocarbon depletion. In the vast seismogenic Groningen gas field in the northeast Netherlands, for example, reservoir depletion will cause an ongoing increase in shear and normal stress on the fault section in and near the reservoir interval leading to rupture nucleation (e.g. Buijze, van den Bogert et al., 2019; Orlic \& Wassing, 2013; Zbinden et al., 2017). Gas production in the Netherlands (and other anthropogenic activities in the subsurface) involves layered sedimentary system, for which frictional properties are expected to vary significantly along the faults. Friction measurements on gouges from typical lithologies in the Groningen field showed significant variability in RSF properties of the reservoir and over- and underburden lithologies (Hunfeld et al., 2017). Current numerical models of depletion-induced seismicity have not evaluated the sensitivity of rupture size to these variations in frictional strength and stability extensively, although variations of frictional strength have been incorporated statistically in seismological models of the Groningen field (Bourne et al., 2018). Incorporation of a distribution of VW asperities on a fault subjected to pressure diffusion due to waste water injection shows that fault zone heterogeneity affected the seismicity rate and b-value with respect to analytical solutions (Almakari et al., 2019). We recommend to investigate the effect of frictional heterogeneity on fault slip behavior and event magnitude for future modeling studies of induced seismicity. In particular we recommend to investigate the relation between the length-scale of the frictional heterogeneity (e.g. the sedimentary layering), the length-scale of the induced stress perturbation, and the typical nucleation length-scales of the faulting process. If these length-scales are of the same order, frictional variability may have a large effect on the earthquake dynamics, (Ray \& Viesca, 2017), as was also observed in our study. Incorporation of frictional heterogeneity along fault subjected to anthropogenic loading will lead to improved understanding of the slip behavior as well as potential rupture sizes, and the potential for rupture to propagate outside its nucleation area into other fault lithologies. 


\section{5. Conclusions}

We investigated experimentally the sliding characteristics of three $350 \mathrm{~mm}$ long frictionally heterogeneous faults and one homogeneous fault sandwiched by PMMA blocks. The fault lithology was controlled by gouge and consisted of a $80 \mathrm{~mm}$ long central velocityweakening (VW) segment, flanked by two velocity-strengthening (VS) segments. The VW segment was composed of gypsum gouge, and the VS segments were composed of either calcite, quartz, or kaolinite gouge. The confining stress $\sigma_{2}$ was stepped during the experiments from 5 to $0.3 \mathrm{MPa}$, corresponding to an order of magnitude difference in macroscopic normal stress (10.5 to $1 \mathrm{MPa})$. Here we summarize the main findings:

- unstable sliding was observed for all three heterogeneous fault compositions at nearly all the experimental conditions evaluated.

- at $\sigma_{2}=5 \mathrm{MPa}$ partial ruptures occurred which predominantly ruptured the VW gypsum segment, and propagated to certain extent into the VS segment. The smallest ruptures were observed for calcite - gypsum, the largest for kaolinite - gypsum. The corresponding stress drops of 0.02 to $0.1 \mathrm{MPa}$, were more than 5 times smaller than the stress drops observed on the homogeneous gypsum fault which ruptured over its entire length. Slip rates on the VW segment were on the order of $0.01 \mathrm{~ms}^{-1}$.

- $\quad$ significant precursory slip occurred on the VW segment during the interseismic period, amounting up to $50 \%$ of the total slip.

- towards lower $\sigma_{2}$ the sliding behavior differed per fault composition:

- for calcite-gypsum, a transition to slow slip events with a duration of $10-20$ s was observed

○ for quartz-gypsum, a transition to near-stable sliding was observed

○ for kaolinite-gypsum, stick-slips persisted

- however, the heterogeneous state of stress on the fault also plays a role.

- shear stress concentrations form at the edges of the VW segment, promoting occurrence of small, slow stick-slip events

- normal stress concentrated on the VW segment due to differences in gouge compaction. this effect was strongest for kaolinite - gypsum, causing the fault to remain unstable even at low $\sigma_{2}$.

- these sliding characteristics are generally consistent with, and provide experimental validation to, numerical models of frictionally heterogeneous faults governed by rate-and-state friction. The results show that including frictional heterogeneity, on top of stress heterogeneity, is important for understanding sliding behavior of faults subjected to tectonic and/or anthropogenic stressing. 
Chapter 5

\section{6. Acknowledgements}

This study was performed in the context of the research program "Studies on fault (re)activation and dynamic friction and failure behavior" (Research Agreement UI49294) funded by the Nederlandse Aardolie Maatschappij (NAM). This program focuses on a fundamental understanding of the physical mechanisms of production-induced reservoir compaction and induced seismicity in the Groningen gas field. CEA employees Yuntao Ji, Wenbo Qi and Yan-Qun Zhuo, and UU employees Thony van der Gon-Netscher and Floris van Oort are thanked in particular for technical assistance in the laboratories at CEA and UU. Furthermore the authors would like to thank Pablo Ampuero for discussions on fault stability. André Niemeijer is supported by the European Research Council, starting grant SEISMIC (335915) and by the Dutch Research Council (NWO) Vidi-grant 854.12.001. We thank TNO for providing the license for DIANA FEA. 
Chapter 5 
Chapter 5 
Chapter 6 


\section{Modeling of rupture induced by reservoir}

\section{production: Effect of heterogeneous fault properties}

\section{1. Introduction}

Over the past two decennia seismic events induced by gas production from the Groningen field $\left(\mathrm{M}_{\mathrm{L}}<3.6\right)$ in the north of the Netherlands have developed into a serious problem within Dutch society. The first earthquake in the Groningen field was recorded in 1991, almost 30 years after the start of production (Figure 6-1). Since then, the number and magnitude of the events have increased. To improve seismic hazard assessment, it is important to better constrain which fault geometries are most prone to generating seismic events, and to identify the key parameters controlling earthquake magnitude. In particular, it is important to assess the potential for ruptures to propagate outside the $100-300 \mathrm{~m}$ thick sandstone reservoir interval, because constraining the down-dip extent of rupture provides insight into the dimensions of the maximum rupture that can occur in the field and hence the maximum event magnitude that is likely. Previous geomechanical modeling studies have indicated that seismic events mostly remain within the reservoir interval, but this depends strongly on the assumed in-situ stress and fault geometry, on the stress changes induced by depletion (hence on the assumed rock mechanical behavior), and on the assumed fault frictional properties (Buijze, van den Bogert et al., 2019). Over the past few years, intensive research (Spiers et al., 2017) has significantly improved our understanding and characterization of the rock and fault mechanical behavior relevant for seismicity in the Groningen field, and detailed data are now available on the reservoir compaction behavior (Filippidou et al., 2019; Hol et al., 2018; Pijnenburg et al., 2018) and on the frictional properties of fault rocks derived from the Groningen lithologies (Hunfeld et al., 2017). Integration of these new findings into geomechanical modeling offers a means to help better resolve the questions of which fault geometries are prone to generating (larger) events and whether rupture is likely to grow beyond the reservoir interval.

Modeling studies performed to date have already contributed greatly to understanding the mechanics and the spatiotemporal characteristics of production-induced seismicity in the Groningen field and other gas fields experiencing induced seismicity. Two main branches of models can be recognized: statistics-based seismic source or seismological models and deterministic geomechanical models, each having their own goals and merits.

Photograph previous page: Normal fault in the Upper Rotliegend, exposed in the Münden Quarry, Germany. On the right side of the fault (the footwall) we find Rotliegend sandstone, whereas on the left side of the fault (the hanging wall) upper parts of the Rotliegend and the Basal Zechstein sequence is found, consisting of dolomite, and carbonates. 
Seismic source models are an essential component of a Probabilistic Seismic Hazard Analysis (PSHA), and provide a probabilistic estimate of earthquake locations and magnitudes (Bourne \& Oates, 2017a). The seismic source models may be purely statistical (Dost et al., 2017). Alternatively they may incorporate geomechanical factors in the probabilistic hazard assessment, such as a relation between compaction strain and the induced events (Bourne et al., 2014; Bourne et al., 2015), based on the theory of Kostrov (1974) which relates volumetric strain to seismic moment, the effect of locally enhanced shear strains due to fault offset on the occurrence of the induced events (Bourne \& Oates, 2017b), and/or visco-elastic stress relaxation and rate-and-state dependent seismicity response to stress changes (Bourne $\&$ Oates, 2018). Note that in these models the stresses on the faults and fault failure are not explicitly resolved, but the presence of faults with offset is incorporated through local, smoothed, topographic gradients, which are translated into locally enhanced shear strains and increased Coulomb stress changes, and therefore have a higher probability of exceeding the
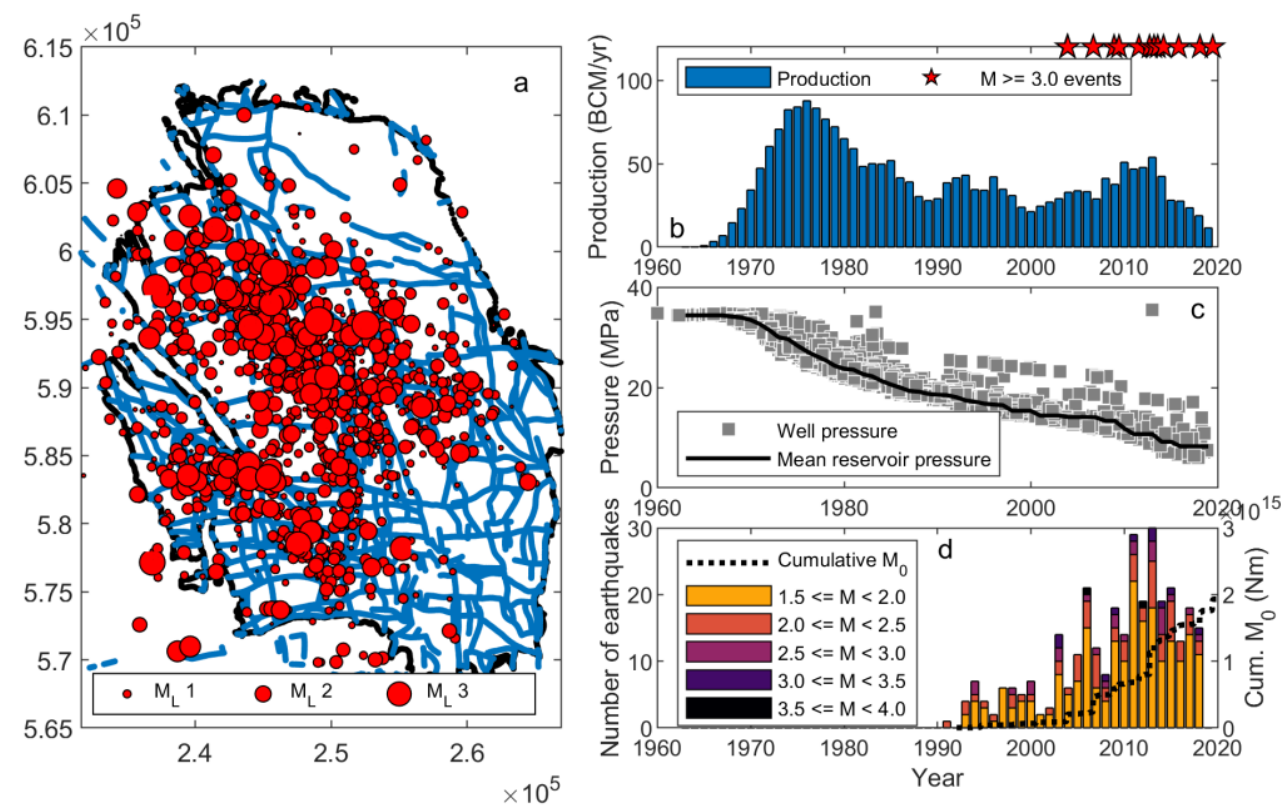

Figure 6-1. Seismicity and operational parameters in the Groningen field, in the northeast of the Netherlands. a) Hypocenters of induced events recorded in and around the Groningen field since 1991 to January 2020 (www.knmi.nl, $24-01-2020)$. Black line: field outline (www.nlog.nl), blue lines: faults identified at reservoir level (courtesy of NAM, 2017). b) Annual production volume (www.nam.nl) and timing of M>3 events c) Pressures measured in the reservoir at different wells in the field over time (www.nam.nl). The black line indicates the mean reservoir pressure. $d$ ) histogram of $M>1.5$ earthquakes recorded over with time. Magnitude of completeness of the catalog is $M_{c} 1.5$ or smaller from 1995 onwards. 
fault strength. In the seismic source model of Dempsey et al. (2017), faults stresses were explicitly incorporated along the fault strike directions, in additional to a stochastic stress variability. Potentially, also the model approach presented by Van Wees et al. (2019) which computes in a fast manner the stress changes on hundreds of fault planes in a structurally complex reservoir (e.g. c.f the Groningen geometries) can be used as a seismic source model in a PSHA.

In more deterministic geomechanical models, the geometry of the reservoir and of faults, and the stress changes due to production, can be explicitly modeled. These deterministic models are usually too slow to generate statistically robust seismicity rates and hence calibrate model parameters against field data, but instead focus on a better understanding of the physical processes controlling the response of the field to production and leading to induced events. Geomechanical models may encompass the entire field or a large portion of the field (Lele et al., 2015; Lele et al., 2016; Sanz et al., 2015), or they may focus on a more generic portion of the reservoir system containing a single fault in order to focus on the fault mechanical response to depletion and local stress-strain evolution (e.g. Buijze et al., 2017; van den Bogert, 2015), similar to geomechanical models used for e.g. $\mathrm{CO}_{2}$ injection (Cappa \& Rutqvist, 2011; Cappa \& Rutqvist, 2012; Rutqvist et al., 2013; Urpi et al., 2016).

Some of the first geomechanical modeling work on induced seismicity in the gas fields in the Netherlands focused on the Eleveld field, a smaller gas field to the south of Groningen (The Netherlands) where several events up to M 2.7 occurred in 1991 and 1992 (Nagelhout \& Roest, 1997; Roest \& Kuilman, 1994). These models incorporated crosssections of the depleting reservoir offset by several faults, and recognized how poro-elastic stressing and compaction of reservoir compartments offset by a fault led to a more critical stress state on the fault and caused fault reactivation. Fault offset was found to be important because as the offset reservoir compartments compact, gradients in vertical displacement form across the fault, resulting in locally concentrated fault stresses that promote fault reactivation relative to stress changes in a reservoir compartment which is not offset by a fault. A displacement gradient resulting from compaction of the reservoir compartment along a boundary fault had also been proposed conceptually as a mechanism for depletion-induced events in the USA (Pennington et al., 1986). The stress-enhancing effect of displacement gradients along faults offsetting the reservoir was subsequently recognized in 3D models of a generic reservoir geometry (Mulders, 2003) and of the Bergermeer field (Orlic \& Wassing, 2013), and further investigated in generic 2D fault models (van den Bogert, 2015; Zbinden et al., 2017). The 2D study by Zbinden et al., (2017), for example, showed that delayed pressure diffusion from low-permeability faults caused a relatively high pressure in the fault with respect to the reservoir pressure, which resulted in the stress path becoming more unstable with depletion time. Also, salt creep just above faults that offset the reservoir formation can reduce the normal stress within the reservoir and thus promote fault reactivation (Haug et al., 2018; Wassing et al., 2017). This is the result of the difference in 


\section{Chapter 6}

horizontal stress in the salt (isotropic stress state) and the rock formation against which it is juxtaposed (horizontal stress is a fraction of the vertical stress). The horizontal stresses along the juxtaposition of salt with the other rock formation must be balanced, which results in horizontal strains in the rock formation and rotation and redistribution of stress to the formation below, resulting in a lower normal stress on steeply dipping faults (Wassing et al., 2017). Geomechanical models incorporating time-dependent reservoir compaction (creep) indicate that seismic moment may continue to increase after stopping reservoir production (van Wees et al., 2018), but much less so than in seismic source models by Bourne et al. (2014) where compaction is assumed as the main driver for seismicity, rather than stress changes that drive the seismicity in Van Wees et al. (2018).

With the exception of the above studies by Zbinden et al. (2017) and Wassing et al. (2017), fault behavior has typically been incorporated in geomechanical models using a static, steady-state friction coefficient without any weakening. This allows the point at which critical stressing of the fault is attained to be modeled as well as fault slip to occur, but does not make a distinction between subsequent seismic or aseismic fault slip driven by on-going depletion. In other words, the frictional weakening mechanisms needed to produce accelerating slip and seismic instability (e.g. Niemeijer, A. et al., 2012) are not included. Modeling approaches addressing natural seismicity typically include slip-dependent (e.g. Andrews, D. J., 1976; Day, 1982; Harris \& Day, 1997) or rate-and-state dependent frictional weakening mechanisms (e.g. Ben-Zion \& Rice, 1997; Lapusta et al., 2000; Okubo, 1989). Whereas an (artificially imposed - i.e. not resulting from tectonic loading) high-stress nucleation zone or high stresses near lithological transitions cause nucleation of seismicity in these models, in the case of induced seismicity a specific induced state of stress is responsible for rupture nucleation. Seismic rupture and wave propagation resulting from stresses induced by fluid injection have for example been modeled using a slip-weakening friction model (Cappa \& Rutqvist, 2012).

The effect of frictional weakening was incorporated recently in generic $2 \mathrm{D}$ gas reservoir models based on the Groningen field to understand depletion-induced earthquake nucleation and event size better, using a fully dynamic rupture analysis (Buijze et al., 2019, Buijze et al., 2017). Depending on the assumed frictional weakening properties, and on the initial in-situ stress and the fault geometry, fault rupture remained mostly limited to the region experiencing production-induced stress (i.e. mainly the reservoir interval). In these models, peak fault friction and frictional weakening behavior, associated with slip parallel to the fault dip direction, was kept uniform along the entire fault length. However, recent experimental evidence shows that the steady state friction coefficient and the amount of frictional weakening of fault materials (simulated gouges) derived from the different lithological units in the Groningen field varies with the source or protolith lithology (Hunfeld et al., 2017, Hunfeld, 2020). The effect of the variations in frictional strength, and in frictional weakening behavior, along fault dip have not yet been investigated in a geomechanical modeling framework. In general, and specifically for the Groningen field, it is important to assess the 
effect of such mechanical heterogeneities along the fault dip, for example to elucidate which fault geometries are prone to rupture nucleation, whether rupture is likely to propagate beyond the reservoir depth interval, and how seismic activity rates vary with ongoing reservoir depletion.

The present study addresses the effect of variable, lithology-dependent fault friction and dynamic weakening properties on the onset of rupture and rupture size for a broad range of fault geometries selected randomly from the fault model of the Groningen field (courtesy of NAM, 2017). For each selected fault segment, a 2D Finite Element model was constructed in which two depleting reservoir compartments offset by a normal fault were simulated, with a reservoir thickness, fault dip, and fault offset following from the reservoir fault model. Five stratigraphic units were incorporated, including the Slochteren sandstone reservoir, the overlying Ten Boer claystone, Basal Zechstein formation, and Zechstein salt, and the underlying Carboniferous. For each of the lithological juxtapositions present along the fault in the model, the corresponding fault friction parameters were assigned after Hunfeld et al. (2017) and Hunfeld (2020). The elastic properties of the reservoir formation were computed from the stress path parameter and uniaxial compressibility measured in uniaxial strain experiments on Slochteren sandstone samples (Filippidou et al., 2019; Hol et al., 2018). Both the frictional parameters and reservoir properties are subject to significant uncertainties. These uncertainties were accounted for by assigning a probability density distribution for each input parameter, and running many model realizations that randomly sampled from these distributions. Values for the initial stress ratio were similarly sampled from a distribution. From the model realizations with the randomly sampled fault geometrical properties and input parameters, the depletion-induced fault stresses, and the pressure change required for fault reactivation and the nucleation of instability were obtained. To compute the subsequent rupture propagation and rupture length, a fully dynamic simulation would be too computer-intensive to be feasible. Instead, rupture size was approximated through an analysis using Linear Elastic Fracture Mechanics theory for crack growth and stability, in the manner demonstrated in models of natural seismicity (Dempsey \& Suckale, 2017; Galis et al., 2015; Ripperger et al., 2007) and of induced seismicity in the along-strike direction (Dempsey \& Suckale, 2017). From the resulting distributions in rupture size, several key geomechanical parameters were identified that control the onset of rupture and the rupture size, as well as the fraction of events that propagates beyond the reservoir interval and under which circumstances.

\section{2. Modeling workflow for production-induced stresses, fault reactivation, and rupture size}

The modeling approach used to investigate the effect of down-dip fault zone heterogeneity on the onset of seismic rupture and rupture size embodies the following two steps: 


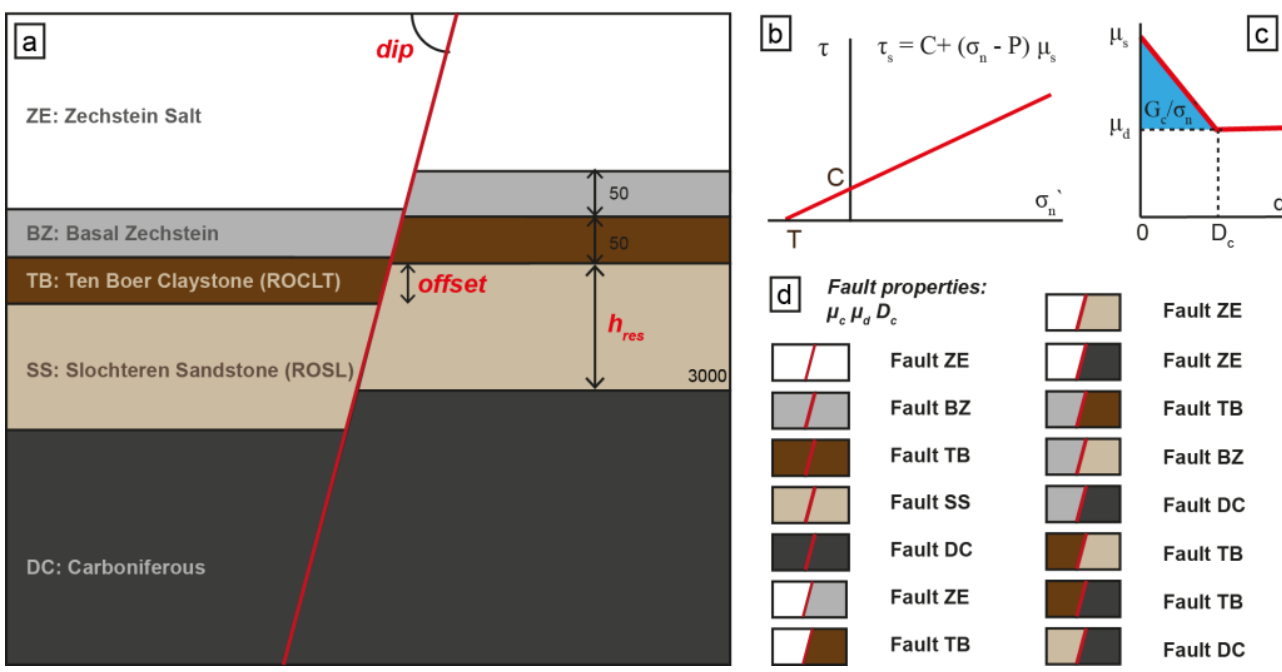

Figure 6-2. Key geometric and fault mechanical characteristics employed in the present modeling study of the effect of variable, lithology-determined fault frictional properties on rupture and seismogenesis in the Groningen gas field, N.E. Netherlands. a) Generic 2D model for a segment of the Groningen reservoir system, containing a single normal fault cutting the five main lithological formations present in the system. Variable parameters are the thickness of the Slochteren reservoir sandstone $h_{\text {res, }}$ the vertical offset, and the fault dip (bold red text). b) Mohr Coulomb friction with failure shear strength or static shear stress $\tau_{s}$, static friction coefficient $\mu_{s}$ normal stress $\sigma_{n}$, pore pressure $P$, and cohesion $C$. For the current model setup cohesion is assumed to be zero. c) Once the Mohr Coulomb criterion has been met, friction evolves according to the linear slip weakening diagram with dynamic friction coefficient $\mu_{d}$ and slip-weakening distance $D_{c}$. d) Assignment of fault properties to various lithological juxtapositions that may occur in the model. The fault properties of the weakest fault rock are assigned to the fault when two different formations are juxtaposed, with $T B<D C<S S<B Z$. For the $Z E$ juxtaposition friction of $Z E\left(\mu_{s} 0.8\right)$ was used.

The first step consists of a 2D Finite Element (FE) model of two depleting, horizontal reservoir compartments offset by a normal fault, based on the Groningen stratigraphy and fault characteristics (Figure 6-2). In this model, the depletion-induced stress changes, fault reactivation (first fault element reaches the failure strength), and subsequent aseismic slip in the nucleation phase are computed, up to the depletion pressure at which the critical nucleation length is reached and instability sets in as in Chapter 2 and Buijze et al. (2019). The stresses obtained from this step are saved.

In the second step, rupture length along the fault dip is computed from the saved stresses using Linear Elastic Fracture Mechanics (LEFM) theory for crack equilibrium. This is much faster than the fully dynamic analysis used in Chapter 2 and Buijze et al. (2019), so that a larger parameter space can be investigated.

Over 1,500 realizations of the FE model are run to explore the effect of fault friction, reservoir geometry, and in-situ stress. For each realization of the FE model, the fault and reservoir geometry are sampled from the PETREL model of the Groningen field (provided by NAM, 2017). Fault friction and frictional weakening, and elastic properties of the 
reservoir, are sampled from distributions based on experimental data. In the following, I start with a brief introduction on the Groningen field stratigraphy. I then describe the FE model setup, the distributions of input parameters used, and the (experimental) basis for these distributions. Finally, I present the LEFM theory used to approximate rupture length.

\section{2. 1. Main stratigraphic units and fault structures in the Groningen field}

Gas from the Groningen field is produced mainly from the Slochteren Formation (ROSL) of the Upper Rotliegend Group (Permian Age). The stratigraphy is described in detail by e.g. De Jager and Visser (2017). The Slochteren Formation is composed of a sequence of predominantly fluvial and aeolian sandstones with porosities between 10 to $24 \%$ and permeabilities from 1 to $1000 \mathrm{mD}$ (de Jager \& Visser, 2017). The top of the Rotliegend Group is located at a depth of $2400 \mathrm{~m}$ in the south of the field, but deepens to $2900 \mathrm{~m}$ in the north of the field (Figure 1-3b). The thickness of the reservoir increases towards the north, from $50 \mathrm{~m}$ in the southeast to over $300 \mathrm{~m}$ in the north of the field (Figure 1-3c). The Slochteren Formation is overlain by the Ten Boer Claystone also of the Upper Rotliegendes Group, which has a thickness of several tens of meters in the south to over $80 \mathrm{~m}$ in the north. The Ten Boer Claystone is comprised of silts and shales, and also contains sandstone streaks that may also experience depletion (Burkitov et al., 2016). The Ten Boer Claystone is overlain by the Triassic Zechstein formation. The bottom $50 \mathrm{~m}$ of this Zechstein formation is comprised of a sequence of anhydrite and carbonates - also called the Basal Zechstein formation. The Basal Zechstein is overlain by a 100-1000 m thick rocksalt formation. The substrate (or "underburden") below the Slochteren Reservoir is of Carboniferous age and is comprised of siltstones, intercalated with rare coal seams. An angular discomformity exists between the Carboniferous underburden and the Slochteren reservoir.

Over a thousand normal faults have been interpreted in the Slochteren Formation on 3D seismics (Kortekaas \& Jaarsma, 2017; e.g. NAM, 2016b). Figure 6-3 shows the Groningen fault model where the location of the faults at the reservoir depth level is shown. The dominant fault trend in the field is NNW-SSE, but secondary trends include E-W and N$\mathrm{S}$ fault sets. These faults have been formed and reactivated during different tectonic events (Chapter 1, Figure 1-4). The faults do not continue into the Zechstein salt, which mechanically decouples the formations below and above because of its ductile nature. However, the faults can be traced for more than $1000 \mathrm{~m}$ into the Carboniferous substrate (Kortekaas \& Jaarsma, 2017; NAM, 2016b). The fault model shown in Figure 2 is subdivided in 15,000 points representing fault sections of $40 \mathrm{~m}$, each related to a specific strike, dip, vertical offset, and reservoir thickness. The dip of the faults as measured in the Slochteren reservoir is generally quite steep with an average dip of $77^{\circ}$ (NAM, 2016b; Wentinck, 2016). Normal offset along the fault varies mostly from 0 to $100 \mathrm{~m}$, thus juxtaposing the various lithologies described in the previous paragraph against each other (Figure 6-3). 

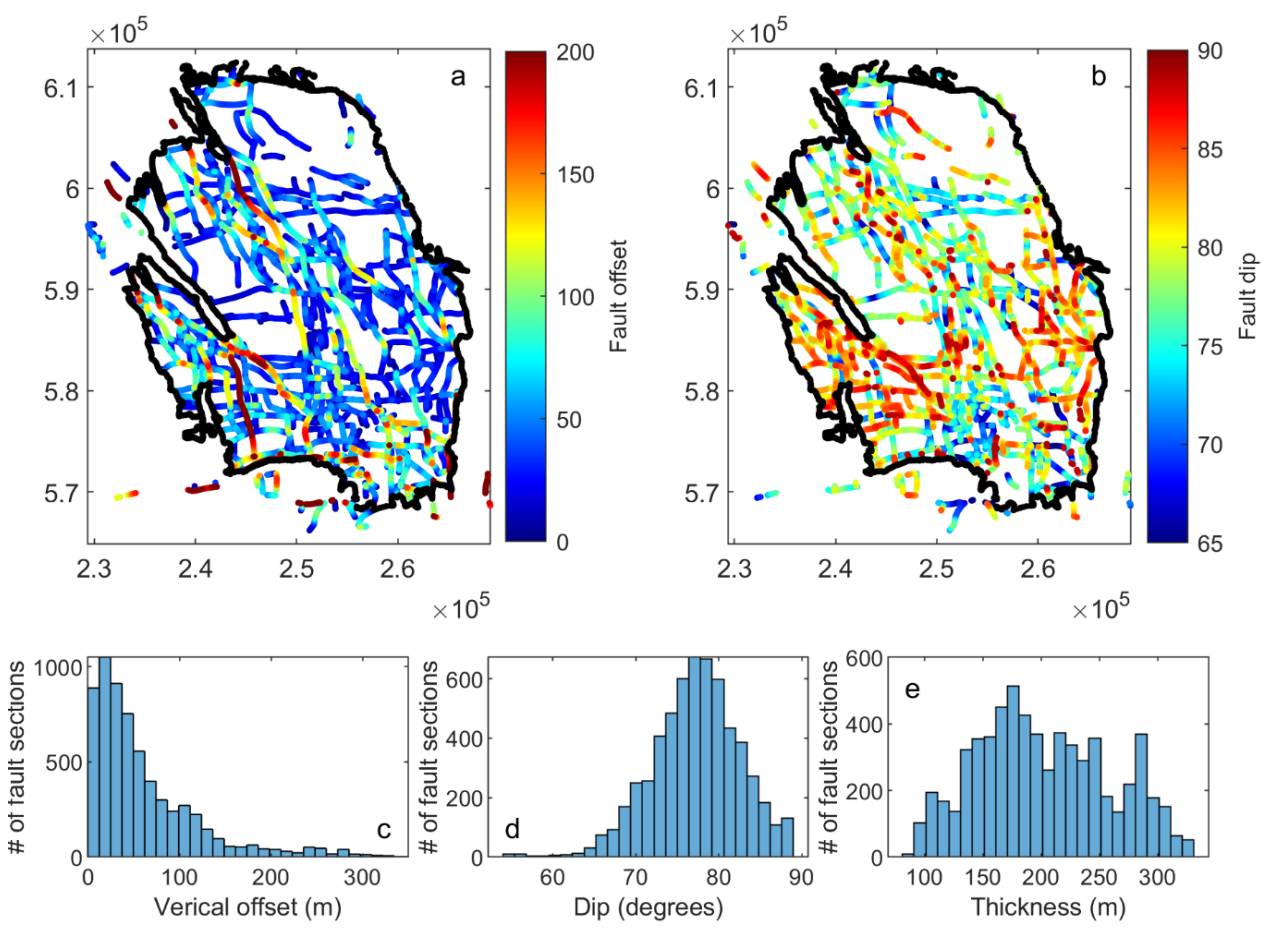

Figure 6-3. Reservoir fault map. a) Top view of faults recognized in the Groningen fault model (courtesy of NAM, 2017). Colors indicate the normal fault offset. Coordinate system: Rijsdriehoek (RD New). b) Same as a) with color coding now representing fault dip. $c$-e) Histrograms of vertical offset, fault dip, and reservoir thickness along each fault section from the fault model.

\section{2. 2. Generic $2 D$ model for a faulted reservoir segment and specification of initial} stress state

The first step of the modeling approach consists of a geomechanical model in which the stresses were computed on a fault offsetting two depleting reservoir compartments. A simplified rectangular segment of the reservoir system is simulated with a 2D plane-strain FE model using the commercially available Finite Element package DIANA FEA v10.3 (Figure 6-2a). In the model a single normal fault cuts the five key lithological units characterizing the Groningen field (Section 6. 2. 1. ): the Zechstein salt (ZE), the Basal Zechstein (BZ) which is here combined in a single unit, the Ten Boer claystone (TB), the Slochteren reservoir sandstone (SS), and the Carboniferous underburden (DC). The depth of the base of the footwall compartment of the Slochteren reservoir is set at $-3000 \mathrm{~m}$, consistent with depths found in the center and northern half of the field (Chapter 1, Figure 1-3). For each model realization, a specific fault strike, fault dip, vertical reservoir offset, and reservoir thickness are assigned by randomly selecting one of the discretized fault section of the 
Groningen fault model (Figure 6-3a and b, Section 6. 2. 1. ) and taking the corresponding values for the strike, dip, vertical offset, and thickness. The thickness of both reservoir compartments is the same on either side of the fault. The thickness of the Ten Boer is kept constant with a value of $50 \mathrm{~m}$, and the thickness of the Basal Zechstein is also constant with $50 \mathrm{~m}$. The total depth of the model is $6000 \mathrm{~m}$, and the top of the model domain is set at a depth of $1200 \mathrm{~m}$. The width of the model domain is $4000 \mathrm{~m}$.

\section{2. 2. Initial stresses and pressures}

The density of the different formations is kept constant at $2600 \mathrm{kgm}^{-3}$. The total vertical stress $\sigma_{v}$ is computed from the weight of the formations and a stress load $\sigma_{\text {top }}$ that simulates the overburden weight above $-1200 \mathrm{~m}$

$$
\sigma_{v}=-\rho g h+\sigma_{\text {top }} .
$$

where $\rho$ is the density of the formations below $-1200 \mathrm{~m}$ depth, $g$ is the gravitational constant, and $h$ is the depth. The value of $\sigma_{t o p}$ was chosen such that the vertical stress at the reservoir depth of $-3000 \mathrm{~m}$ was equal to $66 \mathrm{MPa}$, consistent with the average vertical stress gradient in the Groningen field (van Eijs, 2015) The field-wide total minimum horizontal stress $\sigma_{v}$ is initialized through the total stress ratio $K_{0}$

$$
K_{0}=\sigma_{h} / \sigma_{v}
$$

Unfortunately, no minifrac test data were available to provide information on the initial, predepletion (before 1963) minimum horizontal stress in the Groningen field (van Eijs, 2015). Also mud loss events during drilling of the first wells did not give information on the minimum horizontal stress in the reservoir as these events often happened in different lithological units (Van Eijs, 2015). The pre-depletion minimum horizontal stress is thus highly uncertain. Here, I take values of $K_{0}$ from a uniform distribution between 0.68 (critical stress for optimally oriented faults with a friction coefficient of 0.6 and a dip of $65^{\circ}$ ) and 0.82 (stable). For the Zechstein salt formations, a $K_{0}$ of 1.0 was assigned to simulate the effect of salt creep on the relaxation of shear stresses over geological time (Haug et al., 2018). The maximum horizontal stress is oriented NNW-SSE, with reported orientations varying between 320 and $5^{\circ}$ or $50-95^{\circ}$ (van Eijs, 2015); here it is assumed that the maximum horizontal stress is normally distributed with a mean of 342 and a standard deviation of $10^{\circ}$. The magnitude of the maximum horizontal stress is $1.05-1.2$ that of the minimum horizontal stress (van Eijs, 2015); here an average value of 1.1 is used. For each model realization an apparent stress ratio $K_{\text {Oapp }}$ is calculated which gives the ratio between the horizontal stress in the model plane and the vertical stress. This ratio is calculated from the fault strike assigned to the fault, the direction of the maximum horizontal stress (sampled from the aforementioned normal distribution), the total horizontal stress ratio $K_{0}$, and the ratio between the total maximum horizontal and minimum horizontal stresses (1.1). 
Pore pressure in the overburden is hydrostatic with a saline water density of 1150 $\mathrm{kgm}^{-3}$. Inside the Slochteren reservoir a gas pressure gradient is prescribed $\left(150 \mathrm{kgm}^{-3}\right)$, with a reservoir pressure of $35 \mathrm{MPa}$ at $3000 \mathrm{~m}$ depth, which results in a small overpressure with respect to the saline gradient. Pressure changes in the model are one-way coupled to the mechanical behavior. During depletion a uniform pressure change of $\Delta P$ is prescribed in the reservoir and in the fault elements flanking the reservoir. The surrounding formations and fault segments outside of the reservoir are assumed to be impermeable. In a separate series of simulations the effect of depletion of Ten Boer is also investigated, with the same $\Delta P$ as in the Slochteren prescribed to the Ten Boer formation and elements flanking the Ten Boer.

\section{2. 2. 2 Rock mechanical properties of the key formations}

All lithological formations represented in Figure 6-2 are modeled assuming linear elastic material behavior. Visco-elasticity of the Zechstein salt and elastoplasticity of the reservoir rock are not incorporated as this would be too computer intensive. Stress relaxation due to salt creep was approximated by assigning a $K_{0}$ of 1 to the Zechstein salt formation (Section 6. 2. 2. 1), thus assuming complete relaxation of all shear stresses (Haug et al., 2018; Orlic \& Wassing, 2013; Wassing et al., 2017). Elastoplastic reservoir behavior has been recognized in experiments. Specifically, conventional triaxial tests (Pijnenburg et al. 2019) and uniaxial strain compaction experiments (Hol et al., 2018) on Slochteren samples at the in-situ conditions showed a large fraction (40 - 50\%) of inelastic strain when the porosity is $>20 \%$ (Chapter 3, Pijnenburg et al., 2019). The stress-strain response in the experiments was, however, near-linear, and an earlier FE modeling study in Chapter 2 showed that the inelastic compaction response to reservoir depletion can be approximated by linear elastic behavior using the 'apparent' elastic parameters determined during loading - i.e. linear fits to the experimental elastic + plastic stress-strain response during depletion at stresses and pressures relevant to the reservoir, under uniaxial strain boundary conditions (Chapter 2). The apparent elastic properties used for the reservoir formation are represented in terms of two prime parameters for sandstone compaction determined from pressure depletion steps during the uniaxial strain depletion experiments by Hol et al. (2018): the stress path parameter $\gamma_{h}\left(=\Delta \sigma_{h} / \Delta P\right)$ and the uniaxial strain compressibility or uniaxial compaction coefficient $C_{m}$ which relates the vertical strain change to the pressure change $\left(C_{m}=\Delta \varepsilon_{v} / \Delta P\right)$. The stress path parameter $\gamma_{h}$ measured during loading ranged from 0.65 to 0.9 (Figure 6-4a). The compressibility obtained during loading varied from 4 to $1.4 \cdot 10^{-4} \mathrm{MPa}^{-1}$, in agreement with the compressibility inverted from INSAR data on surface subsidence (Smith et al., 2019). For each model realization values are taken from the two distributions of $\gamma_{h}$ and $C_{m}$ shown in Figure 6-4. The stress path parameter $\gamma_{\mathrm{h}}$ was translated into the Poisson's ratio $v$ using

$$
v=\frac{\alpha-\gamma_{h}}{2 \alpha-\gamma_{h}}
$$


where $\alpha$ is Biot's coefficient. The Biot coefficient for the Groningen sandstone is smaller than 1 as it is a cohesive sandstone. Experiments indicate the Biot coefficient for the Slochteren sandstone is $0.7-0.9$ (Filippidou et al., 2019); here 0.9 is assumed. Note that the effect of the Biot coefficient on the onset of fault reactivation can be significant, and if one is specifically interested in comparing the onset of events with the field production history a broader range should be incorporated. The Young's modulus $E$ can be computed from

$$
E=\frac{(1+v)(1-2 v)}{(1-v) C_{m} / \alpha}
$$

For convenience and to allow fast computation of rupture length in the next step (Section 6. 2. 5. ), the same elastic properties are assigned to the other formations (the Carboniferous, Ten Boer, Basal Zechstein and Zechstein salt units). When modeling depletion of Ten Boer a compaction coefficient $C_{m}$ of $5 \cdot 10^{-5} \mathrm{MPa}^{-1}$ was prescribed, about half the value prescribed for the Slochteren sandstone. This is based on the in-situ compaction measurements which indicate that compaction rates in the Ten Boer are about half of those in the Slochteren (Cannon \& Kole, 2018).
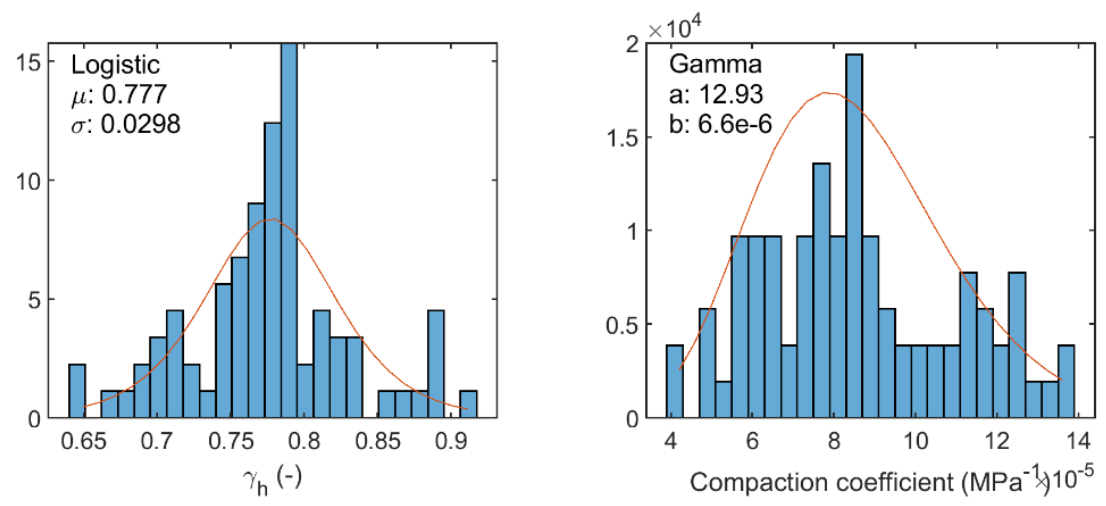

Figure 6-4. Experimentally determined values for stress path and compaction coefficient (Hol et al., 2018). The experiments were performed on Slochteren sandstone cores with a wide range of porosities (15 - 27\%) retrieved from the Groningen field. Production was simulated by decreasing the pore pressure under uniaxial strain conditions at constant vertical stress simulating overburden pressure. Histograms are normalized to form a probability density distribution, total number of datapoints is 84. Blue: data, orange: best fitting distribution.

\section{2. 2. 3 Fault frictional properties}

Following Hunfeld et al. (2017), the composition of the fault rocks (gouges) developed in the relatively small (typically $<100 \mathrm{~m}$ ) offset faults cutting the Groningen reservoir system is assumed to be similar to the composition of the formation or formations abutting against each fault. Since the faults in Groningen intersect a number of different lithologies, fault friction may vary significantly down-dip along the fault. In the present $2 \mathrm{D}$ generic model for a faulted reservoir segment, as illustrated in Figure 6-2, the fault is subdivided into a number of fault segments, one for each juxtaposition type present for the 
vertical offset in the model realization in question (Figure 6-2d). Note here that the number and type of juxtapositions varies from simulation to simulation depending on the fault offset and reservoir thickness. For each uniquely juxtaposed section of fault, fault frictional behavior is taken to be controlled by a linear slip-weakening function, for which a lithologyspecific peak friction $\mu_{s}$, a dynamic friction $\mu_{d}$, and a slip-weakening distance $D_{c}$ must be specified (Figure 6-2c). The ranges of frictional values used in this study are based on friction experiments on simulated fault gouges derived from all lithologies excluding the Zechstein salt (Figure 6-4). The data employed for all but the rocksalt unit are taken from both lowand high velocity shearing experiments, as well as slide-hold-slide experiments, performed on the gouges (Hunfeld et al., 2017; Hunfeld et al., 2019). For the static friction I use a range of values based on steady-state friction values obtained from low-velocity experiments, peak friction values obtained from the longest hold times during slide-hold-slide experiments, and peak friction values obtained from the high-velocity experiments. Dynamic friction and critical slip-weakening distance were based on the high-velocity experiments (Hunfeld, 2020). Note that the high velocity experiments were performed over shorter slip distances than is usual for such experiments to better simulate the conditions relevant to induced events. Slip rate was accelerated from 0 to $1 \mathrm{~ms}^{-1}$ and back over less than $0.2 \mathrm{~m}$, a slip distance relevant to the induced seismic events with magnitudes up to 3.5 (e.g. Kraaijpoel et al., 2013). Measured ranges of the friction parameters and the corresponding experimental conditions are summarized in Figure 6-5 for all formations except the Zechstein rocksalt. As seen in Figure 3, different juxtapositions are present along the fault in each simulation. For the fault sections where two different lithologies are juxtaposed, the fault properties (static and dynamic friction, slip-weakening distance) of the weakest of the two lithologies are assigned, where TB $<$ DC $<$ SS $<$ BZ. For the Zechstein rocksalt and any juxtaposition with the rocksalt, a static and dynamic friction coefficient of 0.8 was assigned to prevent updip propagation (consistent with the assumed $K_{0}$ of 1 and termination of faults in the Zechstein). 


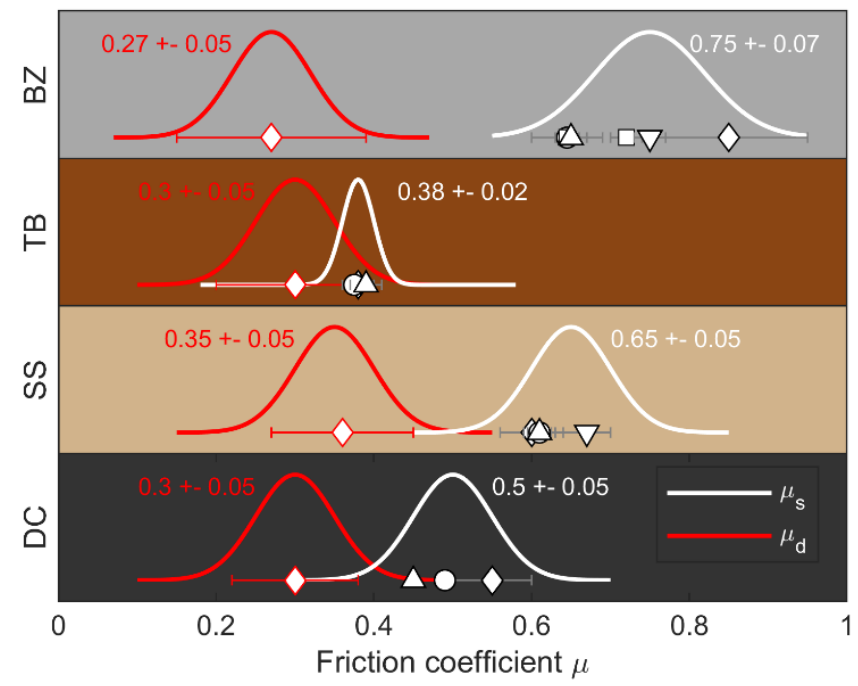

\begin{tabular}{|ll|}
\hline & $\mu_{\mathrm{d}} 2-20 \mathrm{MPa}, \mathrm{RT}$, slip pulse, water, Hunfeld et al. (thesis) \\
$\nabla$ & $\mu_{\mathrm{s}} 2-20 \mathrm{MPa}, \mathrm{RT}$, slip pulse, water, Hunfeld et al. (thesis) \\
$\bigcirc$ & $\mu_{\mathrm{s}} 40 \mathrm{MPa}, 100^{\circ} \mathrm{C}, 0.1-10 \mu \mathrm{m} / \mathrm{s}$, brine, Hunfeld et al., 2017 \\
$\square$ & $\mu_{\mathrm{s}} 40 \mathrm{MPa}, 50-150^{\circ} \mathrm{C}, 0.1-10 \mu \mathrm{ms}-1$, brine, Hunfeld et al., 2019 \\
$\square$ & $\mu_{\mathrm{s}} 40 \mathrm{MPa}, 50-150^{\circ} \mathrm{C}, 0.1-10 \mu \mathrm{ms}-1$, gas, Hunfeld et al., 2019 \\
$\triangle$ & $\mu_{\mathrm{s}} 40 \mathrm{MPa}, 100^{\circ} \mathrm{C}, 1 \mu \mathrm{m} / \mathrm{s}$, brine, Hunfeld et al., in press \\
$\nabla$ & $\mu_{\mathrm{s}} 40 \mathrm{MPa}, 100^{\circ} \mathrm{C}, 1,000,000 \mathrm{~s}$ hold, brine, Hunfeld et al., in press
\end{tabular}

Figure 6-5. Summary of frictional properties measured in experiments on simulated fault gouges from lithologies of the Groningen field and corresponding distributions used as model input. Lithologies are as in Figure 6-2a, with BZ: Basal Zechstein, TB: Ten Boer claystone, SS: Slochteren sandstone, and DC: Carboniferous. Experimental conditions are summarized in the legend, in the following order: effective normal stress, temperature, slip rate, and pore fluid content. RT: room temperature. Slip pulse: high velocity experiments accelerating from 0 to $1 \mathrm{~ms}^{-1}$ and back within $0.2 \mathrm{~m}$ of total slip. 1,000,000s hold indicates friction measured during shearing after a hold period of $1,000,000 \mathrm{~s}$.

The peak friction measured by Hunfeld (2020) in the HV experiments (white diamonds), and the steady state friction coefficients measured in the low velocity experiments (other white symbols), were highest for the Basal Zechstein, followed by the Slochteren sandstone, the Carboniferous, and the Ten Boer gouge materials. The gouge derived from the Basal Zechstein showed the biggest friction drop to a dynamic friction of 0.27. Dynamic friction values of the other three gouges were in the range $0.3-0.35$. Based on the experimental values for each lithology, normal probability distribution functions were defined for $\mu_{s}$ and $\mu_{d}$ as shown in Figure 6-5. For each model realization a random sample is drawn from these distributions. The weakening distances observed in the high velocity experiments were $0.05-0.1 \mathrm{~m}$ (Hunfeld, 2020). Uncertainties in $D_{c}$ are, however, significant. The acceleration in the high velocity experiments is limited (the time to reach $1 \mathrm{~ms}^{-1}$ is 0.1 s), which may result in a larger $D_{c}$ with respect to the abrupt acceleration expected for 


\section{Chapter 6}

earthquakes. To capture a larger uncertainty in (the order of magnitude of) $D_{c}$ a uniform distribution of $\log _{10} D c$ between $-3(0.001 \mathrm{~m})$ and $-0.7(0.15 \mathrm{~m})$ was used.

\section{2. 3. Finite element modeling procedure}

The FE modeling procedure consists of stress initialization followed by a quasi-static loading phase during which the stress changes due to reservoir depletion and aseismic fault reactivation are modeled, up to the point of nucleation of instability. Fault reactivation is characterized by the pressure at which the first fault element reaches its failure strength $\tau_{s}$. As the fault is reactivated and the size of the aseismic slip zone on the fault increases in size with ongoing depletion, the step size of the pressure change is decreased automatically, based on the number of iterations required for convergence (tolerance of the force balance is set to $\left.1 \cdot 10^{-6}\right)$. Numerical instability signifies the onset of the nucleation of dynamic instability, i.e. the point at which the slip zone can continue to grow spontaneously, i.e. without further pore pressure decrease. Normal and shear stresses on the fault are saved after this step, and used as input for computing rupture size.

\section{2. 4. Element sizes in the fault and formations}

The stress-strain evolution within the formations (Figure 6-2a) is computed using an unstructured FE mesh composed of linear quadrilateral and triangular axisymmetric (Q8AXI, T6AXI) or plane-strain (Q8EPS, T6EPS) elements (see DIANA v10.3 Manual). The fault is modeled with line interface elements (LI8F). To have enough resolution to accurately compute the growth of the slip zone during the nucleation phase, it is important that the element size is several times smaller than the process zone, i.e the length of the growing slip zone, or "shear crack", over which the friction drops from the static to the dynamic value. For a Mode II shear crack (appropriate for modeling dip-slip motion on a fault in 2D) and propagation at low velocities, the crack tip process zone length $\Lambda_{0}$ is given by (Palmer \& Rice, 1973)

$$
\Lambda_{0}=\frac{9 \pi}{32} \frac{\mu_{I I}}{W}=\frac{9 \pi}{32} \frac{\mu_{I I} D_{c}}{\left(\tau_{s}-\tau_{d}\right)} .
$$

here $\mu_{I I}$ is the mode II shear modulus defined as $E /(2(1+v)(1-v)), W$ is the weakening rate of the slip weakening function (slope of the slip-weakening diagram in Figure 6-2c divided by the effective normal stress $\sigma_{n}{ }^{\prime}$ ), $D_{c}$ is the slip-weakening distance, $\tau_{s}$ is the failure strength $\mu_{s} \sigma_{n}{ }^{\prime}$, and $\tau_{d}$ is the dynamic shear stress $\mu_{d} \sigma_{n}{ }^{\prime}$. Taking a minimum $D_{c}$ of $1 \mathrm{~mm}$, as used in our model approach, a high estimate of the friction drop of 0.4 for the Slochteren formation (Figure 6-5), a representative shear modulus of $5 \mathrm{GPa}$ of the Slochteren formation, and a $\sigma_{n}$, value of $30 \mathrm{MPa}$ for faults in Groningen (see Chapter 2), gives a minimum likely estimate for the process zone length of $0.4 \mathrm{~m}$. To resolve nucleation at such length-scales, an element size of $0.1 \mathrm{~m}$ was used for the fault elements in the reservoir interval. The fault elements of the fault segments abutting the other formations coarsen gradually to a maximum of $20 \mathrm{~m}$ at 
the model boundaries. The element size within the body of the reservoir formation coarsens from $0.1 \mathrm{~m}$ adjacent to the fault to a maximum of $20 \mathrm{~m}$ at the lateral reservoir edges. In the other formations, the element size gradually increases with distance from the element sizes specified in the reservoir and/or the fault to a maximum element size of $75 \mathrm{~m}$ at the model boundaries.

\section{2. 5. Approximating rupture size using linear elastic fracture mechanics}

The FE model yields the depletion-induced stresses, and specifically their values at a) the point of fault reactivation, b) during initial stable rupture growth and c) at the initiation of unstable seismic slip. Previous modeling studies showed that the arrest of rupture on a slip-weakening fault can be approximated using fracture mechanics theory for crack growth (Ampuero \& Ben-Zion, 2008; Galis et al., 2015; Ripperger et al., 2007). Such an approximation of rupture size on 1-D faults with stochastic stress distributions was also used by Dempsey \& Suckale (2017). Fracture mechanics theory has also been applied successfully to predict different event sizes seen in large-scale experimental faults (Kammer et al., 2015). In the following, I summarize the theoretical background for approximating rupture size using linear elastic fracture mechanics.

\section{2. 5. 1 Linear elastic fracture mechanics theory for equilibrium crack growth}

The energy balance for crack propagation involves the strain energy release rate $G$ per unit fault area, on the one hand, and the fracture energy $G_{c}$ per unit fault area, on the other. The energy release rate $G$ is the amount of elastically stored strain energy in the medium around the crack (rupture zone) that is released for a unit incremental increase in crack (or rupture) length (Andrews, D. J., 1976), i.e. unit crack extension for a 1D crack in a $2 \mathrm{D}$ model such as the present model. The fracture energy $G_{c}$ represents the energy that is dissipated on the fault during frictional weakening - i.e. the area under the slip weakening function above the dynamic shear stress level. For a linear slip-weakening function, $G_{c}$ is given

$$
G_{c}=\frac{\left(\tau_{s}-\tau_{d}\right) D_{c}}{2}=\frac{\sigma_{n}{ }^{\prime}\left(\mu_{s}-\mu_{d}\right) D_{c}}{2}
$$

where $\tau_{s}$ is the fault failure strength, $\tau_{d}$ is the dynamic fault strength, and $D_{c}$ is the slipweakening distance (Figure 6-2b). The limiting criterion for equilibrium crack growth (rupture), and equivalently for rupture arrest (zero crack velocity), corresponds to the condition that the energy release rate $G$ at both crack tips is equal to the fracture energy $G_{c}$, i.e. when the Griffith criterion (e.g. Ampuero \& Ben-Zion, 2008)

$$
G_{ \pm}=G_{c}
$$




\section{Chapter 6}

is fulfilled. The sign \pm indicates each of the crack tip positions. If the energy release rate is smaller than the fracture energy $\left(G_{ \pm}<G_{c}\right)$ then insufficient energy is available to drive crack propagation and the rupture will not grow. If the energy release rate is larger than the fracture energy $\left(G_{ \pm}>G_{c}\right)$ the crack tip will propagate unstably. This criterion is applicable within the small-scale yielding limit, where the size of the process zone (Equation 6-5) is much smaller than the crack length $2 a$. Hence the Griffith criterion applies when $\Lambda_{0} \ll 2 a$.

Now, the energy release rate for a quasi-static Mode II crack in 1D can be written as a function of the static stress intensity factor $K$ at both crack tips (Ampuero \& Ben-Zion, 2008)

$$
G_{ \pm}=\frac{K_{ \pm}^{2}}{2 \mu_{I I}}
$$

The stress intensity factor $K$ itself depends on the half-length $a$ of the crack, as well as the distribution of the stress drop $\Delta \tau$ (shear stress at the start of rupture $\tau_{0}$ minus the dynamic shear stress $\tau_{d}$ ) within the crack length ( $-a$ to $a$ ). In the context of modelling fault rupture, and especially in the case of the heterogeneous production-induced stresses and heterogeneous frictional fault properties simulated in our model, the stress drop varies along the fault dip. For a variable stress drop along the fault, $K$ at the crack tips of a 1-D expanding crack can be calculated using (e.g. Rice, 1980)

$$
K_{ \pm}=\frac{1}{\sqrt{\pi a}} \int_{-a}^{a} \Delta \tau(x+\xi) w_{ \pm}\left(\frac{\xi}{a}\right) d \xi,
$$

where $x$ is the position of the center of the crack on the fault $(a=0)$ given in our models as length along the fault (i.e. depth $/ \cos (90-$ dip $)), a$ is the crack half-length, with \pm indicating each of the crack tip positions $x \pm a, \Delta \tau$ is the stress drop distribution within the crack as with $\xi$ is the integration variable over the crack length $-a$ to $a$, and $w$ is a weight function which is given by (Rice, JR, 1979)

$$
w_{ \pm}(z)=\sqrt{\frac{1 \pm z}{1 \mp z}}=\frac{1 \pm z}{\sqrt{1-z^{2}}}
$$

where $z=\xi / a$ is the position within the crack relative to the crack tip location. This function weighs the heterogeneous stress drop within the crack such that the stress drop values closest to the crack tip will have the most influence on the stress intensity factor. As the mesh size on the fault segments beyond the reservoir gradually increase, I interpolate the modeled stress drop on the fault at a constant spacing of $1 \mathrm{~m}$. The stress intensity factor of Equation 6-9 can be written in an even part and an odd part (Ampuero, written communication) where the even part represents the average crack intensity factor and the odd part the difference between both crack tips 


$$
K_{\text {even }}=\frac{K_{+}+K_{-}}{2}, K_{\text {odd }}=\frac{K_{+}-K_{-}}{2}
$$

which gives the related even and odd parts of the weight function

$$
w_{\text {even }}(z)=\frac{1}{\sqrt{1-z^{2}}}, w_{\text {odd }}(z)=\frac{z}{\sqrt{1-z^{2}}} .
$$

Combining Equation 6-11 and Equation 6-8 now gives

$$
K_{\text {even }}=\left(\sqrt{G_{+} 2 \mu_{I I}}+\sqrt{G_{-} 2 \mu_{I I}}\right) / 2, K_{\text {odd }}=\left(\sqrt{G_{+} 2 \mu_{I I}}-\sqrt{G_{-} 2 \mu_{I I}}\right) / 2
$$

For the arrest criterion $G_{ \pm}=G_{c}$ (Equation 6-7), the even and odd stress intensity factors $K_{\text {even }}$ and $K_{\text {odd }}$ reduce to the following two equilibrium equations

$$
G_{\text {even }}=\frac{K_{\text {even }}^{2}}{2 \mu_{I I}}=G_{c},
$$

and

$$
K_{\text {odd }}=0
$$

Note that an overshoot factor $\eta$ can optionally be included to account for effects such as dynamic overshoot (e.g. Galis et al., 2015) which changes $K_{\text {even }}{ }^{2}$ to $\left(\eta K_{\text {even }}\right)^{2}$, and $K_{\text {odd }}$ to $\eta K_{\text {odd }}$ . Here this factor was set to 1 , as previous studies have shown good agreement between fully dynamic simulations and the LEFM approximation using $\eta=1$ (Galis et al., 2015). In the next sections, I show how these crack extension equilibrium conditions and the extent of the corresponding crack stability fields vary depending on the stress distribution and available stress drop on the fault. Crack stability fields are indicated using the ratio between the energy release rate and the fracture energy $K_{\text {even }}^{2} / 2 \mu_{I I} G_{c}>1$ or $G_{\text {even }} / G_{c}>1$ (unstable), and $G_{\text {even }} / G_{c}$ $<0$ (stable).

\section{3. Variability of rupture lengths and nucleation styles for depletion-induced stress profiles}

The present FE model computes the stress changes resulting from the depletion of two reservoir compartments offset by a fault (Figure 6-3). The stresses on the fault, at the onset of instability, together with fault frictional properties are then used to calculate an approximate rupture length using the method described above. In this section, I show in detail some of the characteristic stability fields obtained from the stress distributions taken from selected simulations. 


\section{Chapter 6}

\section{3. 1. Variability in rupture lengths observed in different simulations}

In the FE calculation, both the shear and normal stresses on the fault change with depletion (see also Chapter 2). Fault offset results in a heterogeneous stress state along the fault dip, with the most critical stresses developing at the top of the hanging wall and base of the footwall. This is illustrated in Figure 6-6, which shows an example of one of the model realizations, i.e. for a reservoir offset of $40 \mathrm{~m}$, a fault dip of $73^{\circ}$, and an initial stress ratio $K_{0}$ of 0.75 . Note how the different lithologies (Figure 6-6a) result in a variable $\tau_{s}$ and $\tau_{d}$ along the fault dip (Figure 6-6b). Prior to depletion, the initial shear stress $\tau_{\text {ini }}$ was slightly below the dynamic shear stress $\tau_{d}$ along all fault segments - i.e. the stress drop is negative and the configuration is inherently stable because it requires work to be supplied to propagate the rupture at the dynamic stress level, instead of energy being transferred from the surrounding formations to fault slip (Figure 6-6b). During depletion, the shear stress in the reservoir interval was raised above the dynamic shear stress. Two shear stress concentrations developed at along-fault locations of -2970 and $-3130 \mathrm{~m}$ (Figure 6-6b), first attaining the failure shear stress $\tau_{s}$ at the shallowest of the two concentrations.

Though slip zones formed at both stress concentrations, nucleation of instability first occurred at the shallower stress concentration at $-2970 \mathrm{~m}$ along fault. Nucleation occurred after a specific length of the fault had slipped aseismically - i.e. the critical nucleation length. The observed nucleation length in the model agrees well with the universal critical nucleation length $L_{c}$ that is insensitive to the driving stress distribution, as defined by (Uenishi \& Rice, 2003)

$$
L_{c}=1.158 \frac{\mu_{I I}}{W}=1.158 \frac{\mu_{I I} D_{c}}{\sigma_{n}^{\prime}\left(\mu_{s}-\mu_{d}\right)}
$$

Note that this nucleation length holds only when slip occurring in the nucleation zone does not exceed the slip-weakening distance $D_{c}$. In the next section, several examples are shown where this criterion is not fulfilled. In the current example, the $L_{c}$ as defined by Equation 6-16, was $10 \mathrm{~m}$ and hence the critical nucleation half-length $L_{c 05}$ that is shown in Figure 6-6d is $5 \mathrm{~m}$.

At the onset of instability (at which the shear stress is defined as $\tau_{0}$ ) the available pointwise stress drop on the fault in the reservoir interval was $2-4 \mathrm{MPa}$, whereas outside the reservoir the stress drop available on the fault is still negative as shear stress here is not strongly affected by reservoir depletion (Figure 6-6b, c). From the shear stresses at the onset of instability, the energy release rates (Equations 6-8, 6-14) are computed for crack halflengths up to $1200 \mathrm{~m}$. For each crack half-length the boundary between the stable region and unstable region $G_{\text {even }} / G_{c}=1$ (Equation 6-14) can be drawn at the corresponding fault position, forming a stability map as shown in Figure 6-6d. In the green regions, $G / G_{c}$ is smaller than 1 (stable) and in the orange regions $G / G_{c}$ is larger than 1 (unstable). The yellow line gives the second equilibrium condition $K_{\text {odd }}=0$ (Equation 6-15) and indicates the crack center. At crack half-lengths larger than the nucleation half-length, unstable crack propagation will 
occur when $G / G_{c}>1-$ i.e. within the orange region. The arrest conditions can then be tracked as the crack half-length increases (i.e. the crack grows). The arrest location is defined when both equilibrium conditions given by 6-14 and 6-15 are satisfied - i.e. at the intersection of the boundary between the stable and unstable regions with the crack center. The arrest location for the example in Figure 6-6d is indicated by the white circle, at a crack half-length of $114 \mathrm{~m}$. The approximated rupture length for this simulation is thus $228 \mathrm{~m}$, centered around $-3046 \mathrm{~m}$ along the fault. Propagation of rupture was thus mainly down-dip; the upper extent of the approximated rupture is at $-2932 \mathrm{~m}$ within the TB-SS juxtaposition, $38 \mathrm{~m}$ shallower than the nucleation site, whereas the lower extent of the rupture is $-3160 \mathrm{~m}$. This is caused by the favorable state of stress for propagation along the fault segment within the Slochteren reservoir interval. Note that a second set of yellow lines (Equation 6-15) appears from the deeper stress concentration at $-3130 \mathrm{~m}$. After a crack half-length of $70 \mathrm{~m}$ these merge with the crack center originating from $-2970 \mathrm{~m}$, indicating merging of the two slip zones that formed at both stress concentrations. Arrest updip occurs because of the low shear stress region found around $-2940 \mathrm{~m}$ induced by depletion of the offset reservoir. Note that stresses in the ZE fault segment are always inherently stabilizing (Figure 6-6b) due to the high imposed $K_{0}$, and even if rupture would overcome the low shear stress region, the updip extent of rupture will still be limited by the stress in the Zechstein. Arrest down-dip occurs because of the low shear stress found below the reservoir depth interval and the low initial stress in the underburden (Figure 6-6b).
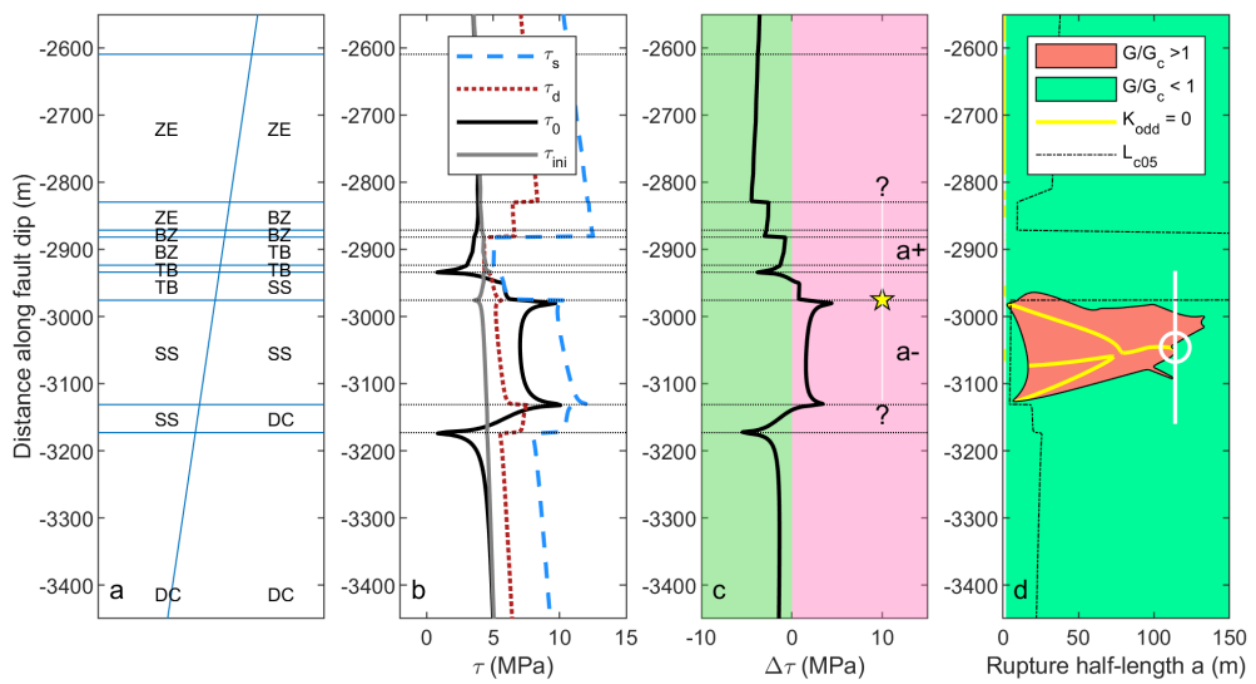

Figure 6-6. Example of depletion-induced fault stresses generated by the FE model and the related crack stability and approximated rupture length. The example shown here has the following main input parameters: dip $=73^{\circ}, K_{0}$ $=0.75$, offset $=40 \mathrm{~m}$, thickness $=189, \mu_{s S S}=0.62, \mu_{d S S}=0.32 \mu_{s D C}=0.5, \mu_{d D C}=0.35$ a) Lithologies on both sides of the fault, as a function of distance along the fault $=$ depth $/ \cos (90-$ dip $)$, b) initial shear stress $\tau_{\text {ini }}$ and shear stress at the onset of instability $\tau_{0}$ with distance along the fault. Dynamic shear stress $\tau_{d}$ and static fault strength $\tau_{s}$ are indicated by the dotted and dashed lines, respectively, c) Stress drop along the fault, yellow star indicates the 


\section{Chapter 6}

depth at which nucleation of instability occurs, $d$ ) Stability map for rupture propagation. Green: stable regions $G / G_{c}$ $<1$, orange: unstable regions $G / G_{c}>1$. The boundary between the two regions is given by Equation 6-14. Yellow line: position of the crack center (Equation 6-15). The white circle indicates the arrest position, and the white line the approximated rupture length.

In the example shown in Figure 6-6, rupture extended across the entire reservoir depth interval, as the stresses there are sufficiently high for rupture to propagate from the top of the hanging wall to the bottom of the footwall. This is not always the case. Two further examples of depletion-induced fault stresses and the predicted equilibrium conditions are shown in Figure 6-7, for the same initial stress ratio $K_{0}$ of 0.75 but different fault geometries and frictional properties. In the first example (Figure 6-7a), stress concentrations still form but the relatively steep fault dip of $81^{\circ}$ (see the figure caption for input values) results in lower shear stresses in the reservoir interval compared to the previous example. After attaining the critical nucleation half-length $L_{c 05}$ of $3 \mathrm{~m}$ for the SS fault segment and reaching instability, the shear stress $\tau_{0}$ exceeds $\tau_{d}$ and reaches $\tau_{s}$ only at the top of the hanging wall and base of the foot wall. The stability diagram indicates that subsequent unstable rupture propagation is only possible around the stress concentration at $-2880 \mathrm{~m}$ (Figure 6-7a). The rupture half-length at the arrest conditions is $21 \mathrm{~m}$, giving a total rupture length of $42 \mathrm{~m}$ which is much less than the reservoir thickness of $213 \mathrm{~m}$.
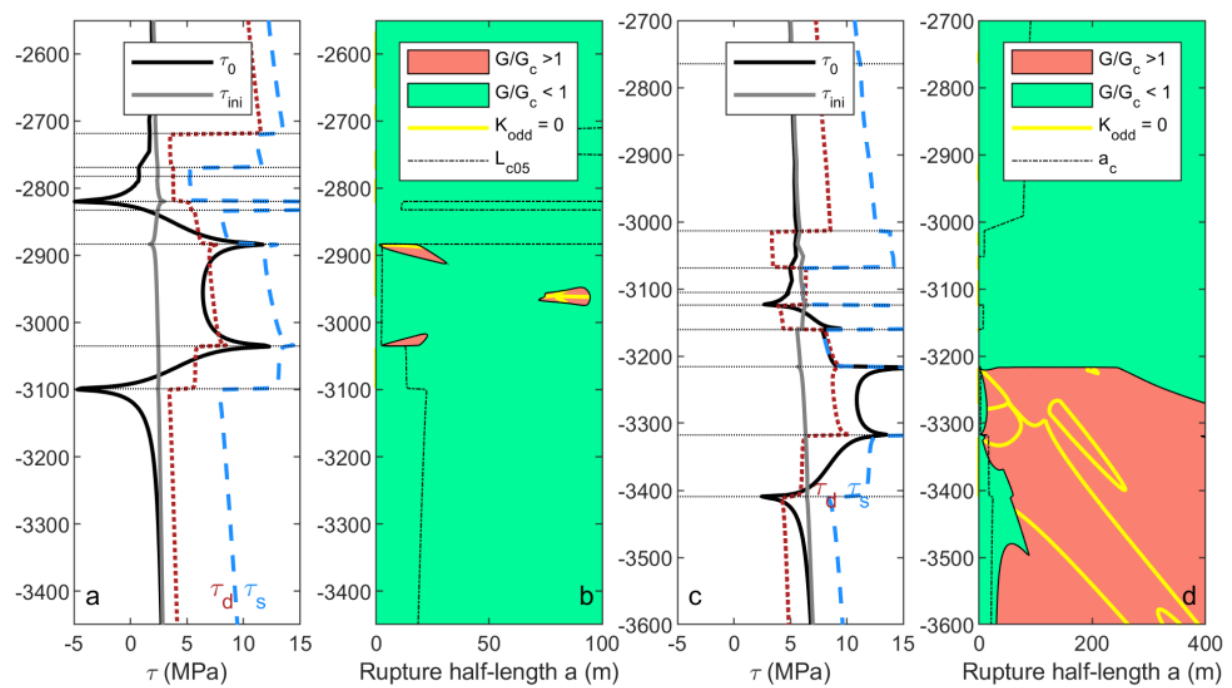

Figure 6-7. Further examples of depletion-induced fault stresses generated from the FE model and the related stability fields, for two model realizations with a rupture smaller and larger than the reservoir height. The example shown in $a$ and $b$ here has the following main input parameters: dip $=81^{\circ}, K_{0}=0.75$, offset $=65 \mathrm{~m}$, thickness $=$ $179, \mu_{s S S}=0.65, \mu_{d S S}=0.39 \mu_{s D C}=0.5, \mu_{d D C}=0.35$. The example shown in $c$ and $d$ is from a simulation that has the following main input parameters: dip $=65^{\circ}, K_{0}=0.75$, offset $=81 \mathrm{~m}$, thickness $=175, \mu_{s S S}=0.78, \mu_{d S S}=0.42$ $\mu_{s D C}=0.48, \mu_{d D C}=0.25$. $a$ and $\left.c\right)$ initial shear stress $\tau_{\text {ini }}$ and shear stress at the onset of instability $\tau_{0}$ with distance 
along the fault. Dynamic shear stress $\tau_{d}$ and static fault strength $\tau_{s}$ are indicated by the dotted and dashed lines, respectively, $b$ and $d)$ Stress drop along the fault, $d$ ) Stability map for rupture propagation. Green: stable regions $G / G_{c}<1$, orange: unstable regions $G / G_{c}>1$. The boundary between the two regions is given by Equation 6-14. Yellow line: crack center (Equation 6-15).

The stress state on the fault is more unstable in the second example, where the fault dip is $65^{\circ}$ and dynamic friction in the Carboniferous underburden $\mu_{d D C}$ of 0.25 is low (Figure 6-7c and d). After attaining the critical nucleation length of $50 \mathrm{~m}\left(L_{c 05}=25 \mathrm{~m}\right.$ in the SS fault segment) the shallowest slip zone propagates downdip and merges with the deeper slip zone. Subsequently, continued unilateral propagation into the underburden is predicted; the equilibrium conditions for rupture arrest are not met under the stress conditions and frictional properties of this model realization.

The depletion-induced stress profile thus results in different ruptures: i) ruptures that nucleate at the slip zone at one of the two stress concentrations and merge with the second slip zone so that rupture spans the entire reservoir depth interval, ii) ruptures that nucleate from the slip zone at one of the stress concentrations, but are arrested before they merge with the second slip zone and thus only span part of the reservoir depth interval, and iii) ruptures that propagate (indefinitely) beyond the reservoir interval, depending on the state of stress in and frictional properties of the Carboniferous. These rupture types were also recognized in the fully dynamic simulations presented in Chapter 2 and by Van den Bogert, 2018.

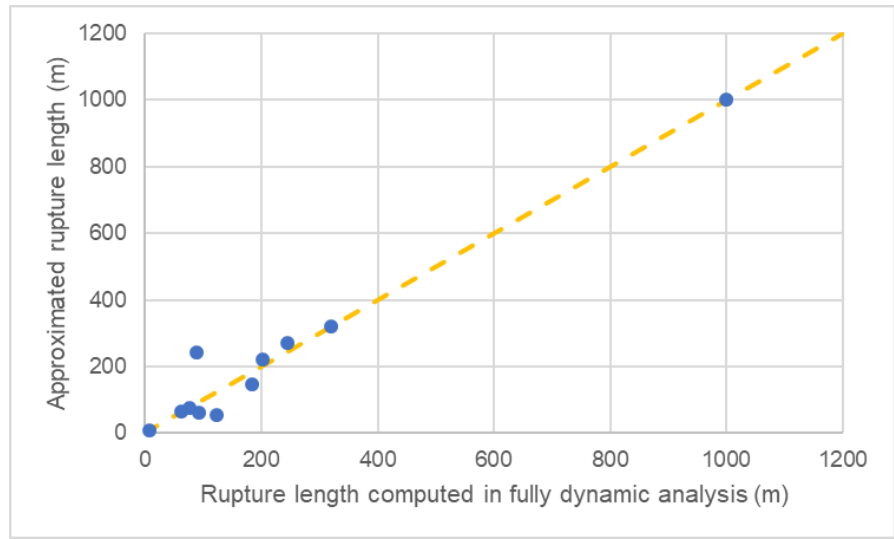

Figure 6-8. Comparison between approximated rupture sizes and rupture sizes computed in a fully dynamic analysis. Rupture lengths were computed for a number of randomly selected simulations with different input parameters.

To test the approximation of rupture size using the LEFM theory as described in Section 6. 2. 5. , rupture lengths were also computed in a fully dynamic analysis for a selected number of simulations. Mostly, the agreement between the approximated and fully dynamic rupture lengths was good with $<10 \%$ difference (Figure 6-7). In some cases, a larger difference was observed, e.g. for the simulation for which an approximated rupture length of $244 \mathrm{~m}$ was computed, but a rupture length of $88 \mathrm{~m}$ was observed. In this case, the two arrest 


\section{Chapter 6}

criteria given by Equations 6-14 and 6-15 were very close together for a wide range of crack half-lengths, and the exact crack-length at which both criteria are met was difficult to determine and sensitive to model assumptions. Under most other conditions however the LEFM approximation was good.

Table 6-1 Classification of nucleation types observed in the different model realizations.

\begin{tabular}{|c|c|c|c|c|}
\hline Type & $S C U_{\max }$ & $D_{a} / D_{c}$ & $\Delta P_{i}$ & Comment \\
\hline Type00 & $<1$ & N/A & N/A & No reactivation anywhere \\
\hline Type0A & $>1$ & $<1$ & N/A & Critical nucleation length not reached $\left(\mathrm{L}_{\mathrm{a}}<\mathrm{L}_{\mathrm{c}}\right)$ \\
\hline Туре0В & $>1$ & $>1$ & N/A & $\begin{array}{l}\text { Critical nucleation length exceeded }\left(\mathrm{L}_{\mathrm{a}}<\mathrm{L}_{\mathrm{c}}\right) \text {, aseismic } \\
\text { slip beyond } \mathrm{D}_{\mathrm{c}}\end{array}$ \\
\hline Type11 & $>1$ & $<1$ & $<35$ & Critical nucleation length attained by the first slip zone \\
\hline Туре1В & $>1$ & $>1$ & $<35$ & $\begin{array}{l}D_{c} \text { not exceeded, } L_{c} \text { not reached but instability due to } \\
\text { merging of slip zones }\end{array}$ \\
\hline Туре $2 \mathrm{~A}$ & $>1$ & $<1$ & $<35$ & $\begin{array}{l}D_{c} \text { exceeded by aseismic slip in one of the slip zones } \\
\text { but critical nucleation length attained by one of the slip } \\
\text { zones }\end{array}$ \\
\hline Type2B & $>1$ & $>1$ & $<35$ & $\begin{array}{l}D_{c} \text { exceeded on one slip zone but instability due to } \\
\text { merging of slip zones }\end{array}$ \\
\hline
\end{tabular}

\section{3. 2. Different types of unstable slip nucleation}

For the examples in the previous section, the production-induced stresses led to the nucleation of seismic instability at one of the stress concentrations on the fault. However, for some model realizations, nucleation of instability occurred in a different fashion, or did not occur at all. It is important to consider the nucleation phase, as the extent of aseismic slip and stress release affects the subsequent propagation of rupture. Here I summarize the different types of nucleation of instability (or lack thereof) observed in the models (see Table 6-1). 

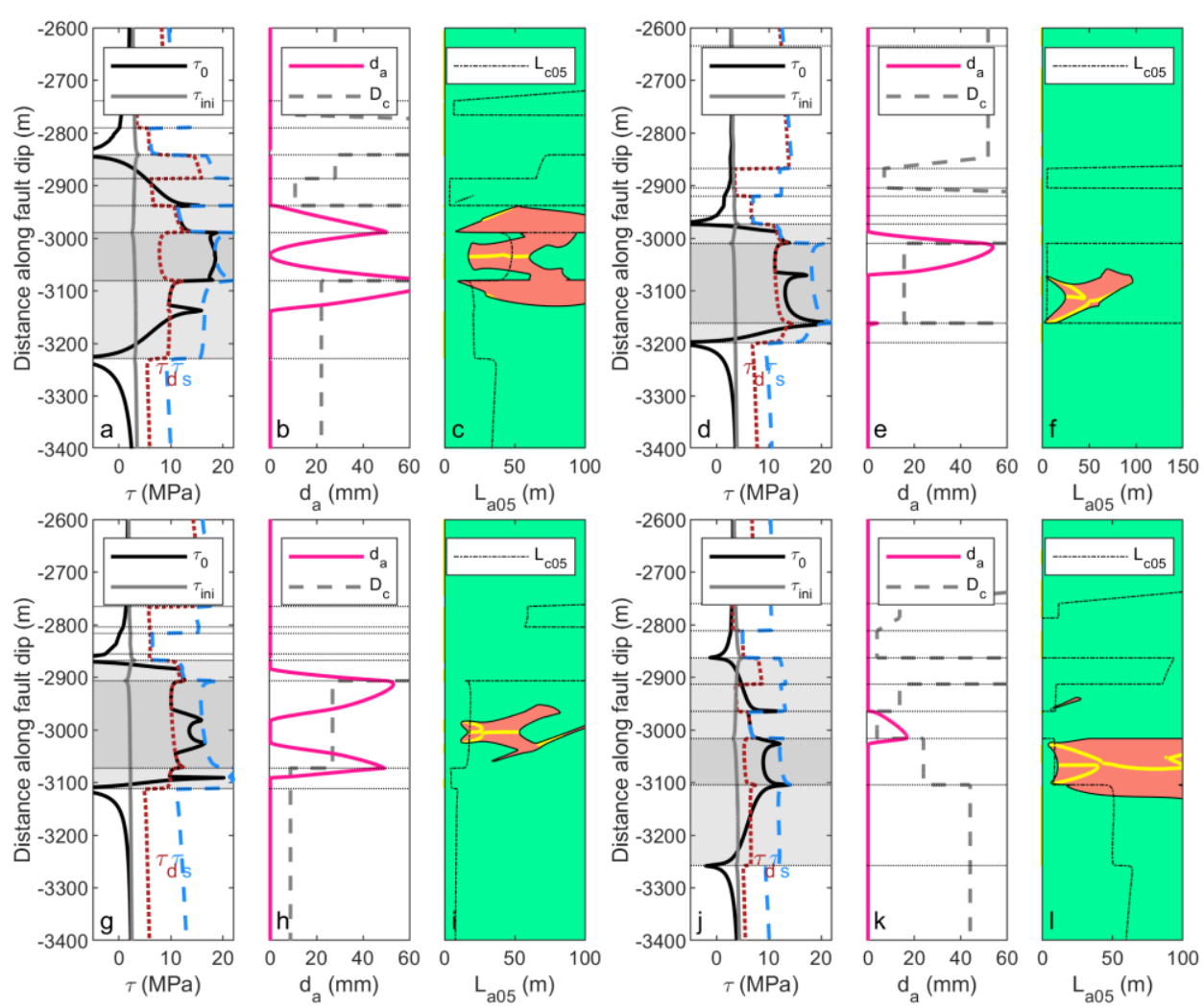

Figure 6-9. Four different types of nucleation of instability due to depletion-induced stress changes. For each example the fault shear stresses (a,d,g,j), aseismic slip $d_{a}(b, e, h, k)$, and the stability fields (c,f,i,l)are shown. Shear stresses and colors of the stability fields are the same as in Figure 6-6 and Figure 6-7. Semi-transparent gray areas indicate the position of the SS reservoir hanging wall and footwall. The main input parameters for the example ac are : dip $=77^{\circ}, K_{0}=0.78$, offset $=144 \mathrm{~m}$, thickness $=233, \mu_{s S S}=0.7, \mu_{d S S}=0.3 \mu_{s D C}=0.5, \mu_{d D C}=0.3$, for the example in $d$-fare: dip $=72^{\circ}, K_{0}=0.82$, offset $=35 \mathrm{~m}$, thickness $=179, \mu_{s S S}=0.64, \mu_{d S S}=0.39 \mu_{s D C}=0.47, \mu_{d D C}$ $=0.34$, for the example in $g-i:$ dip $=77^{\circ}, K_{0}=0.81$, offset $=38 \mathrm{~m}$, thickness $=200, \mu_{s S S}=0.6, \mu_{d S S}=0.38 \mu_{s D C}=$ $0.54, \mu_{d D C}=0.24$, and for the example in $j-l:$ dip $=75^{\circ}, K_{0}=0.75$, offset $=148 \mathrm{~m}$, thickness $=233, \mu_{s S S}=0.69$, $\mu_{d S S}=0.3 \mu_{s D C}=0.55, \mu_{d D C}=0.3$. a-c) nucleation between the two slip zones, with both slip zone lengths smaller than the critical nucleation length size (Type1B), d-e) Nucleation as the deepest slip zone reached the critical nucleation length, whereas slip within the shallowest slip zone had exceeded $D_{c}(T y p e 2 A)$, g-i) nucleation between the two slip zones, with both slip zone lengths exceeding the critical nucleation length and slip exceeding the slipweakening distance (Type 2B). j-l) aseismic slip in TB-SS juxtaposition between -2970 and $-3010 \mathrm{~m}$, nucleation in SS-SS.

In some model realizations, no fault reactivation occurs at all, i.e. nowhere on the fault is the failure shear stress criterion met (Type00). In other cases, fault reactivation does occur, but the size of the aseismic slip zone $L_{a}$ does not reach the critical nucleation length $L_{c}$ during reservoir depletion, and no instability occurs. This limited size of the aseismic slip zone can be due to a) highly localized stress concentrations surrounded by regions of low 


\section{Chapter 6}

stress (Type0A), or b) the maximum slip in the slip zone exceeding the slip-weakening distance which causes the slip zone to expand beyond the nucleation length without further instability (Type0B), violating the large-scale yield criterion underlying the theoretical nucleation length (Uenishi \& Rice, 2003). In turn, this can occur because the peaked stress concentration results in a significant amount of local slip, or because the critical nucleation length-scale is larger than the length-scale over which depletion-induced stresses occur -i.e. roughly the reservoir thickness. In the latter case the finite extent of the depletion-induced stress changes restricts the growth of the slip zone, and aseismic slip continues to increase. Instability does nucleate when the largest of the two slip zones (typically the shallower one) reaches the critical nucleation length $L_{c}$ with slip within this zone remaining less than or equal to the slip-weakening distance $D_{c}$ (Type1A) - as observed in the examples shown in the previous sections. In a few simulations, the two slip zones related to the two stress concentrations interact and instability occurs because they merge before either one attains the critical nucleation length (Type1B). This type of instability tends to occur when stress concentrations are relatively close together. Figure 6-9a-c, for example, shows nucleation of instability on a $72^{\circ}$ dipping fault in a reservoir with a thickness of $156 \mathrm{~m}$, and an offset of $197 \mathrm{~m}$ - i.e. larger than the thickness of the reservoir. Between $-3140 \mathrm{~m}$ and $-3190 \mathrm{~m}$, the Ten Boer unit is juxtaposed against the Slochteren sandstone or the Carboniferous, with the fault properties being governed by the weaker Ten Boer fault characteristics (Figure 6-5). In this example, instability nucleates because the upper and lower slip zones merged before either attained the critical nucleation length of $52 \mathrm{~m}$. Note, though, that the state of stress between the slip zones was already close to failure.

In some other cases, aseismic slip exceeds $D_{c}$ within one of the slip zones before the slip zone reaches the critical nucleation length, violating the large-scale yielding conditions underlying the theoretical nucleation length. In this case the slip zone grows beyond the critical nucleation length without nucleation of instability as for the Type0B response. Contrary to the Type0B response, instability still nucleates when the second slip zone reaches the nucleation length without exceeding $D_{c}$ (Type2A). An example of this Type 2a instability is shown in Figure 6-9d-e. The shallower slip zone expands to $140 \mathrm{~m}$, i.e. to over half of the reservoir interval accommodating a maximum slip of $40 \mathrm{~mm}$ (Figure 6-9e). Its length thus exceeds the nucleation length of $20 \mathrm{~m}$, but instability nucleates at the deeper slip zone. Note that the calculated event size remains limited and does not propagate to the top of the reservoir interval at $-2830 \mathrm{~m}$ (Figure 6-9f), as the shear stress has dropped to the dynamic value in the shallowest slip zone during the nucleation phase (Figure 6-9d). When $D_{c}$ is exceeded in both slip zones, and both slip zones expand aseismically beyond the critical nucleation length, as in Figure 6-9g-i, instability was still observed in some models when these two slip zones approached each other and merged (Type2B). The resulting rupture length is relatively small, as shear stress was reduced to the dynamic shear stress over a significant portion of the fault within the reservoir interval during the aseismic nucleation phase (Figure 6-9g,i). Finally, nucleation of a small instability can also occur from a slip zone 
in which $D_{c}$ has been exceed, but continued loading causes another instability point to be reached at a slip zone length larger than the nucleation length $L_{c}$ (Figure 6-9j-1).

\section{4. Pressure change at the onset of instability and rupture lengths obtained for model ensemble}

Here I summarize the reservoir pressure decrease at the onset of instability, and the associated rupture lengths, obtained from 1,500 simulations for fault segments selected randomly from the Groningen fault model (Figure 6-3) and using input parameters sampled from the distributions shown in Figure 6-4 and Figure 6-5 (see alo Section 6. 2. 2. ). Note that the pressure change at the onset of instability is related to the timing of the resulting seismic events through the evolution of gas pressure in the field since the start of production (Figure 1c).

\section{4. 1. Depletion pressure at which instabilities nucleate}

Figure 6-10 summarizes the pressure change at which nucleation of instability was observed in the simulations - i.e. the nucleation pressure change $\Delta P_{0}$. All results for $\Delta P_{0}$ are plotted against a selection of the input parameters in scatterplots (note that for each model realization all input parameters are randomly picked, none of the input parameters shown in Figure 6-10 is kept constant). Nucleation of instability was observed for $\sim 50 \%$ of the model realizations (Type 1 and Type 2 behavior). These instabilities occurred over the full range of pressure changes imposed, i.e. for $\Delta P_{0}$ ranging from 0 (whereby the selected fault segment is critically stressed at the onset of depletion) to almost $35 \mathrm{MPa}-$ i.e. full reservoir depletion. As would be expected, the three parameters determining the initial stress state on the faults, i.e. the initial stress ratio $K_{0}$ and the fault dip, and strike) exerted strong control on $\Delta P_{0}$ for the onset of instability (Figure 6-10a-c). Specifically, the value of $\Delta P_{0}$ increased with increasing $K_{0}$ and dip. For $K_{0}$ values $<0.75$, instability occurred at $\Delta P_{0}$ values $<5 \mathrm{MPa}$ for $10-20$ model realizations, but for larger $K_{0}$ the minimum $\triangle P_{0}$ increased to $10 \mathrm{MPa}$. Moreover, the low $\Delta P_{0}$ of $<5 \mathrm{MPa}$ was obtained for fault dips $<77^{\circ}$ and faults striking $140-180^{\circ}$ - i.e. optimally oriented faults. Most of the events nucleating at low $\Delta P_{0}$ were of Type 1 (Type $1 \mathrm{~A}$ or 1B)- i.e. nucleation from a single slip zone that attained the critical nucleation length or merging of two slip zones, without slip exceeding $D_{c}$ (Table 6-1). 

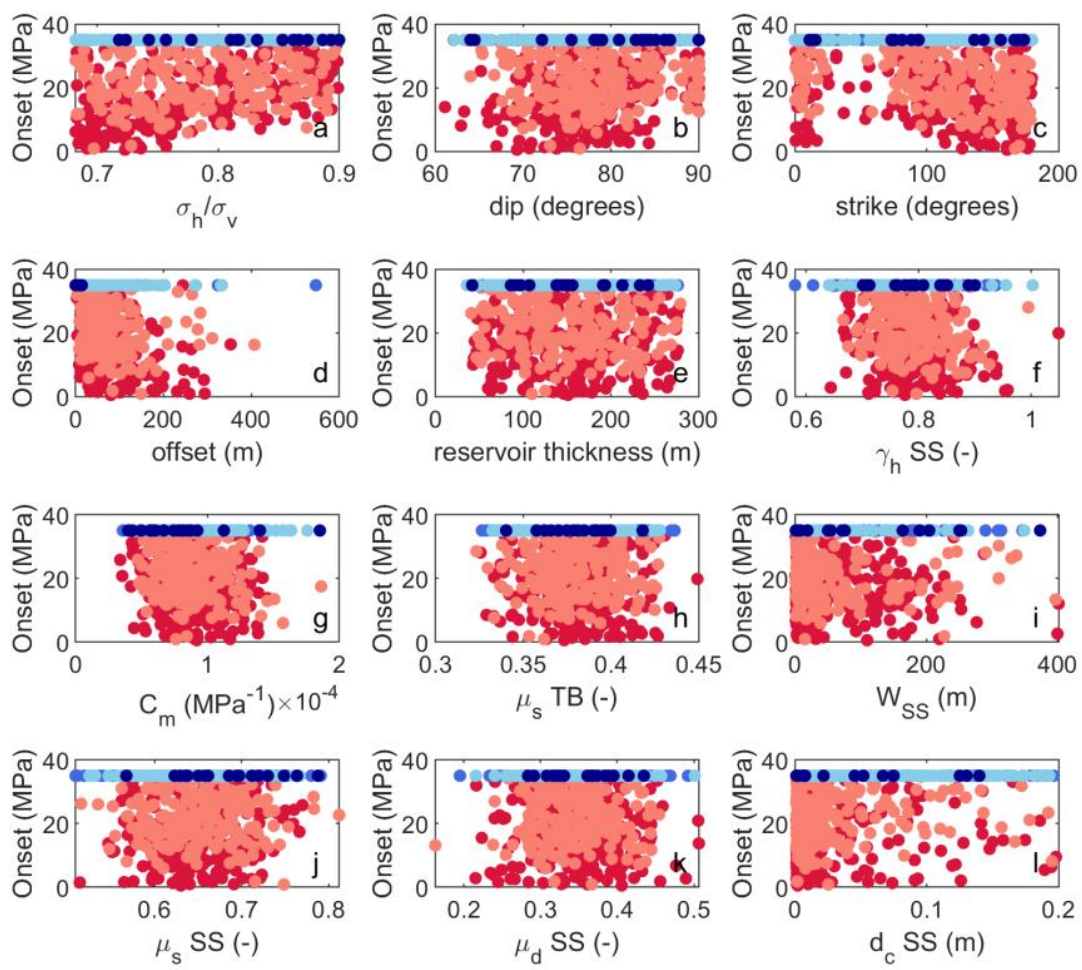

\begin{tabular}{|llllllllll}
\hline & Type00 & - & Type0A & Type0B & $\bullet$ & Type1 & Type2 \\
\hline
\end{tabular}

Figure 6-10. Pressure change $\Delta P_{0}$ at the onset of instability, as observed for the full model ensemble of 1,500 model realizations, plotted against a number of model input parameters. Symbols are color-coded according to the nucleation type, where absence of seismicity corresponds to Type00, TypeOA and TypeOB; these are plotted at a $\triangle P_{0}$ of $35 \mathrm{MPa}$ (see Table 1).

The effect of the input parameters on $\Delta P_{0}$ is not always obvious from the plots in Figure 6-10. In Figure 6-11, the results are grouped into 10 bins for each input parameter. For each bin the fraction of events nucleating at $\Delta P_{0}$ of $0-11 \mathrm{MPa}, 11-23 \mathrm{MPa}$, and $23-$ $35 \mathrm{MPa}$ are shown, as well as the model realizations without instability (Type0), all normalized to the bin size. The stabilizing effect of a larger $K_{0}$ and fault dip discussed in the previous paragraph is much more apparent using this representation. Above stress ratios of 0.8 , almost $50 \%$ of all model realizations did not produce an instability (Figure 6-11a). In addition, at dips exceeding $80^{\circ}$, nucleation of instability was not observed for $50-70 \%$ of the model realizations. Indeed, stable stress ratios and/or unfavorably steep dips resulted mostly in a scenario where no reactivation occurred at all (Type00) or where the nucleation length was not attained (Type0B) (Figure 6-10a). Figure 6-11 also more clearly shows the effect of other input parameters on $\Delta P_{0}$. For small vertical reservoir offsets, for example, a 
relatively high fraction of model realizations showed stable behaviour (Figure 6-11d). With increasing offset, the fraction of instabilities increased strongly and the average nucleation pressure drop $\Delta P_{0}$ decreased. This reflects the effect of higher stress concentrations development with increasing offset, similar to what has been reported in previous studies (Buijze, van den Bogert et al., 2019; van den Bogert, 2015). The fraction of model realizations leading to reactivation also increased with the stress path parameter $\gamma_{h}\left(=\Delta \sigma_{h} / \Delta P\right)$ (Figure 6-11f). A large $\gamma_{h}$ results in a smaller change in horizontal effective stress, whereas the vertical effective stress increase remains $\alpha \Delta P$ for uniaxial conditions. A large $\gamma_{h}$ thus results in a larger differential stress, which causes the state of stress to move closer to the failure line. Also a higher uniaxial compressibility of the reservoir led to an increased fraction of model realizations producing instability (Figure 6-11g). A higher compressibility results in higher vertical strains and a larger amount of compaction, which results in larger vertical displacement gradients across the fault and hence larger stress concentrations. The other input parameters shown in Figure 6-11 and those not shown in Figure 6-11 do not strongly affect the pressure change $\Delta P_{0}$ needed to cause nucleation.
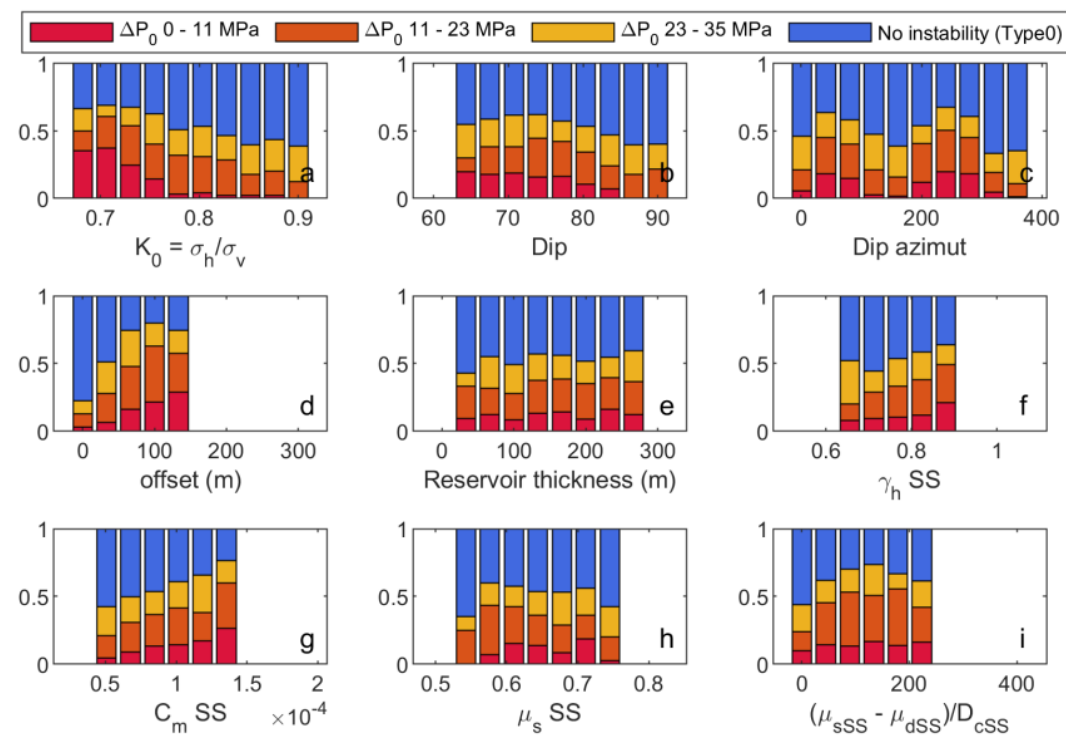

Figure 6-11. Normalized fraction of simulation results within a given range of pressure change required for nucleation $\triangle P_{0}$, as a function of different input parameters. Ten bins were plotted in the bar charts covering the full range of each parameter considered but bins containing less than 20 simulations were discarded. The pressure change required for the onset of instability is defined in three categories: those with a $\triangle P_{0}$ from $0-11 \mathrm{MPa}(\mathrm{red})$, $11-23 \mathrm{MPa}$ (orange), and 23 -35 MPa (yellow). The fraction of model realizations not featuring nucleation of instability is included in blue.

It is interesting to consider the evolution of the number of events with $\Delta P_{0}$, as this is indicative for the behavior of seismicity with ongoing depletion. In Figure 6-12, the fraction 


\section{Chapter 6}

of simulations with a rupture length $>25 \mathrm{~m}$ is shown as a function of $\Delta P$. In Figure 6-10 it was observed that the initial stress ratio $K_{0}$ had a large effect on $\Delta P_{0}$. Therefore, a distinction is made between lower values of $K_{0}$ and higher values of $K_{0}$ (a more stable initial stress state). For the lowest range of $K_{0}$ considered, events are observed from low $\Delta \mathrm{P}$ to high $\Delta \mathrm{P}$, with a peak around $\Delta \mathrm{P} 5-15 \mathrm{MPa}$ but no further trend. The trend for the higher range of $K_{0}$ is very different. In this case, there are no rupture events the first $5 \mathrm{MPa}$ of depletion. Between a $\triangle P$ of 5 and $15 \mathrm{MPa}$ the number of events grows rapidly, and beyond a $\triangle P$ of $15 \mathrm{MPa}$ the number of events per increment of $\Delta \mathrm{P}$ remains relatively constant. The initial state of stress thus results in a different evolution of seismicity with depletion time, with more events occurring during the beginning of depletion for more critical stresses compared to the more stable initial stresses, for which first a period of seismic quiescence is observed, followed by rapid growth. Note that these evolutions will also be sensitive to the fault properties, notably the static friction and cohesion. For now, zero cohesion is assumed, but if there is cohesion then the evolution of the number of seismic events with $\Delta P$ will shift to higher $\Delta P$ (see Discussion).

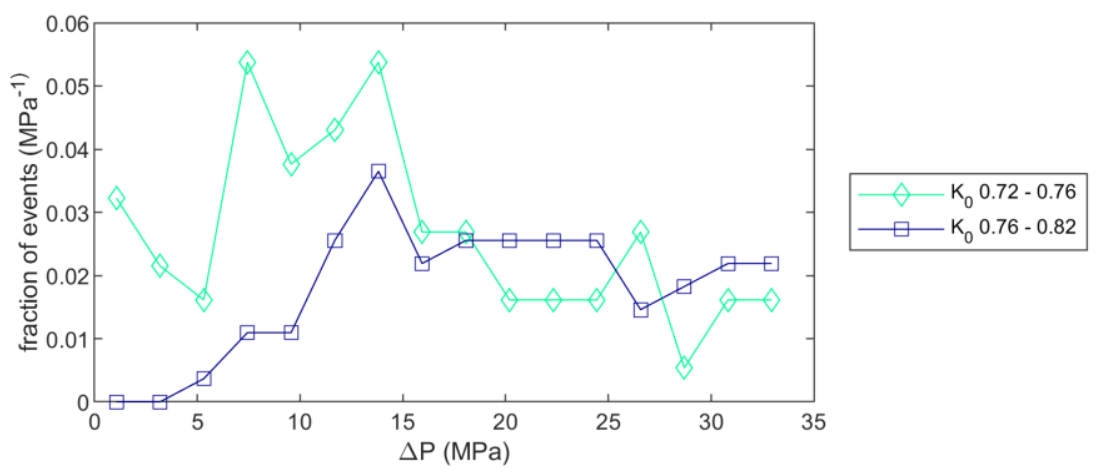

Figure 6-12. Fraction of simulations with a rupture length larger than $25 \mathrm{~m}$ occurring at certain $\triangle P_{0}$ for smaller and larger $K_{0}$. The fraction of events is calculated for a $2 \mathrm{MPa} \triangle P_{0}$ interval, and normalized to the total number of simulations with a rupture length $>25 \mathrm{~m}$ for the $K_{0}$ range in question.

\section{4. 2. Rupture length following nucleation of instability}

For the $\sim 50 \%$ of model realizations at which nucleation of instability occurred, the subsequent rupture size was computed with LEFM using the modeled stresses at $\Delta P_{0}$. Figure 6-13 shows the rupture lengths computed for the simulations in the model ensemble. The results indicate that rupture remained predominantly confined to the reservoir interval for the simulations summarized in Figure 6-13, as the approximate rupture lengths $L_{s}$ fell mostly in the range of several $\mathrm{m}$ to $300 \mathrm{~m}$. Ruptures exceeding $300 \mathrm{~m}$ propagated beyond the reservoir depth interval. Note that the high $K_{0}$ imposed in the Zechstein formation prevented updip propagation (see also Figure 6-6), and hence propagation beyond the reservoir depth interval indicated propagation into the Carboniferous underburden. Propagation into the Carboniferous was observed for only $4 \%$ of the computed rupture lengths, which equals $2 \%$ of all model realizations (including those where instability did not nucleate). Moreover, 
propagation into the Carboniferous occurred for a limited range of conditions, i.e. for stress ratio $K_{0}<0.73$ (Figure 6-13a), fault dips $<77^{\circ}$ (Figure 6-13b), a strike of $150-210^{\circ}$ (Figure 6-13c), and a dynamic friction of the fault in the Carboniferous of $\mu_{d D C}<0.35$ (Figure 6-13k). The static friction of the fault segment in the Carboniferous $\mu_{s D C}$ did not have a clear effect on rupture size for the range that was sampled (0.4-0.6), and neither could the effect of $D_{c D C}$ be recognized. The effect of those friction parameters may be diluted as relatively few simulations lead to rupture propagation into the Carboniferous underburden. Figure 6-14 gives the normalized distributions of rupture size in a bar plot, for different input parameters. The effect of stress ratio and dip is also visible in Figure 6-14a and as these increased, the fraction of smaller events $\left(L_{s}<50 \mathrm{~m}\right)$ increased too. In fact, for a dip $>85^{\circ}$, none of the event lengths exceeded $100 \mathrm{~m}$. The combined effect of the in-situ stress and the dynamic friction in the Carboniferous can also be expressed by the ratio $T$ between the stress drop and the strength drop given $T=\left(\tau_{O D C}-\tau_{d D C}\right) /\left(\tau_{s D C}-\tau_{O D C}\right)$, where $\tau_{0 D C}$ is the average shear stress in the top $1000 \mathrm{~m}$ of Carboniferous underburden and $\tau_{s D C}$ and $\tau_{d D C}$ are the failure shear stress $\mu_{s D C} \sigma_{n D C}$ ' and dynamic shear stress $\mu_{d D C} \sigma_{n D C}$, where $\sigma_{n D C}$ ' is the average effective normal stress in the top $1000 \mathrm{~m}$ of Carboniferous. For $T$ smaller than 0 , the fault is inherently stable; no ruptures propagating deep into the Carboniferous were observed (Figure 6-14l). For $T$ values larger than 0 , a significant fraction of ruptures propagated into the underburden. For most of the events that propagated beyond the reservoir depth interval into the Carboniferous the vertical reservoir offset was relatively small $<50 \mathrm{~m}$ (Figure 6-13d). This is consistent with earlier findings shown in Chapter 2; for smaller offsets the stress concentrations become less strong and rupture propagation outside of the reservoir becomes more likely. So although the onset of rupture became easier with increasing offset (Figure 6-11d), the rupture lengths actually decreased with increasing offset (Figure 6-14d).

For ruptures remaining within the reservoir depth interval, the frictional properties of other fault segments (i.e. dominated by other gouge lithologies) affected the rupture size. The effect of friction is most obvious for fault sections bounded on both sides by the Slochteren sandstone, as this is the zone in which nearly all events nucleated due to the depletion-induced stresses. The signature of the dynamic friction coefficient associated with the Slochteren reservoir unit was the most apparent, with the fraction of larger events increasing as the dynamic friction decreased (Figure 6-14h). No correlations were visible between the frictional properties of Basal Zechstein or Ten Boer fault sections and rupture length. Since no depletion was assumed to occur in these formations, the depletion-induced stress stabilized on fault segments where the Slochteren sandstone footwall was juxtaposed against the Ten Boer and/or the Basal Zechstein. Due to the more stable stresses (i.e. lower shear stress, higher effective normal stress) ruptures do not propagate far into the Ten Boer and Basal Zechstein formation. Note that if depletion is also modeled in the Ten Boer formation, this may affect rupture size. I will discuss this further in Section 5. 

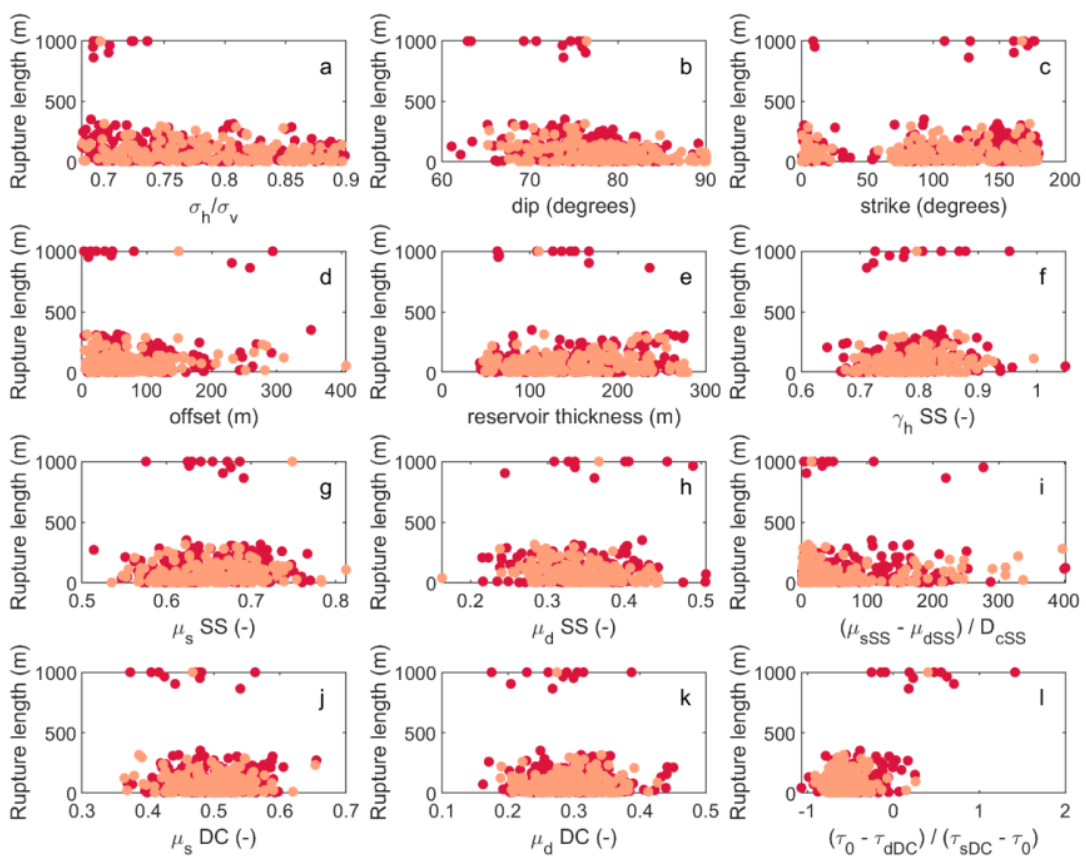

Figure 6-13. Rupture length computed for the simulations in the ensemble for which nucleation of instability was observed ( 500 simulations), plotted against a number of model input parameters. Symbols are color-coded according to the nucleation type, with the red symbols indicating Type1 nucleation, and the salmon symbols indicating Type 2 nucleation (see Table 1). Runaway ruptures that rupture the entire fault are truncated at $1000 \mathrm{~m}$.

Rupture lengths also increased with the reservoir thickness (Figure 6-13e, Figure 6-14e). As shown earlier, events were often arrested at the reservoir boundaries due to the stress concentrations that formed during pore pressure depletion in offset reservoir compartments. This is reflected in the occurrence of e.g. larger rupture lengths of $200-400$ $\mathrm{m}$ predominantly at reservoir thicknesses from 175 - $300 \mathrm{~m}$ (Figure 6-14e). For these reservoir thicknesses, the distribution of event sizes also became more bimodal, with events that span the full reservoir thickness, and smaller events rupturing only part of the reservoir interval (Figure 6-13e). Although the reservoir thickness correlated with the rupture length, no clear correlation was observed between the reservoir thickness and the number of ruptures propagating beyond the reservoir interval.

Another feature that becomes apparent from Figure 6-13 is that the rupture lengths of events that nucleated as a Type1 instability were on average larger than for those that nucleated as Type2. During Type2 nucleation, $D_{c}$ was exceeded and (significant) aseismic slip occurred on the fault prior to instability, reducing the shear stress to the dynamic level. The lack of an available stress drop over parts of the fault resulted in smaller rupture lengths, as also shown in Figure 6-9. However, this does not mean that for this type of events 

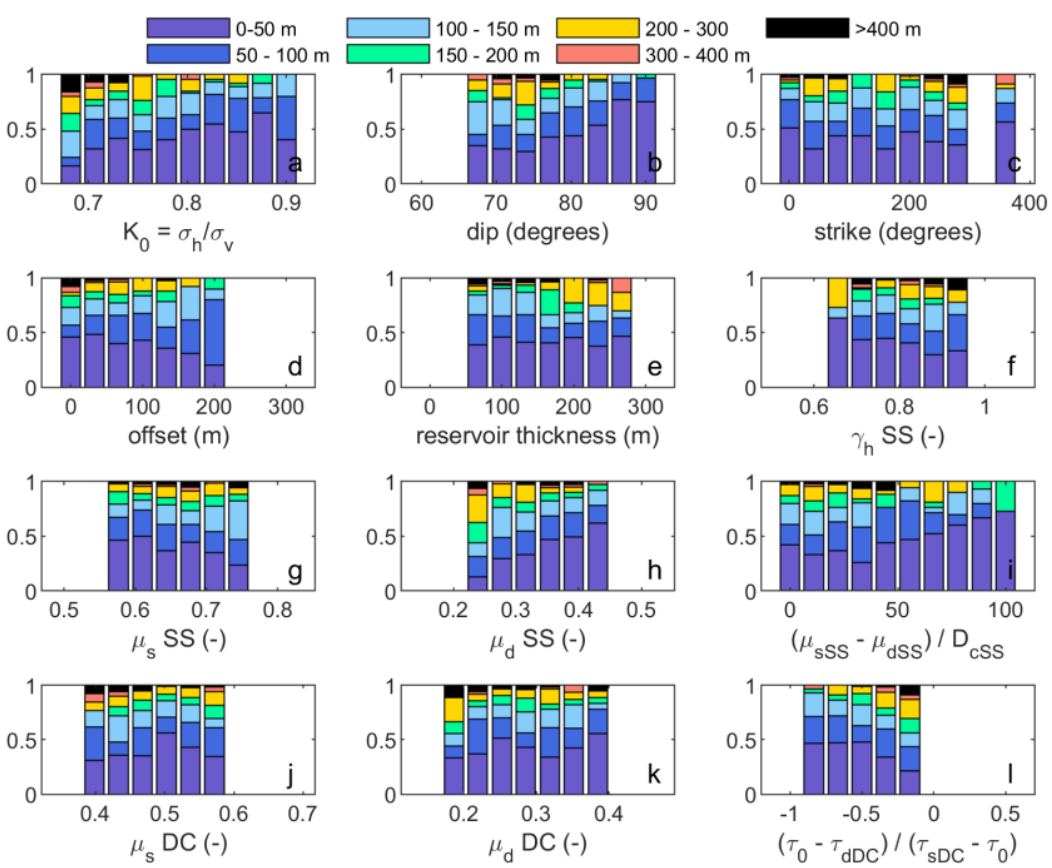

Figure 6-14 Normalized fraction of modeled rupture lengths, within a given range, as a function of different input parameters. Ten bins were plotted in the bar charts covering the full range of each parameter considered but bins containing less than 20 simulations were discarded. Model simulations that did not result in nucleation of rupture were not considered.

propagation into the Carboniferous was not possible. Note that the reduction of shear stress to the dynamic level during the nucleation phase may not be realistic, this will be discussed further in the next section.

\section{5. Effect of depletion of the Ten Boer Formation}

In the model ensemble presented in Section 6. 4. , depletion was prescribed only in the Slochteren formation. However, in-situ pressure measurements show that the Ten Boer unit may also experience depletion (Burkitov et al., 2016). Here I show the effect that depletion of Ten Boer may have on stress changes, on the pressure changes required for the onset of instability, and on rupture lengths. As for the previous section, a model ensemble of 1,500 simulation is considered. 

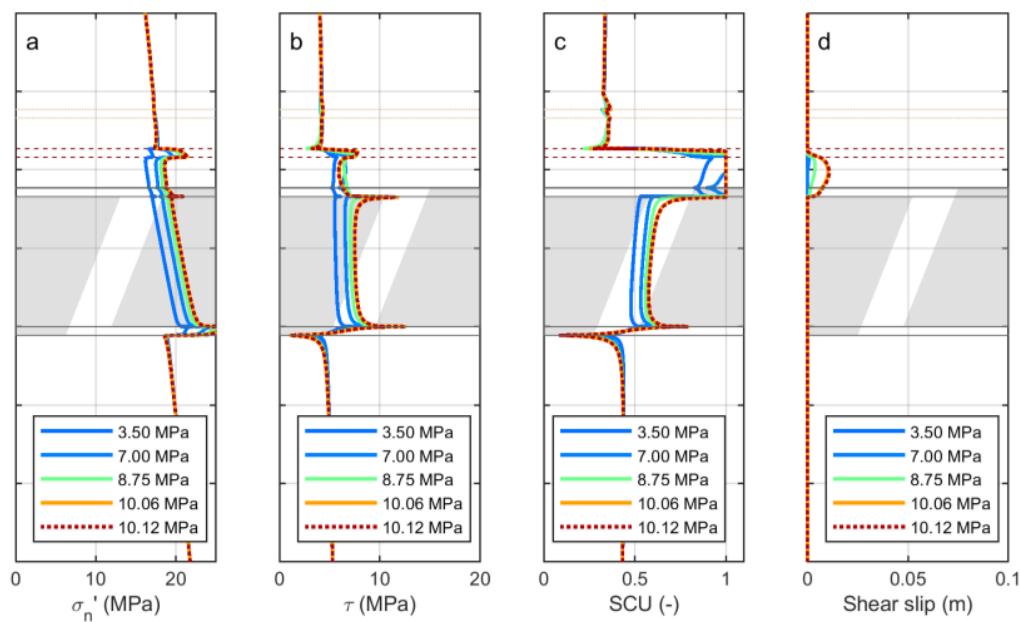

Figure 6-15 Fault stresses for a simulation including depletion of the Ten Boerformation. Depletion in the Ten Boer formation is the same as in the Slochteren reservoir formation. The example shown here has the following input parameters: $\operatorname{dip}=69^{\circ}, K_{0}=0.78$, offset $=11 \mathrm{~m}$, thickness Slochteren reservoir $=177 \mathrm{~m}, \mu_{s S S}=0.62, \mu_{d S S}=0.39$ $\mu_{S T B}=0.38, \mu_{d D C}=0.28, D_{c T B}=0.017 \mathrm{~m}$, Depth interval of the Slochteren reservoir formations is indicated with the gray areas. The top depth of the Ten Boer hanging wall and foot wall formations is shown by the dashed maroon lines, the top depths of the Basal Zechstein with the dotted lines.

As for the Slochteren sandstone, depletion resulted in both an increase in effective normal stress (Figure 6-15a) and shear stress (Figure 6-15b) on the fault segment crosscutting the Ten Boer formation, with the net effect of bringing the fault segment closer to failure (Figure 6-15c). Since static friction of the Ten Boer fault rock is low compared to that of the Slochteren (Figure 6-5), fault reactivation occurs on the Ten Boer fault segments before it does on the Slochteren sandstone fault segments. For most simulations, significant aseismic slip was observed along the fault segment cross-cutting the Ten Boer formation, often reaching several $\mathrm{cm}$ of slip (Figure 6-15d). This aseismic slip in the Ten Boer caused an increase in criticality on the fault segment in the underlying Slochteren sandstone formation, promoting nucleation of instability on Slochteren sandstone fault segments. Nucleation of instability mostly does not occur on the fault segment within the Ten Boer claystone, as the friction drop is relatively small (Figure 6-5). This results in a nucleation length that is often greater than the length of the Ten Boer fault segment, or in exceedance of the slip-weakening distance before attaining the nucleation length. However, nucleation of instability is promoted through stress transfer from the aseismic slip zone in the Ten Boer to the more unstable Slochteren fault segment. Note that the stress transfer updip to the Basal Zechstein fault segment is counteracted by the more stable stresses developing above the depleting formations. 

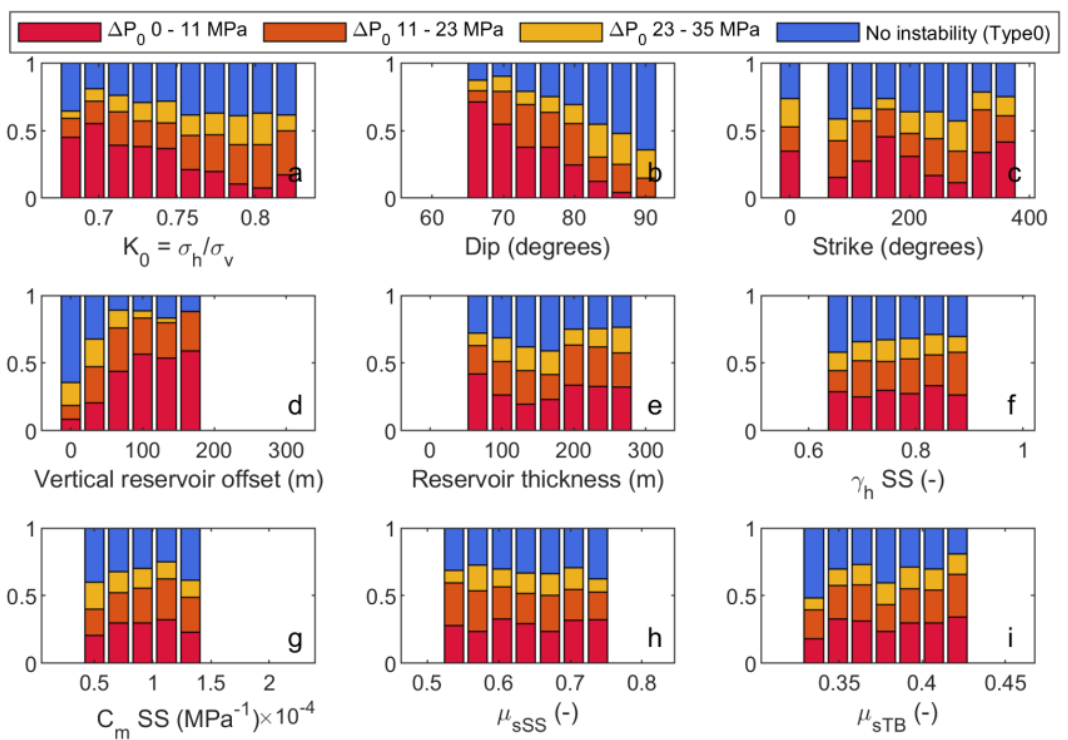

Figure 6-16. Normalized fraction of simulation results within a given range of pressure change required to attain nucleation of instability $\left(\Delta P_{0}\right)$ for the model ensemble considering depletion of the Ten Boer formation. Ten bins were plotted in the bar charts covering the full range of each parameter considered but bins containing less than 20 simulations were discarded. The pressure change required for the onset of instability is defined in three categories: those with a $\triangle P_{0}$ from $0-11 \mathrm{MPa}$ (red), 11 - $23 \mathrm{MPa}$ (orange), and 23 -35 MPa (yellow). The fraction of model realizations not featuring nucleation of instability is included in blue. a) Initial stress ratio $\left.K_{0}, b\right)$ Fault dip, c) Fault strike, d) Vertical reservoir offset, e) Thickness of Slochteren reservoir, f) Stress path parameter $\gamma_{h}\left(=\Delta \sigma_{h} / \Delta P\right)$ for the Slochteren sandstone, $g)$ uniaxial compaction coefficient $C_{m}\left(\Delta \varepsilon_{y} / \Delta P\right)$ of Slochteren sandstone, h) static friction of fault segments in the Slochteren sandstone, and i) static friction coefficient of fault segments cross-cutting or flanking the Ten Boer formation.

Figure 6-16 summarizes the pressure change required for the onset of instability (as in Figure 6-11) for the model ensemble of 1,500 simulations considering the depletion of the Ten Boer formation. Nucleation of instability was observed for $70 \%$ of the simulations, which is $20 \%$ more than for the model ensemble considering depletion of the Slochteren reservoir only. The main trends are comparable to those discussed in Section 6. 4. 1. , with the number of simulations in which instability occurred decreasing with increasing initial stress ratio $\mathrm{K}_{0}$ (Figure 6-16a), with fault dip (Figure 6-16b), with the mismatch between the orientation of $\sigma_{H}\left(342 \pm 10^{\circ}\right)$ and the fault strike (Figure 6-16c), and with decreasing vertical reservoir offset (Figure 6-16d). However, the fraction of simulations that required a low $\Delta P_{0}$ in the range $0-11 \mathrm{MPa}$ was larger than for depletion of the Slochteren only, indicating that depletion of the Ten Boer formation promoted nucleation of instability. 

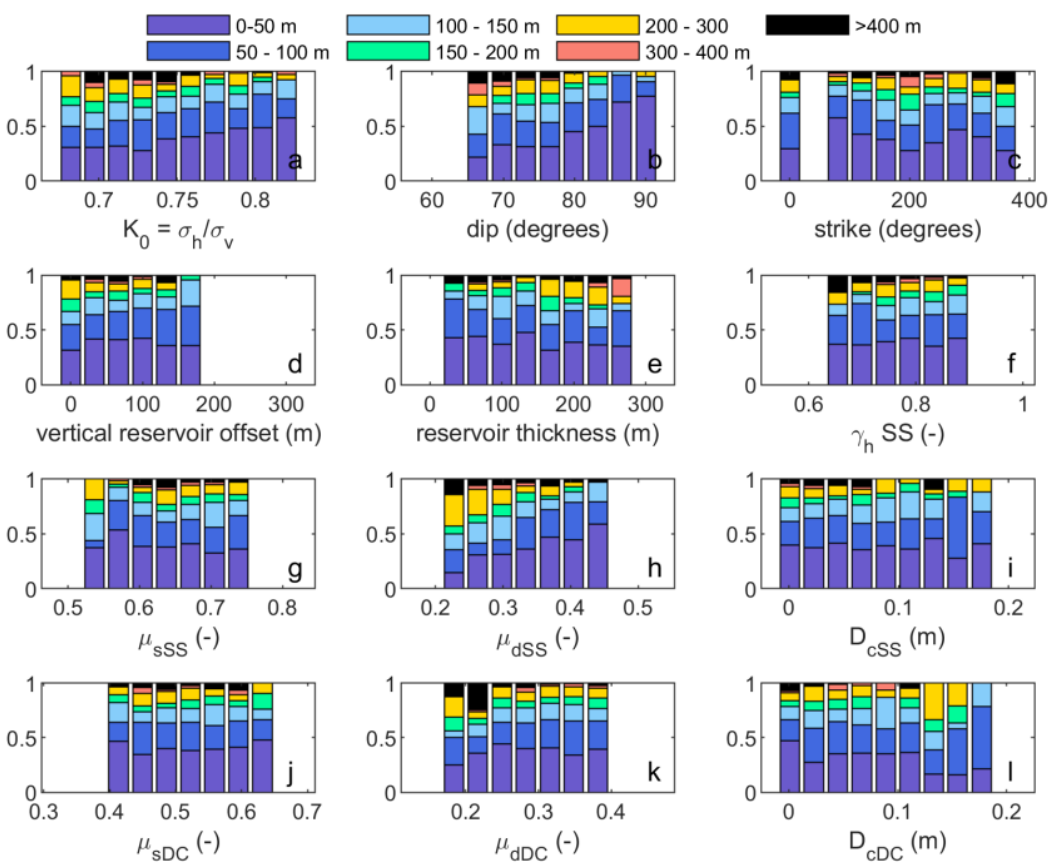

Figure 6-17. Normalized fraction of modeled rupture lengths within a given range, as a function of different input parameters, for the model ensemble incorporating depletion of the Ten Boer formation. Ten bins were plotted in the bar charts covering the full range of each parameter considered but bins containing less than 20 simulations were discarded. Model simulations that did not result in nucleation of rupture were not considered

Figure 6-17 shows the rupture lengths computed for the model simulations for which instability was observed. As for the ensemble without depletion of the Ten Boer, most ruptures remained confined to the reservoir depth interval. Propagation into the Carboniferous underburden occurred for only 3\% of the simulations shown in Figure 6-17, which is equal to $2 \%$ of the total number of simulations in the ensemble. This is a similar fraction to that observed for the model ensemble which considered depletion of the Slochteren sandstone only. The main other trends are also the same as discussed in Section 6. 4. 2. , with rupture sizes increasing with decreasing $K_{0}$ (Figure 6-17a), with decreasing dip (Figure 6-17b), with decreasing mismatch between the orientation of $\sigma_{H}\left(342 \pm 10^{\circ}\right.$ ) (Figure 6-17c), with decreasing offset (Figure 6-17d), and with decreasing dynamic friction coefficient of the Slochteren sandstone fault segments (Figure 6-17h).

\section{6. Discussion}

Pressure changes at the onset of nucleation of instability and resulting rupture lengths have been simulated in a 2D model setup combining FE modeling of stresses and semi-analytical modeling of rupture growth, for a wide range of fault geometries, reservoir rock properties, and fault frictional properties. To achieve this, fault geometries were sampled 
randomly from the Groningen fault model (Figure 6-3), and reservoir and friction properties were sampled randomly from distributions based on experimental results. For about $50 \%$ of the simulations nucleation of instability was observed. For these simulations, the majority of events nucleated within the reservoir depth interval (i.e. where Slochteren sandstone is juxtaposed against Slochteren sandstone) and remained confined to the reservoir depth interval. In the following, I discuss the effects of the assumed formation and fault properties on the rupture lengths of these events, as well as the effect of the initial state of stress. Furthermore, I discuss under which conditions rupture did propagate beyond the reservoir interval into the Carboniferous underburden. Finally, I compare the model results with seismological observations from the Groningen field.

\section{6. 1. Rupture lengths and the effect of assumed formation properties}

Most ruptures remained confined to the reservoir depth interval which equals the depth range for which the depleting formations are juxtaposed. Propagation into the Zechstein rocksalt and further overburden package was always prevented due to the high stress ratio assumed in the salt formation overlying the reservoir system. In this formation a high stress ratio was imposed to simulate the relaxation of shear stresses due to creep, though creep itself was not modeled. Inclusion of more realistic salt material behavior such as viscoelasticity will indeed result in an isotropic stress hence high stress ratio within the salt formation, but can also lead to a localized reduction in effective normal stress on faults offsetting the reservoir formation (Haug et al., 2018; Urai et al., 2016; Wassing et al., 2017). This normal stress reduction is due to the salt 'pushing' against the formations to which it is juxtaposed, and is greatest near the top of the reservoir, but decreases with distance from the reservoir to the salt formation (due to e.g. formations in between). This localized normal stress reduction effect is not captured in this study. Even though $100 \mathrm{~m}$ of Ten Boer and Basal Zechstein are present between the reservoir and the salt, for a fault offset of given magnitude, salt creep may lead to locally lower normal stress near the top of the reservoir than presently modelled, thus lowering the required pressure change for nucleation of instability (Wassing et al., 2017). However, in the models of Wassing et al. (2017), the final rupture length was smaller in the case with viscoelasticity of the salt than for a case without viscoelasticity, as the stress drop was smaller due to the lower normal stress. Incorporating salt creep behavior may thus promote fault reactivation, but would reduce the rupture lengths with respect to the linear elastic material behavior of salt assumed in this study.

Ruptures nucleating within the reservoir depth interval also did not propagate more than $10-20 \mathrm{~m}$ into the overlying fault segments, as the depletion-induced stress changes are characterized by a low shear stress above the interval experiencing depletion (see e.g. Figure 6-6). This shear stress decrease may be less significant given a lower stiffness overburden (Mulders, 2003), but recent laboratory measurements showed that all formations are significantly stiffer than the reservoir formation (Filippidou et al., 2019), so that in fact the shear stress decrease may be stronger than modeled here. Depletion of the Ten Boer often 


\section{Chapter 6}

resulted in aseismic slip on the fault segment cross-cutting Ten Boer, which could lead to increased criticality on the underlying fault segment in the Slochteren sandstone. Stress transfer to the overlying fault segment in the Basal Zechstein was counteracted by the decrease in shear stress on the fault above the depleting Ten Boer formation. Also, (part of) the Basal Zechstein fault segment may be juxtaposed against the Zechstein where stresses are stable, so for the current model setup nucleation did not occur in the Basal Zechstein. The depletion of the Ten Boer can have an effect on seismicity even after depletion from the Slochteren is terminated. Here, I imposed a pressure change equal to that of the pressure change in the Slochteren, but pressure measurements from the field showed that the pressure difference between the Ten Boer and the Slochteren sandstone can be up to 7.5 MPa, with the highest pressure differences found in the north of the field (Burkitov et al., 2016). Once production from the Slochteren formation stops, the pressure in the Ten Boer will gradually lower as it equilibrates to the pressure in the Slochteren formation, thus resulting in a pressure drop of up to 7.5 MPa after stopping production. This pressure drop will cause compaction and fault stressing, and hence may also cause fault reactivation or continuation of the aseismic slip as observed in the model ensemble presented in Section 6. 5. This can in turn cause the nucleation of instability near the top parts of the fault segments cross-cutting the Slochteren sandstone. This is one of the mechanisms that can cause seismic events to continue after production stops, albeit at a lower rate and for a limited amount of time (depending on the rate at which pressure in the Ten Boer equilibrates to that of the reservoir).

Even within the Slochteren sandstone itself, depletion-induced fault stresses are expected to be heterogeneous in the field. Porosity varies with depth in the Slochteren formation, which may cause bands of strong local compaction, consistent with heterogeneities in in-situ measurements made in the reservoir (Cannon \& Kole, 2018). This effect could be investigated in future models by e.g. incorporating a stochastic stress distribution (Dempsey \& Suckale, 2017), or a stress path parameter and compressibility that vary with depth to simulate variations in porosity. The reservoir-scale depletion-induced stress signal is, however, expected to dominate over these smaller length-scale variations, as the difference in strain between a formation experiencing a pressure change and a formation experiencing no pressure change is larger than the difference in strain between for example a higher porosity reservoir interval experiencing $20 \%$ more compaction strain than the average reservoir. In the present simulations, depletion-induced stresses result in a stable stress state (reverse shear stresses may even form) just above and below the reservoir, in agreement with previous modeling studies (Buijze et al., 2019, Mulders, 2003, Orlic \& Wassing, 2013). This stable stress acts as a barrier to rupture propagating down-dip from the reservoir interval (Buijze et al., 2019, Van den Bogert, 2018) into the Carboniferous, which is why reservoir thickness correlates with event size (Figure 6-14e).

Recent experiments have shown that under the Groningen reservoir production conditions a significant fraction (up to 50\%) of the strain is inelastic (Hol et al., 2018; Pijnenburg et al., 2019). The elastoplastic stress-strain response is, however, near-linear for 
almost all porosities investigated, and the modeling study in Chapter 3 indicates that production-induced stress changes of the inelastic Slochteren formation may be approximated with linear elastic behavior by taking the 'apparent' elastic parameters, which was assumed in this chapter (see Section 6. 2. 2. 2). However, modeling of dynamic rupture using elastoplastic reservoir behavior showed that the total slip and event size may be reduced by $10-20 \%$ with respect to linear elastic behavior (Chapter 3). It is not known how the elastoplastic properties during the high strain rate and cyclic stress evolution expected during dynamic rupture differ from those at slow, quasi-static conditions, but elastoplasticity of the reservoir rock will lead to at least some off-fault dissipation of the energy available for rupture and lead to smaller event sizes. During nucleation also significant aseismic slip occurred on the fault for some simulations (e.g. Figure 6-9). This aseismic slip could reduce the fault stresses by several MPa, and hence also the stresses in the surrounding formations will decrease. For elastoplastic behavior as thought relevant for the Slochteren sandstone, the unloading of stresses will be related to different elastic parameters, which could affect the stress redistribution during nucleation. Further investigation of the nucleation process in an elastoplastic reservoir as opposed to a linear elastic reservoir should determine whether this effect is significant.

\section{6. 2. Rupture lengths and the effect of assumed fault properties}

The last tectonic event affecting faults in Groningen was minor inversion in the Late Cretaceous and Early Tertiary (De Jager en Visser, 2017). Recent experiments reported by Hunfeld (submitted) showed that substantial fault healing may be expected in Slochteren sandstone fault gouge, causing an increase in fault strength of several MPa. This strength increase could in part be an increase in friction due to densification of the gouge, and in part an increase in cohesion due to cementation (Hunfeld, submitted, Tenthorey \& Cox, 2006). The strength increase was incorporated partly by including the higher friction (i.e. increase in strength defined in $\tau / \sigma_{n}$ ') of the healed gouges in the slide-hold-slide experiments into the parameter range on which the distribution of friction was based (Figure 6-5). The presence of additional cohesion or friction strengthens the faults, causing the nucleation pressure change to increase - i.e. it would shift the curves in Figure 6-12 towards larger $\triangle P$. However, the additional fault strength can also cause more unstable fault behavior, as reactivation causes an extra stress drop related to the removal of the additional friction and cohesion over a short slip distance of $0.1-1 \mathrm{~mm}$ (Hunfeld, submitted). Similar to frictional weakening, cohesion weakening can result in seismic instability (Buijze et al., 2017, Van den Ende \& Niemeijer, 2019). Relatively short slip-weakening distances down to $1 \mathrm{~mm}$ were included in the sensitivity analysis, but significant additional strength due to friction and cohesion due to healing over geological time was not. It would be interesting to incorporate an additional strength drop over short distances of $<1 \mathrm{~mm}$ as seen in the healing experiments (Hunfeld, thesis), followed by a second strength drop over longer distances $(<0.2 \mathrm{~m})$ as seen in the high velocity experiments (Hunfeld, thesis), and study the effect on rupture nucleation and size. 
The dynamic friction of fault segments in the Carboniferous underburden affects the available stress drop in the underburden and thus the potential for rupture growth. High velocity experiments at a normal stress of $20 \mathrm{MPa}$ have demonstrated dynamic friction coefficients of $0.3 \pm 0.08$, with imposed slip velocities of $1 \mathrm{~ms}^{-1}$ and a total slip $<0.2 \mathrm{~m}$ for gouges derived from the Carboniferous (Hunfeld, thesis). These are the first experiments at conditions relevant for small to medium magnitude earthquakes. However, significant uncertainties remain. First, acceleration, slip rates and displacements during dynamic rupture can be highly variable, which may have a strong effect on the dynamic friction as the evolution of temperature and pore pressure in the fault zone are dependent on the slip history, in particular the peak slip velocity (see e.g. Sone \& Shimamoto, 2009). Second, the Carboniferous underburden itself is heterogeneous, consisting of silts, shales, and sandstone streaks, as well as dispersed coals. Its composition also varies spatially below the Groningen field, as there is an angular unconformity between the Slochteren sandstone and the Carboniferous (www.nlog.nl). The fault composition may be more clay-rich than the host rock from which the samples were derived, though on the other hand the fault composition may also be enriched in fragments derived from the sandstone interval. It would be worthwhile to study the composition of fractures and fault observed in cores taken from the Carboniferous, though these may be scarce.

For the assumed slip-weakening law, once the static fault strength has been overcome aseismic slip occurs, up to the point that the critical nucleation length is reached and seismic instability can nucleate (Uenishi \& Rice, 2003). Continued aseismic slip was also observed when the critical slip-weakening distance $D_{c}$ is reached before the slip zone attains the critical nucleation length (e.g. Uenishi \& Rice, 2003), after which the slip zone grows beyond the critical nucleation length at the 'dynamic' shear stress level - i.e. the shear stress following from the dynamic friction coefficient. It is not expected that the actual dynamic stresses during rupture are reached at slow slip rates, and this is one of the shortcomings of the slip-weakening model. The Type 2 rupture lengths observed in this study may thus be underestimated as significant stress relaxation may have occurred during the nucleation phase. If the stress drop during nucleation is smaller, the nucleation length will also change, which affects the pressure change required for reactivation.

Considering the importance of the friction parameters and the assumed frictional weakening function discussed in the previous paragraphs, further experimental research into the high velocity behavior and relevant mechanisms for fault materials derived from sedimentary sequences found within and below the Groningen reservoir system is needed. In particular, for faults which may have experienced healing the weakening mechanisms and magnitudes are not clear. A better understanding of the weakening mechanisms and the development of a microphysical model would aid in a better description of friction as a function of normal stress, slip rate, and lithology. Taking into account the points discussed above, and assuming the parameter ranges considered in the modeling approach are realistic and that the prescribed fault behavior is valid for most of the simulations, the results suggest 
that the along-dip extent of ruptures is typically not larger than $200-300 \mathrm{~m}$, and may be on average smaller than the model results due to more heterogeneous stresses and elastoplastic behavior of the reservoir. A small fraction $(<4 \%)$ of ruptures did propagate into the Carboniferous underburden.

\section{6. 3. Potential for ruptures to propagate into the underburden}

Of paramount importance for magnitude estimates in the Groningen field is the potential for ruptures to propagate beyond the reservoir interval. Although $96 \%$ of simulated ruptures remained confined to the reservoir interval, $4 \%$ did propagate downwards into the Carboniferous underburden. This occurred only for the combination of stress ratios smaller than 0.73 , well-oriented faults in the stress field, fault dips smaller than $80^{\circ}$, and a dynamic fault friction in the underburden (Carboniferous) $<0.35$. Of these factors, the stress ratio and the dynamic friction are the most uncertain. Although the measured initial stress orientations are rather consistent and the vertical stress is well known (van Eijs, 2015), the horizontal stress magnitudes in the reservoir and the underburden are highly uncertain; no stress measurements have been performed below the reservoir. Measurements of the initial stress within the reservoir formation are also not available or reliable (van Eijs, 2015). The range covered by the current model simulations $\left(K_{0} 0.68-0.82\right)$, is very large, ranging from critically stressed at the lowermost values to stable at the higher values. This is reflected by the significant changes of the nucleation pressure changes $\Delta P_{0}$ (Figure 6-11a) and the rupture lengths (Figure 6-14a) with the $K_{0}$ in our models. If the (lithology-specific) stress ratio could be better constrained by e.g. leak-off tests, this would give a much better control on the expected rupture lengths.

The regional stress reflects plate-tectonic forces and isostasy, but the transmission of stress from the far-field plate tectonic forces probably varies per lithology. For example, soft clay-rich formations may relax shear stresses which results in a more isotropic stress state, whereas stiff formations can support higher shear stresses (Cornet \& Röckel, 2012). The upper Carboniferous is composed of silts, shales, and sands which are found to be relatively stiff for sedimentary rocks (Filippidou et al., 2019). Not much stress relaxation is likely to have occurred since the latest tectonic events (Cretaceous) due to creep of these stiff formations, although if the faults are filled with clay-rich material they could partly relax shear stresses. One kilometer below the reservoir a (likely very stiff) carbonate platform of Dinantian age is present, with major fault structures along the boundaries that continue up to the reservoir (Kortekaas \& Jaarsma, 2017). It would be interesting to model what the effects are of the major faults, the carbonate platforms and other lithological units in the vicinity of Groningen, and of salt creep, on the local stress field of the Groningen area, with a view to assessing how close to critical Groningen fault sections below the reservoir were before gas production started. Indirect observations suggest that the stress state is not critical. Decennia of production preceded the onset of (measurable) seismicity in 1991 (Figure 6-1), which suggests a relatively large stress change was needed before the attainment of critical stresses 


\section{Chapter 6}

on faults and the occurrence of failure, at least in the reservoir. This contrasts sharply with induced seismicity in regions such as in Oklahoma and Pohang, where small stress changes led to relatively large events on critically stressed, tectonically loaded faults in the crystalline basement (e.g. Keranen et al., 2014; Kim et al., 2018). Also, In Groningen, the vast majority of events to date have occurred within or close to the reservoir formation (Spetzler \& Dost, 2017a; Willacy et al., 2018) where stress changes are largest, and not far below the reservoir where poroelastic stress changes would be an order of magnitude smaller. Calibration of model parameters for a seismic source model incorporating the along-strike stresses and fault orientations against seismicity data in Groningen indicated that the initial state of stress was not critical (Dempsey \& Suckale, 2017). Also, the evolution of seismic rupture with $\triangle P$ for the more stable stress range was more consistent with the late onset of seismicity in the Groningen field than for the more unstable stress range (Figure 6-12), also consistent with an initial stress that is not critical.

Additionally, reservoir offset will affect the potential for propagation into the underburden. For smaller offsets the stable stress region is smaller, which increases the potential for ruptures to propagate across the stable stress region. Indeed, rupture propagation into the underburden is observed mostly for faults with offsets smaller than $50 \mathrm{~m}$. This suggests that the highest potential for larger rupture events is on faults with little offset.

\section{6. 4. Comparison with seismological observations from the Groningen field and suggestions for further research}

Nearly all modeled rupture events nucleated within the reservoir formation and remained confined to the reservoir formation. This is consistent with seismological observations, which place the hypocenters of events within or very close to the reservoir formation (Spetzler \& Dost, 2017a; Willacy et al., 2018). A larger reservoir offset resulted in a larger fraction of nucleated instabilities. This is also consistent with the observation that most larger events could be linked to faults clearly visible on seismics - i.e. faults with (significant) offset (Willacy et al., 2018). The largest magnitude events in Groningen were the Huizinge earthquake of $\mathrm{M}_{\mathrm{L}} 3.6$ on the $16^{\text {th }}$ of August 2012 and the Zeerijp earthquake of $\mathrm{M}_{\mathrm{L}} 3.4$ on the $8^{\text {th }}$ of January 2018 (Dost \& Kraaijpoel, 2013; Kraaijpoel \& Dost, 2013; Spetzler \& Dost, 2017a; Wentinck, 2018). The radius of the ruptured area for these events was estimated at $400-500 \mathrm{~m}$, with several cm of slip. Such an event size could be accommodated within the reservoir, if the aspect ratio of the rupture (width:height) would be at least 4:1. Interestingly, these larger events seemed to be related to faults with relatively little offset. . It is possible that these larger events propagated for a small distance into the Carboniferous. In general, however, seismological data on event locations and sizes suggest the events remained within the reservoir, consistent with the present modeling results for a non-critical initial stress.

Ideally, in future, alongside the incorporation of an improved (micro-physics based) description of friction (Section 6. 6. 2. ), the most important parameters identified in this 
study (in particular the in-situ stress ratio, but also the distributions of the static and dynamic friction coefficient) should be calibrated against field data. This could be achieved by simulating depletion and stress development at all fault segments in the fault model for many different combinations of input parameters, and then tuning to obtain the event rates or seismic moment that matches observed seismicity (cf. Demspey et al., 2017). The computation of stress in the current model workflow takes too long (several minutes) to incorporate the model uncertainties and generate enough event catalogs for such a calibration. For future research this step could be accelerated by e.g. incorporating an analytical solution for the stress development in a producing reservoir along an offset fault (Jansen et al., 2019; Lehner, 2019), in combination with a criterion for rupture nucleation. This could be done by considering the critical nucleation length or assuming the nucleation length is smaller than the resolution of the fault elements and taking the first element that fails as the nucleation site (Dempsey \& Suckale, 2016). Sensitivity to the nucleation process could be investigated by comparing against the model realizations in this study. The analysis could even be extended to 3D, by using recent 3D fast models for the computation of stress changes in faulted, geometrically complex reservoirs (van Wees et al., 2019), and/or analytical solutions for elongated, along-strike rupture propagation for ruptures confined along the fault dip (Weng \& Ampuero, 2019). The current study forms a first step in understanding the alongdip behavior of production-induced rupture, considering stresses and friction that are heterogeneous along the fault dip.

\section{7. Conclusions}

Assessing the key factors controlling induced event sizes in the seismogenic Groningen field is important for seismic hazard analysis. In particular, it is important to assess the possibility for ruptures to propagate beyond the reservoir interval. In this study, I simulated the nucleation and down-dip lengths of ruptures developed in a 2D model setup combining FE modeling of stresses and semi-analytical modeling of rupture growth using a linear elastic fracture mechanics theory for crack growth. Fault and reservoir geometries (dip, strike, offset, and reservoir thickness) were sampled randomly from the fault segments present in the Groningen fault catalogue. A wide range of in-situ stresses was considered, and reservoir and friction properties were sampled randomly from distributions based on experimental results. In light of these recent experiments, lithology-specific frictional properties were assigned to the various lithological juxtapositions present along the fault dip of the model. Simulations were performed for depletion of the Slochteren sandstone only, and for depletion of both the Ten Boer and the Slochteren formations. The main findings are as follows:

- A large fraction of the model realizations (50\%) did not result in fault reactivation or nucleation of an instability at all. Many of the fault segments in the Groningen field are not well oriented, as the strike is not always in line with the regional stress fields and the dips are relatively steep. 
- The pressure change required for reactivation increased with the initial stress ratio, fault dip, difference in strike direction with regard to the maximum stress orientation. It decreased with reservoir offset, the horizontal stress path parameters, and the uniaxial compressibility.

- The majority of unstable ruptures remained limited in extent to within the reservoir depth interval (i.e. depth range over which depletion occurs). Propagation beyond the reservoir interval into the underburden occurred for a small fraction $(<2 \%)$ of the simulations.

- Downward propagation beyond the reservoir into the underburden only occurred for a combination of stress ratios $<0.73$, fault dips $<80^{\circ}$, well oriented faults and a dynamic friction $<0.35$ in the underburden.

- Depletion of the Ten Boer formation promoted the nucleation of instability at lower pressure changes compared to depletion from the Slochteren formation only. This was the result of the occurrence of aseismic slip on the fault segments cross-cutting the Ten Boer formation and the resulting stress transfer to other fault segments.

- The variable slip-weakening behavior assigned to the fault and the related critical nucleation length resulted in the following types of nucleation behavior:

- Fault reactivation, but no nucleation of instability because aseismic slip was larger than the slip-weakening distance.

- Nucleation of instability as the slip zone reached the critical nucleation length.

- Nucleation of instability due to the coalesence of (aseismic) slip zones that formed due to the heterogeneous stress.

In particular in the latter case significant aseismic slip occurred over large parts of the fault during the nucleation process, resulting in a smaller rupture length.

- Compared to the results presented in this study, models using a constant friction or a negligible nucleation length would tend to underestimate the pressure change required for failure and overestimate rupture length.

- Lengths of ruptures remaining within the reservoir depth interval decreased with an increase in the initial stress ratio, fault dip, reservoir offset, reservoir thickness, and dynamic friction of the Slochteren sandstone fault material.

- Our findings are generally consistent with hypocenter locations and magnitudes of seismic events recorded in the Groningen field. For future research, it is important to better quantify the frictional weakening behavior of the (likely initially cohesive) fault rocks for faults that have been inactive for long periods of time. In addition, the current analysis should be extended so that the model parameters can be calibrated against field data. 


\section{8. Acknowledgments and Data}

This study was performed in the context of the research program "Studies on fault (re)activation and dynamic friction and failure behavior" (Research Agreement UI49294) funded by the Nederlandse Aardolie Maatschappij (NAM). This program focuses on a fundamental understanding of the physical mechanisms of production-induced reservoir compaction and induced seismicity in the Groningen gas field. I would like to thank Pablo Ampuero for his help with the fracture mechanics approximation of rupture size and discussions on rupture dynamics. Furthermore I would like to thank Luuk Hunfeld for discussions on friction and friction experiments. Gerd-Jan Schreppers of DIANA FEA B.V. is thanked for his support and discussions on numerical modeling. André Niemeijer is supported by the European Research Council, starting grant SEISMIC (335915) and by the Dutch Research Council (NWO) Vidi-grant 854.12.001. I thank TNO for providing the license for DIANA FEA. 
Chapter 6 

Chapter 7 


\section{Conclusions: Summary and Outlook}

Human operations in the subsurface, related to the production of geo-resources or geological storage and disposal, inevitably cause the state of stress in the subsurface to change. This may lead to induced seismic events that can be felt at the surface and potentially cause damage to housing and infrastructure. One instance where this is observed is the Groningen gas field in the N.E. Netherlands. Seismic events $\left(\mathrm{M}_{\mathrm{L}}<3.5\right)$ induced by gas production from this field have become a serious issue in recent years, causing damage to over a thousand houses, social unrest and political upheaval, culminating in an early phaseout of gas production from what is one of the world's largest gas fields. In this thesis, I have reported results from a combination of geomechanical models and scaled experiments that aim to investigate the relationship between (production-induced) fault stresses and the nucleation and propagation of seismic instability. The models and experiments provide insight into the stress-forcing mechanisms that lead to seismic instability as well as the associated rupture characteristics and hence induced event sizes. This helps to constrain how and where production-induced seismic events nucleate and to identify the key factors affecting the size of the induced ruptures, ultimately contributing to improved seismic hazard assessment.

The geomechanical models developed here were based on the lithostratigraphy, and fault geometries found in the Groningen gas field. The modeling approach adopted extends previous geomechanical models addressing the mechanisms of depletion-induced seismicity (Mulders, 2003; Nagelhout \& Roest, 1997; Orlic \& Wassing, 2013; Roest \& Kuilman, 1994; van den Bogert, 2015). These earlier studies focused mainly on the stress changes leading to static fault reactivation, but did not consider rapid frictional weakening of the fault in the post-failure regime - which is the key ingredient required for initiating seismic instability. In the present geomechanical modeling work, frictional weakening was assigned to the fault configurations addressed, in order to simulate depletion-induced nucleation, growth and final arrest of the induced seismic instability, and hence to determine the final rupture size and key factors influencing rupture size. In Chapter 2, I modeled the behavior of a generic reservoir geometry, consisting of two depleting reservoir compartments offset by a fault with slipweakening properties, using a 2D plane-strain model. The problem was addressed using DIANA Finite Element Analysis, a commercially available Finite Element (FE) package (DIANA 10.3 User Manual, 2019). The goal was to investigate the conditions leading to the nucleation of depletion-induced rupture and the subsequent extent of rupture, i.e. the rupture

Picture previous page: Faults mapped in the Groningen field. The outline of the Groningen gas field is indicated with the bordeaux line. Colors indicate the depth of the Upper Rotliegend reservoir formation, ranging from $2500 \mathrm{~m}$ in the south to over $3000 \mathrm{~m}$ in the north. 


\section{Chapter 7}

length within the fault, which is a proxy for the seismic event size in 3D. To achieve this, a simplified uniform pressure field was imposed within the depleting reservoir compartments to simulate production. The imposed pressure changes resulted in stress changes within and compaction of the reservoir compartments, as well as stress-strain changes in the surrounding lithologies and on the fault, ultimately causing fault reactivation. The stress changes on the fault are due to poroelastic stress changes associated with compactive volumetric strain occurring in the depleting reservoir formation. These stress changes can locally be significantly amplified due to the existence of compaction gradients across faults that offset depleting reservoir compartments. After fault reactivation in my modeling runs, stable, aseismic slip occurred (the so-called nucleation phase) until the slip zone size reached large enough dimensions to cause the onset of seismic instability. Once this point was reached, the induced seismic rupture propagated spontaneously from the nucleation zone with no further pressure depletion being required. This stage was modeled numerically in a fully dynamic analysis. A wide range of reservoir offsets, initial stresses and frictional weakening parameters were investigated in the model, to determine the key parameters controlling the size of the induced seismic rupture events, and in particular, the potential for seismic rupture to grow beyond the reservoir depth interval.

In later modeling chapters presented in this thesis, special emphasis has been placed on the integration of independent experimental reservoir compaction (Pijnenburg, 2019) and fault friction (Hunfeld et al., 2017; Hunfeld et al., 2019; Hunfeld, 2020) data into the geomechanical models. Compaction experiments on Slochteren reservoir sandstone cores obtained from the field, performed at the in-situ reservoir conditions, showed that the measured compaction strain contained a significant fraction $(<50 \%)$ of inelastic (irreversible) strain, even though the stress-strain response was near-linear and previously assumed elastic (Hol et al., 2018; Pijnenburg et al., 2018; Pijnenburg et al., 2019). This combined elasticplus-inelastic deformation behavior could be adequately described by a Modified Cam-Clay (MCC) type elastoplasticity (Pijnenburg et al., 2019). In Chapter 3, I extended the FE model used in Chapter 2 by assigning the MCC behavior observed in the experiments to the simulated reservoir formation, with the aim of assessing the effect of MCC elastoplasticity on reservoir compaction, stress changes, fault reactivation, and induced seismic events at the reservoir scale. The classical formulation of the MCC model (Roscoe et al., 1958; Roscoe \& Burland, 1968) was used as it is a readily available material model in DIANA FEA (DIANA 10.3 User Manual, 2019). This MCC formulation is similar to the MCC model formulated by Pijnenburg et al. (2019) but differs in the sense that plastic and elastic hardening are both nonlinear, while the slope of the critical state line is constant. The MCC description used in this chapter was first validated/tuned against both the triaxial (Pijnenburg et al., 2018) and uniaxial (Hol et al., 2018) experimental compaction data, using a simple one-element FE model with triaxial or uniaxial strain boundary conditions. Subsequently, the 2D field-scale model was used to compute the deformation field, stress changes, and fault reactivation behavior due to reservoir depletion. To assess the effect of the MCC material behavior, the 
results for the elastoplastic reservoir were compared with results obtained for a reservoir with equivalent linear elastic behavior. This linear elastic reservoir was modeled with apparent elastic properties - i.e. apparent elastic properties determined from the near-linear stressstrain evolution seen in single-element model runs simulating compaction of a sandstone sample with MCC elastoplastic properties undergoing unidirectional pore pressure depletion under uniaxial strain conditions.

Besides implementing experimental data on compaction into my geomechanical models, I also made use of experimentally determined friction data on simulated fault gouges derived from the key lithologies present in the Groningen reservoir system (Hunfeld et al., 2017; Hunfeld et al., 2019; Hunfeld, 2020), see Chapter 6. Here, the FE model described in Chapter 2 was modified to incorporate the following five lithological units based on the Groningen stratigraphy: the Permian (Zechstein) rocksalt, the underlying Basal Zechstein anhydrite-carbonate caprock to the reservoir system, the Ten Boer claystone, the Slochteren reservoir sandstone, and the Carboniferous substrate or "underburden" at the base of the sequence (de Jager \& Visser, 2017; Visser \& Viota, 2017). Hunfeld et al. (2017, 2019) and Hunfeld (2020) performed low- and high-velocity friction experiments on simulated gouges derived from the last four of these lithologies. These experiments showed significant differences in steady state fault sliding strength (static friction coefficient), but also in dynamic weakening behavior (dynamic friction coefficient, slip-weakening distance) between these different gouges. For each lithological juxtaposition found downdip along the fault, the frictional properties of the weakest member were assigned to define the frictional and slip-weakening behavior. The effects of the different lithology-specific friction parameters on fault reactivation and rupture size were analyzed by means of a stochastic geomechanical analysis to account for the substantial variability and uncertainties in the fault friction data. For each lithology (except the Zechstein salt), probability distributions were specified for the frictional properties. Friction values were sampled randomly from these distributions in more than a thousand simulations. Besides the lithology-specific friction data, other input parameters and their uncertainties were also incorporated in this ensemble. For each simulation, a faulted reservoir segment configuration was selected by randomly selecting a fault segment from the fault model of the Groningen field (courtesy of NAM, 2017), which contains hundreds of faults and over 15,000 fault segments. Using the geological model, the reservoir thickness, fault dip, strike, and normal offset were used to specify the faulted reservoir segment geometry. In addition, probability distributions were specified for the reservoir stress path and compressibility, and the initial in-situ stress. By including these input parameters and their uncertainties, the effects of pore fluid pressure reduction (reservoir depletion) on fault reactivation, rupture sizes and the potential for seismic rupture propagation outside the reservoir could be evaluated. Reservoir depletion and the onset of rupture nucleation were modeled in a similar fashion to that described in Chapter 2. However, final rupture length was approximated using analytical solutions from fracture 


\section{Chapter 7}

mechanics theory, as the fully dynamic simulation was too computer-intensive to run the required number of model realizations.

In addition to the geomechanical modeling work, sliding experiments on scaled faults were performed using a horizontal biaxial deformation apparatus located at the Institute of Geology, China Earthquake Administration, Beijing (Chapter 4 and Chapter 5). These scaled experiments were densely instrumented to allow detailed observation of the nucleation of seismic slip instability and comparison with and/or validation of the geomechanical models described above. In the experiments, a $350 \mathrm{~mm}$ long and $50 \mathrm{~mm}$ high vertical fault zone was created along a diagonal sawcut made through a rectangular (300 x $200 \times 50 \mathrm{~mm})$ polymethylmethacrylate (PMMA) block. PMMA was used instead of a 'real' rock because its stiffness is 15 - 25 times lower, which down-scales the critical size of the nucleation process to a length-scale that can be captured within the experimental length-scale. In Chapter 4 , the entire fault zone was filled with a single, continuous, $2 \mathrm{~mm}$-thick layer of crushed and sieved gypsum powder. This material was selected as a fault gouge analog material, as it is known to deform in a frictionally unstable manner, at the imposed experimental conditions, through stick-slip behavior (i.e. laboratory earthquakes), thus offering scope to simulate seismic events analogous to those in the Groningen field. However, faults in Groningen cross-cut the different sedimentary lithologies discussed above. In Chapter 5, the effect of the resulting fault zone heterogeneity was simulated experimentally by creating variable gouge lithologies and hence variable frictional properties along the experimental fault. In these heterogeneous fault experiments, an $80 \mathrm{~mm}$-long center-segment of gypsum gouge was flanked by two, $135 \mathrm{~mm}$-long segments containing a second gouge material, prepared from quartz, kaolinite, or calcite. In both the gypsum-only experiments (Chapter 4) and two-gouge experiments (Chapter 5), the enclosing PMMA forcing blocks, and hence the fault, were isotropically loaded to $5 \mathrm{MPa}$ in the horizontal biaxial machine. Subsequently, shear slip was imposed along the experimental fault by keeping the normal stress in one direction $\left(\sigma_{3}\right)$ at 5 $\mathrm{MPa}$ and imposing a constant compressive displacement rate of $1 \mu \mathrm{m} \mathrm{s}^{-1}$ in the direction parallel to the longest dimension of the PMMA blocks $\left(\sigma_{l}\right)$. To study the deformation field around the fault zone, 23 strain gauge rosettes were placed on the bottom of one of the PMMA forcing blocks along the fault margin at a distance of $10 \mathrm{~mm}$ from the fault, recording continuously at $500 \mathrm{kHz}$. In addition, Digital Image Correlation applied to low- (1 fps) and high-framerate (5000 - $9000 \mathrm{fps}$ ) imaging of the PMMA surface exposed at the top margin of the fault was employed, in order to track the displacement field in the PMMA blocks flanking the gouge-filled fault. Using DIANA FEA, as also used for the field-scale models, a Finite Element model of the experimental setup was constructed to model the stresses on the fault and to assess the relationship between these stresses and the observed nucleation and propagation of seismic events.

The numerical modeling results presented in this thesis have shown how stresses develop in a depleting reservoir, how these may lead to nucleation of rupture and which key factors control rupture size. In this way, the results presented aid understanding of the 
physical mechanisms causing depletion-induced seismic events in a faulted reservoir system. The numerical modeling work is strengthened by the integration of laboratory-based compaction and friction behavior. In the following, I summarize and draw together the main findings obtained in the different chapters. Subsequently, the implications for seismicity in the Groningen field that follow from this thesis are discussed. Lastly, recommendations for future research are suggested.

\section{1. Summary of main findings}

\section{1. 1. Stress changes and nucleation of seismic instability in geomechanical models and} large-scale experiments

In the geomechanical models presented in this thesis, static fault strength is governed by Mohr Coulomb friction. Once the static friction coefficient is attained within any element on the fault, fault reactivation and plastic fault slip (irreversible slip) occurs, and friction on that element decreases linearly with plastic fault slip - i.e. according to a linear slipweakening friction 'law' (Chapter 2, Chapter 3, and Chapter 6), similar to the behavior recorded in seismic slip pulse experiments by Hunfeld (2020). Frictional weakening is an essential component for modeling depletion-induced seismic instability, which also causes a distinct nucleation phase that follows fault reactivation but precedes the unstable seismic slip phase. During this nucleation phase a (small) part of the fault slips aseismically, growing in size as the depletion-induced stresses on the fault continue to build up, until the size of the slipping patch reaches a critical dimension - i.e. the critical nucleation length $L_{c}$. Beyond this point no further stress increase is required to drive rupture (no stable solution exists) and the slip zone on the fault can expand spontaneously (e.g. Uenishi \& Rice, 2003). It is important that the nucleation zone is resolved with enough elements, used to model the fault $(\sim 15-20$ elements within $L_{c}$, see further Chapter 2). If this is not the case, or if one does not consider any frictional weakening at all but assumes sliding characterized by a constant static friction coefficient, fault reactivation becomes dependent on fault element size which is crucial to avoid.

The nucleation phase and related critical nucleation length (critical slip zone size) have been extensively studied in modeling seismicity and dynamic rupture, for both slipweakening friction as used in this thesis (e.g. Ampuero et al., 2002; Campillo \& Ionescu, 1997; Uenishi \& Rice, 2003), as well as rate-and-state dependent friction (Ampuero \& Rubin, 2008; e.g. Lapusta et al., 2000; Rice, J. R., 1993; Rubin \& Ampuero, 2005). However, information on the nucleation phase associated with natural and especially induced earthquakes, is difficult to derive from seismological data because of its predominantly aseismic nature and small amounts of associated slip. In Chapter 4, the nucleation process was studied in the laboratory in a scaled experimental setup. The experimental data obtained from strain gauge measurements and Digital Image Correlation revealed that portions of the experimental faults filled only with gypsum gouge experienced aseismic slip, prior to the 


\section{Chapter 7}

nucleation of the seismic slip event. Most aseismic slip was observed near the fault ends, which were also the locations where the slip events nucleated. Stresses obtained from the strain gauge data in combination with stresses calculated using Finite Element models of the experimental setup showed that the ratio of shear to normal stress $\tau / \sigma_{n}$ ' was heterogeneous along the fault and concentrated near the fault ends. These stress concentrations at the ends of the faults resulted predominantly from the experimental boundary conditions, and formed preferential sites for the nucleation of instability.
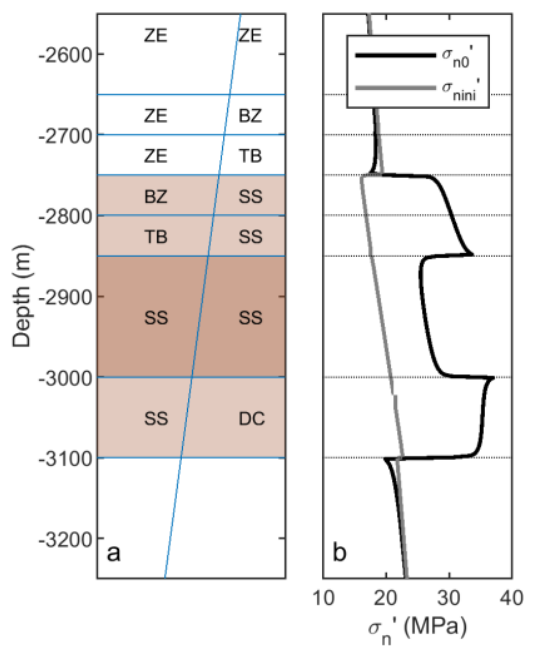
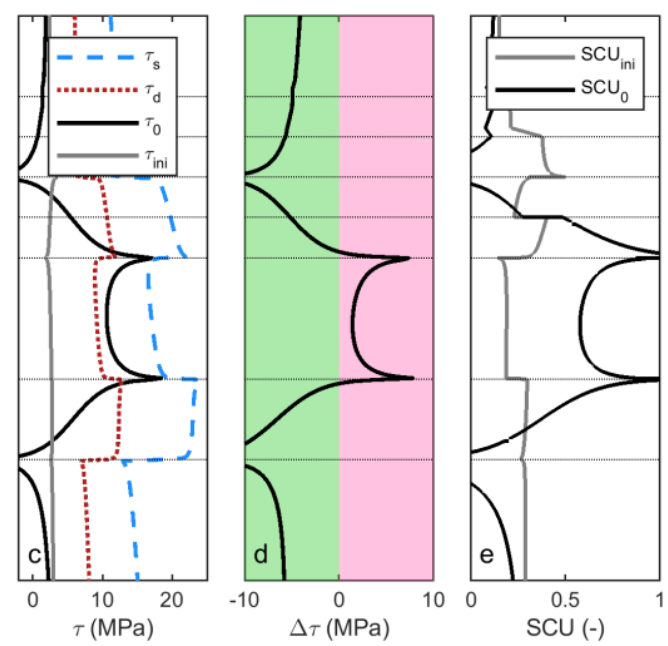

Figure 7-1. Example of modeled fault stresses, stress changes and stress drop as a result of reservoir depletion. The simulation shown incorporates five different lithologies based on the Groningen field, with ZE: Zechstein salt, BZ: Basal Zechstein, TB: Ten Boer, SS: Slochteren sandstone reservoir, and DC: Carboniferous underburden (see also Chapter 6). For the current simulation the following input parameters are used: fault dip $=75^{\circ}$, reservoir thickness $=250 \mathrm{~m}$, vertical offset $=100 \mathrm{~m}, K_{0}=0.82$. For convenience, a constant static friction coefficient $\mu_{s}$ of 0.65 and a constant dynamic friction coefficient of 0.35 are used along the fault. a) Depth ranges of different lithologies juxtaposed along the fault. Shaded region indicates the reservoir compartments (SS) which are subject to pressure depletion. $b)$ Effective normal stress on the fault before depletion $\left(\sigma_{\text {nini }}\right)$ and at the onset of nucleation of instability $\left(\sigma_{n 0}{ }^{\prime}\right)$, which occurs after a pressure change of $20.8 \mathrm{MPa}$. c) Shear stress on the fault before depletion $\left(\tau_{\text {ini }}\right)$ and at the onset of nucleation of instability $\left(\tau_{0}\right)$, which occurs after a pressure change of 20.8 MPa. Additionally, the static shear strength $\tau_{s}\left(=\sigma_{n 0}{ }^{\prime} \mu_{s}\right)$ and dynamic shear strength $\tau_{s}\left(=\sigma_{n 0}{ }^{\prime} \mu_{d}\right)$ at the onset of instability are illustrated with respectively the dashed blue line and the dotted red line. $d)$ Stress drop $\Delta \tau\left(=\tau_{0}-\tau_{d}\right)$ at the onset of instability. Pink area indicates a positive stress drop, green area a negative stress drop (stabilizing). e) Shear capacity utilization (SCU) indicating the proximity to failure. $S C U=\tau / \tau_{f}=\tau /\left(\mu_{s} \sigma_{n}{ }^{\prime}+C\right)$.

Similarly, field scale Finite Element models showed that the specific geometry of the producing reservoir resulted in significant stress concentrations. Depletion and associated compaction of two offset reservoir compartments resulted in a vertical displacement gradient across the fault offsetting the compartments, which in turn resulted in concentrated shear stress $\tau$ and effective normal stress $\sigma_{n}$ ' values near the top of the hanging wall reservoir compartment and the base of the footwall reservoir compartment (Figure 7-1, Chapter 2, Chapter 6). The net effect of these stress changes is an increased fault criticality ( $S C U$ ) at the 
top of the hanging wall and base of the footwall reservoir compartments, and a decreased fault criticality below and above the reservoir depth interval. In the example shown in Figure 7-1 the most critical stresses (highest SCU) are found at $-2850 \mathrm{~m}$ and $-3000 \mathrm{~m}$ depth (Figure 7-1e). As in the large-scale experiment reported in Chapter 4, fault reactivation was promoted at these stress concentrations and was followed by the occurrence of aseismic slip over multiple fault elements, prior to the onset of seismic instability. The pressure change required to advance the size of the nucleation zone from the size of one fault element to the critical nucleation length was typically up to several $\mathrm{MPa}$, though for low offset reservoir compartments it was less than $1 \mathrm{MPa}$. The nucleation behavior seen is different from previous geomechanical modeling studies, where fault behavior was governed by a static friction coefficient without frictional weakening (e.g. Lele et al., 2016; Mulders, 2003; Orlic \& Wassing, 2013; van den Bogert, 2015). In those studies, (aseismic) fault reactivation was taken as a proxy for the occurrence of seismic slip. Not incorporating frictional weakening behavior and not properly resolving the related nucleation length will thus give a different value for the pressure change required for instability, and will also make this value mesh size dependent.

For the three different dynamic friction coefficients $(0.35,0.45$, and 0.55$)$ used in the fully dynamic modeling work presented in Chapter 2 of this thesis, the critical nucleation length, i.e. the dip-parallel length of the zone that was slipping aseismically before the onset of instability, was $10-20 \mathrm{~m}$. However, the friction (slip weakening) parameters used in obtaining this result are subject to significant uncertainties. In Chapter 6, results from over 1,000 simulations of depletion-induced stresses are presented, using friction parameters that were randomly sampled from distributions based on experimental data. The critical nucleation lengths obtained for the randomly sampled friction parameters varied from $1 \mathrm{~m}$ to several tens of meters, increasing with increasing slip weakening distance and decreasing with increasing friction drop.

The heterogeneous fault stresses caused by reservoir depletion in the modeling work presented in Chapters 2 and 6 also produced different styles of nucleation behavior: instability nucleated not only from slip zones at the top or bottom of the faulted reservoir section, but also when two aseismic slip zones growing at these sites of elevated $\tau / \sigma_{n}$, coalesced (refer Figure 7-2a, b). Complexity in the nucleation behavior was also seen in the scaled laboratory experiments in Chapter 4. Besides dm-scale stress heterogeneities related to the boundary conditions imposed in these experiments, local heterogeneous compaction of the gouge layer caused cm-scale stress variations, which resulted in heterogeneous (aseismic) slip along the fault (Figure 7-2c). For some of the observed slip events, this resulted in more complex nucleation and coalescence behavior (Chapter 4). In the experiments aseismic slip was $\sim 10-20 \%$ of the slip during the fast slip event, whereas in the geomechanical models this fraction could be up to $50 \%$. In some of the reservoir scale simulations, significant aseismic slip (more than several $\mathrm{cm}$ ) was observed within the nucleation zone slip patch on the fault prior to reaching the critical length, thus lowering the 


\section{Chapter 7}

shear stress on the fault as in the example in Figure 7-2a, b. This relaxation of shear stress led to a smaller size of the subsequent seismic rupture (Chapters 2 and 6). Both the experiments and models thus show that it is important to consider aseismic slip occurring prior to rupture.
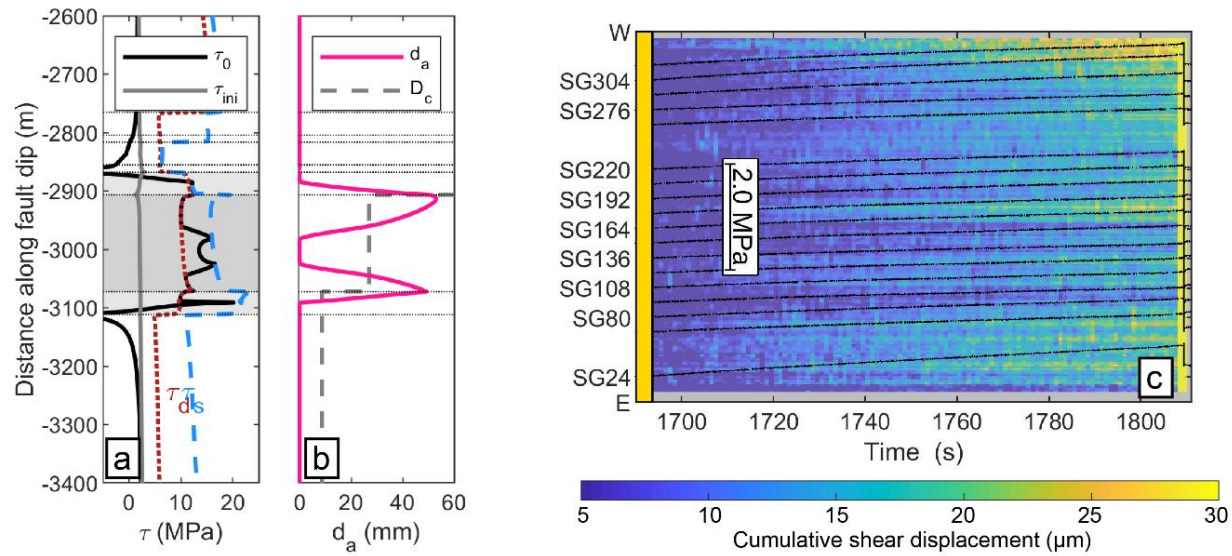

Figure 7-2. Nucleation and aseismic slip observed in geomechanical models (Chapter 6) and large-scale experiments on the homogeneous gypsum fault (Chapter 4). Model results in a and $b$ are for a simulation with the following main input parameters: dip $=77^{\circ}, K_{0}=0.81$, offset $=38 \mathrm{~m}$, thickness $=200$, static and dynamic friction of the Slochteren sandstone fault segment $\mu_{s S S}=0.6$ and $\mu_{d S S}=0.38$, and static and dynamic friction of the Carboniferous underburden $\mu_{s D C}=0.54$ and $\mu_{d D C}=0.2$ (see also Section 6. 3. 2. ). a) Initial, pre-depletion shear stress $\tau_{\text {ini }}$ and shear stress at the onset of instability $\tau_{0}$ along the fault. In addition, the static and dynamic shear stress $\tau_{s}\left(=\mu_{s} \sigma_{n}{ }^{\prime}\right)$ and $\tau_{d}\left(=\mu_{d} \sigma_{n}{ }^{\prime}\right)$ along the fault are indicated by respectively the blue dashed and red dotted line. $b$ ) aseismical shear slip $d_{a}$ along the fault at the onset of instability. For reference, the slip-weakening distance $D_{c} i$ s shown. c) Aseismic slip preceding a stick-slip event on a large-scale experimental fault filled with gypsum gouge (Chapter 4), at a minimum horizontal stress of $5 \mathrm{MPa}$ and a displacement rate $d_{1}$ of $1 \mu \mathrm{ms}^{-1}$. Aseismic slip measurements are overlain with local shear stress measurements obtained from strain gauges along the fault. The scale bar (2 MPa) is shown in the figure.

\section{1. 2. Pressure changes required for nucleation of instability in a producing gas reservoir}

In the geomechanical modeling work reported in Chapters 2, 3 and 6, fault reactivation is defined in terms of the reservoir pressure change $\Delta P$ that first initiates failure and plastic slip (meaning irreversible fault slip) on any fault element. Fault reactivation is promoted by low initial stress ratios of horizontal to vertical normal stress $K_{0}\left(=\sigma_{h} / \sigma_{v}\right)$ within the reservoir, by fault dips between 60 and $70^{\circ}$, by fault strikes running (sub)-parallel to the maximum horizontal stress $\sigma_{H}$, and by high values of both the stress path parameter $\gamma_{h}$ $\left(=\Delta \sigma_{h} / \Delta P\right)$ and reservoir compressibility $C_{m}$ (Figure 7-3). For example, for $K_{0}<0.72$ (Figure 7-3a) and for $C_{m}$ larger than $1.2 \cdot 10^{-4} \mathrm{MPa}^{-1}$ (Figure 7-3g) more than $20 \%$ of all simulations gave a pressure change required for nucleation of instability $\left(\Delta P_{0}\right)$ smaller than 

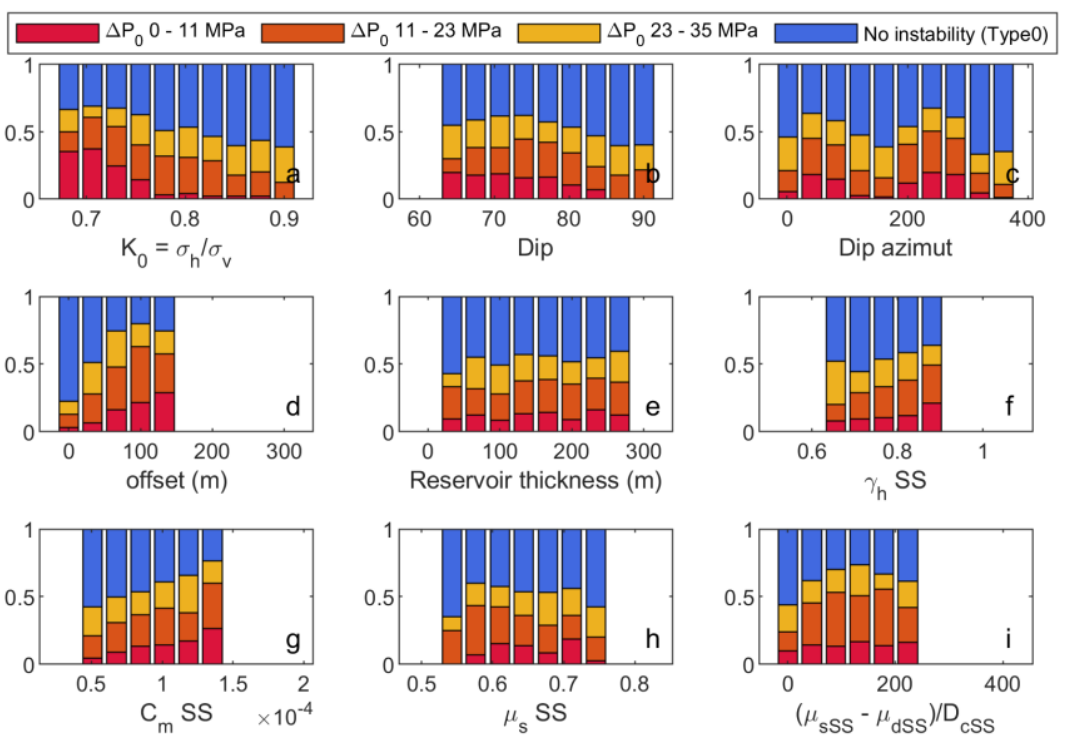

Figure 7-3 Pressure changes required for the onset of instability, for the model ensemble described in Chapter 6. Normalized fraction of the 1,000 simulation results within a given range of pressure change required for nucleation $\Delta P_{0}$, as a function of different input parameters. Note that for each simulation, all input parameters were sampled randomly from the distributions described in Chapter 6. Ten bins were plotted in the bar charts covering the full range of each parameter considered but bins containing less than 20 simulations were discarded. The pressure change required for the onset of instability is defined in three categories: those with a $\triangle P_{0}$ from $0-11 \mathrm{MPa}$ (red), $11-23 \mathrm{MPa}$ (orange), and 23 -35 MPa (yellow). The fraction of model realizations not featuring nucleation of instability is included in blue. Input parameters shown are a) initial stress ratio $K_{0}, b$ ) fault dip, c) dip azimuth (mean strike of $\sigma_{H}$ is $342 \pm 10^{\circ}$ ), d) vertical offset, e) Slochteren reservoir thickness, f) horizontal stress path parameter $\gamma_{h}$ $\left(=\Delta \sigma_{h} / \Delta P\right)$ prescribed in the Slochteren sandstone (SS) formation, $\left.g\right)$ uniaxial compaction coefficient $C_{m}$ which is the vertical strain change with pressure $\left(=\Delta \varepsilon_{y} / \Delta P\right)$ prescribed in the Slochteren sandstone formation, $\left.h\right)$ static friction coefficient $\mu_{\text {sss }}$ on fault segments flanked on both sides by Slochteren sandstone, i) frictional weakening rate, with static and dynamic friction coefficients of fault segments in the Slochteren sandstone $\mu_{s S S}$ and $\mu_{d S s}$ and slip weakening distance $D_{\text {cSs. }}$.

$11 \mathrm{MPa}$, while $50 \%$ of all simulations yielded a $\triangle P_{0}$ smaller than $23 \mathrm{MPa}$. The initial stress ratio determines how close the faults are to failure prior to depletion, and hence a lower $K_{0}$ (more unstable stress ratio) required less pressure change (and resulting stress changes) than higher values of $K_{0}$. The uniaxial compaction coefficient $C_{m}$ controls the amount of compaction, which is important for the magnitude of the stress concentrations developing on offset faults (Figure 7-1), with larger compaction resulting in larger gradients of vertical displacement across offset faults, larger stress concentrations and smaller $\Delta P_{0}$. Additionally, reservoir offset on faults also favored fault reactivation at low $\Delta P_{0}$ compared with reservoir compartments with little or no offset (Figure 7-3d), as stress concentrations on faults offsetting depleting reservoir compartments (see e.g. Figure 7-1) increased with offset of the producing reservoir (Chapter 2). In line with this, depletion of offset reservoir compartments leads to locally much higher values of the stress path parameter near faults than obtained 


\section{Chapter 7}

remotely, where the stress path parameter reflects undisturbed uniaxial compaction. The fraction of seismic events that nucleated at higher $\Delta P_{0}>23 \mathrm{MPa}$ (yellow part of bar chart) increased with increasing $K_{0}$, lower values of $\gamma_{h}$, and poorly oriented faults with dip azimuths $120-180^{\circ}$ and $360-10^{\circ}$ (i.e. angles $>40^{\circ}$ with respect to the mean strike of $\sigma_{H}$ of $342^{\circ}$ ) and dips smaller than $65^{\circ}$ and larger than $80^{\circ}$ (Figure 7-3). For around $50 \%$ of the simulations realized in Chapter 6, no nucleation of instability occurred at all. Although the absence of nucleation was observed across all input parameter ranges, the fraction of simulations not yielding nucleation increased to $>50 \%$ with increasing $K_{0}$ values $(>0.77)$, steep fault dips $\left(>80^{\circ}\right)$, high angles between fault strike and $\sigma_{H}\left(>40^{\circ}\right)$, small offsets on faults $(<50 \mathrm{~m})$, and low reservoir compressibilities $C_{m}\left(<1 \cdot 10^{-4} \mathrm{MPa}^{-1}\right)$.

\section{1. 3. Size of seismic ruptures induced by gas production}

Once an aseismic slip patch has attained its critical nucleation length, no further depletion is required to drive seismic rupture, which can self-propagate beyond the nucleation zone into other regions of the reservoir interval and other formations. The final rupture size (defined here as the along-dip length of the fault that slipped seismically - i.e. at slip rates > $0.01 \mathrm{~ms}^{-1}$ ) depends primarily on the combination of the assumed in-situ stress and fault frictional properties, in particular the dynamic friction coefficient (Chapter 2). For low initial stress ratios $K_{0}\left(=\sigma_{h} / \sigma_{v}\right)$ and/or low dynamic friction values, the rupture sizes increased and also the potential for rupture to propagate outside of the reservoir increased. This was confirmed by the stochastic geomechanical analysis given in Chapter 6 , which explored a much larger parameter space and showed that rupture sizes decreased with increasing $K_{0}$ (Figure 7-4a) and with increasing dynamic fault friction $\mu_{d S S}$ in the Slochteren sandstone (Figure 7-4h), as well as with increasing fault dip (Figure 7-4b), with increasing misorientation between fault strike and the direction of $\sigma_{H}$ (Figure 7-4c), and with decreasing reservoir thickness (Figure 7-4e). Unfortunately, the initial stress ratio is poorly constrained (van Eijs, 2015). Further knowledge about its magnitude and uncertainty distribution would greatly aid in further constraining modeled rupture sizes. Besides the initial stress, however, dynamic friction, dip, strike, reservoir thickness, and the heterogeneous, depletion-induced state of stress on the fault also had a strong effect on rupture size. As highlighted already, the heterogeneous stress developed mostly from the reservoir offset. Whereas a larger reservoir offset promoted fault reactivation (Figure 7-1d), such offsets generally led to smaller rupture sizes. This can be seen in Figure 7-4d where the larger rupture sizes $(>400 \mathrm{~m})$ are found mostly for small offsets. Rupture was often arrested in the regions of stable stress that developed during depletion at the top of the reservoir in the footwall and at the base of the reservoir in the hanging wall. This is the reason why reservoir thickness also affected rupture size as seen in Figure 7-4f, where the larger events in each bin correlate with the reservoir thickness as they were arrested at the top and bottom boundaries of the reservoir.

Of particular interest is the potential for rupture to propagate beyond the reservoir interval. For the ranges of initial stress $K_{0}$, lithology-specific friction parameters and 
formation-specific geomechanical parameters considered in Chapter 6, more than 95\% percent of the seismic events were arrested within the reservoir depth interval. Propagation into the overburden was always prevented due to the isotropic stress ratio assumed for the Zechstein cap rock, which is a realistic assumption as salt creep relaxes internal shear stresses to values close to $0 \mathrm{MPa}$ on time scales much shorter than geological timescales (Haug et al., 2018; Orlic \& Wassing, 2013; Wassing et al., 2017). Propagation of rupture beyond the reservoir interval into the Carboniferous underburden was only observed for a stress ratio < 0.73 , a dip $<80^{\circ}$, favorably oriented faults (i.e. those with a fault strike close to the direction of $\sigma_{H}$ ) and a dynamic friction $<0.35$ in the Carboniferous (Figure 7-4k). Additionally, propagation into the underburden mostly occurred for reservoir offsets smaller than $50 \mathrm{~m}$ (Figure 7-4d). This is because, for offsets below $50 \mathrm{~m}$, the width and magnitude of the zone of stable stress concentration below the reservoir became smaller and progressively easier to overcome by rupture propagating down-dip from the reservoir interval.
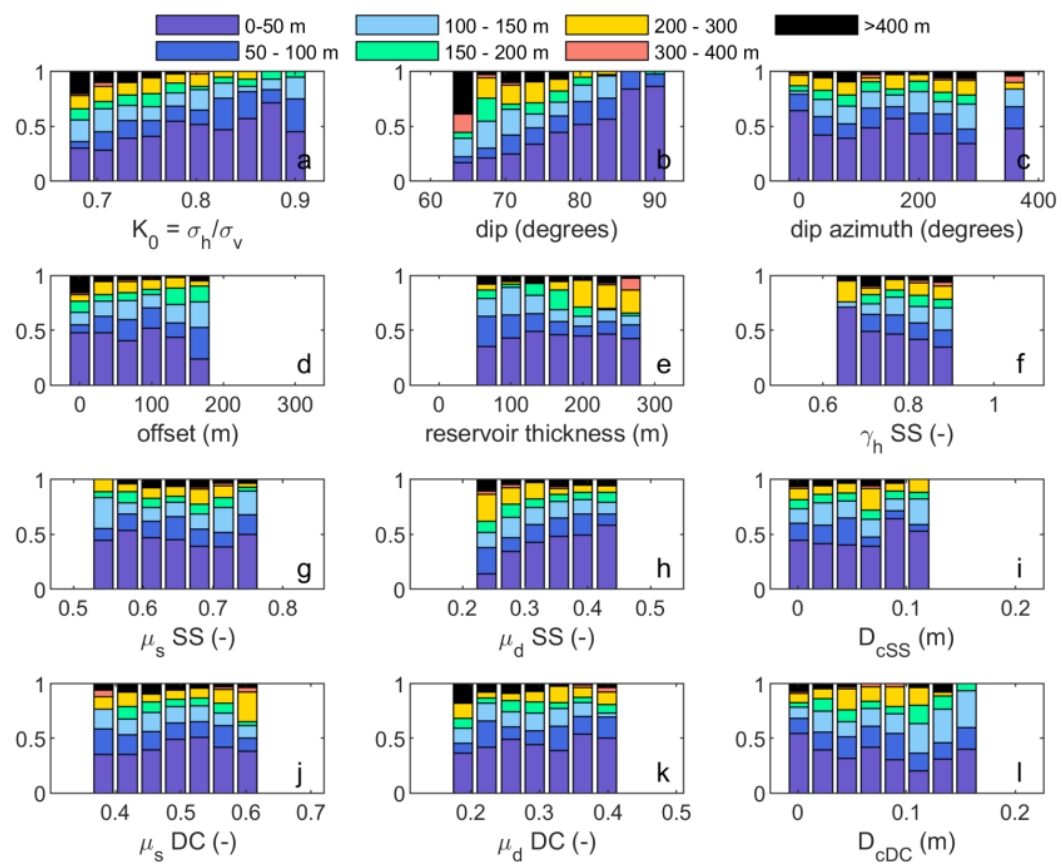

Figure 7-4 Normalized fraction of modeled rupture lengths as a function of different input parameters for the model ensemble presented in Chapter 6. Fractions were computed for 10 bins spanning the range of each input parameters, but bins containing less than 20 simulations were discarded. Model realizations that did not result in nucleation of rupture (i.e. those shown in blue in Figure 7-3) were not considered. a) initial stress ratio $K_{0}, b$ ) fault dip, c) dip azimuth (the mean strike of $\sigma_{H}$ is $342 \pm 10^{\circ}$ ), d) vertical reservoir offset, e) thickness of the Slochteren reservoir formation, $f$ ) horizontal stress path parameter $\left.\gamma_{h}\left(=\Delta \sigma_{h} / \Delta P\right), g-i\right)$ static and dynamic friction coefficients and slipweakening distance for fault segments in the Slochteren sandstone, $j-l$ ) static and dynamic friction coefficients and slip-weakening distance for fault segments in the Carboniferous underburden. 


\section{Chapter 7}

\section{1. 4. Effects of elastoplastic reservoir behavior on fault reactivation and rupture size}

The geomechanical modeling approach summarized above (Sections 7. 1. 1. - 7. 1. 3. ), and presented in detail for the fully dynamic case in Chapter 2, assumed linear elastic material properties for the reservoir and other formations. In Chapter 3 reservoir compaction was also modeled using Modified Cam-Clay (MCC) elastoplasticity, following experimental observations that demonstrated that a significant fraction of the compaction strain in Slochteren reservoir sandstone cores is inelastic (Hol et al., 2018; Pijnenburg et al., 2018) and could be described by an MCC yield envelope with linear hardening, constant elasticity, and a varying slope of the critical state line (Pijnenburg et al., 2019). The MCC model used in Chapter 3 (Roscoe et al., 1958; Roscoe \& Burland, 1968) was validated and tuned against experimental results on Slochteren sandstone cores. The compaction data obtained from both triaxial (Pijnenburg et al., 2018) and uniaxial (Hol et al., 2018) compaction experiments could be largely matched using the MCC model. The field-scale geomechanical models subsequently showed that depletion-induced stress development obtained using an elastoplastic reservoir can be adequately approximated using linear elastic material properties, if the appropriate 'apparent elastic' parameters are used. The apparent elastic parameters are those obtained from linear fits to the near-linear stress-strain curves obtained during depletion under uniaxial strain conditions (from modeling with a single element MCC model, or stress-strain curves obtained experimentally), and include both the elastic and inelastic response. However, a number of other differences in stress development during depletion did arise from using the elastoplastic material behavior. MCC elastoplasticity and the related hardening caused the modeled horizontal stress path parameter $\gamma_{h}\left(=\Delta \sigma_{h} / \Delta P\right)$ to increase with the mean effective stress $\left(\sigma_{1}^{\prime}+2 \sigma_{3}^{\prime}\right) / 3$ assumed at the start of depletion. In other words, for the same material properties but a higher starting mean effective stress, the change in total horizontal stress was larger (more unstable) per unit pore pressure depletion. This means that to determine the stress path and/or apparent elastic parameters mentioned above, it is important to consider the initial mean effective stress relevant to the problem that is modeled, e.g. the initial mean effective stress in the Groningen field in this case. Simultaneously, for the same initial mean effective stress, the stress path parameter decreased with ongoing depletion. This is because the MCC stress-strain response was near-linear but not fully linear, with a mildly decreasing slope in p'-q space (Figure 3-4). The outcome is that, for an elastoplastic reservoir, the horizontal stress path parameter decreases (i.e. become more stable) with increasing depletion, with a decrease of $\sim 0.1$ in progressing from the initial state $(\triangle P=0 \mathrm{MPa})$ to full reservoir depletion $(\triangle P=35 \mathrm{MPa})$.

I also considered the effect of MCC elastoplasticity on rupture nucleation and dynamic rupture in the field-scale geomechanical model (Chapter 3). Simulating a reservoir with MCC behavior resulted in a larger critical nucleation length, and smaller dynamic ruptures for a given depletion pressure, compared to a linear elastic reservoir with apparent 
elastic properties. The final slip displacement achieved in rupture events within an elastoplastic reservoir was $10-20 \%$ less than for those within a linear elastic reservoir. For some dynamic ruptures, elastoplasticity also resulted in smaller final rupture lengths compared to those within a linear elastic reservoir. Rupture lengths were not always smaller, because the heterogeneous fault stresses imposed a strong control on rupture arrest, masking the effect of elastoplasticity on rupture length. In general, then, reservoir elastoplasticity will result in smaller rupture sizes than expected from models assuming linear elastic behavior. However, the effect on the estimated event moment magnitude $M_{w}$ (which requires an assumption of the aspect ratio W:L of rupture, i.e. an assumption for the rupture length in the third dimension $\mathrm{W}$, as moment magnitude depends on the rupture area as well as average fault slip, see Chapter 3) is moderate for aspect ratios up to $4 ; 10-20 \%$ less slip and $20 \%$ decrease in rupture size results in a 0.1 to 0.5 smaller moment magnitude.

\section{1. 5. Effects of heterogeneous fault friction}

Gouge lithology within faults cutting sedimentary sequences, such as those in the Groningen field, can vary significantly along fault dip and strike. These variations in lithology translate into variations in fault strength and fault stability, with some lithologies being more prone to unstable sliding (seismic events) and others more prone to stable sliding (aseismic slip). In the framework of rate-and-state friction modeling (Dieterich, 1979; Ruina, 1983), unstable sliding is related to velocity-weakening (VW) friction, and stable sliding to velocity-strengthening friction (VS). The scaled heterogeneous fault experiments reported in Chapter 4 of this thesis, featured an 80 mm-long VW fault segment flanked by two $135 \mathrm{~mm}$ long VS segments showed that the size of the VW segment with respect to the critical nucleation length and the combination of materials present along the fault controlled the average slip behavior. For VW segments close to the critical nucleation length, unstable sliding (seismic slip) events were observed, with events that nucleated in the VW segment propagating across $20-80 \%$ of the VS segments. In the time interval between unstable slip events, significant aseismic slip occurred on the VS segments but also on the VW segment itself. Aseismic slip on the VW segment released up to $50 \%$ of the stress-buildup in the PMMA forcing blocks adjacent to the VW fault gouge segments. This aseismic slip is driven by high stresses transferred to the VW fault segment by aseismic slip occurring continuously within the neighboring VS segments. When the critical nucleation length was increased to become much larger $(\sim 10 \mathrm{x})$ than the extent of the VW segment, by lowering the normal stress in the scaled experiments, the macroscopic slip behavior changed, depending on the combinations of fault lithologies. For VS kaolinite segments with a central VW gypsum segment, unstable slip events persisted. However, for VS quartz plus a central VW gypsum segment, only small slip events rupturing the end of the VW segment persisted to large critical nucleation lengths. For VS calcite segments flanking the VW gypsum segment faultwide slow slip events were observed. These different slip behaviors observed in the experiment are consistent with slip modes seen in RSF models of slip events on a 


\section{Chapter 7}

heterogeneous fault with a similar geometry - i.e. a VW asperity flanked by VS segments (Barbot, 2019; Luo \& Ampuero, 2018; Skarbek et al., 2012).

\section{2. Implications}

\section{2. 1. Implications for the Groningen gas field}

The geomechanical models explored in this thesis, for generic Groningen reservoir sections, show a large variability in the magnitude of reservoir pore pressure change required for nucleation of depletion-induced seismic events, depending on the input parameters (Chapter 6). This pressure change is an important model result, since, when coupled with reservoir depletion vs. time data, it yields information on the timing of seismic events. From 1970 to 2015, the average pore pressure in the Groningen field decreased nearly linear from $35 \mathrm{MPa}$ to $8 \mathrm{MPa}$, translating to an average pressure change of $0.6 \mathrm{MPa}$ per year (see Figure 1-2). In Groningen, the first earthquake that was recorded occurred in 1991, almost 30 years after the start of production. The average cumulative pressure change in 1991 was $16 \mathrm{MPa}$. Note that seismicity with $\mathrm{M}<2.5$ may have occurred prior to 1991 , but could have gone unnoticed because of the limited seismic network coverage at the time. After 1991, the number and size of earthquakes increased with ongoing depletion. For seismic source models that can be used in the Probabilistic Seismic Hazard Analysis (PSHA) performed for Groningen (Bourne et al., 2014; Bourne et al., 2015; Bourne \& Oates, 2017a; Bourne \& Oates, 2017b; Bourne et al., 2018; Dempsey \& Suckale, 2017), capturing this trend of increasing seismicity rates is an important requirement. As an example, incorporating the likelihood of failure using an extreme threshold distribution can give the required initial nonlinear in seismic activity rates seen in the Groningen field, as the first failures occur in the tail of this distribution, with more and more events occurring in the body of the distribution as pressure depletion continues (Bourne \& Oates, 2017b).

Even though the geomechanical models in this thesis have been simplified in terms of pressure history, are in 2D, have not been calibrated against seismicity observed in the field, and are not meant to generate seismicity rates, it is important to consider the physical properties affecting the pressure changes (and hence the timing) of the seismic events modeled in Chapter 6 using a model ensemble of $>1,000$ simulations. Figure 7-5 shows the number of events generated per $2 \mathrm{MPa}$ pressure change interval, for different ranges of the initial stress ratio $K_{0}$. For the more unstable initial stress range $\left(K_{0}=0.72\right.$ to 0.76$)$, events are observed from the beginning of depletion, reaching a frequency peak in the range of $5-15$ MPa pressure drop. For the more stable initial stress states $\left(K_{0}=0.76\right.$ to 0.82$)$, events start later (after additional depletion), build up gradually, and beyond around $15 \mathrm{MPa}$ depletion remain at a roughly constant number of events per MPa pressure change. In the first scenario $\left(K_{0}=0.72\right.$ to 0.76 ), faults are closer to failure and get reactivated after relatively low pressure changes due to the stress concentrations that build up where faults offset the depleting reservoir. In the second scenario $\left(K_{0}=0.76\right.$ to 0.82$)$, initially no seismic events occurred. The 
subsequent gradual increase in seismicity reflects the progressive reactivation of different fault orientations and dips in the field. At $\triangle P$ exceeding $15 \mathrm{MPa}$ the event rates stabilize. If the Biot coefficient within the reservoir rock is lower or cohesion is present on the faults, this trend will presumably shift to higher $\Delta P$, which would be more consistent with the field observations where no seismicity is recorded at $\Delta P<15 \mathrm{MPa}$, and the majority of events occurred at $\Delta P>20 \mathrm{MPa}$. The model ensemble thus gives a nonlinear evolution of seismicity with time, as also observed in the seismic source model incorporating the probability of fault failure through an extreme threshold distribution by Bourne et al., (2017). Note that the mechanisms are not the same. In the paper by Bourne et al., (2017) fault orientation is not explicitly modeled, and the nonlinear seismicity rates derive from a combination of Coulomb stress changes and the assumed probability distribution of exceeding failure. Here the nonlinear evolution of seismic events with depletion largely results from the different fault geometries (strike, dip, and vertical offset) as well as different static friction coefficients sampled by the model ensemble that require different pressure changes for reactivation, providing a more deterministic means of generating seismicity rates. If the current model chain could be faster, model results could be compared to seismicity rates observed in the field, and the input parameters could be tuned and/or validated.

Another aspect emerging from the geomechanical models is that the effective normal stress acting on the faults increases with ongoing depletion, as the effective stresses keep increasing. For the slip-weakening friction law employed in Chapters 2, 3, and 6, this means that the stress drop would increase with depletion, and possibly also the rupture size and hence the event magnitude. However, within the uncertainties in seismological estimates of the stress drop, such an increase may not be apparent and the effect on seismic magnitudes is uncertain.

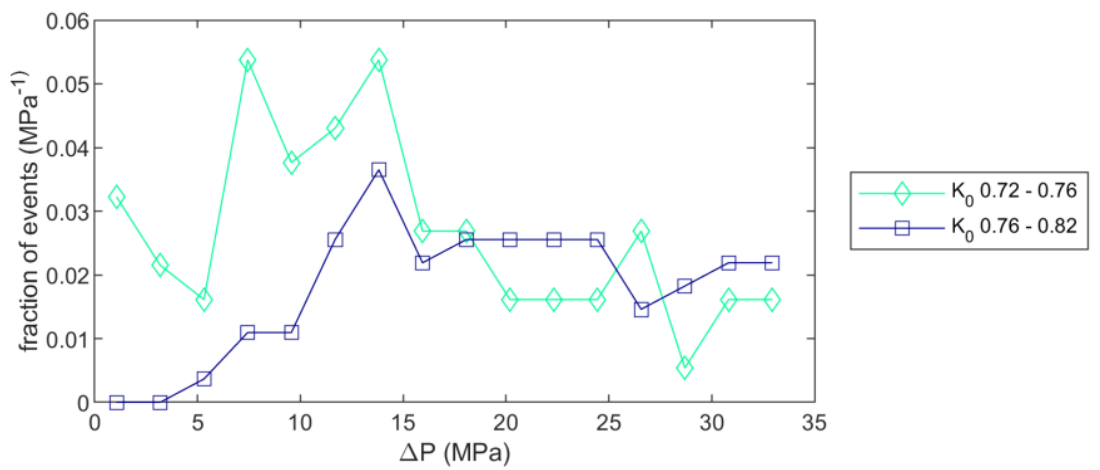

Figure 7-5. Fraction of events (from the total amount of model simulations in the ensemble reported in Chapter 6 within the specified range of $K_{0}$, occurring per 2 MPa decrease in reservoir pore pressure, for different ranges of initial stress ratio $K_{0}\left(=\sigma_{h} / \sigma_{v}\right)$. 
For some of the generic Groningen simulations performed, significant aseismic slip occurred on the fault during the nucleation phase, for instance along fault segments characterized by friction parameters with a low static friction coefficient and little or no slip weakening. The occurrence of aseismic slip follows from the assumed frictional weakening function. If the slip-weakening friction model is indeed applicable for the quasi-static nucleation phase on the faults in Groningen, then part of the strain energy that builds up around faults will be dissipated into aseismic fault slip during stable, aseismic growth of the nucleation zone, before unstable seismic rupture. Aseismic slip during the nucleation phase and the related dissipation and reduction of shear stresses have not previously been considered in modeling studies on depletion-induced seismicity by others, though it is important as it will lead to smaller simulated earthquakes (Chapter 6). It is important, however, to keep in mind that the same slip-weakening function was assumed to hold at the low velocities typical for nucleation as well as at high velocities relevant to dynamic rupture. In reality, less aseismic slip may occur during the nucleation phase in the absence of weakening, but this remains a matter of further research.

The results obtained in Chapter 3 showed that stress changes produced by depletion of a reservoir with Modified Cam-Clay elastoplastic properties, appropriate for the Groningen reservoir and similar sandstone reservoirs, could be adequately approximated assuming a linear elastic reservoir response defined in terms of 'apparent' elastic properties. This approximation is possible because the elastoplastic stress-strain response measured in experiments at the in-situ reservoir conditions (Hol et al., 2018) and the stress-strain response modeled using the validated MCC material behavior under uniaxial depletion conditions relevant to the reservoir (Chapter 3) is near-linear. The implication is that, under the stress condition relevant to depletion, linear poroelasticity may be used to simulate the (one-way) stress-strain response of the Groningen reservoir to depletion, as outlined in Chapters 1 and 6 and other geomechanical modeling studies. Secondary effects of MCC elastoplasticity not captured by linear elasticity, are the increase in the horizontal stress path parameter $\gamma_{h}\left(=\Delta \sigma_{h}\right.$ $/ \triangle P$ ) observed with increasing initial mean effective stress, and the decrease in the horizontal stress path parameter with ongoing depletion (Chapter 3). The increase in stress path parameter with initial mean effective stress would imply that deeper parts of the Groningen reservoir will be characterized by increasingly unstable stress paths. However, it may be difficult to distinguish such effects from variations in stress path arising from variations in lithology or porosity. At the same time, the decrease in stress path parameter with progressive depletion implies that the stress path becomes more stable with depletion. Such a stabilizing effect is inconsistent with the fact that seismicity has been observed to increase after 1991 (Figure 1-2). The stabilizing effect due to elastoplastic deformation may be masked by the trend related to progressive reactivation of different fault orientations as seen in Figure 7-5. An additional effect of elastoplasticity that is not captured by linear elasticity is stress path hysteresis - i.e. upon reinjection the slope of the stress path will be different compared to the stress path during depletion. Very limited reinjection occurs in the Groningen field, but 
studies investigating potential reinjection scenarios should consider stress path hysteresis (e.g. TNO (2015).

Table 7-1 Example calculations of moment magnitude for different scenarios. L: rupture lengths along dip, W:L aspect ratio of rupture width (along strike), A: rupture area, d: assumed average slip, M0: seismic moment $\left(M_{0}=\right.$ GAd, where a shear modulus of $6.5 \cdot 10^{9}$ is assumed), and moment magnitude $M_{w}(A k i, 1966)$.

\begin{tabular}{|c|c|c|c|c|c|c|}
\hline Scenario & $L$ & $W: L$ & $A$ & $d$ & MO & Mw \\
\hline Confined to SS & 200 & 1 & $4.00 \mathrm{E}+0$ & 0.01 & $2.60 \mathrm{E}+1$ & 2.2 \\
\hline Confined to SS - slip $50 \mathrm{~mm}$ & 200 & 1 & $4.00 \mathrm{E}+0$ & 0.05 & $1.30 \mathrm{E}+1$ & 2.7 \\
\hline Confined to SS & 200 & 5 & $2.00 \mathrm{E}+0$ & 0.01 & $1.30 \mathrm{E}+1$ & 2.7 \\
\hline Confined to SS - slip $50 \mathrm{~mm}$, W:L 5:1 & 200 & 5 & $2.00 \mathrm{E}+0$ & 0.05 & $6.50 \mathrm{E}+1$ & 3.1 \\
\hline Confined to $\mathrm{RO}(=\mathrm{SS}+\mathrm{TB})$ & 270 & 1 & $7.29 \mathrm{E}+0$ & 0.01 & $4.74 \mathrm{E}+1$ & 2.4 \\
\hline Confined to RO - slip $50 \mathrm{~mm}$ & 270 & 1 & $7.29 \mathrm{E}+0$ & 0.05 & $2.37 \mathrm{E}+1$ & 2.8 \\
\hline Confined to RO, W:L 5:1 & 270 & 5 & $3.65 \mathrm{E}+0$ & 0.01 & $2.37 \mathrm{E}+1$ & 2.8 \\
\hline Confined to RO - slip $50 \mathrm{~mm}, \mathrm{~W}: \mathrm{L}$ 5:1 & 270 & 5 & $3.65 \mathrm{E}+0$ & 0.05 & $1.18 \mathrm{E}+1$ & 3.3 \\
\hline Confined to RO - slip $50 \mathrm{~mm}, \mathrm{~W}: \mathrm{L}$ 10:1 & 270 & 10 & $7.29 \mathrm{E}+0$ & 0.05 & $2.37 \mathrm{E}+1$ & 3.5 \\
\hline $50 \mathrm{~m}$ beyond thickness $\mathrm{RO}$ & 320 & 1 & $1.02 \mathrm{E}+0$ & 0.01 & $6.66 \mathrm{E}+1$ & 2.5 \\
\hline $50 \mathrm{~m}$ beyond thickness RO - slip $50 \mathrm{~mm}$ & 320 & 1 & $1.02 \mathrm{E}+0$ & 0.05 & $3.33 \mathrm{E}+1$ & 2.9 \\
\hline $50 \mathrm{~m}$ beyond thickness $\mathrm{RO}-\mathrm{W}: \mathrm{L}$ 5:1 & 320 & 5 & $5.12 \mathrm{E}+0$ & 0.01 & $3.33 \mathrm{E}+1$ & 2.9 \\
\hline $50 \mathrm{~m}$ beyond thickness RO - slip $50 \mathrm{~mm}$ & 320 & 5 & $5.12 \mathrm{E}+0$ & 0.05 & $1.66 \mathrm{E}+1$ & 3.4 \\
\hline $100 \mathrm{~m}$ beyond thickness RO & 370 & 1 & $1.37 \mathrm{E}+0$ & 0.01 & $8.90 \mathrm{E}+1$ & 2.6 \\
\hline $100 \mathrm{~m}$ beyond thickness RO - slip $50 \mathrm{~mm}$ & 370 & 1 & $1.37 \mathrm{E}+0$ & 0.05 & $4.45 \mathrm{E}+1$ & 3.0 \\
\hline $100 \mathrm{~m}$ beyond thickness RO - W:L 5:1 & 370 & 5 & $6.85 \mathrm{E}+0$ & 0.01 & $4.45 \mathrm{E}+1$ & 3.0 \\
\hline $100 \mathrm{~m}$ beyond thickness $\mathrm{RO}$ - slip $50 \mathrm{~mm}$ & 370 & 5 & $6.85 \mathrm{E}+0$ & 0.05 & $2.22 \mathrm{E}+1$ & 3.5 \\
\hline $100 \mathrm{~m}$ beyond thickness RO - slip $100 \mathrm{~mm}$ & 370 & 5 & $6.85 \mathrm{E}+0$ & 0.1 & $4.45 \mathrm{E}+1$ & 3.7 \\
\hline $200 \mathrm{~m}$ beyond thickness RO - slip $100 \mathrm{~mm}$ & 470 & 5 & $1.10 \mathrm{E}+0$ & 0.1 & $7.18 \mathrm{E}+1$ & 3.8 \\
\hline
\end{tabular}

The maximum magnitude $M_{\max }$ that is possible or can be expected in the Groningen field is an important parameter for PSHA. A current estimate of the distribution based on expert opinion ranges from $\mathrm{M}_{\mathrm{w}} 4.0$ to 7.0 , with a modal value of 4.5 (e.g. Bommer \& van 


\section{Chapter 7}

Elk, 2017). If seismogenic rupture is limited to the reservoir depth interval, this would limit the $M_{\max }$ as this depends on the maximum dimension of the rupture. However, propagation along fault strike must be considered too before full constraints on $M_{\max }$ can be given. Of all the simulations reported in Chapter 6 , less than $5 \%$ of seismic ruptures propagated beyond the reservoir depth interval into the Carboniferous underburden. This implies that $95 \%$ of seismic ruptures will remain within the reservoir depth interval for the slip weakening model employed in Chapter 6. Propagation beyond the reservoir occurred only for initial stress ratios $K_{0}<0.73$, dynamic fault friction values in the Carboniferous $<0.35$, fault dips $<80^{\circ}$, faults strikes aligned with $\sigma_{H}$, and fault offsets generally less than $50 \mathrm{~m}$. In broad terms, the finding that most simulated ruptures tend to remain confined to the reservoir depth interval is consistent with the locations of real hypocenters actually determined within the reservoir depth interval, though the uncertainty in hypocenter depth is of the order of the reservoir thickness (Spetzler \& Dost, 2017a; Willacy et al., 2018). The model finding that ruptures remain confined to the reservoir is also consistent with the earthquake magnitudes that occurred to date. Specifically, the largest events in Groningen to date were the Huizinge earthquake of $\mathrm{M}_{\mathrm{L}} 3.6$ on the $16^{\text {th }}$ of August 2012, the Westeremden $\mathrm{M}_{\mathrm{L}} 3.5$ on 8 August 2006, and the Zeerijp earthquake of $\mathrm{M}_{\mathrm{L}} 3.4$ on the $8^{\text {th }}$ of Jaunary 2018 (Dost \& Kraaijpoel, 2013; Kraaijpoel \& Dost, 2013; Spetzler \& Dost, 2017a; Wentinck, 2018). Spectral analysis presented by Kraaijpoel \& Dost (2013) estimated the radius of the ruptured area for the Huizinge and Zeerijp events at $400-500 \mathrm{~m}$ (area $5-8 \cdot 10^{5} \mathrm{~m}^{2}$ ), with several cm's of slip. For aspect ratios of 5:1, such an event could be accommodated within the reservoir interval (Table 7-1)

Table 7-1 shows several example calculations of the moment magnitude, for different rupture lengths, aspect ratios, and average fault slip comparable to that observed in the rupture models $\left(\mathrm{M}_{0}=\mathrm{GAd}\right)$. At the location of the Huizinge and Zeerijp events, the thickness of the Upper Rotliegend Group (Slochteren sandstone + Ten Boer) is $\sim 270 \mathrm{~m}$ (Figure 7-6). The thickness of the Slochteren sandstone alone is $200 \mathrm{~m}$ (Figure 1-3). For these reservoir thicknesses, most observed event magnitudes can be accommodated within the reservoir depth interval. The $\mathrm{M}_{\mathrm{L}} 3.4$ - 3.6 events and related rupture areas could potentially be accommodated within the reservoir depth interval, but this requires a relatively high aspect rate and/or large average fault slip (W:L = 10:1, d>0.05 m, Table 7-1). Likely aspect ratios of ruptures for the fault geometries and stresses in the Groningen field are unknown and will depend on the state of stress and the frictional weakening and stress drop distribution on the faults; potential aspect ratios should be studied further as in e.g. Weng \& Ampuero (2019) with stress distributions for the Groningen fault geometries. Even so, an aspect ratio of 10:1 is very high, and for natural earthquakes only observed for a number of strike-slip events and not for dip-slip events (Figure 2 in Weng \& Ampuero, 2019). It may be more likely instead that the $\mathrm{M}_{\mathrm{L}} 3.4$ - 3.6 events propagated for some distance beyond the reservoir depth interval, sampling a (small) section of the underburden; $50-100 \mathrm{~m}$ propagation outside the reservoir depth interval allows for $\mathrm{M}_{\mathrm{L}} 3.4-3.6$ events at a lower 
aspect ratio of 5:1. Interestingly, the Huizinge $\mathrm{M}_{\mathrm{L}}$ 3.6, Zeerijp $\mathrm{M}_{\mathrm{L}} 3.4$ events as well as the Westeremden $\mathrm{M}_{\mathrm{L}} 3.5$ event, all seem related to faults with relatively little offset (Figure 7-6), as also noted by Wentinck (2018). The vertical offset on the fault in the vicinity of the Zeerijp event is $40 \mathrm{~m}$ (Wentinck, 2018), and near the Huizinge event $30 \mathrm{~m}$. In the model ensemble presented in Chapter 6 and Figure 7-4 it was seen that the potential for propagation into the underburden increased for these smaller offsets. Some propagation into the underburden for these largest events is thus consistent with the model results.

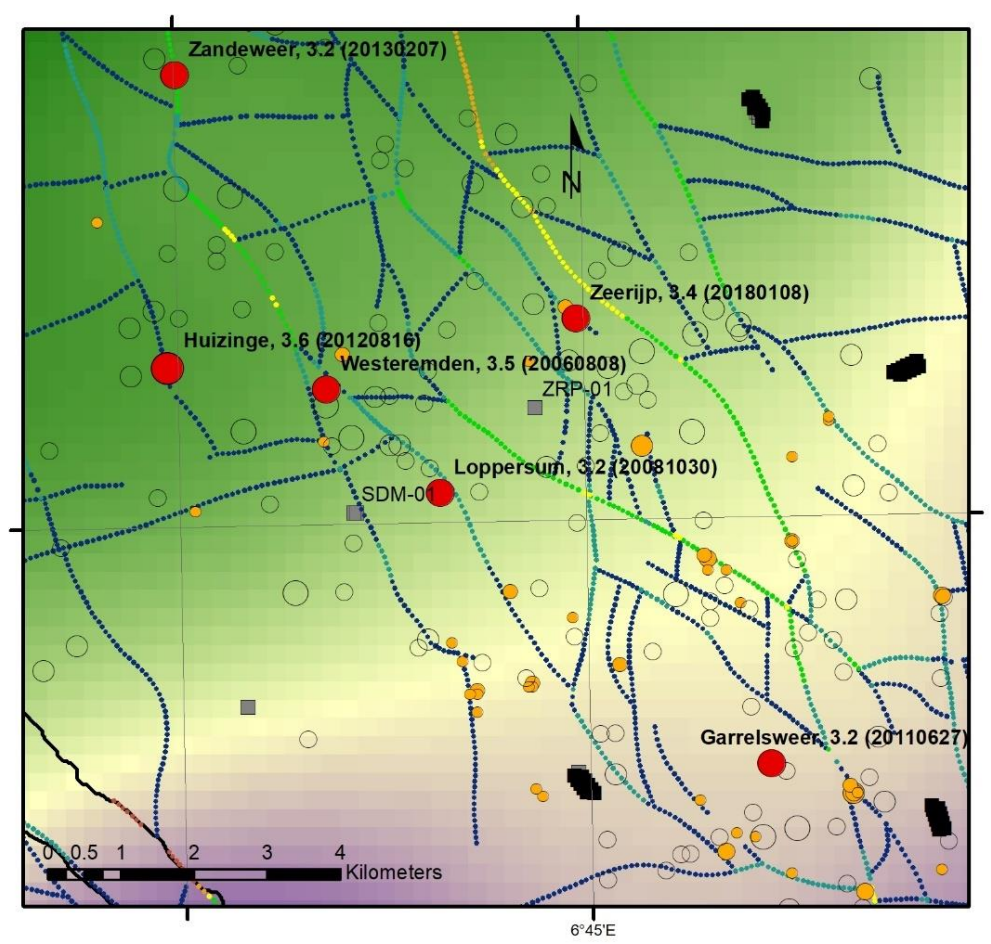

$$
\begin{aligned}
& \text { Event magnitude } \\
& \text { - } \quad 0.1-1.0 \\
& \text { - } \quad 1.1-1.5 \\
& \text { - } 1.6-2.0 \\
& \text { - } 2.1-2.5 \\
& \text { - } 2.6-3.0 \\
& \text { - } 3.1-3.5 \\
& 3.6-4.0 \\
& \text { - } 51-100 \\
& \text { - } 101-150 \\
& 151 \text { - } 200 \\
& 201 \text { - } 250 \\
& 251-300
\end{aligned}
$$

Thickness RO (m)

High : 300 Low : 200

Figure 7-6. Induced event locations and faults in the Loppersum area. Red and transparent circles indicate events from the KNMI catalog (www.knmi.nl, retrieved January 2020), with red circles used for magnitudes larger than 3. Location uncertainty of events before 2014 may be 500 - $1000 \mathrm{~m}$ (Dost et al., 2017). The location of the Huizinge $\left(M_{L} 3.6\right)$ and Zeerijp $\left(M_{L} 3.4\right)$ events have been modified to the relocated position (Wentinck, 2018). Orange circles show events recorded by the shallow borehole network from January 2015 to August 2018, with hypocenters determined by full-waveform event location methods (Willacy et al., 2018). Spatial errors are $<100 \mathrm{~m}$. Color background indicates the thickness of the Upper Rotliegend Group (www.nlog.nl) - i.e.(Slochteren sandstone and Ten Boer claystone (www.dinoloket.nl/nomenclature-deep). Closed in and producing wells are indicated with respectively the gray and black squares, with labels indicating the Stedum-01 and Zeerijp-01 wells. .

In summary, the location of the modeled events is consistent with hypocenter depth and the modeled rupture sizes generally indicate that events remain confined to the reservoir depth interval, which is consistent with the observed event sizes, and which implies an initial stress state that is not critical. However, some propagation beyond the reservoir depth interval could have occurred for the largest events in the Groningen field. Assuming propagation 


\section{Chapter 7}

beyond the reservoir depth interval remains limited to 100-200 m, and assuming aspect ratio's $<5: 1$, implies that magnitudes larger than $M>4.0$ are unlikely to occur. Note that the amount of slip assumed in Table 7-1 is based on the model results. The slip depends on the stress drop, which is determined by the amount of frictional weakening - i.e. the assumed static and dynamic friction coefficient. If a larger amount of frictional weakening is incorporated, more slip would occur leading to larger seismic moments. Again it remains important to continue studies into the potential frictional weakening behavior of the Groningen lithologies.

\section{2. 2. Broader implications}

Both the field-scale geomechanical models and the experiments described in this thesis show that stress concentrations are important for the nucleation of seismic events. In the case of natural seismicity, such stress concentrations also play a key role, in particular at marked lithological or rheological transitions, such as at the base of the seismogenic zone or at the edges of strong lithological inclusions (stress concentrators) within a weaker, creeping matrix (e.g.Barbot, 2019; Chen, Ting \& Lapusta, 2019; Luo \& Ampuero, 2018; Veedu \& Barbot, 2016). Although stress concentrations promote the nucleation of rupture, they may also cause relatively small events as the stresses beyond the nucleation zone could be much lower. The linear fracture mechanics theory (Chapter 6) has proven useful in approximating rupture arrest and final rupture size for fault with heterogeneous (induced) stresses, under the assumption of slip-weakening friction. The theory can also be used to study the effect of stress heterogeneities on rupture sizes in other subsurface operations such as fluid injection (e.g. Galis et al., 2017), doublet circulation for geothermal energy, enhanced geothermal systems (Gaucher et al., 2015), $\mathrm{CO}_{2}$ storage, etc., for which the stress changes are often localized to the reservoir or aquifer affected by the operations. For injection operations, the stress heterogeneities imposed by cooling will also be important (Candela, T. \& Fokker, 2017).

Sandstone elastoplasticity is not only relevant for hydrocarbon production or for the Groningen gas reservoir. With the ongoing energy transition, broader use of the subsurface will include geothermal energy production (Stichting Platform Geothermie et al., 2018), aquifer thermal energy storage, as well as natural gas, $\mathrm{CO}_{2}$ and perhaps $\mathrm{H}_{2}$ storage in depleted reservoirs. Many low-temperature geothermal systems and storage projects in the Netherlands and Northwest and Central Europa target porous sandstone reservoir formations (Buijze, van Bijsterveldt et al., 2019; Evans et al., 2012; Franz et al., 2018; Orlic et al., 2013; Vrijlandt et al., 2019). In the Netherlands these include (lateral equivalents of) the Slochteren sandstone in smaller depleted gas fields, as well as depleted Triassic (Bunter) reservoirs and Triassic and Jurassic/Cretaceous aquifers (Muntendam-Bos et al., 2008; Orlic \& Wassing, 2013; Veldkamp et al., 2015; Vrijlandt et al., 2019; Willems, 2017). To mitigate fault reactivation in such projects, it is important to compute poroelastic and thermoelastic stress changes on faults using the appropriate material behavior. Under conditions relevant to reservoir depletion, the present study has shown that the Modified Cam-Clay elastoplastic 
response could be approximated with linear elastic behavior, but for the different stresses expected in a geothermal doublet situation or during injection of $\mathrm{CO}_{2}$ or natural gas, this approximation may not hold. Specifically, elastoplastic behavior as described by Modified Cam-Clay models can result in strong nonlinearities in stress path, which would not be captured using a linear elastic model. In the case of geothermal doublet operation effective stresses will decrease near the injection well because of an increase in pressure and a decrease in temperature. Thermal stresses may be very large and the dilatant side of the yield cap may be reached, causing dilatant behavior and strain softening. Near the production well more compressive behavior and hardening is expected. Turning to storage applications, injection of $\mathrm{CO}_{2}$, for example, into depleted gas reservoirs will lead to stress path hysteresis; the stress path during injection (unloading) will not be the same as during reservoir depletion. The same applies to injection of $\mathrm{H}_{2}, \mathrm{~N}_{2}$ as well as gas storage where injection and depletion are cyclic (Muntendam-Bos et al., 2008; Nagelhout \& Roest, 1997; Orlic \& Wassing, 2013). After the first injection-depletion cycle most of the deformation will likely be elastic as in the experiments by Pijnenburg et al. (2019). In this thesis, modeled stress paths parameters using the MCC model tuned against experiments were both higher during loading than unloading, or vice versa lower during loading than unloading, depending on the initial mean effective stress (Chapter 3, Figure ref). Future work should focus on better experimental quantification of the relative magnitude of the loading and unloading stress path parameters for porous sandstones. Finally, around open-hole sections of wellbores in sandstone reservoirs that show a component of inelastic deformation behaviour as well as elastic, incorporation of an appropriate elastoplastic behavioral model is of major importance, since stresses may be locally very concentrated and reach well into the plastic regime, leading to dilatant failure and serious wellbore stability issues (Fokker et al,. in press; Singh et al, in preparation).

\section{3. Unresolved issues and further recommendations}

\section{3. 1. Limitations of the current work and suggestions for improvement}

A number of possibly important processes, properties and mechanisms have not been addressed or not been addressed sufficiently in this study. These include the presence of cohesion in faults, the velocity dependence of fault friction, the effect of salt creep, depletion of gas pressure in the Ten Boer Claystone, and smaller scale lithological and geometrical variations. Here, I shall consider these and make suggestions for future research.

The faults in the Groningen reservoir have been inactive since the Cretaceous (Kortekaas \& Jaarsma, 2017). During this tectonically quiet period, healing of the fault rocks may occur. Slide-hold-slide experiments on fault gouges derived from the Groningen field lithologies (Basal Zechstein, Ten Boer claystone, Slochteren sandstone, and the Carboniferous underburden) have shown that the less clay-rich gouges derived from the Slochteren and the Basal Zechstein formations are prone to healing, which causes the friction and/or the cohesion to increase (Hunfeld, 2020). Upon reactivation, this extra fault strength 


\section{Chapter 7}

may be removed within less than $1 \mathrm{~mm}$ of fault slip. On the one hand, this additional fault strength would delay fault reactivation and instability. On the other hand, it provides an additional stress drop and can result in more unstable behavior of faults in the Slochteren sandstone. Future models should incorporate this behavior, for example by including a weakening function that has two slip weakening distances; one related to the removal of cohesion, and one related to the frictional weakening at high slip rates.

In this study it is assumed that the slip-weakening friction law holds during both the slow, quasi-static nucleation and fast dynamic rupture. During the nucleation phase, aseismic slip occurs after the static strength has been exceeded, up to the point that the critical nucleation length is reached and seismic instability can nucleate (Uenishi \& Rice, 2003). Note that aseismic slip persists beyond the critical nucleation length, if the slip-weakening distance $D_{c}$ is reached (i.e. if maximum possible strength loss has occurred), before the slip zone attains the critical nucleation length (e.g. Uenishi \& Rice, 2003). In such a scenario, the slip zone expands aseismically beyond the critical nucleation length at a 'dynamic' shear stress level determined by the dynamic friction coefficient (the post slip weakening friction level). In this way, shear stress on a significant fraction of the fault may be relaxed during the nucleation phase, resulting in smaller events (see Chapter 6). However, it is not expected that the truly dynamic strengths during rupture are reached at slow slip rates, as during fast, seismic slip rates the frictional weakening mechanisms are different from those at slow slip rates, and the amount of frictional weakening is larger at high slip rates (Di Toro et al., 2011). This is one of the shortcomings of the assumption that the slip-weakening model is applicable to both the slow nucleation phase and fast dynamic rupture. As an alternative to slip weakening, evolving fault friction during slip can also be expressed in terms of its velocity and state dependence (rate-and-state friction). Enhanced velocity weakening can be prescribed to occur above a certain threshold slip rate, usually above $0.1 \mathrm{~ms}^{-1}$ (e.g. Ampuero $\&$ Ben-Zion, 2008; Rojas et al., 2009) consistent with the strong weakening observed at these velocities in experiments (e.g. Di Toro et al., 2011). Rate-and-state parameters measured for the Groningen lithologies at low sliding velocities are generally velocity-strengthening (stable sliding), except in the Basal Zechstein (Hunfeld et al., 2017). If the faults within the Slochteren sandstone are velocity-strengthening, nucleation of rupture is not expected in the reservoir. This is at odds with the observation that most seismic events occur within the reservoir depth interval (Spetzler \& Dost, 2017a; Willacy et al., 2018), which is also the depth range experiencing stress increases due to depletion as shown in Chapters 2 and 6. One explanation is that the stress drop resulting from the loss of the cohesion that may be present on the faults (see previous paragraph) could very well provide a mechanism for initiating the instability within the Slochteren sandstone faults. Further research should be done to investigate which (combination) of formulations for friction would be most relevant for the faults in a Groningen-type tectonic setting (i.e. faults that may be initially cohesive), ideally with the aid of a microphysical model to underpin the physics (e.g. Van den Ende et al., 2018). As a first step one could model the depletion-induced rupture nucleation using a 
combination of an initial, slip-dependent friction or strength drop, with a velocity-dependent friction formulation with velocity-strengthening at low velocities and strong velocity weakening at high velocities, consistent with the removal of cohesion seen in slide-hold-slide experiments (Hunfeld, 2020), low-velocity sliding experiments (Hunfeld et al., 2017), and high-velocity sliding experiments (Hunfeld, 2020) on Slochteren gouge material.

Another aspect not considered in my generic geomechanical models of the Groningen situation is the effect of creep in the Zechstein rocksalt unit on the stress distribution on faults that offset the underlying reservoir and surrounding formations. Creep of the Zechstein salt can result in a significant reduction of the fault normal stress in the underlying formations, i.e. in the Basal Zechstein, the Ten Boer and the Slochteren sandstone, as the stresses in the salt are isotropic and the salt "presses" against the formations against which it is juxtaposed and locally causes a lower horizontal state of stress. Several modeling studies have shown that the normal stress reduction can extend to more than $100 \mathrm{~m}$ below the Zechstein salt formation in a Groningen type lithostratigraphy (Haug et al., 2018; Wassing et al., 2017). This promotes fault reactivation in the Basal Zechstein, the Ten Boer, and the Slochteren sandstone.

Depletion of the Ten Boer caused an increase in the stresses and stress concentrations along the fault segments cutting the Ten Boer, as in the Slochteren sandstone (see Section 6. 5. and Figure 6-15). Reactivation within fault segments cutting the Ten Boer occurred at lower pressure changes compared to reactivation of fault segments in the Slochteren sandstone, as the static friction coefficient was significantly lower. However, fault reactivation resulted in significant aseismic slip; the fault rocks in the Ten Boer are likely clay-rich and not prone to healing or therefore to generating cohesion (Hunfeld, 2020), and hence the friction drop of the Ten Boer fault rocks was limited (0.05 - 0.1) (Hunfeld, 2020, Figure 6-5). This small friction drop resulted in a relatively large nucleation length compared to e.g. the Slochteren sandstone fault rocks (possibly larger than the thickness of the Ten Boer which is $\sim 50 \mathrm{~m}$ ), which causes more aseismic slip before the onset of instability. This aseismic slip in the Ten Boer led to stress transfer to fault segments in the underlying Slochteren formation, promoting the onset of instability in this formation. Stress transfer due to aseismic slip leading to triggering of small events has also been observed in dm-scale injection experiments (Cappa et al., 2019; De Barros et al., 2018). Aseismic slip can thus be an important stressing mechanism not only for injection-induced seismicity, but also for depletion-induced and other types of (induced) seismicity. Aseismic slip might be especially relevant in the Groningen field after field closure in 2022 as some time-dependent relaxation processes will continue such as salt creep and pressure re-equilibration. If the pressure change in the Ten Boer lags behind the pressure change in the Slochteren as observed especially in the north of the field (Burkitov et al., 2016), pressure diffusion from the Ten-Boer will continue to cause a lowering of the pressure within the Ten Boer after termination of production. Ongoing stress changes and aseismic slip can then still lead to nucleation of rupture in the Slochteren and Basal Zechstein sections. Aseismic slip may itself also occur in 


\section{Chapter 7}

a time-dependent fashion (creep). For future work, I suggest further modeling efforts addressing the effect of salt creep and aseismic fault slip, including thermally activated creep, on stress transfer and the onset and size of induced events for the typical stratigraphy of the Groningen field. To do so, it is again important to incorporate the appropriate fault friction properties as discussed in the previous paragraph. This may be of key importance in understanding how the field behaves after production has ceased.

Although the main lithological units were incorporated in the geomechanical model in Chapter 6, smaller-length-scale variations within formations were not incorporated. Within the Slochteren reservoir the porosity varies with depth, which causes the amount of compaction to vary with depth with for example porous intervals experiencing a large amount of compaction (Cannon \& Kole, 2018). Such variability will cause additional stress heterogeneity on the fault. Also, clay-rich layers may be present within the Slochteren sandstone. Smaller-length scale geometrical variations (fault roughness) were also not incorporated. Roughness is expected to lead to a more heterogeneous stress state on the fault. I suggest further modeling to investigate the minimum length scale (with respect to the critical nucleation length and process zone size) at which variations in lithology and stress may become important (Ray \& Viesca, 2017; Ray \& Viesca, 2019), using the nucleation length-scales obtained in Chapter 6 and applying stress field variability on much larger or smaller length-scales.

\section{3. 2. Further recommendations}

The large-scale experiments presented in Chapter 4 and 5 are useful for studying the nucleation and rupture process and for comparison with theory and/or modeling studies. The results in Chapter 5 showed the effect of a single velocity-weakening patch flanked by velocity strengthening patches on the macroscopic fault behavior. It would be interesting to use such experiments to further study the effect of frictional heterogeneity on the macroscopic fault properties, in particular considering the length-scale of the frictional heterogeneity with respect to the length-scale related to e.g. the critical nucleation length. A modeling study by Ray \& Viesca (2017) showed how sliding on a fault with frictional variability at length-scales much smaller becomes comparable to the behavior for a frictionally homogeneous fault. In the large-scale experiments, multiple patches with different lengths and lithologies may be included under different normal stresses to study the macroscopic fault response as a function of e.g. patch length. This is especially relevant for upscaling frictional parameters in layered sedimentary systems as in Groningen.

Models are only as good as the constitutive models incorporated and other input. Despite the Groningen field being one of the best-studied fields in the world with a vast amount of publicly available information and data (www.nlog.nl, https://www.nam.nl/feitenen-cijfers/onderzoeksrapporten.html), some of the model input parameters used here are still very uncertain. In particular the initial stress ratio $K_{0}$ is poorly constrained (van Eijs, 2015), but it has a large effect on the modeled event timing and event sizes. Additional constraints 
on $K_{0}$ from field measurementss or regional stress modeling would aid significantly in constraining which faults in the field are likely to fail and how large the event sizes can become. Also, the dynamic fault friction properties are subject to significant uncertainties (Hunfeld, 2020). The high-velocity experiments by Hunfeld (2020) used to determine these properties were the first to focus on the weakening behavior at small displacement and using simulated faults with lithologies relevant to the Groningen field. Because of the shallow nature of the depletion-induced events in Groningen, and of induced events in general, the normal stress range that can be investigated in the high-velocity experiments at least approaches the in-situ normal stress. I advocate further high-velocity experiments under similar conditions to provide more details on the weakening mechanisms. An important issue in these experiments would be the dynamic weakening behavior of a dry or gas-filled fault gouge (as may be found in the Slochteren and Ten Boer units) versus a brine-filled fault gouge (as may be found in the Slochteren below the gas-water contact and in the Carboniferous underburden). The type of pore fluid could result in different pressurization mechanisms and dynamic friction values. Related to this, it would be interesting to consider the effect of the permeability of the host rock and its effect on thermal pressurization within the fault.

Regardless of the number of experiments and measurements performed, uncertainties will always remain. For future research on induced seismicity in the Groningen field, I recommend that the most important parameters identified in this study (initial stress, static and dynamic friction, stress path) should be calibrated against the observed seismic event magnitudes or seismicity rates, and the results compared with what we know from experiments to seek consistency and hence establish confidence. This could be done by simulating depletion and stress development at all fault segments in the fault model for many different combinations of input parameters (some of which may be linked to additional field data such as the porosity), and calibrating the resulting event rates or seismic moment against observed seismicity as in e.g. Dempsey et al. (2017). In the current study, I have not considered a pressure history that is spatially varying, but history-matched pressure models are available for the Groningen field (Burkitov et al., 2016; NAM, 2016a; e.g. van Oeveren et al., 2017) and could be used in such an analysis. The computation of stress in the current model workflow takes too long (several minutes) to incorporate the model uncertainties and generate enough event catalogs for such a calibration. This step could be sped up, for example by incorporating an analytical solution for the stress developing in a producing reservoir along a fault with offset (Jansen et al., 2019; Lehner, 2019), in combination with a criterion for rupture nucleation - e.g. one could compute the theoretical critical nucleation length and check at which point when the failure stress has been attained over this length, or assume rupture occurs if one fault element fails (e.g. Dempsey \& Suckale, 2017). Sensitivity to the nucleation process could be investigated by comparing against the model realizations in this study. Subsequent rupture lengths can be computed in the same way as in Chapter 6 and by Dempsey \& Suckale (2017). Such a physics-based approach with the calibrated parameters 


\section{Chapter 7}

could also be used to forecast seismicity rates (Dempsey \& Suckale, 2017), and can be compared with the more statistical seismic source models currently available (Bourne et al., 2015; Bourne \& Oates, 2017a; Bourne \& Oates, 2017b; Bourne et al., 2018; Bourne \& Oates, 2018). This would aid in identifying which physical parameters are responsible for the seismicity rates and magnitudes observed in the Groningen field, and what the uncertainty bands of the input parameters are. Such an approach improves the predictive value of the models, which in turn can be used to assess seismic hazard in the last years of gas production from the Groningen field, and in the years after production stops as seismicity may continue for some time. The models may further be applied to other hydrocarbon fields in the Netherlands and elsewhere around the world, and also have direct relevance to other energy technologies that target similar lithologies, such as geothermal energy production, $\mathrm{CO}_{2}$ storage, energy storage, and water injection. 


\section{References}

Aben, F., Doan, M., Gratier, J., \& Renard, F. (2017). High strain rate deformation of porous sandstone and the asymmetry of earthquake damage in shallow fault zones. Earth and Planetary Science Letters, 463, 81-91.

Aki, K. (1966). Generation and propagation of $G$ waves from the Niigate earthquake of June 16, 1964. Part 2. Estimation of earthquake moment, released energy, and stressstrain drop from the G wave spectrum. Bulletin of the Earthquake Research Institute, $44,73-88$.

Almakari, M., Dublanchet, P., Chauris, H., \& Pellet, F. (2019). Effect of the injection scenario on the rate and magnitude content of injection-induced seismicity: Case of a heterogeneous fault. Journal of Geophysical Research: Solid Earth,

Ampuero, J., \& Ben-Zion, Y. (2008). Cracks, pulses and macroscopic asymmetry of dynamic rupture on a bimaterial interface with velocity-weakening friction. Geophysical Journal International, 173 (2), 674-692.

Ampuero, J., \& Rubin, A. M. (2008). Earthquake nucleation on rate and state faults ? Aging and slip laws. Journal of Geophysical Research: Solid Earth, 113 (B1), B01302.

Ampuero, J., Vilotte, J. -., \& Sánchez-Sesma, F. J. (2002). Nucleation of rupture under slip dependent friction law: Simple models of fault zone. Journal of Geophysical Research: Solid Earth, 107 (B12), ESE 2-1-ESE 2-19.

Andrews, D. (2005). Rupture dynamics with energy loss outside the slip zone. Journal of Geophysical Research: Solid Earth, 110 (B1)

Andrews, D. J. (1976). Rupture velocity of plane strain shear cracks. Journal of Geophysical Research, 81 (32), 5679-5687.

Ariyoshi, K., Hori, T., Ampuero, J., Kaneda, Y., Matsuzawa, T., Hino, R., \& Hasegawa, A. (2009). Influence of interaction between small asperities on various types of slow earthquakes in a 3-D simulation for a subduction plate boundary. Gondwana Research, 16 (3-4), 534-544.

Barbot, S. (2019). Slow-slip, slow earthquakes, period-two cycles, full and partial ruptures, and deterministic chaos in a single asperity fault. Tectonophysics, , 228171. 


\section{References}

Baud, P., Vajdova, V., \& Wong, T. (2006). Shear-enhanced compaction and strain localization: Inelastic deformation and constitutive modeling of four porous sandstones. Journal of Geophysical Research: Solid Earth, 111 (B12)

Bayart, E., Svetlizky, I., \& Fineberg, J. (2016). Fracture mechanics determine the lengths of interface ruptures that mediate frictional motion. Nature Physics, 12 (2), 166.

Beach, A., Lawson Brown, J., Welbon, A. I., McCallum, J. E., Brockbank, P., \& Knott, S. (1997). Characteristics of fault zones in sandstones from NW England: application to fault transmissibility. Geological Society, London, Special Publications, 124 (1), 315324.

Ben-David, O., Cohen, G., \& Fineberg, J. (2010). The dynamics of the onset of frictional slip. Science (New York, N.Y.), 330 (6001), 211-214.

Ben-Zion, Y., \& Rice, J. R. (1997). Dynamic simulations of slip on a smooth fault in an elastic solid. Journal of Geophysical Research: Solid Earth, 102 (B8), 17771-17784.

Bhattacharya, P., Rubin, A. M., Bayart, E., Savage, H. M., \& Marone, C. (2015). Critical evaluation of state evolution laws in rate and state friction: Fitting large velocity steps in simulated fault gouge with time-, slip-, and stress-dependent constitutive laws. Journal of Geophysical Research: Solid Earth, 120 (9), 6365-6385.

Bhattacharya, P., Rubin, A. M., \& Beeler, N. M. (2017). Does fault strengthening in laboratory rock friction experiments really depend primarily upon time and not slip? Journal of Geophysical Research: Solid Earth, 122 (8), 6389-6430.

Biot, M. A. (1941). General Theory of Three-Dimensional Consolidation. Journal of Applied Physics, 12 (2), 155-164.

Bischoff, M., Bönnemann, C., Ceranna, L., Fritz, J., Gestermann, N., Pasternak, M., \& Plenefish, T. (2015). Kurzbericht zum Erdbeben bei Emstek (Landkreis Cloppenburg) am 19.12.2014. Seismologische Auswertung, Hannover: LBEG and BGR.

Bischoff, M., Bönnemann, C., Fritz, J., Gestermann, N., \& Plenefish, T. (2013). Untersuchungsergebnisse zum Erdbeben bei Völksersen (Landkreis Verden) am 22.11.2012. $L B E G$ and BGR.

Bischoff, M., Ceranna, L., Fritz, J., Gestermann, N., \& Plenefish, T. (2014). Untersuchungsergebnisse zum Erdbeben bei Syke (Landkreis Diepholz) am 01.05.2014. Seismologische Auswertung , Hannover: LBEG and BGR. 
Bischoff, M., Ceranna, L., Fritz, J., Gestermann, N., \& Plenefish, T. (2016). Kurzbericht zum Erdbeben bei Völkersen (Landkreis Verden) am 22. April 2016, ML 3.1. Seismologische Auswertung, Hannover: LBEG and BGR.

Bischoff, M., Gestermann, N., Pasternak, M., Plenefish, T., \& Schindewolf, A. (2019). Bericht zu den Erdbeben bei Lastrup (LK Cloppenburg) im September und Oktober 2018, M < 3.6. Seismologische Auswertung, Hannover: LBEG and BGR.

Bommer, J. J., Stafford, P. J., Edwards, B., Dost, B., van Dedem, E., Rodriguez-Marek, A., Kruiver, P., van Elk, J., Doornhof, D., \& Ntinalexis, M. (2017). Framework for a ground-motion model for induced seismic hazard and risk analysis in the Groningen gas field, the Netherlands. Earthquake Spectra, 33 (2), 481-498.

Bommer, J. J., \& van Elk, J. (2017). Comment on "The maximum possible and the maximum expected earthquake magnitude for production-induced earthquakes at the gas field in Groningen, The Netherlands” by Gert Zöller and Matthias Holschneider. Bulletin of the Seismological Society of America, 107 (3), 1564-1567.

Bouchon, M., Durand, V., Marsan, D., Karabulut, H., \& Schmittbuhl, J. (2013). The long precursory phase of most large interplate earthquakes. Nature Geoscience, 6 (4), 299. Bouchon, M., Karabulut, H., Aktar, M., Ozalaybey, S., Schmittbuhl, J., \& Bouin, M. P. (2011). Extended nucleation of the $1999 \mathrm{Mw} 7.6$ Izmit earthquake. Science (New York, N.Y.), 331 (6019), 877-880.

Bourne, S. J., \& Oates, S. J. (2017a). Development of statistical geomechanical models for forecasting seismicity induced by gas production from the Groningen field. Netherlands Journal of Geosciences, 96 (5), s175-s182.

Bourne, S. J., \& Oates, S. J. (2017b). Extreme Threshold Failures Within a Heterogeneous Elastic Thin Sheet and the Spatial-Temporal Development of Induced Seismicity Within the Groningen Gas Field. Journal of Geophysical Research: Solid Earth, 122 (12), 10,299-10,320.

Bourne, S. J., \& Oates, S. J. (2018). The influence of stress rates on induced seismicity rates within the Groningen gas field. Assen: Nederlandse Aardolie Maatschappij B.V. doi: https://nam-onderzoeksrapporten.dataapp.nl/reports/download/groningen/en/e0cd632a-8e06-48bd-b65c-e3afd5110ed3. (Executed by: Shell Research. Editors: van Elk, Jan and Doornhof, Dirk)

Bourne, S. J., Oates, S. J., Bommer, J. J., Dost, B., van Elk, J., \& Doornhof, D. (2015). A Monte Carlo Method for Probabilistic Hazard Assessment of Induced Seismicity due 


\section{References}

to Conventional Natural Gas Production. Bulletin of the Seismological Society of America, 105 (3), 1721-1738.

Bourne, S. J., Oates, S. J., \& van Elk, J. (2018). The exponential rise of induced seismicity with increasing stress levels in the Groningen gas field and its implications for controlling seismic risk. Geophysical Journal International, 213 (3), 1693-1700.

Bourne, S. J., Oates, S. J., van Elk, J., \& Doornhof, D. (2014). A seismological model for earthquakes induced by fluid extraction from a subsurface reservoir. Journal of Geophysical Research: Solid Earth, 119 (12), 8991-9015.

Breckels, I., \& Van Eekelen, H. (1982). Relationship between horizontal stress and depth in sedimentary basins. Journal of Petroleum Technology, 34 (09), 2,191-2,199.

Buijze, L., van Bijsterveldt, L., Cremer, H., Paap, B., Veldkamp, H., Wassing, B. B., van Wees, J., van Yperen, G. C., \& ter Heege, J. H. (2019). Review of induced seismicity in geothermal systems worldwide and implications for geothermal systems in the Netherlands. Netherlands Journal of Geosciences, 98

Buijze, L., van den Bogert, P., Wassing, B. B. T., \& Orlic, B. (2019). Nucleation and Arrest of Dynamic Rupture induced by Reservoir Depletion. Journal of Geophysical Research: Solid Earth,

Buijze, L., van den Bogert, P. A. J., Wassing, B. B. T., Orlic, B., \& ten Veen, J. (2017). Fault reactivation mechanisms and dynamic rupture modelling of depletion-induced seismic events in a Rotliegend gas reservoir. Netherlands Journal of Geosciences, 96 (5), s131-s148.

Burkitov, U., van Oeveren, H., Valvatne, P., van Elk, J., \& Doornhof, D. (2016). Groningen Field Review 2015 Subsurface Dynamic Modelling Report. Report No. EP201603238100, Assen: NAM.

Campillo, M., \& Ionescu, I. R. (1997). Initiation of antiplane shear instability under slip dependent friction. Journal of Geophysical Research: Solid Earth, 102 (B9), 2036320371

Candela, T., Osinga, S., Ampuero, J., Wassing, B., Pluymaekers, M., Fokker, P. A., van Wees, J., de Waal, H. A., \& Muntendam-Bos, A. G. (2019). Depletion-induced seismicity at the Groningen gas field: Coulomb rate-and-state models including differential compaction effect. Journal of Geophysical Research: Solid Earth, 124 (7), 7081-7104. 
Candela, T., \& Fokker, P. A. (2017). Thermo- Poro- Elastic Stressing and Time-Dependent Earthquakes Nucleation: A Semi-Analytical Injection Model 51st U.S.Rock Mechanics/Geomechanics Symposium. San Francisco, California, USA: American Rock Mechanics Association.

Cannon, M., \& Kole, P. (2018). The First Year of Distributed Strain Sensing (DSS). Monitoring in the Groningen Gas Field. Report No. SR.17.00934, Assen: NAM.

Cappa, F., \& Rutqvist, J. (2011). Modeling of coupled deformation and permeability evolution during fault reactivation induced by deep underground injection of $\mathrm{CO} 2$. International Journal of Greenhouse Gas Control, 5, 336.

Cappa, F., \& Rutqvist, J. (2012). Seismic rupture and ground accelerations induced by CO2 injection in the shallow crust. Geophysical Journal International, 190 (3), 1784-1789.

Cappa, F., Scuderi, M. M., Collettini, C., Guglielmi, Y., \& Avouac, J. (2019). Stabilization of fault slip by fluid injection in the laboratory and in situ. Science Advances, 5 (3), eaau4065.

Chen, T., \& Lapusta, N. (2019). On behaviour and scaling of small repeating earthquakes in rate and state fault models. Geophysical Journal International, 218 (3), 2001-2018.

Chen, T., \& Lapusta, N. (2009). Scaling of small repeating earthquakes explained by interaction of seismic and aseismic slip in a rate and state fault model. Journal of Geophysical Research, 114 (B01311)

Childs, C., Manzocchi, T., Walsh, J. J., Bonson, C. G., Nicol, A., \& a, M. P. J. S. (2009). A geometric model of fault zone and fault rock thickness. Journal of Structural Geology, 31, 117.

Collettini, C., Niemeijer, A., Viti, C., Smith, S. A., \& Marone, C. (2011). Fault structure, frictional properties and mixed-mode fault slip behavior. Earth and Planetary Science Letters, 311 (3-4), 316-327.

Cornet, F. H., \& Röckel, T. (2012). Vertical stress profiles and the significance of "stress decoupling". Tectonophysics, 581, 193-205.

Dahm, T., Krüger, F., Stammler, K., Klinge, K., Kind, R., Wylegalla, K., \& Grasso, J. (2007). The 2004 Mw 4.4 Rotenburg, Northern Germany, Earthquake and Its Possible Relationship with Gas Recovery. Bulletin of the Seismological Society of America, 97 (3), 691-704. 


\section{References}

Das, I., \& Zoback, M. (2013). Long-period, long-duration seismic events during hydraulic stimulation of shale and tight-gas reservoirs - Part 1: Waveform characteristics. Geophysics, 78 (6), KS97-KS108.

Day, S. M. (1982). Three-dimensional simulation of spontaneous rupture: the effect of nonuniform prestress. Bulletin of the Seismological Society of America, 72 (6A), 1881-1902.

Day, S. M., Dalguer, L. A., Lapusta, N., \& Liu, Y. (2005). Comparison of finite difference and boundary integral solutions to three-dimensional spontaneous rupture. Journal of Geophysical Research: Solid Earth, 110 (B12), B12307.

De Barros, L., Guglielmi, Y., Rivet, D., Cappa, F., \& Duboeuf, L. (2018). Seismicity and fault aseismic deformation caused by fluid injection in decametric in-situ experiments. Comptes Rendus Geoscience, 350 (8), 464-475.

de Jager, J., \& Visser, C. (2017). Geology of the Groningen field - an overview.

Netherlands Journal of Geosciences, 96 (5), s3-s15.

de Meer, S., \& Spiers, C. J. (1997). Uniaxial compaction creep of wet gypsum aggregates. Journal of Geophysical Research: Solid Earth, 102 (B1), 875-891.

De Waal, J., Roest, J., Fokker, P., Kroon, I., Breunese, J., Muntendam-Bos, A., Oost, A., \& Van Wirdum, G. (2012). The effective subsidence capacity concept: How to assure that subsidence in the Wadden Sea remains within defined limits? Netherlands Journal of Geosciences, 91 (3), 385-399.

Dempsey, D., \& Suckale, J. (2016). Collective properties of injection-induced earthquake sequences: 1. Model description and directivity bias. Journal of Geophysical Research: Solid Earth, 121 (5), 3609-3637.

Dempsey, D., \& Suckale, J. (2017). Physics-based forecasting of induced seismicity at Groningen gas field, the Netherlands. Geophysical Research Letters, 44 (15), 77737782.

Di Toro, G., Han, R., Hirose, T., De Paola, N., Nielsen, S., Mizoguchi, K., Ferri, F., Cocco, M., \& Shimamoto, T. (2011). Fault lubrication during earthquakes. Nature, 471 (7339), 494-498.

DIANA 10.1 User Manual. (2016).

DIANA 10.3 User Manual. (2019). https://dianafea.com/manuals/d103/Diana.html

Dieterich, J. H. (1979). Modeling of rock friction. 1. Experimental results and constitutive equations. Journal of Geophysical Research, 84, 2161. 
Dieterich, J. H. (1992). Earthquake nucleation on faults with rate-and state-dependent strength. Tectonophysics, 211 (1-4), 115-134.

Dodge, D. A., Beroza, G. C., \& Ellsworth, W. (1995). Foreshock sequence of the 1992 Landers, California, earthquake and its implications for earthquake nucleation. Journal of Geophysical Research: Solid Earth, 100 (B6), 9865-9880.

Dodge, D. A., Beroza, G. C., \& Ellsworth, W. (1996). Detailed observations of California foreshock sequences: Implications for the earthquake initiation process. Journal of Geophysical Research: Solid Earth, 101 (B10), 22371-22392.

Doser, D. I., Baker, M. R., Luo, M., Marroquin, P., Ballesteros, L., Kingwell, J., Diaz, H. L., \& Kaip, G. (1992). The not so simple relationship between seismicity and oil production in the Permian Basin, west Texas. Pure and Applied Geophysics, 139 (34), 481-506.

Doser, D. I., Baker, M. R., \& Mason, D. B. (1991). Seismicity in the War-Wink gas field, Delaware Basin, west Texas, and its relationship to petroleum production. Bulletin of the Seismological Society of America, 81 (3), 971-986.

Dost, B., Goutbeek, F. H., Van Eck, T., \& Kraaijpoel, D. (2012). Monitoring induced seismicity in the North of the Netherlands: status report 2010. Scientific Report , Report No. WR 2012-03, De Bilt: Royal Netherlands Meteorological Institute.

Dost, B., \& Kraaijpoel, D. (2013). The August 16, 2012 earthquake near Huizinge (Groningen). De Bilt: KNMI.

Dost, B., Ruigrok, E., \& Spetzler, J. (2017). Development of seismicity and probabilistic hazard assessment for the Groningen gas field. Netherlands Journal of Geosciences, 96 (5), s235-s245.

Duan, B., \& Oglesby, D. D. (2006). Heterogeneous fault stresses from previous earthquakes and the effect on dynamics of parallel strike-slip faults. Journal of Geophysical Research: Solid Earth, 111 (B5), - B05309.

Dunham, E. M. (2007). Conditions governing the occurrence of supershear ruptures under slip-weakening friction. Journal of Geophysical Research: Solid Earth, 112

Dunham, E. M., Belanger, D., Cong, L., \& Kozdon, J. E. (2011). Earthquake Ruptures with Strongly Rate-Weakening Friction and Off-Fault Plasticity, Part 1: Planar Faults. Bulletin of the Seismological Society of America, 101 (5), 2296-2307.

Ellsworth, W. L., \& Beroza, G. C. (1995). Seismic Evidence for an Earthquake Nucleation Phase. Science, 268 (5212), 851-855. 


\section{References}

Evans, K. F., Zappone, A., Kraft, T., Deichmann, N., \& Moia, F. (2012). A survey of the induced seismic responses to fluid injection in geothermal and $\mathrm{CO} 2$ reservoirs in Europe. Geothermics, 41 (0), 30-54.

Fagereng, Å, \& Sibson, R. H. (2010). Melange rheology and seismic style. Geology, 38 (8), 751-754.

Faulkner, D., Lewis, A., \& Rutter, E. (2003). On the internal structure and mechanics of large strike-slip fault zones: field observations of the Carboneras fault in southeastern Spain. Tectonophysics, 367 (3-4), 235-251.

Filippidou, A., Hol, S., van der Linden, A., Marcelis, F., van Coom, A., Homburg, J., . . Verberne, B. A. (2019). Groningen geomechanical laboratory testing of the Zeerijp3A compaction study - An overview of the experimental compaction measurements. Assen: Nederlandse Aardolie Maatschappij B.V. . (Executing organizations: ExxonMobil Upstream Research Company, Shell Global Solutions International B.V., Utrecht University. Editors: van Elk, Jan, and Doornhof, Dirk)

Firme, P. A., Quispe, R. Q., Roehl, D., Oliveira, M. F., Parotidis, M., \& Glassborow, B.A Comparative Study of Constitutive Models for Reservoir Compaction and Surface Subsidence. ISRM Conference on Rock Mechanics for Natural Resources and Infrastructure-SBMR 2014

Fisher, Q., \& Knipe, R. (1998). Fault sealing processes in siliciclastic sediments. Geological Society, London, Special Publications, 147 (1), 117-134.

Fjaer, E., Holt, R. M., Horsrud, P., Raaen, A. M., \& Risnes, R. (2008). Petroleum related rock mechanics (2nd Edition ed.) Elsevier.

Franz, M., Barth, G., Zimmermann, J., Budach, I., Nowak, K., \& Wolfgramm, M. (2018). Geothermal resources of the North German Basin: exploration strategy, development examples and remaining opportunities in Mesozoic hydrothermal reservoirs. Geological Society, London, Special Publications, 469

Fredman, N., Tveranger, J., Semshaug, S., Braathen, A., \& Sverdrup, E. (2007). Sensitivity of fluid flow to fault core architecture and petrophysical properties of fault rocks in siliciclastic reservoirs: a synthetic fault model study. Petroleum Geoscience, 13 (4), 305-320.

Fukuyama, E., Xu, S., Yamashita, F., \& Mizoguchi, K. (2016). Cohesive zone length of metagabbro at supershear rupture velocity. Journal of Seismology, 20 (4), 1207-1215. 
Fukuyama, E., \& Madariaga, R. (1998). Rupture dynamics of a planar fault in a 3D elastic medium: Rate- and slip-weakening friction. Bulletin of the Seismological Society of America, 88 (1), 1-17.

Galis, M., Ampuero, J. P., Mai, P. M., \& Cappa, F. (2017). Induced seismicity provides insight into why earthquake ruptures stop. Science Advances, 3 (12)

Galis, M., Pelties, C., Kristek, J., Moczo, P., Ampuero, J., \& Mai, P. M. (2015). On the initiation of sustained slip-weakening ruptures by localized stresses. Geophysical Journal International, 200 (2), 888-907.

Gaucher, E., Schoenball, M., Heidbach, O., Zang, A., Fokker, P. A., Van Wees, J. D., \& Kohl, T. (2015). Induced seismicity in geothermal reservoirs: A review of forecasting approaches. Renewable and Sustainable Energy Reviews, 52, 1473-1490.

Geertsma, J.Problems of Rock Mechanics In Petroleum Production Engineering. 1st ISRM Congress. International Society for Rock Mechanics, 1966.

Geertsma, J. (1973). Land subsidence above compacting oil and gas reservoirs. Journal of Petroleum Technology, (June), 734.

Goebel, T. H. W., Weingarten, M., Chen, X., Haffener, J., \& Brodsky, E. E. (2017). The 2016 Mw5.1 Fairview, Oklahoma earthquakes: Evidence for long-range poroelastic triggering at $>40 \mathrm{~km}$ from fluid disposal wells. Earth and Planetary Science Letters, 472, 50-61.

Guérin-Marthe, S., Nielsen, S., Bird, R., Giani, S., \& Di Toro, G. (2019). Earthquake Nucleation Size: Evidence of Loading Rate Dependence in Laboratory Faults. Journal of Geophysical Research: Solid Earth, 124 (1), 689-708.

Haak, H. W., Dost, B., \& Goutbeek, F. H. (2001). Seismische analyse van de aardbevingen bij Alkmaar op 9 en 10 september en Bergen aan Zee op 10 oktober 2001. Technical Report, Report No. TR-239, De Bilt: KNMI.

Hanks, T. C., \& Kanamori, H. (1979). A Moment Magnitude Scale. Journal of Geophysical Research, 84 (85), 2348-2350.

Harris, R. A., \& Day, S. M. (1997). Effects of a low-velocity zone on a dynamic rupture. Bulletin of the Seismological Society of America, 87 (5), 1267-1280.

Haug, C., Nüchter, J. -., \& Henk, A. (2018). Assessment of geological factors potentially affecting production-induced seismicity in North German gas fields. Geomechanics for Energy and the Environment, 16, 15-31. 


\section{References}

Hettema, M. H. H., Papamichos, E., \& Schutjens, P. M. T. M. (2002). Subsidence delay: field observations and analysis. Oil \& Gas Science and Technology, 57 (5), 443-458.

Hettema, M. H. H., Schutjens, P. M. T. M., Verboom, B. J. M., \& Gussinklo, H. J. (2000). Production-induced compaction of a sandstone reservoir: The strong influence of stress path. SPE Reservoir Evaluation and Engineering, August

Hol, S., Mossop, A., van der Linden, A., Zuiderwijk, P. M. M., \& Makurat, A. (2015). Long-term compaction behavior of Permian sandstones - An investigation into the mechanisms of subsidence in the Dutch Wadden Sea. 49th US Rock Mechanics / Geomechanics Symposium, ARMA 15-6184, 1-8.

Hol, S., van der Linden, A., Bierman, S., Marcelis, F., \& Makurat, A. (2018). Rock physical controls on production-induced compaction in the Groningen Field. Scientific Reports, 8 (1), 7156.

Holt, R.Reservoir stress path: Evaluation of core and field data. Vail Rocks 1999, The 37th US Symposium on Rock Mechanics (USRMS)

Holt, R., Gheibi, S., \& Lavrov, A.Where does the stress path lead? Irreversibility and hysteresis in reservoir geomechanics. 50th US Rock Mechanics/Geomechanics Symposium

Hough, S. E., \& Page, M. (2016). Potentially Induced Earthquakes during the Early Twentieth Century in the Los Angeles Basin. Bulletin of the Seismological Society of America, 106 (6), 2419-2435.

Hunfeld, L. B. (2020). Frictional properties of simulated fault gouges from the Groningen gas field and implications for induced seismicity. (PhD Dissertation, Utrecht University).

Hunfeld, L. B., Chen, J., Niemeijer, A. R., \& Spiers, C. J. (2019). Temperature and gas/brine content affect seismogenic potential of simulated fault gouges derived from Groningen gas field caprock. Geochemistry, Geophysics, Geosystems, 20 (6), 28272847.

Hunfeld, L. B., Niemeijer, A. R., \& Spiers, C. J. (2017). Frictional Properties of Simulated Fault Gouges from the Seismogenic Groningen Gas Field Under In Situ P-T Chemical Conditions. Journal of Geophysical Research: Solid Earth, 122 (11), 89698989.

Ida, Y. (1972). Cohesive force across the tip of a longitudinal-shear crack and Griffith's specific surface energy. Journal of Geophysical Research, 77 (20), 3796-3805. 
Ide, S., Beroza, G. C., Shelly, D. R., \& Uchide, T. (2007). A scaling law for slow earthquakes. Nature, 447 (7140), 76-79.

Ikari, M. J., Carpenter, B. M., \& Marone, C. (2016). A microphysical interpretation of rateand state-dependent friction for fault gouge. Geochemistry, Geophysics, Geosystems, 17 (5), 1660-1677.

Ikari, M. J., Niemeijer, A. R., \& Marone, C. (2011). The role of fault zone fabric and lithification state on frictional strength, constitutive behavior, and deformation microstructure. Journal of Geophysical Research: Solid Earth, 116 (B8), - B08404.

Ito, Y., Obara, K., Shiomi, K., Sekine, S., \& Hirose, H. (2007). Slow earthquakes coincident with episodic tremors and slow slip events. Science, 315 (5811), 503-506.

Jansen, J., Singhal, P., \& Vossepoel, F. (2019). Insights from closed-form expressions for injection-and production-induced stresses in displaced faults. Journal of Geophysical Research: Solid Earth, 124 (7), 7193-7212.

Jin, L., \& Zoback, M. D. (2018). Fully Dynamic Spontaneous Rupture Due to Quasi-Static Pore Pressure and Poroelastic Effects: An Implicit Nonlinear Computational Model of Fluid-Induced Seismic Events. Journal of Geophysical Research: Solid Earth, 123 (11), 9430-9468.

Kammer, D. S., \& McLaskey, G. C. (2019). Fracture energy estimates from large-scale laboratory earthquakes. Earth and Planetary Science Letters, 511, 36-43.

Kammer, D. S., Radiguet, M., Ampuero, J., \& Molinari, J. (2015). Linear elastic fracture mechanics predicts the propagation distance of frictional slip. Tribology Letters, 57 (3), 23.

Kaneko, Y., Nielsen, S. B., \& Carpenter, B. M. (2016). The onset of laboratory earthquakes explained by nucleating rupture on a rate-and-state fault. Journal of Geophysical Research: Solid Earth, 121 (8), 6071-6091.

Kaneko, Y., Lapusta, N., \& Ampuero, J. (2008). Spectral element modeling of spontaneous earthquake rupture on rate and state faults: Effect of velocity-strengthening friction at shallow depths. Journal of Geophysical Research: Solid Earth, 113 (B9), - B09317.

Kato, N., Yamamoto, K., Yamamoto, H., \& Hirasawa, T. (1992). Strain-rate effect on frictional strength and the slip nucleation process. Tectonophysics, 211 (1-4), 269282.

Ke, C., McLaskey, G. C., \& Kammer, D. S. (2018). Rupture Termination in LaboratoryGenerated Earthquakes. Geophysical Research Letters, 45 (23), 12,784-12,792. 


\section{References}

Keranen, K. M., Weingarten, M., Abers, G. A., Bekins, B. A., \& Ge, S. (2014). Sharp increase in central Oklahoma seismicity since 2008 induced by massive wastewater injection. Science, 320 (6195), 448-451.

Kim, K., Ree, J., Kim, Y., Kim, S., Kang, S. Y., \& Seo, W. (2018). Assessing whether the $2017 M_{\mathrm{w}} 5.4$ Pohang earthquake in South Korea was an induced event. Science (New York, N.Y.), 360 (6392), 1007.

Kole, P. (2015). In-situ compaction measurements using gamma ray markers. Assen: Nederlandse Aardolie Maatschappij B.V. . (Editors: van Elk, Jan, and Doornhof, Dirk)

Kortekaas, M., \& Jaarsma, B. (2017). Improved definition of faults in the Groningen field using seismic attributes. Netherlands Journal of Geosciences, 96 (5), s71-s85.

Kostrov, V. (1974). Seismic moment and energy of earthquakes, and seismic flow of rock. Physics of the Solid Earth, 1, 13-21.

Kraaijpoel, D., \& Dost, B. (2013). Implications of salt-related propagation and mode conversion effects on the analysis of induced seismicity. Journal of Seismology, 17 (1), 95-107.

Kumar, A., Zorn, E., Hammack, R., \& Harbert, W. (2019). Long-period, long-duration seismic events and their probable role in reservoir stimulation and stage productivity. SPE Reservoir Evaluation \& Engineering, 22 (02), 441-457.

Langer, S., Weatherley, D., Olsen-Kettle, L., \& Finzi, Y. (2013). Stress heterogeneities in earthquake rupture experiments with material contrasts. Journal of the Mechanics and Physics of Solids, 61 (3), 742-761.

Lapusta, N., Rice, J. R., Ben-Zion, Y., \& Zheng, G. (2000). Elastodynamic analysis for slow tectonic loading with spontaneous rupture episodes on faults with rate- and statedependent friction. Journal of Geophysical Research: Solid Earth, 105 (B10), 2376523789.

Latour, S., Schubnel, A., Nielsen, S., Madariaga, R., \& Vinciguerra, S. (2013). Characterization of nucleation during laboratory earthquakes. Geophysical Research Letters, 40 (19), 5064-5069.

Leeman, J., Saffer, D., Scuderi, M., \& Marone, C. (2016). Laboratory observations of slow earthquakes and the spectrum of tectonic fault slip modes. Nature Communications, 7 , 11104. 
Lehner, F. (2019). An analysis of depletion-induced fault stressing: New closed-form analytical solutions. Assen: Nederlandse Aardolie Maatschappij B.V. . (Executing organization: Shell Global Solutions International B.V. Editors: van Elk, Jan, and Doornhof, Dirk)

Lele, S. P., Garzon, J. L., Hsu, S., DeDontney, N., Searles, K. H., \& Sanz, P. F. (2015). Groningen 2015 geomechanical analysis. Exxon Mobiel Upstream Research Company, Spring TX, USA, Final Report, Assen: NAM.

Lele, S. P., Hsu, S., Garzon, J. L., DeDontney, N., Searles, K. H., Gist, G. A., . . Dale, B. A. (2016). Geomechanical Modeling to Evaluate Production-Induced Seismicity at Groningen Field Society of Petroleum Engineers.

Ligtenberg, H., Okkerman, J. A., \& de Keijzer, M. (2011). Fractures in the dutch rotliegend - an overview. In J. Grötsch, \& R. Gaupp (Eds.), The Permian Rotliegend of the Netherlands (SEPM Special PUblication 98 ed., pp. 229-244. Tulsa, Oklahoma: SEPM.

Linde, A. T., Gladwin, M. T., Johnston, M. J., Gwyther, R. L., \& Bilham, R. G. (1996). A slow earthquake sequence on the San Andreas fault. Nature, 383 (6595), 65.

Liu, F., \& Borja, R. I. (2013). Extended finite element framework for fault rupture dynamics including bulk plasticity. International Journal for Numerical and Analytical Methods in Geomechanics, 37 (18), 3087-3111.

Lowry, A. R. (2006). Resonant slow fault slip in subduction zones forced by climatic load stress. Nature, 442 (7104), 802.

Lu, X., Lapusta, N., \& Rosakis, A. J. (2007). Pulse-like and crack-like ruptures in experiments mimicking crustal earthquakes. Proceedings of the National Academy of Sciences, 104 (48), 18931-18936.

Luo, Y., \& Ampuero, J. (2018). Stability of faults with heterogeneous friction properties and effective normal stress. Tectonophysics, 733, 257-272.

Ma, S., Ma, J., \& Liu, L. (2002). Experimental evidence for seismic nucleation phase. Chinese Science Bulletin, 47 (9), 769-773.

Ma, S., \& He, C. (2001). Period doubling as a result of slip complexities in sliding surfaces with strength heterogeneity. Tectonophysics, 337 (1-2), 135-145.

Mair, K., \& Marone, C. (1999). Friction of simulated fault gouge for a wide range of velocities and normal stresses. Journal of Geophysical Research: Solid Earth, 104 (B12), 28899-28914. 


\section{References}

Marketos, G., Govers, R., \& Spiers, C. J. (2015). Ground motions induced by a producing hydrocarbon reservoir that is overlain by a viscoelastic rocksalt layer: a numerical model. Geophysical Journal International, 203 (1), 228-242.

Marone, C. (1998). Laboratory-derived friction laws and their application to seismic faulting. Annual Review of Earth and Planetary Sciences, 26, 643.

McGarr, A. (2014). Maximum magnitude earthquakes induced by fluid injection. Journal of Geophysical Research: Solid Earth, 119 (2), 1008-1019.

Mclaskey, G. C., \& Yamashita, F. (2017). Slow and fast ruptures on a laboratory fault controlled by loading characteristics. Journal of Geophysical Research: Solid Earth, $122(5), 3719-3738$.

McLaskey, G. C., \& Kilgore, B. D. (2013). Foreshocks during the nucleation of stick-slip instability. Journal of Geophysical Research: Solid Earth, 118 (6), 2982-2997.

Ministry of Economic Affairs. (2016). Definitief instemmingsbesluit gaswinning Groningen. .

(https://www.rijksoverheid.nl/binaries/rijksoverheid/documenten/kamerstukken/2016/ 09/23/kamerbrief-over-definitief-instemmingsbesluit-gaswinning-

groningen/kamerbrief-over-definitief-instemmingsbesluit-gaswinning-groningen.pdf)

Ministry of Economic Affairs. (2017). Wijziging Instemmingsbesluit Winningsplan Groningenveld.

Ministry of Economic Affairs and Climate Policy. (2018). Kamerbrief Gaswinning Groningen. .

(https://www.rijksoverheid.nl/binaries/rijksoverheid/documenten/kamerstukken/2018/ 03/29/kamerbrief-over-gaswinning-groningen/kamerbrief-over-gaswinninggroningen.pdf)

Ministry of Economic Affairs and Climate Policy. (2019). Gaswinningsniveau Groningen in 2019-2020. .

(https://www.rijksoverheid.nl/binaries/rijksoverheid/documenten/kamerstukken/2019/ 09/10/kamerbrief---gaswinningsniveau-groningen-in-2019-2020/Kamerbrief+-

+Gaswinningsniveau+Groningen+in+2019-2020.pdf)

Mossop, A. (2012). An Explanation for Anomalous Time Dependent Subsidence. 46th US Rock Mechanics / Geomechanics Symposium, ARMA 12-518, 1-8. 
Muhuri, S. K., Dewers, T. A., Scott, T. E., \& Reches, Z. (2003). Interseismic fault strengthening and earthquake-slip instability: Friction or cohesion? Geology, 31 (10), 881-884.

Mulders, F. M. M. (2003). Modelling of stress development and fault slip in and around a producing gas reservoir. (Doctoral Thesis, Technical University of Delft).

Munda, J., Pradhan, P., \& Nayak, A. (2014). Review on the performance of Modified Cam Clay Model for fine grained soil. Journal of Civil Engineering and Environmental Technology, 1 (5), 65-71.

Muntendam-Bos, A. G., \& De Waal, J. A. (2013). Reassessment of the probability of higher magnitudes in the Groningen gas field. Confidential Final Report, d.d. 16-012013 , State Supervision of Mines.

Muntendam-Bos, A. G., Wassing, B. B. T., Geel, C. R., Louh, M., \& Van Thienen-Visser, K. (2008). Bergermeer seismicity study. Report No. 2008-U-R1071/B, Utrecht: TNO.

Nadeau, R. M., \& Dolenc, D. (2005). Nonvolcanic tremors deep beneath the San Andreas Fault. Science, 307 (5708), 389-389.

Nagelhout, A. C. G., \& Roest, J. P. A. (1997). Investigating fault slip in a model of an underground gas storage facility. International Journal of Rock Mechanics and Mining Sciences, 34 (3-4, Paper Nr. 212)

NAM. (2013). Technical addendum to the Winningsplan Groningen 2013: Subsidence, induced earthquakes and seismic hazard analysis in the Groningen field. NAM.

NAM. (2014). Voortgangsrapport Diepe Geofoons. Voortgangsrapport, Assen: Nederlandse Aardolie Maatschappij B.V.

NAM. (2015). Voortgangsrapport Diepe Geofoons. Voortgangsrapport, Assen: Nederlandse Aardolie Maatschappij B.V.

NAM. (2016a). Groningen Pressure Maintenance (GPM) Study - Progress Report February 2016. Assen: NAM B.V.

NAM. (2016b). Technical Addendum to the Winningsplan Groningen 2016: Production, Subsidence, Induced earthquakes and Seismic Hazard and Risk Assessment in the Groningen Field. Technical Report, Report No. EP201603238413, Assen: Nederlandse Aardolie Maatschappij B.V.

NAM. (2016c). Winningsplan Groningen Gasveld 2016. EP201604259068, Assen: Nederlandse Aardolie Maatschappij B.V. . (https://www.nam.nl/algemeen/mediatheek-en-downloads/winningsplan-2016.html) 


\section{References}

NAM. (2019a). Seismic Hazard and Risk Assessment Groningen Field update for Production Profile GTS - raming 2019 (bijlage bij 33529,nr.591). . (https://www.rvo.nl/sites/default/files/2019/05/Seismic\%20Hazard\%20and\%20Risk\% 20Assessment $\% 20$ Groningen $\% 20$ Field $\% 20$ update $\% 20$ for $\% 20$ Production $\% 20$ Profile \%20GTS\%20-\%20raming\%202019\%20March\%202019 anm.pdf)

NAM. (2019b). Seismic monitoring Groningen field deep downhole arrays. Synthesis report 2013 - 2018. Assen: Nederlandse Aardolie Maatschappij B.V.

Nepveu, M., van Thienen-Visser, K., \& Sijacic, D. (2016). Statistics of seismic events at the Groningen field. Bulletin of Earthquake Engineering, 14 (12), 3343-3362.

Niemeijer, A. R., \& Vissers, R. L. (2014). Earthquake rupture propagation inferred from the spatial distribution of fault rock frictional properties. Earth and Planetary Science Letters, 396, 154-164.

Niemeijer, A., Toro, G. D., Griffith, W. A., Bistacchi, A., Smith, S. A. F., \& Nielsen, S. (2012). Inferring earthquake physics and chemistry using an integrated field and laboratory approach. Journal of Structural Geology,

Norbeck, J. H., \& Horne, R. N. (2018). Maximum magnitude of injection-induced earthquakes: A criterion to assess the influence of pressure migration along faults. Tectonophysics, 733, 108-118.

Obara, K. (2002). Nonvolcanic deep tremor associated with subduction in southwest Japan. Science, 296 (5573), 1679-1681.

Obara, K., Hirose, H., Yamamizu, F., \& Kasahara, K. (2004). Episodic slow slip events accompanied by non-volcanic tremors in southwest Japan subduction zone. Geophysical Research Letters, 31 (23)

Ohnaka, M., \& Kuwahara, Y. (1990). Characteristic features of local breakdown near a crack-tip in the transition zone from nucleation to unstable rupture during stick-slip shear failure. Tectonophysics, 175 (1-3), 197-220.

Ohnaka, M., Kuwahara, Y., Yamamoto, K., \& Hirasawa, T. (1986). Dynamic Breakdown Processes and the Generating Mechanism for High-Frequency Elastic Radiation During Stick-Slip Instabilities. Earthquake Source Mechanics, 37, 13-24.

Ohnaka, M., \& Shen, L. (1999). Scaling of the shear rupture process from nucleation to dynamic propagation: Implications of geometric irregularity of the rupturing surfaces. Journal of Geophysical Research: Solid Earth, 104 (B1), 817-844. 
Okubo, P. G. (1989). Dynamic rupture modeling with laboratory-derived constitutive relations. Journal of Geophysical Research: Solid Earth, 94 (B9), 12321-12335.

Okubo, P. G., \& Dieterich, J. H. (1981). Fracture energy of stick-slip events in a large scale biaxial experiment. Geophysical Research Letters, 8 (8), 887-890.

Orlic, B., \& Wassing, B. B. T. (2012). Modeling stress development and fault slip in producing hydrocarbon reservoirs overlain by rock salt caprocks. 46th US Rock Mechanics / Geomechanics Symposium;, Chicago 2012.

Orlic, B., \& Wassing, B. B. T. (2013). A Study of Stress Change and Fault Slip in Producing Gas Reservoirs Overlain by Elastic and Viscoelastic Caprocks. Rock Mechanics and Rock Engineering, 46 (3), 421-435.

Orlic, B., Wassing, B. B. T., \& Geel, C. R. (2013). Field Scale Geomechanical Modeling for Prediction of Fault Stability During Underground Gas Storage Operations in a Depleted Gas Field in the Netherlands American Rock Mechanics Association.

Palmer, A. C., \& Rice, J. R. (1973). The Growth of Slip Surfaces in the Progressive Failure of Over-Consolidated Clay. Proceedings of the Royal Society of London A:

Mathematical, Physical and Engineering Sciences, 332 (1591), 527-548.

Pampillón, P., Santillán, D., Mosquera, J. C., \& Cueto-Felgueroso, L. (2018). Dynamic and quasi-dynamic modeling of injection-induced earthquakes in poroelastic media.

Journal of Geophysical Research: Solid Earth, 123 (7), 5730-5759.

Peng, Z., \& Gomberg, J. (2010). An integrated perspective of the continuum between earthquakes and slow-slip phenomena. Nature Geoscience, 3 (9), 599.

Pennington, W. D., Davis, S. D., Carlson, S. M., DuPree, J., \& Ewing, T. E. (1986). The evolution of seismic barriers and asperities caused by the depressuring of fault planes in oil and gas fields of South Texas. Bulletin of the Seismological Society of America, 76 (4), 939-948.

Pijnenburg, R. P. J. (2019). Deformation behavior of reservoir sandstones from the seismogenic Groningen gas field; an experimental and mechanistic study. (Doctoral dissertation, Utrecht University, Utrecht, The Netherlands).

Pijnenburg, R. P. J., Hangx, S. J. T., \& Spiers, C. J. (2019). Inelastic deformation of the Slochteren sandstone: Stress-strain relations and implications for induced seismicity in the Groningen gas field. Journal of Geophysical Research: Solid Earth, 124 (5), 5254-5282. 


\section{References}

Pijnenburg, R. P. J., Verberne, B. A., Hangx, S. J. T., \& Spiers, C. J. (2018). Deformation Behavior of Sandstones From the Seismogenic Groningen Gas Field: Role of Inelastic Versus Elastic Mechanisms. Journal of Geophysical Research: Solid Earth, 123 (7), $5532-5558$.

Pruiksma, J. P., Breunese, J. N., van Thienen-Visser, K., \& de Waal, J. A. (2015). Isotach formulation of the rate type compaction model for sandstone. International Journal of Rock Mechanics and Mining Sciences, 78, 127-132.

Rafieepour, S., Miska, S. Z., Ozbayoglu, E., Yu, M., Takach, N. E., Zhang, J., \& Majidi, R.Experimental study of reservoir stress path and hysteresis during depletion and injection under different deformational conditions. 51st US rock mechanics/geomechanics symposium

Rathbun, A. P., \& Marone, C. (2013). Symmetry and the critical slip distance in rate and state friction laws. Journal of Geophysical Research: Solid Earth, 118 (7), 37283741 .

Ray, S., \& Viesca, R. C. (2017). Earthquake nucleation on faults with heterogeneous frictional properties, normal stress. Journal of Geophysical Research: Solid Earth, 122 (10), 8214-8240.

Ray, S., \& Viesca, R. C. (2019). Homogenization of fault frictional properties. Geophysical Journal International, 219 (2), 1203-1211.

Rice, J. R. (1993). Spatio-temporal complexity of slip on a fault. Journal of Geophysical Research, 98 (B6), 9885.

Rice, J. (1979). The mechanics of earthquake rupture Division of Engineering, Brown University Providence.

Ripperger, J., Ampuero, J. -., Mai, P. M., \& Giardini, D. (2007). Earthquake source characteristics from dynamic rupture with constrained stochastic fault stress. Journal of Geophysical Research: Solid Earth, 112 (B4)

Roest, J. P. A., \& Kuilman, W.Geomechanical analysis of small earthquakes at the Eleveld gas reservoir.

Rogers, G., \& Dragert, H. (2003). Episodic tremor and slip on the Cascadia subduction zone: The chatter of silent slip. Science, 300 (5627), 1942-1943.

Rojas, O., Dunham, E.,M., Day, S.,M., Dalguer, L.,A., \& Castillo, J.,E. (2009). Finite difference modelling of rupture propagation with strong velocity-weakening friction. Geophysical Journal International, 179 (3), 1831-1858. 
Romijn, R. (2017). Groningen Velocity Model 2017 - Groningen full elastic velocity model. Assen: Nederlandse Aardolie Maatschappij B.V. . (Editors: van Elk, Jan, and Doornhof, Dirk)

Roscoe, K. H., \& Burland, J. B. (1968). On the generalized stress-strain behaviour of wet clay. In L. Heyman, \& F. A. Leckie (Eds.), Engineering Plasticity (pp. 535-609. Cambridge: Cambridge University Press.

Roscoe, K. H., Schofield, A. N., \& Wroth, C. P. (1958). On The Yielding of Soils. Géotechnique, 8 (1), 22-53.

Rubin, A. M., \& Ampuero, J. -. (2005). Earthquake nucleation on (aging) rate and state faults. Journal of Geophysical Research: Solid Earth, 110 (B11), - B11312.

Ruina, A. (1983). Slip Instability and State Variable Friction Laws. Journal of Geophysical Research, 88 (370), 10.

Ruiz, S., Aden-Antoniow, F., Baez, J., Otarola, C., Potin, B., del Campo, F., Poli, P., Flores, C., Satriano, C., \& Leyton, F. (2017). Nucleation phase and dynamic inversion of the Mw 6.9 Valparaíso 2017 earthquake in Central Chile. Geophysical Research Letters, 44 (20), 10,290-10,297.

Ruiz, S., Metois, M., Fuenzalida, A., Ruiz, J., Leyton, F., Grandin, R., Vigny, C., Madariaga, R., \& Campos, J. (2014). Intense foreshocks and a slow slip event preceded the 2014 Iquique Mw 8.1 earthquake. Science (New York, N.Y.), 345 (6201), 1165-1169.

Rutqvist, J., Rinaldi, A. P., Cappa, F., \& Moridis, G. J. (2013). Modeling of fault ractivation and induced seismicity during hydraulic fracturing of Shale-Gas reservoir. Journal of Petroleum Science and Engineering, 107, 31-44.

Santarelli, F. J., Tronvoll, J. T., Svennekjaer, M., Skeie, H., Henriksen, R., \& Brati, R. K. (1998). Reservoir stress path: The depletion and the rebound. SPE/ISRM 47350, SPE/SRM Eurock '98 held in Trondheim, Norway, 8-10 July 1998

Sanz, P. F., Lele, S. P., Searles, K. H., Hsu, S., Garzon, J. L., Burdette, J. A., . . Hector, P. D. (2015). Geomechanical Analysis to Evaluate Production-Induced Fault Reactivation at Groningen Gas Field Society of Petroleum Engineers.

Schmidt, D., \& Gao, H. (2010). Source parameters and time-dependent slip distributions of slow slip events on the Cascadia subduction zone from 1998 to 2008. Journal of Geophysical Research: Solid Earth, 115 (B4) 


\section{References}

Schmittbuhl, J., Chambon, G., Hansen, A., \& Bouchon, M. (2006). Are stress distributions along faults the signature of asperity squeeze? Geophysical Research Letters, 33 (13)

Segall, P., \& Fitzgerald, S. D. (1998). A note on induced stress changes in hydrocarbon and geothermal reservoirs. Tectonophysics, 289, 117.

Segall, P. (1989). Earthquakes triggered by fluid extraction. Geology, 17 (10), 942-946.

Segall, P., Grasso, J. R., \& Mossop, A. (1994). Poroelastic stressing and induced seismicity near the Lacq gas field, southwestern France. Journal of Geophysical Research, 99 (B8), 15.

Segall, P., \& Lu, S. (2015). Injection-induced seismicity: Poroelastic and earthquake nucleation effects. Journal of Geophysical Research: Solid Earth, 120 (7), 5082-5103.

Segall, P. (1985). Stress and subsidence resulting from subsurface fluid withdrawal in the epicentral region of the 1983 Coalinga Earthquake. Journal of Geophysical Research: Solid Earth, 90 (B8), 6801-6816.

Selvadurai, P. A., \& Glaser, S. D. (2015). Laboratory-developed contact models controlling instability on frictional faults. Journal of Geophysical Research: Solid Earth, 120 (6), 4208-4236.

Shapiro, S., Krüger, O., Dinske, C., \& Langenbruch, C. (2011). Magnitudes of induced earthquakes and geometric scales of fluid-stimulated rock volumes. Geophysics, 76 (6), WC55-WC63.

Shibazaki, B., Matsuzawa, T., Tsutsumi, A., Ujiie, K., Hasegawa, A., \& Ito, Y. (2011). 3D modeling of the cycle of a great Tohoku-oki earthquake, considering frictional behavior at low to high slip velocities. Geophysical Research Letters, 38 (21)

Simoni, L., Salomoni, V., \& Schrefler, B. (1999). Elastoplastic subsidence models with and without capillary effects. Computer Methods in Applied Mechanics and Engineering, $171(3-4), 491-502$.

Skarbek, R. M., Rempel, A. W., \& Schmidt, D. A. (2012). Geologic heterogeneity can produce aseismic slip transients. Geophysical Research Letters, 39 (21)

Smith, J. D., Avouac, J., White, R. S., Copley, A., Gualandi, A., \& Bourne, S. J. (2019). Reconciling the long-term relationship between reservoir pore pressure depletion and compaction in the Groningen region. Journal of Geophysical Research: Solid Earth, 124 (6), 6165-6178.

Socquet, A., Valdes, J. P., Jara, J., Cotton, F., Walpersdorf, A., Cotte, N., Specht, S., Ortega-Culaciati, F., Carrizo, D., \& Norabuena, E. (2017). An 8 month slow slip 
event triggers progressive nucleation of the 2014 Chile megathrust. Geophysical Research Letters, 44 (9), 4046-4053.

Soltanzadeh, H., \& Hawkes, C. D. (2008). Semi-analytical models for stress change and fault reactivation induced by reservoir production and injection. Journal of Petroleum Science and Engineering, 60, 71.

Soltanzadeh, H., \& Hawkes, C. D. (2009). Induced poroelastic and thermoelastic stress changes within reservoirs during fluid injection and production. Porous Media: Heat and Mass Transfer, Transport and Mechanics, , 27.

Sone, H., \& Shimamoto, T. (2009). Frictional resistance of faults during accelerating and decelerating earthquake slip. Nature Geosci, 2 (10), 705-708.

Sone, H., \& Zoback, M. D. (2014). Time-dependent deformation of shale gas reservoir rocks and its long-term effect on the in situ state of stress International Journal of Rock Mechanics and Mining Sciences69

Spetzler, J., \& Dost, B. (2017a). Hypocentre estimation of induced earthquakes in Groningen. Geophysical Journal International, 209 (1), 453-465.

Spetzler, J., \& Dost, B. (2017b). Probabilistic Seismic Hazard Analysis for Induced Earthquakes in Groningen, Update June 2017. De Bilt: KNMI.

Spiers, C. J., Hangx, S. J., \& Niemeijer, A. R. (2017). New approaches in experimental research on rock and fault behaviour in the Groningen gas field. Netherlands Journal of Geosciences, 96 (5), s55-s69.

Stichting Platform Geothermie, DAGO, Stichting Warmtenetwerk, \& EBN. (2018). Masterplan Aardwarmte in Nederland.

Svetlizky, I., \& Fineberg, J. (2014). Classical shear cracks drive the onset of dry frictional motion. Nature, 509 (7499), 205-208.

Tape, C., Holtkamp, S., Silwal, V., Hawthorne, J., Kaneko, Y., Ampuero, J. P., Ji, C., Ruppert, N., Smith, K., \& West, M. E. (2018). Earthquake nucleation and fault slip complexity in the lower crust of central Alaska. Nature Geoscience, 11 (7), 536.

Tenthorey, E., \& Cox, S. F. (2006). Cohesive strengthening of fault zones during the interseismic period: An experimental study. Journal of Geophysical Research: Solid Earth, 111 (B9), n/a-n/a.

Tesei, T., Collettini, C., Barchi, M. R., Carpenter, B. M., \& Di Stefano, G. (2014). Heterogeneous strength and fault zone complexity of carbonate-bearing thrusts with 


\section{References}

possible implications for seismicity. Earth and Planetary Science Letters, 408, 307318.

Thielicke, W., \& Stamhuis, E. J. (2014). PIVlab - Towards user-friendly, affordable and accurate digital Particle Image Velocimetry in MATLAB. Journal of Open Research Software, 2 (1)

TNO. (2013). Toetsing van de bodemdalingsprognoses en seismische hazard ten gevolge van gaswinning van het Groningen veld. Eindrapport, Report No. R11953, Utrecht: TNO.

TNO. (2015). Injection related induced seismicity and its relevance to nitrogen injection: Modelling of geomechanical effects of injection on fault stability. Report No. TNO 2015 R11259, Utrecht: TNO. . (Sponsored by: Nederlandse Aardolie Maatschappij B.V.)

Toro, G. D., Han, R., Hirose, T., Paola, N. D., Nielsen, S., Mizoguchi, K., Ferri, F., Cocco, M., \& Shimamoto, T. (2011). Fault lubrication during earthquakes. Nature, 471

Uenishi, K., \& Rice, J.,R. (2003). Universal nucleation length for slip-weakening rupture instability under nonuniform fault loading. Journal of Geophysical Research, 108 (B1), 2042.

Urai, J. L., Kettermann, M., Abe, S., \& Virgo, S. (2016). Aspects of fault zones around the Rotliegend reservoirs and the possible effects of salt in the fault zones on rates of seismicity in these zones. Report of a short project in April - may 2016, IGEM, EMR and RWTH Aachen University. . (Supervised by: State Supervision of Mines, Ministerie van Economische Zaken)

Urpi, L., Rinaldi, A. P., Rutqvist, J., Cappa, F., \& Spiers, C. J. (2016). Dynamic simulation of CO2-injection-induced fault rupture with slip-rate dependent friction coefficient Geomechanics for Energy and the Environment 7

van Assema, B. (2017). Seismic interpretation and depth conversion of Top Carboniferous in the Groningen field. Assen: Nederlandse Aardolie Maatschappij B.V. . (Editors: Jan van Elk and Dirk Doornhof)

van den Bogert, P. A. J. (2015). Impact of various modelling options on the onset of fault slip and fault slip response using 2-dimensional Finite-Element modelling. Restricted , Report No. SR.15.11455, Rijswijk: Shell Global Solutions International B.V. van den Bogert, P. A. J. (2018). Depletion-induced fault slip and seismic rupture. 2D Geomechanical models for the Groningen field, The Netherlands. Assen: Nederlandse 
Aardolie Maatschappij B.V. . (Executing organisation: Shell Global Solutions International B.V.. Editors: van Elk, Jan and Doornhof, Dirk)

Van den Ende, M., Chen, J., Ampuero, J., \& Niemeijer, A. (2018). A comparison between rate-and-state friction and microphysical models, based on numerical simulations of fault slip. Tectonophysics, 733, 273-295.

Van Eck, T., Goutbeek, F., Haak, H., \& Dost, B. (2006). Seismic hazard due to smallmagnitude, shallow-source, induced earthquakes in The Netherlands. Engineering Geology, 87, 105.

van Eijs, R. M. H. E. (2015). Neotectonic stresses in the Permian Slochteren Formation of the Groningen Field. KNMI Scientific Report, Report No. EP201510210531, Assen: NAM.

Van Eijs, R. M. H. E., \& van der Wal, O. (2017). Field-wide reservoir compressibility estimation through inversion of subsidence data above the Groningen gas field. Netherlands Journal of Geosciences, 96 (5), s117-s129.

van Oeveren, H., Valvatne, P., Geurtsen, L., \& van Elk, J. (2017). History match of the Groningen field dynamic reservoir model to subsidence data and conventional subsurface data. Netherlands Journal of Geosciences, 96 (5), s47-s54.

van Thienen-Visser, K., \& Fokker, P. A. (2017). The future of subsidence modelling: compaction and subsidence due to gas depletion of the Groningen gas field in the Netherlands. Netherlands Journal of Geosciences, 96 (5), s105-s116.

van Thienen-Visser, K., Pruiksma, J. P., \& Breunese, J. (2015). Compaction and subsidence of the Groningen gas field in the Netherlands. Proceedings of the International Association of Hydrological Sciences, 372, 367-373.

van Wees, J., Buijze, L., van Thienen-Visser, K., Nepveu, M., Wassing, B. B. T., Orlic, B., \& Fokker, P. A. (2014). Geomechanics response and induced seismicity during gas field depletion in the Netherlands. Geothermics, 52 (0), 206-219.

van Wees, J., Osinga, S., van Thienen-Visser, K., \& Fokker, P. A. (2018). Reservoir creep and induced seismicity: inferences from geomechanical modeling of gas depletion in the Groningen field. Geophysical Journal International, 212 (3), 1487-1497.

van Wees, J., Pluymaekers, M., Osinga, S., Fokker, P. A., Van Thienen-Visser, K., Orlic, B., Wassing, B. B. T., Hegen, D., \& Candela, T. (2019). 3-D mechanical analysis of complex reservoirs: a novel mesh-free approach. Geophysical Journal International, 219 (2), 1118-1130. 


\section{References}

Veedu, D. M., \& Barbot, S. (2016). The Parkfield tremors reveal slow and fast ruptures on the same asperity. Nature, 532 (7599), 361.

Veldkamp, J. G., Mijnlieff, H., Bloemsma, M., Donselaar, R., Henares, S., Redjosentono, A., \& Weltje, G. J.Permian Rotliegend Reservoir Architecture of the Dutch Koekoekspolder Geothermal Doublet. World Geothermal Congress 2015, Melbourne, Australia, 19 - 25 April.

Verweij, J. M., Simmelink, H. J., Underschultz, J., \& Witmans, N. (2012). Pressure and fluid dynamic characterisation of the Dutch subsurface. Netherlands Journal of Geosciences, 91 (4), 465.

Viesca, R. C., \& Rice, J. R. (2012). Nucleation of slip-weakening rupture instability in landslides by localized increase of pore pressure. Journal of Geophysical Research: Solid Earth, 117 (B3)

Visser, C. A., \& Viota, J. L. S. (2017). Introduction to the Groningen static reservoir model. Netherlands Journal of Geosciences, 96 (5), s39-s46.

Vrijlandt, M. A. W., Struijk, E. L. M., Brunner, L. H., Veldkamp, J. G., Witmans, N., Maljers, D., \& van Wees, J. D. (2019). ThermoGIS update: a renewed view on geothermal potential in the Netherlands. Eur Geotherm Congr, , 226, 1-9.

Wallace, L. M., Webb, S. C., Ito, Y., Mochizuki, K., Hino, R., Henrys, S., Schwartz, S. Y., \& Sheehan, A. F. (2016). Slow slip near the trench at the Hikurangi subduction zone, New Zealand. Science, 352 (6286), 701-704.

Wassing, B. B. T., Buijze, L., \& Orlic, B. (2017). Fault reactivation and fault rupture in producing gas fields with elastic and visco-elastic caprocks. 51st Rock Mechanics Symposium San Francisco, ARMA 17-355

Wassing, B. B. T., Buijze, L., \& Orlic, B. (2016). Modelling of Fault Reactivation and Fault Slip in Producing Gas Fields Using a Slip-weakening Friction Law American Rock Mechanics Association.

Wei, M., Kaneko, Y., Liu, Y., \& McGuire, J. J. (2013). Episodic fault creep events in California controlled by shallow frictional heterogeneity. Nature Geoscience, 6 (7), 566.

Weng, H., \& Ampuero, J. (2019). The Dynamics of Elongated Earthquake Ruptures. Journal of Geophysical Research: Solid Earth, 124 (8), 8584-8610. 
Wentinck, H. M. (2015). Induced seismicity in the Groningen field - statistical assessment of tremors along faults in a compacting reservoir. Report No. SR.15.11335, Rijswijk: Shell Global Solutions International B.V.

Wentinck, H. M. (2016). Induced seismicity in the Groningen field: Second statistical assessment of tremors along faults in a compacting reservoir. Assen: Nederlandse Aardolie Maatschappij B.V.

Wentinck, H. M. (2018). Dynamic modelling of large tremors in the Groningen field using extended seismic sources. Assen: Nederlandse Aardolie Maatschappij B.V.

Wibberley, C. A. J., Yielding, G., \& Di Toro, G. (2008). Recent advances in the understanding of fault zone internal structure: a review. Geological Society, London, Special Publications, 299 (1), 5-33.

Willacy, C., van Dedem, E., Minisini, S., Li, J., Blokland, J. W., Das, I., \& Droujinine, A. (2018). Application of full-waveform event location and moment-tensor inversion for Groningen induced seismicity. The Leading Edge, 37 (2), 92-99.

Willems, C. J. L. (2017). Doublet deployment strategies for geothermal Hot Sedimentary Aquifer exploitation. Application to the Lower Cretaceous Nieuwerkerk Formation in the West Netherlands Basin. (PhD, Technical University Delft).

Wong, T., David, C., \& Zhu, W. (1997). The transition from brittle faulting to cataclastic flow in porous sandstones: Mechanical deformation. Journal of Geophysical Research: Solid Earth, 102 (B2), 3009-3025.

Xu, S., Fukuyama, E., Yamashita, F., Mizoguchi, K., Takizawa, S., \& Kawakata, H. (2018). Strain rate effect on fault slip and rupture evolution: Insight from meter-scale rock friction experiments. Tectonophysics, 733, 209-231.

Yamashita, F., Fukuyama, E., Mizoguchi, K., Takizawa, S., Xu, S., \& Kawakata, H. (2015). Scale dependence of rock friction at high work rate. Nature, 528 (7581), 254.

Yamashita, F., Fukuyama, E., Xu, S., Mizoguchi, K., Kawakata, H., \& Takizawa, S. (2018). Rupture preparation process controlled by surface roughness on meter-scale laboratory fault. Tectonophysics, 733, 193-208.

Yerkes, R. F., \& Castle, R. O. (1976). Seismicity and faulting attributable to fluid extraction. Engineering Geology, 10 (2-4), 151-167.

Zbinden, D., Rinaldi, A. P., Urpi, L., \& Wiemer, S. (2017). On the physics-based processes behind production-induced seismicity in natural gas fields. Journal of Geophysical Research: Solid Earth, 122 (5), 3792-3812. 
Zecevic, M., Daniel, G., \& Jurick, D. (2016). On the nature of long-period long-duration seismic events detected during hydraulic fracturingOn the nature of LPLD events. Geophysics, 81 (3), KS113-KS121.

Zhang, J., Wong, T., \& Davis, D.High pressure embrittlement and shear-enhanced compaction Berea sandstone: Acoustic emission measurement and microstructural observation. The 31th US Symposium on Rock Mechanics (USRMS)

Zhuo, Y., Liu, P., Chen, S., Guo, Y., \& Ma, J. (2018). Laboratory observations of tremorlike events generated during preslip. Geophysical Research Letters, 45 (14), 69266934. 